\title{
Uncertainty and Sensitivity of Contaminant Travel Times from the Upgradient Nevada Test Site to the Yucca Mountain Area
}

\author{
prepared by \\ Jianting Zhu, Karl F. Pohlmann, Jenny B. Chapman, Charles E. Russell, \\ Rosemary W. H. Carroll, and David S. Shafer \\ submitted to \\ Nevada Site Office \\ National Nuclear Security Administration \\ U.S. Department of Energy \\ Las Vegas, Nevada
}

February 2009

Publication No. 45230 
Reference herein to any specific commercial product, process, or service by trade name, trademark, manufacturer, or otherwise, does not necessarily constitute or imply its endorsement, recommendation, or favoring by the United States Government or any agency thereof or its contractors or subcontractors. The views and opinions of authors expressed herein do not necessarily state or reflect those of the United States Government of any agency thereof.

This report has been reproduced directly from the best available copy.

Available for sale to the public, if paper, from:

\author{
U.S. Department of Commerce \\ National Technical Information Service \\ 5285 Port Royal Road \\ Springfield, VA 22161 \\ Phone: 800.553.6847 \\ Fax: 703.605.6900 \\ Email: orders@ntis.gov \\ Online ordering: http://www.ntis.gov/ordering.htm
}

Available electronically at http://www.osti.gov/bridge.

Available for a processing fee to the U.S. Department of Energy and its contractors, in paper, from:

U.S. Department of Energy

Office of Scientific and Technical Information

P.O. Box 62

Oak Ridge, TN 37831-0062

Phone: 865.576.8401

Fax: 865.576.5728

Email: reports@adonis.osti.gov 


\title{
Uncertainty and Sensitivity of Contaminant Travel Times from the Upgradient Nevada Test Site to the Yucca Mountain Area
}

\author{
prepared by \\ Jianting Zhu, Karl F. Pohlmann, Jenny B. Chapman, Charles E. Russell, \\ Rosemary W. H. Carroll, and David S. Shafer \\ Division of Hydrologic Sciences \\ Desert Research Institute \\ Nevada System of Higher Education
}

Publication No. 45230

submitted to

Nevada Site Office

National Nuclear Security Administration

U.S. Department of Energy

Las Vegas, Nevada

February 2009

The work upon which this report is based was supported by the U.S. Department of Energy under Contract No. DE-AC52-06NA26383. Approved for public release; further dissemination unlimited. 
THIS PAGE LEFT INTENTIONALLY BLANK 


\section{ABSTRACT}

Yucca Mountain (YM), Nevada, has been proposed by the U.S. Department of Energy as the nation's first permanent geologic repository for spent nuclear fuel and highlevel radioactive waste. In this study, the potential for groundwater advective pathways from underground nuclear testing areas on the Nevada Test Site (NTS) to intercept the subsurface of the proposed land withdrawal area for the repository is investigated. The timeframe for advective travel and its uncertainty for possible radionuclide movement along these flow pathways is estimated as a result of effective-porosity value uncertainty for the hydrogeologic units (HGUs) along the flow paths. Furthermore, sensitivity analysis is conducted to determine the most influential HGUs on the advective radionuclide travel times from the NTS to the YM area. Groundwater pathways are obtained using the particle tracking package MODPATH and flow results from the Death Valley regional groundwater flow system (DVRFS) model developed by the U.S. Geological Survey (USGS). Effectiveporosity values for HGUs along these pathways are one of several parameters that determine possible radionuclide travel times between the NTS and proposed YM withdrawal areas. Values and uncertainties of HGU porosities are quantified through evaluation of existing site effective-porosity data and expert professional judgment and are incorporated in the model through Monte Carlo simulations to estimate mean travel times and uncertainties. The simulations are based on two steady-state flow scenarios, the pre-pumping (the initial stress period of the DVRFS model), and the 1998 pumping (assuming steady-state conditions resulting from pumping in the last stress period of the DVRFS model) scenarios for the purpose of long-term prediction and monitoring. The pumping scenario accounts for groundwater withdrawal activities in the Amargosa Desert and other areas downgradient of YM. Considering each detonation in a clustered region around Pahute Mesa (in the NTS operational areas 18,19, 20, and 30) under the water table as a particle, those particles from the saturated zone detonations were tracked forward using MODPATH to identify hydraulically downgradient groundwater discharge zones and to determine the particles from which detonations will intercept the proposed YM withdrawal area. Out of the 71 detonations in the saturated zone, the flowpaths from 23 of the 71 detonations will intercept the proposed YM withdrawal area under the pre-pumping scenario. For the 1998 pumping scenario, the flowpaths from 55 of the 71 detonations will intercept the proposed YM withdrawal area. Three different effective-porosity data sets compiled in support of regional models of groundwater flow and contaminant transport developed for the NTS and the proposed YM repository are used. The results illustrate that mean minimum travel time from underground nuclear testing areas on the NTS to the proposed YM repository area can vary from just over 700 to nearly 700,000 years, depending on the locations of the underground detonations, the pumping scenarios considered, and the effective-porosity value distributions used. Groundwater pumping scenarios are found to significantly impact minimum particle travel time from the NTS to the YM area by altering flowpath geometry. Pumping also attracts many more additional groundwater flowpaths from the NTS to the YM area. The sensitivity analysis further illustrates that for both the pre-pumping and 1998 pumping scenarios, the uncertainties in effective-porosity values for five of the $27 \mathrm{HGUs}$ considered account for well over 90 percent of the effective-porosity-related travel time uncertainties for the flowpaths having the shortest mean travel times to YM. 


\section{ACKNOWLEDGEMENTS}

This work is performed under contract number DE-AC52-06NA26383 for the U.S. Department of Energy, National Nuclear Security Administration Nevada Site Office. We thank Tammy Kluesner (DRI) for the data compilation and editing assistance. Feng Pan (DRI) helped generate some random effective-porosity values. Discussion and suggestions from Ming Ye at Florida State University are also appreciated. 


\section{CONTENTS}

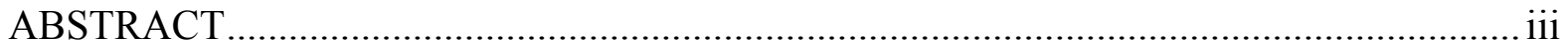

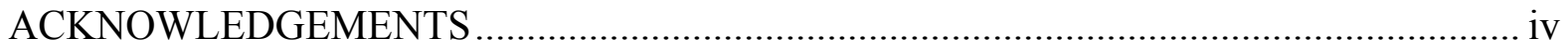

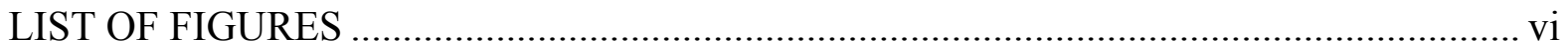

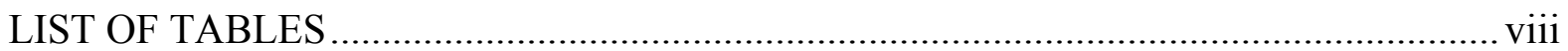

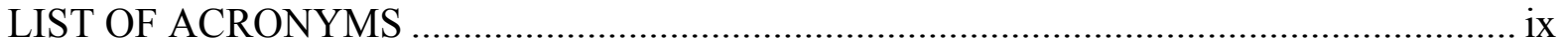

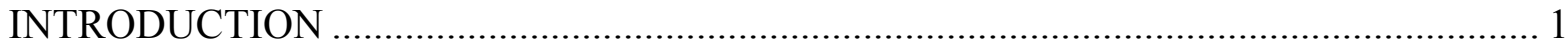

OVERVIEW OF REGIONAL GROUNDWATER FLOW MODEL .................................. 3

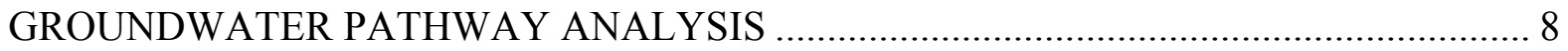

UNDERGROUND NUCLEAR TESTS ................................................................. 9

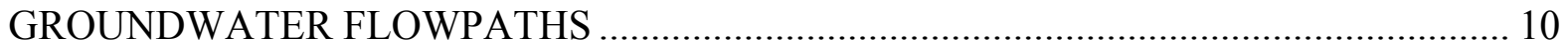

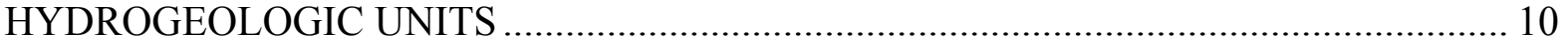

Unconsolidated Cenozoic Basin-fill Sediments and Local Young Volcanic Rocks ......... 17

Consolidated Cenozoic Basin-Fill Deposits - Volcanic- and Sedimentary-Rock Unit

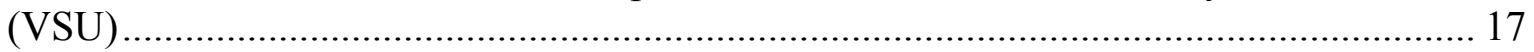

Volcanic Rocks of the Southwestern Nevada Volcanic Field ...................................... 17

HGUs Associated with Mesozoic, Paleozoic, and Late Proterozoic Sedimentary Rocks .. 19

HGUs Associated with Crystalline Metamorphic Rocks and Plutons ............................. 20

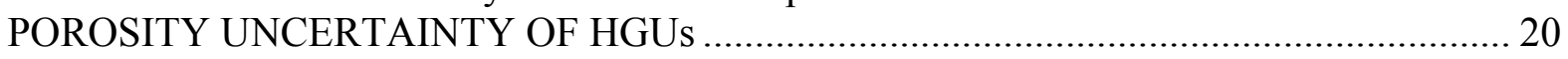

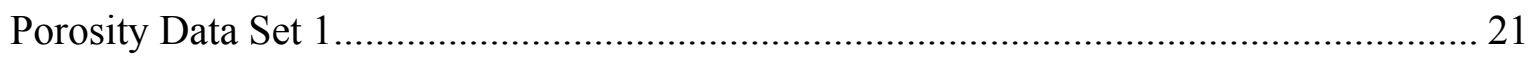

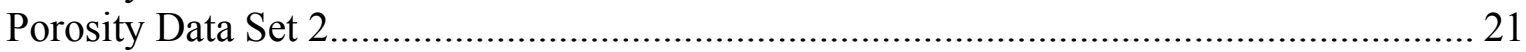

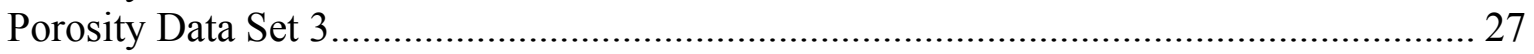

UNCERTAINTY ANALYSIS OF PARTICLE TRAVEL TIME IN RELATION TO

EFFECTIVE-POROSITY UNCERTAINTIES ............................................................. 33

Procedure for Monte Carlo Simulations ................................................................... 33

Sensitivity Analysis of Travel Times.......................................................................... 34

RESULTS AND DISCUSSION OF UNCERTAINTY AND SENSITIVITY ANALYSIS . 36

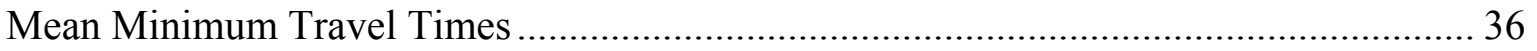

PRE-PUMPING CONDITIONS ........................................................................... 39

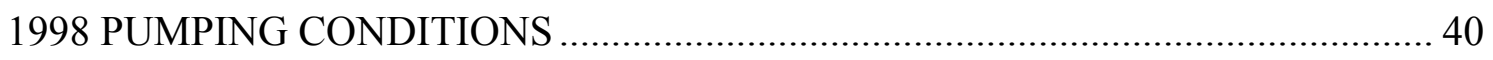

Coefficients of Variation of the Minimum Travel Times ................................................. 41

Significance of HGU Porosities on the Minimum Travel Time Uncertainties................... 41

Distributions of Minimum Travel Time ....................................................................... 49

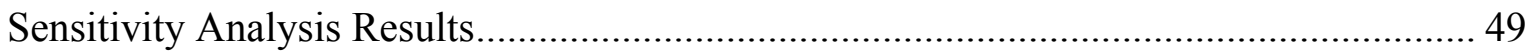

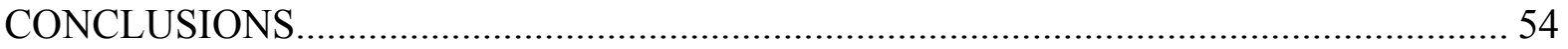

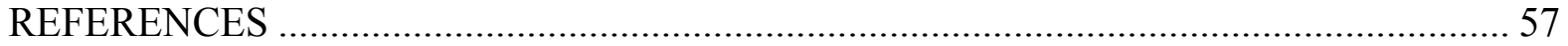

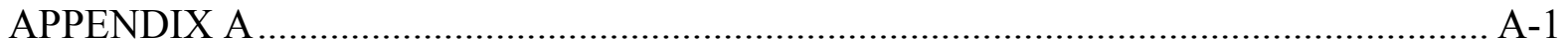

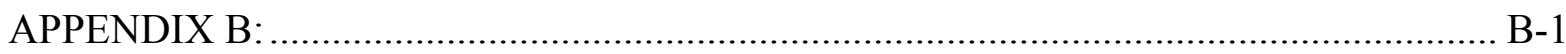

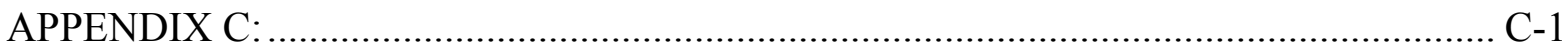




\section{LIST OF FIGURES}

1. Model domain, locations of NTS and the proposed YM withdrawal area, major upgradient underground nuclear detonations, and pumping wells (1998 scenario)......2

2. Map showing the location of the Death Valley regional groundwater flow system model in relation to regional geographic features and other major regional flow models. From Belcher, (2004).

3. East-west cross section across a portion of the Death Valley regional groundwater flow system model domain showing general configuration of the model layers. ........5

4. Simulated discharge areas, major recharge areas, constant-head boundary flows, and steady-state stress period hydraulic head in the uppermost active model layer of the Death Valley regional groundwater flow system model, Nevada and California (from Blainey et al., 2006, figure 2).

5. Flowpaths of all 71 particles located in the saturated zone as a result of the prepumping steady-state flow scenario.

6. Flowpaths of all 71 particles located in the saturated zone as a result of the 1998 pumping steady-state flow scenario.

7. Flowpaths of 23 particles (out of total 71) toward YM as a result of the prepumping steady-state flow scenario (flowpaths pass through YM to discharge zone).

8. Flowpaths of 55 particles (out of total 71) toward YM as a result of the 1998 pumping steady-state flow scenario (flowpaths pass through YM).

9. Effective-porosity distributions for PVA, TMVA, CFPPA, Lower VSU, and Upper VSU based on Effective-porosity Data Set 1.

10. Effective-porosity distributions for PVA, TMVA, CFPPA, Lower VSU, and Upper VSU based on Effective-porosity Data Set 2.

11. Effective-porosity distributions for PVA, TMVA, CFPPA, Lower VSU, and Upper VSU based on Effective-porosity Data Set 3.

12. Epistemic distribution for some HGUs, probability density function, and cumulative probability function.

13. Mean travel time from detonations to YM boundaries, based on three different effective-porosity sets under pre-pumping conditions.

14. Mean travel time from detonations to YM boundaries, based on three different effective-porosity data sets under 1998 pumping conditions, (a) for detonations whose mean travel times based on Effective-porosity Data Set 1 are less than 10,000 years, (b) for detonations whose mean travel times based on Effectiveporosity Data Set 1 are between 10,000 and 50,000 years, (c) for detonations whose mean travel times based on Effective-porosity Data Set 1 are over 50,000 years. 38

15. Coefficient of variation (CV) of travel time from detonations to $\mathrm{YM}$ boundaries, based on three different effective-porosity data sets under pre-pumping conditions...... 
16. Coefficient of variation (CV) of travel time from detonations to YM boundaries, based on three different effective-porosity data sets under 1998 pumping conditions, (a) for detonations whose mean travel times based on Effectiveporosity Data Set 1 are less than 10,000 years, (b) for detonations whose mean travel times based on Effective-porosity Data Set 1 are between 10,000 to 50,000 years, and (c) for detonations whose mean travel times based on Effectiveporosity Data Set 1 are over 50,000 years.

17. Coefficient of variation (CV) of minimum travel time to the YM area from Chancellor, Cybar, and Amarillo, in relation to the effective-porosity uncertainties of HGUs when only one HGU has randomly variable effective-porosity and the porosities for other HGUs are set to equal the mean values under pre-pumping conditions.

18. Coefficient of variation (CV) of minimum travel time to the YM area from (a) Purse and (b) Tenabo, in relation to the effective-porosity uncertainties of HGUs when only one HGU has randomly variable effective-porosity and the porosities for other HGUs are set to equal the mean values under 1998 pumping conditions.....44

19. Distribution of minimum travel time to YM boundaries from Chancellor-CybarAmarillo, which has the shortest mean minimum travel times based on all three effective-porosity data sets under pre-pumping conditions. (a) Effective-porosity Data Set 1, (b) Effective-porosity Data Set 2, and (c) Effective-porosity Data Set 3.

20. Distribution of minimum travel time to YM boundaries from detonations that have the shortest mean minimum travel times based on various scenarios under 1998 pumping conditions. (a) from Purse based on Effective-porosity Data Set 1, (b) from Purse based effective-porosity Set 2, and (c) Tenabo based on Effectiveporosity Data Set 3

21. Scatterplots of all 250 Monte Carlo realization results of minimum travel time to YM from the indicated detonations and the minimum travel time to YM of regression models that use only the porosities of five most influential HGUs. (a) Pre-pumping conditions and, (b) 1998 pumping conditions 


\section{LIST OF TABLES}

1. Major detonations in Areas 18, 19, 20, and 30 of NTS ..................................... 11

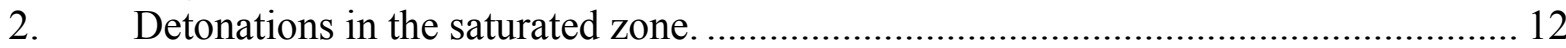

3. Hydrogeologic units for the Death Valley regional groundwater flow system hydrogeologic framework model (from Belcher, 2004, chapter B)......................... 18

4. Effective-porosity Data Set 1 - Assignment of effective-porosity Distributions to Death Valley regional groundwater flow system HGUs based on UGTA regional model and YM studies (Bedinger et al., 1989; IT Corporation, 1996b).................... 22

5. Effective-porosity Data Set 2 - Assignment of effective-porosity distributions to Death Valley regional groundwater flow system HGUs based on Pahute MesaOasis Valley model transport parameters.

6. Effective-porosity Data Set 3 - Assignment of effective-porosity distributions to Death Valley regional flow system HGUs based on Yucca Mountain transport parameters.

7. Correlation between HGUs in the Death Valley regional groundwater flow system model and the Pahute Mesa-Oasis Valley flow model.

8. Correlation between HGUs in the Death Valley regional groundwater flow system model and the Yucca Mountain Saturated Zone Site-Scale Flow Model.

9. HGU effective-porosity means and standard deviations used in the Monte Carlo simulations

10. Squared standardized regression coefficients for Effective-porosity Data Set 1 and Effective-porosity Data Set 2.

11. Squared standardized regression coefficients for Effective-porosity Data Set 3....... 53 


\section{LIST OF ACRONYMS}

$\begin{array}{ll}\text { BRU } & \text { Belted Range unit } \\ \text { CFBCU } & \text { Crater Flat-Bullfrog confining unit } \\ \text { CFPPA } & \text { Crater Flat-prow Pass aquifer } \\ \text { CFTA } & \text { Crater Flat-tram aquifer } \\ \text { CHD } & \text { Constant head } \\ \text { CHVU } & \text { Calico Hills volcanic-rock unit } \\ \text { CV } & \text { coefficient of variation } \\ \text { DRN } & \text { drain } \\ \text { DVRFS } & \text { Death Valley regional groundwater flow system } \\ \text { ET } & \text { evapotranspiration } \\ \text { HGUs } & \text { hydrogeologic units } \\ \text { HSUs } & \text { hydrostratigraphic units } \\ \text { HUF2 } & \text { hydrogeologic-unit flow } \\ \text { ICU } & \text { intrusive-rock confining unit } \\ \text { LCA } & \text { lower carbobiate-rock aquifer } \\ \text { LCCU } & \text { lower clastic-rock confining unit } \\ \text { LFU } & \text { lava flow unit } \\ \text { LHS } & \text { Latin hypercube sampling } \\ \text { NTS } & \text { Nevada Test Site } \\ \text { OAA } & \text { older alluvial aquifer } \\ \text { OACU } & \text { older alluvial confining unit } \\ \text { OBS } & \text { observation } \\ \text { OVU } & \text { older volcanic-rock unit } \\ \text { PVA } & \text { paintbrush volcanic-rock aquifer } \\ \text { RCH } & \text { recharge } \\ \text { SCU } & \text { sedimentary-rock confining unit } \\ \text { SEN } & \text { sensitivity } \\ \text { SWNVF } & \text { Southwestern Nevada volcanic field } \\ \text { TMVA } & \text { Thirsty Canyon-Timber Mountain volcanic-rock aquifer } \\ \text { UCA } & \text { upper carbonate-rock aquifer } \\ \text { UCCU } & \text { upper clastic-rock confining unit } \\ \text { UTM } & \text { Universal Transverse Mercator } \\ \text { VSU } & \text { volcanic- and sedimentary-rock unit } \\ \text { WVU } & \text { Wahmonie volcanic-rock unit } \\ \text { YAA } & \text { younger alluvial aquifer } \\ \text { YACU } & \text { younger alluvial confining unit } \\ \text { YM } & \text { Yucca Mountain } \\ \text { YVU } & \text { younger volcanic-rock unit } \\ \text { XCU } & \text { crystalline-rock confining unit } \\ & \end{array}$


THIS PAGE LEFT INTENTIONALLY BLANK 


\section{INTRODUCTION}

Yucca Mountain (YM) has been proposed as a deep geologic repository for the disposal of spent fuel and high-level radioactive waste (see Figure 1, the area within the blue box). If YM is licensed as a repository by the Nuclear Regulatory Commission, it will be important to identify the potential for radionuclides to migrate from underground nuclear testing areas located on the Nevada Test Site (NTS) to the hydraulically downgradient proposed repository area to ensure that monitoring does not incorrectly attribute to repository failure radionuclides originating from other sources. Early studies of groundwater flowpaths (IT Corporation, 1996a, Zhu et al., 2006) indicated that there is a potential for contaminants from the NTS to migrate to the YM area. In this study, results from the Death Valley regional groundwater flow system (DVRFS) model are used to investigate potential groundwater migration pathways and associated travel times from the NTS to the proposed YM repository area. Using the simulated groundwater flow results from the DVRFS model along with the particle tracking package MODPATH, the three-dimensional groundwater advective pathways and the contaminant travel times from the major underground test areas in the NTS to the YM region are simulated. This study focuses on evaluating whether travel times for advective flow along these pathways are significant with regard to the prospective monitoring time frame at the proposed repository. Major underground detonations in the NTS operational areas 18, 19, 20, and 30 (around Pahute Mesa seen in Figure 1) are treated as possible radionuclide sources (particles) in MODPATH. Included is uncertainty in effective-porosity as this is a critical variable in the determination of travel time. Uncertainty in effective-porosity is quantified through evaluation of existing site data from the literature and expert judgment and is then incorporated in the particle tracking algorithm through Monte Carlo simulations. The most important hydrogeologic units (HGUs) of the DVRFS model that form flowpaths from the NTS to the YM region are identified and the uncertainties in effective-porosity values of these significant HGUs are evaluated as to how they affect radionuclide migration times. Also identified are the particles from the NTS detonations with the shortest possible travel times that are most likely to impact the YM area and any future monitoring plans.

Uncertainty studies typically consist of two closely related steps called uncertainty analysis and sensitivity analysis (Helton et al., 2005). The focus of uncertainty analyses is to obtain the output uncertainty that derives from uncertainty in the inputs, whereas the focus of sensitivity analyses is to determine the relationship between the uncertainties in the output to those in the inputs. Both steps are undertaken here. Therefore, in terms of uncertainty studies, the objectives of this study are to: 1) investigate uncertainty associated with estimates of minimum travel times from major underground detonations in the upgradient NTS to the proposed YM withdrawal areas, 2) quantify the sensitivity of minimum particle travel times to the input parameters (i.e., porosities of the $27 \mathrm{HGUs),} \mathrm{and} \mathrm{3)} \mathrm{identify} \mathrm{the} \mathrm{most}$ influential input variables to the uncertainties of minimum travel times to the YM areas that would help facilitate future characterization of formation porosities to reduce the uncertainty of minimum travel time estimates and design possible future monitoring networks. 


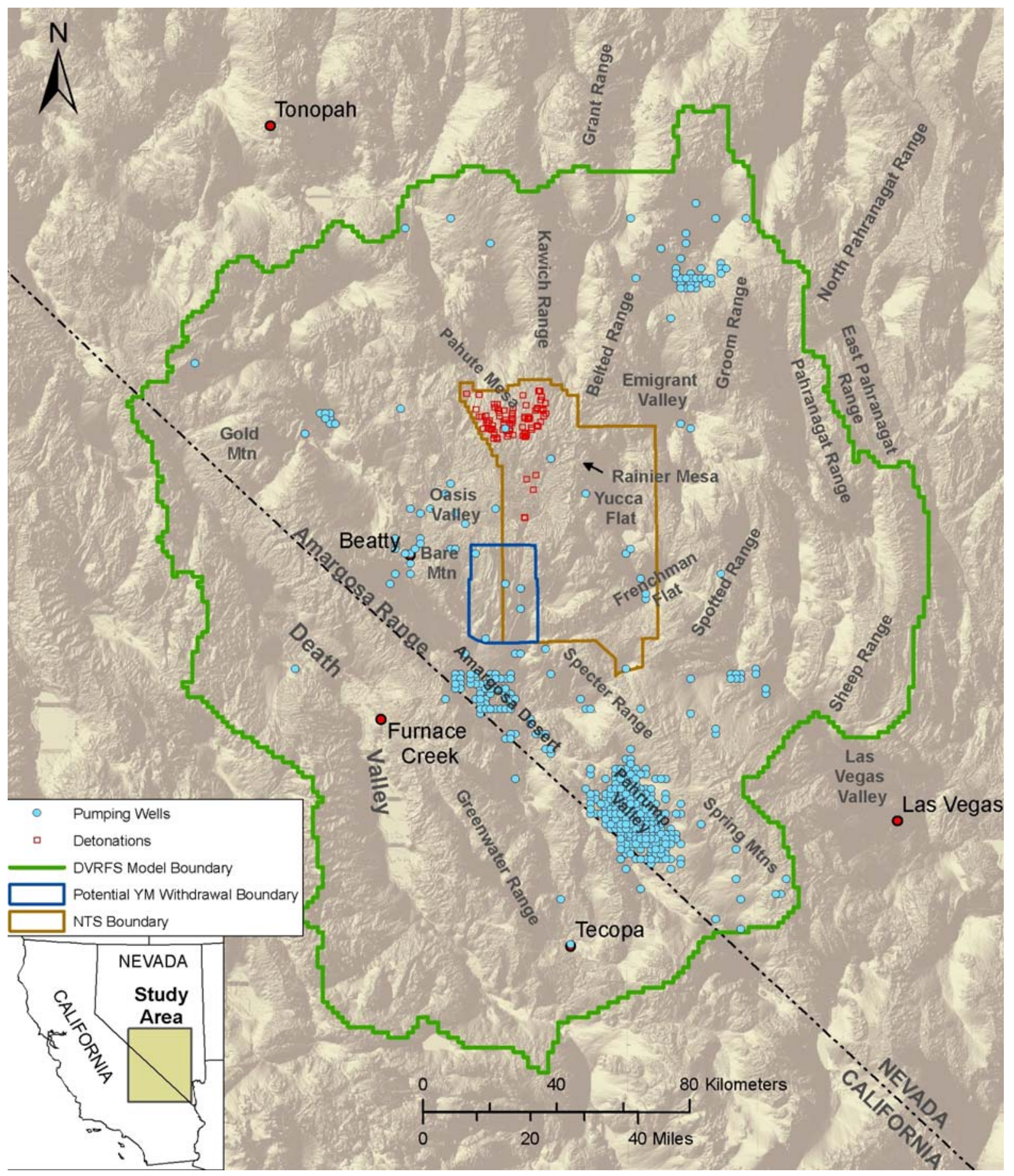

Figure 1. Model domain, locations of NTS and the proposed YM withdrawal area, major upgradient underground nuclear detonations, and pumping wells (1998 scenario). 


\section{OVERVIEW OF REGIONAL GROUNDWATER FLOW MODEL}

Groundwater flow analysis of previous regional groundwater flow modeling for the NTS (e.g., IT Corporation, 1996a; Zhu et al., 2006) suggests the potential exists for contaminants to migrate from the NTS to the YM areas. However, few investigations have looked at the travel timeframe of possible radionuclide migration from the NTS to the YM region. Due to the limited upgradient extent of the previous YM site-scale flow models, we use as the regional DVRFS model (Belcher, 2004) is used as the groundwater flow modeling framework because it covers YM, the NTS, and a large region surrounding them. The DVRFS model developed by the U.S. Geological Survey provides for this study groundwater flow-paths and volumetric flow rates in the region surrounding Yucca Mountain. Groundwater advective velocities are computed from the DVRFS model results using the particle tracking code MODPATH. The DVRFS model was developed for DOE to support investigations at the NTS and the proposed Yucca Mountain high-level nuclear waste repository (Belcher, 2004). Figure 1 outlines the DVRFS model boundary (green line in the figure). The DVRFS model is the most recent and comprehensive model of geology and groundwater flow in the region. It covers an area of approximately $40,000 \mathrm{~km}^{2}$ in southeastern California and southwestern Nevada. It is a three-dimensional transient groundwater flow model of the Death Valley region that incorporates decades of groundwater flow system study and previous less extensive groundwater flow models together with new data to provide greater detail for the complex model. Groundwater flow in the Death Valley region is composed of several interconnected, complex flow systems. Groundwater flow occurs in three subregions in relatively shallow and localized flow-paths that are superimposed on deeper, regional flow-paths.

The general characteristics of the DVRFS model as they pertain to this study are summarized below from Belcher (2004). The DVRFS model utilizes the three dimensional groundwater flow code MODFLOW-2000 (version 1.13) (Harbaugh et al., 2000) and related modular flow packages to simulate flow in the greater Death Valley region, covering an area similar to previous regional models developed for Yucca Mountain (D’Agnese et al., 1997) and the NTS (IT Corporation, 1996; Figure 2). The MODFLOW-2000 code will hereafter be referred to in this report as MODFLOW.

The simulation mesh is oriented north-south in alignment with the Universal Transverse Mercator (UTM) grid (NAD1927) and is discretized in plan view into 160 columns and 194 rows. All cells outside the model boundary shown as the heavy green line on Figure 2 are inactive and all cells within the boundary are active. Sixteen model layers are used, with 15 of them ranging in thickness from 50 to about $300 \mathrm{~m}$ (Figure 3). Layer 1 forms the top of the model and its upper elevation is set to the simulated potentiometric surface. Attempts were made to run the model as unconfined, but stable solutions could not be obtained and therefore the model was configured as confined. Transient time steps specify yield for the top layer, thereby partially accounting for unconfined conditions. Layer 16 forms the base of the model and extends to 4,000 $\mathrm{m}$ below sea level. Model layer elevations do not conform to HGUs elevations owing to the irregular shapes of the geologic units that result from depositional and structural processes in the region (Belcher, 2004). Time is divided into one steady-state stress period that simulates conditions prior to the initiation of groundwater pumping in 1913, followed by 86 one-year transient stress periods that include groundwater pumping through the year 1998. 


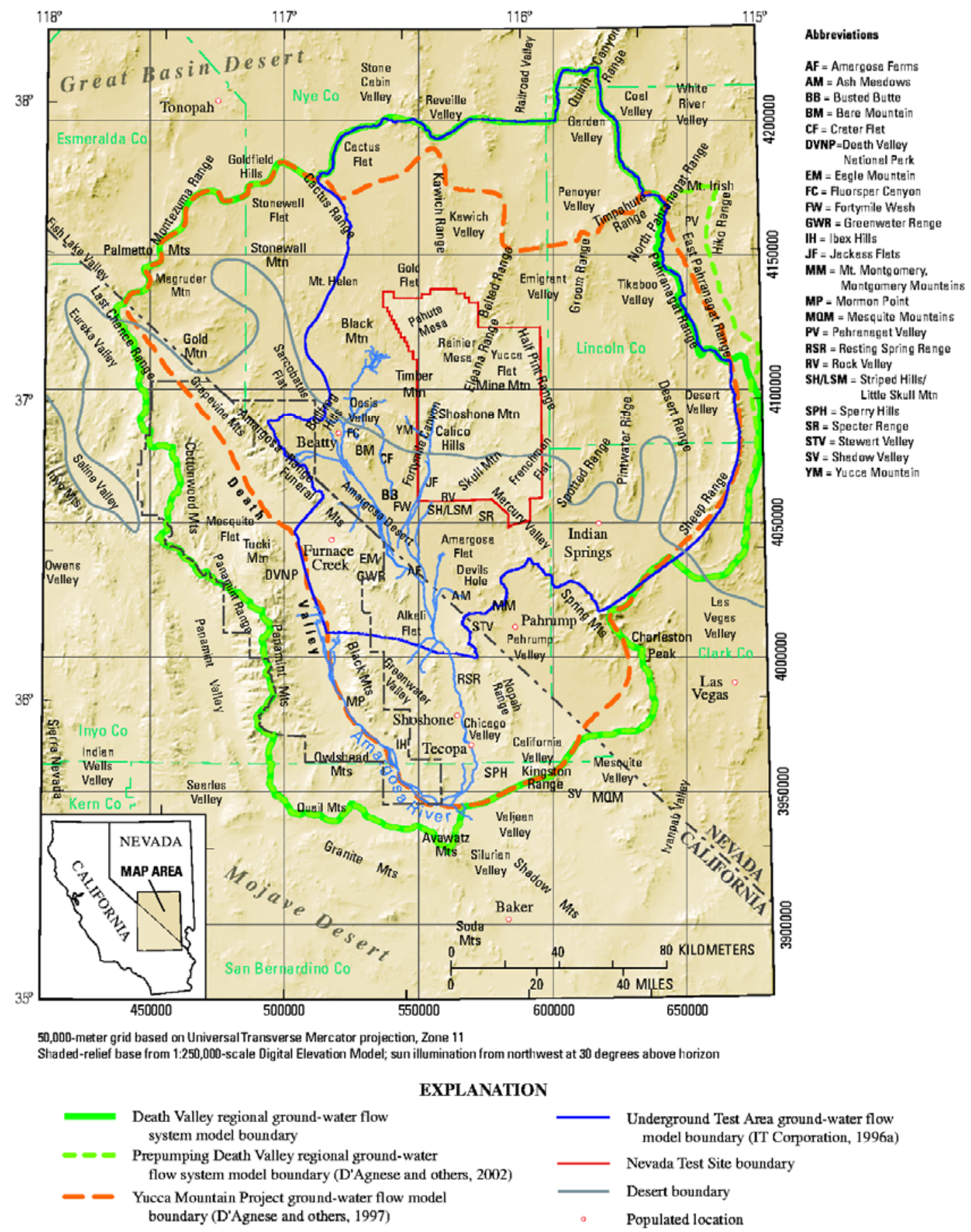

Figure 2. Map showing the location of the Death Valley regional groundwater flow system model in relation to regional geographic features and other major regional flow models. From Belcher, (2004). 

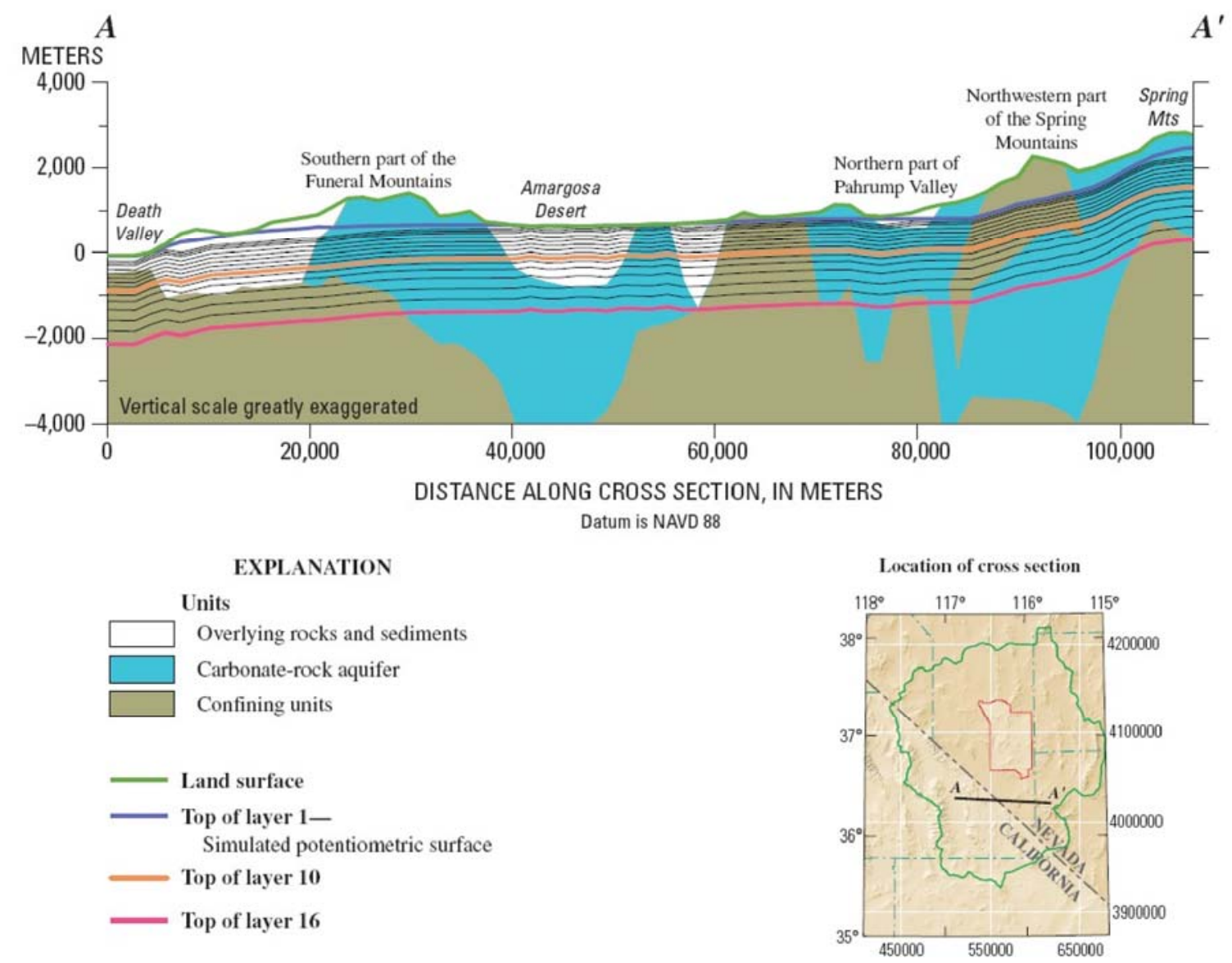

Figure 3. East-west cross section across a portion of the Death Valley regional groundwater flow system model domain showing general configuration of the model layers. From chapter $F$ of Belcher (2004).

Lateral model boundaries are configured as constant head using the constant head (CHD) package, allowing flow into and out of the model from adjacent basins (Figure 4). One segment is treated as no-flow where it coincides with the groundwater divide in the Spring Mountains and is parallel to the hydraulic gradient between the Spring Mountains and the Kingston Range to the south. Heads on all the boundaries were interpolated from a map of the regional potentiometric surface and flow rates across the boundary segments were estimated using water-budget and Darcy calculations. The flow rates were used as observations during model calibration, though they were given less weight than the other, measured observations.

Hydraulic properties are assigned on the basis of HGUs using the hydrogeologic-unit flow (HUF2) package (Anderman and Hill, 2000). Values of hydraulic conductivity, storage coefficient, vertical anisotropy, and depth decay of hydraulic conductivity (KDEP package) for the HGUs are based on Belcher et al. (2001) and vary spatially by zonation within HGUs based primarily on spatial distribution of geologic properties (Belcher, 2004). Hydrogeologic units in all layers (except the top layer) were assigned values of storage coefficient as obtained from literature sources and were not adjusted during calibration 


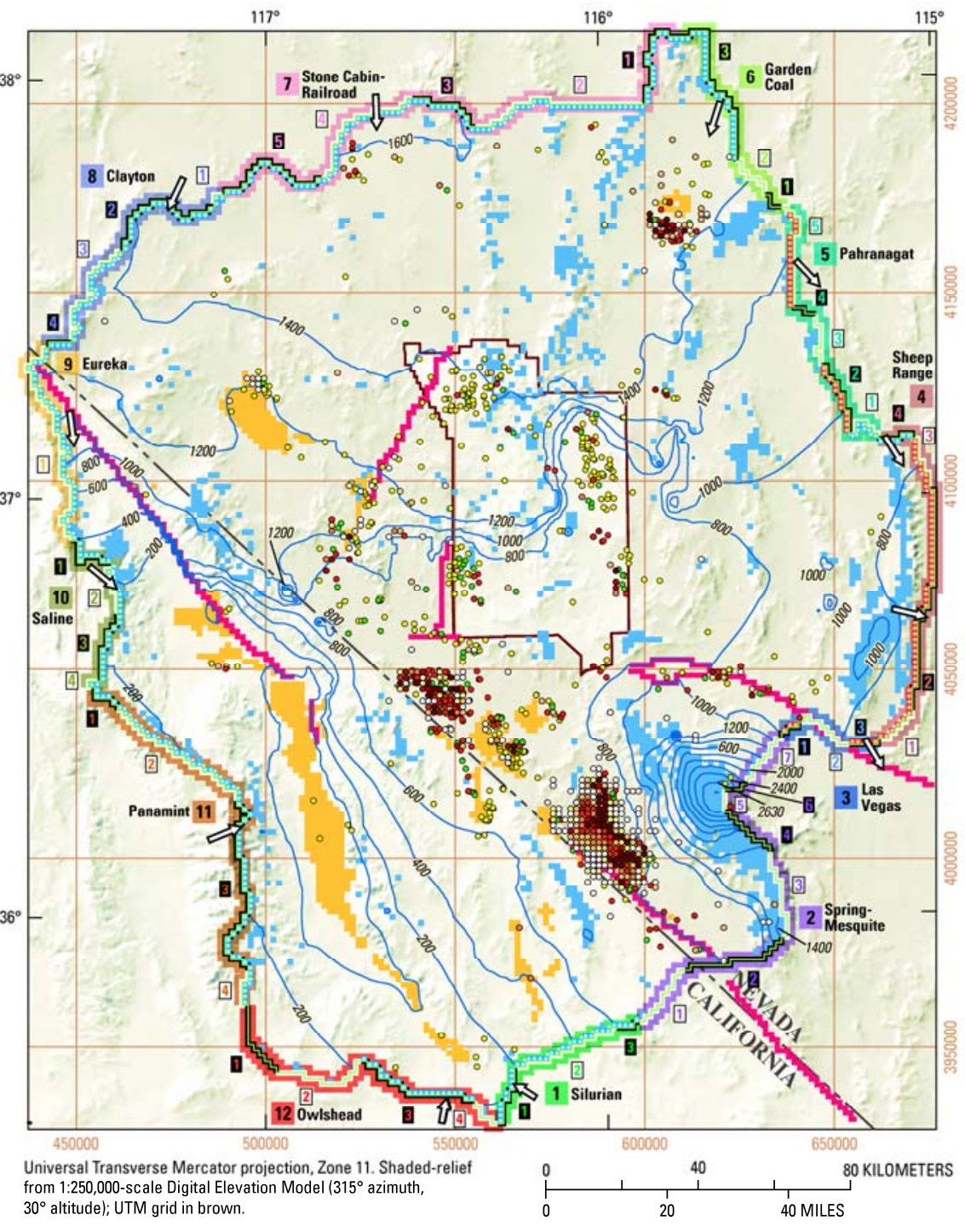
from 1:250,000-scale Digital Elevation Model (315 azimuth

EXPLANATION
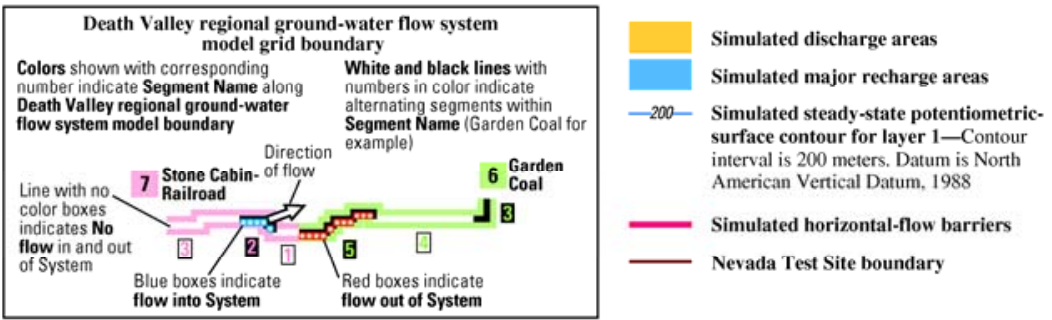
Simulated pumping well and tota withdrawal by model cell, in cubic meters per day (1913-98)
- Less than 50,000
- 50,000 to 100,000
100,000 to 500,000
500,000 to $1,000,000$
$1,000,000$ to $5,000,000$
- $5,000,000$ to $10,000,000$
Greater than $10,000,000$

Figure 4. Simulated discharge areas, major recharge areas, constant-head boundary flows, and steady-state stress period hydraulic head in the uppermost active model layer of the Death Valley regional groundwater flow system model, Nevada and California (from Blainey et al., 2006, figure 2). 
(values estimated during calibration testing were all unrealistically high). The top layer was simulated as confined and so the assigned values of specific storage were equivalent to the values of specific yield for those HGUs present in the top layer. Vertical anisotropy was set to a value of 5,000 for basin-fill aquifers and confining units, where stratification is most likely to increase horizontal conductivity relative to vertical. Intrusive, crystalline, and clastic confining HGUs were assigned vertical anisotropy values of 1.267 , while carbonate and volcanic-rock HGUs were considered isotropic. Values of hydraulic conductivity were reduced exponentially with increasing depth in most HGUs based on results from the UGTA regional model (IT Corporation, 1996a). Calibration was improved through incorporation of depth decay in all volcanic-rock and basin-fill HGUs, though slight adjustments were made to the initial depth-decay parameter values reported in IT Corporation (1996a). Depth decay was also applied throughout the lower carbonate aquifer. In this case, rates were reduced from initial values in several zones to improve model fit.

The rates and distribution of groundwater recharge are based on a net infiltration model for the Death Valley region (Hevesi et al., 2003) and are parameterized in the recharge $(\mathrm{RCH})$ package. Recharge rates are considered constant at their average annual values over the entire transient simulation time, but are highly variable in space (Figure 4). The highest recharge rates are simulated in the higher elevations of mountain ranges, including the Spring Mountains and Sheep Range. Natural discharge is simulated as evapotranspiration (ET) and spring flow using the drain (DRN) package, which simulates groundwater discharge through a head-dependent boundary. Major natural discharge areas within the model are simulated at Death Valley, Sarcobatus Flat, and Ash Meadows. Though their discharge rates are lower, Oasis Valley and Pahrump Valley are important natural discharge areas near the NTS and Yucca Mountain (Figure 4).

Calibration of the model utilizes the parameter-estimation methods included in MODFLOW, i.e., finding values of model parameters that minimize the weighted least squares objective function through nonlinear regression of simulated values and observations (Hill, 1998). The model was first calibrated to steady-state flow conditions (stress period 1) and the results used as the initial conditions for the transient flow stress periods. The model was then calibrated again to the transient conditions. During calibration, comparison of simulated values to observed values is coordinated in the observation (OBS) package. The DVRFS model observations include hydraulic head as single values and head changes over time (HOB package), drains (i.e., ET and spring discharge) (DROB package), and flow estimates at constant-head boundaries (CHOB package). Sensitivities of observations and parameters are calculated for use in sensitivity analyses and for nonlinear regression during parameter estimation using the sensitivity (SEN) process.

An important issue that is subject to significant uncertainty is the time frame associated with groundwater flowpaths. A critical parameter that significantly dictates groundwater travel time is the formation effective porosity. It is our main goal in this study to estimate the migration times and their associated uncertainties for radionuclides originating from the NTS underground tests, based on the limited existing site effective-porosity data sources and expert professional judgment combined with Monte Carlo simulations and sensitivity analyses. 
The time frame associated with pathway tracking backwards to the recharge zones is typically quite long, on the order of hundreds to hundreds of thousands years. Therefore, for long term prediction and monitoring, an assumption of steady-state flow may not be worse than an unknown transient flow scenario extended into the very distant future under highly uncertain future climactic and other conditions. To develop the flow conditions needed for pathway tracking purposes, two steady-state flow scenarios were constructed from the DVRFS model: the pre-pumping (the initial stress period of the model) and the 1998 pumping (assuming steady-state conditions based on pumping in the last stress period of the model) scenarios. The pumping well locations are shown in Figure 1. Also, because of the long time frames typically discussed in this study, the time difference between when the detonations actually took place, which span over a few decades, is of negligible importance. Therefore, the fact that the tests actually took place at different times in the past is omitted when referring to the contaminant migration time, and assume that all tests took place at the same time.

\section{GROUNDWATER PATHWAY ANALYSIS}

MODPATH (Pollock, 1994) is a particle tracking post-processing package that was developed to calculate three-dimensional flowpaths using output from steady-state or transient groundwater flow simulations by MODFLOW, the USGS finite-difference groundwater flow model. Using particle tracking techniques, groundwater advective flowpath are tracked forward from major underground detonations inside the NTS to examine whether groundwater pathways originating from the NTS would eventually intercept the proposed withdrawal areas for YM and to estimate the time frames associated with the flowpaths from the NTS to the YM region. MODPATH uses a semi-analytical particle tracking scheme that allows an analytical expression of the particle's flowpath to be obtained within each finite-difference grid cell of the DVRFS finite-difference model. Particle paths are calculated by tracking particles from one cell to the next until the particle reaches a boundary, an internal sink/source, or satisfies some other termination criteria. The particle tracking algorithm used by MODPATH can be implemented for either steady-state or transient flow fields. For steady-state flow, the partial differential equation describing conservation of mass in a three-dimensional groundwater flow system can be expressed as

$$
\frac{\partial}{\partial x}\left(\varphi v_{x}\right)+\frac{\partial}{\partial y}\left(\varphi v_{y}\right)+\frac{\partial}{\partial z}\left(\varphi v_{z}\right)=W
$$

where $v_{x}, v_{y}$, and $v_{z}$ are the principal components of the average linear groundwater velocity vector, $\varphi$ is the effective porosity, and $W$ is the volume rate created or consumed by internal sources and sinks per unit volume of aquifer. The finite-difference approximation of Equation (1) can be thought of as a mass-balance equation for a finite-sized cell of aquifer that accounts for water flowing into and out of the cell, and for water generated or consumed within the cell.

To compute path lines, it is necessary to calculate values of the principal components of the velocity vector at every point in the flow field based on the inter-cell flow rates from the DVRFS finite-difference model output. MODPATH uses simple linear interpolation to calculate the principal velocity components at points within a cell. Linear interpolation produces a continuous velocity vector field within each individual cell that identically 
satisfies the differential conservation Equation (1) everywhere within the cell. The movement of a particle, $\mathrm{p}$, through a three-dimensional finite-difference cell can be tracked by

$$
\begin{aligned}
& x_{p}\left(t_{2}\right)=x_{1}+\left(\frac{1}{A_{x}}\right)\left[v_{x p}\left(t_{1}\right) \exp \left(A_{x} \Delta t\right)-v_{x 1}\right] \\
& y_{p}\left(t_{2}\right)=y_{1}+\left(\frac{1}{A_{y}}\right)\left[v_{y p}\left(t_{1}\right) \exp \left(A_{y} \Delta t\right)-v_{y 1}\right] \\
& z_{p}\left(t_{2}\right)=z_{1}+\left(\frac{1}{A_{z}}\right)\left[v_{z p}\left(t_{1}\right) \exp \left(A_{z} \Delta t\right)-v_{z 1}\right]
\end{aligned}
$$

where $x_{p}\left(t_{2}\right), y_{p}\left(t_{2}\right)$, and $z_{p}\left(t_{2}\right)$ are the particle p's coordinates at the current time $t_{2}, x_{1}, y_{1}$, and $z_{1}$ are the cell's face coordinates, $A_{x}, A_{y}$, and $A_{z}$ are the components of the velocity gradient within the cell, $v_{x p}\left(t_{1}\right), v_{y p}\left(t_{1}\right)$, and $v_{z p}\left(t_{1}\right)$ are the particle's velocity components at time $t_{1}$; and $v_{x 1}, v_{x 2}$, and $v_{x 3}$ are the velocity components across face $x_{1}, x_{2}$, and $x_{3}$. The coordinates of the particle at any future time $\left(t_{2}\right)$ can be calculated directly from $(2 \mathrm{a})$ through $(2 \mathrm{c})$. For a detailed description of how to implement $(2 a)$ through $(2 c)$ into the numerical algorithm and deal with special cases, interested readers are referred to the user's guide for MODPATH (Pollock, 1994).

\section{UNDERGROUND NUCLEAR TESTS}

The NTS has served as the principal facility for nuclear testing by the DOE, its predecessor agencies, and the U.S. Department of Defense. Between the years 1951 and 1992, 100 atmospheric and 828 underground nuclear tests were conducted at the NTS (DOE, 2000). Most of the underground nuclear tests occurred in four geographic areas of the NTS: Frenchman Flat, Yucca Flat, Rainier Mesa, and Pahute Mesa (DOE, 1977). In the study by Zhu et al. (2006), the potential groundwater migration pathways were investigated by tracking backward from the proposed YM repository area toward groundwater recharge zones based on the flow output from the DVRFS model. Simulated pathways that pass nuclear testing areas indicated regions on the NTS where potentially contaminated groundwater flow may originate. The results indicated that a significant portion of recharge that could migrate toward the YM area comes from a clustered region around Pahute Mesa (in the NTS operational areas 18,19, 20, and 30), where relatively higher elevations provide conditions conducive to greater groundwater recharge. Therefore, the focus of this study is for the underground detonations in these areas, which are shown in Figure 1 as the red squares. Table 1 lists locations and depths of these detonations (DOE, 2000). Note that the total depth of the emplacement borehole was typically used as a proxy for the actual depth of burial for a detonation. However, for some of the early detonations, a room was mined at some depth within the borehole to facilitate testing of the device. This additional information provided an upper boundary on the actual depth of burial for these detonations. Transport simulations captured this additional information by simulating two depths of burials for these detonations, one in the mined room and the other at the total depth of the emplacement borehole. These instances are designated within the table by redundant listing of the detonation name, with the mined room designated by a "-1" extension to the detonation name. Therefore, those designated by "-1" extension in Table 1 do not imply separate 
detonations, rather they were included to account for uncertainty of the actual burial depth. The depth of burial information was derived from Raytheon Services of Nevada (1990). From the locations, depths and surface elevations of the underground detonations, and the water table depths from the DVRFS model, it is determined that 71 of the 100 detonations considered in this study were in the saturated zone. Based on the pathway tracking results, it was found that flowpaths from 23 of the 71 saturated zone detonations will intercept YM under the pre-pumping scenario, while flowpaths from 55 of the 71 will intercept the YM area under the 1998 pumping conditions. Since the underground detonations in the unsaturated zone have lower potential for introducing radionuclides to the saturated zone, this study is focused on the underground detonations in the saturated zone. Table 2 shows the detonations that were in the saturated zone and also indicates if the particles from these detonations will intercept the saturated zone beneath the proposed YM withdrawal area.

\section{GROUNDWATER FLOWPATHS}

Considering contaminants potentially migrating from each detonation under the groundwater table as a particle, potential contaminants from those saturated zone detonations were tracked forward using MODPATH to identify hydraulically downgradient groundwater discharge zones and to assess the sources of contaminants that will intercept the proposed YM withdrawal area. Figure 5 shows groundwater flowpaths for all 71 particles located in the saturated zone resulting from the pre-pumping steady-state flow scenario, and Figure 6 indicates the flowpaths of the same 71 particles for the 1998 pumping scenario. Out of these 71 detonations in the saturated zone, the flowpaths from 23 of the 71 detonations will intercept the proposed YM withdrawal area under the pre-pumping scenario (see Figure 7). For the 1998 pumping scenario, the flowpaths from 55 of the 71 detonations will intercept the YM withdrawal area (see Figure 8).

A conclusion can be drawn from these results. Groundwater pumping not only increases the groundwater travel velocity from the detonations to YM area, but also induces more detonation flowpaths to intercept the YM area. Because of pumping, many flowpaths to the west of the YM area are now drawn to the YM area, as can be seen from a comparison between Figures 5 and 6. From Table 2, it can be observed that all flowpaths that pass through the YM area under the pre-pumping conditions will also intercept the YM area under the pumping scenario, with the exception of Camembert, under the pumping scenario. In addition, particles from many more detonations that do not intercept the YM area under the pre-pumping conditions will pass through the YM area. It seems that the intensive pumping in the Amargosa Desert, especially those pumping wells in the western part of the well cluster in the valley, result in more direct flowpaths from the underground detonations to the YM area.

\section{HYDROGEOLOGIC UNITS}

The rocks and deposits forming the hydrostratigraphic framework for the groundwater flow system in the DVRFS region are termed the HGUs. An HGU has considerable lateral extent and is assumed to have reasonably distinct hydrologic properties because of its geological and structural characteristics (Belcher, 2004). The unconsolidated sediments and consolidated rocks of the DVRFS have been subdivided into 27 HGUs. These HGUs are based primarily on the work of Winograd and Thordarson (1975) as modified by Laczniak et al. (1996). Table 3 shows the HGUs for the DVRFS hydrogeologic framework 
Table 1. Major detonations in Areas 18, 19, 20, and 30 of NTS.

\begin{tabular}{|c|c|c|c|c|c|c|c|c|c|}
\hline \begin{tabular}{|l|} 
Detonation \\
\end{tabular} & X UTM (m) & Y UTM (m) & Dep. (m) & Elev. (m) & Detonation & X UTM (m) & Y UTM (m) & Dep. (m) & Elev. (m) \\
\hline Johnnie Boy & 559242.75 & 4108410.49 & 0.58 & 1544.00 & Molbo & 547630.25 & 4119653.01 & 637.95 & 1873.00 \\
\hline Danny Boy & 556408.17 & 4107170.72 & 33.53 & 1641.00 & Gibne & 551245.94 & 4123224.43 & 569.98 & 1937.00 \\
\hline Sulky & 558473.16 & 4104078.38 & 27.43 & 1597.00 & Jefferson & 549644.50 & 4124102.37 & 608.99 & 1955.00 \\
\hline Sheepshead & 556409.36 & 4120262.00 & 680.01 & 2033.00 & Cabra & 547847.74 & 4128196.84 & 566.01 & 1907.00 \\
\hline Towanda & 559850.09 & 4122948.46 & 685.80 & 2085.00 & Salut & 545309.32 & 4122302.80 & 608.08 & 1873.00 \\
\hline Tierra & 561600.95 & 4126067.61 & 640.08 & 2118.00 & Egmont & 544586.87 & 4124739.67 & 609.60 & 1839.00 \\
\hline Chancellor & 557174.54 & 4125148.74 & 685.80 & 2013.00 & Kappeli & 552213.13 & 4124561.71 & 640.08 & 1982.00 \\
\hline Nebbiolo & 555871.94 & 4121035.02 & 832.10 & 2038.00 & Serena & 549800.12 & 4127764.43 & 597.10 & 1942.00 \\
\hline Serpa & 560679.14 & 4130942.55 & 632.46 & 2028.00 & Goldstone & 546734.47 & 4121201.18 & 655.32 & 1887.00 \\
\hline Harzer & 559810.57 & 4128495.48 & 670.56 & 2073.00 & Bodie & 552127.91 & 4124006.46 & 634.90 & 1991.00 \\
\hline Hosta & 560572.09 & 4133493.56 & 655.32 & 2076.00 & Darwin & 544412.48 & 4124184.03 & 579.12 & 1849.00 \\
\hline Labquark & 561408.22 & 4128174.18 & 615.70 & 2100.00 & Kernville & 546864.81 & 4129633.56 & 561.14 & 1899.00 \\
\hline Lockney & 555434.29 & 4120144.58 & 615.70 & 2045.00 & Belmont & 547721.48 & 9.76 & 5.03 & 1871.00 \\
\hline Cybar & 557170.01 & 4125814.38 & 627.89 & 2017.00 & Delamar & 543535.58 & 4122293.43 & 579.12 & 1875.00 \\
\hline Scotch & 555843.19 & 4125361.67 & $1,092.40$ & 2034.00 & Hardin & 551172.79 & 4120672.29 & 625.14 & 1943.00 \\
\hline Scotch - 1* & 555843.19 & 4125361.67 & 978.41 & 2034.00 & Contact & 552114.14 & 4126225.26 & 640.08 & 1980.00 \\
\hline Alamo & 555239.37 & 4122805.95 & 670.56 & 1964.00 & Comstock & 549558.45 & 4123658.09 & 620.27 & 1960.00 \\
\hline Kearsarge & 561499.29 & 4127842.01 & 670.56 & 2102.00 & Barnwell & 552416.04 & 4120458.06 & 600.76 & 2031.00 \\
\hline Amarillo & 557350.34 & 4125371.83 & 657.15 & 2019.00 & Pipkin & 549560.41 & 4123325.27 & 624.84 & 5.00 \\
\hline Houston & 555 & 5.98 & .36 & 1.00 & Tenabo & 5.88 & 0.42 & & .00 \\
\hline Halfbeak & 562104.09 & 4129954.46 & 879.04 & 2043.00 & Hornitos & 545123.01 & 4123965.93 & 609.60 & 1846.00 \\
\hline Bexar & 560879.68 & 4127726.54 & 629.72 & 2118.00 & Bullion & 551419.23 & 4123891.15 & 687.32 & 1950.00 \\
\hline Junction & 556732.00 & 4125034.79 & 657.45 & 2013.00 & Hoya & 550733.95 & 4119893.04 & 676.66 & 1951.00 \\
\hline Rickey & 560727.29 & 4124286.11 & 968.35 & 2116.00 & Montello & 549479.57 & 4121993.48 & 14.94 & 61.00 \\
\hline Rickey - 1* & 560727.29 & 4124286.11 & 682.75 & 2116.00 & Benham & 546738.79 & 4120424.61 & $1,463.04$ & 1887.00 \\
\hline Chartreuse & 560040.67 & 4133489.73 & 678.18 & 2064.00 & Benham - 1* & 546738.79 & 4120424.61 & $1,404.21$ & 1887.00 \\
\hline Muenster & 559106.27 & 4127824.81 & $1,539.24$ & 2082.00 & Knickerbocker & 546107.50 & 4122307.14 & & 1878.00 \\
\hline Muenster - $1^{*}$ & 559106.27 & 4127824.81 & $1,452.37$ & 2082.00 & Jorum & 547750.91 & 4129638.56 & $1,174.39$ & 1898.00 \\
\hline Inlet & 556146.19 & 4119816.47 & 830.28 & 2025.00 & Fontina & 545384.23 & 4124854.88 & $1,280.77$ & 1837.00 \\
\hline Estuary & 556349.05 & 4129248.13 & $1,003.40$ & 2025.00 & Fontina - ${ }^{*}$ & 545384.23 & 4124854.88 & $1,234.44$ & 1837.00 \\
\hline Estuary - $1^{*}$ & 556349.05 & 4129248.13 & 917.45 & 2025.00 & Greeley & 552455.55 & 4128335.33 & $1,280.16$ & 1945.00 \\
\hline Sled & 557901.39 & 4122601.98 & $1,223.16$ & 2057.00 & Rex & 550171.21 & 4124993.04 & 671.78 & 1971.00 \\
\hline Stinger & 561027.06 & 4131832.65 & 685.80 & 2035.00 & Boxcar & 548206.06 & 4127533.23 & $1,434.08$ & 1914.00 \\
\hline Scroll & 555353.77 & 4132347.99 & 228.60 & 2032.00 & Boxcar - 1* & 548206.06 & 4127533.23 & $1,165.86$ & 1914.00 \\
\hline Pool & 559581.69 & 4123279.39 & $1,025.96$ & 2076.00 & Palanquin & 542276.10 & 4125837.14 & 85.34 & 1861.00 \\
\hline Camembert & 556017.54 & 4125806.61 & $1,338.68$ & 2033.00 & Cabriolet & 543073.38 & 4125952.14 & 51.82 & 1862.00 \\
\hline Emmenthal & 562304.37 & 4126849.43 & 588.87 & 2104.00 & Handley & 541290.05 & 4128051.08 & $1,249.68$ & 1772.00 \\
\hline Mast & 560216.21 & 4133712.89 & 929.64 & 2068.00 & Handley - 1* $^{*}$ & 541290.05 & 4128051.08 & $1,207.62$ & 1772.00 \\
\hline Almendro & 557993.90 & 4122047.89 & $1,082.04$ & 2069.00 & Cheshire & 551432.12 & 4121783.31 & $1,301.19$ & 1947.00 \\
\hline Backbeach & 556051.57 & 4120703.39 & 679.70 & 2040.00 & Stilton & 542242.58 & 4132493.54 & 998.22 & 1667.00 \\
\hline Panir & 556994.96 & 4125480.35 & 716.28 & 2013.00 & Chateaugay & 545843.25 & 4121972.87 & 617.22 & 1876.00 \\
\hline Fondutta & 559635.69 & 4128161.39 & 643.13 & 2072.00 & Schooner & 538432.17 & 4132808.03 & 111.25 & 1668.00 \\
\hline Buteo & 550456.50 & 4121777.40 & 774.19 & 1960.00 & Purse & 544224.64 & 4126180.00 & 602.59 & 1828.00 \\
\hline Duryea & 550456.50 & 4121777.40 & 544.37 & 1960.00 & Tybo & 546656.23 & 4119314.73 & 793.09 & 1880.00 \\
\hline Colby & 546869.77 & 4128746.04 & $1,273.45$ & 1904.00 & Kasseri & 552197.96 & 4127002.39 & $1,264.92$ & 1957.00 \\
\hline Farm & 552298.34 & 4125116.96 & 688.85 & 1979.00 & Buggy-A & 556040.27 & 4095630.43 & 41.15 & 1560.00 \\
\hline Colwick & 551251.36 & 4122336.92 & 633.07 & 1946.00 & Buggy-B & 556039.53 & 4095741.36 & 41.15 & 1560.00 \\
\hline Pepato & 548297.89 & 4126979.04 & 680.62 & 1913.00 & Buggy-C & 555950.57 & 4095740.77 & 41.15 & 1561.00 \\
\hline Tafi & 546368.67 & 4123196.11 & 680.01 & 1859.00 & Buggy-D & 555950.57 & 4095740.77 & 41.15 & 1560.00 \\
\hline Kash & 548391.64 & 4126092.04 & 644.96 & 1911.00 & Buggy-E & 555861.60 & 4095740.19 & 41.15 & 1560.00 \\
\hline
\end{tabular}

* The total depth of the emplacement borehole was typically used as a proxy for the actual depth of burial for a detonation. However, for some of the early detonations, a room was mined at some depth within the borehole to facilitate testing of the device. This additional information provided an upper boundary on the actual depth of burial for these detonations. Transport simulations captured this additional information by simulating two depths of burials for these detonations, one in the mined room and the other at the total depth of the emplacement borehole. These instances are designated within the table by redundant listing of the detonation name, with the mined room designated by a "-1" extension to the detonation name. 
Table 2. Detonations in the saturated zone.

\begin{tabular}{|c|c|c|c|c|c|}
\hline $\begin{array}{l}\text { Detonation } \\
\text { Name }\end{array}$ & $\begin{array}{l}\text { Path to YM? } \\
\text { (Pre-pumping) }\end{array}$ & $\begin{array}{c}\text { Path to YM? } \\
\text { (1998 pumping) }\end{array}$ & $\begin{array}{l}\text { Detonation } \\
\text { Name }\end{array}$ & $\begin{array}{l}\text { Path to YM? } \\
\text { (Pre-pumping) }\end{array}$ & $\begin{array}{c}\text { Path to YM? } \\
\text { (1998 pumping) }\end{array}$ \\
\hline Sheepshead & YES & YES & Jefferson & & \\
\hline Chancellor & YES & YES & Cabra & & YES \\
\hline Nebbiolo & & YES & Salut & & YES \\
\hline Serpa & YES & YES & Egmont & & YES \\
\hline Harzer & YES & YES & Kappeli & & \\
\hline Cybar & YES & YES & Serena & & YES \\
\hline Scotch & & YES & Goldstone & & YES \\
\hline Scotch-1 & YES & YES & Kernville & & YES \\
\hline Alamo & & YES & Belmont & & YES \\
\hline Amarillo & YES & YES & Hardin & & \\
\hline Halfbeak & YES & YES & Contact & & \\
\hline Junction & & YES & Comstock & & \\
\hline Rickey & YES & YES & Pipkin & & \\
\hline Chartreuse & YES & YES & Tenabo & & YES \\
\hline Muenster & YES & YES & Hornitos & & YES \\
\hline Muenster-1 & YES & YES & Bullion & & \\
\hline Inlet & YES & YES & Hoya & & YES \\
\hline Estuary & YES & YES & Benham & YES & YES \\
\hline Estuary-1 & & YES & Benham-1 & & YES \\
\hline Sled & YES & YES & Knickerbocker & & YES \\
\hline Stinger & YES & YES & Jorum & & YES \\
\hline Pool & YES & YES & Fontina & & YES \\
\hline Camembert & YES & & Fontina-1 & & YES \\
\hline Mast & YES & YES & Greeley & & YES \\
\hline Almendro & YES & YES & Rex & & YES \\
\hline Backbeach & YES & YES & Boxcar & & YES \\
\hline Panir & & YES & Boxcar-1 & & YES \\
\hline Fondutta & YES & YES & Handley & & \\
\hline Buteo & & & Handley-1 & & \\
\hline Colby & & YES & Cheshire & & \\
\hline Farm & & & Stilton & & \\
\hline Colwick & & & Chateaugay & & YES \\
\hline Pepato & & YES & Purse & & YES \\
\hline Tafi & & YES & Tybo & & YES \\
\hline Kash & & YES & Kasseri & & \\
\hline Molbo & & YES & & & \\
\hline
\end{tabular}




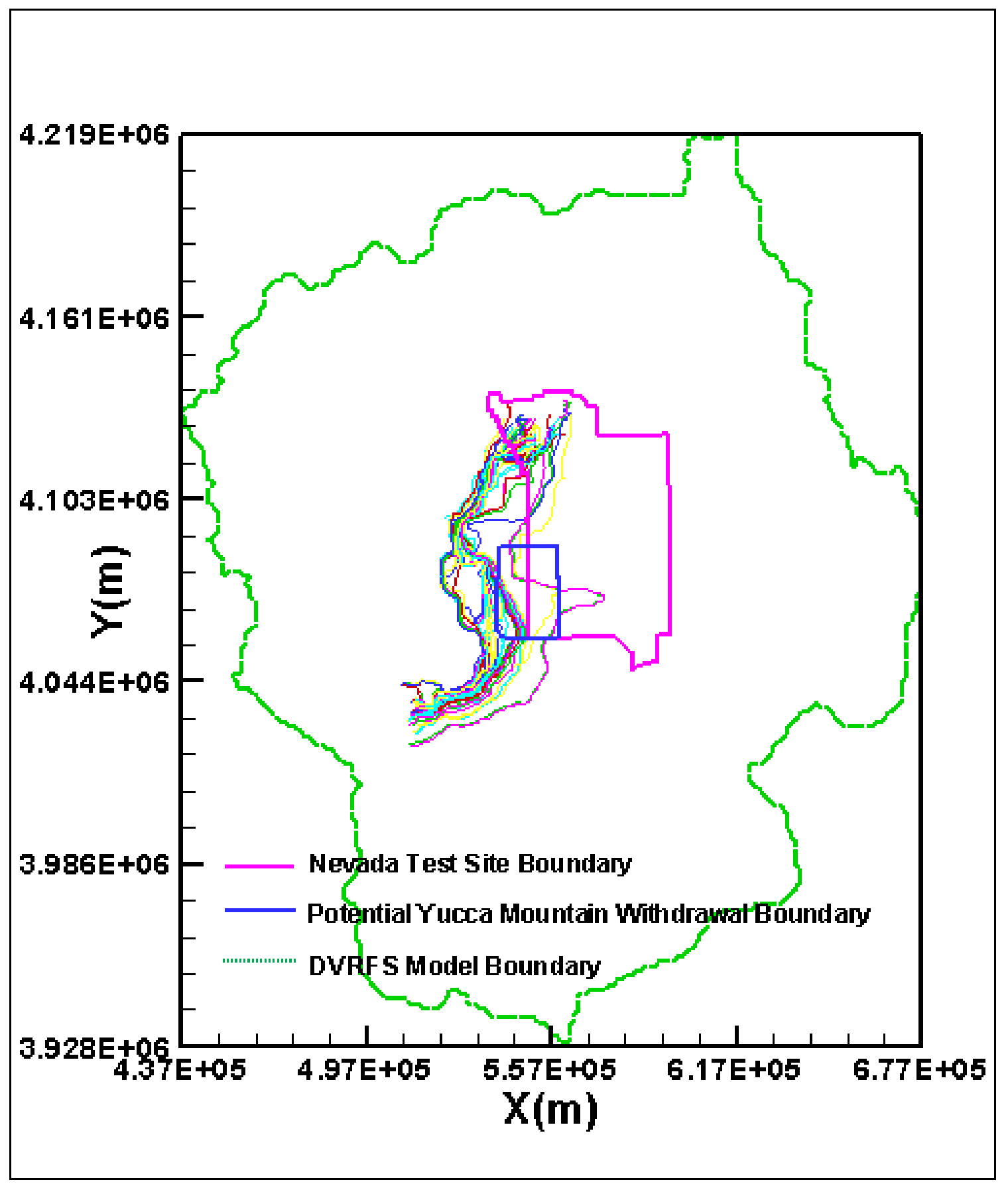

Figure 5. Flowpaths of all 71 particles located in the saturated zone as a result of the pre-pumping steady-state flow scenario. 


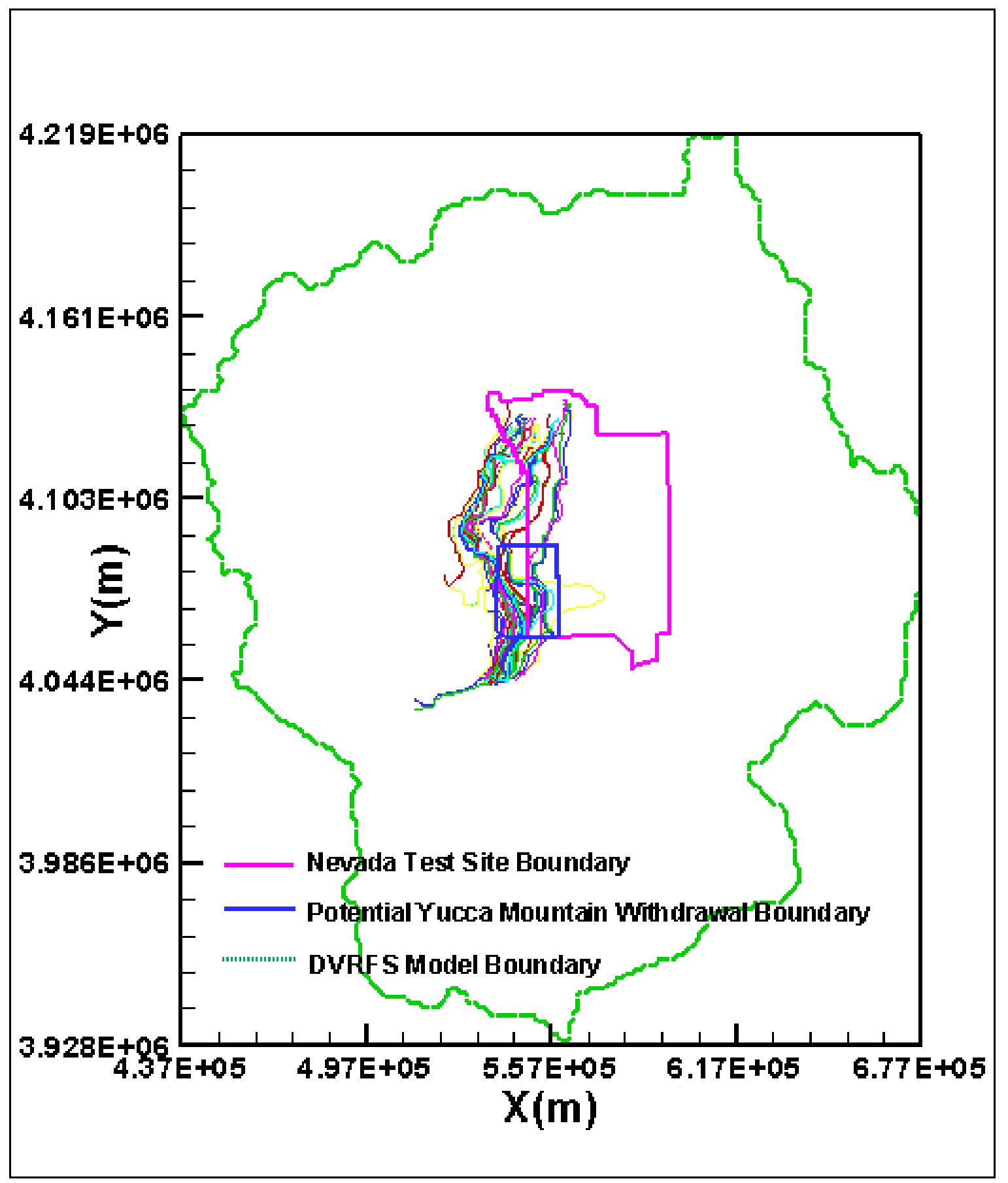

Figure 6. Flowpaths of all 71 particles located in the saturated zone as a result of the 1998 pumping steady-state flow scenario. 


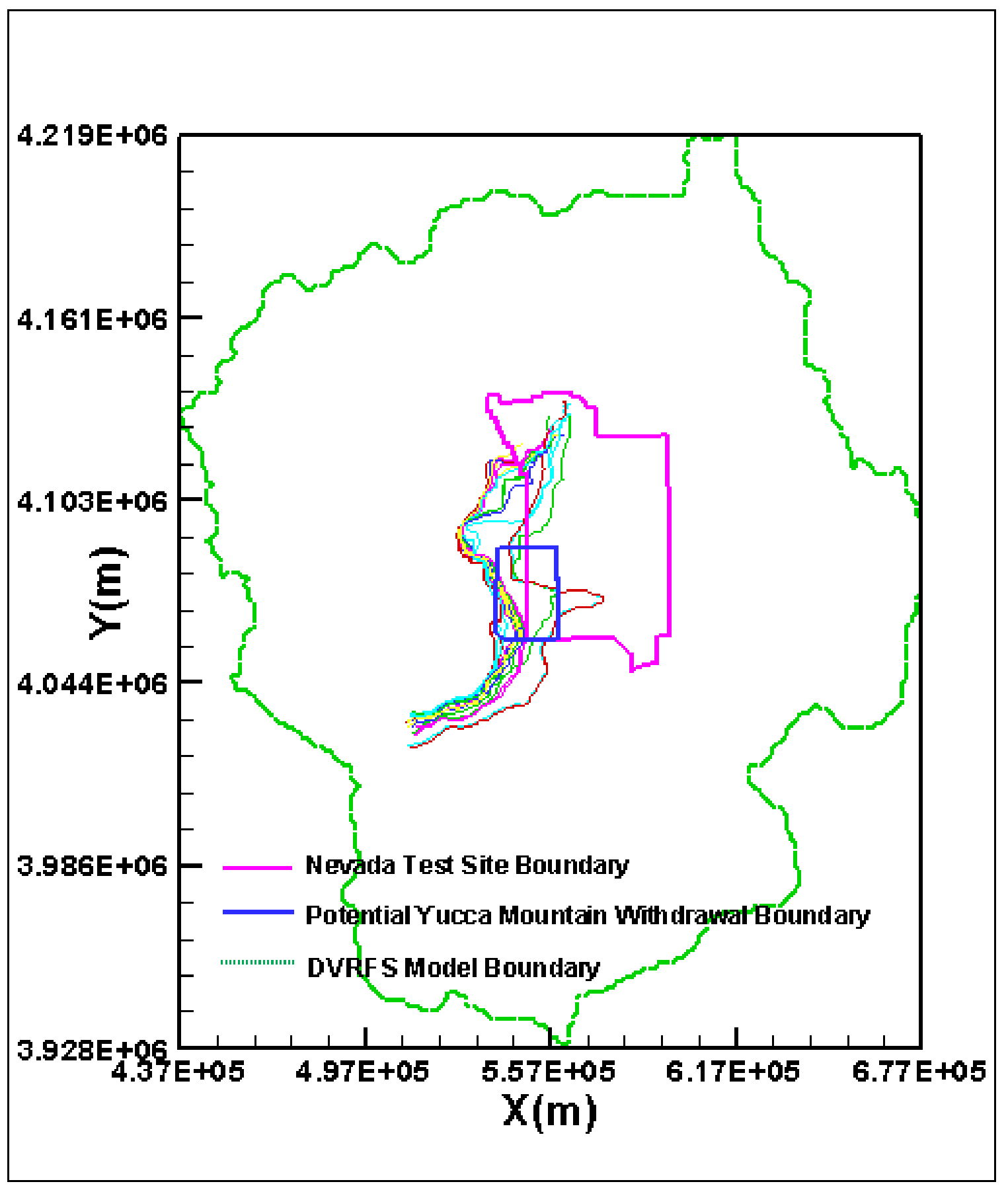

Figure 7. Flowpaths of 23 particles (out of total 71) toward YM as a result of the pre-pumping steady-state flow scenario (flowpaths pass through YM to discharge zone). 


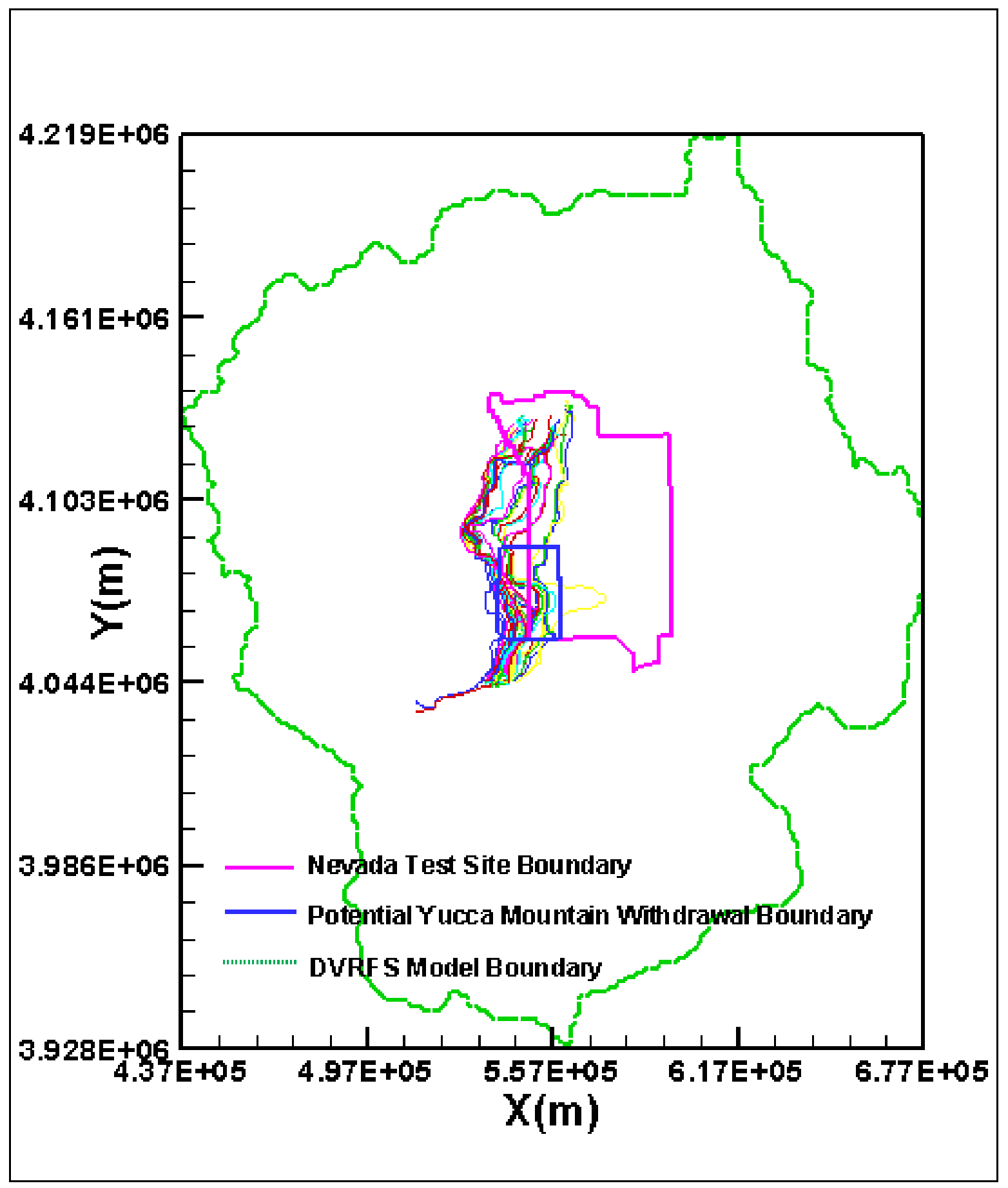

Figure 8. Flowpaths of 55 particles (out of total 71) toward YM as a result of the 1998 pumping steady-state flow scenario (flowpaths pass through YM). 
model. A general description of these HGUs is given below. Refer to Belcher (2004) for more detailed description and discussion.

\section{Unconsolidated Cenozoic Basin-fill Sediments and Local Young Volcanic Rocks}

Unconsolidated Cenozoic basin-fill sediments consist of coarse-grained alluvial and colluvial deposits, fine-grained basin axis deposits, local lacustrine limestones, and spring discharge deposits, and are divided into six HGUs. Relatively local basaltic- and rhyoliticlava flows and tuffs form another HGU.

Younger and older alluvial aquifers (YAA and OAA) are coarse-grained surficial units. In general, fluvial deposits are predominantly sandy gravel with interbedded gravelly sand and sand. These HGUs tend to be aquifers, but finer-grained sediments and intercalated volcanic rocks locally can impede groundwater flow. Younger and older alluvial confining units (YACU and OACU) typically are mixtures of moderately to well-stratified silt, clay, and fine sand. The thickness is poorly constrained but may range from 1 to $10 \mathrm{~m}$ for Holocene deposits and may be greater than $300 \mathrm{~m}$ for the older deposits. The hydrologic properties of these deposits can differ greatly over short distances because of abrupt changes in grain size, fracturing, and consolidation. Lava-flow units (LFU) are not laterally extensive and because the LFU is typically above the water table, the unit is not a regional aquifer. Younger volcanic-rock units (YVU) mostly lies above the water table and is thought to have limited influence on groundwater flow in the DVRFS region.

\section{Consolidated Cenozoic Basin-Fill Deposits - Volcanic- and Sedimentary-Rock Unit (VSU)}

The VSU consists of all Cenozoic basin-filling sedimentary and volcanic rocks, except for the named rocks in the vicinity of the Southwestern Nevada Volcanic Field (SWNVF) and the alluvial HGUs discussed earlier. They consist of a broad range of both volcanic and sedimentary rocks including lavas, welded and unwelded tuffs, and alluvial, fluvial, colluvial, eolian, paludal, and lacustrine sediments. The VSU is lithologically diverse and rock types are complexly interfingered. The VSU was divided into two units, the Lower VSU and Upper VSU in the DVRFS model. The Lower VSU consists of those rocks that underlie the named volcanic rocks of the SWNVF; the Upper VSU consists of those rocks that overlie the named volcanic rocks of the SWNVF.

\section{Volcanic Rocks of the Southwestern Nevada Volcanic Field}

Volcanic rocks that emanate from the SWNVF are widely distributed in the westcentral part of the DVRFS region; associated caldera collapse structures of the SWNVF dominate the northwestern and west-central parts of the NTS. The volcanic-rock units of the SWNVF are important HGUs because they are thick enough in the vicinity of the NTS to be important subregional aquifers. The major underground nuclear detonations considered in this study were conducted in the volcanic rock underlying Pahute Mesa at the NTS. The recommended high-level nuclear waste repository at YM would also be located in these volcanic rocks. The volcanic-rocks units are divided at the group level into nine HGUs, 
Table 3. Hydrogeologic units for the Death Valley regional groundwater flow system hydrogeologic framework model (from Belcher, 2004, chapter B).

\begin{tabular}{|c|c|c|}
\hline $\begin{array}{c}\text { HGU } \\
\text { abbreviation }\end{array}$ & $\begin{array}{l}\text { Hydrogeologic } \\
\text { unit name }\end{array}$ & Description \\
\hline YAA & Younger alluvial aquifer & Pliocene to Holocene coarse-grained basin-fill deposits \\
\hline YACU & Younger alluvial confining unit & Pliocene to Holocene playa and fine-grained basin-fill deposits \\
\hline OAA & Older alluvial aquifer & Pliocene to Holocene coarse-grained basin-fill deposits \\
\hline OACU & Older alluvial confining unit & Pliocene to Holocene playa and fine-grained basin-fill deposits \\
\hline LA & Limestone aquifer & Cenozoic limestone, undivided \\
\hline LFU & Lava flow unit & $\begin{array}{l}\text { Cenozoic basalt cones and flows and surface outcrops of rhyolite-lava } \\
\text { flows }\end{array}$ \\
\hline YVU & Younger volcanic-rock unit & Cenozoic volcanic rocks that overlie the Thirsty Canyon Group \\
\hline Upper VSU & $\begin{array}{l}\text { Upper volcanic- and } \\
\text { sedimentary-rock unit }\end{array}$ & $\begin{array}{l}\text { Cenozoic volcanic and sedimentary rocks, undivided, that overlie } \\
\text { volcanic rocks of SWNVF }\end{array}$ \\
\hline TMVA & $\begin{array}{l}\text { Thirsty Canyon-Timber } \\
\text { Mountain volcanic-rock } \\
\text { aquifer }\end{array}$ & $\begin{array}{l}\text { Miocene Thirsty Canyon and Timber Mountain Groups, plus Stonewall } \\
\text { Mountain Tuff, undivided }\end{array}$ \\
\hline PVA & $\begin{array}{l}\text { Paintbrush volcanic-rock } \\
\text { aquifer }\end{array}$ & Miocene Paintbrush Group \\
\hline CHVU & Calico Hills volcanic-rock unit & Miocene Calico Hills Formation \\
\hline WVU & Wahmonie volcanic-rock unit & Miocene Wahmonie and Salyer Formations \\
\hline CFPPA & Crater Flat-Prow Pass aquifer & Miocene Crater Flat Group, Prow Pass Tuff \\
\hline CFBCU & $\begin{array}{l}\text { Crater Flat-Bullfrog confining } \\
\text { unit }\end{array}$ & Miocene Crater Flat Group, Bullfrog Tuff \\
\hline CFTA & Crater Flat-Tram aquifer & Miocene Crater Flat Group, Tram Tuff \\
\hline BRU & Belted Range unit & Miocene Belted Range Group \\
\hline OVU & Older volcanic-rock unit & $\begin{array}{l}\text { Oligocene to Miocene; near the NTS consists of all volcanic rocks older } \\
\text { than the Belted Range Group. Elsewhere, consists of all tuffs that } \\
\text { originated outside of the SWNVF }\end{array}$ \\
\hline Lower VSU & $\begin{array}{l}\text { Lower volcanic- and } \\
\text { sedimentary-rock unit }\end{array}$ & $\begin{array}{l}\text { Cenozoic volcanic and sedimentary rocks, undivided; where named } \\
\text { Cenozoic volcanic rocks exist, Lower VSU underlies them }\end{array}$ \\
\hline SCU & $\begin{array}{l}\text { Sedimentary-rock confining } \\
\text { unit }\end{array}$ & Paleozoic and Mesozoic sedimentary and volcanic rocks \\
\hline UCA & Upper carbonate-rock aquifer & $\begin{array}{l}\text { Paleozoic carbonate rocks (UCA only used where UCCU exists, } \\
\text { otherwise UCA is lumped with LCA) }\end{array}$ \\
\hline UCCU & $\begin{array}{l}\text { Upper clastic-rock confining } \\
\text { unit }\end{array}$ & $\begin{array}{l}\text { Upper Devonian to Mississippian Eleana Formation and Chainman } \\
\text { Shale }\end{array}$ \\
\hline LCA_T1 & $\begin{array}{l}\text { Lower carbonate-rock aquifer } \\
\text { (thrusted) }\end{array}$ & Cambrian through Devonian predominantly carbonate rocks - thrusted \\
\hline LCCU_T1 & $\begin{array}{l}\text { Lower clastic-rock confining } \\
\text { unit (thrusted) }\end{array}$ & $\begin{array}{l}\text { Late Proterozoic through Lower Cambrian primarily siliciclastic rocks } \\
\text { (including the Pahrump Group and Noonday dolomite) - thrusted }\end{array}$ \\
\hline LCA & Lower carbonate-rock aquifer & Cambrian through Devonian predominantly carbonate rocks \\
\hline $\mathrm{LCCU}$ & $\begin{array}{l}\text { Lower clastic-rock confining } \\
\text { unit }\end{array}$ & $\begin{array}{l}\text { Late Proterozoic through Lower Cambrian primarily siliciclastic rocks } \\
\text { (including the Pahrump Group and Noonday dolomite) }\end{array}$ \\
\hline $\mathrm{XCU}$ & Crystalline-rock confining unit & Middle Proterozoic metamorphic and igneous rocks \\
\hline ICU & Intrusive-rock confining unit & All intrusive rocks, regardless of age \\
\hline
\end{tabular}

except for the Crater Flat Group. The Crater Flat Group is subdivided at the formation level with three separate HGUs (i.e., Prow Pass, Bullfrog, and Tram tuffs).

Thirsty Canyon-Timber Mountain volcanic-rock aquifer (TMVA) is composed of the volcanic rocks of the Timber Mountain Group, the Thirsty Canyon Group, and the Stonewall Flat Tuff (Sawyer et al., 1994). The Paintbrush volcanic-rock aquifer (PVA) is composed of rhyolite tuffs and lavas of the Paintbrush Group. Paintbrush Group rocks at YM are generally above the water table. Paintbrush group rocks lie above the water table in the eastern and central parts of Pahute Mesa, and below the water table in the western part of Pahute Mesa 
(Laczniak et al., 1996). The Calico Hills volcanic-rock unit (CHVU) is a sequence of thick rhyolite-lava flows and intercalated, variably welded ash-flow deposits and nonwelded ashfall deposits that lie between the Crater Flat Group and Paintbrush Group rocks at YM and Pahute Mesa (Sawyer et al., 1994). The CHVU is an aquifer in the central and western parts of Pahute Mesa. In the northeastern part of Pahute Mesa and beneath the southern part of YM, relatively minor lava flows are isolated between thick intervals of nonwelded ash-flow tuff, and the CHVU functions as a confining unit. The Wahmonie volcanic-rock unit (WVU) is composed of the Wahmonie Formation. The Wahmonie Formation consists of andesiticand dacitic-lava flows, tephra, and related volcaniclastic deposits.

The Crater Flat Group consists of three principal units: the Tram Tuff, overlain by the Bullfrog Tuff, and the Prow Pass Tuff and two local units, the tuff of Pool, and the rhyolite of Inlet (Sawyer et al., 1994). To maintain consistency with the three-dimensional geologic framework model constructed for the proposed geologic repository for high-level radioactive waste at YM, the Prow Pass, Bullfrog, and Tram tuffs of the Crater Flat Group are treated as separate HGUs. The Crater Flat Group rocks are present in the Pahute Mesa area as well as in the vicinity of YM and Crater Flat. The Crater Flat-Prow Pass Aquifer (CFPPA) consists of the Prow Pass Tuff of the Crater Flat Group and local time-equivalent tuffs and rhyolite-lava flows present in the subsurface beneath Pahute Mesa. The Bullfrog Tuff of the Crater Flat Group comprises the Crater Flat-Bullfrog confining unit (CFBCU). The Tram Tuff of the Crater Flat Group constitutes the Crater Flat-tram aquifer (CFTA).

The Belted Range units (BRU) are composed of the Grouse Canyon Tuff and associated pre-caldera lava flows and post caldera lavas and tuffs of the Dead Horse Flat Formation (Sawyer et al., 1994). Aquifers in the BRU include both thick post-caldera rhyolitic lavas of the Dead Horse Flat Formation and welded Grouse Canyon Tuff. Belted Range Group rocks are not present in the southern parts of the SWNVF, including YM. Aquifers in the BRU include both thick post-caldera rhyolitic lavas of the Dead Horse Flat Formation and the welded Grouse Canyon Tuff. The lavas are highly fractured and form the principal aquifer unit on the eastern part of Pahute Mesa. The Older Volcanic-rock Unit (OVU) consists of Oligocene and early Miocene volcanic rocks that consist of ash-flow tuff, ash-fall tuff, reworked tuff, tuff breccia, lava flows, and volcaniclastic rocks. The OVU may be subdivided into two general groups: (1) those volcanic rocks in and near, and perhaps originating from, the SWNVF, and (2) volcanic rocks that originated from volcanic centers to the north of the SWNVF. The OVU is important in Yucca and Frenchman flats, where it separates the overlying fractured volcanic-rock aquifers from the underlying regional carbonate-rock aquifer. The OVU is saturated in much of the central part of Yucca Flat, and measured transmissivities are very low.

\section{HGUs Associated with Mesozoic, Paleozoic, and Late Proterozoic Sedimentary Rocks}

The pre-Cenozoic sedimentary rocks of the DVRFS region are grouped into five HGUs: the sedimentary-rock confining unit (SCU), upper carbonate-rock aquifer (UCA), upper clastic-rock confining unit (UCCU), lower carbonate-rock aquifer (LCA), and lower clastic-rock confining unit (LCCU). The SCU consists of unmetamorphosed Mesozoic cratonic sedimentary rocks in the eastern part of the DVRFS region and metavolcanic rocks that are sparsely exposed in the western part of the DVRFS region. Hydraulic properties of the SCU vary according to grain size and sorting in the different units. Some of these rocks 
are regional aquifers on the Colorado Plateau east of the DVRFS region, but most exposures of the SCU either lie outside the boundary of the DVRFS region or are too small or shallow to have significance in the regional groundwater flow system. The UCA includes Pennsylvanian and Mississippian limestone, dolomite, and calcareous shales in the vicinity of the NTS. The UCA exists primarily in the area of Yucca Flat. In general, the rocks of the UCA are of only local importance and are not significant in the regional flow system. The UCCU is composed of Upper Devonian through Mississippian synorogenic siliciclastic and carbonate rocks including the Eleana Formation and the Chainman Shale. The EleanaChainman section is a locally important siliciclastic-rock confining unit in the vicinity of the NTS. The Paleozoic carbonate rocks of the LCA are widely distributed in the eastern part of the DVRFS region. The lower to middle Paleozoic carbonate-rock succession forms the major regional carbonate-rock aquifer in the eastern two-thirds of the Great Basin. The LCA carbonate rocks have an aggregate thickness of as much as $8,000 \mathrm{~m}$ and are generally the most permeable rocks in the DVRFS.

The LCCU consists of Middle Proterozoic to Cambrian siliciclastic rocks and subordinate dolomite, and locally, their metamorphic equivalents. The LCCU has long been considered a major confining unit in the DVRFS and, along with the crystalline confining unit (XCU), represents the hydraulic basement for the DVRFS (D'Agnese et al., 1997). The lower hydraulic conductivity of the rock matrix permits negligible groundwater movement, but in many places the rocks are highly fractured and locally brecciated.

\section{HGUs Associated with Crystalline Metamorphic Rocks and Plutons}

The rocks of the intrusive-rock confining unit (ICU) include granodiorite, quartz monzonite, granite, and tonalite. Mesozoic and Cenozoic plutonic rocks in the DVRFS region are widely scattered, poorly exposed, and not abundant in the northeastern two-thirds of the DVRFS. The ICU acts mostly as a confining unit. Although small quantities of water may pass through these intrusive crystalline rocks, where fractured or weathered zones exist, the fractures are poorly connected, and these rocks generally impede groundwater flow. The XCU consists of Early Proterozoic quartzofeldspathic schist, augen gneiss, granitic intrusive rocks, and metamorphosed Middle and Late Proterozoic sedimentary rocks. Groundwater likely is present only locally in the XCU where the rock is fractured. Because the fractures are poorly connected, these rocks act mostly as confining units or barriers to flow.

\section{POROSITY UNCERTAINTY OF HGUS}

Three distinct effective-porosity data sets originating from several different sources are used in this study to estimate groundwater advective travel times in the DVRFS model. The original effective-porosity data were compiled in support of regional models of groundwater flow and contaminant transport developed for the NTS and the proposed YM repository. The mean and standard deviation values used in this study for all HGUs in the DVRFS model are generated from these sources and are summarized by HGU in Tables 4 through 6. It should be noted that most of the HGUs comprise multiple geologic formations and associated lithologies. Thus the distributions of effective-porosity values for each HGU as discussed below include not only the parametric uncertainty associated with each lithologic composition and/or formation, but also the uncertainty arising from compositing multiple formations and lithologies into single HGUs. 


\section{Porosity Data Set 1}

Porosity Data Set 1 (see Table 4) combines effective-porosity values compiled for early Yucca Mountain studies (Bedinger et al., 1989) and for a regional groundwater flow model developed for the NTS (IT Corporation, $1996 \mathrm{a}, \mathrm{b}$ ). Bedinger et al. (1989) summarized effective-porosity values at the regional scale for classes of rocks common in the Basin and Range province and reported their results as the mean and 83.5 percentile for each class. IT Corporation (1996b) reported statistical summaries of effective-porosity for individual HGUs in the NTS region in various forms (bulk, matrix, and fracture) though data on all forms are not available for all HGUs. Within data set 1, preference was given to fracture or bulk values reported by IT Corporation (1996b), as these data are generally directly applicable to HGUs in the DVRFS model. The DVRFS HGUs not included in the IT dataset were assigned porosities for analogous rock types from Bedinger et al. (1989). In this study, the effectiveporosity values for all 27 HGUs in the DVRFS model are randomly generated based on the statistics and assumed probability distribution functions (PDFs) for uncertainty analysis using Monte Carlo simulations. The effective-porosity values for most HGUs in effective-porosity Data Set 1 were assumed to be normally distributed, however, effective-porosity values for HGUs having low mean porosities and relative large standard deviations were assumed to be log-normally distributed to prevent generation of negative values. The HGUs assigned lognormal effective-porosity distributions are the LCCU, LCCU_T1, TMVA, UCCU, XCU and ICU. Overall, there are 17 distinct distributions in effective-porosity Data Set 1. Figure 9 plots histograms of effective-porosity values of five HGUs based on 250 realizations that were generated using the Latin hypercube sampling (LHS) (Iuzzolino, 2003). As will be shown later, these five HGUs are the most influential in terms of the travel time uncertainties for detonations that have the shortest travel time to the YM areas. The histograms of effective-porosity values for all of the HGUs are included in Appendix A (Figures A1 through A17). As can be seen from these figures, TMVA, LCCU and LCCU_T1, UCCU, $\mathrm{XCU}$, and ICU have log-normal distributions, while other HGUs follow normal distributions.

\section{Porosity Data Set 2}

Porosity Data Set 2 (see Table 5) is based on effective-porosity statistics compiled by DOE for a radionuclide transport model encompassing Pahute Mesa on the NTS and the downgradient Oasis Valley (Rehfeldt et al., 2003). This model focused on a much smaller region than is included in the DVRFS model and to incorporate this higher level of detail, DOE has divided the hydrogeologic section into more units. It should also be noted that at the NTS, DOE defines HGUs as categories of rocks (e.g., alluvial aquifer, clastic confining unit, carbonate aquifer) that are characterized by their ability to transmit groundwater, which is primarily controlled by lithologic properties, degree of fracturing, and secondary mineral alteration (Winograd and Thordarson, 1975; IT Corporation, 1996b). Hydrogeologic units are grouped to form hydrostratigraphic units (HSUs) that represent the major layers of the hydrostratigraphic framework and groundwater flow models. Spatial variation in hydraulic properties within selected HSUs (the model was particularly sensitive to properties in certain regionally extensive HSUs) is accounted for by assigning different hydraulic conductivities to specific zones within these model layers (Rehfeldt et al., 2003). 
Table 4. Effective-porosity Data Set 1 - Assignment of effective-porosity Distributions to Death Valley regional groundwater flow system HGUs based on UGTA regional model and YM studies (Bedinger et al., 1989; IT Corporation, 1996b).

\begin{tabular}{|c|c|c|c|}
\hline HGU & Mean Porosity & Standard Deviation & Source \\
\hline LCA & 0.09000 & 0.01000 & IT Corporation (1996b), LCA, fracture, see note 1 \\
\hline LCA_T1 & 0.09000 & 0.01000 & IT Corporation (1996b), LCA, fracture, see note 1 \\
\hline LCCU & 0.03300 & 0.02600 & IT Corporation (1996b), LCCU \\
\hline LCCU_T1 & 0.03300 & 0.02600 & IT Corporation (1996b), LCCU \\
\hline LFU & 0.08000 & 0.02650 & Bedinger et al. (1989), Lava flows, see note 2 \\
\hline OVU & 0.14300 & 0.04600 & IT Corporation (1996b), BAQ, bulk, see note 3 \\
\hline PVA & 0.09000 & 0.02500 & Bedinger et al. (1989), Tuffs and lava flows, see note 4 \\
\hline OACU & 0.32000 & 0.03500 & Bedinger et al. (1989), Basin fill (unconsolidated, fine-grained) \\
\hline TMVA & 0.16200 & 0.11500 & IT Corporation (1996b), TMA, bulk \\
\hline $\mathrm{CHVU}$ & 0.17000 & 0.02433 & Bedinger et al. (1989), Combination, see note 5 \\
\hline CFTA & 0.03000 & 0.01000 & Bedinger et al. (1989), Welded and fractured tuff \\
\hline CFBCU & 0.03000 & 0.01000 & Bedinger et al. (1989), Welded and fractured tuff \\
\hline CFPPA & 0.03000 & 0.01000 & Bedinger et al. (1989), Welded and fractured tuff \\
\hline YVU & 0.10820 & 0.01686 & Bedinger et al. (1989), Combination, see note 6 \\
\hline YACU & 0.32000 & 0.03500 & Bedinger et al. (1989), Basin fill (unconsolidated, fine-grained) \\
\hline UCA & 0.09000 & 0.01000 & IT Corporation (1996b), LCA, fracture, see note 1 \\
\hline UCCU & 0.08800 & 0.04500 & IT Corporation (1996b), UCCU \\
\hline YAA & 0.36000 & 0.09000 & IT Corporation (1996b), AA, bulk \\
\hline $\mathrm{XCU}$ & 0.00010 & 0.00013 & Bedinger et al. (1989), Metamorphic; intrusives (depth > 300m) \\
\hline WVU & 0.16000 & 0.01700 & IT Corporation (1996b), WLA, bulk \\
\hline LA & 0.09000 & 0.01000 & IT Corporation (1996b), LCA, fracture, see note 1 \\
\hline OAA & 0.36000 & 0.09000 & IT Corporation (1996b), AA, bulk \\
\hline Lower VSU & 0.16000 & 0.03600 & IT Corporation (1996b), AA, bulk \\
\hline SCU & 0.30000 & 0.05833 & Bedinger et al. (1989), Combination, see note 7 \\
\hline BRU & 0.28400 & 0.08200 & IT Corporation (1996b), TBA, bulk \\
\hline Upper VSU & 0.16000 & 0.03600 & IT Corporation (1996b), AA, bulk \\
\hline ICU & 0.00010 & 0.00013 & Bedinger et al. (1989), Metamorphic; intrusives (depth > 300m) \\
\hline
\end{tabular}

1. Mean of carbonate rock types: (1) fractured, karstic, cavernous, and (2) dense to moderately dense

2. Mean of two rock types: (1) fractured and cavernous lava flows, and (2) moderately dense to dense lava flows

3. Mean of all three tuff rock types

4. Mean of two rock types: (1) fractured and cavernous lava flows, and (2) welded and fractured tuff (based on DVRFS HGU descriptions)

5. Mean of (1) lava flows and (2) nonwelded tuffs

6. Mean of all tuff and lava flow rock types

7. Mean of (1) consolidated clastic sedimentary rocks and (2) nonwelded tuffs

The major layers in the DVRFS model are termed HGUs (rather than HSUs) and the classification system is based primarily on the work of Winograd and Thordarson (1975) as modified by Laczniak et al. (1996). Although the nomenclature occasionally differs, correlations between DVRFS HGUs and Pahute Mesa HSUs have been established (Faunt et al., 2004; Bechtel Nevada, 2006) and the spatial configurations of the hydrogeologic models at the regional scale are generally similar. The term HGU will be used in this report to be consistent with the nomenclature in the DVRFS model. Correlations between the 46 HGUs used in the Pahute Mesa model and the 27 HGUs in the DVRFS model are listed in Table 7. 

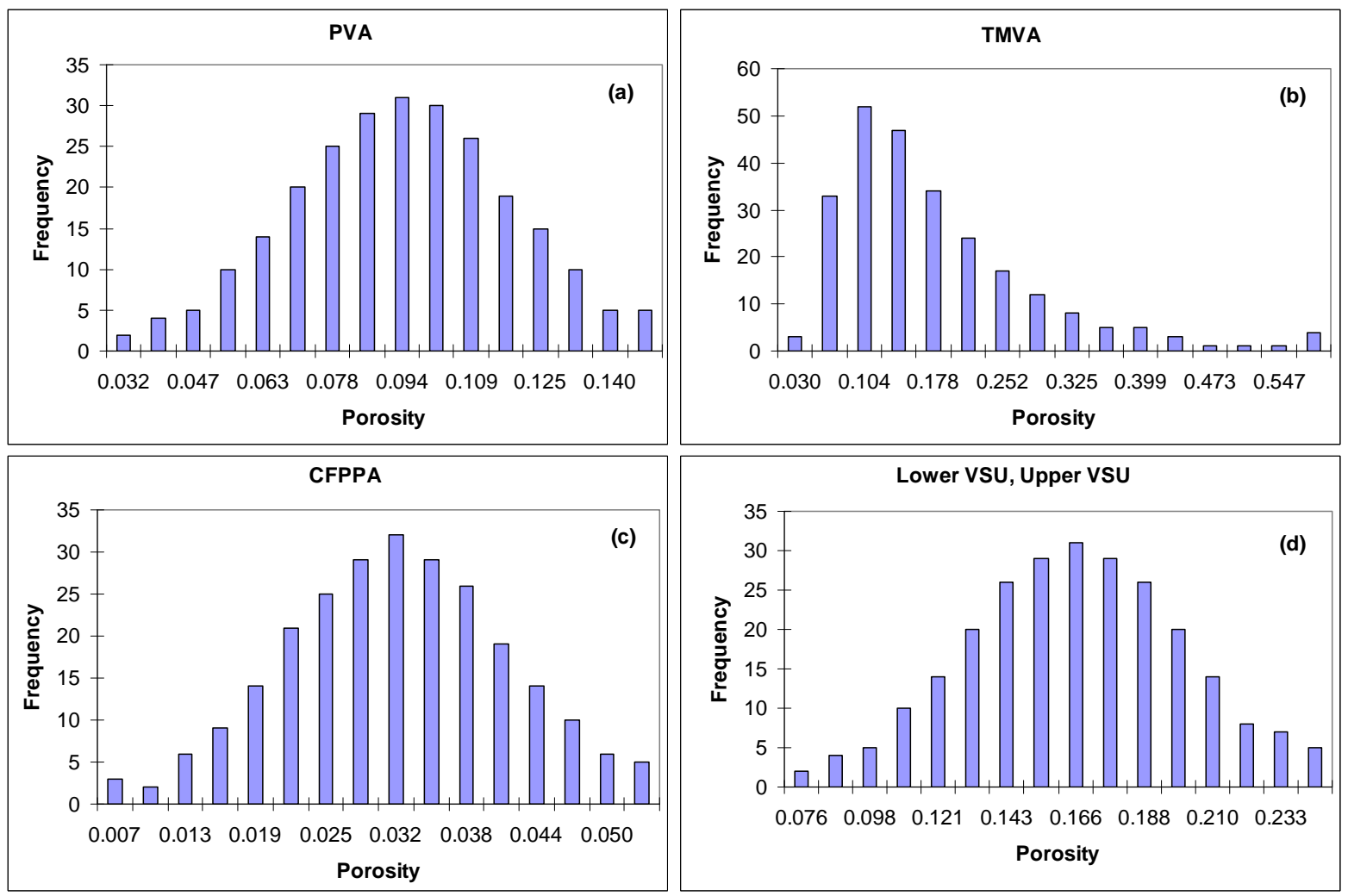

Figure 9. Effective-porosity distributions for PVA, TMVA, CFPPA, Lower VSU, and Upper VSU based on Effective-porosity Data Set 1.

Based on the effective-porosity datasets and the effective-porosity distributions calculated by Rehfeldt et al. (2003, Table 6-15) for the Pahute Mesa model, the 27 HGUs in the DVRFS model were consolidatedinto four hydrogeologic groups having a total of 10 distinct effective-porosity distributions (Table 6). For this effective-porosity set, Figure 10 plots histograms of effective-porosity values of the most influential five HGUs based on 250 realizations that were generated using the LHS. The histograms of effective-porosity values for all of the HGUs are included in Appendix A. In cases where multiple Pahute Mesa HGUs correlate to a single DVRFS HGU the lowest lower bound, mean, and upper bound of the distributions are used. There are also a few DVRFS HGUs that are not present at Pahute Mesa. For these HGUs, effective-porosity distributions for similar HGUs are used as described below.

Group A includes volcanic-rock aquifers and volcanic-rock confining units. Rehfeldt et al. (2003) analyzed a range of fracture and effective-porosity data for fractured volcanic rocks at the NTS and YM to estimate distributions of effective-porosity values for the fractured volcanic HGUs. These effective-porosity estimates were based on calculations using parallel plate models utilizing core and borehole data from Pahute Mesa, limited tracer tests conducted at Pahute Mesa and YM, and uncertainty distributions developed for studies 
Table 5. Effective-porosity Data Set 2 - Assignment of effective-porosity distributions to Death Valley regional groundwater flow system HGUs based on Pahute Mesa-Oasis Valley model transport parameters. Statistics adapted from Rehfeldt et al. (2003) as described in the text.

\begin{tabular}{|c|c|c|c|c|c|}
\hline \multirow[b]{2}{*}{ HGU Name } & \multirow[b]{2}{*}{ HGU Symbol } & \multicolumn{4}{|c|}{ Porosity Statistics } \\
\hline & & $\begin{array}{l}\text { Lower } \\
\text { Bound }\end{array}$ & Mean & $\begin{array}{l}\text { Upper } \\
\text { Bound }\end{array}$ & $\begin{array}{c}\text { Distribution } \\
\text { Type }\end{array}$ \\
\hline Younger alluvial aquifer & YAA & $2.38 \mathrm{E}-01$ & 3.20E-01 & 4.02E-01 & Normal \\
\hline Younger alluvial confining unit & YACU & 2.38E-01 & 3.20E-01 & 4.02E-01 & Normal \\
\hline Older alluvial aquifer & OAA & 2.38E-01 & 3.20E-01 & 4.02E-01 & Normal \\
\hline Older alluvial confining unit & OACU & $2.38 \mathrm{E}-01$ & $3.20 \mathrm{E}-01$ & 4.02E-01 & Normal \\
\hline Limestone aquifer & LA & $1.00 \mathrm{E}-03$ & $4.00 \mathrm{E}-03$ & $1.00 \mathrm{E}-02$ & Log Normal \\
\hline Lava flow unit & LFU & $1.00 \mathrm{E}-05$ & $4.02 \mathrm{E}-03$ & $4.60 \mathrm{E}-01$ & Log Triangular \\
\hline Younger volcanic-rock unit & YVU & $1.00 \mathrm{E}-05$ & $4.02 \mathrm{E}-03$ & $4.60 \mathrm{E}-01$ & Log Triangular \\
\hline Upper volcanic- and sedimentary-rock unit & Up VSU & 1.00E-05 & 8.94E-02 & 5.50E-01 & Log Triangular \\
\hline Thirsty Canyon-Timber Mtn. volcanic aquifer-rd & TMVA & 1.00E-05 & 1.00E-03 & $1.00 \mathrm{E}-01$ & Log Triangular \\
\hline Paintbrush volcanic-rock aquifer & PVA & $1.00 \mathrm{E}-05$ & $1.00 \mathrm{E}-03$ & $1.00 \mathrm{E}-01$ & Log Triangular \\
\hline Calico Hills volcanic-rock unit & $\mathrm{CHVU}$ & $1.00 \mathrm{E}-05$ & $6.48 \mathrm{E}-02$ & $4.60 \mathrm{E}-01$ & Log Triangular \\
\hline Wahmonie volcanic-rock unit & WVU & $1.00 \mathrm{E}-05$ & $6.48 \mathrm{E}-02$ & 4.60E-01 & Log Triangular \\
\hline Crater Flat-Prow Pass aquifer & CFPPA & $1.00 \mathrm{E}-05$ & 1.00E-03 & $1.00 \mathrm{E}-01$ & Log Triangular \\
\hline Crater Flat-Bullfrog confining unit & CFBCU & $1.00 \mathrm{E}-01$ & 4.00E-01 & $5.50 \mathrm{E}-01$ & Normal \\
\hline Crater Flat-Tram aquifer & CFTA & 1.00E-05 & 4.47E-03 & 5.50E-01 & Log Triangular \\
\hline Belted Range unit & BRU & $1.00 \mathrm{E}-05$ & 1.00E-03 & $1.00 \mathrm{E}-01$ & Log Triangular \\
\hline Older volcanicr-rock Unit & OVU & $1.00 \mathrm{E}-05$ & $8.94 \mathrm{E}-02$ & $5.50 \mathrm{E}-01$ & Log Triangular \\
\hline Lower volcanic- and sedimentary-rock unit & Low VSU & $1.00 \mathrm{E}-05$ & 8.94E-02 & $5.50 \mathrm{E}-01$ & Log Triangular \\
\hline Sedimentary-rock confining unit & SCU & $1.00 \mathrm{E}-05$ & $8.94 \mathrm{E}-02$ & $5.50 \mathrm{E}-01$ & Log Triangular \\
\hline Upper carbonate-rock aquifer & UCA & $1.00 \mathrm{E}-03$ & $4.00 \mathrm{E}-03$ & $1.00 \mathrm{E}-02$ & Log Normal \\
\hline Upper clastic-rock confining unit & UCCU & $5.00 \mathrm{E}-06$ & 3.00E-05 & $5.00 E-04$ & Log Normal \\
\hline Lower carbonate-rock aquifer (thrusted) & LCA_T1 & $1.00 \mathrm{E}-03$ & $4.00 \mathrm{E}-03$ & 1.00E-02 & Log Normal \\
\hline Lower clastic-rock confining unit (thrusted) & LCCU_T1 & $5.00 \mathrm{E}-06$ & 3.00E-05 & $5.00 \mathrm{E}-04$ & Log Normal \\
\hline Lower carbonate-rock aquifer & LCA & $1.00 \mathrm{E}-03$ & $4.00 \mathrm{E}-03$ & $1.00 \mathrm{E}-02$ & Log Normal \\
\hline Lower clastic-rock confining unit & LCCU & $5.00 \mathrm{E}-06$ & $3.00 \mathrm{E}-05$ & $5.00 \mathrm{E}-04$ & Log Normal \\
\hline Crystalline-rock confining unit & $\mathrm{XCU}$ & $5.00 \mathrm{E}-06$ & $3.00 \mathrm{E}-05$ & $5.00 \mathrm{E}-04$ & Log Normal \\
\hline Intrusive-rock confining unit & $\mathrm{ICU}$ & $5.00 \mathrm{E}-06$ & $5.00 \mathrm{E}-05$ & $9.00 \mathrm{E}-03$ & Log Uniform \\
\hline
\end{tabular}

at YM. Estimates of total porosity for bedded and nonwelded (i.e., unfractured) confining units were developed from interpretations of geophysical logs, cuttings samples, and core measurements by Burkhard (1989) and were scaled to effective-porosity using the same relationship described above for alluvium (Rehfeldt et al., 2003).

Group A effective-porosity values follow log triangular distributions. Among them, four HGUs (TMVA, PVA, CFPPA, and BRU) in Group A have identical statistics. For these HGUs, the given mean value (0.001) is interpreted as the geometric mean in this study. After generating 250 realizations based on the given probability density distributions, the arithmetic mean of the generated effective-porosity is about 0.0046 , and the standard deviation is about 0.01 , with coefficient of variation $(\mathrm{CV})$ of over 2 . Their histogram is shown in Figure A22. For the LFU and YVU, the generated random field has a mean value of 0.017 and a CV value of 2.3. The histogram is shown in Figure A20. For the OVU, SCU, Lower VSU, and Upper VSU, the logarithmic value of the given mean in Table 6 is interpreted as the mode (apex of the triangle) in logarithm space in this study (if it were interpreted as the geometric mean, it would be impossible to follow a triangular distribution). Note that Rehfeldt et al. (2003) did not report effective-porosity probability density functions for the SCU and Upper VSU because these units are not present at Pahute Mesa. 
Table 6. Effective-porosity Data Set 3 - Assignment of effective-porosity distributions to Death Valley regional flow system HGUs based on Yucca Mountain transport parameters. Statistics for those HGUs not assigned distributions in BSC (2004a) are developed from data set 2 as described in the text.

\begin{tabular}{|c|c|c|c|c|c|c|}
\hline \multirow[b]{2}{*}{ HGU Name } & \multirow[b]{2}{*}{ HGU Symbol } & \multicolumn{5}{|c|}{ Porosity Statistics } \\
\hline & & $\begin{array}{l}\text { Lower } \\
\text { Bound }\end{array}$ & Mean & $\begin{array}{l}\text { Upper } \\
\text { Bound }\end{array}$ & Distribution & Source \\
\hline Younger alluvial aquifer & YAA & $0.00 \mathrm{E}+00$ & $1.80 \mathrm{E}-01$ & $3.00 \mathrm{E}-01$ & Truncated normal & $\mathrm{a}$ \\
\hline Younger alluvial confining unit & YACU & - & $3.20 \mathrm{E}-01$ & 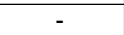 & Normal, SD $=0.153$ & c \\
\hline Older alluvial aquifer & OAA & $0.00 \mathrm{E}+00$ & $1.80 \mathrm{E}-01$ & $3.00 \mathrm{E}-01$ & Truncated normal & a \\
\hline Older alluvial confining unit & OACU & - & $3.20 \mathrm{E}-01$ & - & Normal, SD $=0.153$ & c \\
\hline Limestone aquifer & LA & - & $1.00 \mathrm{E}-02$ & - & Log-normal, CV $=0.59$ & c \\
\hline \begin{tabular}{|l} 
Lava flow unit \\
\end{tabular} & LFU & - & $8.00 \mathrm{E}-02$ & - & Log-triangular, $\mathrm{CV}=2.2$ & $\mathrm{c}$ \\
\hline Younger volcanic-rock unit & YVU & $1.00 \mathrm{E}-05$ & - & $1.00 \mathrm{E}-01$ & Epistemic & $\mathrm{b}$ \\
\hline Upper volcanic- and sedimentary-rock unit & Upper VSU & $0.00 \mathrm{E}+00$ & $1.80 \mathrm{E}-01$ & $3.00 \mathrm{E}-01$ & Truncated normal & $\mathrm{b}$ \\
\hline Thirsty Canyon-Timber Mtn. volcanic-rock aquifer & TMVA & $1.00 \mathrm{E}-05$ & - & $1.00 \mathrm{E}-01$ & Epistemic & $\mathrm{a}$ \\
\hline Paintbrush volcanic-rock aquifer & PVA & $1.00 \mathrm{E}-05$ & - & $1.00 \mathrm{E}-01$ & Epistemic & $\mathrm{a}$ \\
\hline Calico Hills volcanic-rock unit & $\mathrm{CHVU}$ & $1.00 \mathrm{E}-05$ & - & $1.00 \mathrm{E}-01$ & Epistemic & $\mathrm{a}$ \\
\hline Wahmonie volcanic-rock unit & WVU & 1.00E-05 & - & $1.00 \mathrm{E}-01$ & Epistemic & $\mathrm{a}$ \\
\hline Crater Flat-Prow Pass aquifer & CFPPA & 1.00E-05 & - & 1.00E-01 & Epistemic & $\mathrm{a}$ \\
\hline Crater Flat-Bullfrog confining unit & CFBCU & $1.00 \mathrm{E}-05$ & - & $1.00 \mathrm{E}-01$ & Epistemic & $\mathrm{a}$ \\
\hline Crater Flat-Tram aquifer & CFTA & $1.00 \mathrm{E}-05$ & - & $1.00 \mathrm{E}-01$ & Epistemic & $\mathrm{a}$ \\
\hline Belted Range unit & BRU & $1.00 \mathrm{E}-05$ & - & $1.00 \mathrm{E}-01$ & Epistemic & $\mathrm{a}$ \\
\hline Older volcanic-rock unit & OVU & $1.00 \mathrm{E}-05$ & - & $1.00 \mathrm{E}-01$ & Epistemic & $\mathrm{a}$ \\
\hline Lower volcanic- and sedimentary-rock unit & Lower VSU & $0.00 \mathrm{E}+00$ & $1.80 \mathrm{E}-01$ & $3.00 \mathrm{E}-01$ & Truncated normal & $\mathrm{b}$ \\
\hline Sedimentary-rock confining unit & SCU & $0.00 \mathrm{E}+00$ & $1.80 \mathrm{E}-01$ & $3.00 \mathrm{E}-01$ & Truncated normal & $\mathrm{b}$ \\
\hline Upper carbonate-rock aquifer & UCA & - & 1.00E-02 & - & Log-normal, CV = 0.59 & c \\
\hline Upper clastic-rock confining unit & UCCU & - & $1.80 \mathrm{E}-01$ & - & Log-normal, CV = 1.6 & c \\
\hline Lower carbonate-rock aquifer (thrusted) & LCA T1 & - & $1.00 \mathrm{E}-02$ & - & Log-normal, CV $=0.59$ & c \\
\hline Lower clastic-rock confining unit (thrusted) & LCCU_T1 & - & $1.80 \mathrm{E}-01$ & - & Log-normal, CV = 1.6 & c \\
\hline Lower carbonate-rock aquifer & LCA & - & $1.00 \mathrm{E}-02$ & - & Log-normal, CV $=0.59$ & c \\
\hline Lower clastic-rock confining unit & LCCU & - & $1.80 \mathrm{E}-01$ & - & Log-normal, CV = 1.6 & c \\
\hline Crystalline-rock confining unit & $\mathrm{XCU}$ & - & $1.80 \mathrm{E}-01$ & - & Log-normal, CV = 1.6 & c \\
\hline Intrusive-rock confining unit & $\mathrm{ICU}$ & - & $1.00 \mathrm{E}-04$ & - & Log-normal, CV $=1.6$ & c \\
\hline
\end{tabular}

a BSC (2004a)

b Interpreted from similar units, see text for explanation

c Mean from BSC (2004a), SD or CV from same unit in Data Set 2

These units were assigned the same distributions as the Lower VSU, based on their similar lithologic characteristics and stratigraphic relationships. The generated histogram is shown in Figure A21. The mean effective-porosity is 0.044 and the CV of the generated effective-porosity field is about 1.6. The CHVU and WVU are treated the same way as OVU, SCU, Lower VSU, and Upper VSU. The WVU is not present at Pahute Mesa and is assigned the CHVU effective-porosity distribution based on their similar lithologies (Sweetkind et al., 2004, p. 55). The generated histogram is shown in Figure A24. The mean effective-porosity is 0.036 and the $\mathrm{CV}$ of the generated effective-porosity values is about 1.6. The CFTA is treated the same way. The generated histogram is shown in Figure A25. The mean effectiveporosity is 0.02 and the $\mathrm{CV}$ of the generated effective-porosity values is about 2.3. 

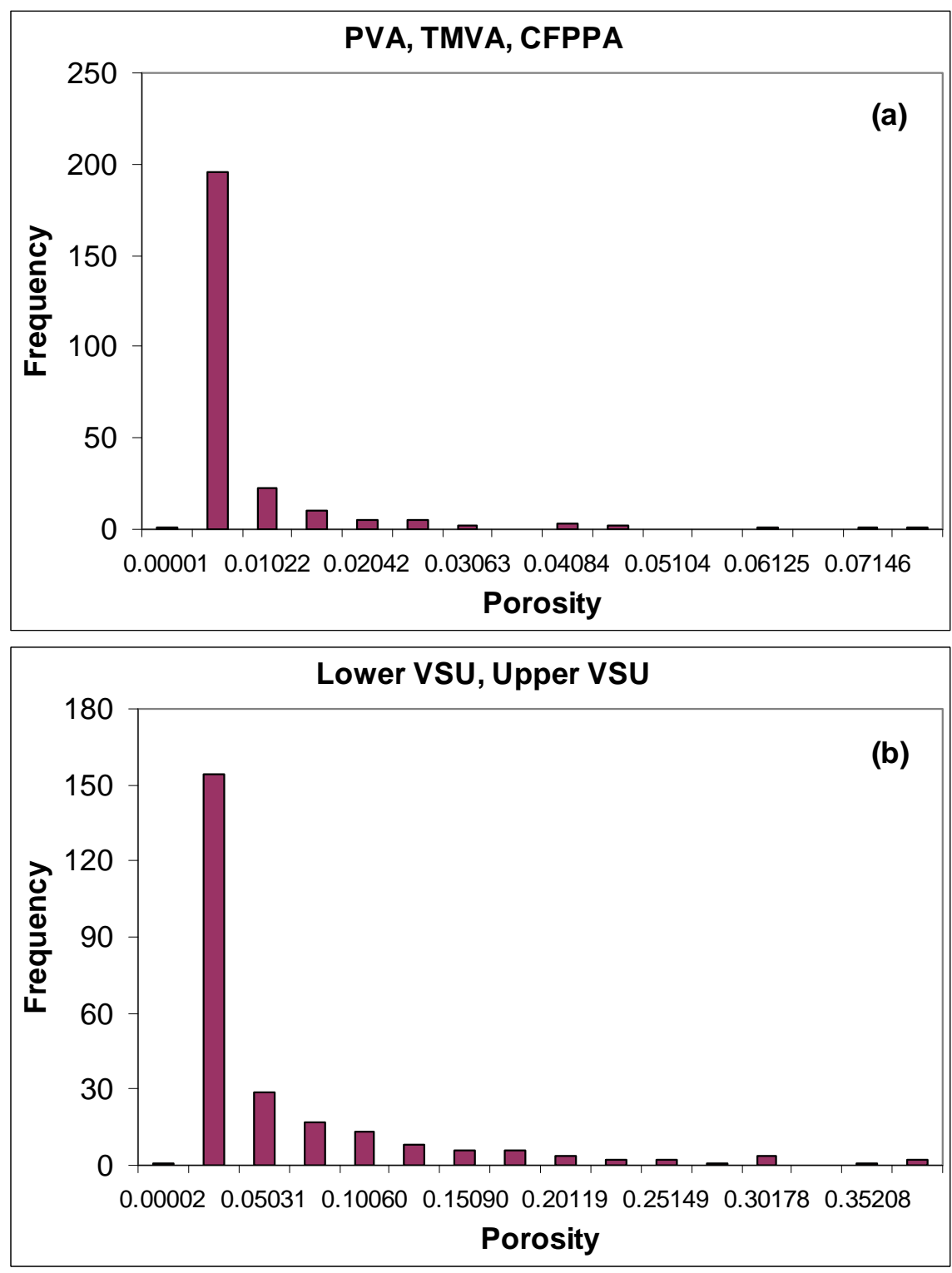

Figure 10. Effective-porosity distributions for PVA, TMVA, CFPPA, Lower VSU, and Upper VSU based on Effective-porosity Data Set 2.

Group B includes alluvial aquifers and confining units. Because the distribution of alluvium is limited at Pahute Mesa and there are few local effective-porosity data, Rehfeldt et al. (2003) utilized data from lithologically similar alluvial units in the Yucca Flat area of the NTS as a surrogate. These data were compiled by Burkhard (1989) from bulk density, grain density, and water content measurements in the unsaturated zone and are reported as average total porosity values for each HGU. Rehfeldt et al. (2003) assumed the alluvium effective-porosity values follow a normal distribution and then shifted the distribution lower by three percent, based on the relationship of total porosity to effective-porosity observed in the alluvium at Frenchman Flat on the NTS (Burbey and Wheatcraft, 1986; Blout et al., 1995), to arrive at the final distribution of effective-porosity. We have assigned the same effective-porosity distribution was assigned to all four alluvial units (YAA, YACU, OAA 
and $\mathrm{OACU}$ ), though it should be noted that the alluvial confining units YACU and OACU are not part of Pahute Mesa-Yucca Mountain flow system (discussed below). It is assumed for the alluvial units that the given range between the lower bound and upper bound covers 90 percent of the normally distributed effective-porosity values. The generated effectiveporosity histogram is plotted in Figure A23. The mean value is the same as that given in Table 6, with the $\mathrm{CV}$ of the generated effective-porosity values being 0.15 . For CFBCU, since the mean value given in Table 6 is not in the middle of the given range, it is assumed that the given range between the lower and upper bound covers 90 percent of the effectiveporosity values. Therefore, it is equivalent to assuming the actual mean is in the middle of the given bound (in random value generation, the given mean in Table 6 is not actually used). The histogram of the generated effective-porosity is shown in Figure A26. The mean effective-porosity is 0.325 and the $\mathrm{CV}$ is 0.42 .

Group $\mathrm{C}$ includes carbonate aquifers, Paleozoic clastic confining units, and a crystalline confining unit. The effective-porosity values of all Group C HGUs follow lognormal distributions. The four carbonate aquifers LA, UCA, LCA_T1, and LCA are assigned the same mean value and standard deviation in logarithm space in generating the random effective-porosity values. These values are -2.46 and 0.25 , respectively as reported by Rehfeldt et al. (2003). The uncertainty range was originally derived for a groundwater flow and tritium transport model of the NTS region (DOE, 1997) from analyses of previously conducted tracer tests performed in the LCA at the Amargosa tracer calibration site south of the NTS (Leap and Belmonte, 1992) and Wells C and C-1 on the NTS (Winograd and West, 1962). The histogram of the generated effective-porosity is shown in Figure A18. The mean effective-porosity is about 0.004 and the $\mathrm{CV}$ is about 0.59 . For the four confining units, UCCU, LCCU_T1, LCCU, and XCU, we interpret the logarithmic values of the given bounds in Table 6 are interpreted as the 90 percent bounds in logarithm space, i.e., the mean value in logarithm space is the average of the logarithmic values of the given bounds. The histogram of the generated effective-porosity is shown in Figure A19. The mean effectiveporosity is about 0.00012 and the $\mathrm{CV}$ is about 1.64 .

Group D includes only the intrusive confining unit ICU whose effective-porosity is assumed to follow a log-uniform distribution. Since it is uniformly distributed in logarithm space, the mean value given in Table 4 is not used in generating the random values for the effective-porosity. The histogram of the generated effective-porosity values is shown in Figure A27. The mean effective-porosity is about 0.0012 and the CV is about 1.66.

\section{Porosity Data Set 3}

Porosity Data Set 3 (see Table 6) represents effective and fracture effective-porosity values compiled for the YM saturated zone flow and transport model abstraction (BSC, 2004a). This effective-porosity dataset was developed for assessment of parametric uncertainty in a transport model constructed to simulate radionuclide breakthrough curves at the YM accessible environment (BSC, 2004a). Porosities are assigned to all 19 HGUs that comprise the saturated zone site-scale flow model upon which the transport model abstraction is based. Correlations of these HGUs with the HGUs used in the DVRFS model were adapted from information about equivalent units and approximate relationships with regional hydrogeologic units as presented in the report describing the hydrogeologic framework model (BSC, 2004b) for the saturated zone site-scale flow model. Table 8 shows 
the correlations between the HGUs in both models assumed for the purpose of assigning effective-porosity values from the YM transport model abstraction to the DVRFS model.

Porosity Set 3 comprises seven distinct distributions from six distribution groups (Table 6). For this effective-porosity data set, Figure 11 plots histograms of the effectiveporosity values of the most influential five HGUs based on 250 realizations that were generated using the LHS. Since for effective-porosity Set 3 there is very limited distribution information on effective-porosity for many HGUs, the same effective-porosity values are used for all HGUs that are grouped together as shown in Table 6. Therefore, there are only seven independent effective-porosity groups for this effective-porosity set. For example, there are $10 \mathrm{HGUs}$ that have epistemic distribution. In the simulations, these $10 \mathrm{HGUs}$ will have the same effective-porosity values for each realization that are generated randomly based on the probability density function and cumulative probability function shown in Figure 12 using LHS. The histograms of effective-porosity values for all of the HGUs are included in Appendix A.

Note that the Yucca Mountain transport abstraction model does not include effectiveporosity distributions for all 19 HGUs. Analysis of flow patterns simulated by the saturated zone site-scale model suggests that nine HGUs do not occur within the flowpath that originates at the proposed repository and because the values of effective-porosity for these units were found to not impact travel times from the repository, constant values were assigned to them in the transport abstraction (BSC, 2004a). The data set compiled by Bedinger et al. (1989) was used as the source of deterministic effective-porosity values for these units (BSC, 2004a). However, since some of the counterparts to these nine units in the DVRFS model are present along flowpaths from Pahute Mesa to YM appropriate effectiveporosity distributions were assigned as described below.

For Group A, effective-porosity follows a truncated normal distribution. Five HGUs fall into this group: YAA, OAA, Upper VSU, Lower VSU, and SCU. BSC (2004a) developed the distribution of effective-porosity for the valley-fill aquifer (corresponding to the YAA and OAA in the DVRFS model) from the Great Basin data set compiled by Beddinger et al. (1989), the NTS Frenchman Flat data set (Burbey and Wheatcraft, 1986), the NTS Pahute Mesa analysis (DOE, 1997), and tracer test results in YM well EWDP-19D1.

The Upper VSU and Lower VSU were assigned to Group A based on their approximate hydrogeologic correlation to the valley-fill aquifer (BSC, 2004b). Note that the effective-porosity for SCU is not given a distribution in Table 8 because it is not present in the YM saturated zone site-scale model. It is included in this distribution group because its hydrogeologic characteristics are similar to the YAA and OAA in the DVRFS model (Faunt et al., 2004). The given effective-porosity mean value is 0.18 and the standard deviation 0.051 . Based on those values, the 250-realization normally distributed effective-porosity values can be generated. Figure A33 shows the histogram of the generated effective-porosity values.

The YM HGUs associated with Groups B through E were not assigned effectiveporosity distributions in the saturated zone site-scale model because they are not present in the simulated flowpath from the proposed repository to the accessible environment (BSC, 
Table 7. Correlation between HGUs in the Death Valley regional groundwater flow system model and the Pahute Mesa-Oasis Valley flow model.

\begin{tabular}{|c|c|c|c|c|}
\hline \multicolumn{2}{|l|}{ Death Valley Regional Flow System Model } & \multicolumn{2}{|l|}{ Pahute Mesa - Oasis Valley Model } & \multirow{2}{*}{ Sources } \\
\hline HGU Name & Symbol & HGU Name & Symbol & \\
\hline Younger alluvial aquifer & YAA & Alluvial Aquifer & AA & $a, b$ \\
\hline Younger alluvial confining unit & YACU & nd & - & $\mathrm{C}$ \\
\hline Older alluvial aquifer & OAA & Alluvial Aquifer & AA & $a, d$ \\
\hline Older alluvial confining unit & OACU & nd & - & $\mathrm{C}$ \\
\hline Limestone aquifer & LA & nd & - & $\mathrm{C}$ \\
\hline Lava flow unit & LFU & Younger volcanic composite unit & YVCM & $\mathrm{b}$ \\
\hline Younger volcanic-rock unit & YVU & Younger volcanic composite unit & YVCM & $\mathrm{a}$ \\
\hline Upper volcanic- and sedimentary-rock unit & Upper VSU & nd & - & C \\
\hline \multirow{11}{*}{ Thirsty Canyon-Timber Mtn. volcanic-rock aquifer } & \multirow{11}{*}{ TMVA } & Windy Wash aquifer & WWA & $\mathrm{a}$ \\
\hline & & Fortymile Canyon composite unit (FCCU) & FCCM & $\mathrm{a}$ \\
\hline & & Timber Mountain aquifer & TMA & $\mathrm{a}$ \\
\hline & & Tannenbaum Hill composite unit & THCM & $\mathrm{a}$ \\
\hline & & Tannenbaum Hill lava-flow aquifer & THLFA & $\mathrm{a}$ \\
\hline & & Timber Mountain composite unit & TMCM & $\mathrm{a}$ \\
\hline & & Fortymile Canyon aquifer & FCA & $\mathrm{a}$ \\
\hline & & Fortymile Canyon composite unit & FCCM & $\mathrm{a}$ \\
\hline & & Detached volcanic aquifer & DVA & $\mathrm{a}$ \\
\hline & & Detached volcanics composite unit & DVCM & $\mathrm{a}$ \\
\hline & & Thirsty Canyon volcanics aquifer & TCVA & $\mathrm{a}$ \\
\hline \multirow{8}{*}{ Paintbrush volcanic-rock aquifer } & \multirow{8}{*}{ PVA } & Paintbrush composite unit & PCM & $\mathrm{a}$ \\
\hline & & Paintbrush vitric-tuff aquifer & PVTA & $\mathrm{a}$ \\
\hline & & Benham aquifer & $\mathrm{BA}$ & $\mathrm{a}$ \\
\hline & & Upper Paintbrush confining unit & UPCU & $\mathrm{a}$ \\
\hline & & Tiva Canyon aquifer & TCA & $\mathrm{a}$ \\
\hline & & Paintbrush lava-flow aquifer & PLFA & $\mathrm{a}$ \\
\hline & & Lower Paintbrush confining unit & LPCU & $\mathrm{a}$ \\
\hline & & Topopah Spring aquifer & TSA & $\mathrm{a}$ \\
\hline \multirow{4}{*}{ Calico Hills volcanic-rock unit } & \multirow{4}{*}{ CHVU } & Calico Hills confining unit & $\mathrm{CHCU}$ & $\mathrm{a}$ \\
\hline & & Calico Hills zeolitic composite unit & $\mathrm{CHZCM}$ & $\mathrm{a}$ \\
\hline & & Calico Hills vitric composite unit & CHVCM & $\mathrm{a}$ \\
\hline & & Calico Hills vitric-tuff aquifer & CHVTA & $\mathrm{a}$ \\
\hline Wahmonie volcanic-rock unit & WVU & nd & - & $\mathrm{C}$ \\
\hline \multirow{4}{*}{ Crater Flat-Prow Pass aquifer } & \multirow{4}{*}{ CFPPA } & Inlet Aquifer & IA & $\mathrm{a}$ \\
\hline & & Kearsarge aquifer & KA & $\mathrm{a}$ \\
\hline & & Crater Flat composite unit & CFCM & $\mathrm{a}$ \\
\hline & & Crater Flat confining unit & CFCU & $\mathrm{a}$ \\
\hline Crater Flat-Bullfrog confining unit & CFBCU & Bullfrog confining unit & $\mathrm{BCU}$ & $\mathrm{a}$ \\
\hline Crater Flat-Tram aquifer & CFTA & Yucca Mtn Crater Flat composite unit & YMCFCM & $\mathrm{a}$ \\
\hline Belted Range unit & BRU & Belted Range aquifer & BRA & $\mathrm{a}$ \\
\hline Older volcanic-rock unit & OVU & Pre-Belted Range composite unit & PBRCM & $\mathrm{a}$ \\
\hline Lower volcanic- and sedimentary-rock unit & Lower VSU & Pre-Belted Range composite unit & PBRCM & $\mathrm{C}$ \\
\hline Sedimentary-rock confining unit & SCU & nd & - & $\mathrm{C}$ \\
\hline Upper carbonate-rock aquifer & UCA & nd & - & $\mathrm{C}$ \\
\hline Upper clastic-rock confining unit & UCCU & Upper clastic confining unit & UCCU & $\mathrm{a}, \mathrm{c}$ \\
\hline Lower carbonate-rock aquifer (thrusted) & LCA_T1 & Lower carbonate aquifer, thrust plate & LCA3 & $\mathrm{a}, \mathrm{c}$ \\
\hline Lower clastic-rock confining unit (thrusted) & LCCU_T1 & Lower clastic confining unit, thrust plate & LCCU1 & $\mathrm{a}, \mathrm{c}$ \\
\hline Lower carbonate-rock aquifer & LCA & Lower carbonate aquifer & LCA & $\mathrm{a}, \mathrm{c}$ \\
\hline Lower clastic-rock confining unit & LCCU & Lower clastic confining unit & LCCU & $\mathrm{a}, \mathrm{c}$ \\
\hline Crystalline-rock confining unit & $\mathrm{XCU}$ & nd & - & $\mathrm{C}$ \\
\hline \multirow{5}{*}{ Intrusive-rock confining unit } & \multirow{5}{*}{ ICU } & Ammonia Tanks intrusive confining unit & ATICU & $\mathrm{a}$ \\
\hline & & Rainier Mesa intrusive confining unit & RMICU & $\mathrm{a}$ \\
\hline & & Claim Canyon intrusive confining unit & $\mathrm{CCICU}$ & $\mathrm{a}$ \\
\hline & & Silent Canyon intrusive confining unit & $\mathrm{SCICU}$ & $\mathrm{a}$ \\
\hline & & Mesozoic granite confining unit & MGCU & $\mathrm{a}$ \\
\hline
\end{tabular}

\section{Sources:}

a Faunt et al. (2004)

b Bechtel Nevada (2006)

c Bechtel Nevada (2002)

d We assume PMOV AA correlates to both DVRFS YAA and OAA

nd = not defined as a separate HGU or not present 
Table 8. Correlation between HGUs in the Death Valley regional groundwater flow system model and the Yucca Mountain Saturated Zone Site-Scale Flow Model. Adapted from BSC (2004b).

\begin{tabular}{|c|c|c|}
\hline \multicolumn{2}{|l|}{ Death Valley Regional Flow System Model } & \multirow{2}{*}{\begin{tabular}{|l|} 
Yucca Mountain Hydrogeologic Framework Model \\
HGU Name (HFM-19)
\end{tabular}} \\
\hline HGU Name & Symbol & \\
\hline Younger alluvial aquifer & YAA & Valley-fill aquifer (alluvium) \\
\hline Younger alluvial confining unit & YACU & Valley-fill confining unit (playas) \\
\hline Older alluvial aquifer & OAA & Valley-fill aquifer (alluvium), Undifferentiated valley fill (leaky) \\
\hline Older alluvial confining unit & OACU & nd \\
\hline Limestone aquifer & LA & Limestone aquifer (amarls) \\
\hline Lava flow unit & LFU & Lava flow aquifer (basalts) \\
\hline Younger volcanic-rock unit & YVU & nd \\
\hline Upper volcanic- and sedimentary-rock unit & Upper VSU & Undifferentiated valley-fill (leaky) \\
\hline Thirsty Canyon-Timber Mtn. volcanic-rock aquifer & TMVA & Upper volcanic aquifer \\
\hline Paintbrush volcanic-rock aquifer & PVA & Upper volcanic aquifer \\
\hline Calico Hills volcanic-rock unit & CHVU & Upper volcanic confining unit \\
\hline Wahmonie volcanic-rock unit & WVU & Upper volcanic confining unit \\
\hline Crater Flat-Prow Pass aquifer & CFPPA & Lower volcanic aquifer - Prow Pass Tuff \\
\hline Crater Flat-Bullfrog confining unit & CFBCU & Lower volcanic aquifer - Bullfrog Tuff \\
\hline Crater Flat-Tram aquifer & CFTA & Lower volcanic aquifer - Tram Tuff \\
\hline Belted Range unit & BRU & nd \\
\hline \multirow{3}{*}{ Older volcanic-rock unit } & \multirow{3}{*}{ OVU } & Older volcanic confining unit \\
\hline & & Older volcanic aquifer \\
\hline & & Lower volcanic confining unit \\
\hline Lower volcanic- and sedimentary-rock unit & Lower VSU & Undifferentiated valley-fill (leaky) \\
\hline Sedimentary-rock confining unit & SCU & nd \\
\hline Upper carbonate-rock aquifer & UCA & Upper carbonate aquifer \\
\hline Upper clastic-rock confining unit & UCCU & Upper clastic confining unit, Upper clastic confining unit - thrust 2 \\
\hline Lower carbonate-rock aquifer (thrusted) & LCA_T1 & Lower carbonate aquifer thrusts 1 and 2 \\
\hline Lower clastic-rock confining unit (thrusted) & LCCU_T1 & Lower clastic confining unit - thrust 1 \\
\hline Lower carbonate-rock aquifer & LCA & Lower carbonate aquifer \\
\hline Lower clastic-rock confining unit & LCCU & Lower clastic confining unit \\
\hline Crystalline-rock confining unit & $\mathrm{XCU}$ & Lower clastic confining unit \\
\hline Intrusive-rock confining unit & $\mathrm{ICU}$ & Granitic confining unit (granites) \\
\hline
\end{tabular}

nd = not defined as a separate HGU or not present

2004a). Instead, representative deterministic effective-porosity values using Bedinger et al. (1989) as the data source were assigned. To incorporate effective-porosity uncertainty in these HGUs, the distribution types and standard deviations or CVs were used as appropriate for the analogous HGUs in effective-porosity Data Set 2. The mean values are those used in the transport abstraction model.

Group B effective-porosity follows a normal distribution and includes the alluvial confining units YACU and OACU. The same value of standard deviation $(0.153)$ that was used for the YACU and OACU in effective-porosity Data Set 2 is used here. The mean (0.32) is the value reported by BSC (2004a) for the valley-fill confining unit. Figure A32 shows the histogram of the generated effective-porosity values for these two HGUs.

Group $\mathrm{C}$ effective-porosity follows a log-normal distribution with a mean of 0.01 and includes the carbonate aquifer units LA, UCA, LCA_T1, and LCA. The Group C HGUs assumed to have the same CV as effective-porosity Data Set 2, which is about 0.59 . 

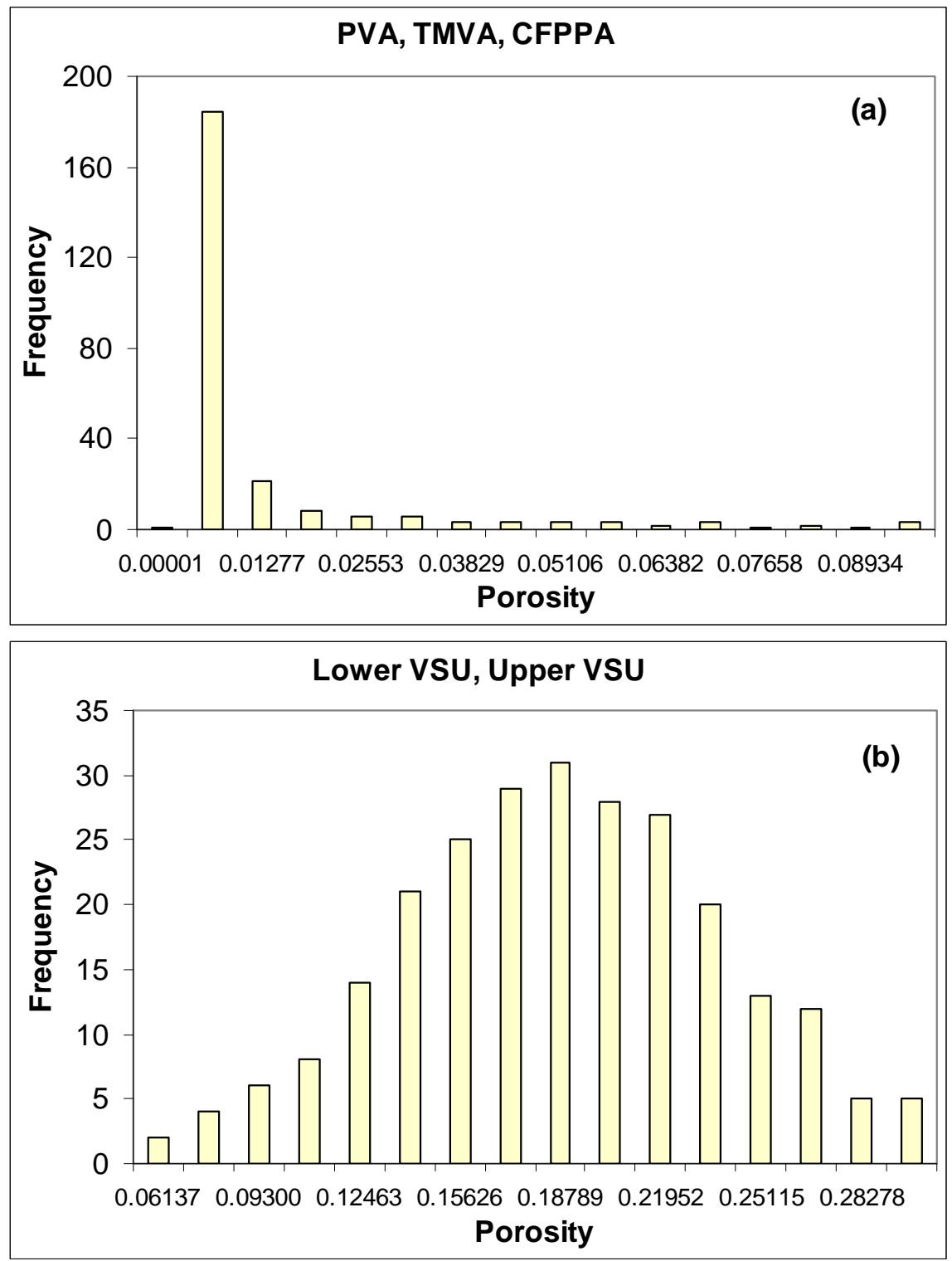

Figure 11. Effective-porosity distributions for PVA, TMVA, CFPPA, Lower VSU, and Upper VSU based on Effective-porosity Data Set 3.

Figure A28 shows a histogram of the generated effective-porosity field. Group C also includes the clastic confining units UCCU, LCCU_T1, and LCCU, and the crystalline confining unit XCU that also follows a log-normal distribution, but with a mean effectiveporosity of 0.18 . Once again, the same CV value as in effective-porosity Set 2, is used here which is about 1.6 for random effective-porosity generation for these HGUs. Figure A29 shows the histogram of the generated effective-porosity values.

For Group D, the effective-porosity values follow a log-triangular distribution. The LFU is the only HGU in this group. Similar to Group C, the CV is assumed to have the same 


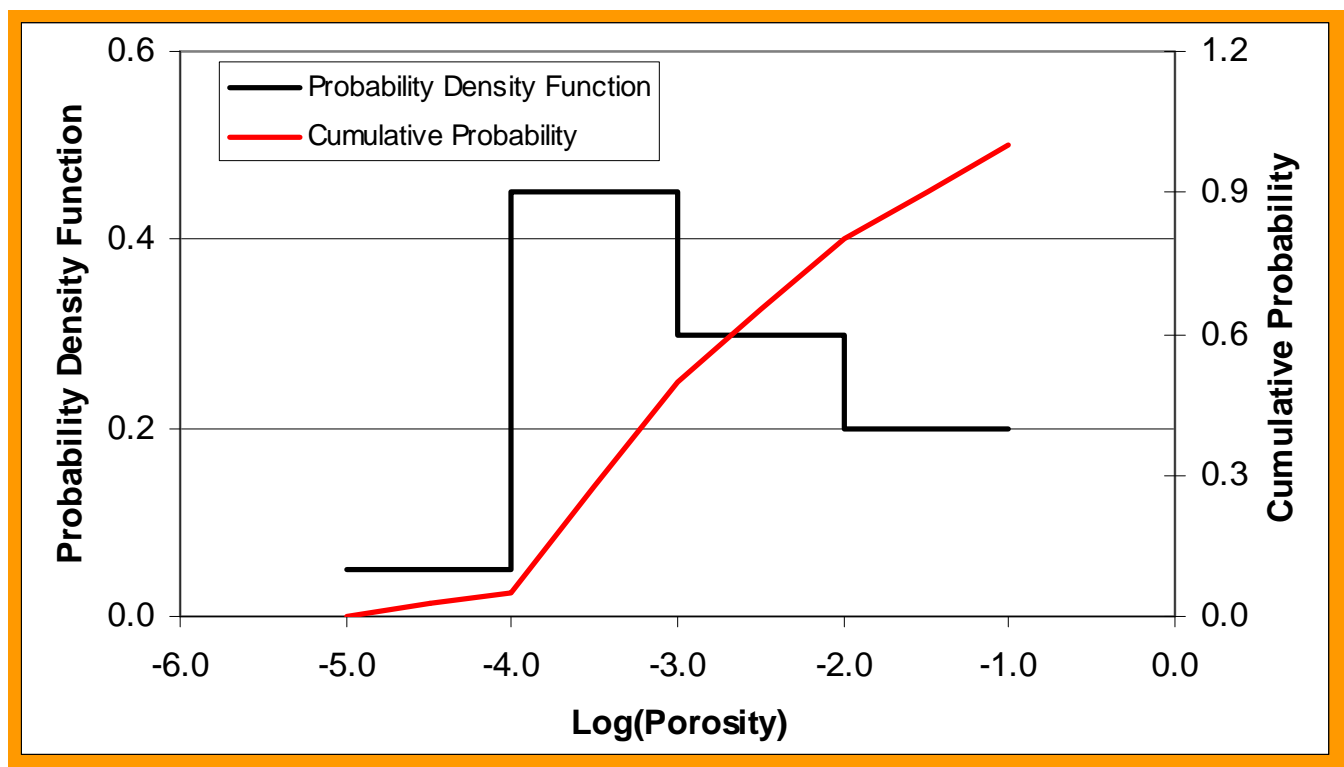

Figure 12. Epistemic distribution for some HGUs, probability density function, and cumulative probability function.

value as effective-porosity Set 2 for the same HGU, which is about 2.2. Figure A30 shows the histogram of the generated effective-porosity values for this HGU.

Group E includes only the intrusive confining unit ICU and its effective-porosity follows a log-uniform distribution. The CV is assumed to have the same value with effectiveporosity Set 2 for the same HGU, which is about 1.6. The histogram of the generated effective-porosity values is shown in Figure A34.

For Group F, the effective-porosity follows an epistemic distribution (BSC, 2004a). The PDF and the cumulative probability function of this distribution are shown in Figure 9. It can be seen that in logarithm space, it is a piece-wise uniform distribution within the given range (from -5 to -1). Group F includes the YVU, TMVA, PVA, CHVU, WVU, CFPPA, CFBCU, CFTA, BRU, and OVU. With the exception of the YVU, which is not present in the YM saturated zone site-scale model, these HGUs encompass the simulated flowpath from the proposed repository to the accessible environment and a single fracture effective-porosity distribution was assigned to the entire group. As summarized by BSC (2004a), the lower bound of effective-porosity uncertainty for these HGUs was based on the results of parallel plate models using fracture characteristics observed in intact cores of volcanic rock from the YM region (CRWMS M\&O, 2000), while the upper bound was based on pumping test and tracer test results from the Yucca Mountain C-wells complex (CRWMS M\&O, 2000). The histogram of the randomly generated effective-porosity values is shown in Figure A31. The mean effective-porosity is about 0.009 and the $\mathrm{CV}$ is about 2.05 .

Table 9 shows summary statistics (means, standard deviations, and CVs) of the randomly generated effective-porosity value realizations for all three effective-porosity data sets used in the Monte Carlo simulations. 
The MODPATH flowpath tracking post-processing package requires effectiveporosity input for each and every model cell. Based on the randomly generated effectiveporosity values of all the 27 DVRFS HGUs, a effective-porosity value is calculated for each DVRFS model cell based on this cell's HGU information, which can be extracted from the HUF package of the DVRFS model. From the HUF package, the extent, depth, and thickness of every HGU can be extracted; and from the DVRFS model spatial discretization, the geometry and spatial location of every DVRFS model cell are known. By combining these two pieces of information, it is possible to find the HGU composition of each DVRFS model cell, expressed as volume fractions of the HGUs that are present in that cell. If a DVRFS model cell contains more than one HGU, the effective-porosity value for a model cell is calculated as a volume-weighted average of the effective-porosity values of the HGUs in the cell.

\section{UNCERTAINTY ANALYSIS OF PARTICLE TRAVEL TIME IN RELATION TO EFFECTIVE-POROSITY UNCERTAINTIES}

The LHS method (Helton and Davis, 2003; Mckay et al., 1979; Iuzzolino, 2003) has been used to generate correlated random values of the porosities. The LHS method is selected for random field generation since it ensures that generated random samples span the full coverage of a random variable obtained from the given statistics, even when the sample size is relatively small. In comparison to the other random sampling methods, LHS requires a smaller number of parameter realizations to yield representative parameter distribution functions (Helton and Davis, 2003; Zhang et al., 2005). This property of LHS reduces the computational cost of Monte Carlo simulations significantly. Another advantage of LHS is that it can easily incorporate parameter correlations into the generated random values.

\section{Procedure for Monte Carlo Simulations}

The DVRFS model was first run for the two steady-state conditions based on the two pumping scenarios (i.e., the pre-pumping prior to 1913 and 1998 pumping), as discussed earlier. From the flow outputs for each pumping scenario, effective-porosity uncertainty is incorporated by performing particle tracking using MODPATH in conjunction with Monte Carlo simulations. The general procedure for Monte Carlo simulations used to quantify the uncertainty in estimates of particle travel times consisted of four steps.

1) Establish the distribution of effective-porosity for each HGU based on the statistical and distribution information presented in the previous section.

2) Randomly select an effective-porosity value from the given distribution for each of the 27 HGUs in the DVRFS model. The random effective-porosity values were generated using LHS. 
Table 9. HGU effective-porosity means and standard deviations used in the Monte Carlo simulations.

HGUs are in DVRFS order

\begin{tabular}{|c|c|c|c|c|c|c|c|c|c|}
\hline & Set 1 & & & Set 2 & & & Set 3 & & \\
\hline $\mathrm{HGU}$ & Mean & SD & $\mathrm{CV}$ & Mean & SD & $\mathrm{CV}$ & Mean & SD & $\mathrm{CV}$ \\
\hline LCA & 0.089998 & 0.009740 & 0.1082 & 0.004056 & 0.002382 & 0.5874 & 0.009930 & 0.005611 & 0.5651 \\
\hline LCA T1 & 0.090000 & 0.009729 & 0.1081 & 0.004058 & 0.002392 & 0.5894 & 0.009930 & 0.005611 & 0.5651 \\
\hline $\mathrm{LCCU}$ & 0.032565 & 0.023613 & 0.7251 & 0.000121 & 0.000199 & 1.6404 & 0.179009 & 0.089623 & 0.5007 \\
\hline LCCU_T1 & 0.032662 & 0.023888 & 0.7314 & 0.000121 & 0.000198 & 1.6378 & 0.179009 & 0.089623 & 0.5007 \\
\hline LFU & 0.080015 & 0.026221 & 0.3277 & 0.017465 & 0.039599 & 2.2674 & 0.082709 & 0.182488 & 2.2064 \\
\hline OVU & 0.142885 & 0.045528 & 0.3186 & 0.044062 & 0.070906 & 1.6092 & 0.009148 & 0.018751 & 2.0497 \\
\hline PVA & 0.089950 & 0.024646 & 0.2740 & 0.004697 & 0.010242 & 2.1803 & 0.009148 & 0.018751 & 2.0497 \\
\hline OACU & 0.319927 & 0.034135 & 0.1067 & 0.319956 & 0.048840 & 0.1526 & 0.319873 & 0.048401 & 0.1513 \\
\hline TMVA & 0.160632 & 0.107209 & 0.6674 & 0.004528 & 0.009561 & 2.1116 & 0.009148 & 0.018751 & 2.0497 \\
\hline $\mathrm{CHVU}$ & 0.169977 & 0.024129 & 0.1420 & 0.035936 & 0.058727 & 1.6342 & 0.009148 & 0.018751 & 2.0497 \\
\hline CFTA & 0.029991 & 0.009662 & 0.3222 & 0.020238 & 0.046630 & 2.3041 & 0.009148 & 0.018751 & 2.0497 \\
\hline CFBCU & 0.030010 & 0.009664 & 0.3220 & 0.324640 & 0.134808 & 0.4153 & 0.009148 & 0.018751 & 2.0497 \\
\hline CFPPA & 0.030000 & 0.009716 & 0.3239 & 0.004672 & 0.010299 & 2.2043 & 0.009148 & 0.018751 & 2.0497 \\
\hline YVU & 0.107993 & 0.016475 & 0.1526 & 0.017175 & 0.038289 & 2.2293 & 0.009148 & 0.018751 & 2.0497 \\
\hline YACU & 0.320080 & 0.034377 & 0.1074 & 0.319931 & 0.048850 & 0.1527 & 0.319873 & 0.048401 & 0.1513 \\
\hline UCA & 0.090010 & 0.009713 & 0.1079 & 0.004056 & 0.002389 & 0.5891 & 0.009930 & 0.005611 & 0.5651 \\
\hline UCCU & 0.087589 & 3122 & 0.4923 & 0.000122 & 203 & 1.6670 & 0.179009 & 39623 & 0.5007 \\
\hline YAA & 0.359937 & 0.088520 & 0.2459 & 0.319867 & 0.049134 & 0.1536 & 0.179866 & 0.050416 & 0.2803 \\
\hline $\mathrm{XCU}$ & 0.000096 & 0.0 & 1.0820 & 0.000120 & 0.0 & 1.6257 & 0.17 & 9623 & 0.5007 \\
\hline WVU & 0.159997 & 0.016967 & 0.1060 & 0.035670 & 0.057763 & 1.6194 & 0.009148 & 0.018751 & 2.0497 \\
\hline LA & 0.089978 & 0.009768 & 0.1086 & 0.004060 & 0.002412 & 0.5940 & 0.009930 & 0.005611 & 0.5651 \\
\hline OAA & 0.359810 & 0.088772 & 0.2467 & 0.320064 & 0.048601 & 0.1518 & 0.179866 & 0.050416 & 0.2803 \\
\hline Lower VSU & 0.159955 & 0.035478 & 0.2218 & 0.044715 & 0.074086 & 1.6569 & 0.179866 & 0.050416 & 0.2803 \\
\hline SCU & 0.300078 & 0.057312 & 0.1910 & 0.044219 & 0.071433 & 1.6154 & 0.179866 & 0.050416 & 0.2803 \\
\hline BRU & 0.284163 & 0.080440 & 0.2831 & 0.004643 & 0.009882 & 2.1283 & 0.009148 & 0.018751 & 2.0497 \\
\hline Upper VSU & 0.160042 & 0.035397 & 0.2212 & 0.044379 & 0.072033 & 1.6231 & 0.179866 & 0.050416 & 0.2803 \\
\hline $\mathrm{ICU}$ & 0.000098 & 0.000109 & 1.1141 & 0.001200 & 0.001992 & 1.6603 & 0.000107 & 0.000162 & 1.5138 \\
\hline
\end{tabular}

3) Calculate effective-porosity values for all DVRFS model cells based on the effectiveporosity values for all $27 \mathrm{HGUs}$ from step 2 and the compositional information of the DVRFS model cells, due to the fact that the cells represent weighted composite of effective-porosity values from different HGUs.

4) Calculate the minimum travel time for each flowpath that starts from one of the underground detonation locations on the NTS that will pass through YM using MODPATH. The minimum travel time is the time when the flowpath intercepts any portion of the YM area as depicted in Figure 1.

After repeating steps 1 to 4 for all 250 realizations for each data set, the PDF and the basic statistics of travel time for each flowpath are computed. The basic statistics include the mean travel time and the uncertainty in the estimate, as represented by the probability density function and the corresponding $\mathrm{CV}$. The same procedure can be conducted for all the underground detonation locations identified and described earlier.

\section{Sensitivity Analysis of Travel Times}

After performing the uncertainty analysis of minimum particle travel times, the next main objective is to develop regression models that relate the minimum travel time to individual input parameters (porosity values for the $27 \mathrm{HGUs).} \mathrm{These} \mathrm{models} \mathrm{are} \mathrm{then} \mathrm{used}$ 
to assess overall sensitivity of the minimum travel time for particular underground detonations in the NTS to the individual HGU porosities. The regression model between the minimum travel time $T$ and input porosities $\varphi_{j}$ can be constructed as (Helton, 1993)

$$
T=b_{0}+\sum_{j=1}^{n} b_{j} \varphi_{j}
$$

where $T$ is the output result, i.e., the minimum travel time from NTS detonation to YM area, $b_{j}(j=0, \ldots, n)$ are the regression coefficients; and $n$ is the number of input porosities.

For each Monte Carlo realization, the regression model can be rewritten as

$$
T_{i}=\sum_{j=0}^{n} b_{j} \varphi_{i j}, i=1,2, \ldots, m
$$

where subscript $i$ is the realization number and $m$ is the total number of realizations. Note $\varphi_{i 0}$ $=1(i=1, \ldots, m)$ and the unknown regression coefficients $\left(b_{j}\right)$ are the same for all Monte Carlo simulations. Equation (4) can be expressed in matrix form as

$$
\mathbf{T}=\boldsymbol{\Phi b}
$$

where

$$
\mathbf{T}=\left[\begin{array}{c}
T_{1} \\
\ldots \\
T_{m}
\end{array}\right], \boldsymbol{\Phi}=\left[\begin{array}{cccc}
1 & \varphi_{11} & \ldots & \varphi_{1 n} \\
\ldots & \ldots & \ldots & \ldots \\
1 & \varphi_{m 1} & \ldots & \varphi_{m n}
\end{array}\right], \mathbf{b}=\left[\begin{array}{c}
b_{0} \\
\ldots \\
b_{n}
\end{array}\right]
$$

The least squares approach seeks to minimize the sum $(\mathbf{T}-\mathbf{\Phi b})^{\mathrm{T}}(\mathbf{T}-\boldsymbol{\Phi b})$, which leads (Draper and Smith, 1981) to

$$
\mathbf{b}=\left(\boldsymbol{\Phi}^{\mathrm{T}} \boldsymbol{\Phi}\right)^{-1} \boldsymbol{\Phi}^{\mathrm{T}} \mathbf{T}
$$

The matrix $\boldsymbol{\Phi}^{\mathrm{T}} \boldsymbol{\Phi}$ is always invertible when the columns of $\boldsymbol{\Phi}$ are linearly independent.

The usefulness of coefficients in Equation (6) is severely limited in sensitivity analysis because they depend on the units of the input variables and output results. To eliminate this dependency, the regression model in Equation (4) can be expressed as

$$
\left(T_{i}-\bar{T}\right) / S=\sum_{j=1}^{n} c_{j}\left(\varphi_{i j}-\bar{\varphi}_{j}\right) / s_{j}
$$

where $\bar{\varphi}_{j}$ and $s_{j}$ are the mean and standard deviation of the input variable $\varphi_{j}$ from all realizations, respectively; and $\bar{T}$ and $S$ are the mean and standard deviation of the minimum travel time to YM from all realizations, respectively. The coefficients $c_{j}\left(=b_{j} s_{j} / S\right)$ in Equation (7) are called standardized regression coefficients, where the absolute value of $c_{j}$ provides a measure of parameter importance in the minimum travel time uncertainty. The regression coefficients for the porosities are normalized relative to the respective standard deviations, which provide a better measure of relative importance of the input effective-porosity variability to the uncertainty in the minimum travel time to YM. 
From Equation (4), the mean of the minimum travel time to YM from the regression model can be calculated as

$$
\bar{T}=\sum_{j=0}^{n} b_{j} \bar{\varphi}_{j}
$$

The mean of the squared minimum travel time and the square of the mean minimum travel time can be expressed as

$$
\begin{aligned}
& \overline{T^{2}}=\sum_{j=0}^{n} b_{j}^{2} \overline{\varphi_{j}^{2}}+2 \sum_{j=0}^{n} \sum_{k=j+1}^{n} b_{j} b_{k} \overline{\varphi_{j} \varphi_{k}} \\
& (\bar{T})^{2}=\sum_{j=0}^{n} b_{j}^{2}\left(\bar{\varphi}_{j}\right)^{2}+2 \sum_{j=0}^{n} \sum_{k=j+1}^{n} b_{j} b_{k} \overline{\varphi_{j}} \overline{\varphi_{k}}
\end{aligned}
$$

Therefore, the variance of the minimum travel time to YM is

$$
\operatorname{Var}(T)=\overline{T^{2}}-(\bar{T})^{2}=\sum_{j=0}^{n} b_{j}^{2} \operatorname{Var}\left(\varphi_{j}\right)+2 \sum_{j=0}^{n} \sum_{k=j+1}^{n} b_{j} b_{k} \operatorname{Cov}\left(\varphi_{j}, \varphi_{k}\right)
$$

Because $\varphi_{j}$ and $\varphi_{k}$ are independent, the covariance between $\varphi_{j}$ and $\varphi_{k}$ is zero (i.e., $\operatorname{Cov}\left(\varphi_{j}, \varphi_{k}\right)=0$ ), so the variance of the minimum travel time in Equation (9) can be simplified as

$$
\operatorname{Var}(T)=\sum_{j=0}^{n} b_{j}^{2} \operatorname{Var}\left(\varphi_{j}\right)
$$

Because $\operatorname{Var}\left(\varphi_{0}\right)=0$, the variance of the minimum travel time to $\mathrm{YM}$ is

$$
\operatorname{Var}(T)=\sum_{j=1}^{n} b_{j}^{2} \operatorname{Var}\left(\varphi_{j}\right)
$$

If the standardized regression coefficients $c_{j}$ are used, Equation (11) then becomes

$$
\operatorname{Var}(T)=\sum_{j=1}^{n} c_{j}^{2} \operatorname{Var}(T)
$$

Therefore, the squared values of standardized regression coefficients $c_{j}^{2}$ simply represent the fractional contribution to the total minimum travel time variances from the individual input variables (i.e, HGU porosities in this study).

\section{RESULTS AND DISCUSSION OF UNCERTAINTY AND SENSITIVITY ANALYSIS Mean Minimum Travel Times}

Besides groundwater flowpaths that possibly connect NTS underground test areas to the proposed YM withdrawal areas, the mean minimum travel time from each individual underground detonation to YM could be used to develop future monitoring programs for assessing contaminant migration. From the 250 realizations of effective-porosity values generated, the particle can be tracked starting from each detonation location forward to a 
location where it intercepts the proposed YM withdrawal area. The minimum travel time of most concern is the time it takes for advective travel from the underground detonation to the $\mathrm{YM}$ area. The minimum travel times to the YM areas vary greatly from detonation to detonation for both groundwater pumping scenarios considered in this study. Figures 13 and 14 show the mean minimum travel times for particles from all detonations that are hydraulically connected to the proposed YM withdrawal area for the pre-pumping and 1998 pumping conditions, respectively. Some underground tests were detonated at close proximity to each other and as a result fall into the same DVRFS cell. In these cases, it is assumed that the particles representing these detonations started at the same location for the sake of simplicity. As a result, some detonations have the same travel times to the YM area, as can be seen from Figures 13 and 14. Note that as discussed previously, all particles were started at the same time in the simulations, despite the differences in detonation dates.

Another conclusion can be drawn from the groundwater flowpath and the mean minimum travel time analysis. Groundwater pumping not only induces particle flowpaths from more detonations to intercept the YM area, but also increases the groundwater travel velocity from the detonations to the YM area. Therefore, pumping has two main effects on the groundwater flows, i.e., increasing flow velocity and inducing more direct flowpaths; both have the overall effect of decreasing groundwater travel times from the detonations to the YM area.

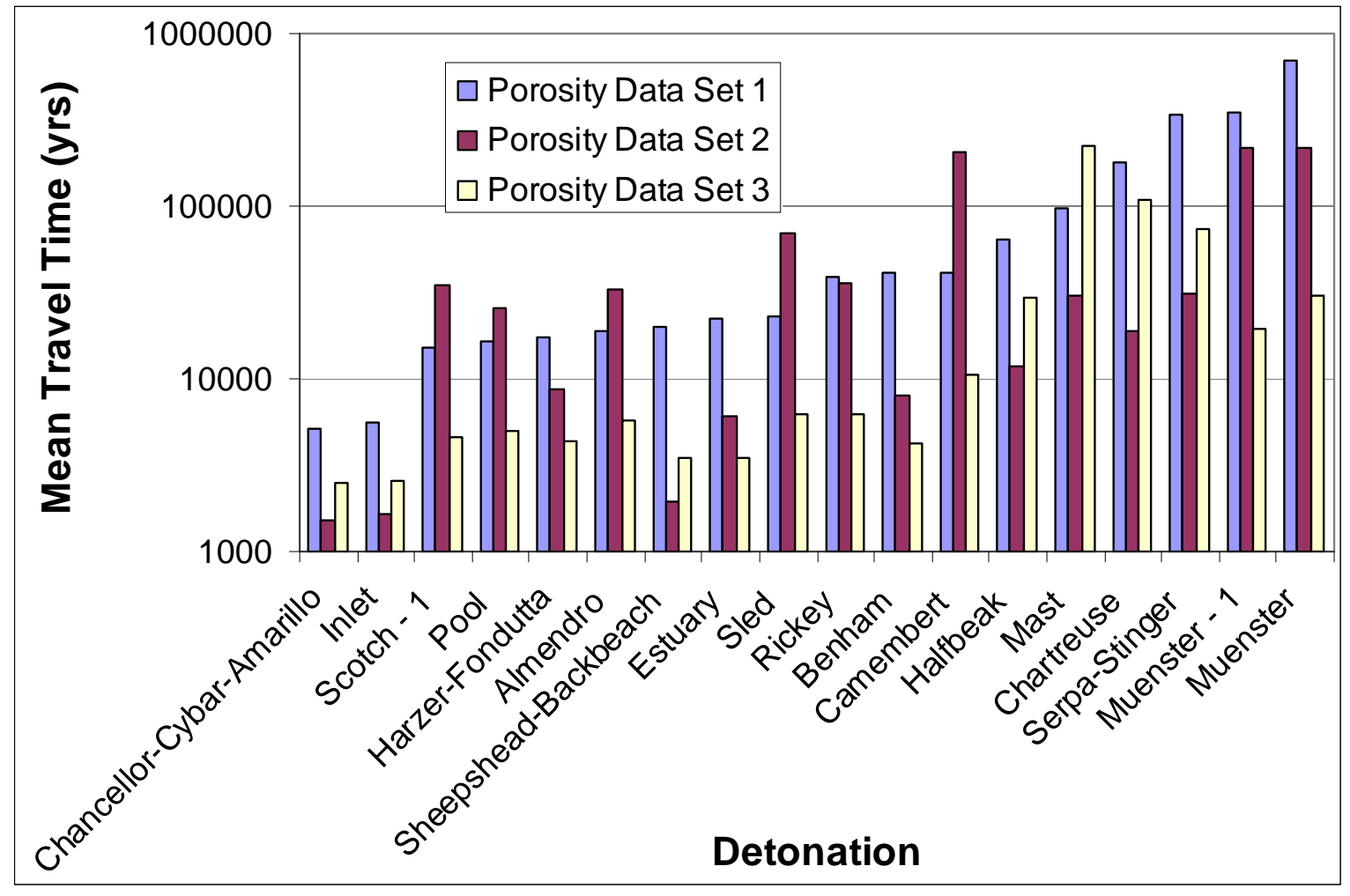

Figure 13. Mean travel time from detonations to YM boundaries, based on three different effectiveporosity sets under pre-pumping conditions. 

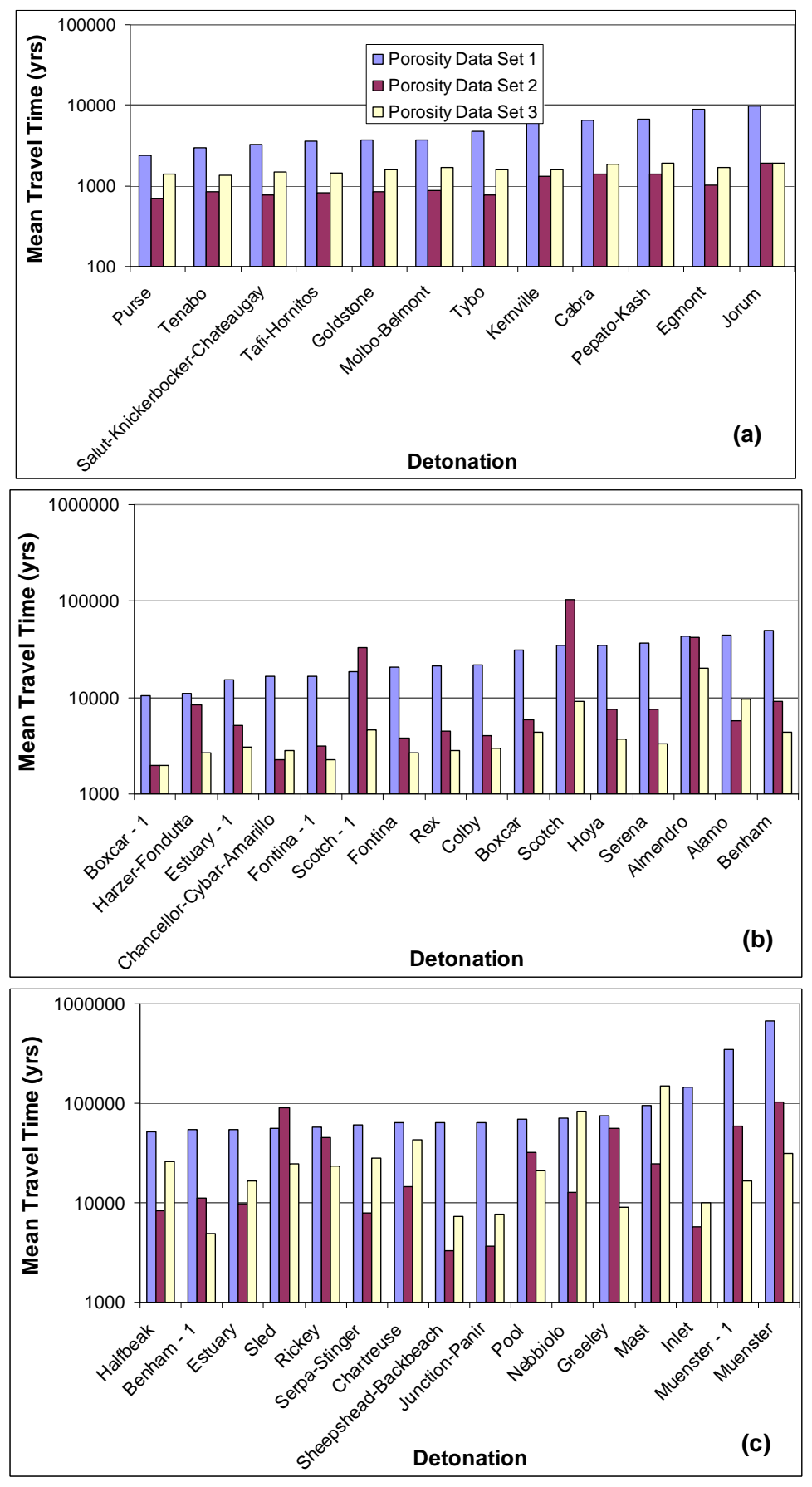

Figure 14. Mean travel time from detonations to YM boundaries, based on three different effectiveporosity data sets under 1998 pumping conditions, (a) for detonations whose mean travel times based on Effective-porosity Data Set 1 are less than 10,000 years, (b) for detonations whose mean travel times based on Effective-porosity Data Set 1 are between 10,000 and 50,000 years, (c) for detonations whose mean travel times based on Effectiveporosity Data Set 1 are over 50,000 years. 


\section{PRE-PUMPING CONDITIONS}

In Figure 13, the detonations are arranged in groups so that the mean minimum travel times are from shortest to longest when using Effective-porosity Data Set 1. It can be seen that the mean minimum travel times for Effective-porosity Data Set 2 and Effective-porosity Data Set 3 are not in the same order as in Effective-porosity Data Set 1.

\section{Porosity Data Set 1}

For the pre-pumping scenario, the mean minimum travel times to YM range from 5,134 years from three detonations (Chancellor, Cyber, and Amarillo) to almost 700,000 years for Muenster. While groundwater travel from the NTS underground tests to YM follows the same pathways for all three effective-porosity data sets discussed previously, the minimum travel time from the NTS to the YM area based on different effective-porosity data sets varies significantly (see discussion below).

Out of the 23 detonations whose groundwater flow trajectory will pass through the YM area based on the pre-pumping flow scenario, flowpaths from Chancellor, Cyber, Amarillo, and Inlet have mean minimum travel times to the YM area under 10,000 years; those from Scotch-1, Pool, Harzer, Fondutta, Almendro, Sheepshead, and Backbeach have mean minimum travel times to YM between 10,000 and 20,000 years; and those from Estuary, Sled, Rickey, Benham, Camembert, Halfbeak, Mast, Chartreuse, Serpa, Stinger, Muenster-1, and Muenster have the mean minimum travel times to the YM area of over 20,000 years.

For most underground detonations, Effective-porosity Data Set 1 produces the longest travel times, because effective-porosity Set 1 has the largest effective-porosity values overall.

\section{Porosity Data Set 2}

Out of the 23 underground detonations whose groundwater flowpaths will pass through the YM area based on the pre-pumping flow scenario, flowpaths from ChancellorCybar-Amarillo, Inlet, Sheepshead-Backbeach, Estuary, Benham, Harzer-Fondutta have mean minimum travel times to the YM area under 10,000 years; those from Halfbeak and Chartreuse have mean minimum travel times between 10,000 and 20,000 years; those from Pool, Mast, Serpa-Stinger, Almendro, Scotch-1, Rickey, Sled, Camembert, Muenster, and those from Muenster-1 have mean minimum travel times to the YM area of over 20,000 years.

\section{Porosity Data Set 3}

Based on Effective-porosity Data Set 3 under the pre-pumping flow scenario, flowpaths from Chancellor-Cybar-Amarillo, Inlet, Sheepshead-Backbeach, Estuary, Benham, Harzer-Fondutta, Scotch-1, Pool, Almendro, Sled, and Rickey have mean minimum travel times to the YM area under 10,000 years; those from Camembert, and Muenster-1 have mean minimum travel times between 10,000 and 20,000 years; those from Halfbeak, Muenster, Serpa-Stinger, Chartreuse, and Mast have mean minimum travel times to the YM area of over 20,000 years. 


\section{PUMPING CONDITIONS}

Figure 14 shows the minimum mean travel times from all detonations that are hydraulically connected to the proposed YM withdrawal area under the 1998 pumping conditions based on all three effective-porosity data sets described earlier.

Porosity Data Set 1

For the 1998 pumping scenario, the mean minimum travel times of particles to the YM area vary from 2,366 years for Purse to about 680,000 years for Muenster. Flowpath from Muenster has the longest travel time for both pumping scenarios. Out of the 55 detonations whose groundwater flow trajectory will pass through the YM area based on the 1998 pumping flow scenario, flowpaths from Purse, Tenabo, Salut, Knickerbocker, Chateaugay, Tafi, Hornitos, Goldstone, Molbo, Belmont, and Tybo have mean minimum travel times to the YM area under 5,000 years; those from Kernville, Cabra, Pepato, Kash, Egmont, and Jorum have mean minimum travel times to the YM area between 5,000 and 10,000 years; those from Boxcar-1, Harzer, Fondutta, Estuary-1, Chancellor, Cybar, Amarillo, Fontina-1, and Scotch-1 have the mean minimum travel times to the YM area between 10,000 and 20,000 years; and those Fontina, Rex, Colby, Boxcar, Scotch, Hoya, Serena, Almendro, Alamo, Benham, Halfbeak, Benham-1, Estuary, Sled, Rickey, Serpa, Stinger, Chartreuse, Sheepshead, Backbeach, Junction, Panir, Pool, Nebbiolo, Greeley, Mast, Inlet, Muenster-1, and Muenster have mean minimum travel times to the YM area of over 20,000 years. Effective-porosity Data Set 1 also produces the longest travel times from most detonations under the 1998 pumping conditions.

Porosity Data Set 2

Out of the 55 detonations whose groundwater flow trajectory will pass through YM under the 1998 pumping flow scenario, flowpaths from Purse, Tybo, Salut-KnickerbockerChateaugay, Tafi-Hornitos, Goldstone, Tenabo, Molbo-Belmont, Egmont, Kernville, PepatoKash, Cabra, Jorum, Boxcar-1, Chancellor-Cybar-Amarillo, Fontina-1, SheepsheadBackbeach, Junction-Panir, Fontina, Colby, and Rex have mean minimum travel times to YM under 5,000 years; those from Estuary-1, Alamo, Inlet, Boxcar, Hoya, Serena, SerpaStinger, Harzer-Fondutta, Halfbeak, Benham, and Estuary have mean minimum travel times to YM between 5,000 and 10,000 years; those from Benham-1, Nebbiolo, and Chartreuse have mean minimum travel times to the YM area between 10,000 and 20,000 years; and those from Mast, Pool, Scotch-1, Almendro, Rickey, Greeley, Muenster-1, Sled, Muenster, and Scotch have mean minimum travel times to the YM area of over 20,000 years.

\section{Porosity Data Set 3}

Based on Effective-porosity Data Set 3 under the 1998 pumping scenario, flowpaths from Tenabo, Purse, Tafi-Hornitos, Salut-Knickerbocker-Chateaugay, Goldstone, Tybo, Kernville, Molbo-Belmont, Egmont, Cabra, Pepato-Kash, Jorum, Boxcar-1, Fontina-1, Fontina, Harzer-Fondutta, Rex, Chancellor-Cybar-Amarillo, Colby, Estuary-1, Serena, Hoya, Boxcar, Benham, Scotch-1, and Benham-1 have mean minimum travel times to the YM area under 5,000 years; those from Sheepshead-Backbeach, Junction-Panir, Greeley, Scotch, and Alamo have mean minimum travel times to the YM area between 5,000 and 10,000 years; those from Inlet, Muenster-1, and Estuary have mean minimum travel times to the YM area from 10,000 to 20,000 years; and those from Almendro, Pool, Rickey, Sled, Halfbeak, Serpa- 
Stinger, Muenster, Chartreuse, Nebbiolo, and Mast have the mean minimum travel times to the YM area of over 20,000 years.

\section{Coefficients of Variation of the Minimum Travel Times}

To assess the uncertainties associated with the travel times, the $\mathrm{CV}$ of the minimum travel time was also calculated for all three effective-porosity sets. Figure 15 shows the CVs of the minimum travel time from detonations to YM boundaries, based on the three different effective-porosity sets under pre-pumping conditions. Figure 16 shows the CVs of the minimum travel time from detonations to YM boundaries, based on the three different effective-porosity sets under pre-pumping conditions. Both figures show that the minimum travel time CVs based on Effective-porosity Data Set 2 and Effective-porosity Data Set 3 are significantly larger than those based on effective-porosity Set 1 . This is due to the fact that Effective-porosity Data Set 2 and Effective-porosity Data Set 3 have significantly larger effective-porosity CVs for most HGUs (see Table 9).

\section{Significance of HGU Porosities on the Minimum Travel Time Uncertainties}

To determine the most dominant HGU controls on the minimum travel times from NTS detonations to the YM area and the associated uncertainties, 27 sets of 250-realization Monte Carlo simulations were also run when only one HGU had randomly variable effectiveporosity and the porosities for other HGUs were set to equal the mean values. Randomly generated effective-porosity results based on Effective-porosity Data Set 1 were used for that

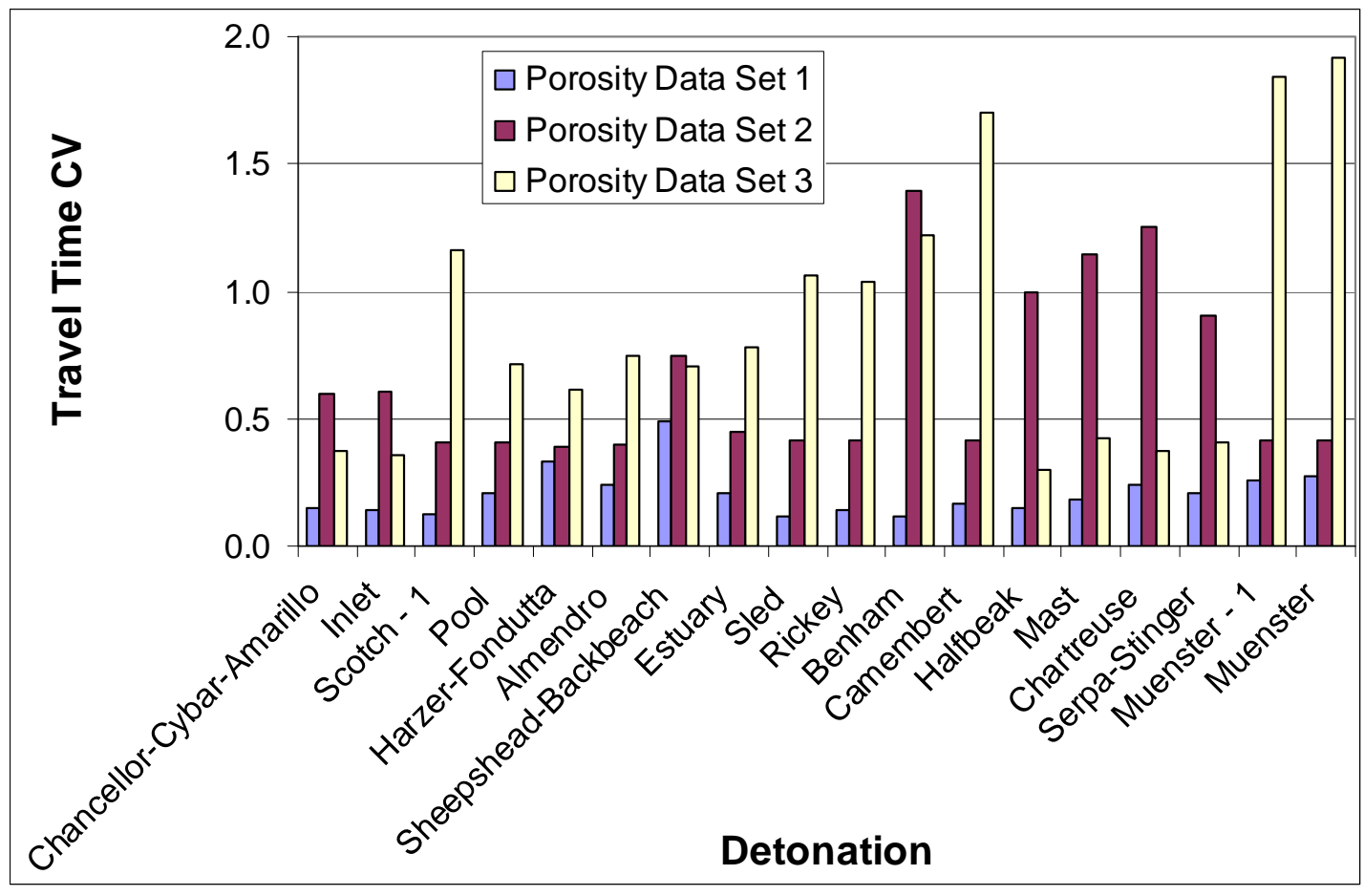

Figure 15. Coefficient of variation (CV) of travel time from detonations to YM boundaries, based on three different effective-porosity data sets under pre-pumping conditions. 

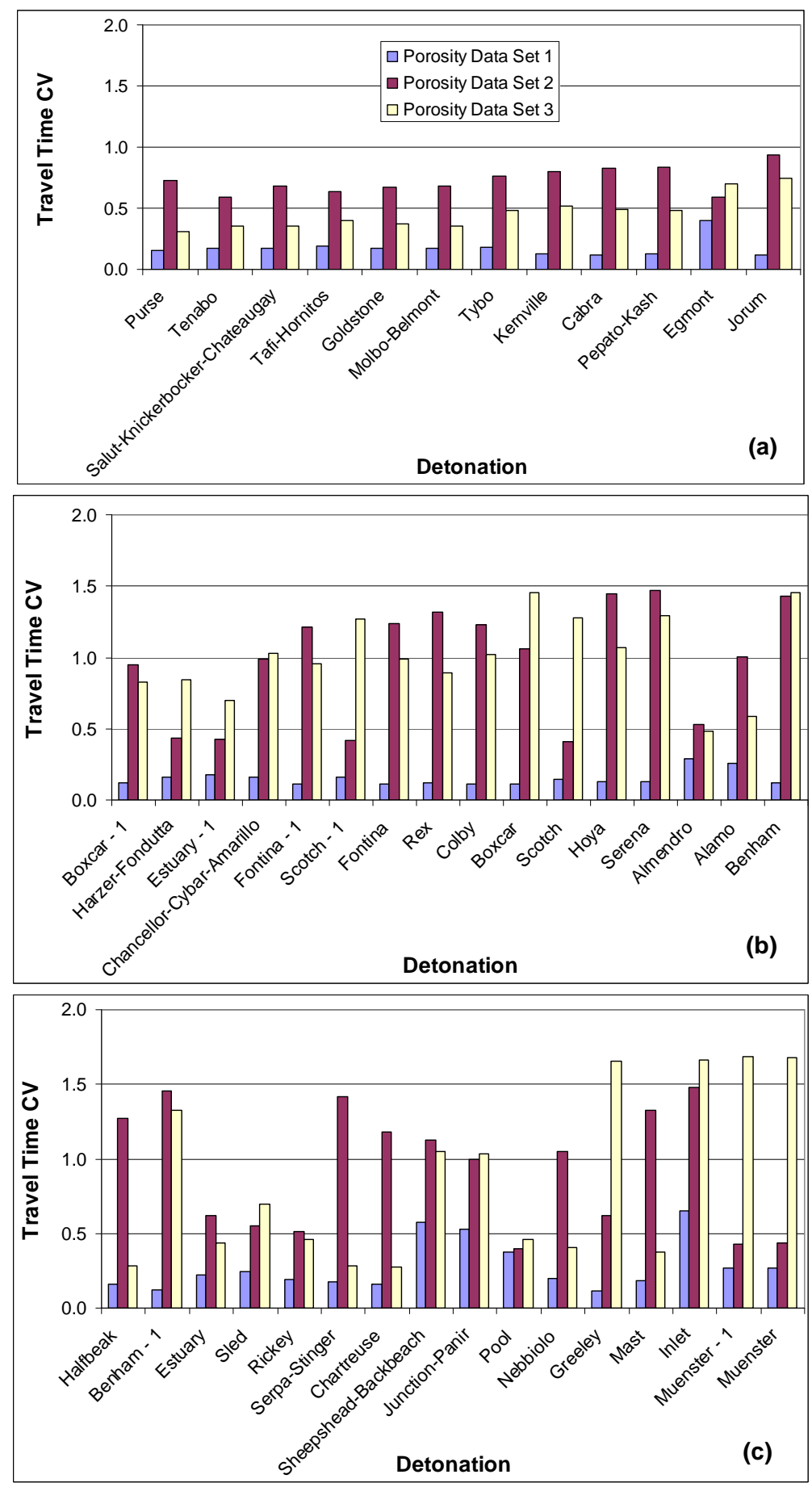

Figure 16. Coefficient of variation (CV) of travel time from detonations to YM boundaries, based on three different effective-porosity data sets under 1998 pumping conditions, (a) for detonations whose mean travel times based on Effective-porosity Data Set 1 are less than 10,000 years, (b) for detonations whose mean travel times based on Effective-porosity Data Set 1 are between 10,000 to 50,000 years, and (c) for detonations whose mean travel times based on Effective-porosity Data Set 1 are over 50,000 years. 


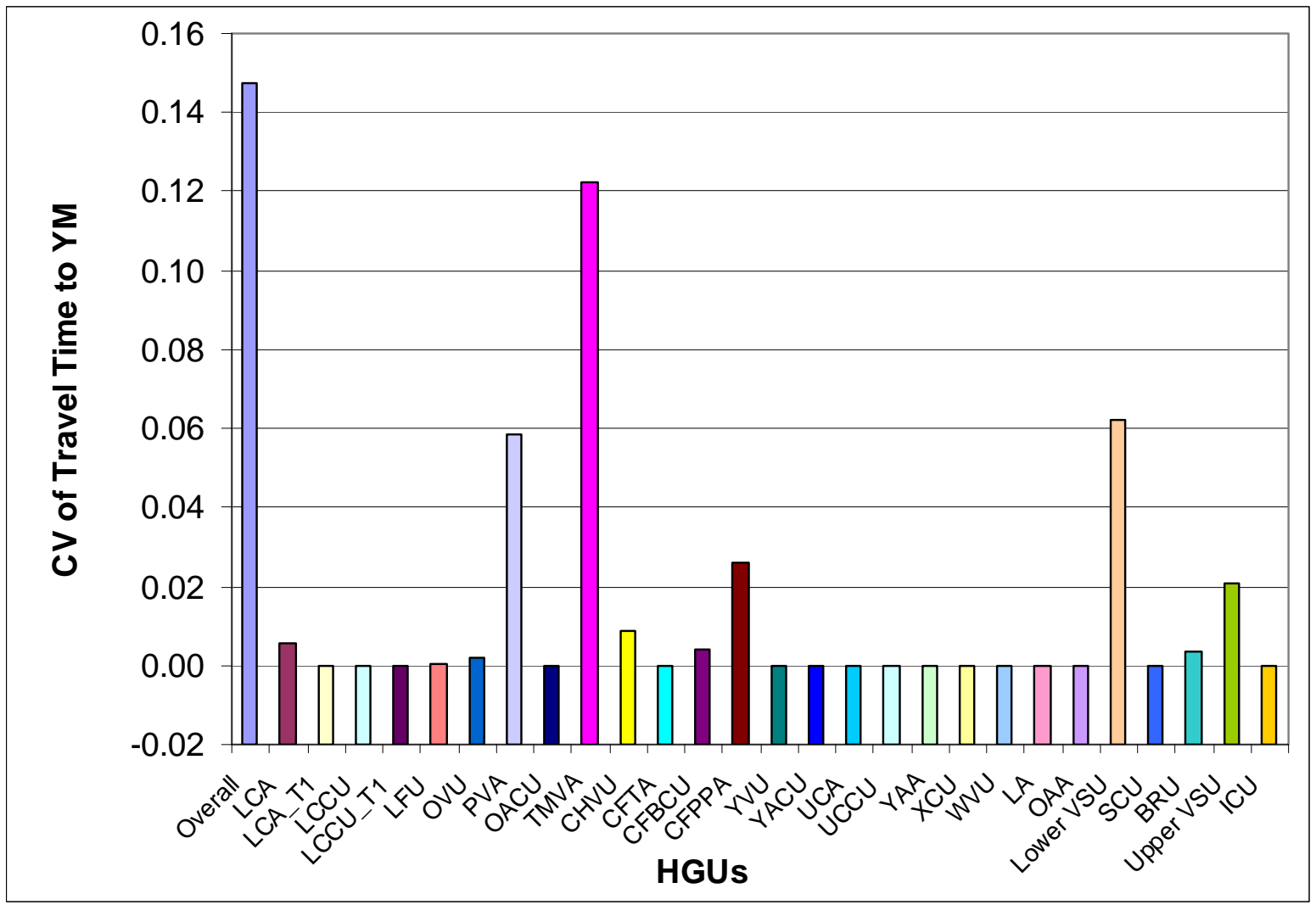

Figure 17. Coefficient of variation (CV) of minimum travel time to the YM area from Chancellor, Cybar, and Amarillo, in relation to the effective-porosity uncertainties of HGUs when only one HGU has randomly variable effective-porosity and the porosities for other HGUs are set to equal the mean values under pre-pumping conditions.

purpose. After each set of simulations, the mean minimum travel times to YM area and their CVs were calculated for all individual detonations whose groundwater flowpaths will intercept the YM area. Figure 17 shows the calculated CV results of the minimum travel times to the YM area in relation to the HGU effective-porosity uncertainties under the prepumping conditions for Chancellor, Cybar and Amarillo. Using all three effective-porosity data sets, flowpaths from Chancellor, Cybar, and Amarillo always have the shortest mean travel time to the YM area under the pre-pumping conditions. Figure 18 shows the simulated $\mathrm{CV}$ results of the minimum travel time to the YM area in relation to the HGU effectiveporosity uncertainties under the 1998 pumping conditions for (a) Purse and (b) Tenabo. Using Effective-porosity Data Sets 1 and 2, flowpath from Purse has the shortest mean travel time to the YM area under the 1998 pumping conditions. Using Effective-porosity Data Set 3, flowpath from Tenabo has the shortest mean travel time to the YM area under the 1998 pumping conditions. The results from the similar analysis for all detonations based on effective-porosity Set 1 for both pre-pumping and 1998 pumping are shown in Appendix B. The figures show the $\mathrm{CV}$ values when only one $\mathrm{HGU}$ (the HGU name is indicated in the $\mathrm{x}$ - 
axis of the figure) has the variable effective-porosity values based on the randomly generated results described previously. In all figures, "Overall" in the x-axis indicates all HGUs have

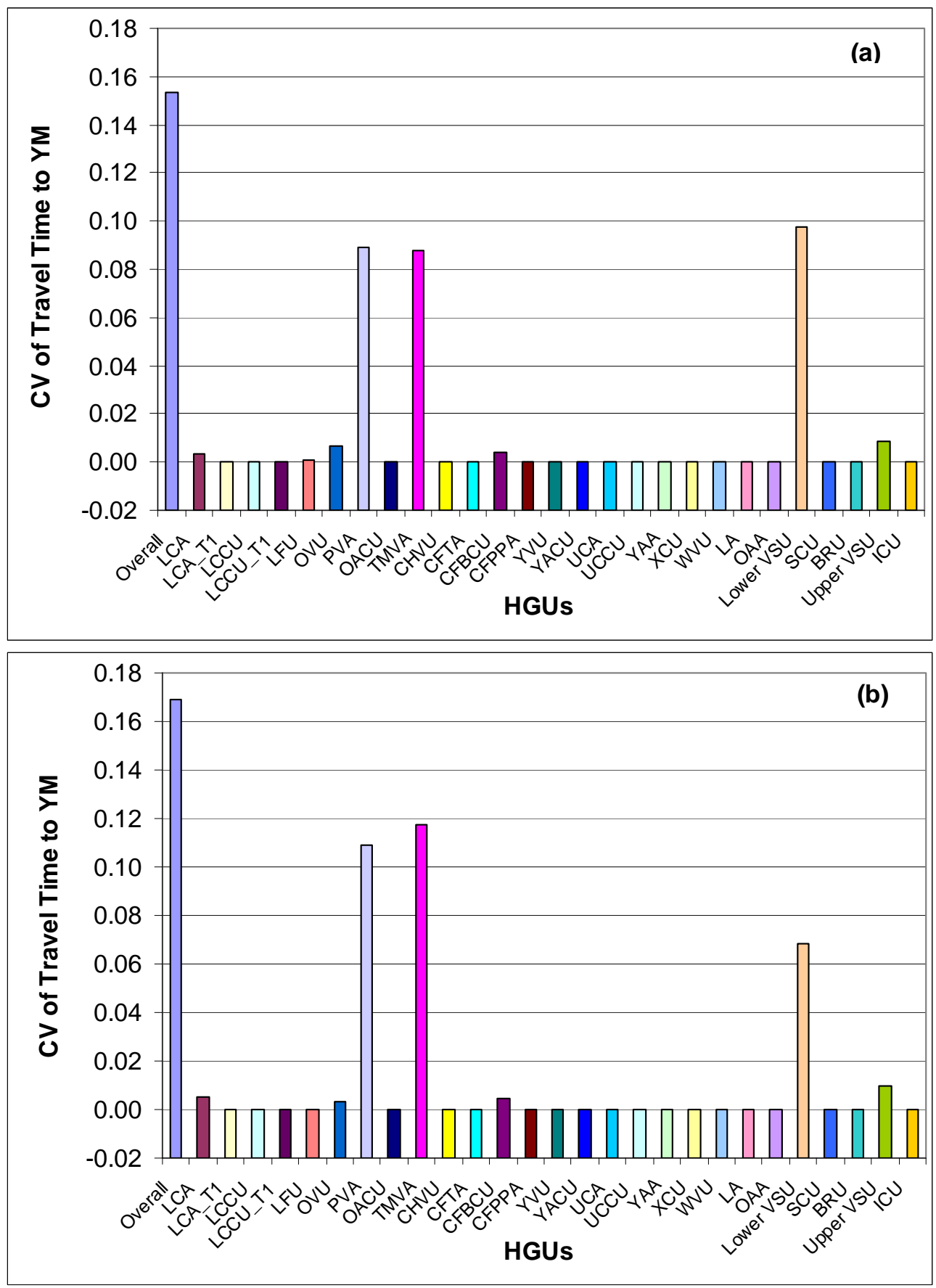

Figure 18. Coefficient of variation (CV) of minimum travel time to the YM area from (a) Purse and (b) Tenabo, in relation to the effective-porosity uncertainties of HGUs when only one HGU has randomly variable effective-porosity and the porosities for other HGUs are set to equal the mean values under 1998 pumping conditions. 
randomly variable porosities, while the HGU name in the x-axis means only this HGU has the random effective-porosity input and all other HGUs' porosities are held constant at their mean effective-porosity values. Therefore, the CV of minimum travel times to the YM area for "Overall" incorporate all possible uncertainties in the HGU effective-porosity values, while that for other scenarios is attributed only to the individual HGUs shown on the $\mathrm{x}$-axis. Although the flowpaths from the 23 detonations will eventually intercept the YM area under the pre-pumping conditions, 18 MODPATH tracking results are presented, since some detonations are located in the same DVRFS model cells, which results in only 18 groundwater flowpaths (Figures B1 through B18 in Appendix B). The figures are arranged according to the mean minimum travel times from shortest to longest.

For the first underground testing group (i.e., Chancellor, Cyber, Amarillo, and Inlet, from which the particles' mean minimum travel times to the YM area are under 10,000 years), it is evident that TMVA (Thirsty Canyon-Timber Mountain volcanic-rock aquifer) has the most significant influence on the minimum travel times and therefore their uncertainties. Other HGUs that also impact the minimum travel times to the YM area from this detonation group include Lower VSU, PVA, Upper VSU, and CFPPA. For the second detonation group (i.e., Scotch-1, Pool, Harzer, Fondutta, Almendro, Sheepshead, and Backbeach, from which the particles' mean minimum travel times to the YM area are between 10,000 and 20,000 years), TMVA seems to once again have the most significant impact on the minimum travel times to the YM area and their uncertainties. Other HGUs have very little impact on the minimum travel times and their uncertainties, except that CFPPA is the most important factor in determining its minimum travel time and the uncertainty to the YM area from Scotch-1. For the third group of detonations (i.e., Estuary, Sled, Rickey, Benham, Camembert, Halfbeak, Mast, Chartreuse, Serpa, Stinger, Muenster-1, and Muenster), there seems to be no common main control to the minimum travel time to the YM area. The only general conclusion that can be drawn is that BRU has the most important impact on those detonations from which the particles have the longest minimum travel times to the YM area. Other HGUs significantly affecting this detonation include: TMVA, PVA, CFBCU, CHVU, CFPPA, Lower VSU, LCCU, and OVU). Note that the conclusion that certain HGUs have significant impact on the minimum travel time uncertainty from certain underground detonations also means that the groundwater flowpaths from these underground tests mainly occur within these controlling HGUs.

The general trend is that for flowpaths from those detonations that take a relatively short time to travel to the YM area, TMVA has the most important impact on the travel times and their uncertainties. For flowpaths from those detonations that take a long time to travel to the YM area, BRU seems to mostly affect their minimum travel time to the YM area and their uncertainties. The majority of the HGUs do not affect (or have very little effect on) the minimum travel times to the YM area and their uncertainties. Those HGUs include: LCA, LCA_T1, LCCU_T1, LFU, OACU, CFTA, YVU, YACU, UCA, UCCU, YAA, XCU, WVU, LA, OAA, SCU, Upper VSU, and ICU.

From Figure 13, it can be observed that Effective-porosity Data Set 2 produces the longest minimum travel time from five detonations (i.e., Scotch-1, Pool, Almendro, Sled, and Camembert). Under pre-pumping scenario, the most influential HGUs on particle travel time from Scotch -1 are CFPPA, CFBCU, TMVA, PVA, Lower VSU, and Upper VSU (see Figure B3). Even though the mean effective-porosity for CFPPA is the smallest from 
Effective-porosity Data Set 2 (0.0046 versus 0.03 and 0.0091$)$, it is CFBCU that causes the minimum travel time from Scotch-1 to be the longest among the three effective-porosity sets. The mean effective-porosity for CFBCU from Effective-porosity Data Set 2 is 0.325 , by far the largest among the three effective-porosity sets. The most influential HGUs on the minimum travel time ffrom Pool and Almendro are TMVA, CFBCU, BRU, Lower VSU, and CFPPA (see Figure B4 and Figure B6). While TMVA is clearly the most important HGU that affects the minimum travel time from Pool, the unusually high CFBCU mean effectiveporosity based on Effective-porosity Data Set 2 is the main reason that Effective-porosity Data Set 2 causes the slightly longer minimum travel time from Pool and Almendro than the other two effective-porosity sets. The most influential HGUs on the travel times of particles from Sled and Camembert are CFBCU, PVA, TMVA, BRU, Lower VSU, CFPPA, and CHVU (see Figure B9 and Figure B12). Since CFBCU is the most dominant HGU and has the largest mean effective-porosity based on Effective-porosity Data Set 2, it is not surprising that Effective-porosity Data Set 2 causes the groundwater flow along Sled's and Camembert's flowpaths to be slower.

Overall, the detonations with mean travel times to the YM withdrawal area boundary of less than 2,000 years are all from Effective-porosity Data Set 2 (Chancellor-CyberAmarillo, Inlet, and Sheepshead-Backbeach). For Chancellor-Cyber-Amarillo and Inlet, the most influential HGUs are TMVA, Lower VSU, PVA, CFBCU, and Upper VSU (see Figure B1 and Figure B2). For TMVA, Effective-porosity Data Set 2 has the smallest mean effective-porosity (0.0045 versus 0.0091 for Effective-porosity Data Set 3 and 0.161 for Effective-porosity Data Set 1). For Sheepshead, the travel time is almost exclusively dominated by TMVA and therefore is smallest based on Effective-porosity Data Set 2.

The Effective-porosity Data Set 3 produces the longest travel time only for Mast. The most influential HGUs on the minimum travel time of particle from Mast are the Lower VSU, LCCU, and OVU (see Figure B14) with the Lower VSU being the most dominant. Since Effective-porosity Data Set 3 indicated the largest effective-porosity among the three sets for Lower VSU (see Table 9), Effective-porosity Data Set 3 produces the longest travel time from Mast.

Figures B19 through B62 show simulated CV results of the minimum travel times to the YM area in relation to the HGU effective-porosity uncertainties under the 1998 pumping conditions for all detonations. The figures are also arranged according to the mean minimum travel times to the YM area from all detonations, from shortest to longest. The 55 particles that will eventually intercept the YM area are actually located in 44 DVRFS model cells. Therefore, results are presented for the 44 groundwater flowpaths.

For the first detonation group (i.e., Purse, Tenabo, Salut, Knickerbocker, Chateaugay, Tafi, Hornitos, Goldstone, Molbo, Belmont, and Tybo, the mean minimum travel times to the YM area are under 5,000 years), only three HGUs have impact on the minimum travel times to the YM area and all other HGUs have no or very little influence on the travel times. These three HGUs are PVA, TMVA, and Lower VSU. For the second detonation group (i.e., Kernville, Cabra, Pepato, Kash, Egmont, and Jorum, the mean minimum travel times to the YM area are between 5,000 to 10,000 years), CHVU also plays an important role in determining and influencing the minimum travel times besides the three HGUs (i.e, PVA, TMVA and Lower VSU) mentioned earlier. For the third group (i.e., Boxcar-1, Harzer, 
Fondutta, Estuary-1, Chancellor, Cybar, Amarillo, Fontina-1, and Scotch-1, the mean minimum travel times to the YM area are between 10,000 and 20,000 years), PVA, TMVA, CHVU, Lower VSU, BRU, CFBCU, and CFPPA are the HGUs that influence their minimum travel times to the YM area. For the last group (i.e., Fontina, Rex, Colby, Boxcar, Scotch, Hoya, Serena, Almendro, Alamo, Benham, Halfbeak, Benham-1, Estuary, Sled, Rickey, Serpa, Stinger, Chartreuse, Sheepshead, Backbeach, Junction, Panir, Pool, Nebbiolo, Greeley, Mast, Inlet, Muenster-1, and Muenster, the mean minimum travel times to the YM area are over 20,000 years), PVA, TMVA, CHVU, Lower VSU, CFBCU, CFPPA, BRU, and LCCU are the important HGUs. In summary, although there are 27 HGUs in the DVFRS region, only eight HGUs (PVA, TMVA, CHVU, Lower VSU, CFBCU, CFPPA, BRU, and LCCU) have an impact on the travel times from detonations in NTS operational areas 18, 19, 20, and 30 to the proposed YM withdrawal area under the 1998 pumping scenarios.

From these analysis results, the HGUs important for the purpose of tracking convective groundwater flows from NTS areas 18, 19, 20, and 30 include PVA, TMVA, CHVU, Lower VSU, Upper VSU, CFBCU, CFPPA, BRU, LCCU, and OVU under both pre-pumping and 1998 pumping conditions. Note that our discussion of HGU importance in contaminant travel time is in relation to the ways in constructing the HGUs for the DVRFS model. In particular, many of the HGUs are composed of multiple geologic units with different effective porosities. Therefore, assigning one single effective-porosity value for each HGU tends to smooth out the heterogeneity of the model domain, which is a main assumption that underlies the DVRFS model. While the pumping-induced flows significantly affect groundwater flowpaths, attract more groundwater flow from the NTS detonation areas to the YM area, and generally reduce the particle travel times from the NTS to the YM area, the pumping-induced flows still pass mainly through the same HGUs. Perhaps most important, for the detonations that might impact the YM area in under 10,000 years, TMVA, PVA, lower VSU, and CHVU are the HGUs that mainly dictate groundwater pathways from upgradient detonations to the proposed YM withdrawal area. TMVA, PVA, and CHVU are the major HGUs in the SWNVF. This is not surprising given the fact that the flow region interest in is in the eastern part of the SWNVF. The TMVA is extensive and covers most of the SWNVF. TMVA thickness exceeding $500 \mathrm{~m}$ occurs at Pahute Mesa and in the vicinity of Timber Mountain. The TMVA reaches a maximum thickness of about 2,600 $\mathrm{m}$ within its source caldera at Timber Mountain. Thick accumulations of intercaldera PVA are present to the north of Yucca Mountain, where it reaches thickness of nearly 2,400 m; however, the PVA at YM and eastern and central Pahute Mesa is generally above the water table. The PVA is below the water table in western Pahute Mesa, east and south of YM, and in Crater Flat. The VSU has been divided into upper and lower parts. The Upper VSU and Lower VSU encompass the Cenozoic volcanic rock units of the SWNVF. The CHVU is exposed at the surface in Calico Hills, Fortymile Canyon, and Paintbrush Canyon, where thicknesses exceed $500 \mathrm{~m}$. Thicknesses of the unit reach about 1,500 $\mathrm{m}$ in the caldera moat just west of Timber Mountain.

For the two different pumping conditions, flowpaths and travel times can be significantly different even from the same detonations. Under the pre-pumping conditions using Effective-porosity Data Set 1, there are no detonation locations where travel time will be less than 5,000 years to the YM area, while there are 11 detonations (i.e., Purse, Tenabo, Salut, Knickerbocker, Chateaugay, Tafi, Hornitos, Goldstone, Molbo, Belmont, and Tybo) 
where travel time will be less than 5,000 years to reach the YM area under the 1998 pumping conditions. None of the 11 YM-bound particles under the 1998 pumping conditions will intercept the YM area under the pre-pumping conditions. In other words, groundwater pumping not only reduces the travel times from NTS detonations to the YM area, but more importantly it induces groundwater flowpaths to the YM area from the detonations, which originally would not intercept YM under pre-pumping conditions. This group of detonations has the smallest mean minimum travel times to the YM area and poses the biggest possibility that radionuclides originating from the NTS detonation area might be transported to the proposed YM withdrawal area a in relatively short time period.

Porosity Data Set 2 produces longest mean travel times from Scotch-1, Scotch, and Sled under 1998 pumping conditions. For Scotch-1, the most influential HGUs are TMVA, CFPPA, CFBCU, PVA, and BRU (see Figure B36). For Scotch, the most influential HGUs are CFBCU, TMVA, CFPPA, BRU, and PVA (see Figure B41). For Sled, the most influential HGUs are TMVA, CFTA, Lower VSU, and CFBCU (see Figure B50). For those detonations, the unusually large effective-porosity of CFBCU from Effective-porosity Data Set 2 is the main reason why this effective-porosity set produces the longest travel time.

Porosity Data Set 3 produces the longest travel time from Nebbiolo and Mast (see Figure 14). For Nebbiolo, the most influential HGUs under the 1998 pumping scenario are TMVA, Lower VSU, LCCU, and PVA (see Figure B57). For Mast, the most influential HGUs under the 1998 pumping scenario are Lower VSU, TMVA, and LCCU (see Figure B59). The quite large effective-porosity for lower VSU and LCCU is the main reason that Effective-porosity Data Set 3 produces the longest travel time.

Overall, the shortest mean travel times from the NTS detonations to the YM withdrawal boundary are from Purse, Tybo, Salut-Knickerbocker-Chateaugay, Tafi-Hornitos, Goldstone, Tenabo, and Molbo-Belmont, all below 1,000 years. They are all associated with effective-porosity Set 2. For all detonations in this group, the most influential HGUs are always Lower VSU, PVA, and TMVA (see Figure B19, Figure B25, Figure B21, Figure B22, Figure B23, Figure B20, and Figure B24, respectively). For these three HGUs, Effectiveporosity Data Set 2 has the smallest mean effective-porosity (see Table 9). This explains why Effective-porosity Data Set 2 produces the smallest travel time from the NTS detonations to YM.

In summary, the mean minimum travel times cover a large range, from about 700 years to almost 700,000 years, depending on the detonation location, the effective-porosity data set used, and the pumping scenario. Among these factors, the detonation location has the biggest impact on the travel time. Groundwater flow in the region is composed of several interconnected, complex flow systems. Since groundwater flow occurs in three subregions in relatively shallow and localized flowpaths that are superimposed on deeper, regional flowpaths, detonations close to each other may travel along very different flowpaths, may result in quite different travel times. For the detonations with more direct flowpaths connecting to the YM area, the mean minimum travel times are typically in the ranges of thousands of years. Earlier ${ }^{14} \mathrm{C}$ analysis (Thomas et al., 2002) of flowpaths from NTS operational area 19 to the YM area indicated the groundwater along the flowpath has a maximum average age of 4,200 $\pm 2,000$ years, which is the time frame of more direct flowpaths illustrated in this study. 


\section{Distributions of Minimum Travel Time}

From Figure 13, it is found that under the pre-pumping conditions, flowpaths from Chancellor-Cybar-Amarillo has the shortest mean minimum travel time to the YM area for all three effective-porosity data sets. Figure 19 plots distributions of the minimum travel time to YM from this detonation group based on all three effective-porosity data sets under prepumping conditions. From Figure 17, it is observed that this detonation group is the most sensitive to the porosities of TMVA, Lower VSU, PVA, and CFPPA under the pre-pumping conditions. Of these four HGUs, only the effective-porosity of TMVA has a lognormal distribution based on Effective-porosity Data Set 1; the other three all have normal distributions. As a result the minimum travel time from Chancellor-Cybar-Amarillo mainly also has normal distribution and is only slightly skewed due to the effect of effective-porosity of TMVA. Based on effective-porosity Set 2, the distribution of minimum travel time from Chancellor-Cybar-Amarillo is positively skewed (Figure 19b). This is largely corresponding to the highly positively skewed effective-porosity distributions of the most influential HGUs based on Effective-porosity Set 2 (see Figure 10). From Figure 16c we can see that the distribution of the minimum travel time from Chancellor-Cybar-Amarillo based on effectiveporosity Set 3 is also positively skewed but to a lesser degree. This is consistent with the fact that two of the five most influential HGUs have a quite normal effective-porosity distribution, while the other three are highly positively skewed (see Figure 11).

From Figure 14, it is found that under the 1998 pumping conditions, flowpath from Purse has the shortest mean minimum travel time to the YM areas based on Effectiveporosity Data Sets 1 and 2, while that from Tenabo has the shortest mean minimum travel time to the YM areas based on Effective-porosity Data Set 3. Figure 20 plots distributions of the minimum travel time to YM boundaries from these detonations based on the three effective-porosity data sets under the 1998 pumping conditions. Note Figures 20a and b are for Purse and Figure 20c is for Tenabo. Figure 18 shows that Purse and Tenabo are overwhelmingly influenced by the porosities of three HGUs, i.e., PVA, TMVA, and Lower VSU. Based on Effective-porosity Data Set 1, PVA and Lower VSU have normal distribution, while TMVA is lognormally distributed. The minimum travel time from Purse, shown in Figure 17a, is largely normally distributed. Based on Effective-porosity Data Set 2, all three HGUs have positively skewed logtriangular distributions. The distribution of the minimum travel time from Purse shown in Figure 20b, which is based on Effective-porosity Data Set 2, is also positively skewed. Based on Effective-porosity Data Set 3, the porosities for PVA and TMVA are highly skewed from the epistemic distribution, while Lower VSU has a normally distributed effective-porosity. The distribution of the minimum travel time from Tenabo, shown in Figure 20c, which is based on Effective-porosity Data Set 3, is somewhat positively skewed, but to a much lesser degree in comparison to Purse, based on Effective-porosity Data Set 2, shown Figure 20b. Appendix C lists complete minimum travel time distributions of flowpaths from all underground detonations that travel through the YM area.

\section{Sensitivity Analysis Results}

To implement the sensitivity analysis using the porosities from a limited number of the most influential HGUs to quantify the relative contributions to the minimum travel time uncertainties from the effective-porosity uncertainties of the individual HGUs, the 

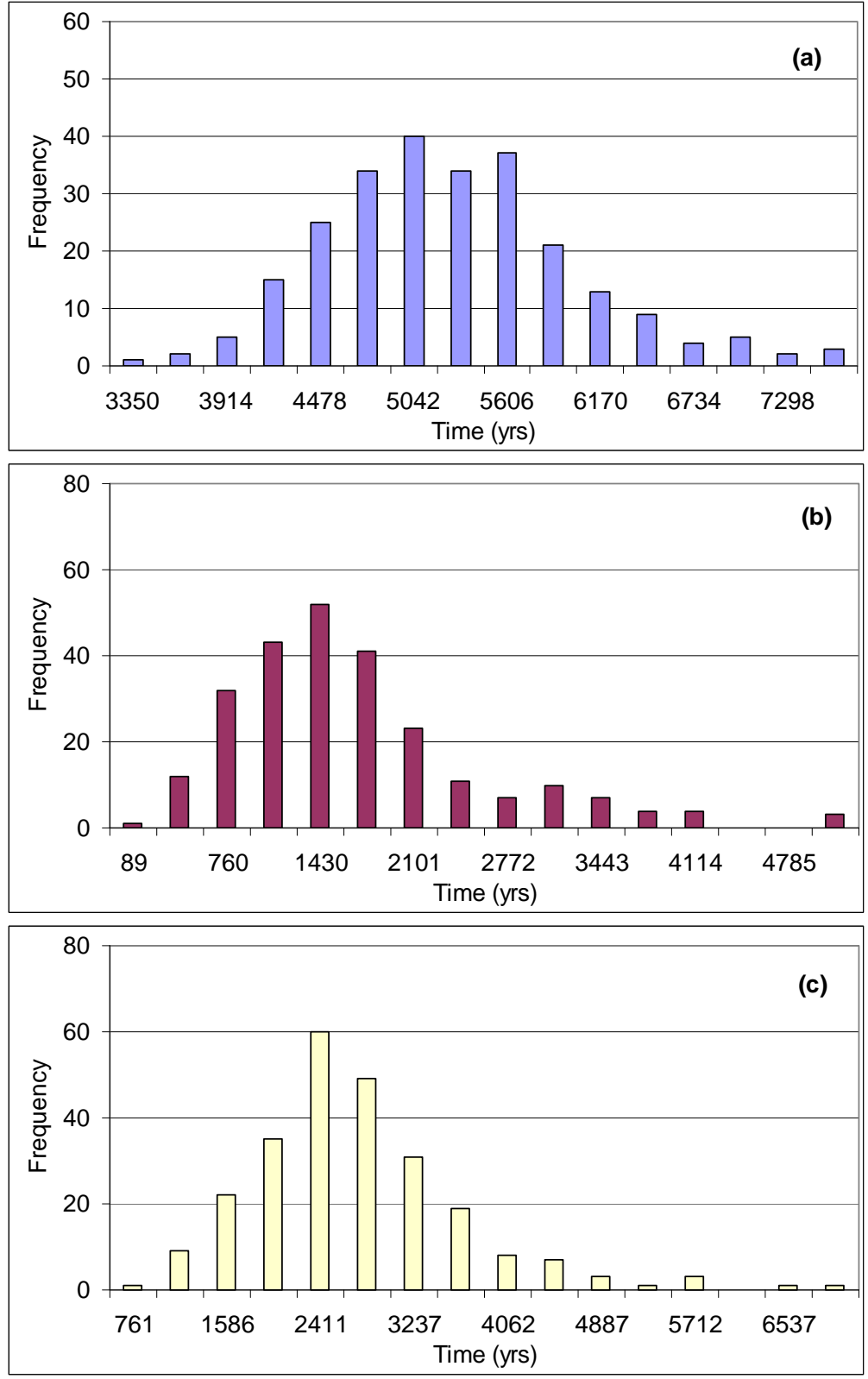

Figure 19. Distribution of minimum travel time to YM boundaries from Chancellor-Cybar-Amarillo, which has the shortest mean minimum travel times based on all three effective-porosity data sets under pre-pumping conditions. (a) Effective-porosity Data Set 1, (b) Effectiveporosity Data Set 2, and (c) Effective-porosity Data Set 3. 

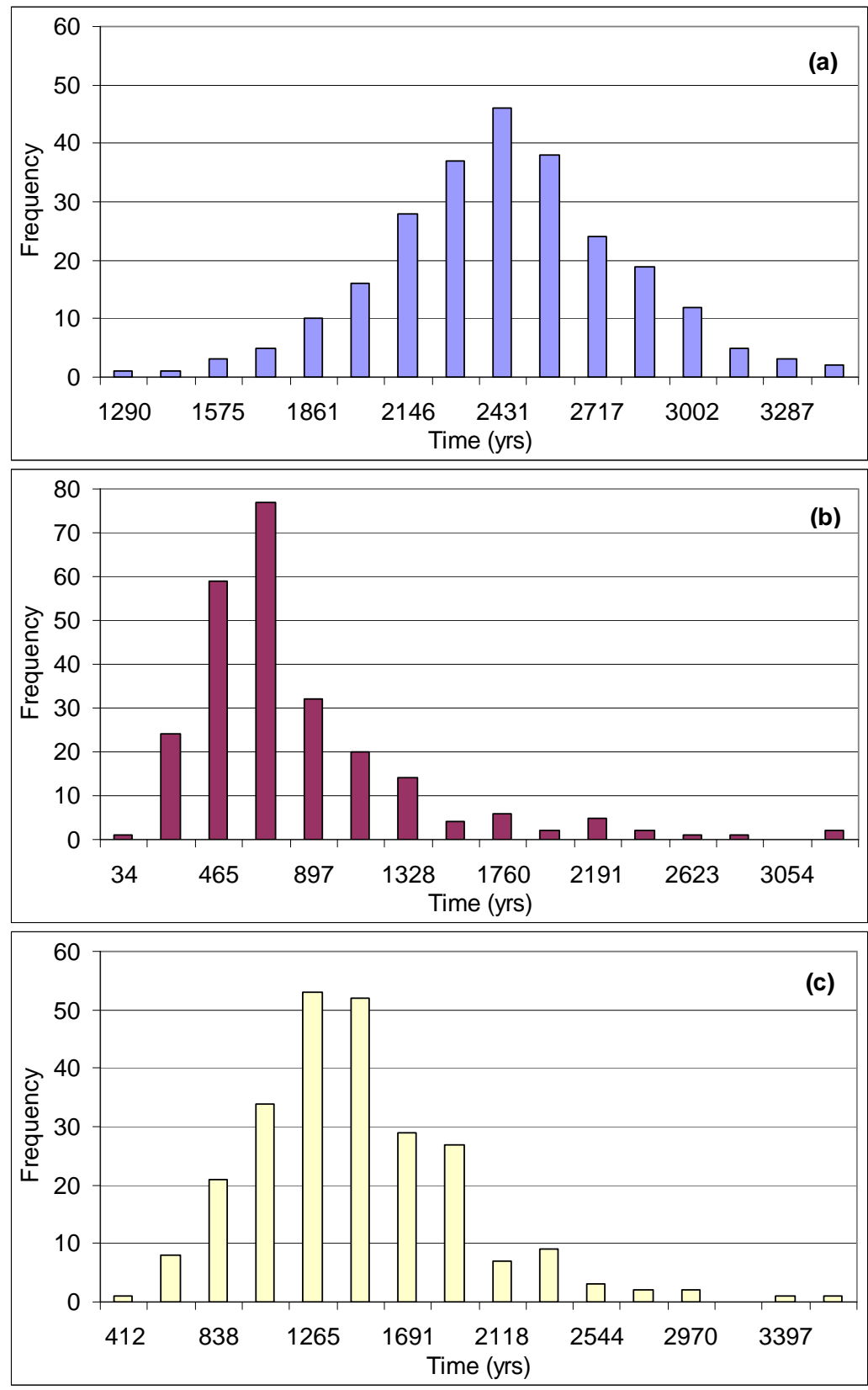

Figure 20. Distribution of minimum travel time to YM boundaries from detonations that have the shortest mean minimum travel times based on various scenarios under 1998 pumping conditions. (a) from Purse based on Effective-porosity Data Set 1, (b) from Purse based effective-porosity Set 2, and (c) Tenabo based on Effective-porosity Data Set 3. 
subsequent sensitivity analysis was based on the results and conclusions seen in Figures 17 and 18. From Figure 13 and Figure 14, it can be concluded that the NTS underground detonations from which the particles have the shortest mean minimum travel times to the YM areas are (1) Chancellor-Cybar-Amarillo, under pre-pumping conditions for all three effective-porosity data sets, (2) Purse under 1998 pumping conditions for Effective-porosity Data Set 1 and Effective-porosity Data Set 2, and (3) Tenabo under 1998 pumping conditions for Effective-porosity Data Set 3. From Figure 17 and Figure 18, the following conclusions have been:

1) For Chancellor-Cybar-Amarillo under pre-pumping conditions, TMVA, Lower VSU, PVA, CFPPA, and upper VSU are the most influential HGUs that affect the minimum travel times to the YM area and their associated uncertainties;

2) For Purse, under 1998 pumping conditions, Lower VSU, PVA, and TMVA are the most important HGUs; and

3) For Tenabo, under 1998 pumping conditions, TMVA, PVA, lower VSU are the dominant HGUs.

Therefore, for those underground detonations producing the smallest mean minimum travel times to the YM area, the following five HGUs porosities are mostly responsible for the minimum travel time uncertainties: 1) PVA, 2) TMVA, 3) CFPPA, 4) lower VSU, and 5) Upper VSU. Using the porosities from these five HGUs as the independent variables and the minimum travel time to the YM area as the dependent variable for all Monte Carlo realizations $(i=1, \ldots, 250)$, regression models were developed as shown in Equation (4). The regression coefficients are obtained from Equation (6), and the corresponding standardized regression coefficients. Based on the standardized regression coefficients, the squared standardized regression coefficients can be calculated. While five of the most influential HGUs have been identified, there are only two independent input effective-porosity values for the sensitivity analysis based on Effective-porosity Data Set 3, due to the limited effective-porosity distribution information for this effective-porosity data set. As explained earlier, for Effective-porosity Data Set 3, there are only seven independent effective-porosity inputs. For example, there are $10 \mathrm{HGUs}$ that have the same epistemic distribution. These 10 HGUs will have the same effective-porosity values for each realization. Therefore, there are only two independent effective-porosity inputs for Effective-porosity Data Set 3, which are (PVA+TMVA+CFPPA) and (Lower VSU+Upper VSU). In other words, the factional contributions to the minimum travel uncertainties from PVA, TMVA, and CFPPA are lumped together. The same statement is also true for Lower VSU and Upper VSU. The squared standardized regression coefficients for these HGU porosities represent the combined contributions to the minimum travel time uncertainties from those lumped HGUs, which cannot be separated further due to the way these porosities were generated for the Monte Carlo simulation inputs.

Tables 10 and 11 present the results of the squared values of the standardized regression coefficients, which illustrate the fractional contribution to the total minimum travel time variances from the most influential HGU porosities, as indicated in Equation (12). Table 10 shows the results for Effective-porosity Data Set 1 and Effective-porosity Data Set 2, while Table 11 is those for Effective-porosity Data Set 3. These results clearly identify the relative importance of $\mathrm{HGU}$ effective-porosity uncertainties to the minimum travel time uncertainties under various combinations of pumping and effective-porosity scenarios. 
Tables 10 and 11 reveal the following quantitative results regarding the relative importance of HGUs in terms of the minimum travel time uncertainties:

1) Under pre-pumping conditions and based on Effective-porosity Data Set 1, the effective-porosity of TMVA is the dominant factor that impacts the minimum travel time uncertainty of the particles along the Chancellor-Cybar-Amarillo groundwater flowpath to YM.

2) Under pre-pumping conditions and based on Effective-porosity Data Set 2, the porosities of lower and upper VSUs account for almost all the minimum travel time uncertainty of the particles along the Chancellor-Cybar-Amarillo flowpath to YM.

3) Under 1998 pumping conditions and based on Effective-porosity Data Set 1, the porosities of lower VSU, PVA, and TMVA all have significant impact on the minimum travel time uncertainty from Purse.

4) Under 1998 pumping conditions and based on Effective-porosity Data Set 2, the effective-porosity of Lower VSU is dominating the minimum travel time uncertainty from Purse to YM.

5) Based on Effective-porosity Data Set 3, the group of PVA, TMVA, and CFPPA and the group of lower and upper VSUs are about equally important in contributing to the minimum travel time uncertainties for the detonations from which the particles have the shortest minimum travel times under respective pumping conditions.

Table 10. Squared standardized regression coefficients for Effective-porosity Data Set 1 and Effective-porosity Data Set 2.

\begin{tabular}{|c|c|c|c|c|}
\hline & \multicolumn{2}{|c|}{ Pre-pumping } & \multicolumn{2}{c|}{$\begin{array}{c}\text { 1998 pumping } \\
\text { Purse }\end{array}$} \\
\cline { 2 - 5 } & $\begin{array}{c}\text { Chancellor-Cybar-Amarillo } \\
\text { Set 1 }\end{array}$ & $\begin{array}{c}\text { Porosity Data } \\
\text { Set 2 }\end{array}$ & $\begin{array}{c}\text { Porosity Data } \\
\text { Set 1 }\end{array}$ & $\begin{array}{c}\text { Porosity Data } \\
\text { Set 2 }\end{array}$ \\
\hline PVA & 0.15778 & 0.01591 & 0.33645 & 0.02581 \\
\hline TMVA & 0.68522 & 0.00298 & 0.32504 & 0.00088 \\
\hline CFPPA & 0.03012 & 0.02555 & 0.00000 & 0.00001 \\
\hline Lower VSU & 0.17687 & 0.53746 & 0.40025 & 0.86360 \\
\hline Upper VSU & 0.01973 & 0.40607 & 0.00313 & 0.08717 \\
\hline
\end{tabular}

Table 11. Squared standardized regression coefficients for Effective-porosity Data Set 3.

\begin{tabular}{|c|c|c|}
\hline & $\begin{array}{c}\text { Pre-pumping } \\
\text { Chancellor-Cybar-Amarillo }\end{array}$ & $\begin{array}{c}1998 \text { pumping } \\
\text { Tenabo }\end{array}$ \\
\hline PVA+TMVA+CFPPA & 0.52667 & 0.48534 \\
\hline Lower+Upper VSU & 0.44760 & 0.48889 \\
\hline
\end{tabular}


To further illustrate validity of the approach of using a limited number of the most influential HGU porosities, Figure 21 shows a scatterplot of all 250 Monte Carlo realization results for the minimum travel times based on the full relationship and those based on the regression models that use only the five selected input HGU porosities. Figure 18 shows that the detailed statistical behavior is captured very well when using the simplified regression models. Slight deviations (and underpredictions) from the full relationship typically appear for small travel time range based on Effective-porosity Data Set 2. For all cases, the predictions from simplified regressions based on only five HGU porosities and the full relationships based on all 27 are fully correlated, with the correlation coefficient of over 0.97 .

\section{CONCLUSIONS}

Using the simulated groundwater flow results from the DVRFS model along with the particle tracking package MODPATH, simulations of three-dimensional groundwater advective pathways and calculation of groundwater travel times indicate that groundwater from major underground test areas on the NTS can reach the proposed YM land withdrawal area. The travel times and pathways were analyzed for both the pre-pumping and post-1998 pumping scenarios. The fastest travel times occur within 10,000 years, the compliance period pursuant to $40 \mathrm{CFR} 197$ for which a standard of 150 microsievert (uSv) per year (15 millirem $\{$ mrem $\}$ per year) committed effective dose equivalent (CEDE) has been established by the U.S. Environmental Project Agency (EPA) for radionuclide exposure from all pathways for the proposed repository, and additional ones potentially reach the area within the 1,000,000-year compliance period for which a $3.5 \mathrm{mSv}$ per year (350 mrem per year) CEDE standard has been proposed. Consequently, the results suggest there is potential for radionuclide contamination associated with underground testing on the NTS to reach the vicinity of Yucca Mountain, and that there may be a need for monitoring to discriminate between contaminants from the NTS that might otherwise be erroneously attributed to releases from the proposed repository.

Some of the main conclusions are as follows.

Groundwater pumping not only increases the groundwater travel velocity from the underground tests to the proposed YM withdrawal area, but also induces more flowpaths to intercept it. Out of these 71 detonations in the saturated zone, the flowpaths of 23 of them will intercept theYM area under the pre-pumping scenario compared to 55 for the 1998 pumping scenario.

Groundwater pumping scenarios also significantly impact the minimum travel time from the detonations to the YM area by altering flowpaths, although the flowpaths usually occur in the same HGUs. Pumping also attracts many more additional groundwater flowpaths from the detonations to the YM area.

The minimum and maximum travel times for detonations varied depending on the effective-porosity data set used in the simulations. The shortest minimum travel times from major detonations to the proposed YM withdrawal boundaries were associated with Effective-porosity Data Set 2. Based on Effective-porosity Data Set 1, the mean travel time from the major detonations in NTS operational areas 18, 19, 20, and 30 to the YM area ranges from 5,134 to almost 700,000 years for the pre-pumping conditions, while for the 

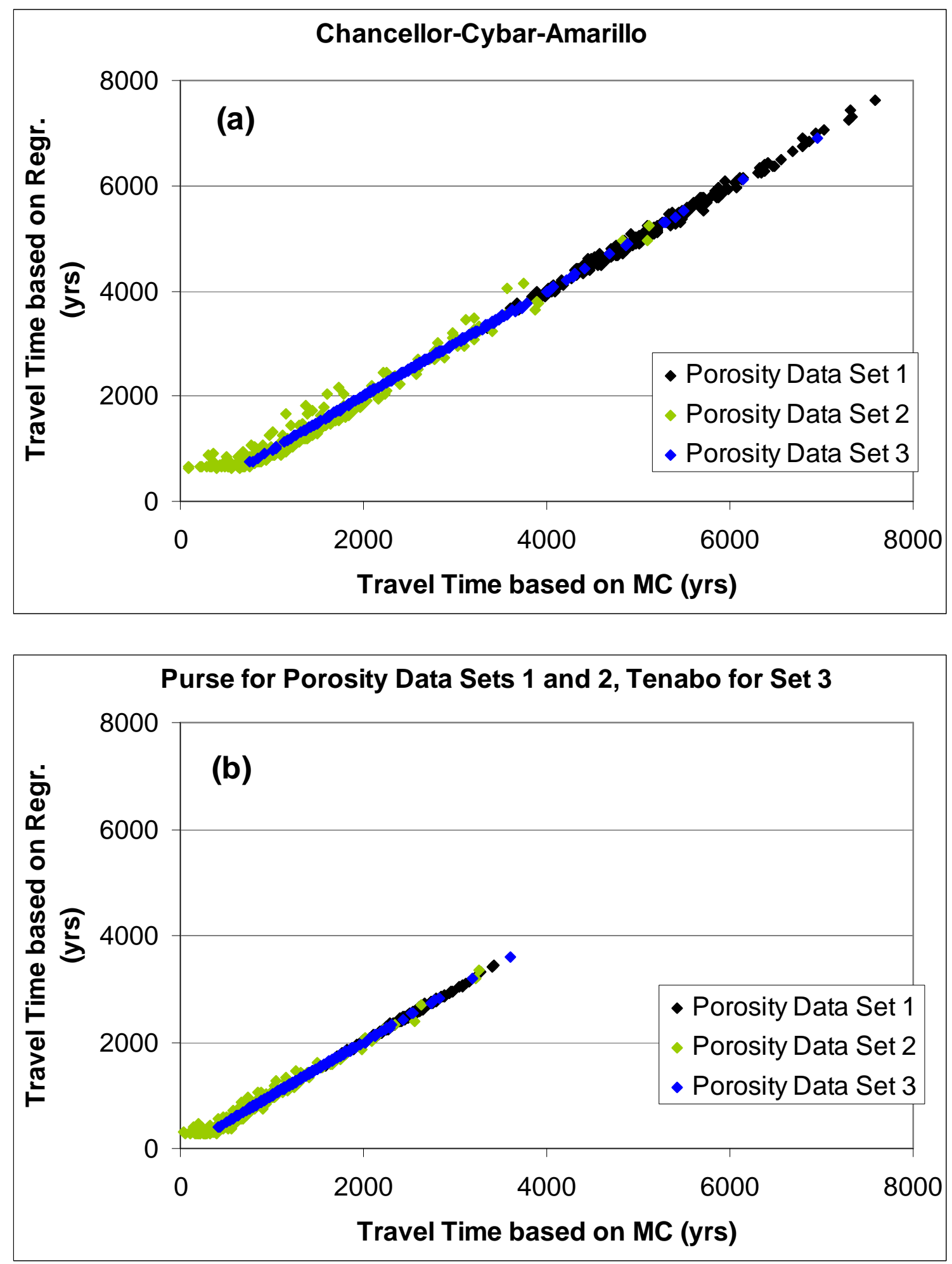

Figure 21. Scatterplots of all 250 Monte Carlo realization results of minimum travel time to YM from the indicated detonations and the minimum travel time to $\mathrm{YM}$ of regression models that use only the porosities of five most influential HGUs. (a) Pre-pumping conditions and, (b) 1998 pumping conditions. 
1998 pumping scenario the mean travel time varies from 2,366 to 680,000 years. Based on Effective-porosity Data Set 2, the mean travel time from the major detonations in NTS areas 18,19, 20, and 30 to the YM area ranges from about 1,500 to over 217,000 years for the pre-pumping conditions, while for the 1998 pumping scenario, the mean travel time varies from over 700 to about 104,000 years. Finally, based on Effective-porosity Data Set 3, the mean travel time from the major detonations in NTS areas 18, 19, 20, and 30 to the YM area ranges from about 2,500 to more than 224,000 years for the pre-pumping conditions, while for the 1998 pumping scenario, the mean travel time varies from over 1,300 to about 147,000 years.

From all three effective-porosity data sets considered in this study, the smallest mean travel time from the NTS test area to the YM withdrawal boundary is only about 700 years, based on Effective-porosity Data Set 2. However, Effective-porosity Data Set 2 and Effective-porosity Data Set 3 have large effective-porosity CVs. As a result, travel time based on those two sets also has large CV and uncertainty.

For both the pre-pumping and 1998 pumping scenarios, porosities of TMVA, PVA, Lower VSU, and CHVU are the HGUs that mainly dictate groundwater pathways from the upgradient detonations to the proposed YM withdrawal area and have the most significant influence on the minimum travel times from those detonations that take less than 10,000 years to travel to the proposed YM repository. Especially based on Effective-porosity Data Set 2 under the 1998 pumping scenario, the mean travel time from many detonations is under 1,000 years and TMVA, PVA, Lower VSU, and CHVU are the most important HGUs in determining travel time.

For those detonations from which the particles have the shortest mean minimum travel time to the YM area, it is found that although $27 \mathrm{HGU}$ porosities affect the minimum travel time predictions, there are five that account for almost all of the minimum travel time variability. The simplified regression models using these five parameters have correlation coefficients of over 0.97 in comparison to the minimum travel time estimates from the full relationships that used all $27 \mathrm{HGU}$ porosities. Quantitatively, the variabilities of individual HGU porosities contribute differently to the minimum travel time uncertainties depending on the pumping conditions and effective-porosity conceptualization scenarios, ranging from less than 1 percent to over 86 percent of the total minimum travel time variance. Should additional characterization data be collected to reduce the uncertainties of the travel time predictions, these HGUs should be the focus. Alternatively, a better breakout of HGUs for these large composite units may also partially reduce the estimation uncertainty. 


\section{REFERENCES}

Anderman, E.R. and M.C. Hill, 2000. MODFLOW-2000, the U.S. Geological Survey Modular Ground-Water Model -- Documentation of the Hydrogeologic-Unit Flow (HUF) Package. U.S. Geological Survey Open-File Report 00-342.

Bechtel-Nevada, 2006. A Hydrostratigraphic Model and Alternatives for the Groundwater Flow and Contaminant Transport Model of Corrective Action Unit 97: Yucca FlatClimax Mine, Lincoln and Nye Counties, Nevada. DOE/NV/11718-1119.

Bechtel SAIC Company (BSC), 2004a. Saturated Zone Flow and Transport Model Abstraction. MDL-NBS-HS-000021 Rev 02.

Bechtel SAIC Company (BSC), 2004b. Hydrogeologic Framework Model for the Saturated Zone Site Scale Flow and Transport Model. MDL-NBS-HS-000024 Rev 00.

Bechtel Nevada, 2002. A Hydrostratigraphic Model and Alternatives for the Groundwater Flow and Contaminant Transport Model of Corrective Action Units 101 and 102: Central and Western Pahute Mesa, Nye County, Nevada. DOE/NV/11718--706.

Bedinger, M.S.; K.A. Sargent, W.H. Langer, F.B. Sherman, J.E. Reed, and B.T. Brady, 1989. Studies of Geology and Hydrology in the Basin and Range Province, Southwestern United States, for Isolation of High-Level Radioactive Waste-Basis of Characterization and Evaluation. U.S. Geological Survey Professional Paper 1370A.

Belcher, W.R. (ed.), 2004. Death Valley Regional Ground-water Flow System, Nevada and California - Hydrogeologic Framework and Transient Ground-water Flow Model, U.S. Geological Survey Scientific Investigation Report 2004-5205.

Belcher, W.R., P.E. Elliott, and A.L. Geldon, 2001. Hydraulic-property Estimates for Use with a Transient Ground-water Flow Model for the Death Valley Regional Groundwater Flow System, Nevada and California. U.S. Geological Survey Water-Resources Investigations Report 01-4210

Blainey, J.B., C.C. Faunt, and M.C. Hill, 2006. A guide for using the transient ground-water flow model of the Death Valley regional ground-water flow system, Nevada and California. U.S. Geological Survey Open-File Report 2006-1104.

Blout, D.O., W.S. Birchfiel, D.P. Hammermeister, K.A. Zukosky, and K.D. Donnelson, 1995. Site Characterization Data from the Area 5 Science Boreholes, Nevada Test Site, Nye County, Nevada, Reynolds Electrical \& Engineering Co., Inc., DOE/NV11432170. Las Vegas, Nevada.

Burbey, T.J., and S.W. Wheatcraft, 1986. Tritium and Chlorine-36 Migration from a Nuclear Explosion Cavity, Desert Research Institute Publication No. 45050. Reno and Las Vegas, Nevada.

Burkhard, N.R., 1989. Physical Properties in LLNL Yucca Flat Areas: The ROCK PILE Concept, Lawrence Livermore National Laboratory, UCRL-100837, CONF-89091639, Livermore, California 
Civilian Radioactive Waste Management System Management \& Operating Contractor (CRWMS M\&O). 2000. Uncertainty Distribution for Stochastic Parameters. ANLNBS-MD-000011 REV 00.

D’Agnese, F.A., G.M. O’Brien, C.C. Faunt, W.R. Belcher, Carma San Juan, 2002. A Threedimensional Numerical Model of Predevelopment Conditions in the Death Valley regional groundwater flow system, Nevada and California: U.S. Geological Survey Water-Resources Investigations Report 02-4102, 114 pp.

D’Agnese, F.A., C.C. Faunt, A.K. Turner, and M.C. Hill, 1997. Hydrogeologic Evaluation and Numerical Simulation of the Death Valley Regional Ground-water Flow System, Nevada, and California: U. S. Geological Survey Water-Resources Investigation Report 96-4300, 124 pp.

U.S, Department of Energy (DOE), 2000. United States Nuclear Tests, July 1945 through September 1992, DOE/NV-209 (Rev. 15), Nevada Operations Office.

U.S, Department of Energy (DOE), 1997. Regional Groundwater Flow and Tritium Transport Modeling and Risk Assessment of the Underground Test Area, Nevada Test Site, Nevada, DOE/NV - 477, Las Vegas, Nevada.

Draper, N.R., and H. Smith, 1981. Applied Regression Analysis (2 ${ }^{\text {nd }}$ ed.), Wiley, New York.

Faunt, C., D. Sweetkind, and W. Belcher, 2004. Three-Dimensional Hydrogeologic Framework Model, Chapter E in Belcher, W.R. (ed.), Death Valley Regional Groundwater Flow System, Nevada and California-Hydrogeologic Framework and Transient Ground-water Flow Model. U.S. Geological Survey Scientific Investigations Report 2004-5205.

Harbaugh, J.W., E.R. Banta, M.C. Hill, and M.G. McDonald, 2000. MODFLOW-2000, The U. S. Geological Survey's Modular Ground-water Flow Model - User Guide to Modularization Concepts and the Ground-water Flow Process: U. S. Geological Survey Open-File Report 00-92, 121 p.

Helton, J.C., 1993. Uncertainty and sensitivity analysis techniques for use in performance assessment for radioactive waste disposal. Reliab. Eng. Syst. Safety 42:327-367.

Helton J.C., and F.J. Davis, 2003. Latin hypercube sampling and the propagation of uncertainty in analyses of complex systems, Reliab. Eng. Syst. Safety, 81:3-69.

Helton, J.C., F.J. Davis, and J.D. Johnson, 2005. A comparison of uncertainty and sensitivity analysis results obtained with random and latin hypercube sampling. Reliab. Eng. Syst. Safety 89:305-330.

Hevesi, J.A., A.L. Flint, and L.E. Flint, 2003. Simulation of net Infiltration and Potential Recharge Using a Distributed Parameter Watershed Model of the Death Valley Region, Nevada and California: U.S. Geological Survey Water-Resources Investigations Report 03-4090, 91 p.

Hill, M.C., 1998. Methods and Guidelines for Effective Model Calibration: U.S. Geological Survey Water-Resources Investigations Report 98-4005, 90 p. 
IT Corporation, 1996a. Groundwater Flow Model Package, Volume IV in Regional Groundwater Flow and Tritium Transport Modeling and Risk Assessment of the Underground Test Area, Nevada Test Site, Nevada, Underground Test Area Subproject, Phase 1, Data Analysis Task, DOE/NV-477, IT Corporation. Las Vegas, Nevada.

IT Corporation. 1996b. Transport Parameter and Source Term Data Documentation Package, Volume V, Underground Test Area Project, Phase I Data Analysis Task. prepared for U.S. Department of Energy, Nevada Operations Office, Las Vegas, Nevada.

Iuzzolino, H., 2003. Users Manual (Rev 00) for LHS, Version 2.51. Civilian Radioactive Waste Management System Management and Operating Contractor, MOL.20040210.0391, Albuquerque, New Mexico.

Laczniak, R.J., J.C. Cole, D.A. Sawyer, and D.A. Trudeau, 1996. Summary of Hydrogeologic Controls on Groundwater Flow at the Nevada Test Site, Nye County, Nevada: U. S. Geological Survey Water-Resources Investigation Report 96-4199, 59 pp.

Leap, D.I. and P.M. Belmonte, 1992. Influence of pore pressure on apparent dispersivity of a fissured dolomitic aquifer. Groundwater, Vol.30 (1):87-95.

Mckay, M.D., R.J. Beckman, and W.J. Conover, 1979. A comparison of three methods for selecting values of input variables in the analysis of output from a computer code. Technometrics. 21(2):239-45

Pollock, D.W., 1994. User's Guide for MODPATH/MODPATH-PLOT, Version 3: A Particle Tracking Post-processing Package for MODFLOW, the U.S. Geological Survey Finite-difference Ground-water Flow Model. U.S. Geological Survey Open-File Report 94-464.

Raytheon Services of Nevada, 1990. Nevada Test Site Drilling and Mining Summary. Available from Bechtel Nevada, Mercury, NV.

Rehfeldt, K., W. Drici, D. Sloop, J. Watrus, T. Beard, M. Sully, C. Benedict, A. Wolfsberg, and P. Reimus, 2003. Contaminant Transport Parameters for the Groundwater Flow and Contaminant Transport Model of Corrective Action Units 101 and 102: Central and Western Pahute Mesa, Nye County, Nevada. Shaw Environmental, Inc., Shaw/13052201, Las Vegas, Nevada

Sawyer, D.A., R.J. Fleck, M.A. Lanphere, R.G. Warren, D.E. Broxton, and M.R. Hudson, 1994. Episodic caldera volcanism in the Miocene southwestern Nevada volcanic fieldRevised stratigraphic framework, 40Ar/39Ar geochronology, and implications for magmatism and extension, Geological Society of America Bulletin, 106, 1304 - 1318.

Sweetkind, D., W. Belcher, C. Faunt, and C. Potter, 2004. Geology and Hydrogeology, Chapter B in Belcher, W.R. (ed.), Death Valley Regional Ground-Water Flow System, Nevada and California-Hydrogeologic Framework and Transient Ground-Water Flow Model. U.S. Geological Survey Scientific Investigations Report 2004-5205.

Thomas, J.M., F.C. Benedict, Jr., T.P. Rose, R.L. Hershey, J.B. Paces, Z.E. Peterman, I.M. Farnham, K.H. Johannesson, A.K. Singh, K.J. Stetzenbach, G.B. Hudson, J.M. Kenneally, G.F. Eaton, and D.K. Smith, 2002. Geochemical and Isotopic Interpretations 
of Groundwater Flow in the Oasis Valley Flow System, Southern Nevada, DOE/NV/11508-56, Nevada Operations Office, National Nuclear Security Administration, U.S. Department of Energy, Las Vegas, Nevada.

Winograd, I.J. and W. Thordarson, 1975. Hydrogeologic and Hydrochemical Framework, South-Central Great Basin, Nevada-California, with Special Reference to the Nevada Test Site, U.S. Geological Survey Professional Paper 712-C.

Winograd, I.J. and L.R. West, 1962. Preliminary Tracer Experiment to Demonstrate Hydraulic Continuity Between Water Wells C and C-1, Yucca Flat, Nevada Test Site, U.S. Geological Survey Technical Letter NTS-20.

Zhang Y., G.F. Pinder, and G.S. Herrera, 2005. Least cost design of groundwater quality monitoring networks, Water Resour. Res., 41, doi:10.1029/2005WR003936.

Zhu, J., K.P. Pohlmann, M. Ye, D.S. Shafer, and R.W.H. Carroll, 2006. Groundwater Pathways from Regions Upgradient of Potential Yucca Mountain Repository, International High-Level Radioactive Waste Management Conference, April 30 - May 4, 2006, Las Vegas, Nevada, pp. 623 - 629. 
APPENDIX A:

Histograms of HGU porosities of all three effective-porosity data sets

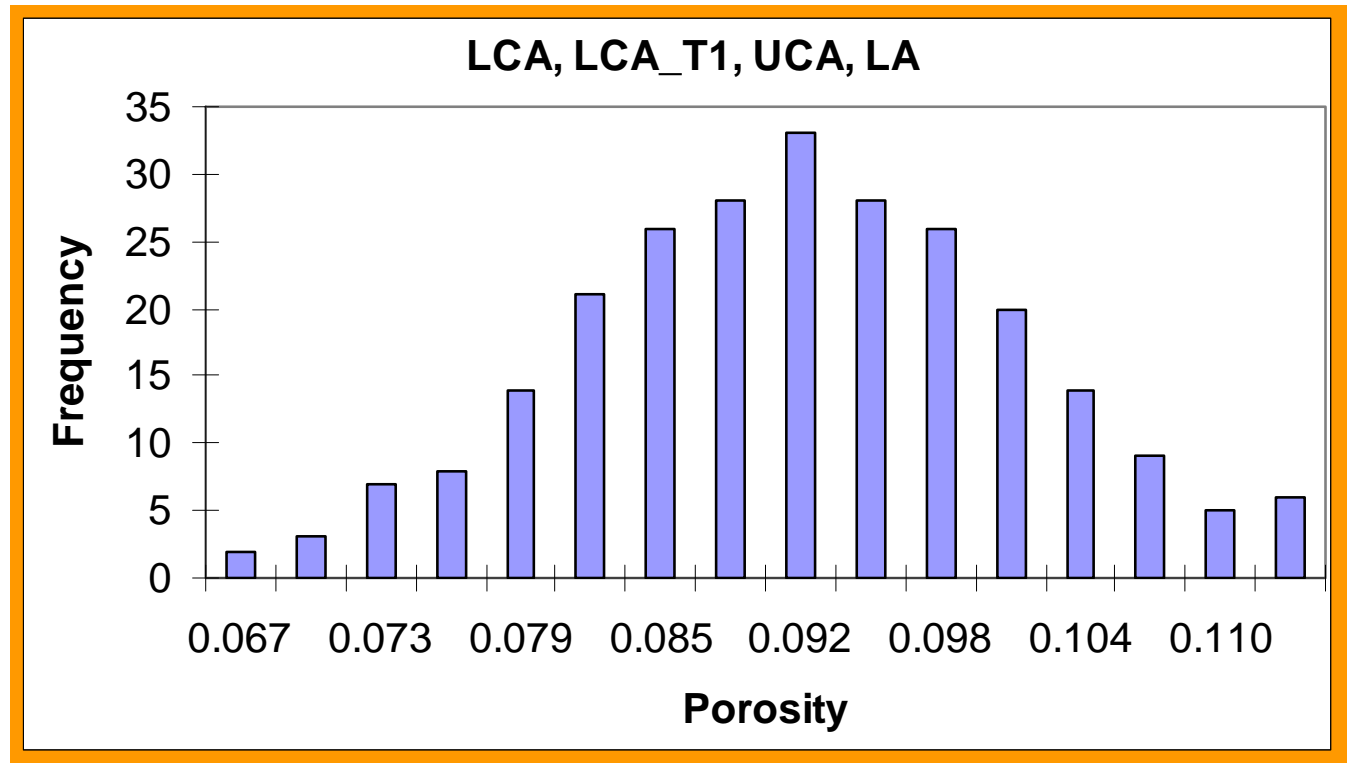

Figure A1. Effective-porosity histogram of LCA, LCA_T1, UCA, and LA based on Effective-porosity Data Set 1.

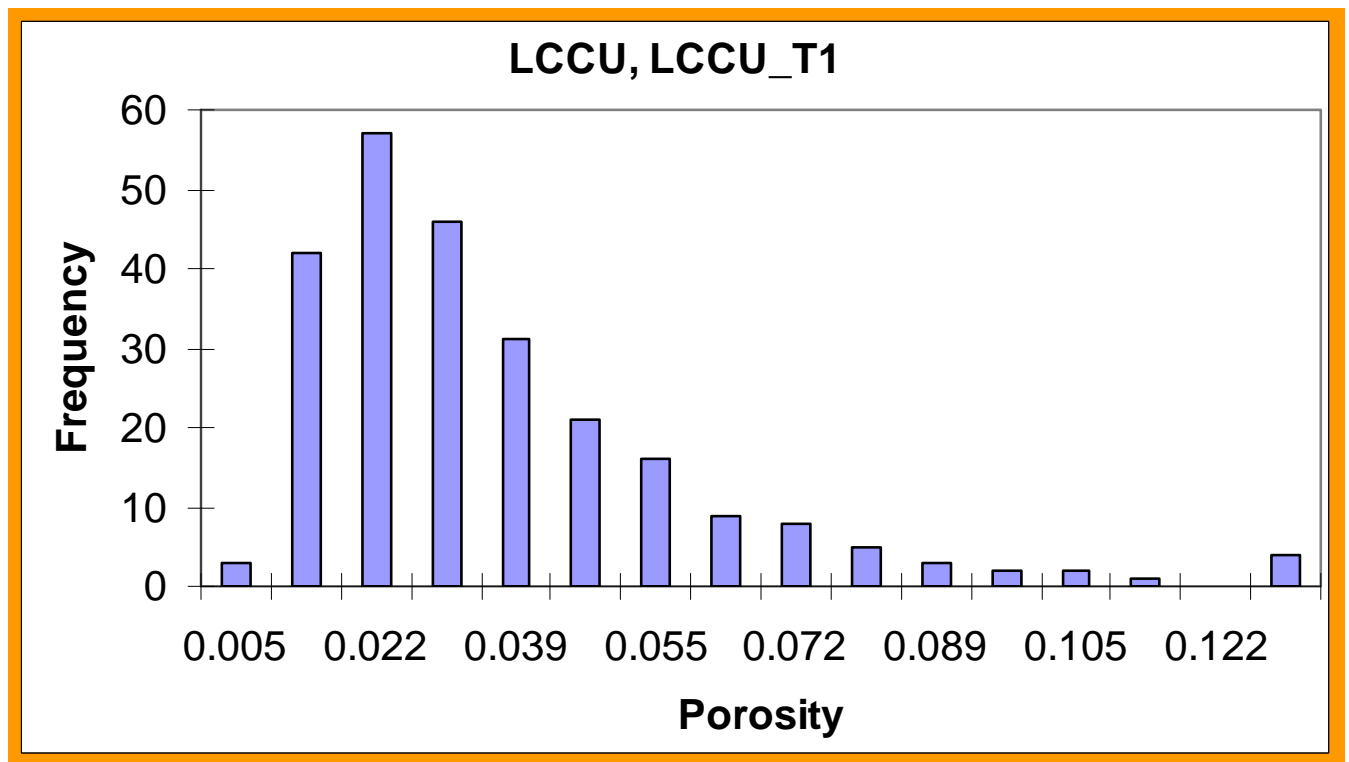

Figure A2. Effective-porosity histogram of LCCU and LCCU_T1 based on Effectiveporosity Data Set 1 . 


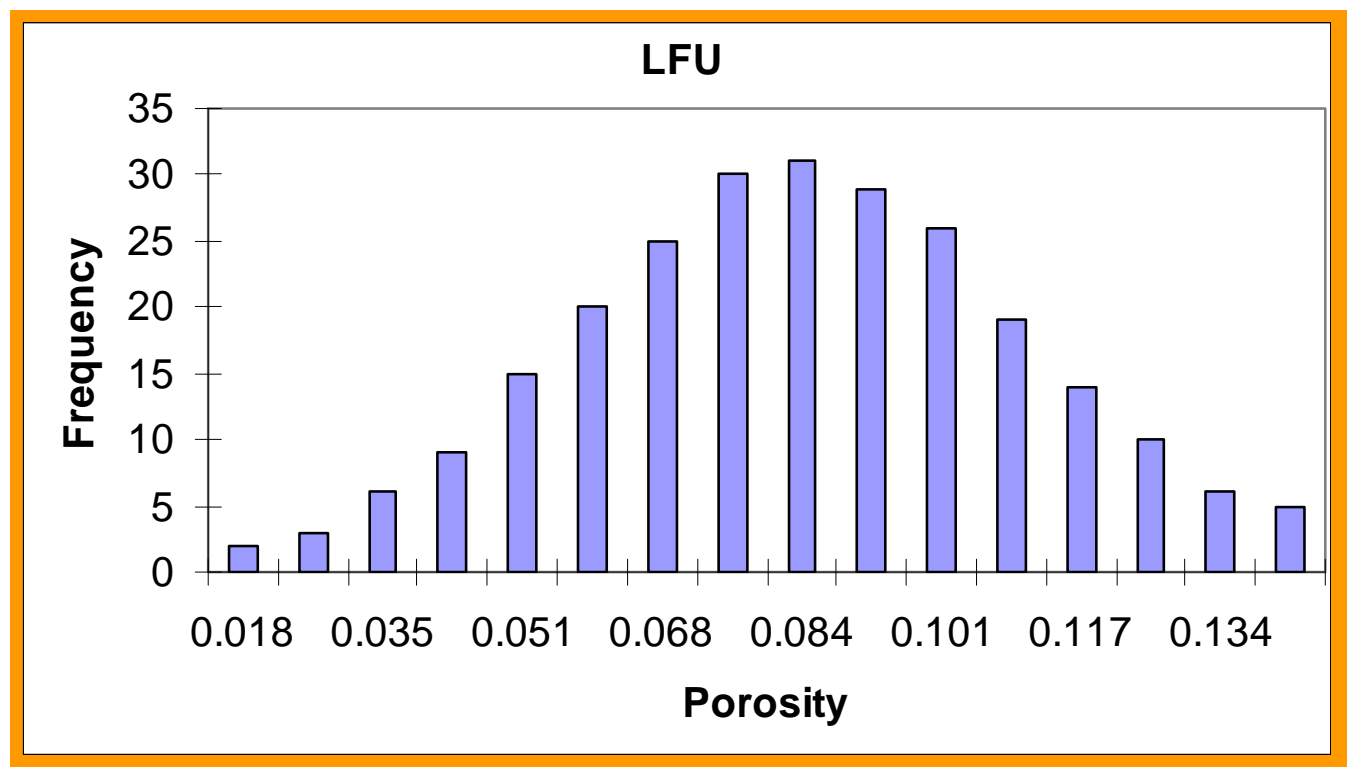

Figure A3. Effective-porosity histogram of LFU based on Effective-porosity Data Set 1.

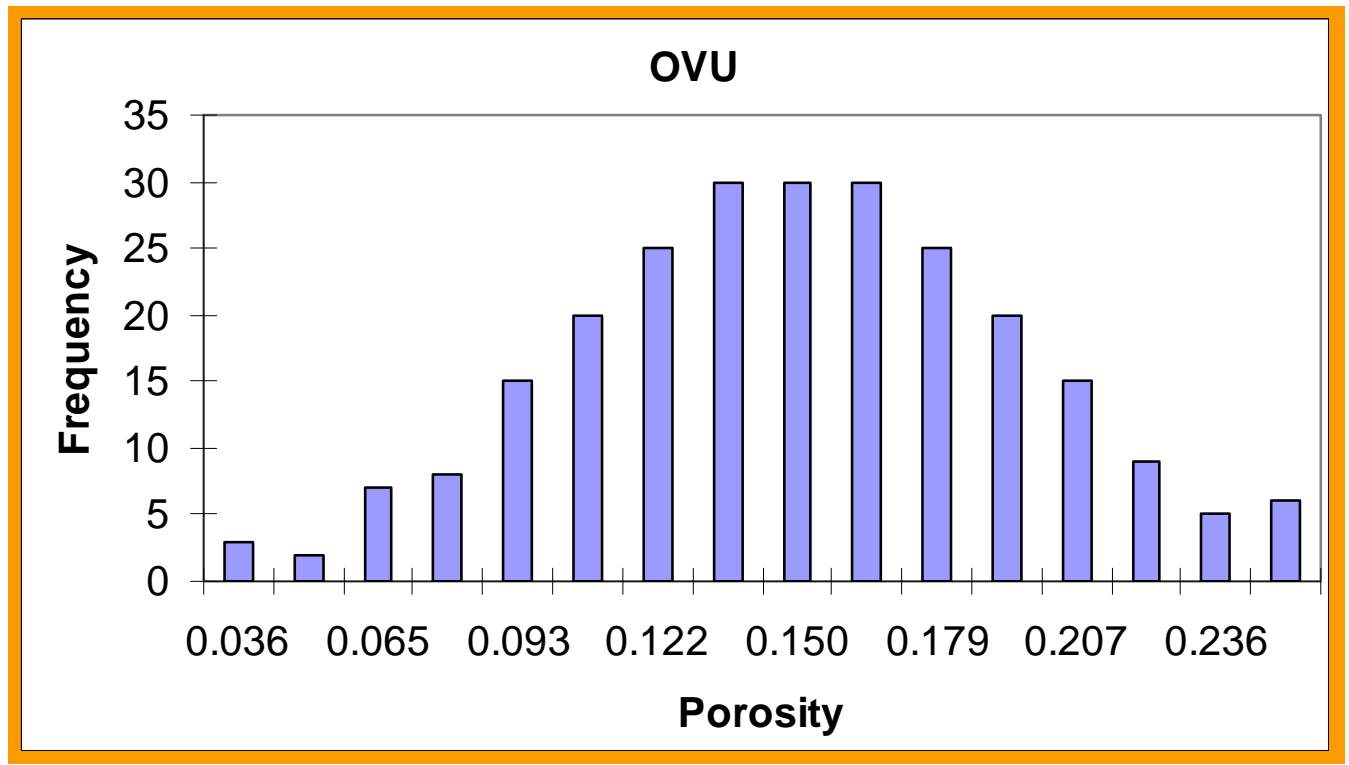

Figure A4. Effective-porosity histogram of OVU based on Effective-porosity Data Set 1. 


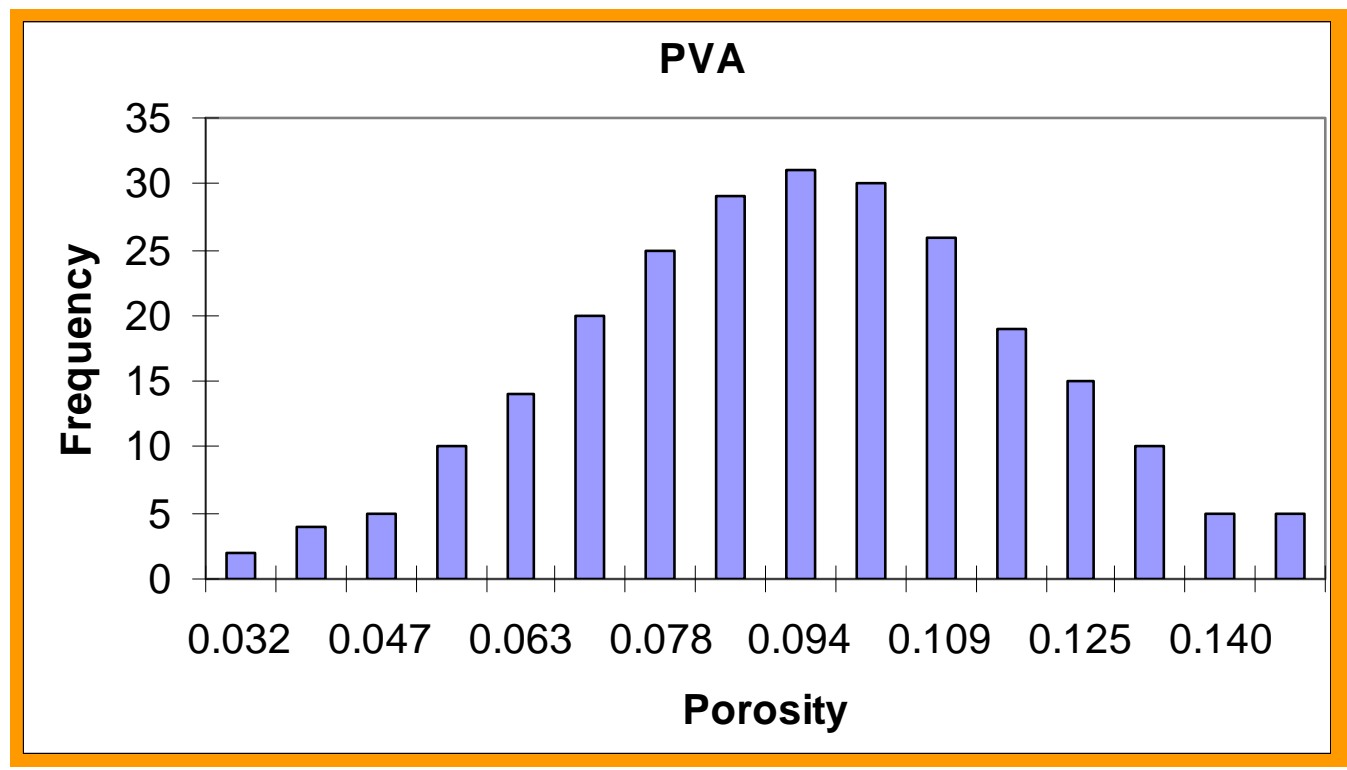

Figure A5. Effective-porosity histogram of PVA based on Effective-porosity Data Set 1.

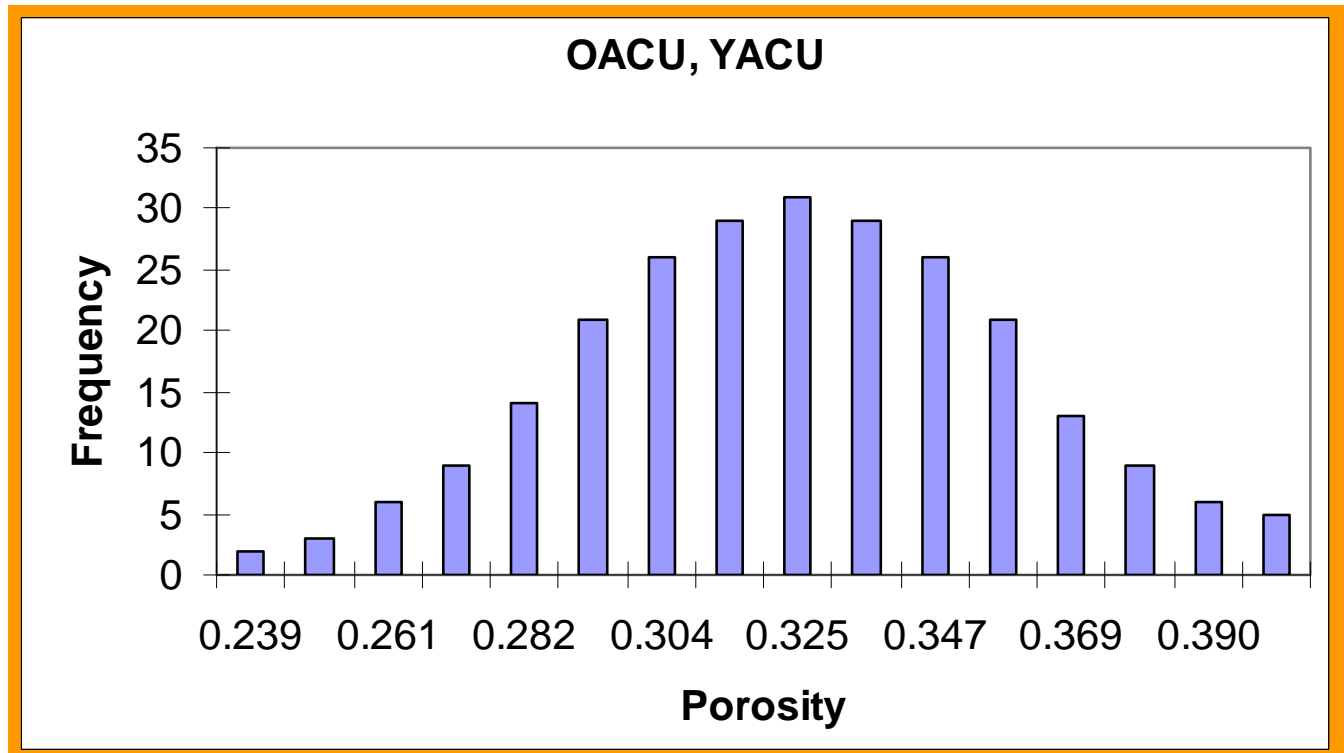

Figure A6. Effective-porosity histogram of OACU and YACU based on Effectiveporosity Data Set 1. 


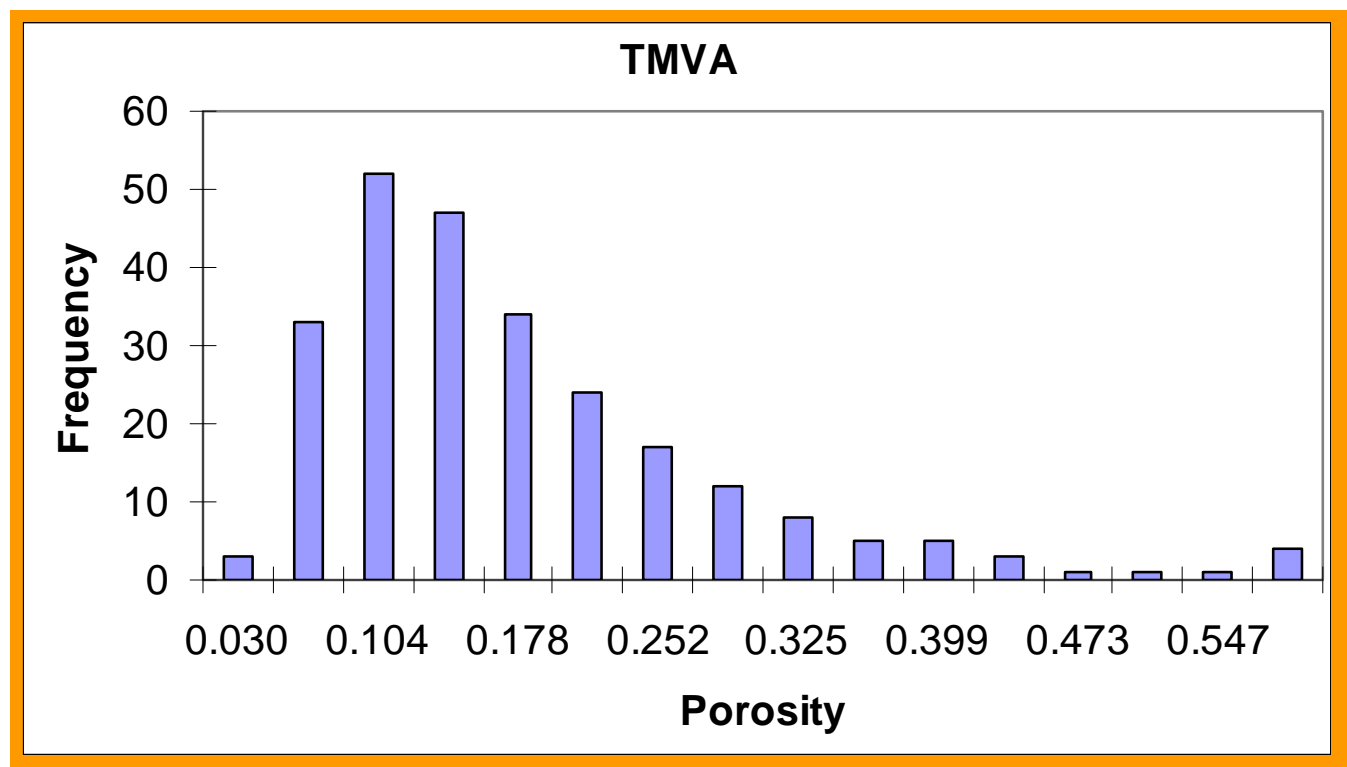

Figure A7. Effective-porosity histogram of TMVA based on Effective-porosity Data Set 1.

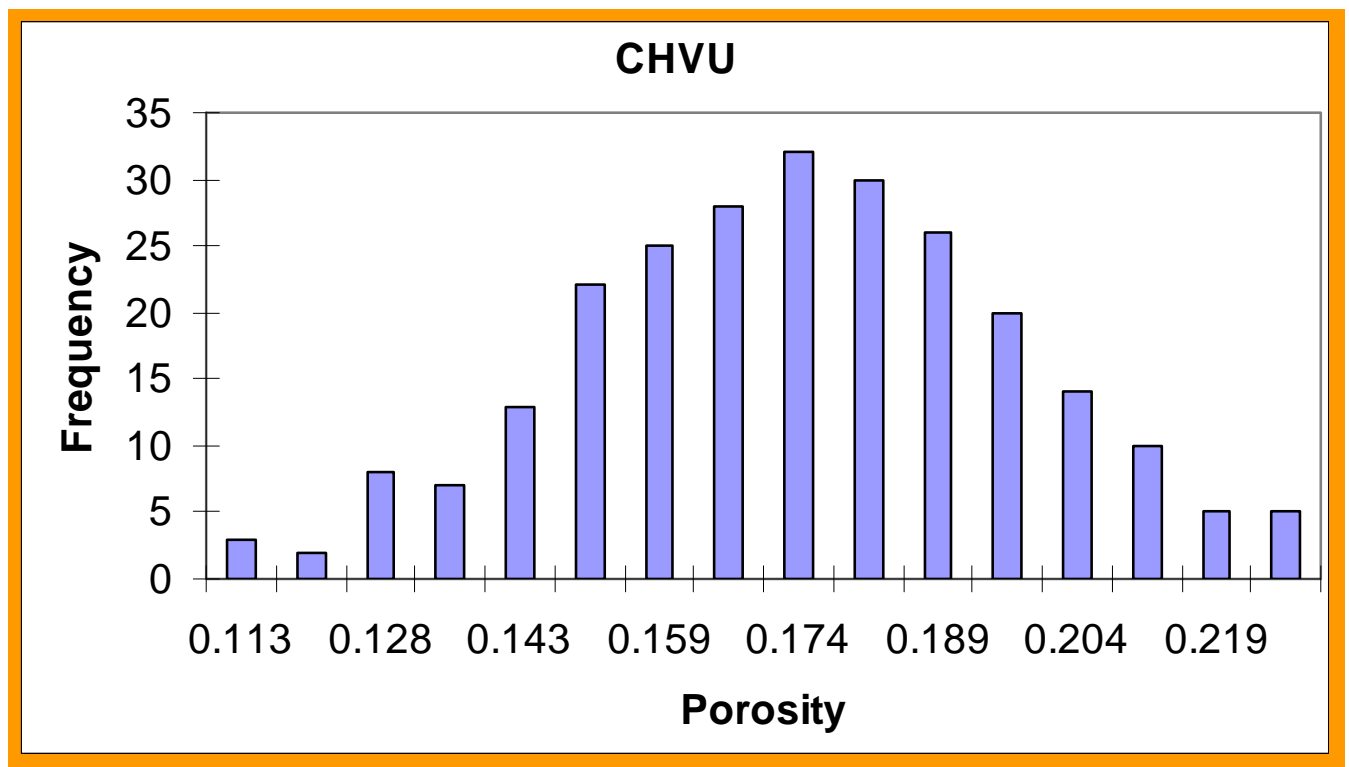

Figure A8. Effective-porosity histogram of CHVU based on Effective-porosity Data Set 1. 


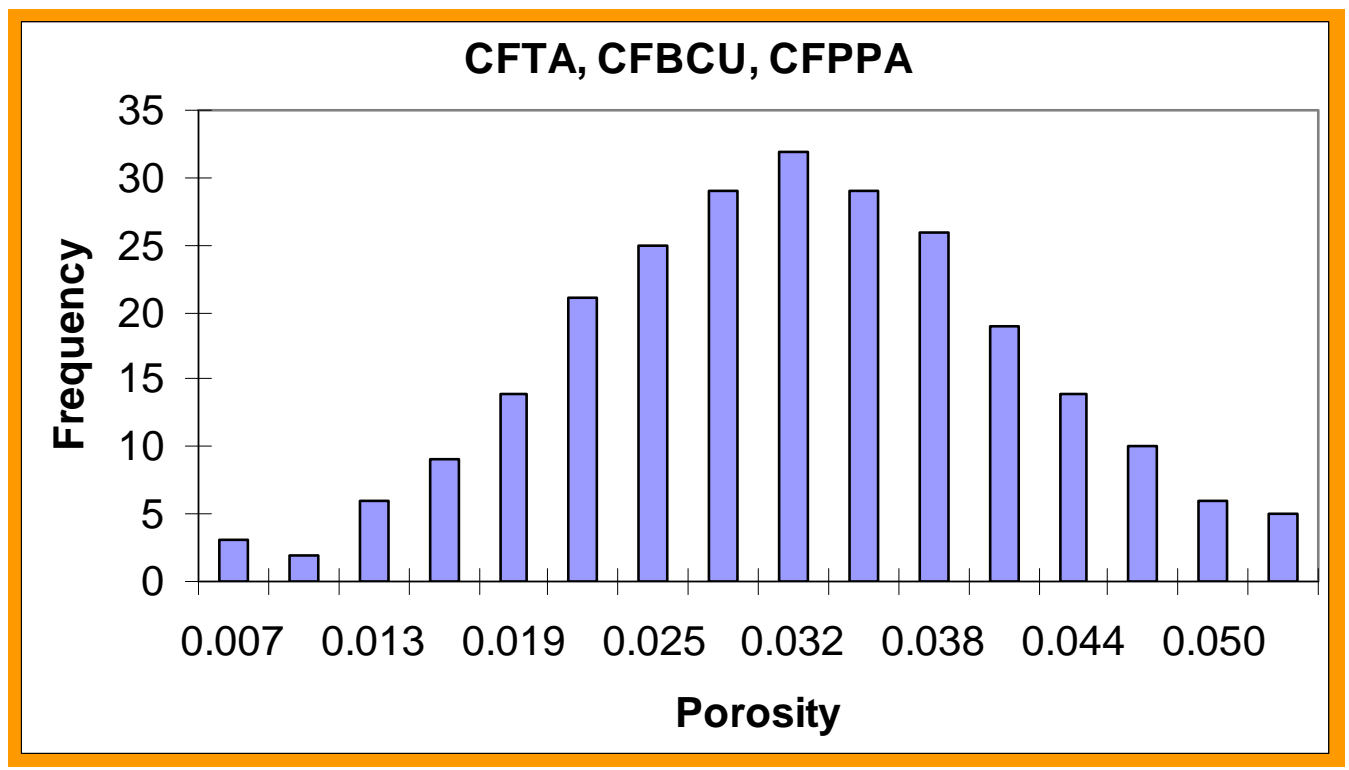

Figure A9. Effective-porosity histogram of CFTU, CFBCU, and CFPPA based on Effective-porosity Data Set 1.

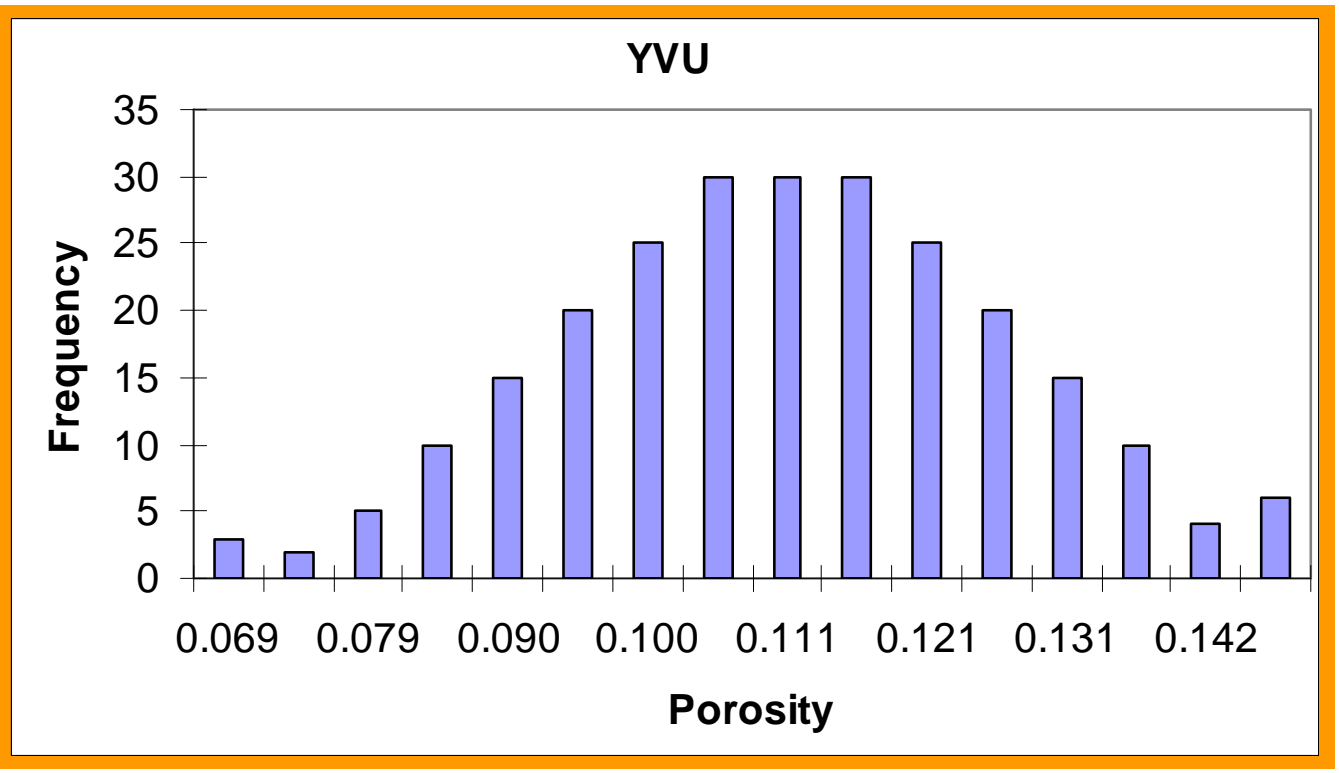

Figure A10. Effective-porosity histogram of YVU based on Effective-porosity Data Set 1. 


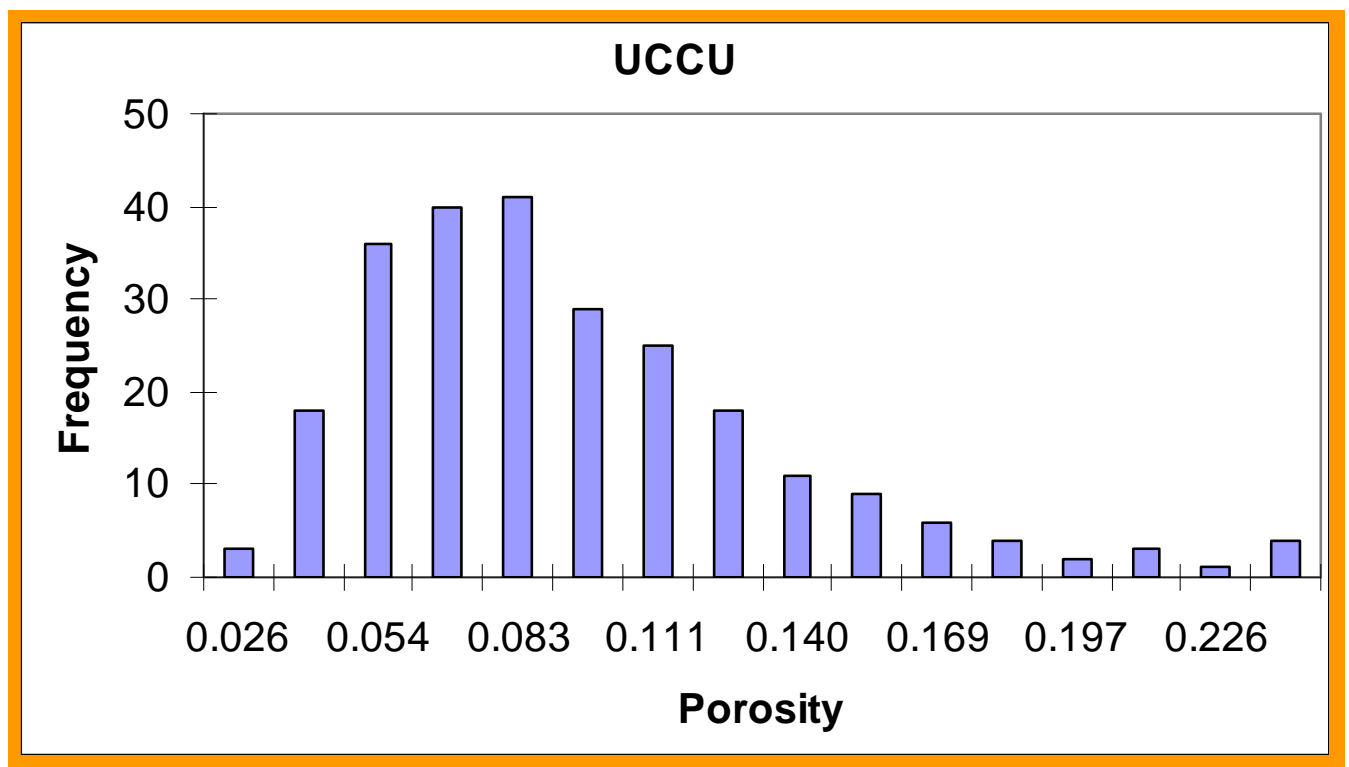

Figure A11. Effective-porosity histogram of UCCU based on Effective-porosity Data Set 1.

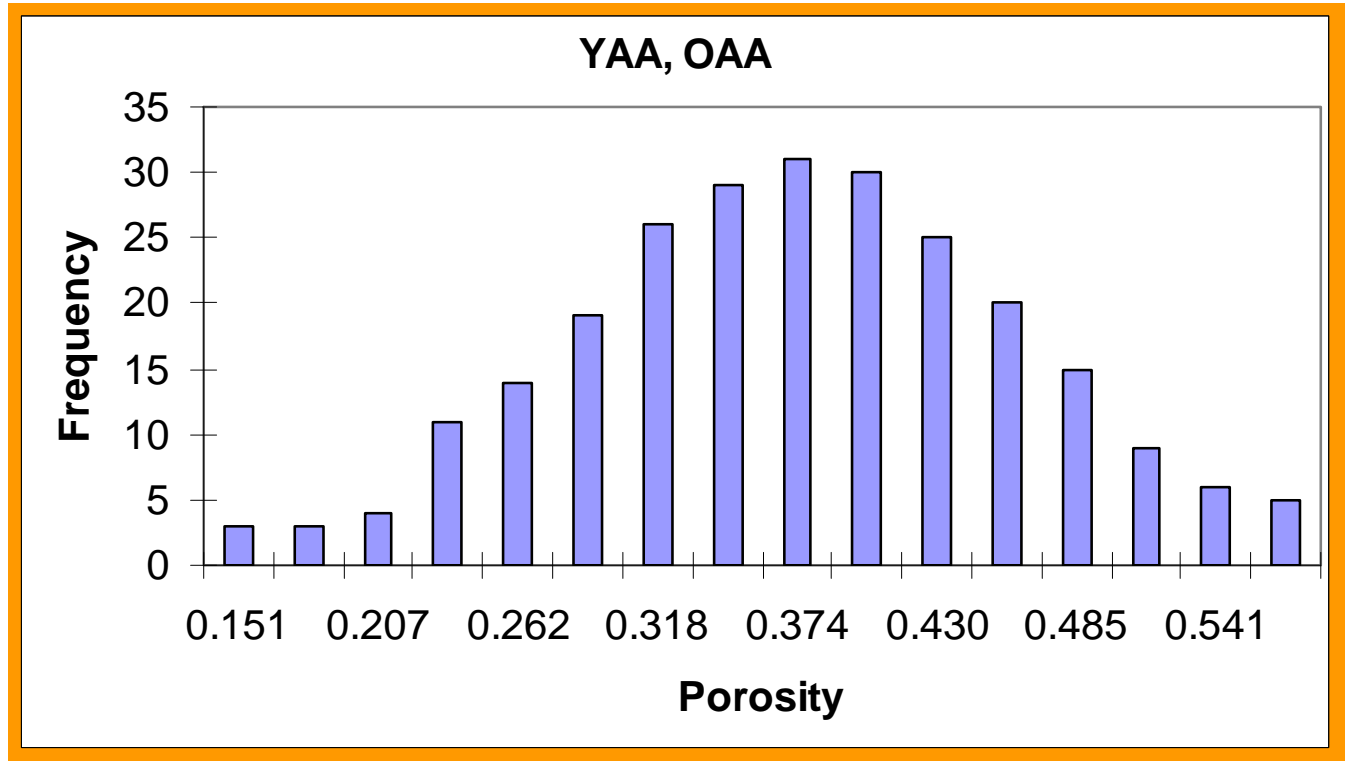

Figure A12. Effective-porosity histogram of YAA and OAA based on Effective-porosity Data Set 1. 


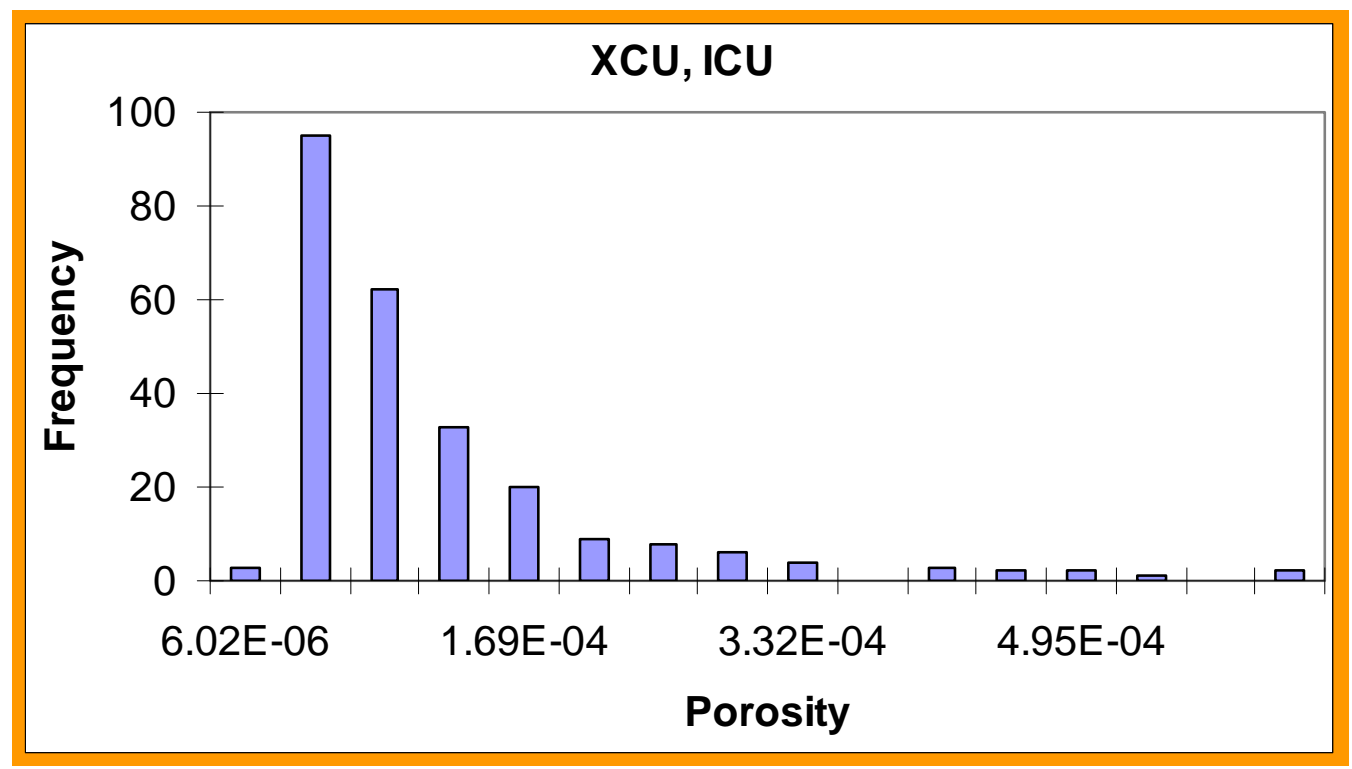

Figure A13. Effective-porosity histogram of XCU and ICU based on Effective-porosity Data Set 1.

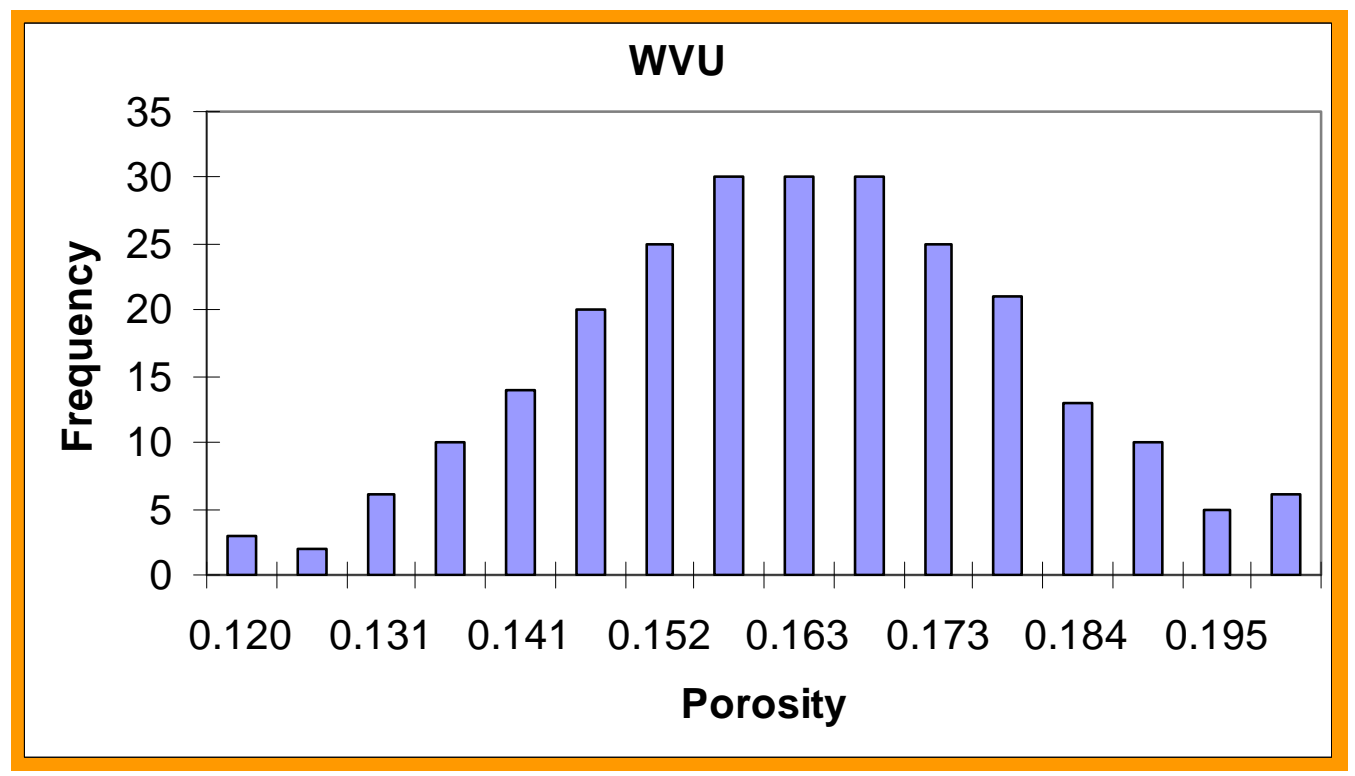

Figure A14. Effective-porosity histogram of WVU based on Effective-porosity Data Set 1. 


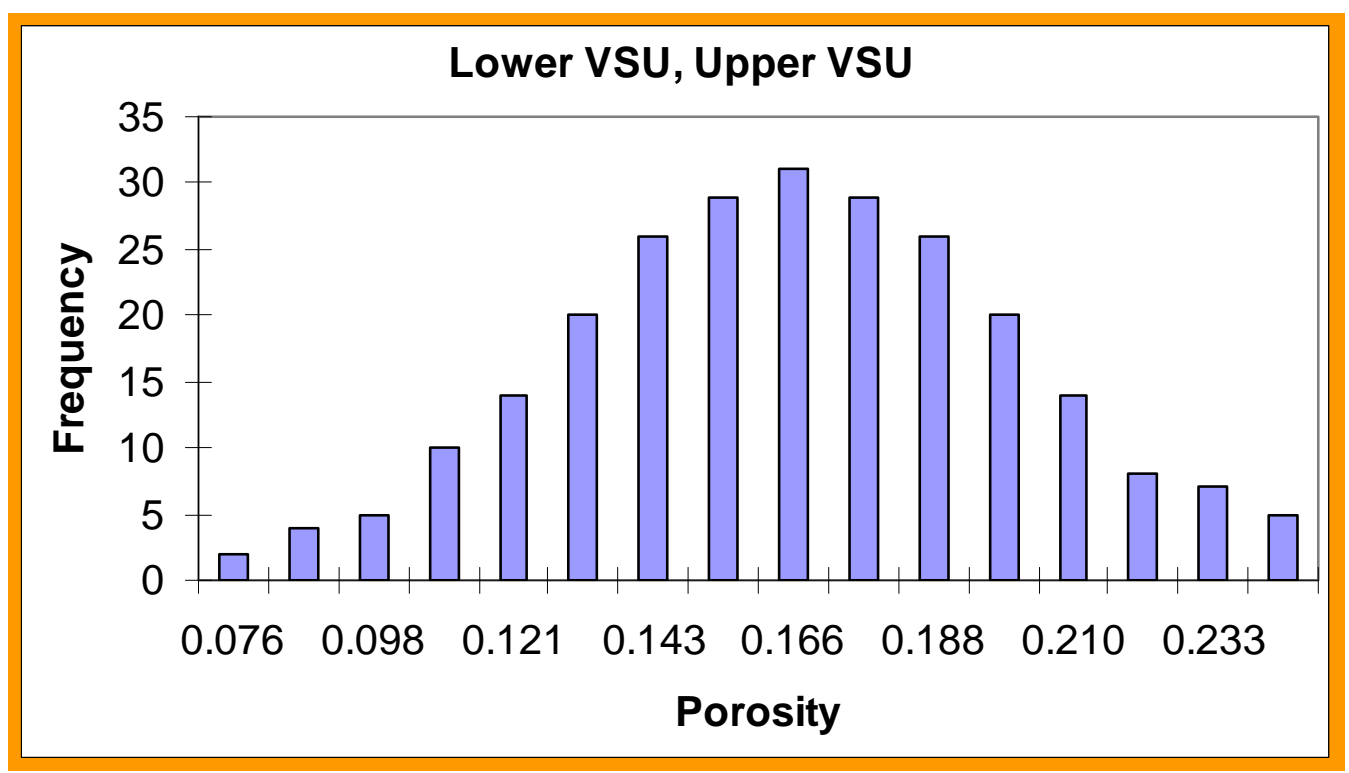

Figure A15: Effective-porosity histogram of Lower VSU and Upper VSU based on Effective-porosity Data Set 1.

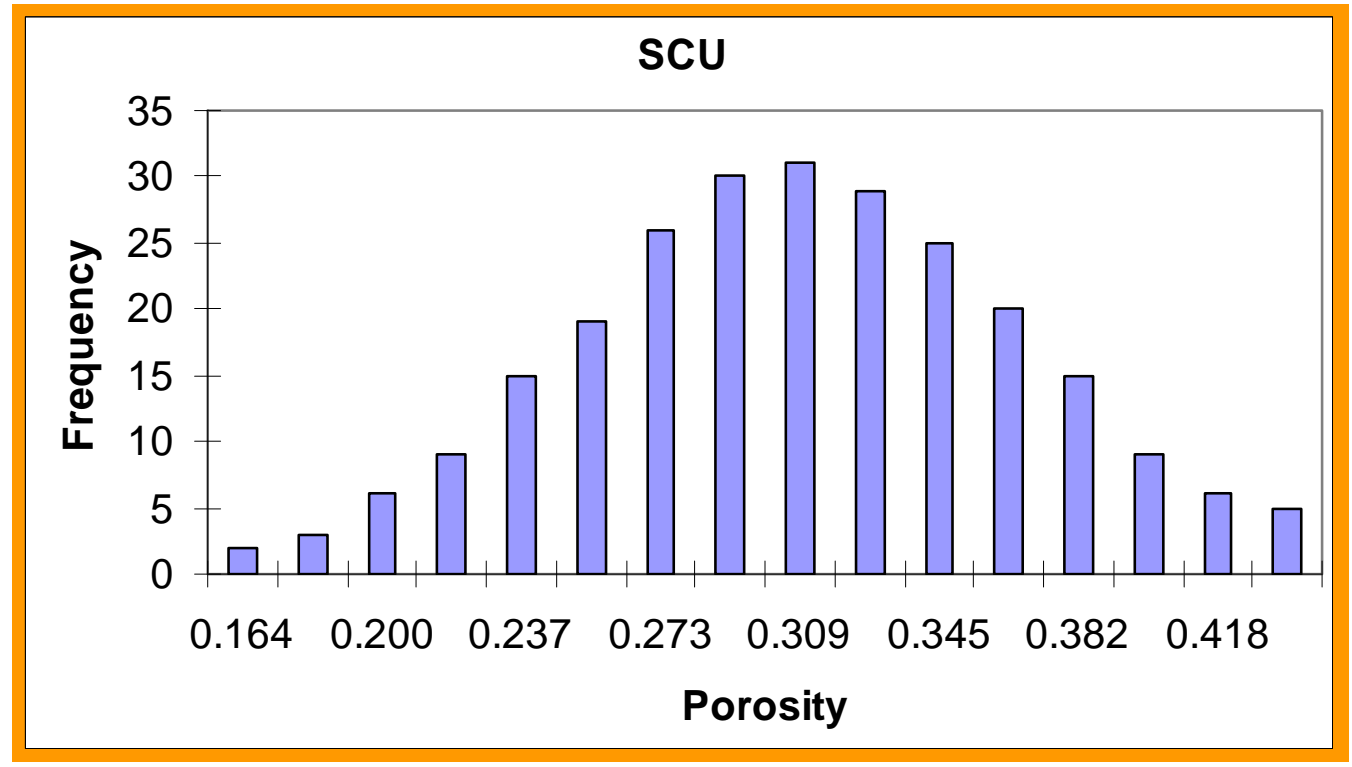

Figure A16. Effective-porosity histogram of SCU based on Effective-porosity Data Set 1. 


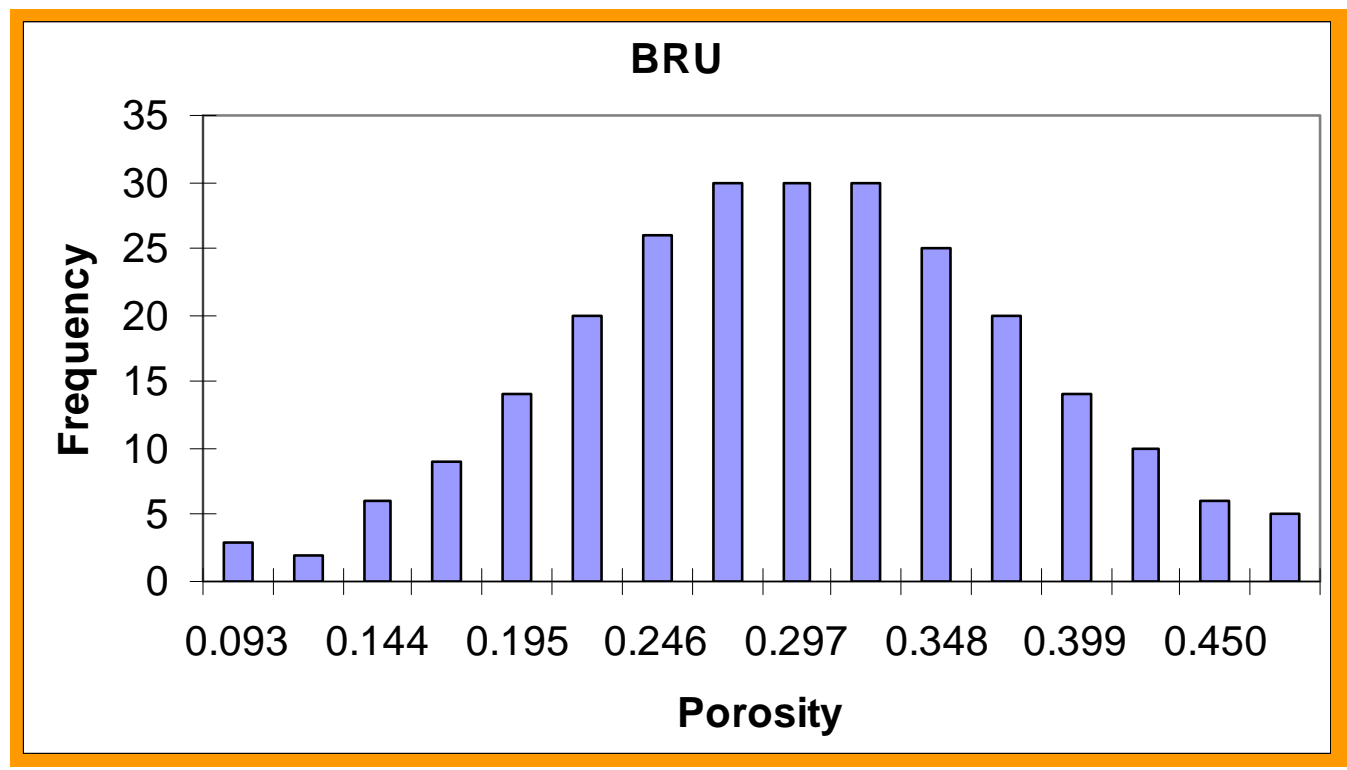

Figure A17. Effective-porosity histogram of BRU based on Effective-porosity Data Set 1.

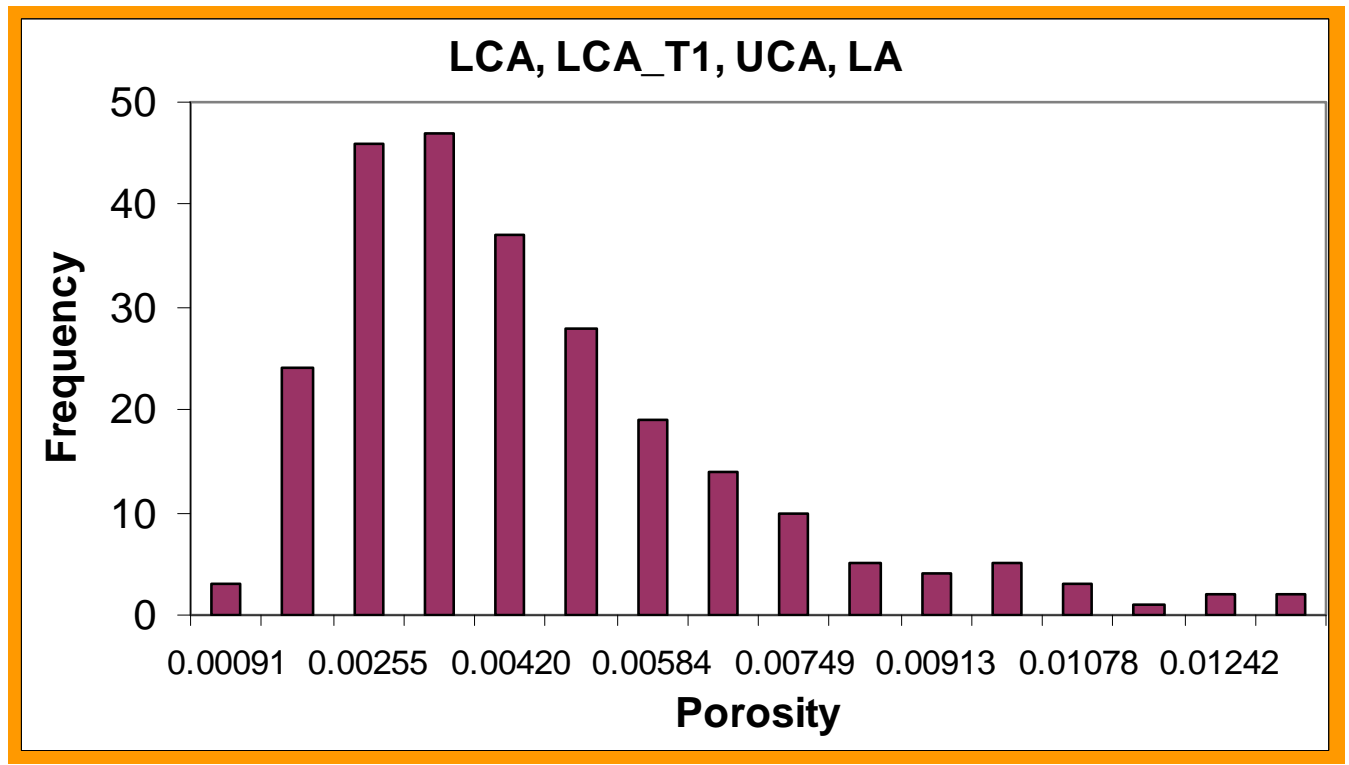

Figure A18. Effective-porosity histogram of LCA, LCA_T1, UCA, and LA based on Effective-porosity Data Set 2. 


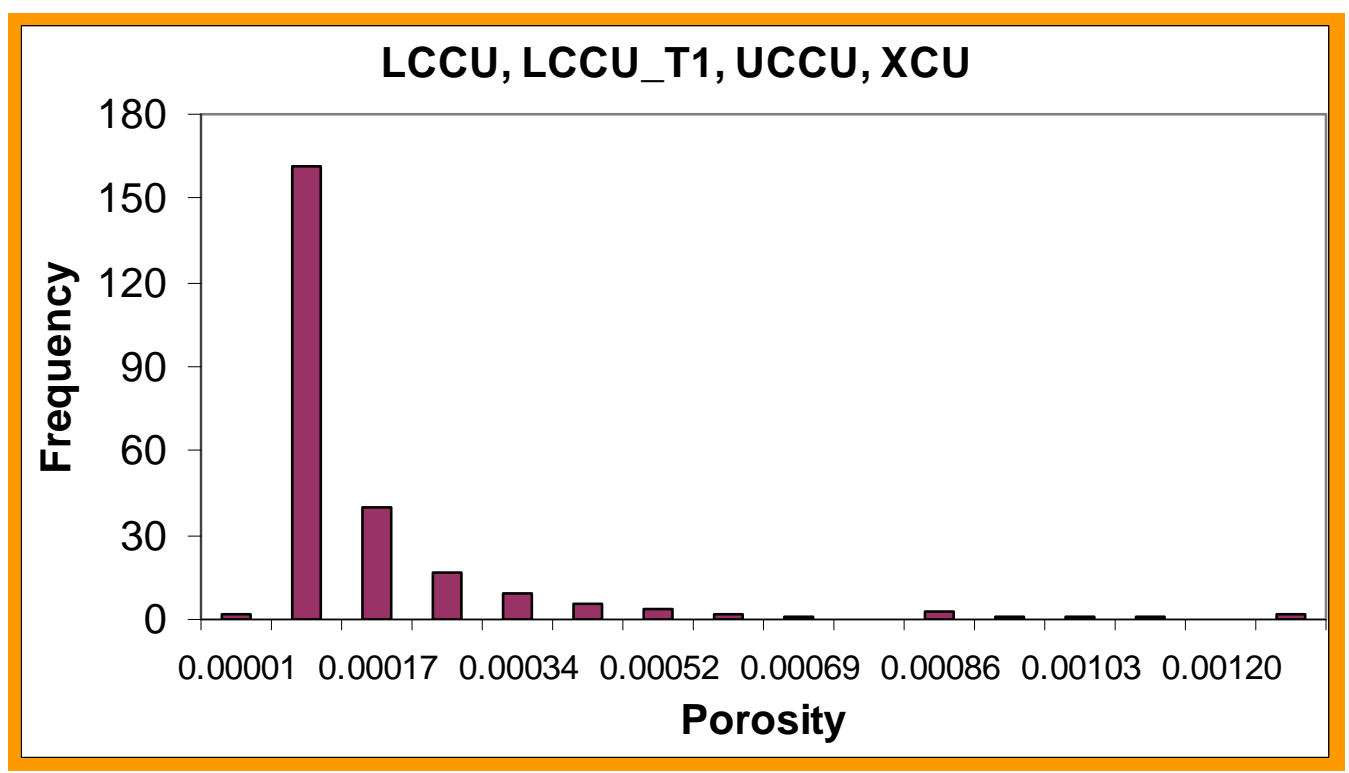

Figure A19. Effective-porosity histogram of LCCU, LCCU_T1, UCCU, and XCU based on Effective-porosity Data Set 2.

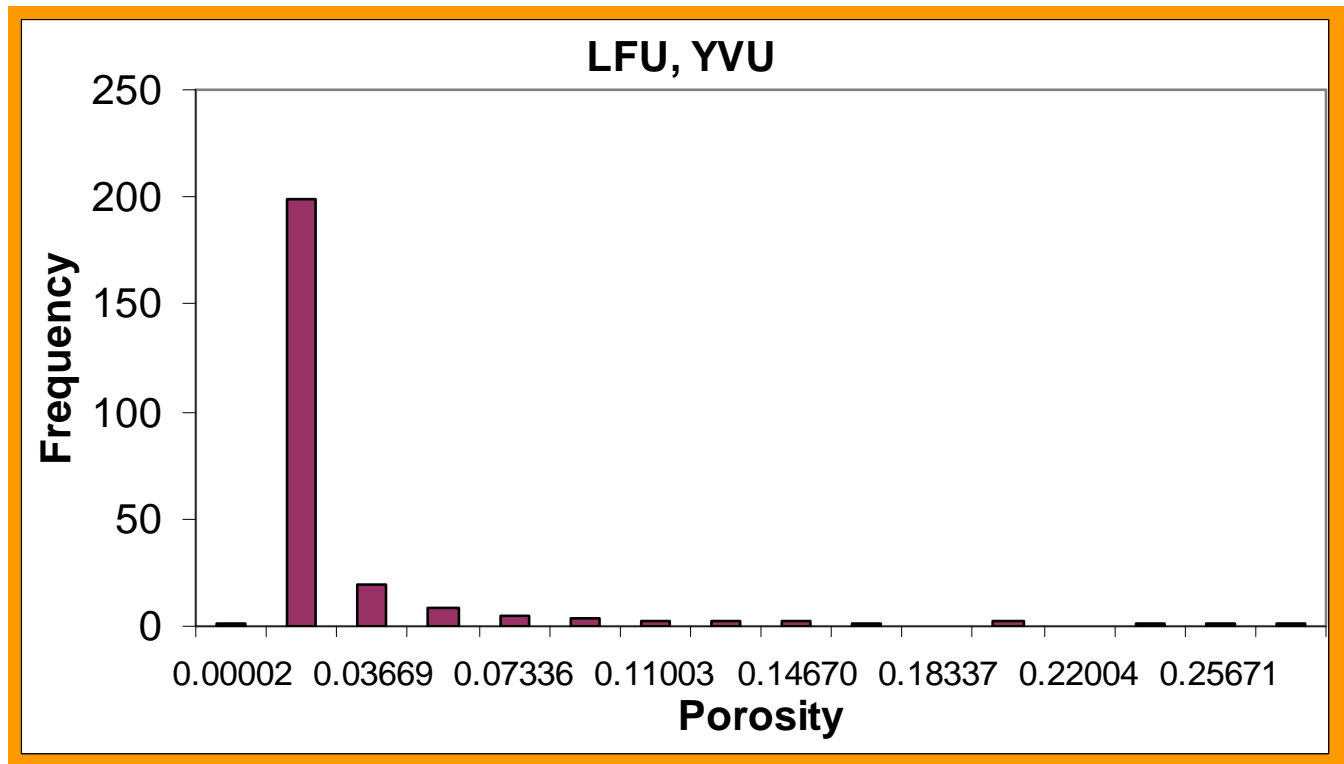

Figure A20. Effective-porosity histogram of LFU, and YVU based on Effective-porosity Data Set 2. 


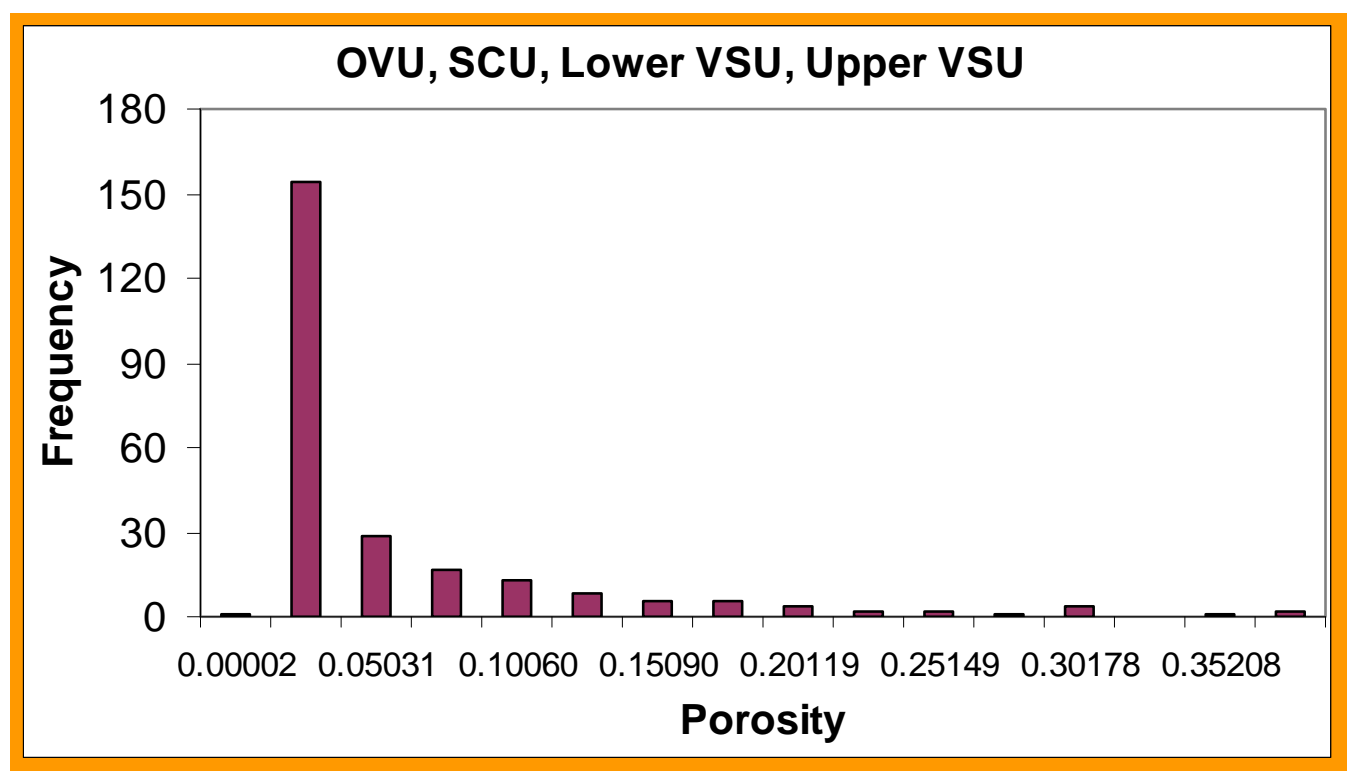

Figure A21. Effective-porosity histogram of OVU, SCU, Lower VSU, and Upper VSU based on Effective-porosity Data Set 2.

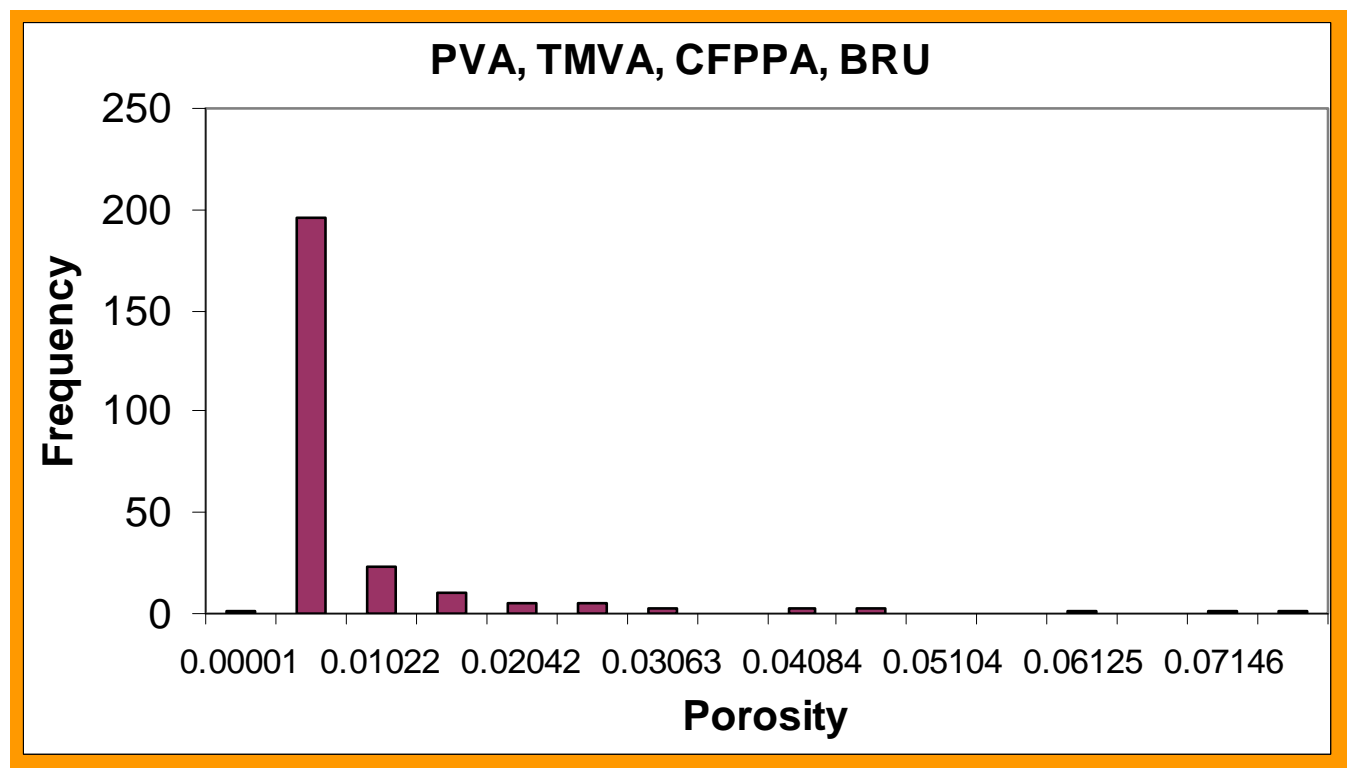

Figure A22. Effective-porosity histogram of PVA, TMVA, CFPPA, and BRU based on Effective-porosity Data Set 2. 


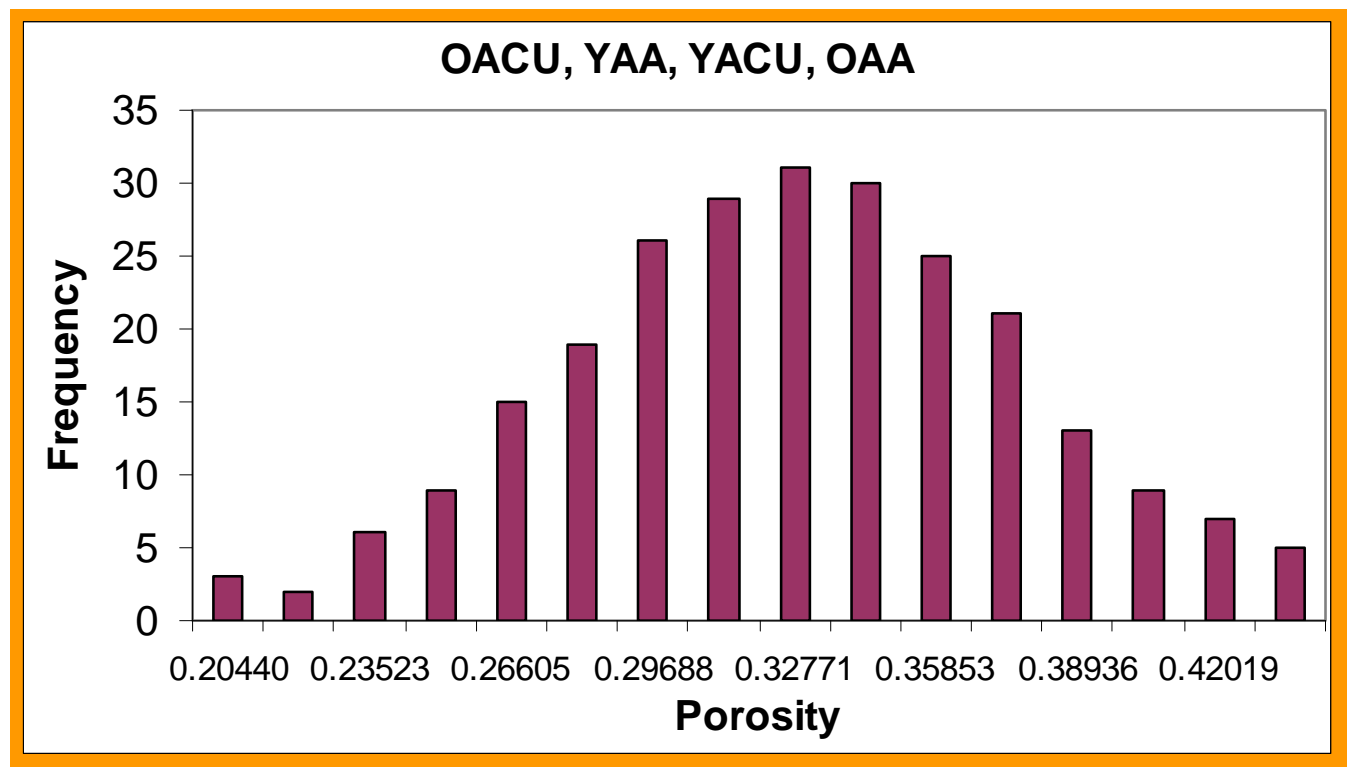

Figure A23. Effective-porosity histogram of OACU, YAA, YACU, and OAA based on Effective-porosity Data Set 2.

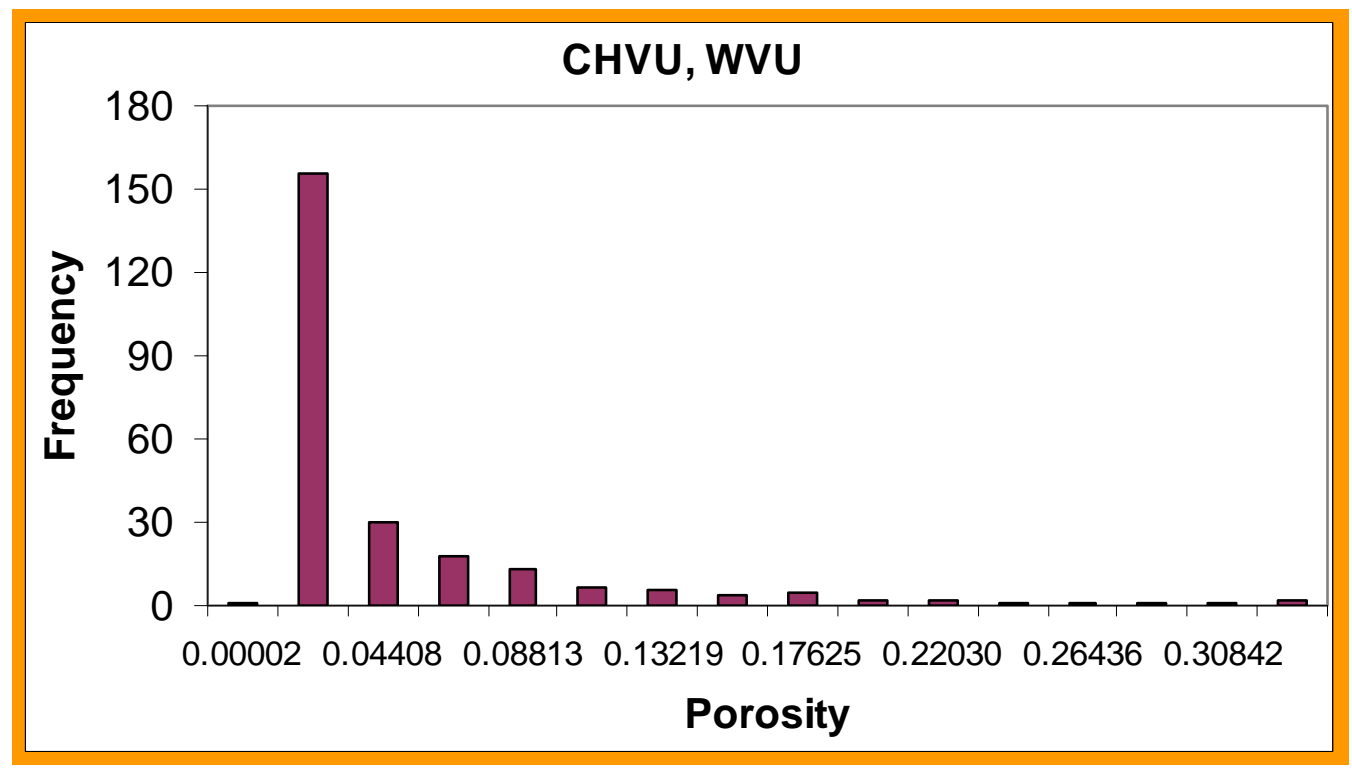

Figure A24. Effective-porosity histogram of CHVU, and WVU based on Effectiveporosity Data Set 2. 


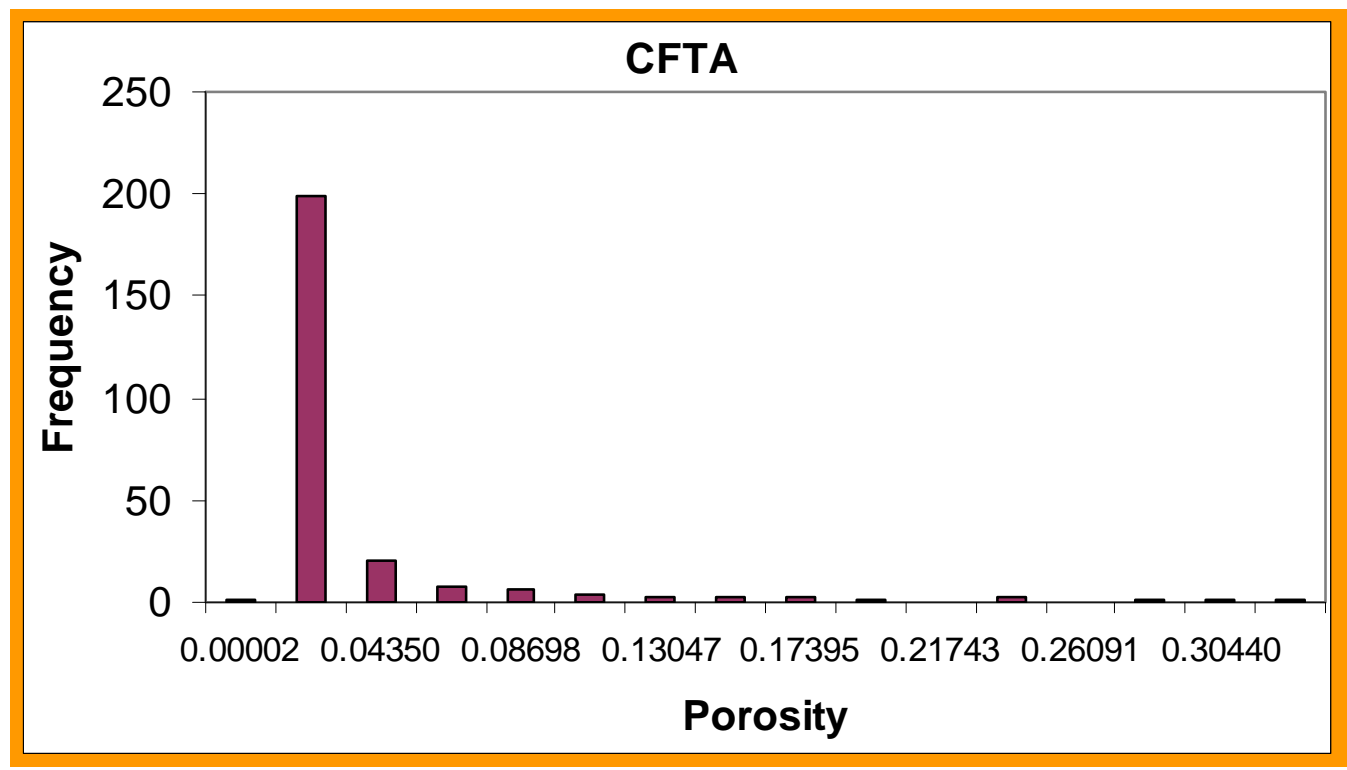

Figure A25. Effective-porosity histogram of CFTA based on Effective-porosity Data Set 2.

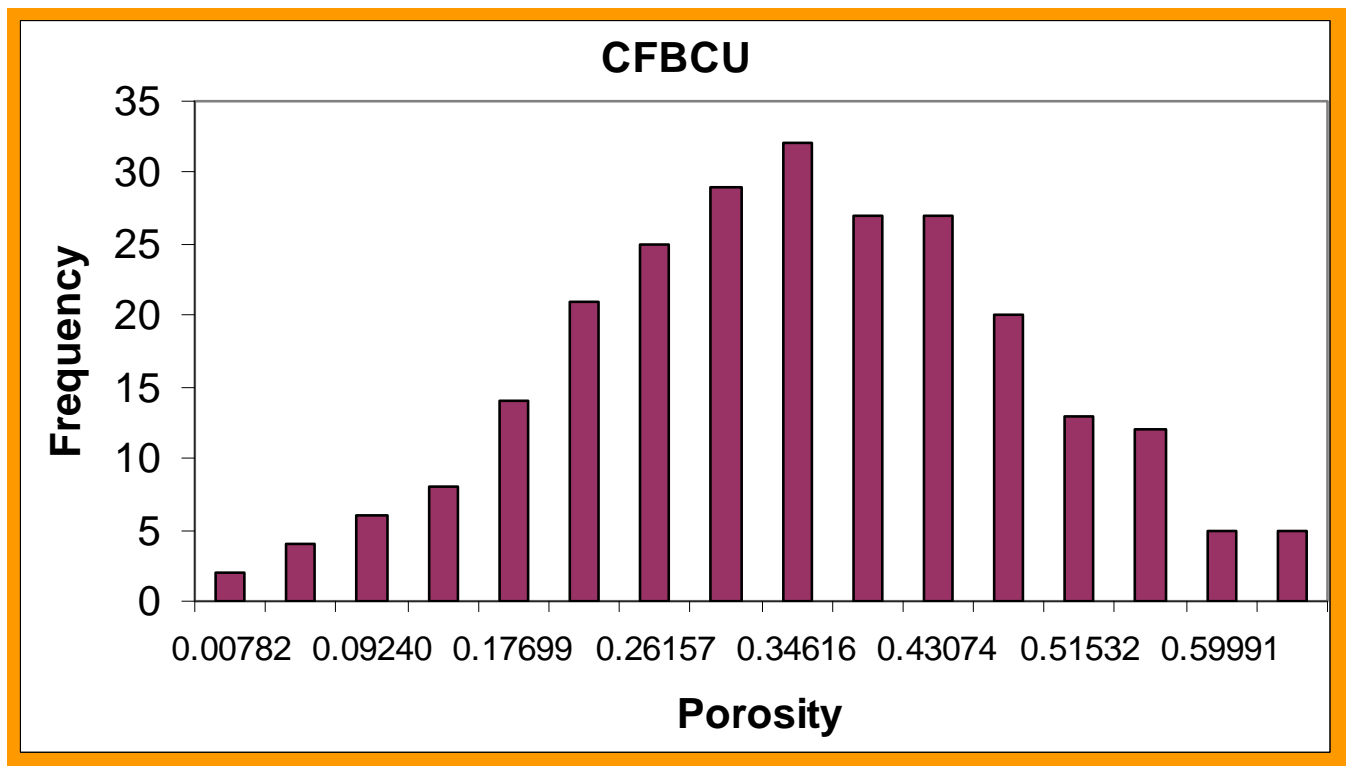

Figure A26: Effective-porosity histogram of CFBCU based on Effective-porosity Data Set 2. 


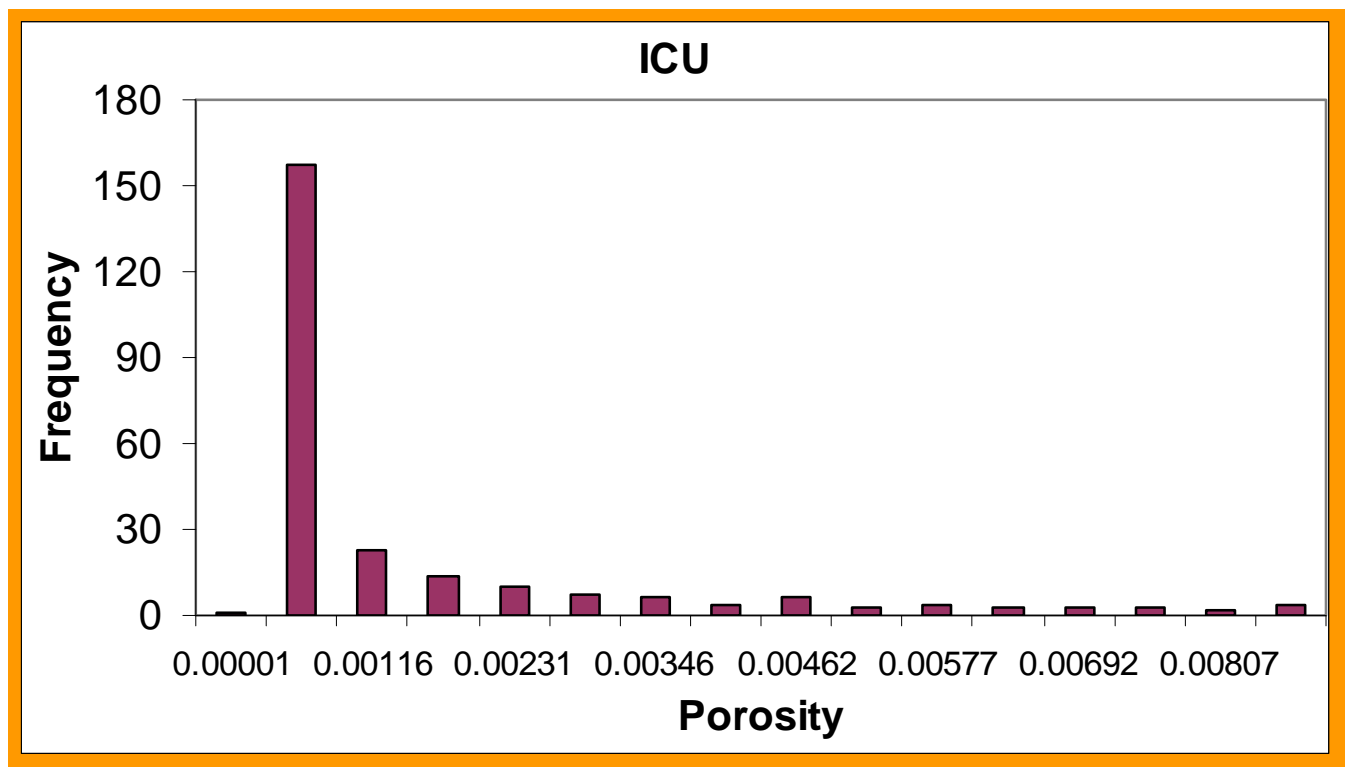

Figure A27. Effective-porosity histogram of ICU based on Effective-porosity Data Set 2.

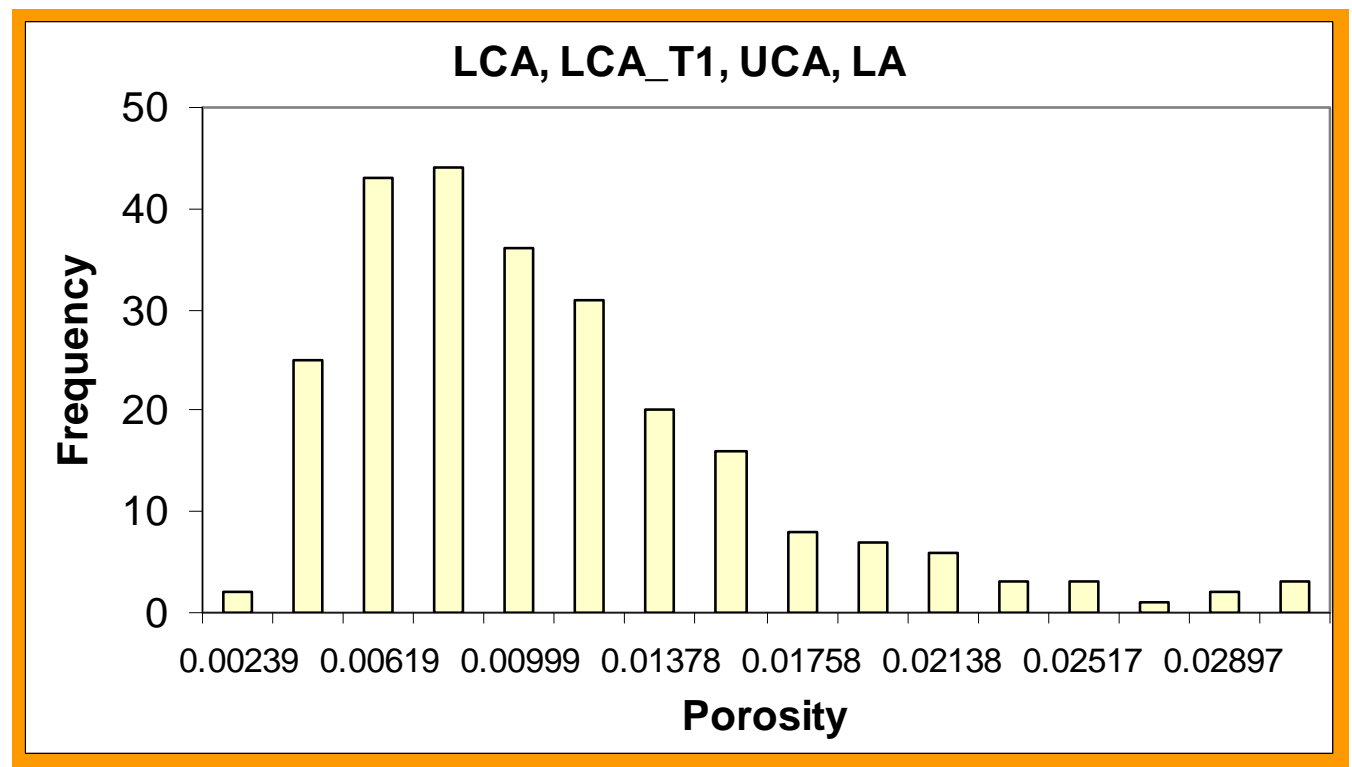

Figure A28. Effective-porosity histogram of LCA, LCA_T1, UCA, LA based on Effectiveporosity Data Set 3. 


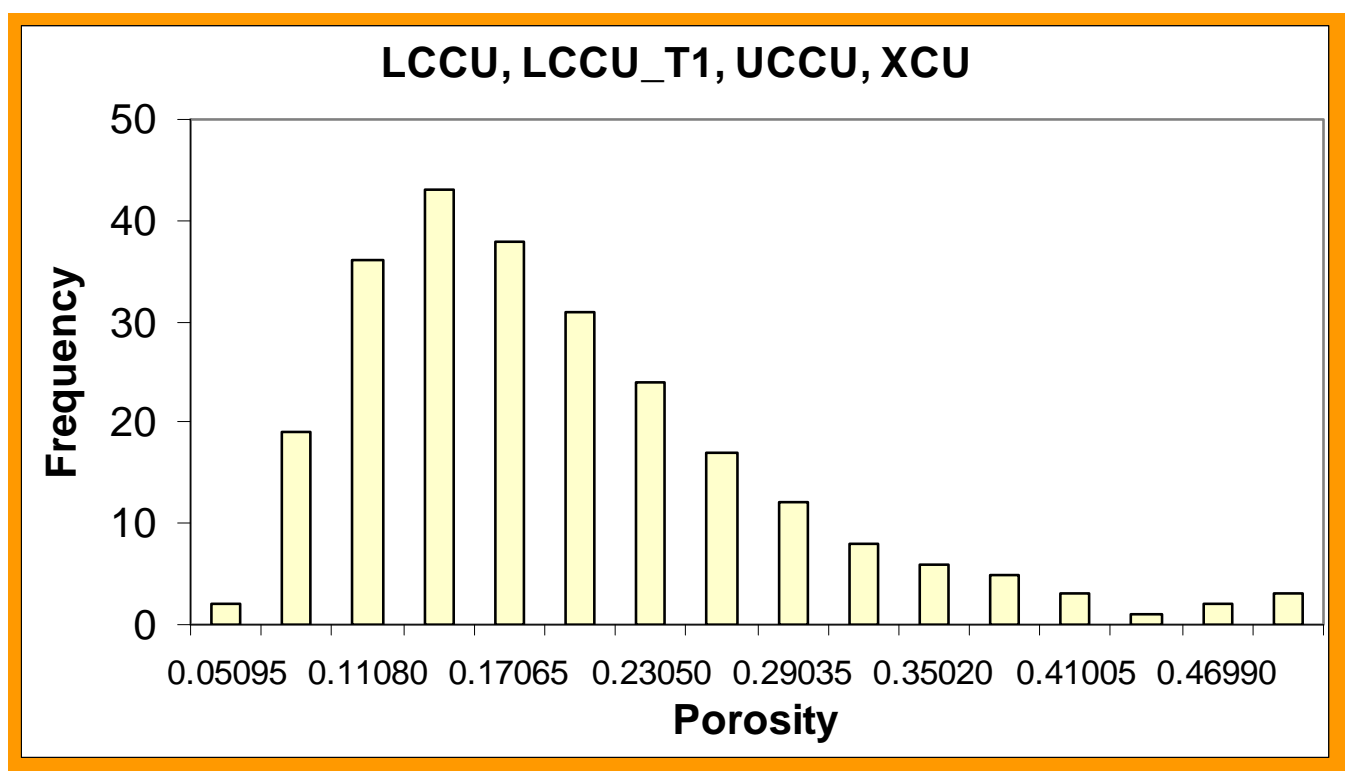

Figure A29. Effective-porosity histogram of LCCU, LCCU_T1, UCCU, and XCU based on Effective-porosity Data Set 3.

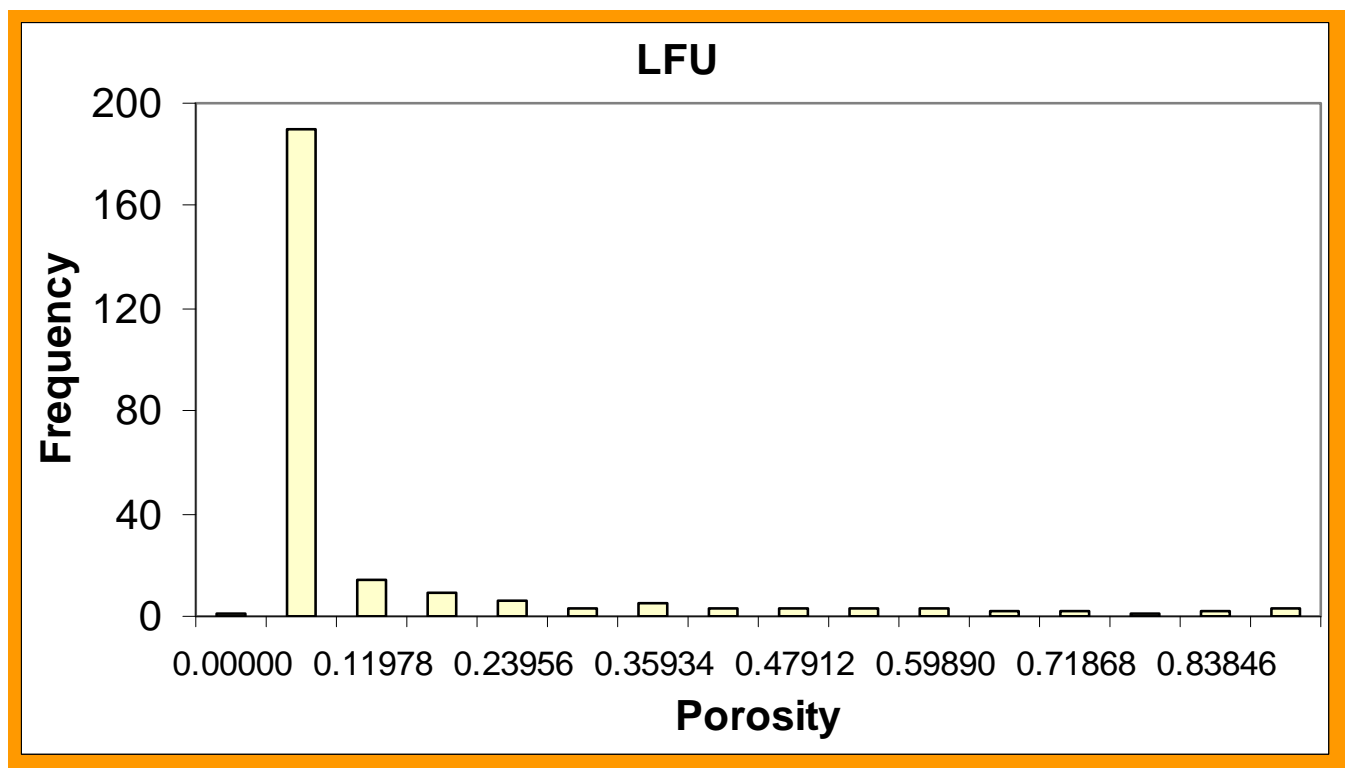

Figure A30. Effective-porosity histogram of LFU based on Effective-porosity Data Set 3. 


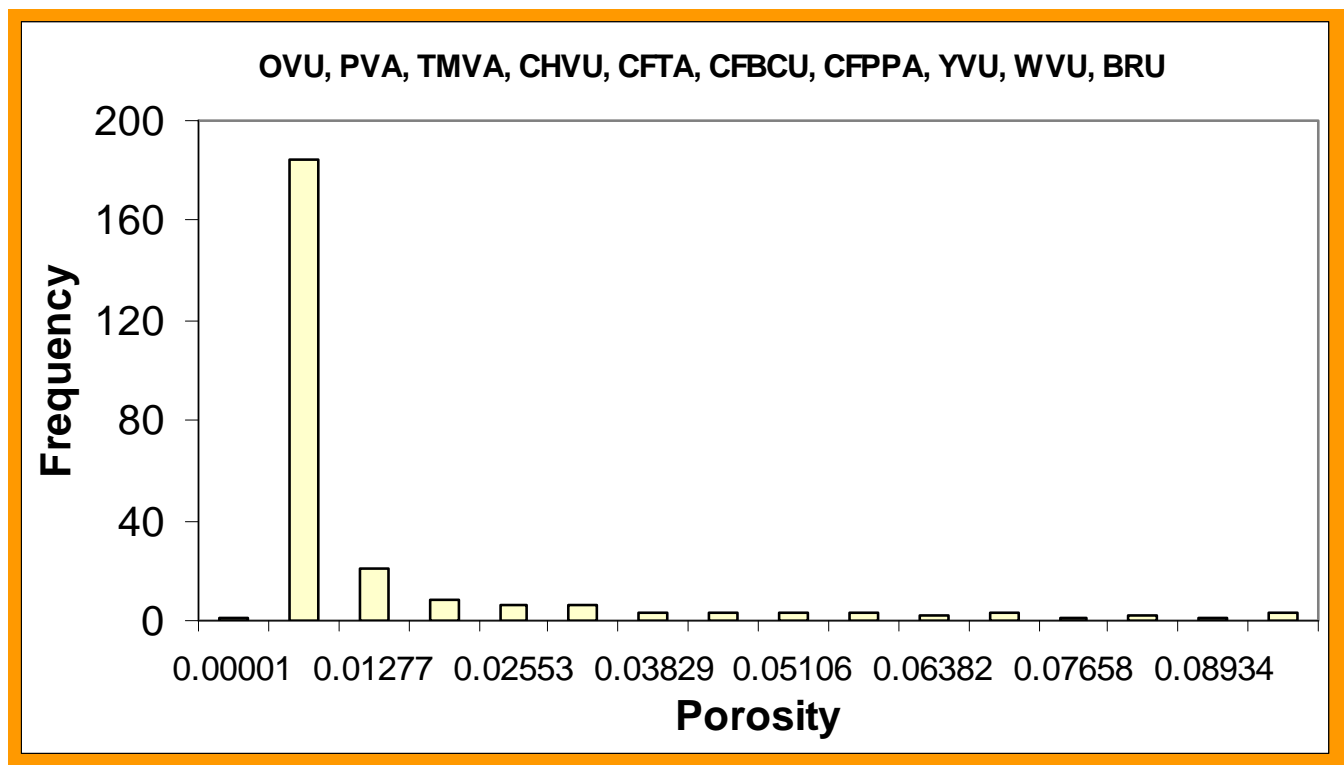

Figure A31. Effective-porosity histogram of OVU, PVA, TMVA, CHVU, CFTA, CFBCU, CFPPA, YVU, WVU, and BRU based on Effective-porosity Data Set 3.

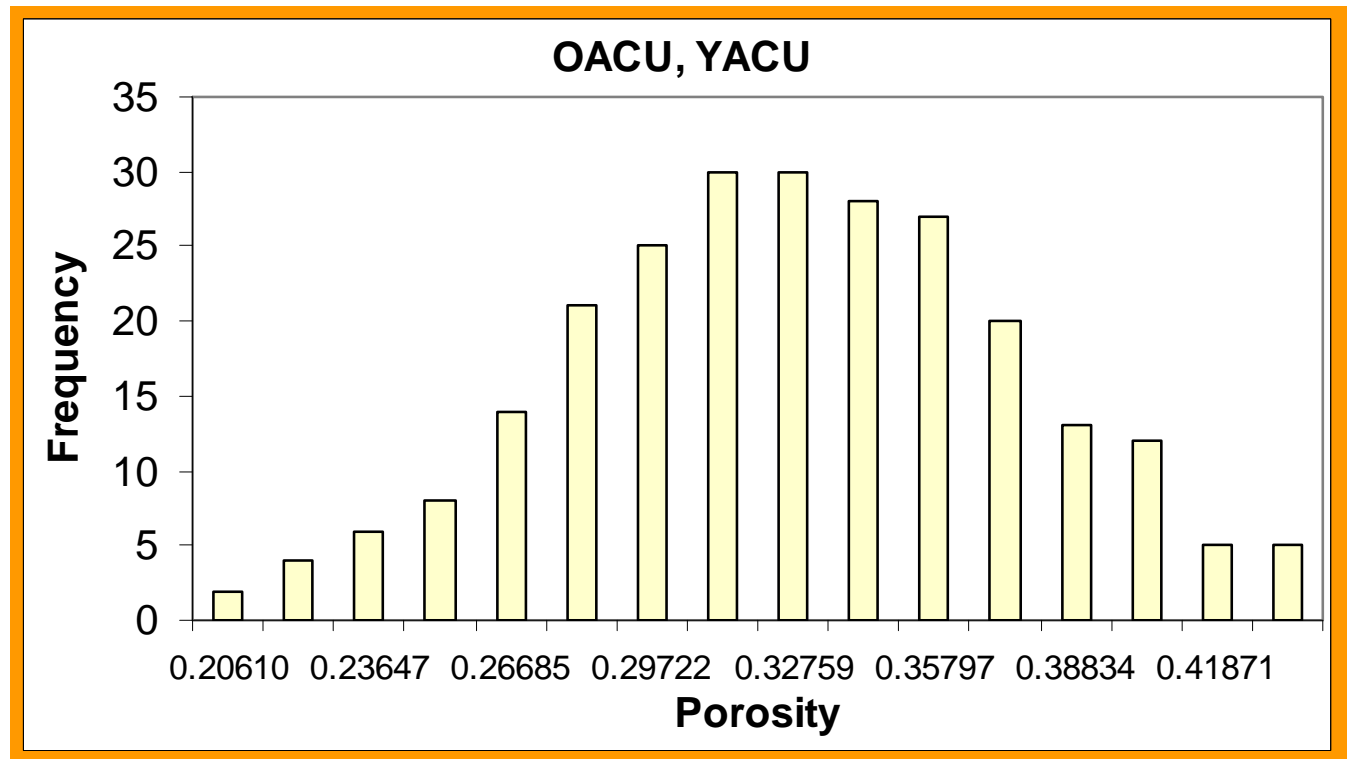

Figure A32. Effective-porosity histogram of OACU and YACU based on Effectiveporosity Data Set 3. 


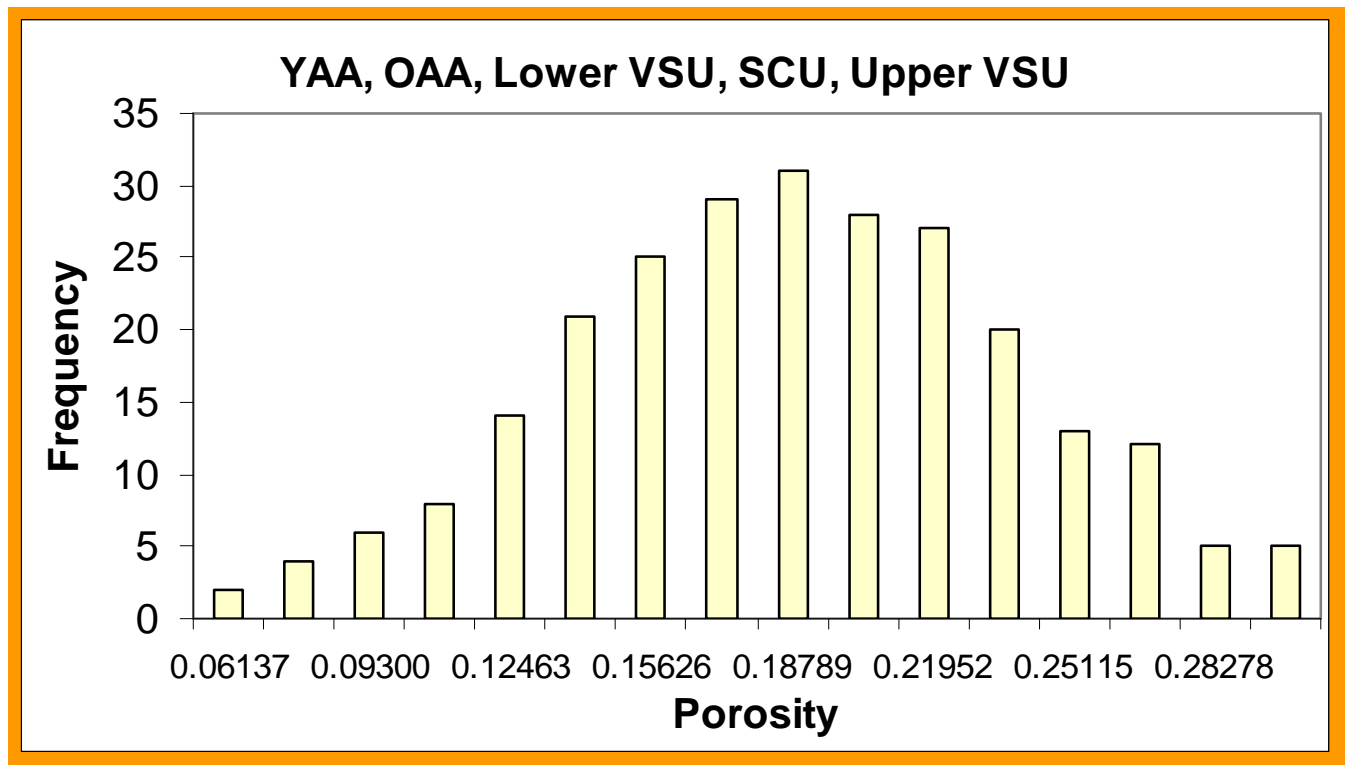

Figure A33. Effective-porosity histogram of YAA, OAA, Lower VSU, and Upper VSU based on Effective-porosity Data Set 3.

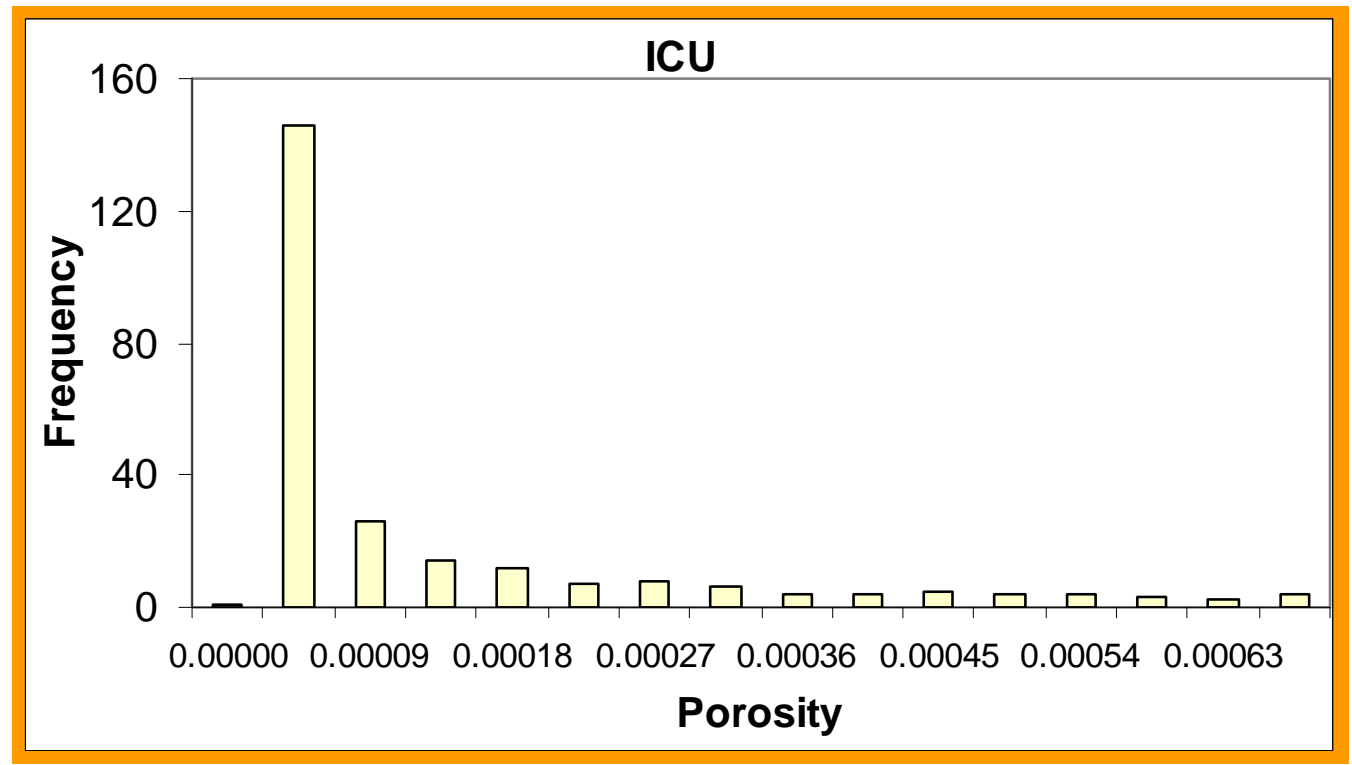

Figure A34. Effective-porosity histogram of ICU based on Effective-porosity Data Set 3. 


\section{APPENDIX B:}

$\mathrm{CV}$ of the minimum travel times to YM area from various detonations when only one HGU has randomly variable effective-porosity and the porosities of other HGUs are set to equal the mean values

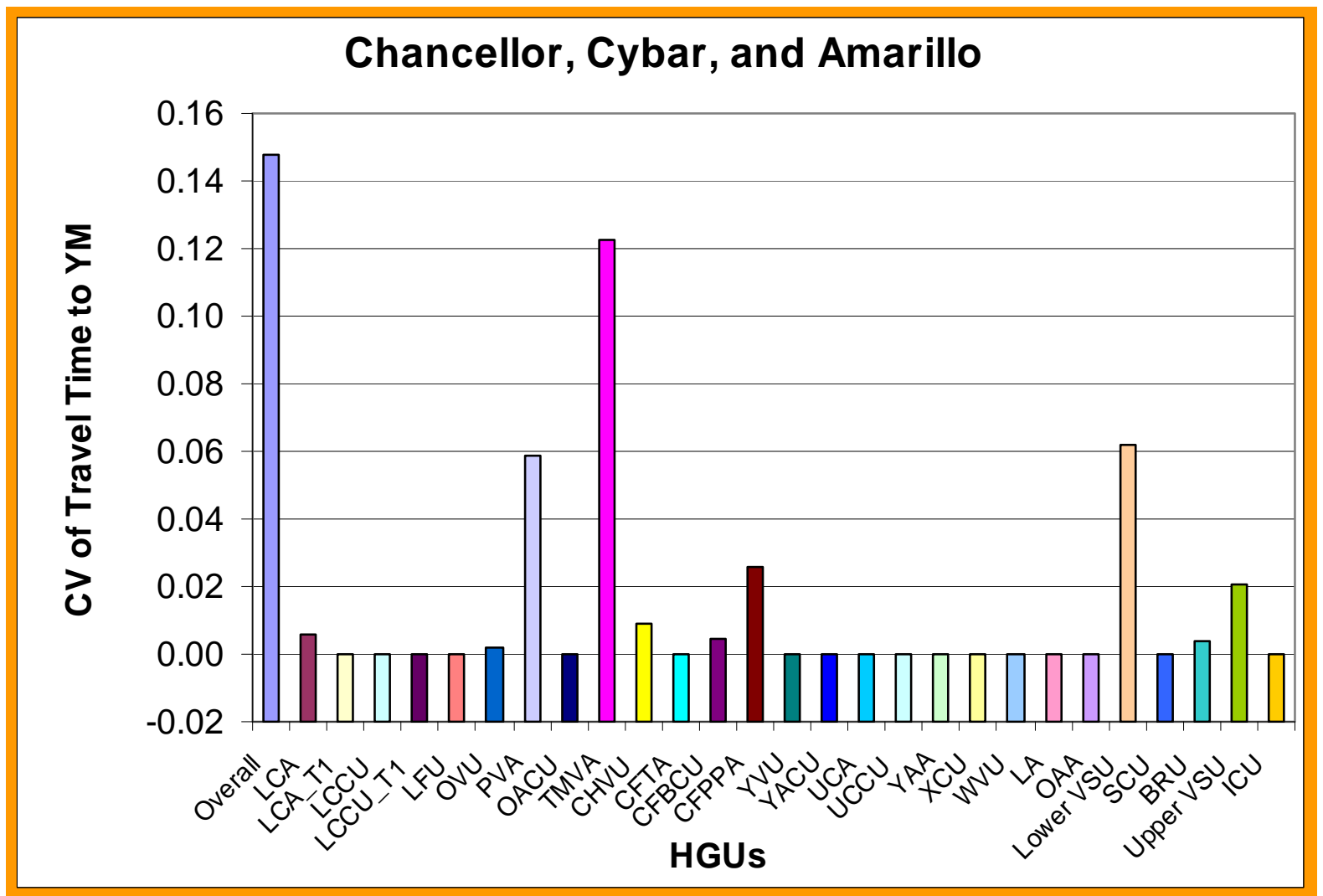

Figure B1. Coefficient of variation (CV) of minimum travel time to the YM area from Chancellor, Cybar and Amarillo, in relation to the effective-porosity uncertainties of Hydrogeologic Units (HGUs) when only one HGU has randomly variable effective-porosity and the porosities for other HGUs are set to equal the mean values under pre-pumping conditions. 


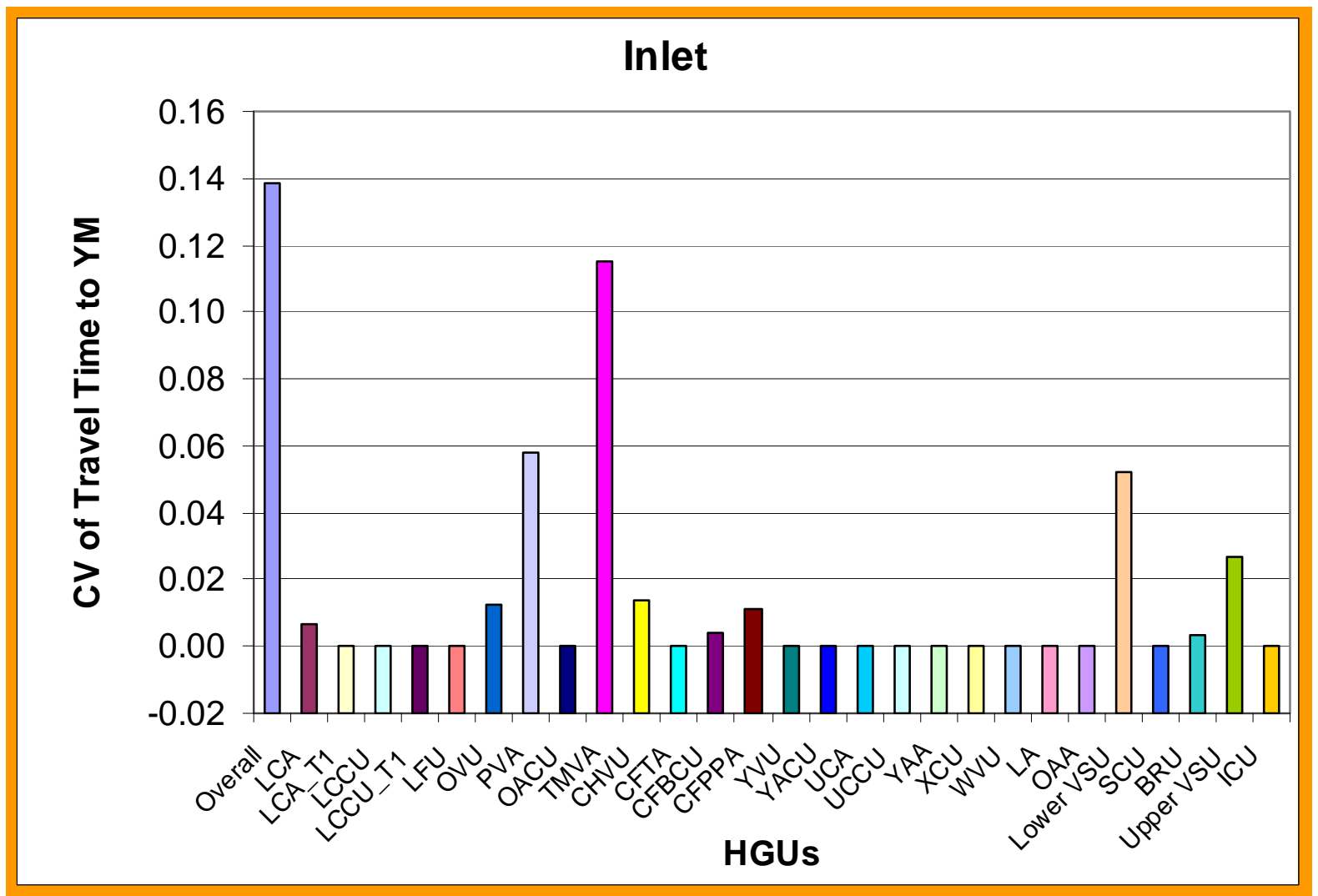

Figure B2. Coefficient of variation $(\mathrm{CV})$ of minimum travel time to the YM area from Inlet, in relation to the effective-porosity uncertainties of Hydrogeologic Units (HGUs) when only one HGU has randomly variable effective-porosity and the porosities for other HGUs are set to equal the mean values under pre-pumping conditions. 


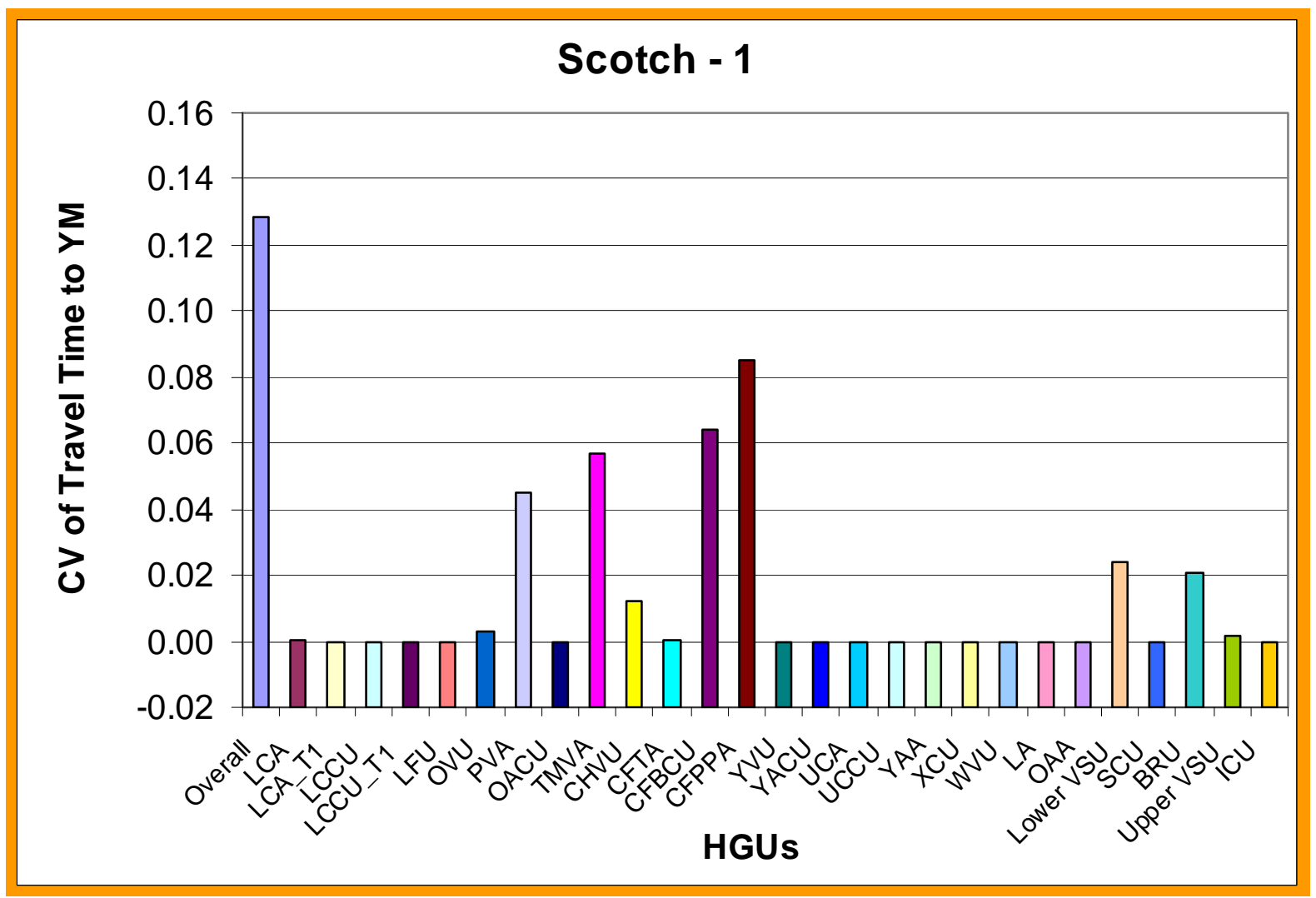

Figure B3. Coefficient of variation (CV) of minimum travel time to the YM area from Scotch-1, in relation to the effective-porosity uncertainties of Hydrogeologic Units (HGUs) when only one HGU has randomly variable effective-porosity and the porosities for other HGUs are set to equal the mean values under prepumping conditions. 


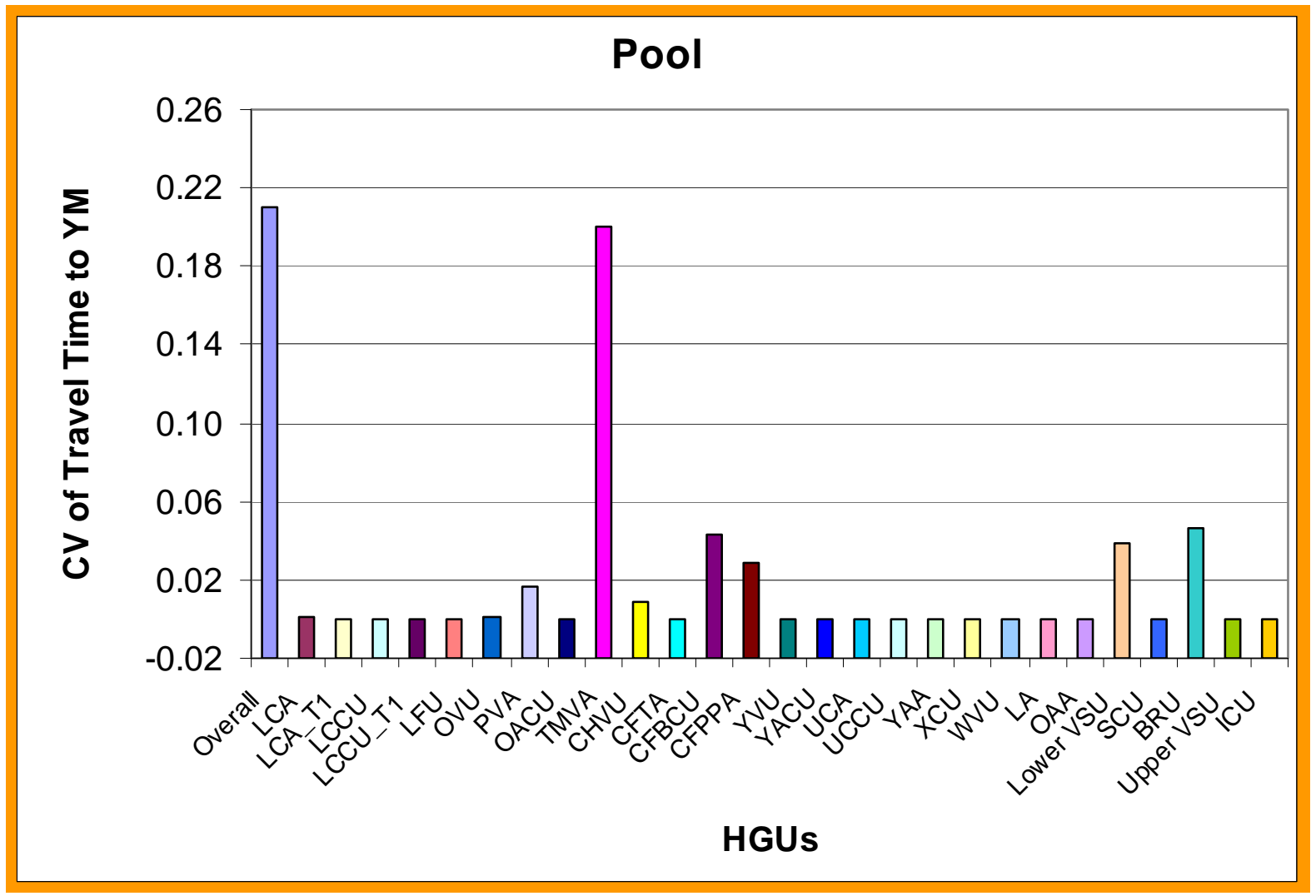

Figure B4. Coefficient of variation (CV) of minimum travel time to the YM area from Pool, in relation to the effective-porosity uncertainties of Hydrogeologic Units (HGUs) when only one HGU has randomly variable effective-porosity and the porosities for other HGUs are set to equal the mean values under pre-pumping conditions. 


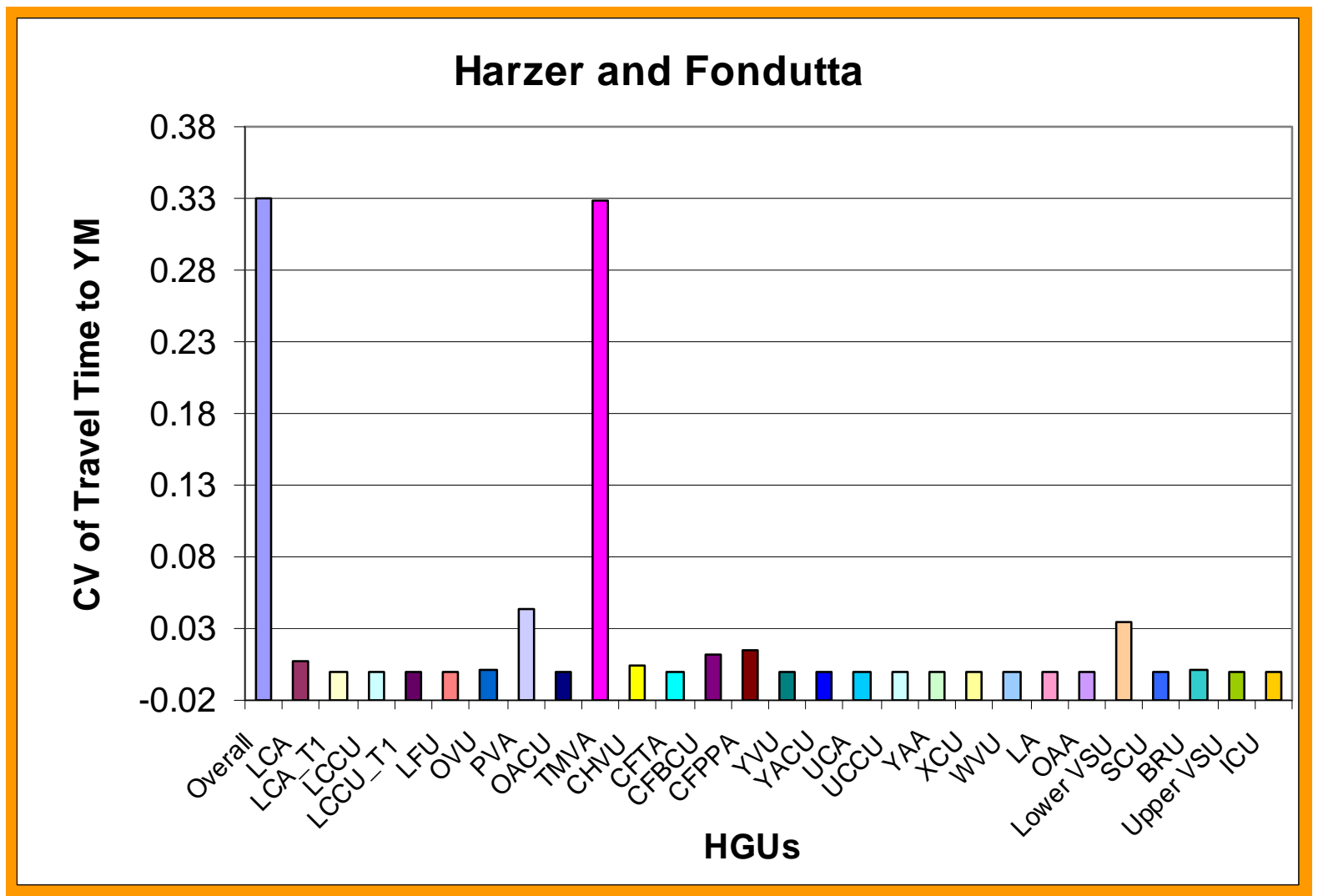

Figure B5. Coefficient of variation (CV) of minimum travel time to the YM area from Harzer and Fondutta, in relation to the effective-porosity uncertainties of Hydrogeologic Units (HGUs) when only one HGU has randomly variable effective-porosity and the porosities for other HGUs are set to equal the mean values under pre-pumping conditions. 


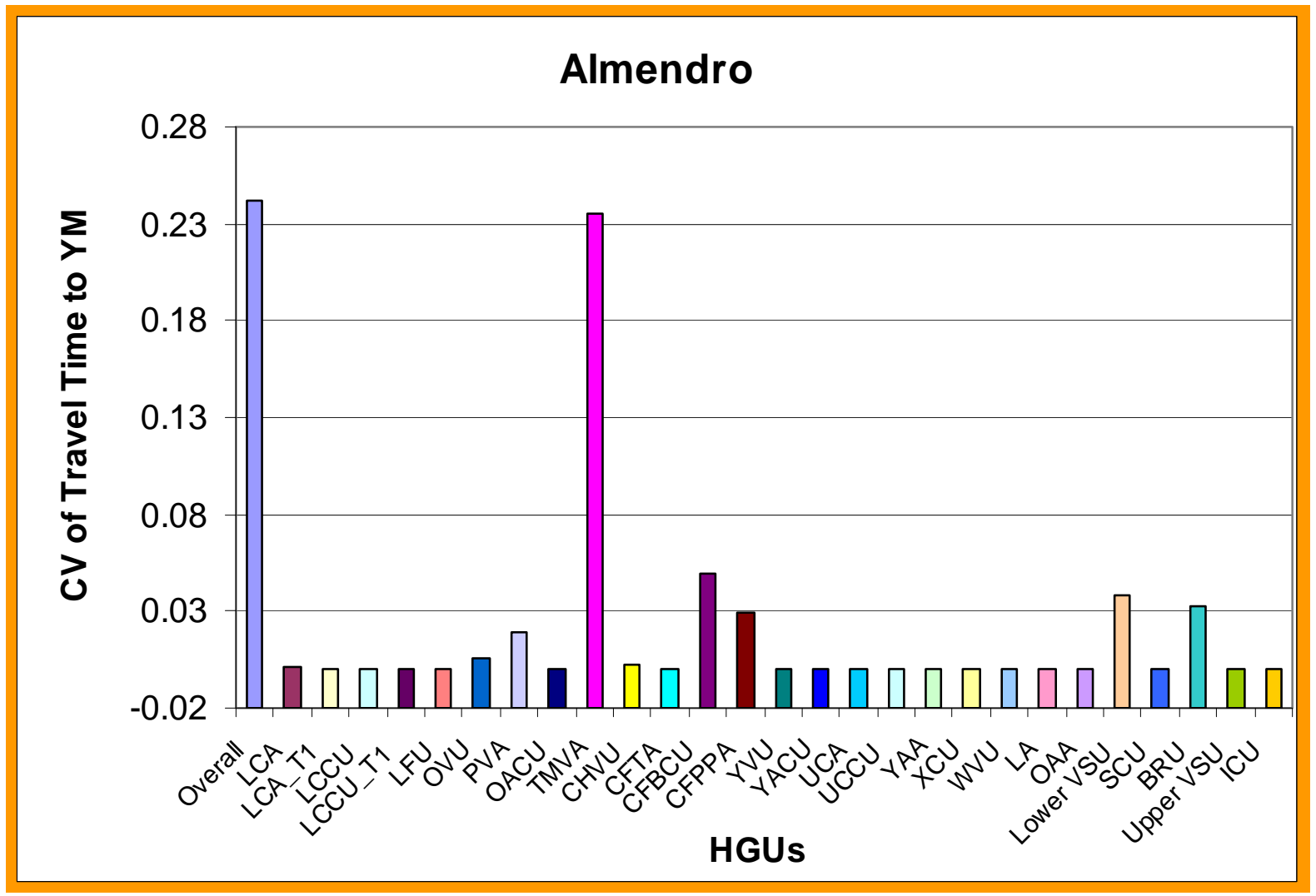

Figure B6. Coefficient of variation (CV) of minimum travel time to the YM area from Almendro, in relation to the effective-porosity uncertainties of Hydrogeologic Units (HGUs) when only one HGU has randomly variable effective-porosity and the porosities for other HGUs are set to equal the mean values under prepumping conditions. 


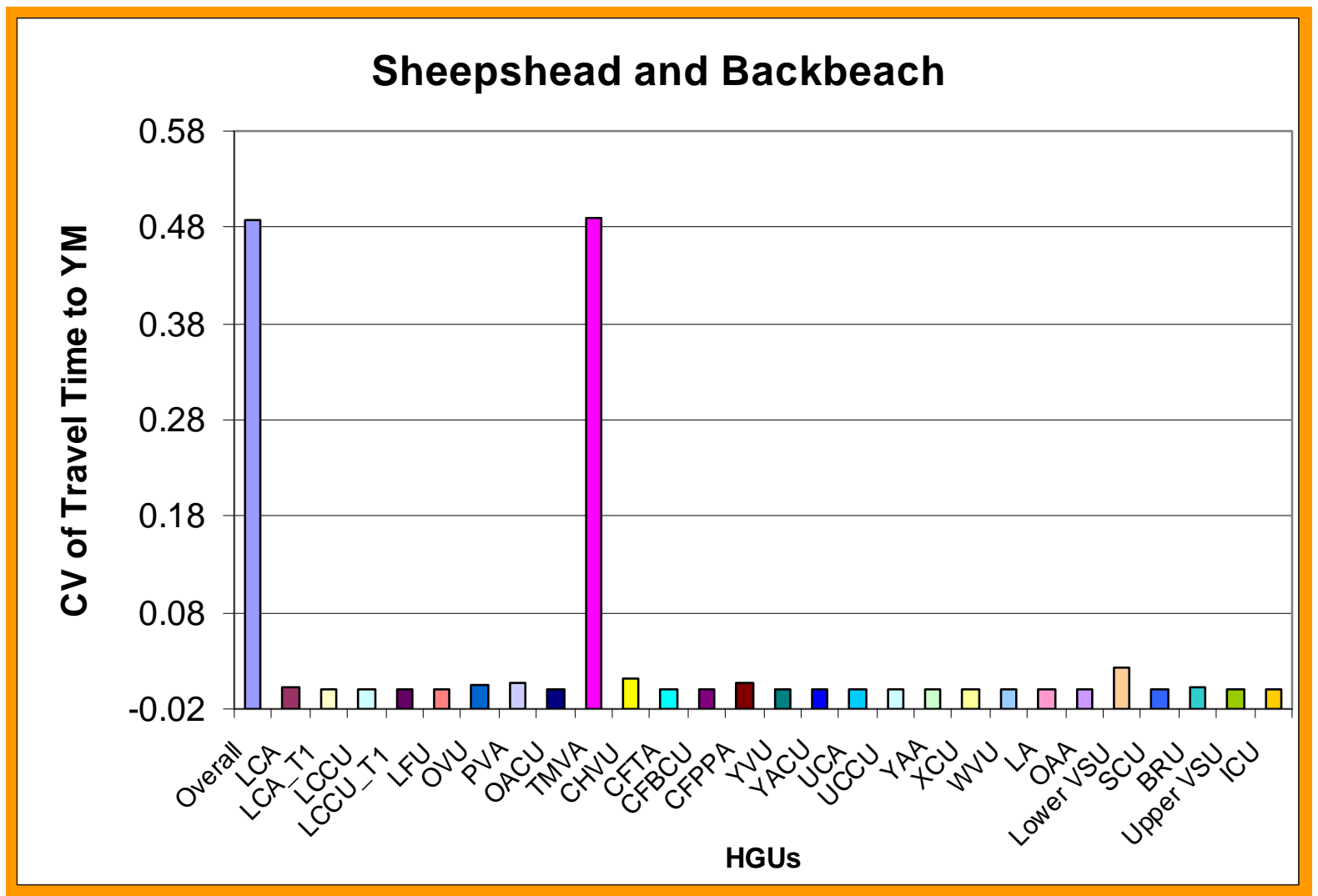

Figure B7. Coefficient of variation (CV) of minimum travel time to the YM area from Sheepshead and Backbeach, in relation to the effective-porosity uncertainties of Hydrogeologic Units (HGUs) when only one HGU has randomly variable effective-porosity and the porosities for other HGUs are set to equal the mean values under pre-pumping conditions. 


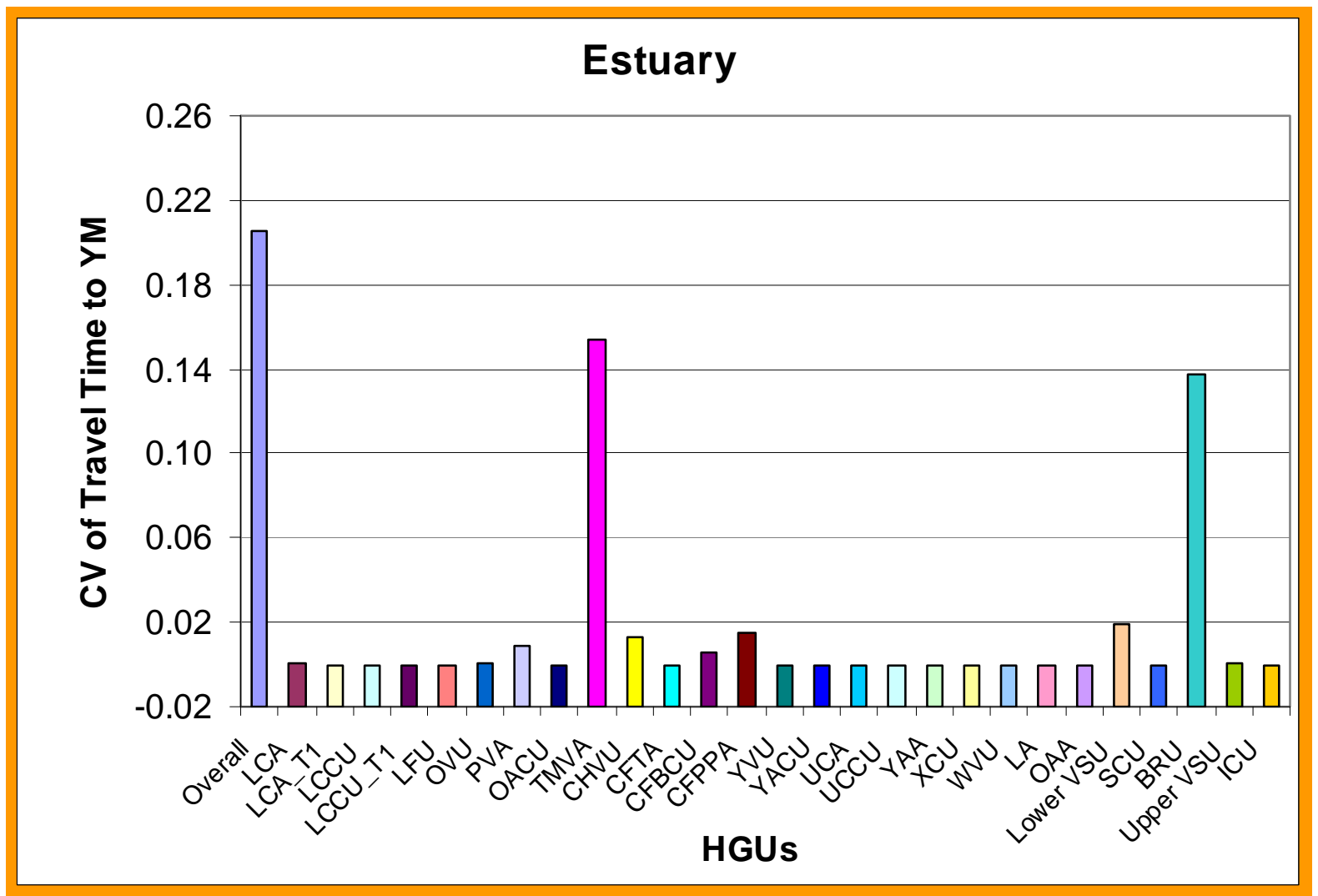

Figure B8. Coefficient of variation $(\mathrm{CV})$ of minimum travel time to the YM area from Estuary, in relation to the effective-porosity uncertainties of Hydrogeologic Units (HGUs) when only one HGU has randomly variable effective-porosity and the porosities for other HGUs are set to equal the mean values under prepumping conditions. 


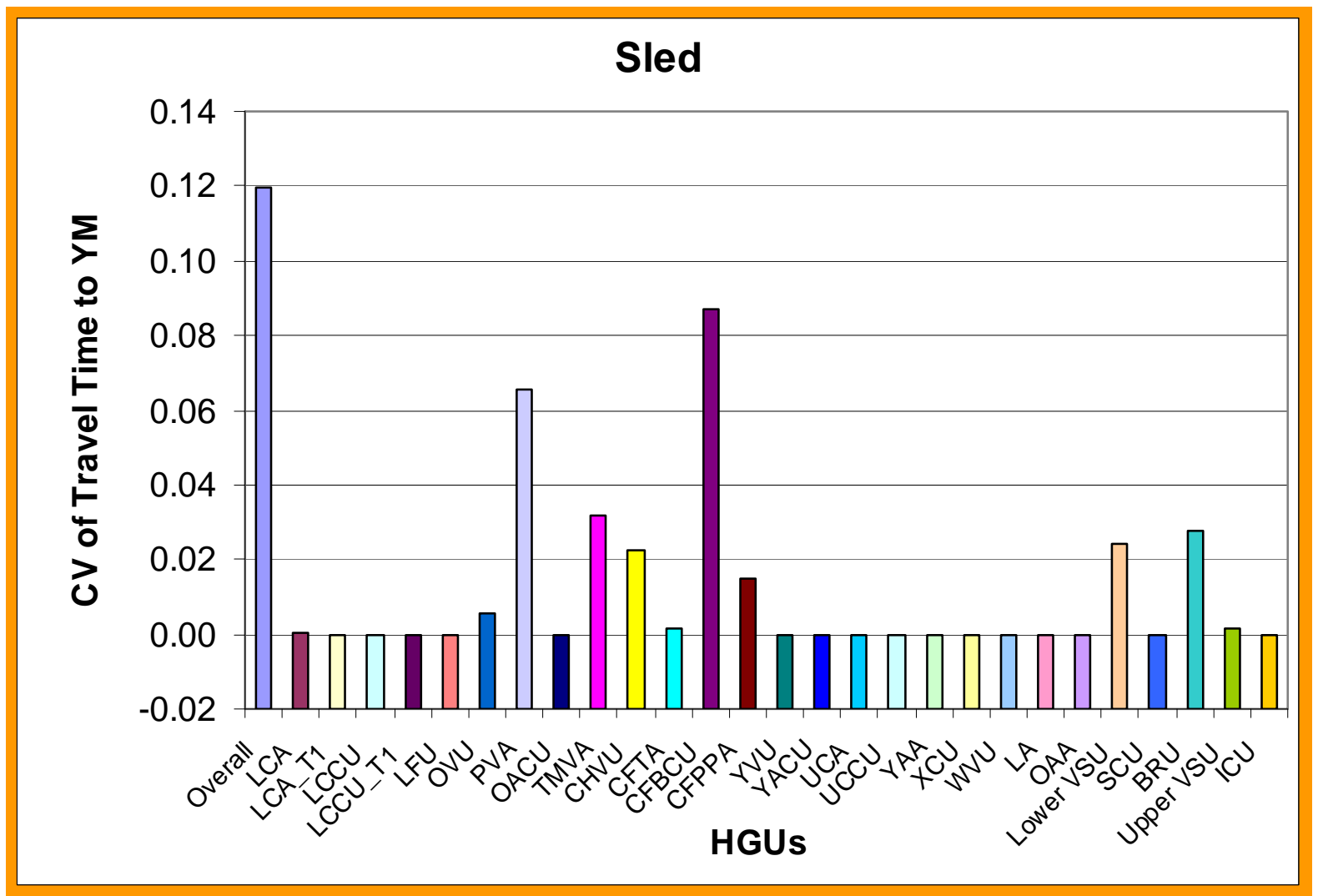

Figure B9. Coefficient of variation (CV) of minimum travel time to the YM area from Sled, in relation to the effective-porosity uncertainties of Hydrogeologic Units (HGUs) when only one HGU has randomly variable effective-porosity and the porosities for other HGUs are set to equal the mean values under pre-pumping conditions. 


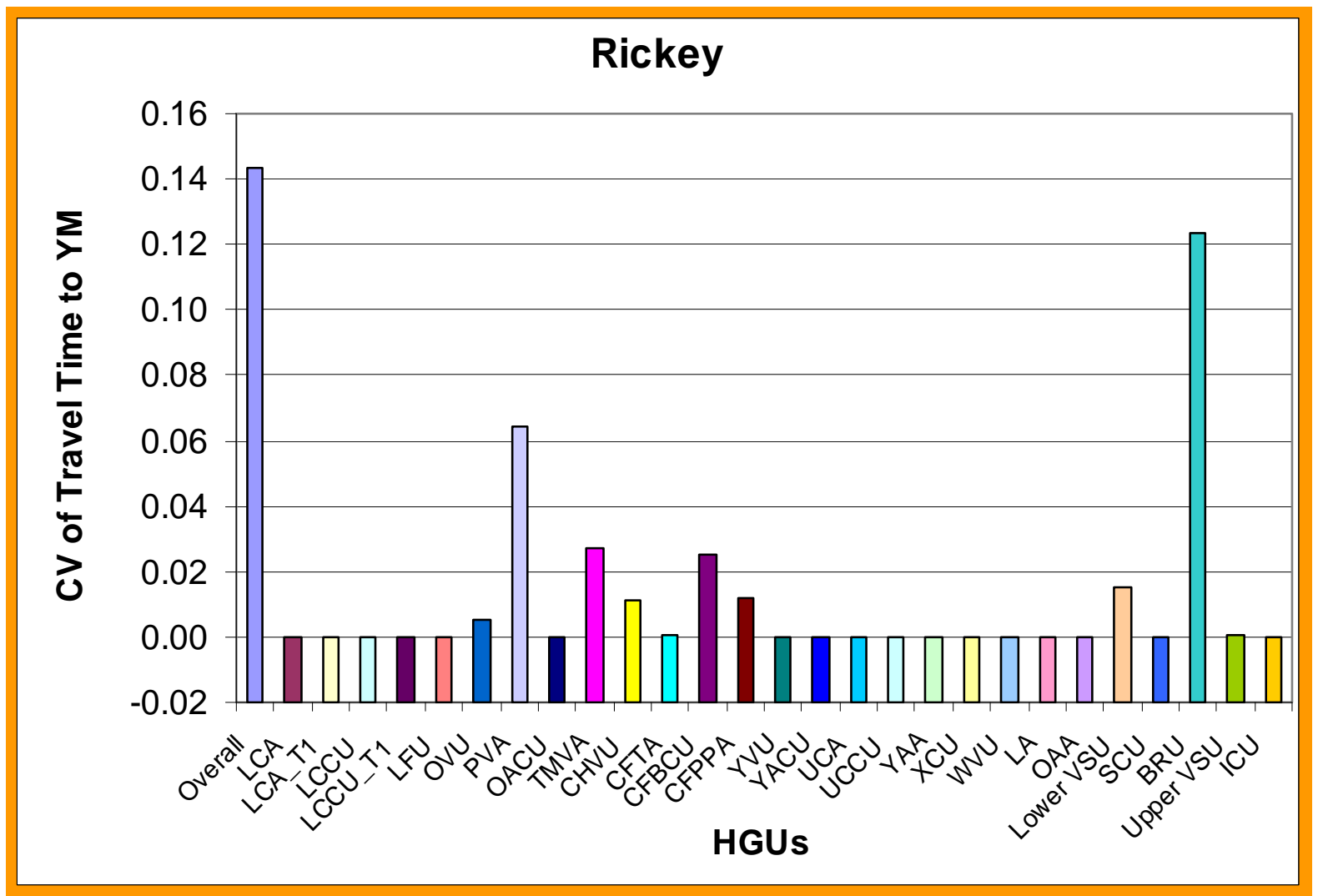

Figure B10. Coefficient of variation $(\mathrm{CV})$ of minimum travel time to the YM area from rickey, in relation to the effective-porosity uncertainties of Hydrogeologic Units (HGUs) when only one HGU has randomly variable effective-porosity and the porosities for other HGUs are set to equal the mean values under prepumping conditions. 


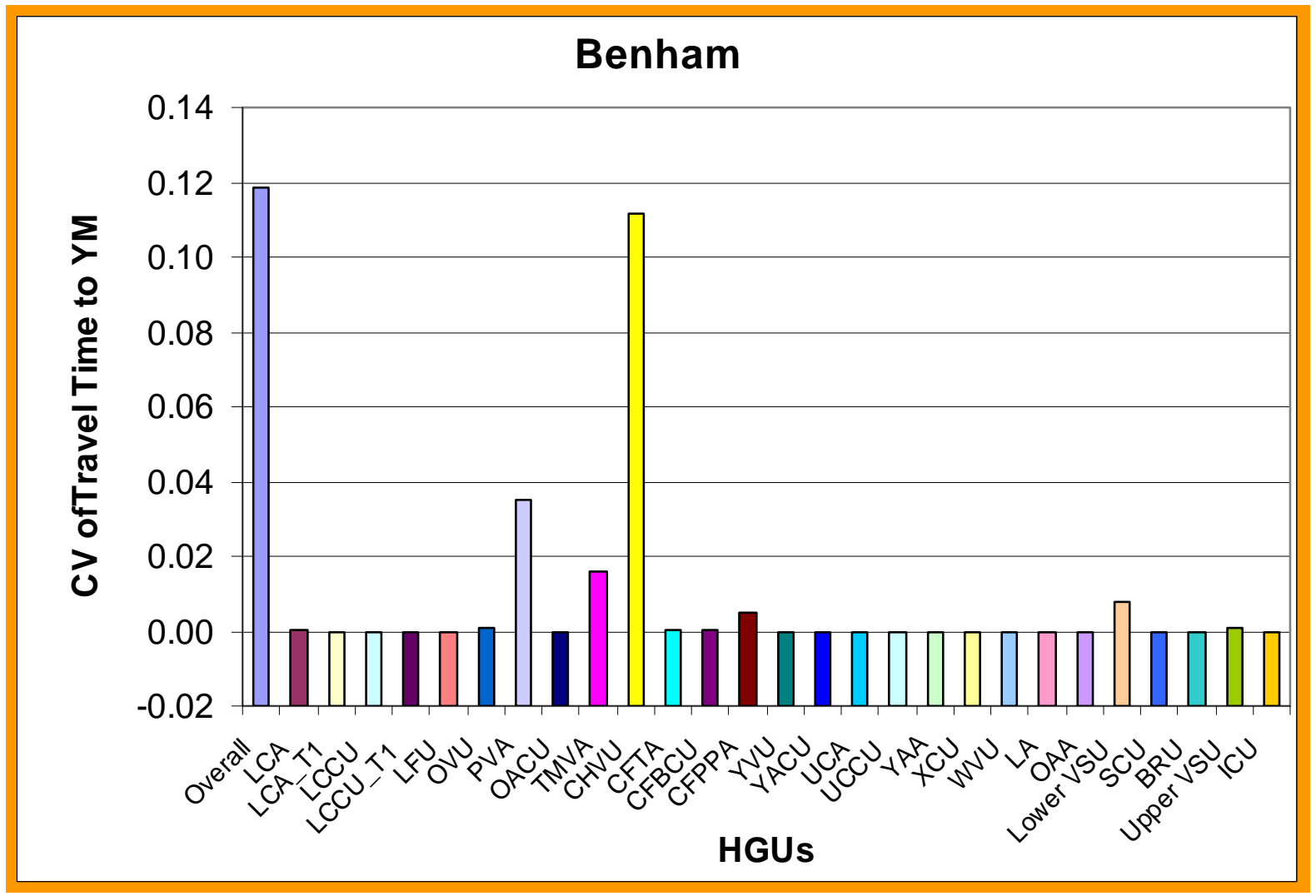

Figure B11. Coefficient of variation $(\mathrm{CV})$ of minimum travel time to the YM area from Benham, in relation to the effective-porosity uncertainties of Hydrogeologic Units (HGUs) when only one HGU has randomly variable effective-porosity and the porosities for other HGUs are set to equal the mean values under prepumping conditions. 


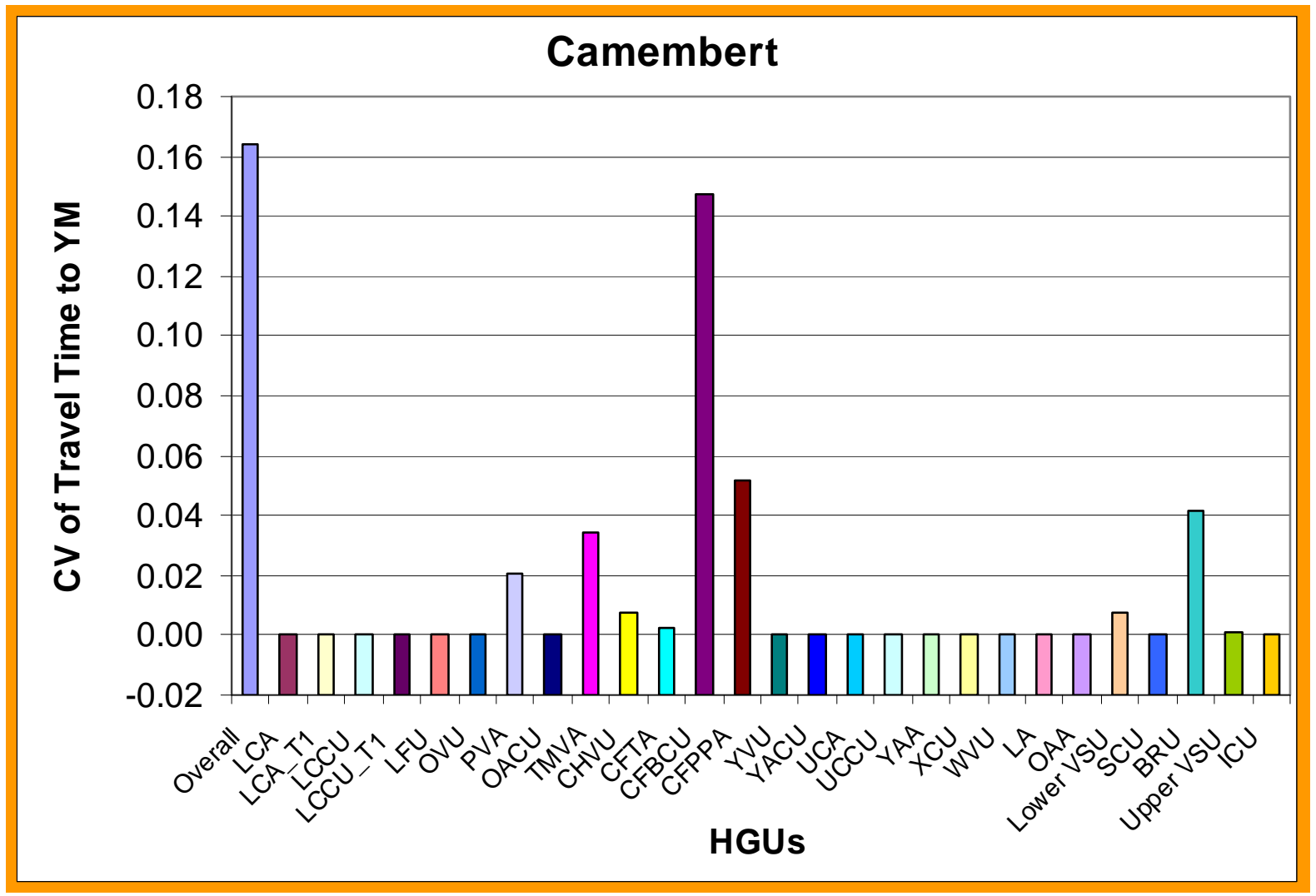

Figure B12. Coefficient of variation $(\mathrm{CV})$ of minimum travel time to the YM area from Camembert, in relation to the effective-porosity uncertainties of Hydrogeologic Units (HGUs) when only one HGU has randomly variable effective-porosity and the porosities for other HGUs are set to equal the mean values under pre-pumping conditions. 


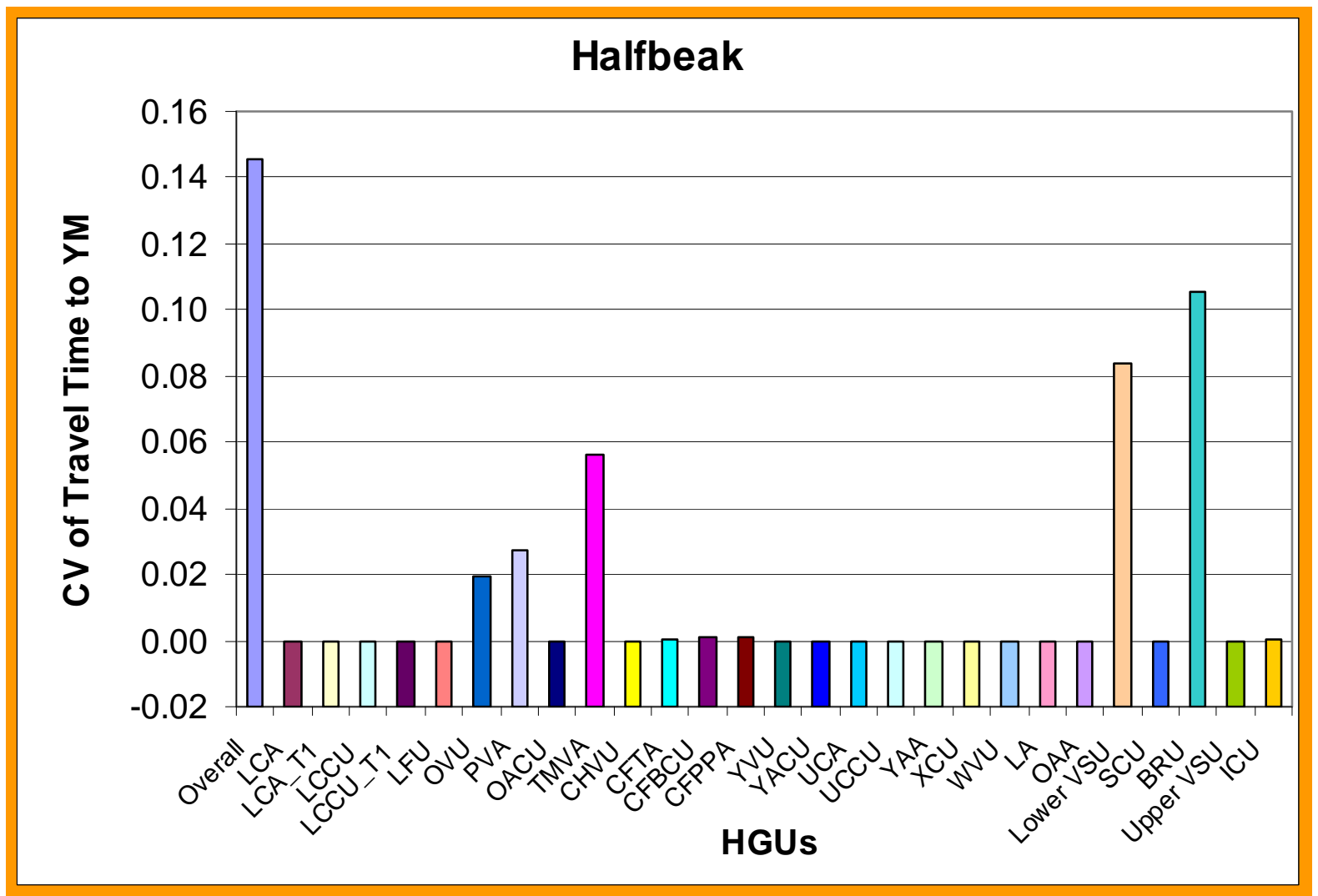

Figure B13. Coefficient of variation (CV) of minimum travel time to the YM area from Halfbeak, in relation to the effective-porosity uncertainties of Hydrogeologic Units (HGUs) when only one HGU has randomly variable effective-porosity and the porosities for other HGUs are set to equal the mean values under prepumping conditions. 


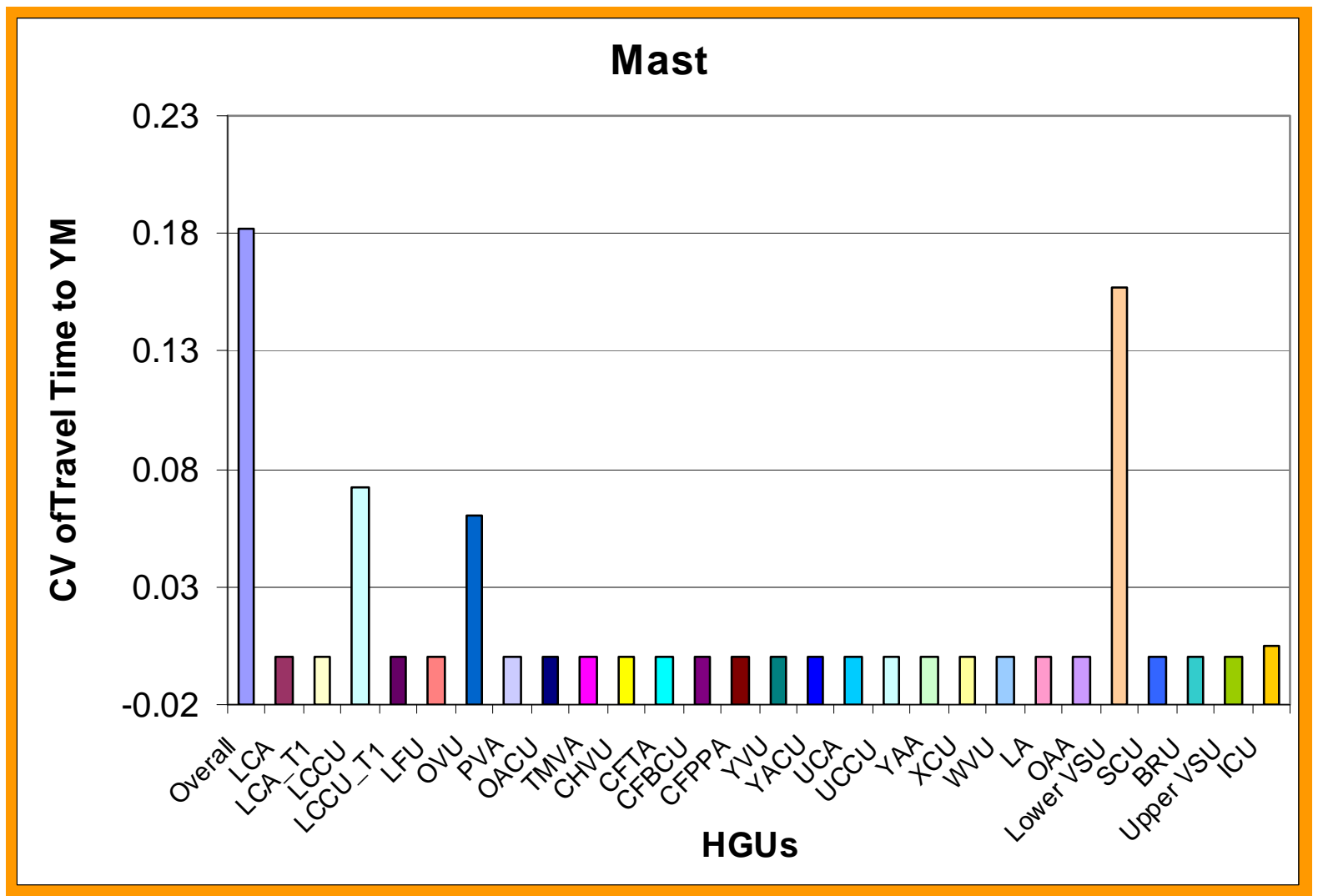

Figure B14. Coefficient of variation $(\mathrm{CV})$ of minimum travel time to the YM area from Mast, in relation to the effective-porosity uncertainties of Hydrogeologic Units (HGUs) when only one HGU has randomly variable effective-porosity and the porosities for other HGUs are set to equal the mean values under prepumping conditions. 


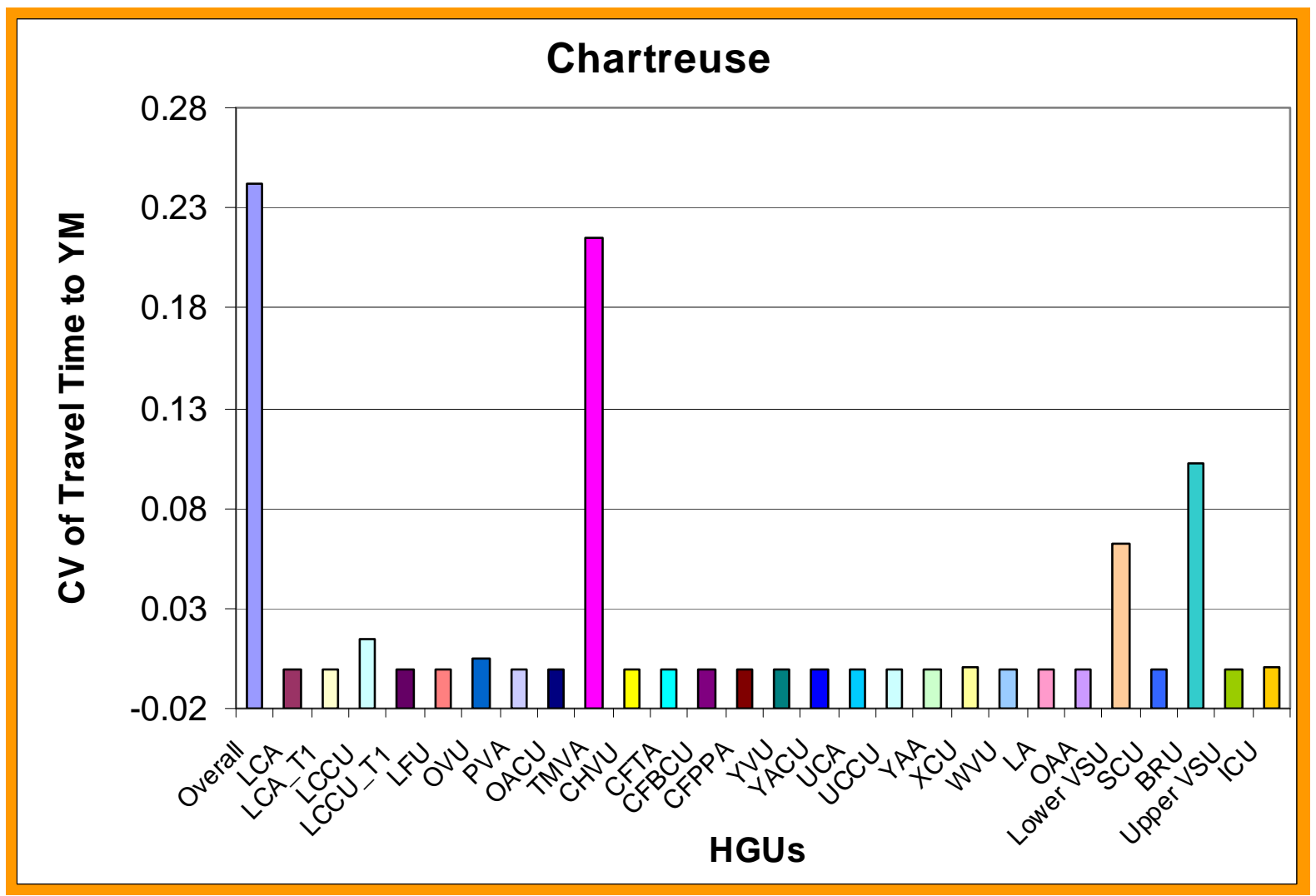

Figure B15. Coefficient of variation $(\mathrm{CV})$ of minimum travel time to the YM area from Chartreuse, in relation to the effective-porosity uncertainties of Hydrogeologic Units (HGUs) when only one HGU has randomly variable effective-porosity and the porosities for other HGUs are set to equal the mean values under prepumping conditions. 


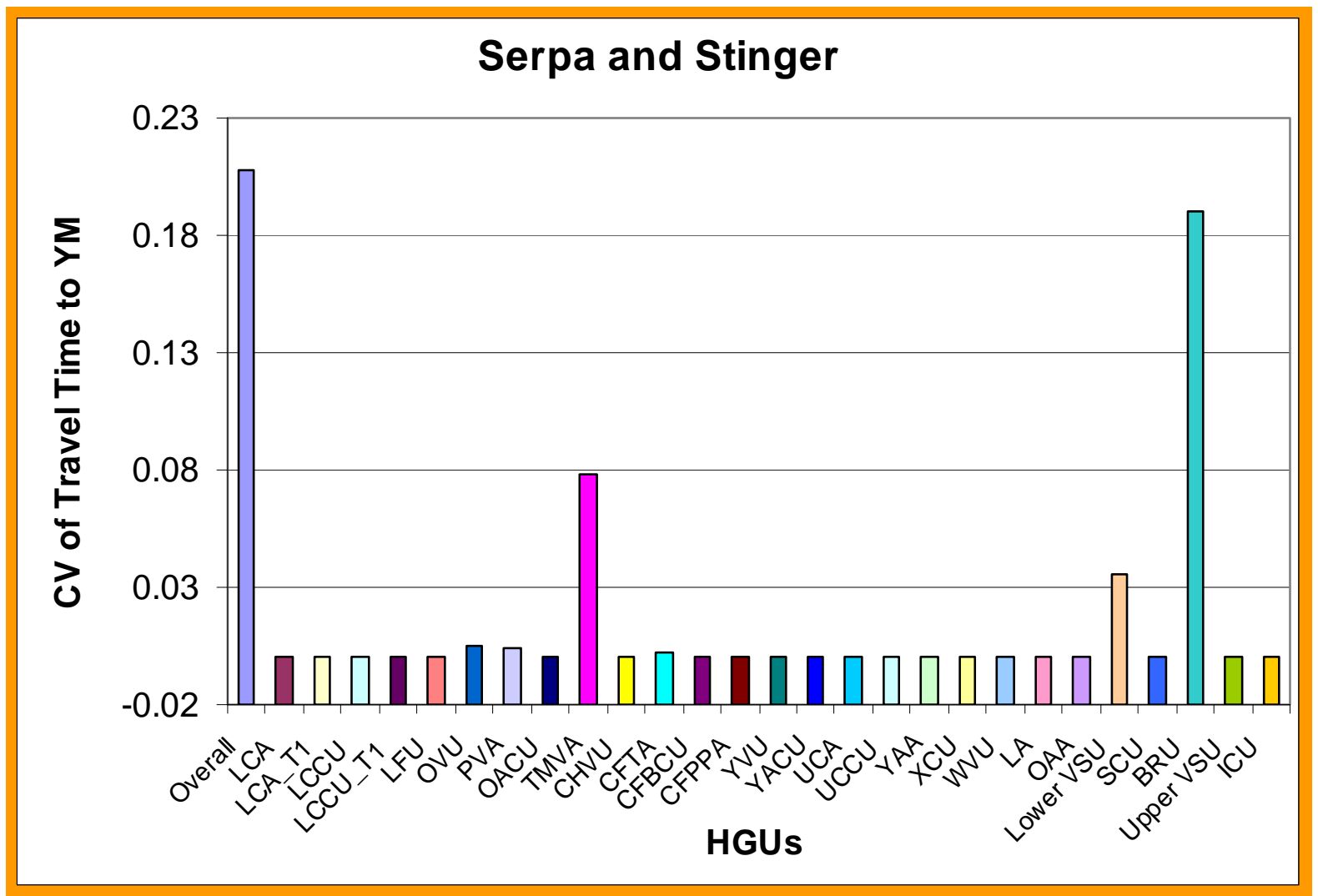

Figure B16. Coefficient of variation $(\mathrm{CV})$ of minimum travel time to the YM area from Serpa and Stinger, in relation to the effective-porosity uncertainties of Hydrogeologic Units (HGUs) when only one HGU has randomly variable effective-porosity and the porosities for other HGUs are set to equal the mean values under pre-pumping conditions. 


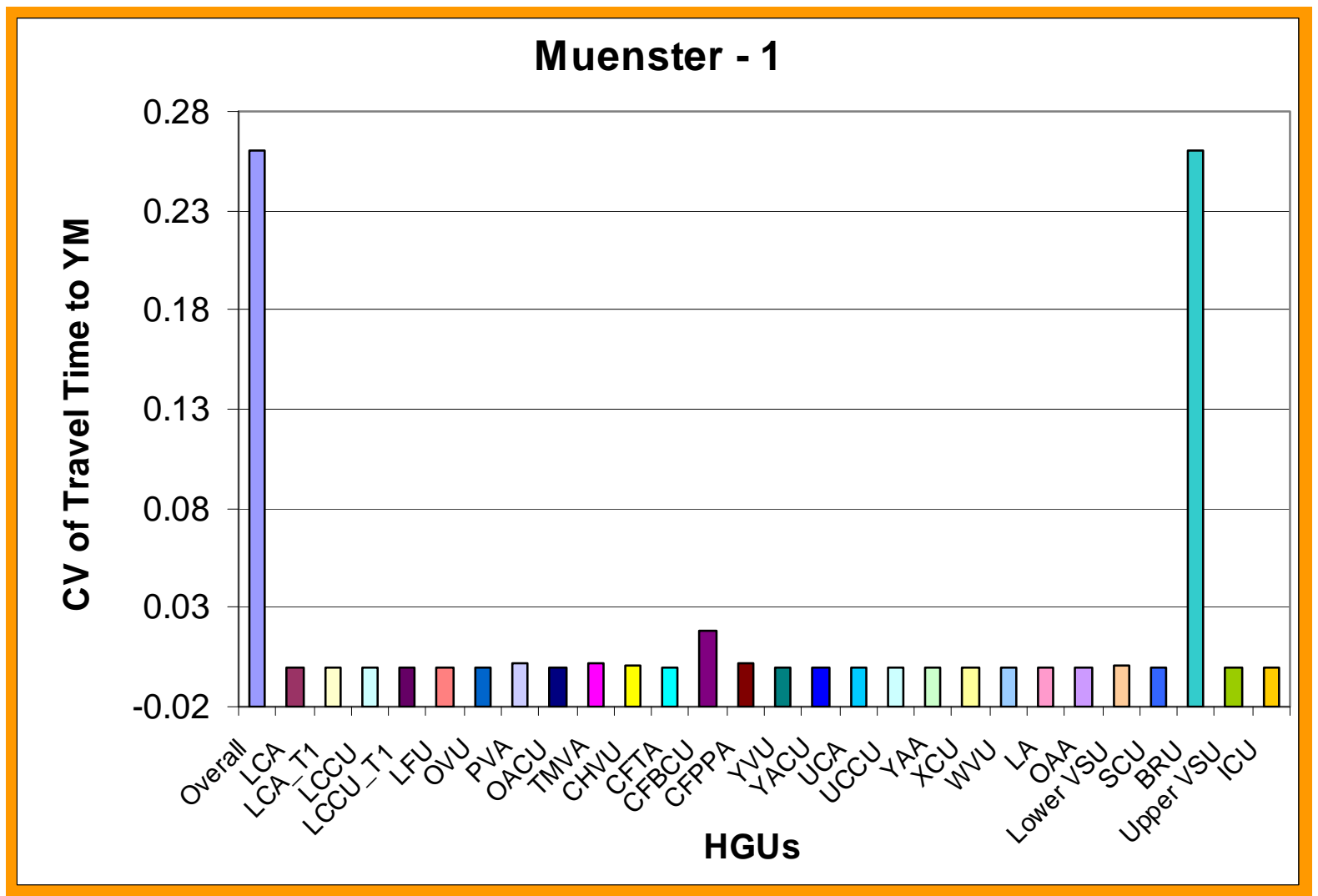

Figure B17. Coefficient of variation $(\mathrm{CV})$ of minimum travel time to the YM area from Muenster - 1, in relation to the effective-porosity uncertainties of Hydrogeologic Units (HGUs) when only one HGU has randomly variable effective-porosity and the porosities for other HGUs are set to equal the mean values under pre-pumping conditions. 


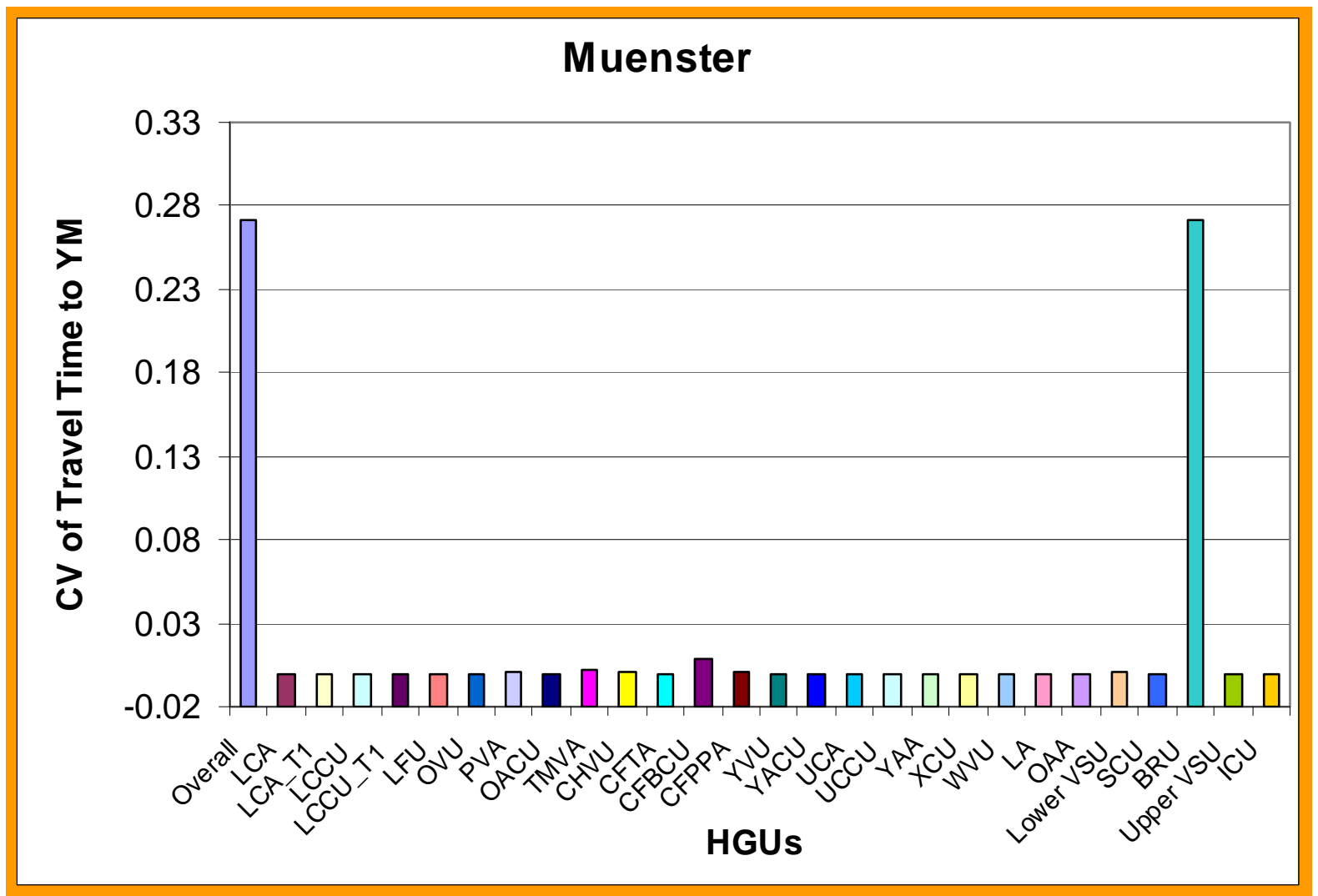

Figure B18. Coefficient of variation (CV) of minimum travel time to the YM area from Muenster, in relation to the effective-porosity uncertainties of Hydrogeologic Units (HGUs) when only one HGU has randomly variable effective-porosity and the porosities for other HGUs are set to equal the mean values under prepumping conditions. 


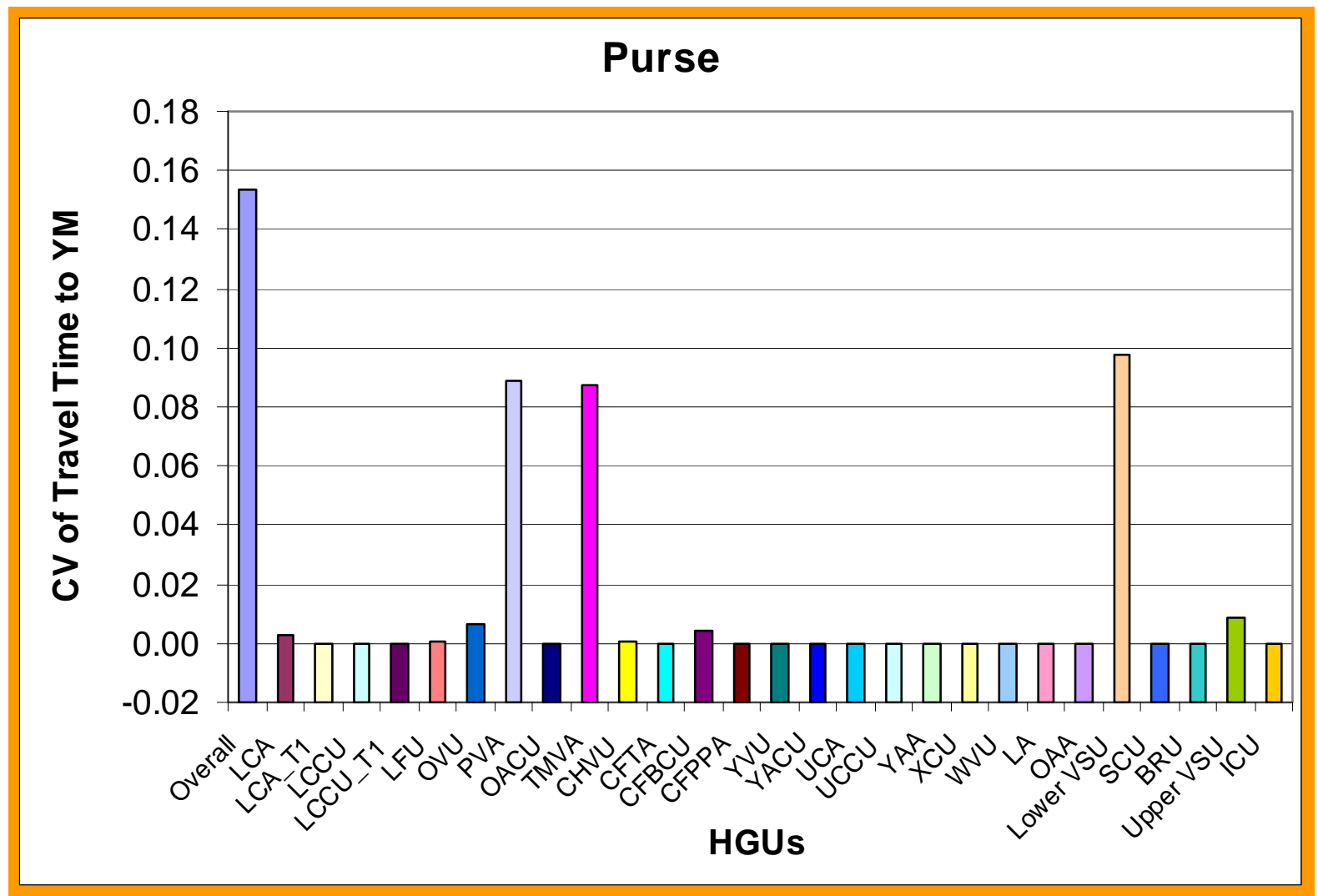

Figure B19. Coefficient of variation (CV) of minimum travel time to the YM area from Purse, in relation to the effective-porosity uncertainties of Hydrogeologic Units (HGUs) when only one HGU has randomly variable effective-porosity and the porosities for other HGUs are set to equal the mean values under 1998 pumping conditions. 


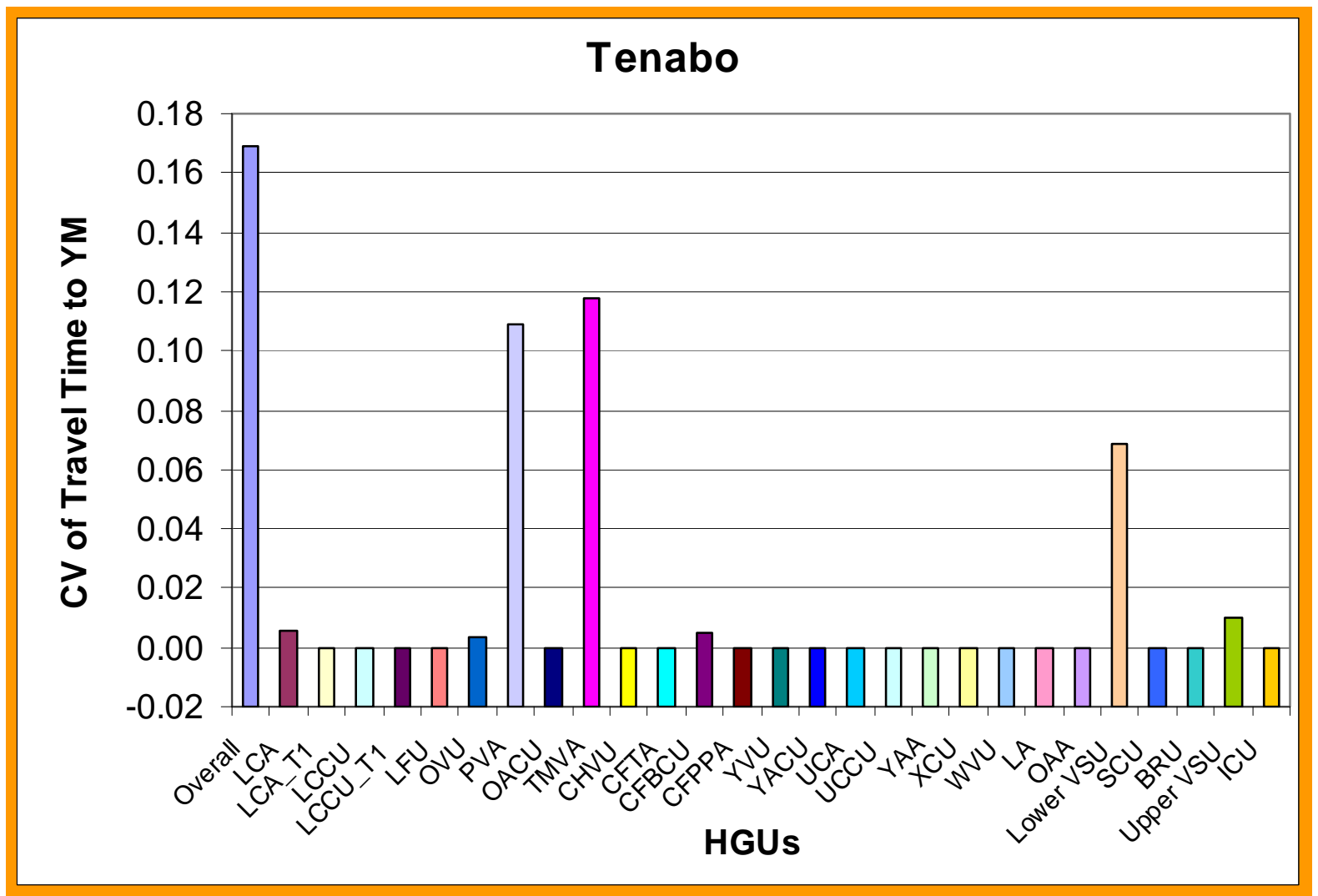

Figure B20. Coefficient of variation (CV) of minimum travel time to the YM area from Tenabo, in relation to the effective-porosity uncertainties of Hydrogeologic Units (HGUs) when only one HGU has randomly variable effective-porosity and the porosities for other HGUs are set to equal the mean values under 1998 pumping conditions. 


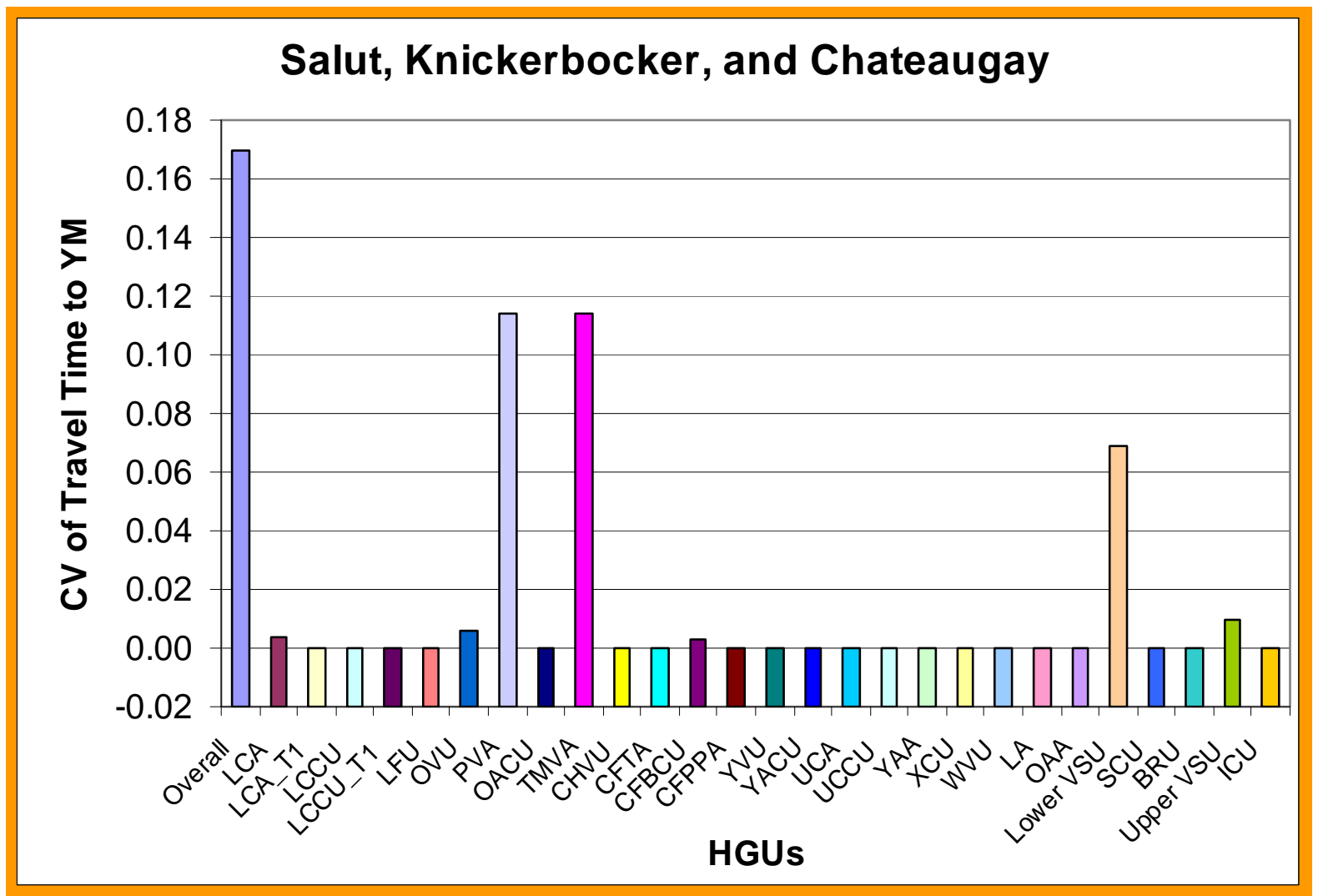

Figure B21. Coefficient of variation (CV) of minimum travel time to the YM area from Salut, Knickerbocker, and Chateaugay, in relation to the effective-porosity uncertainties of Hydrogeologic Units (HGUs) when only one HGU has randomly variable effective-porosity and the porosities for other HGUs are set to equal the mean values under 1998 pumping conditions. 


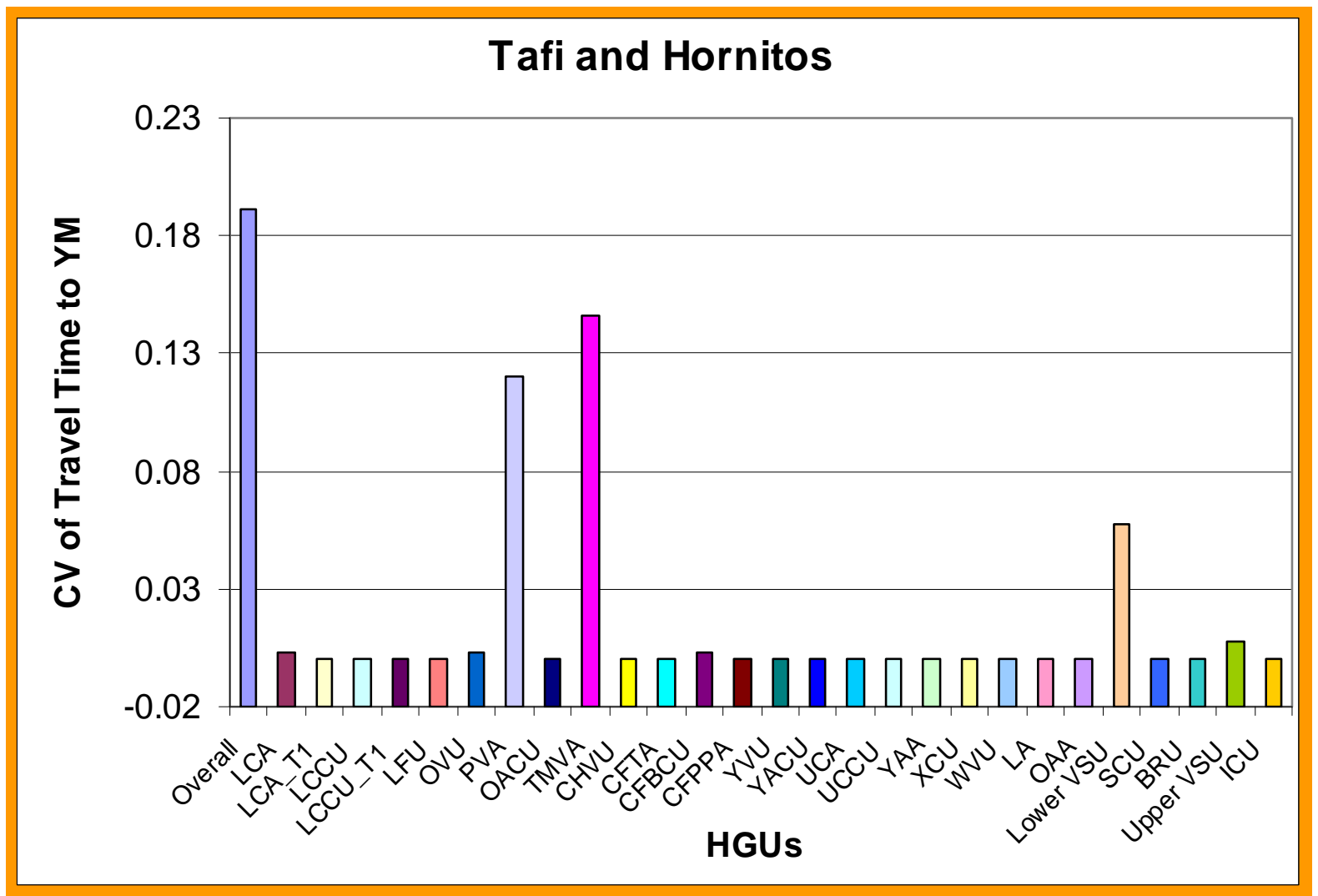

Figure B22. Coefficient of variation $(\mathrm{CV})$ of minimum travel time to the YM area from Tafi and Hornitos, in relation to the effective-porosity uncertainties of Hydrogeologic Units (HGUs) when only one HGU has randomly variable effective-porosity and the porosities for other HGUs are set to equal the mean values under 1998 pumping conditions. 


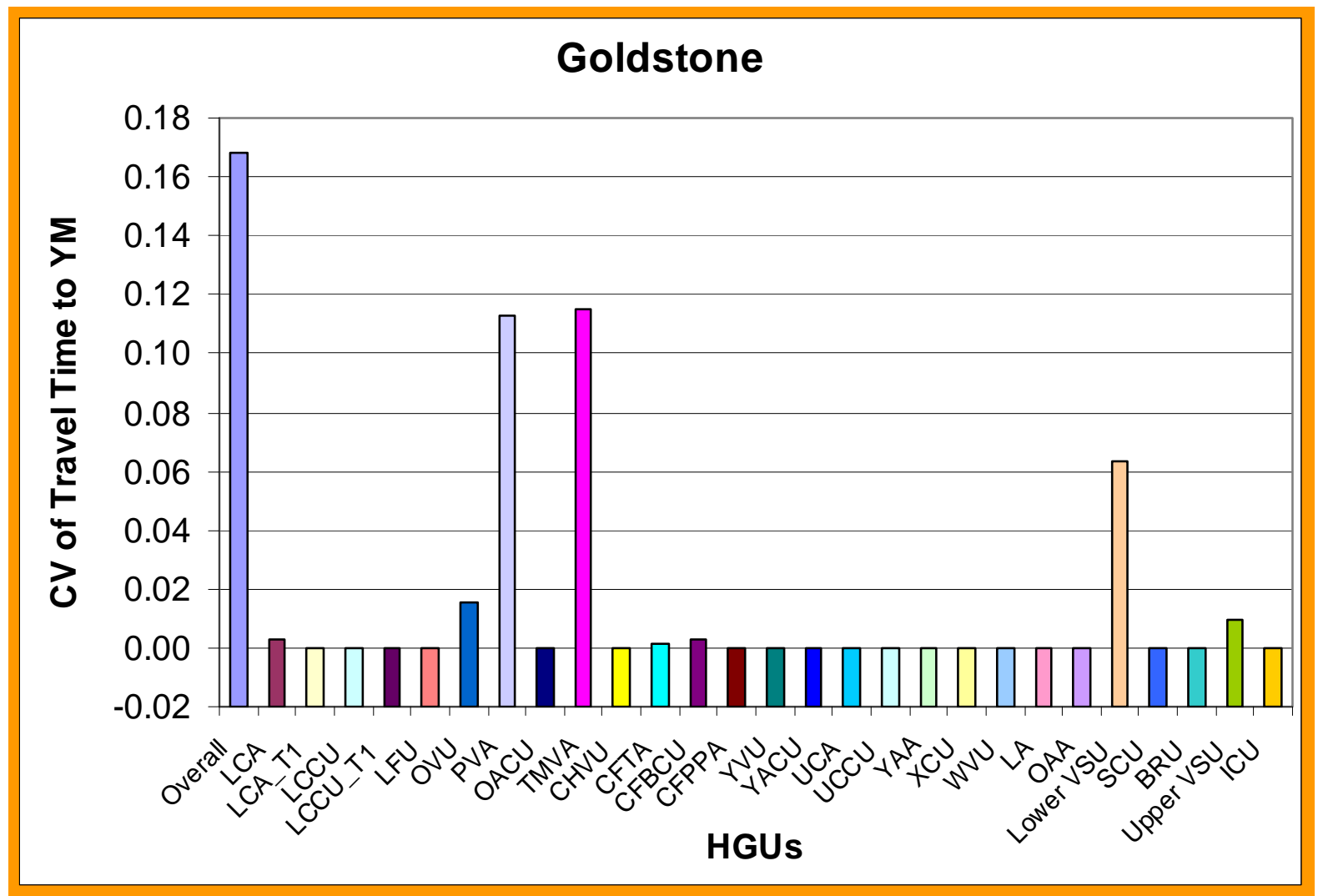

Figure B23. Coefficient of variation (CV) of minimum travel time to the YM area from Goldstone, in relation to the effective-porosity uncertainties of Hydrogeologic Units (HGUs) when only one HGU has randomly variable effective-porosity and the porosities for other HGUs are set to equal the mean values under 1998 pumping conditions. 


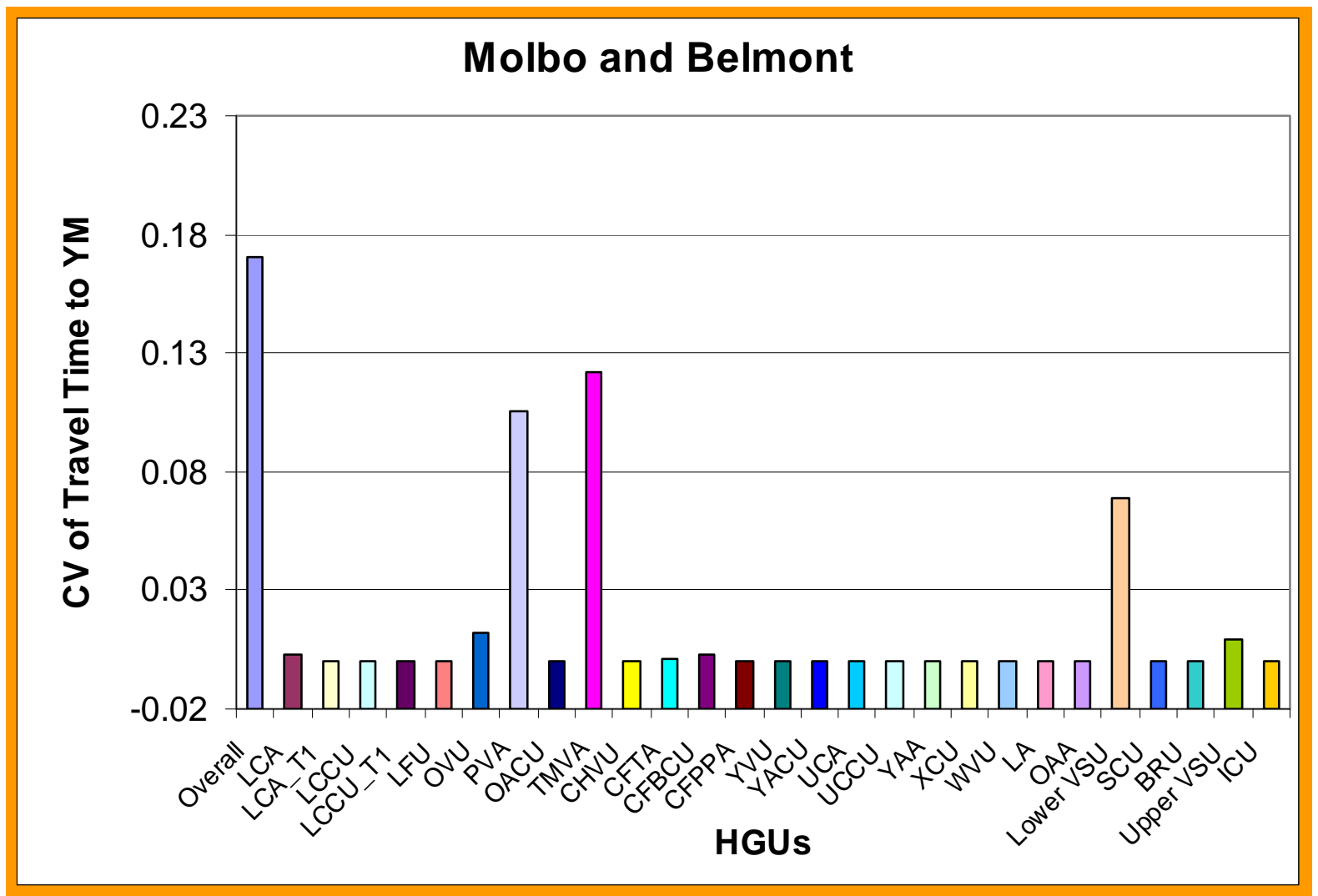

Figure B24. Coefficient of variation $(\mathrm{CV})$ of minimum travel time to the YM area from Molbo and Belmont, in relation to the effective-porosity uncertainties of Hydrogeologic Units (HGUs) when only one HGU has randomly variable effective-porosity and the porosities for other HGUs are set to equal the mean values under 1998 pumping conditions. 


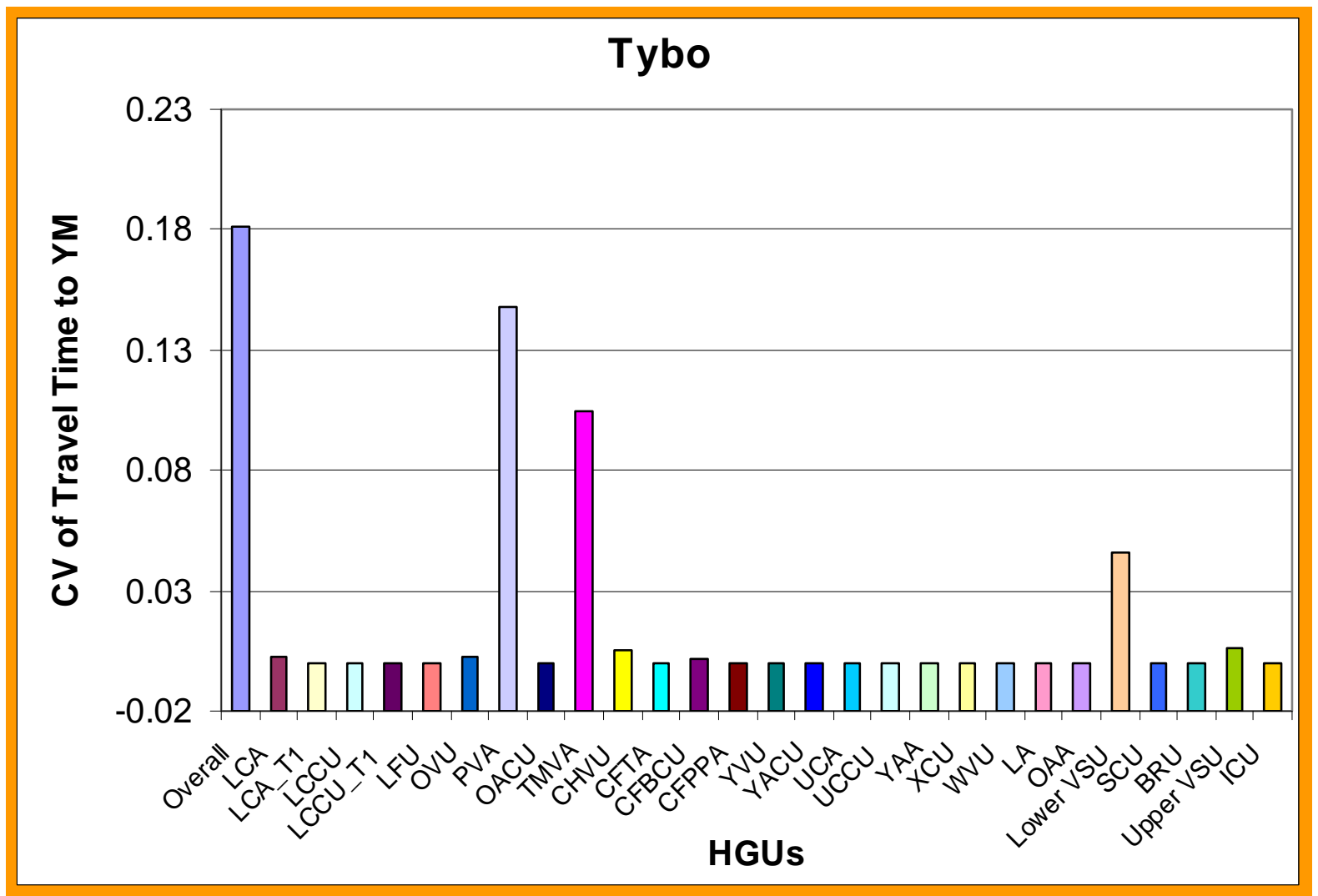

Figure B25. Coefficient of variation $(\mathrm{CV})$ of minimum travel time to the YM area from Tybo, in relation to the effective-porosity uncertainties of Hydrogeologic Units (HGUs) when only one HGU has randomly variable effective-porosity and the porosities for other HGUs are set to equal the mean values under 1998 pumping conditions. 


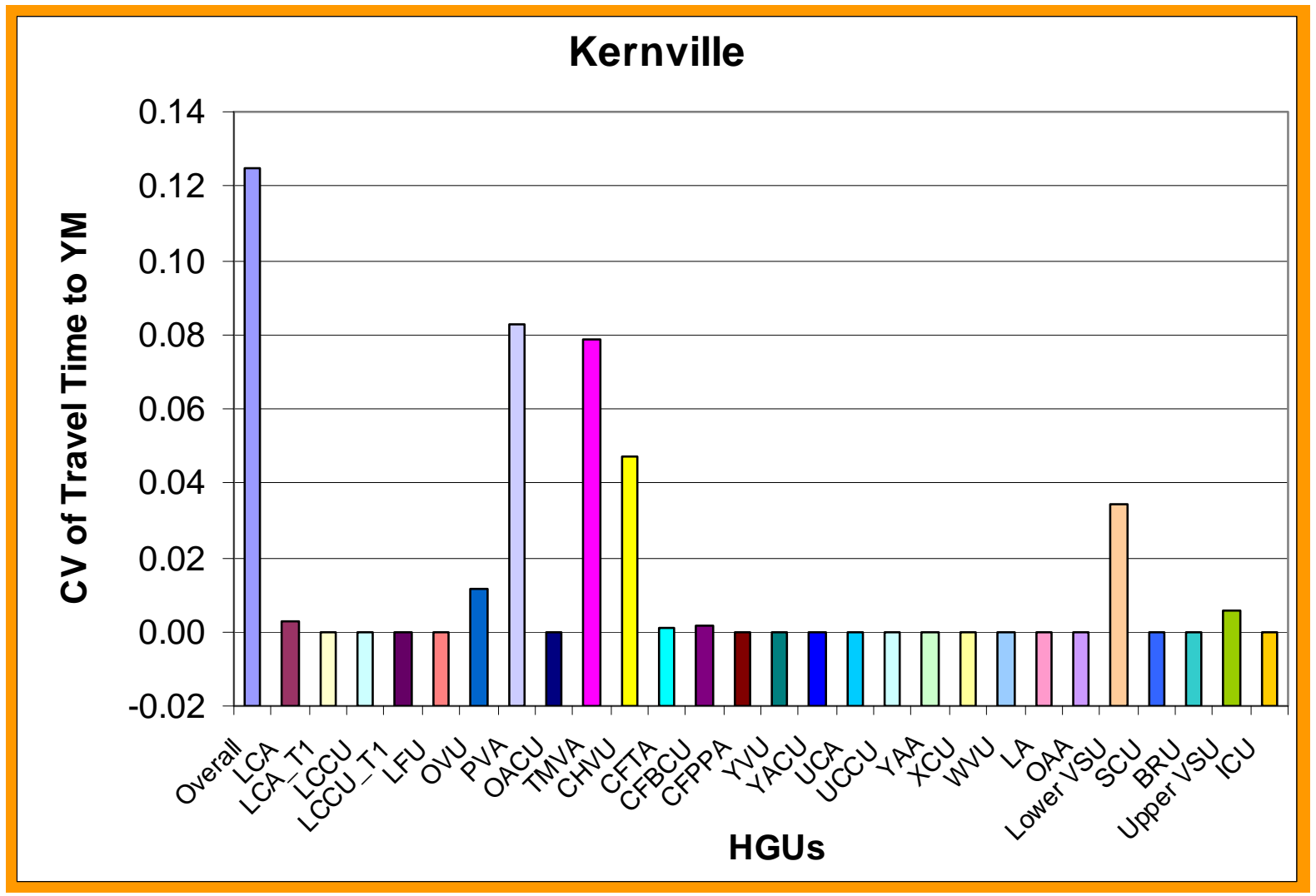

Figure B26. Coefficient of variation (CV) of minimum travel time to the YM area from Kernville, in relation to the effective-porosity uncertainties of Hydrogeologic Units (HGUs) when only one HGU has randomly variable effective-porosity and the porosities for other HGUs are set to equal the mean values under 1998 pumping conditions. 


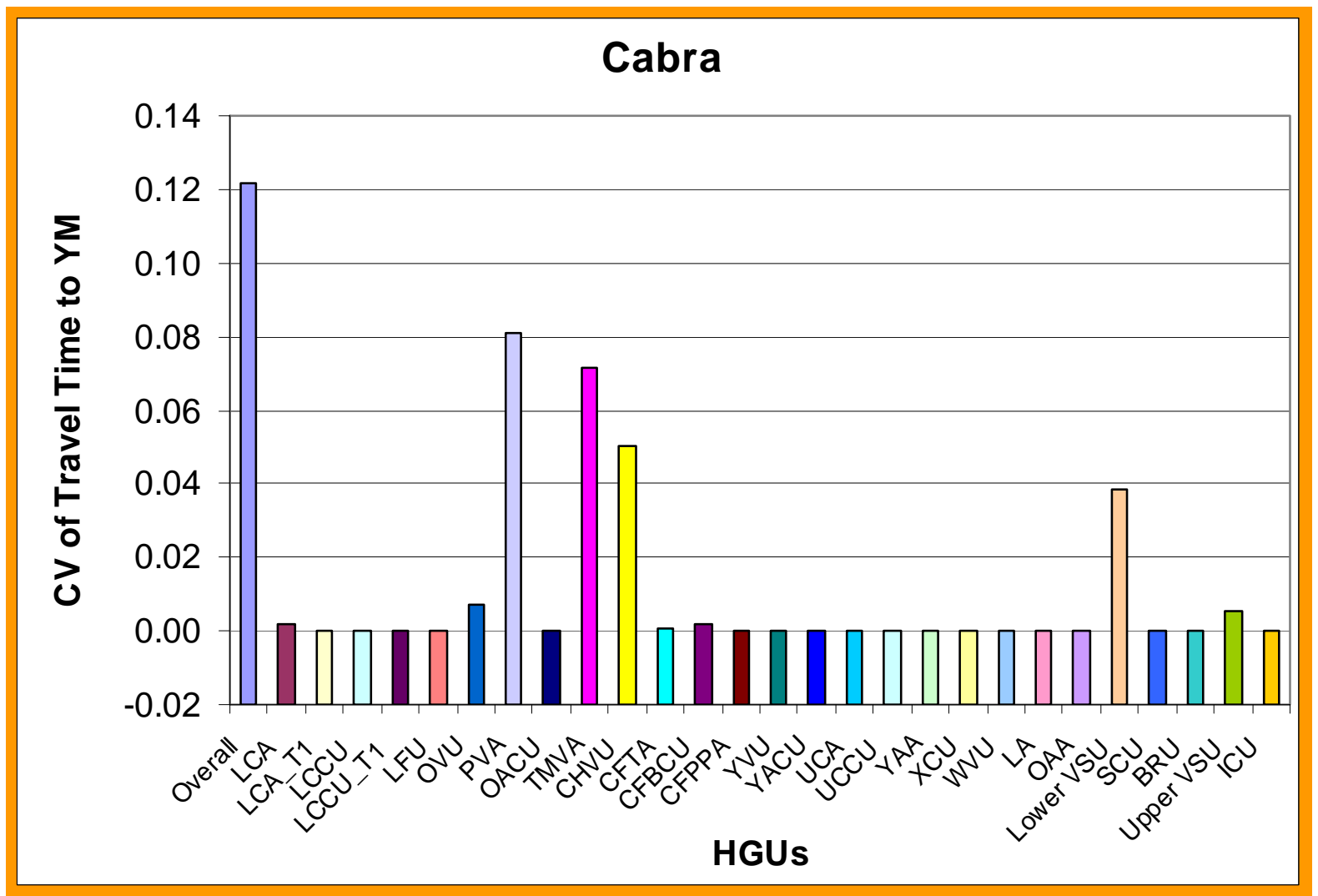

Figure B27. Coefficient of variation $(\mathrm{CV})$ of minimum travel time to the YM area from Cabra, in relation to the effective-porosity uncertainties of Hydrogeologic Units (HGUs) when only one HGU has randomly variable effective-porosity and the porosities for other HGUs are set to equal the mean values under 1998 pumping conditions. 


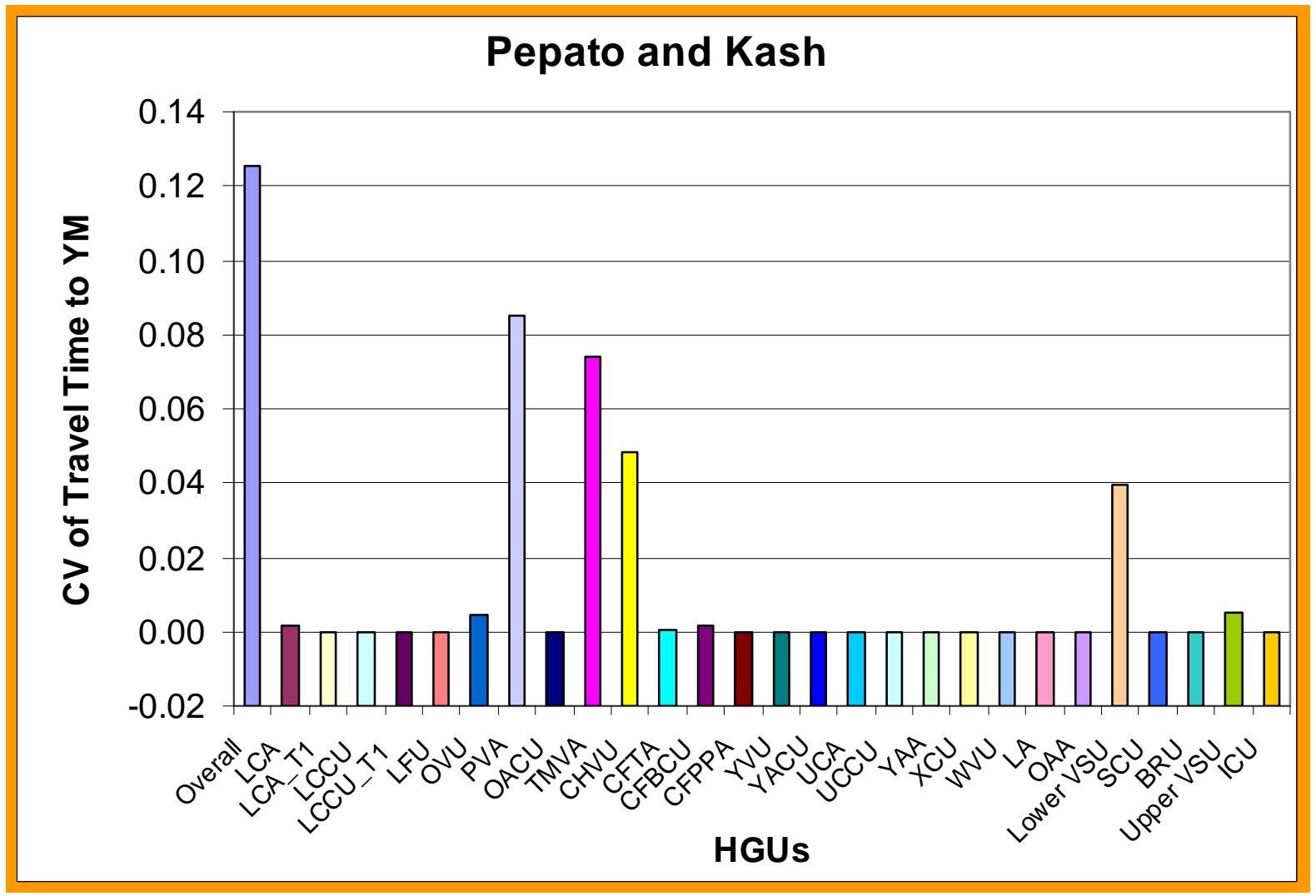

Figure B28. Coefficient of variation (CV) of minimum travel time to the YM area from Pepato and Kash, in relation to the effective-porosity uncertainties of Hydrogeologic Units (HGUs) when only one HGU has randomly variable effective-porosity and the porosities for other HGUs are set to equal the mean values under 1998 pumping conditions. 


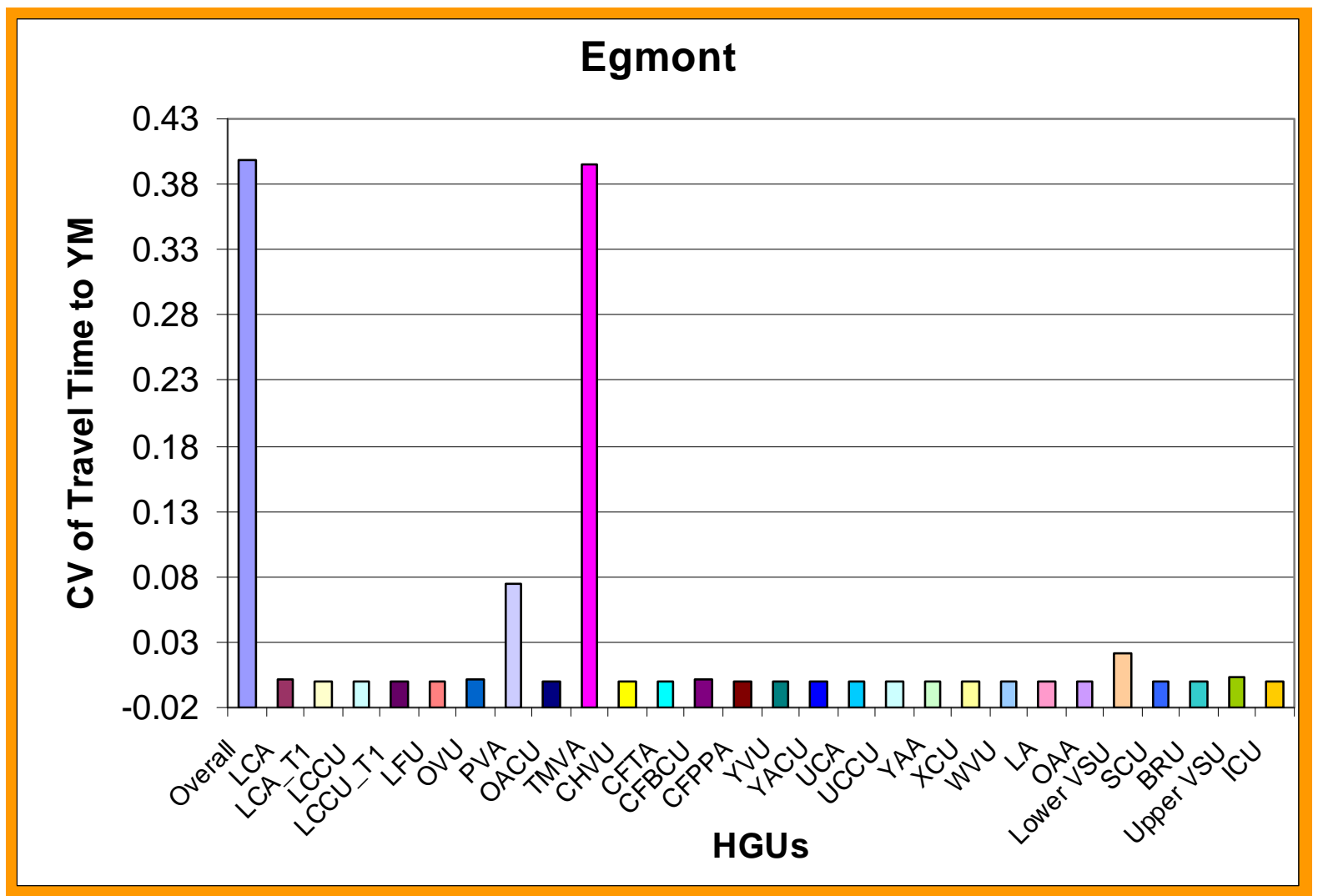

Figure B29. Coefficient of variation (CV) of minimum travel time to the YM area from Egmont, in relation to the effective-porosity uncertainties of Hydrogeologic Units (HGUs) when only one HGU has randomly variable effective-porosity and the porosities for other HGUs are set to equal the mean values under 1998 pumping conditions. 


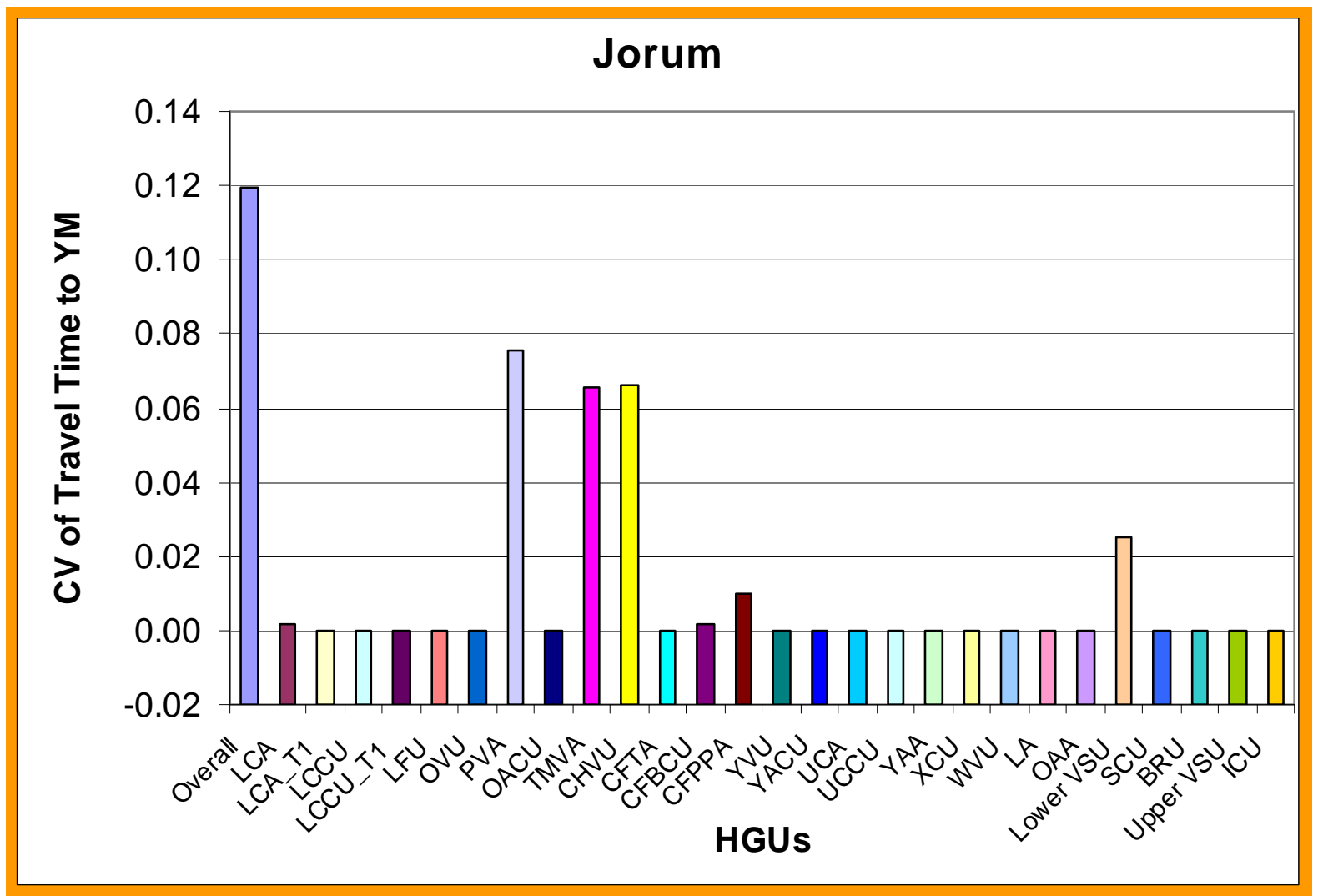

Figure B30. Coefficient of variation $(\mathrm{CV})$ of minimum travel time to the YM area from Jorum, in relation to the effective-porosity uncertainties of Hydrogeologic Units (HGUs) when only one HGU has randomly variable effective-porosity and the porosities for other HGUs are set to equal the mean values under 1998 pumping conditions. 


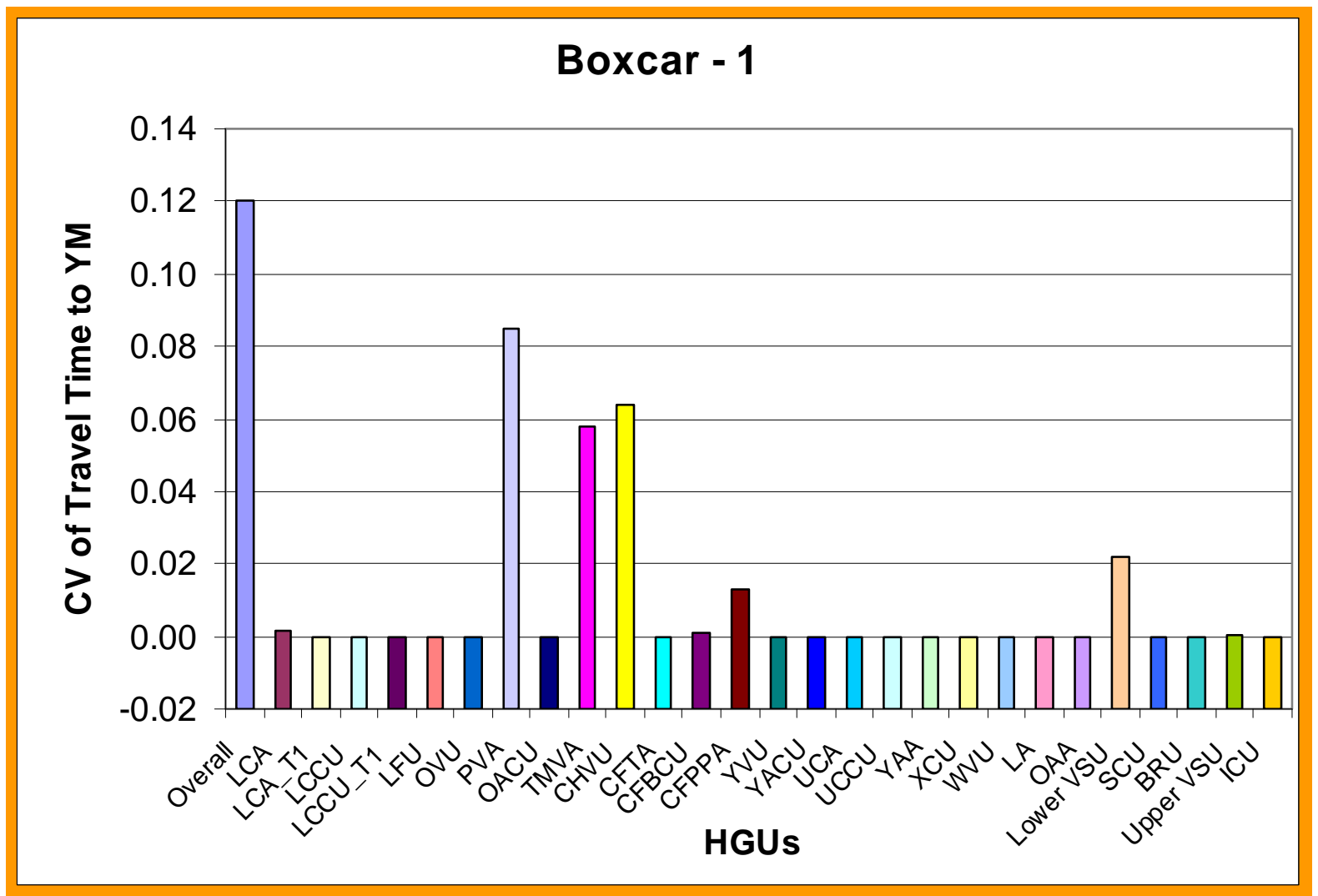

Figure B31. Coefficient of variation $(\mathrm{CV})$ of minimum travel time to the YM area from Boxcar - 1, in relation to the effective-porosity uncertainties of Hydrogeologic Units (HGUs) when only one HGU has randomly variable effective-porosity and the porosities for other HGUs are set to equal the mean values under 1998 pumping conditions. 


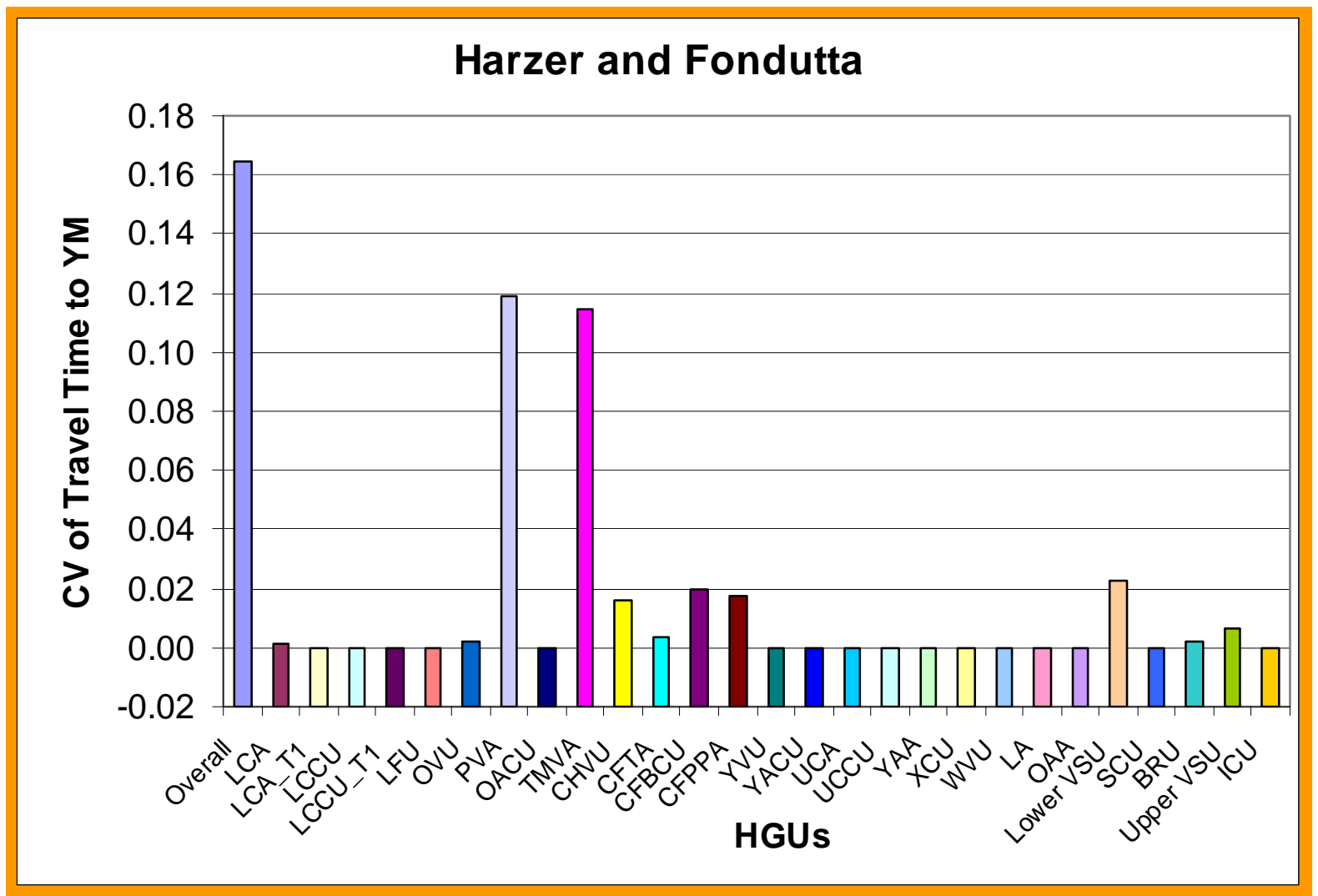

Figure B32. Coefficient of variation $(\mathrm{CV})$ of minimum travel time to the YM area from Harzer and Fondutta, in relation to the effective-porosity uncertainties of Hydrogeologic Units (HGUs) when only one HGU has randomly variable effective-porosity and the porosities for other HGUs are set to equal the mean values under 1998 pumping conditions. 


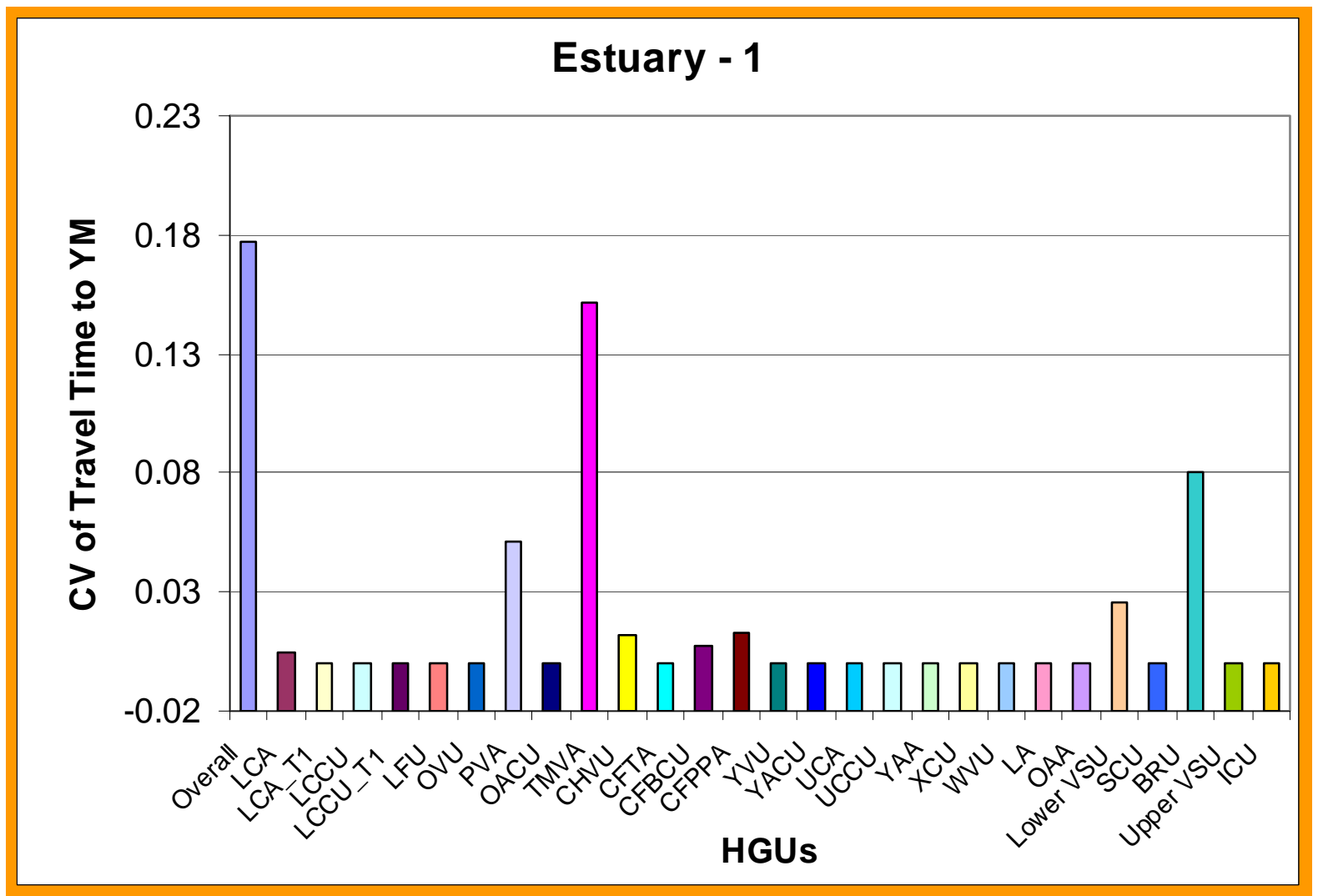

Figure B33. Coefficient of variation $(\mathrm{CV})$ of minimum travel time to the YM area from Estuary - 1, in relation to the effective-porosity uncertainties of Hydrogeologic Units (HGUs) when only one HGU has randomly variable effective-porosity and the porosities for other HGUs are set to equal the mean values under 1998 pumping conditions. 


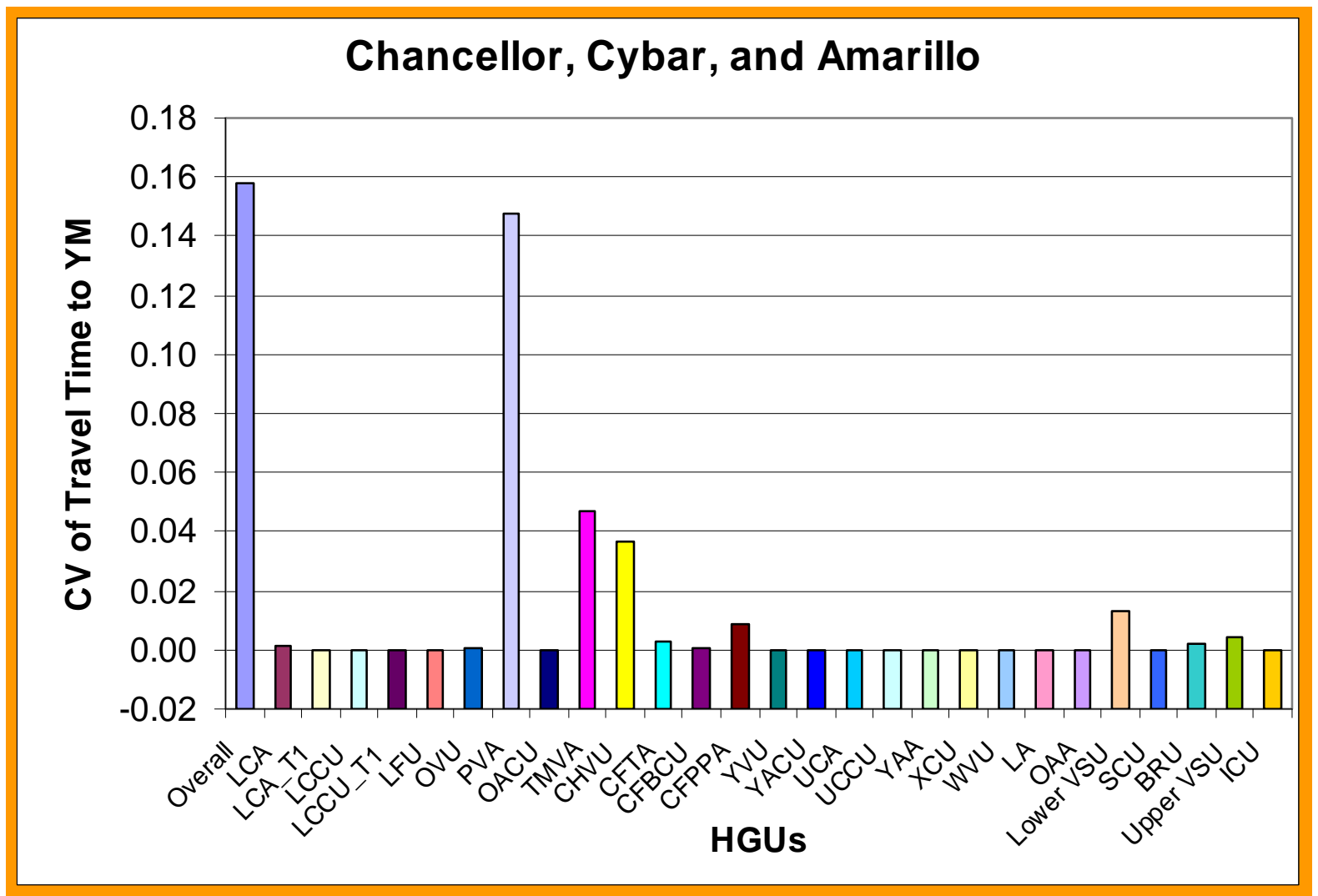

Figure B34. Coefficient of variation $(\mathrm{CV})$ of minimum travel time to the YM area from Chancellor, Cybar, and Amarillo, in relation to the effective-porosity uncertainties of Hydrogeologic Units (HGUs) when only one HGU has randomly variable effective-porosity and the porosities for other HGUs are set to equal the mean values under 1998 pumping conditions. 


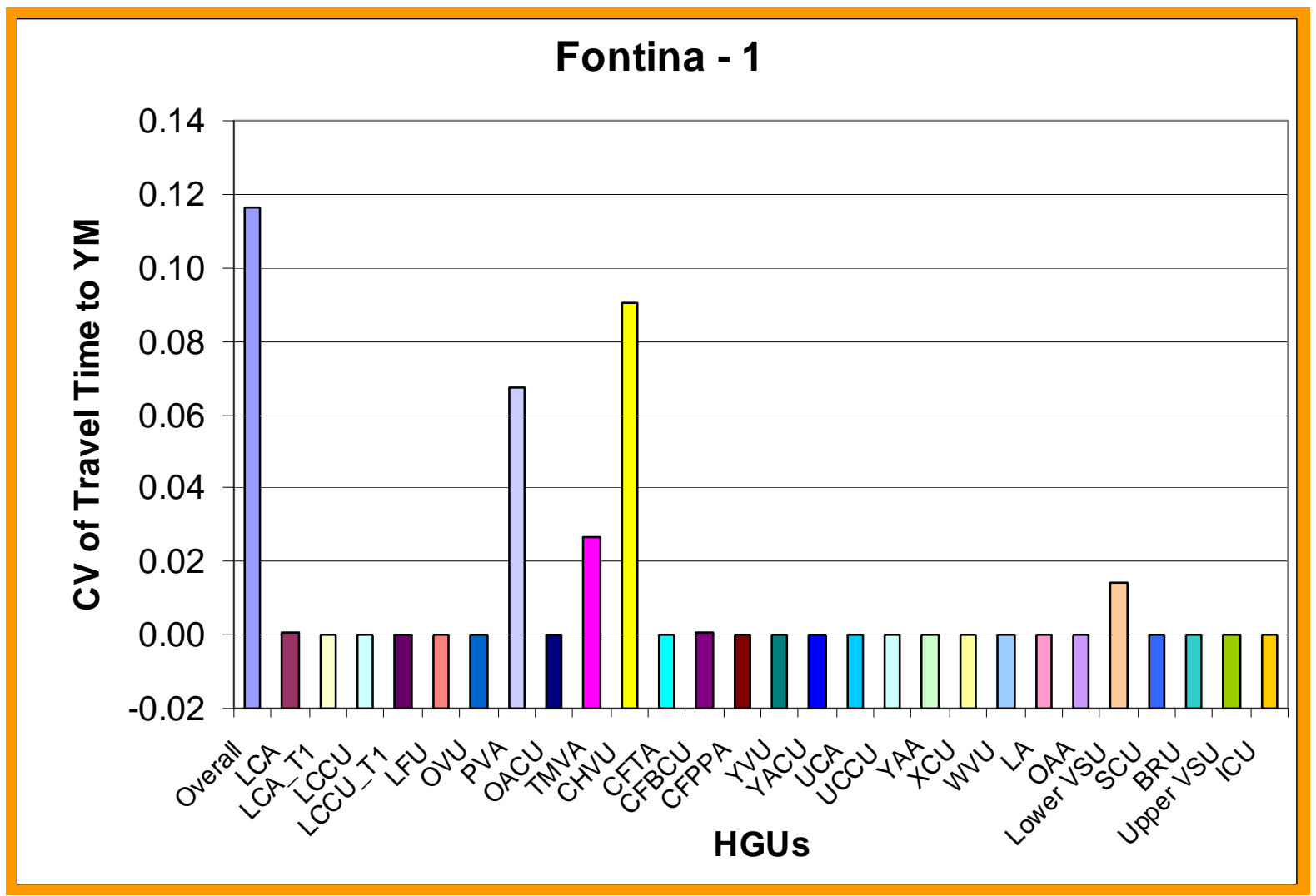

Figure B35. Coefficient of variation $(\mathrm{CV})$ of minimum travel time to the YM area from Fontina - 1, in relation to the effective-porosity uncertainties of Hydrogeologic Units (HGUs) when only one HGU has randomly variable effective-porosity and the porosities for other HGUs are set to equal the mean values under 1998 pumping conditions. 


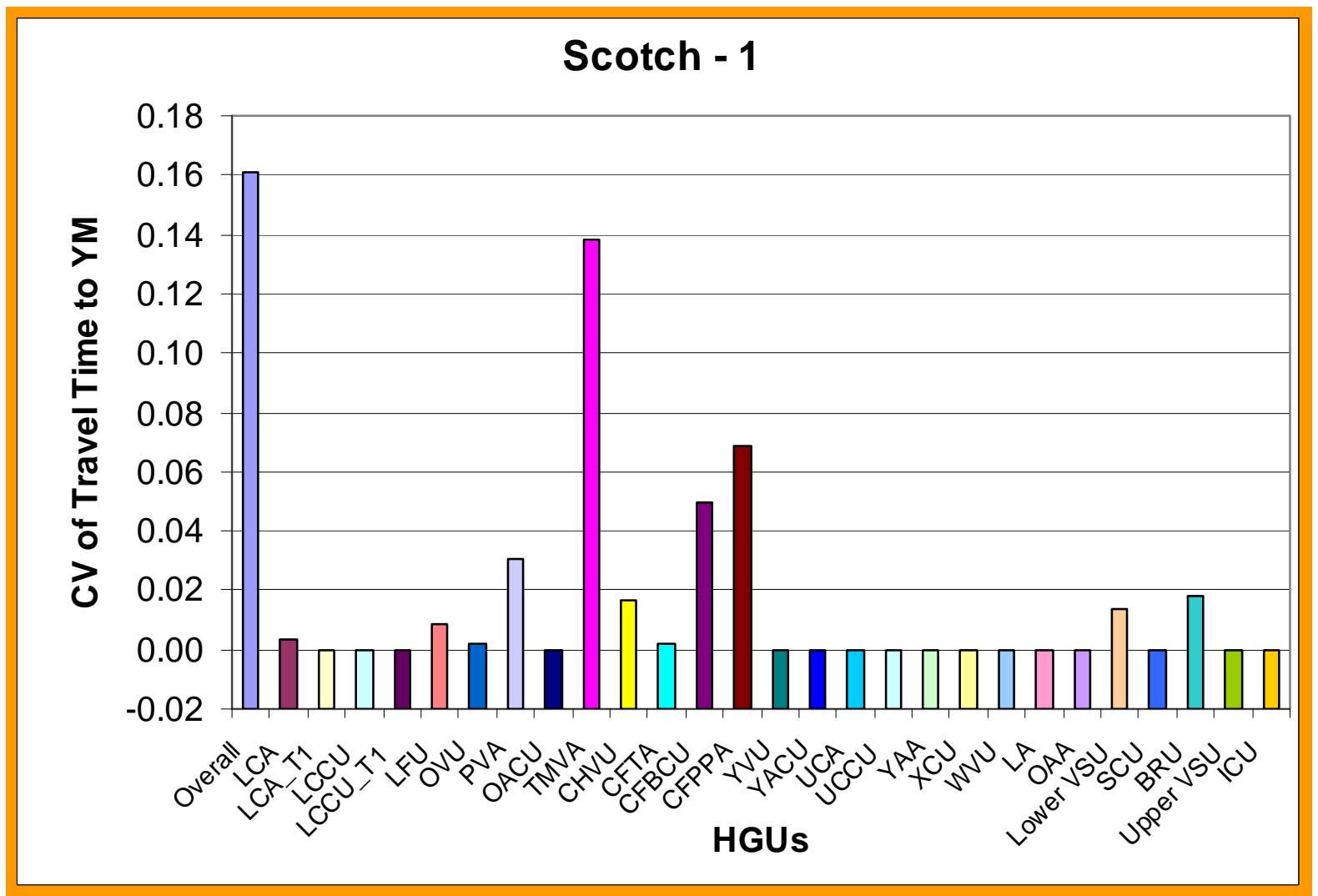

Figure B36. Coefficient of variation (CV) of minimum travel time to the YM area from Scotch -1 , in relation to the effective-porosity uncertainties of Hydrogeologic Units (HGUs) when only one HGU has randomly variable effective-porosity and the porosities for other HGUs are set to equal the mean values under 1998 pumping conditions. 


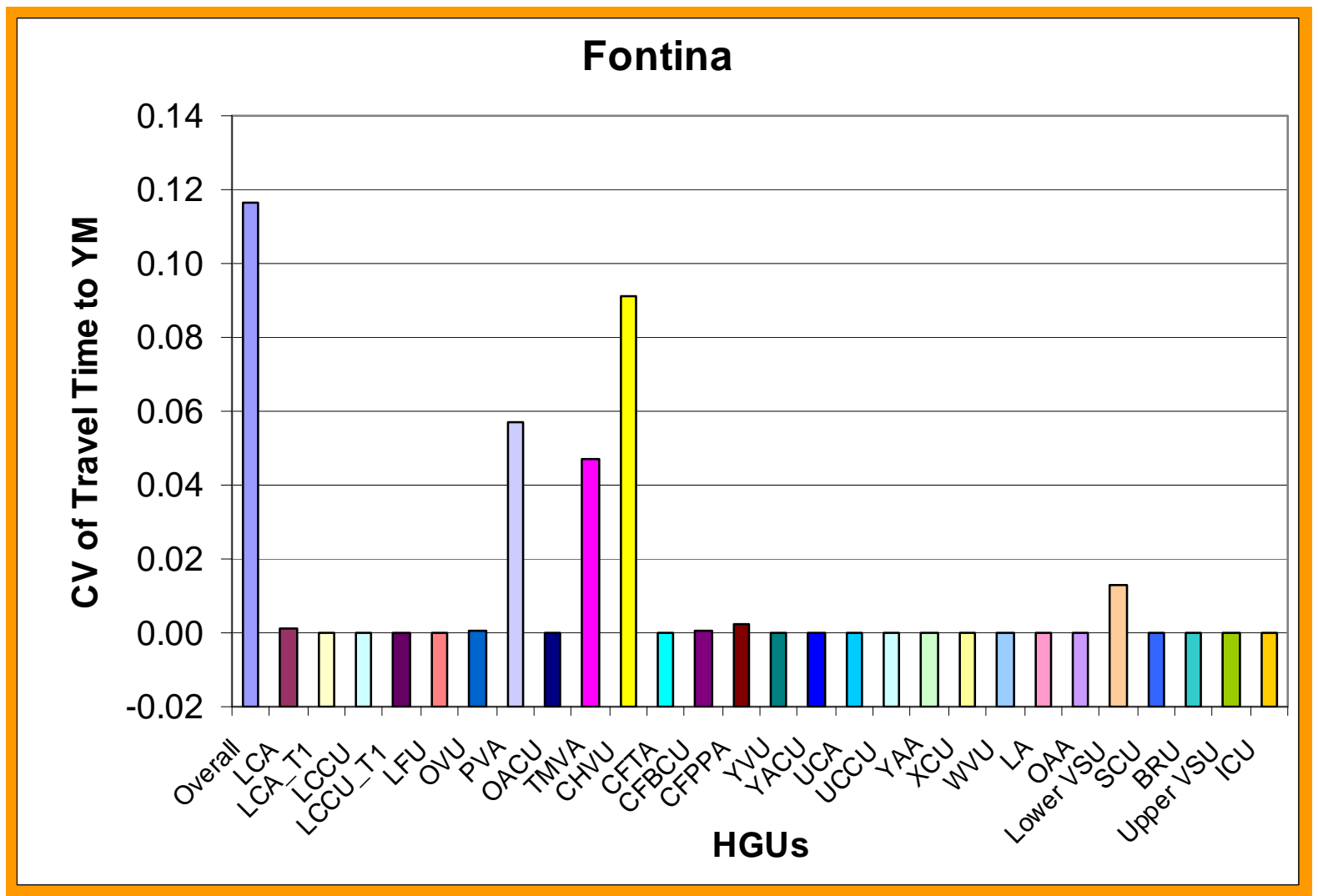

Figure B37. Coefficient of variation $(\mathrm{CV})$ of minimum travel time to the YM area from Fontina, in relation to the effective-porosity uncertainties of Hydrogeologic Units (HGUs) when only one HGU has randomly variable effective-porosity and the porosities for other HGUs are set to equal the mean values under 1998 pumping conditions. 


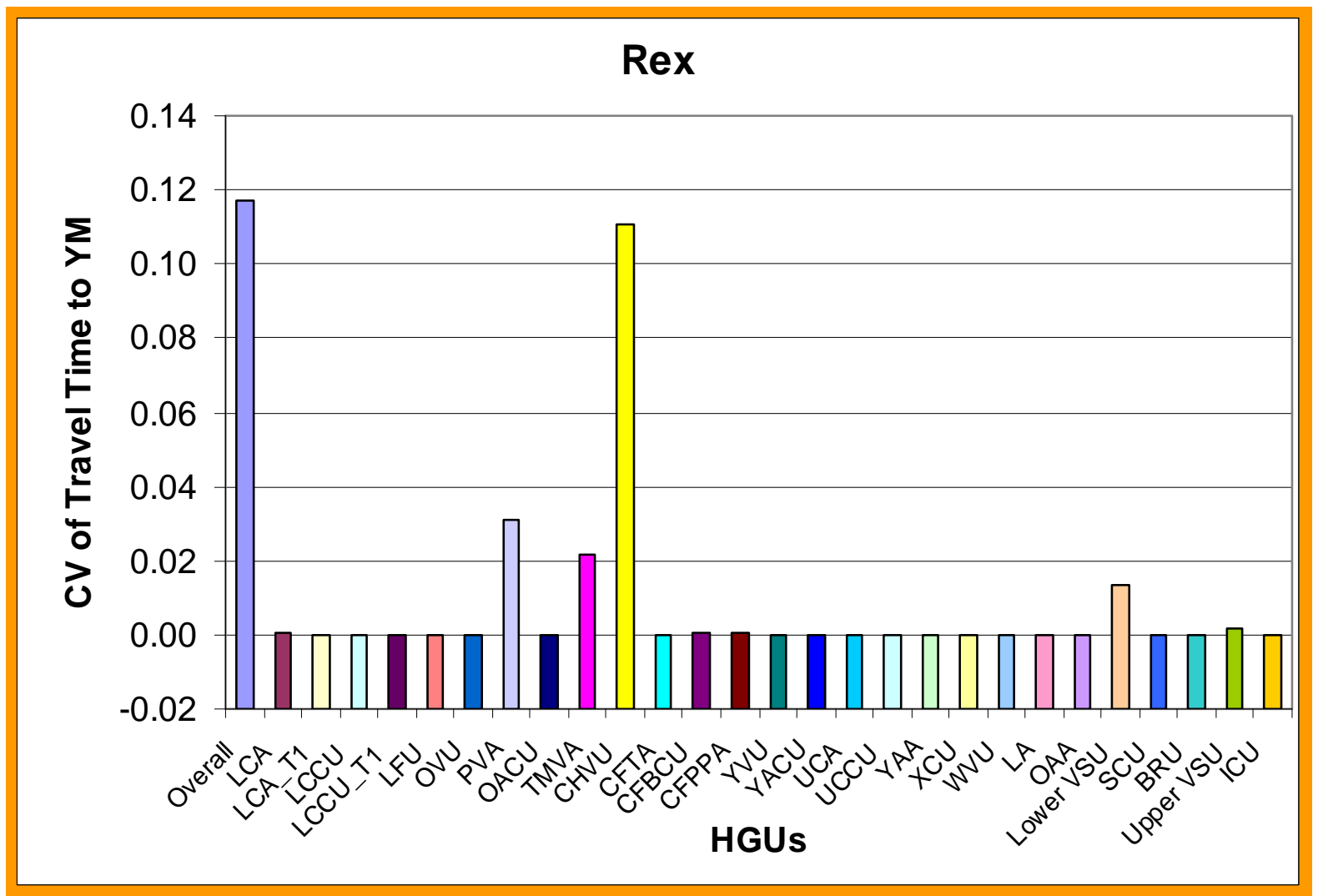

Figure B38. Coefficient of variation (CV) of minimum travel time to the YM area from Rex, in relation to the effective-porosity uncertainties of Hydrogeologic Units (HGUs) when only one HGU has randomly variable effective-porosity and the porosities for other HGUs are set to equal the mean values under 1998 pumping conditions. 


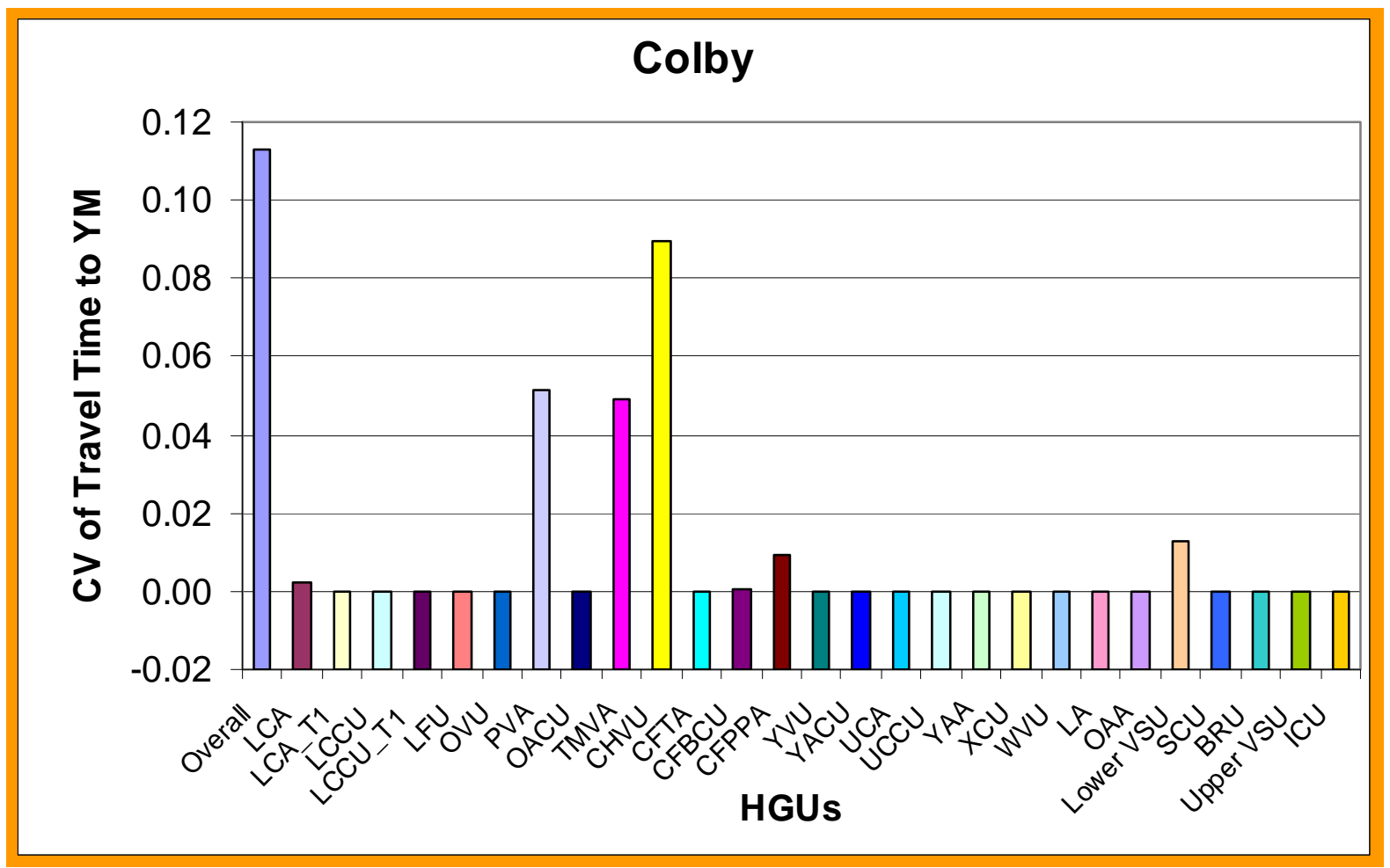

Figure B39. Coefficient of variation (CV) of minimum travel time to the YM area from Colby, in relation to the effective-porosity uncertainties of Hydrogeologic Units (HGUs) when only one HGU has randomly variable effective-porosity and the porosities for other HGUs are set to equal the mean values under 1998 pumping conditions. 


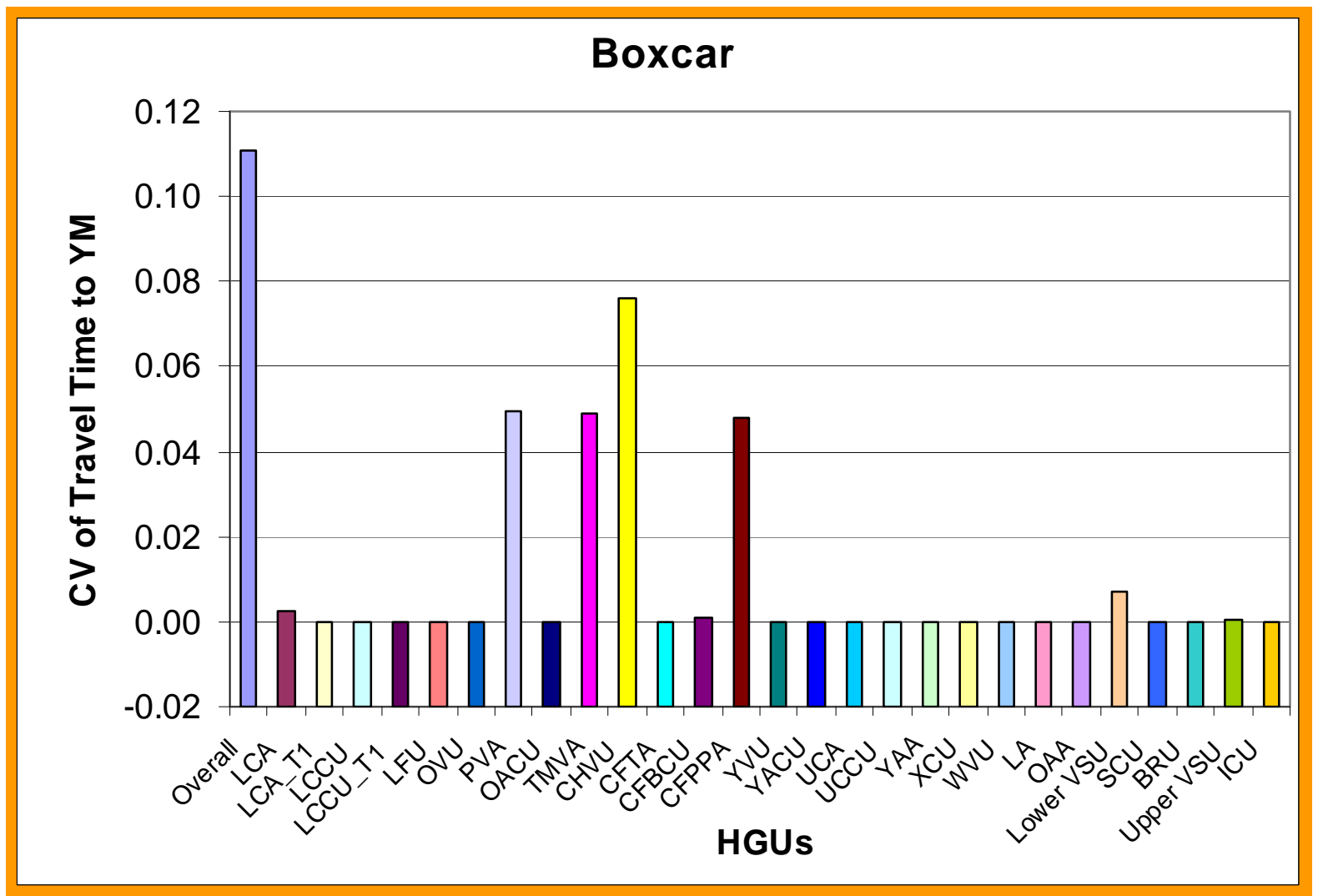

Figure B40. Coefficient of variation (CV) of minimum travel time to the YM area from Boxcar, in relation to the effective-porosity uncertainties of Hydrogeologic Units (HGUs) when only one HGU has randomly variable effective-porosity and the porosities for other HGUs are set to equal the mean values under 1998 pumping conditions. 


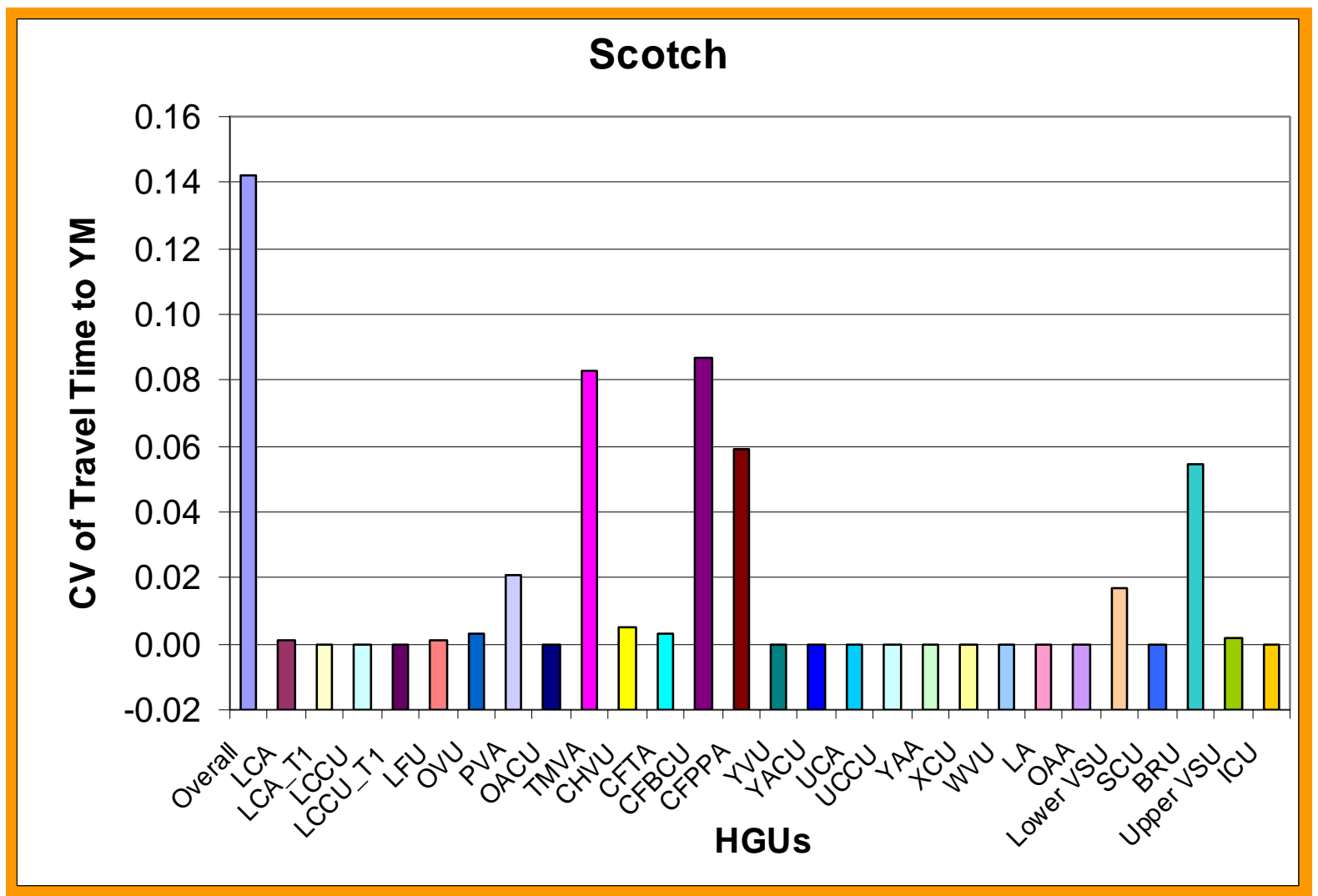

Figure B41. Coefficient of variation (CV) of minimum travel time to the YM area from Scotch, in relation to the effective-porosity uncertainties of Hydrogeologic Units (HGUs) when only one HGU has randomly variable effective-porosity and the porosities for other HGUs are set to equal the mean values under 1998 pumping conditions. 


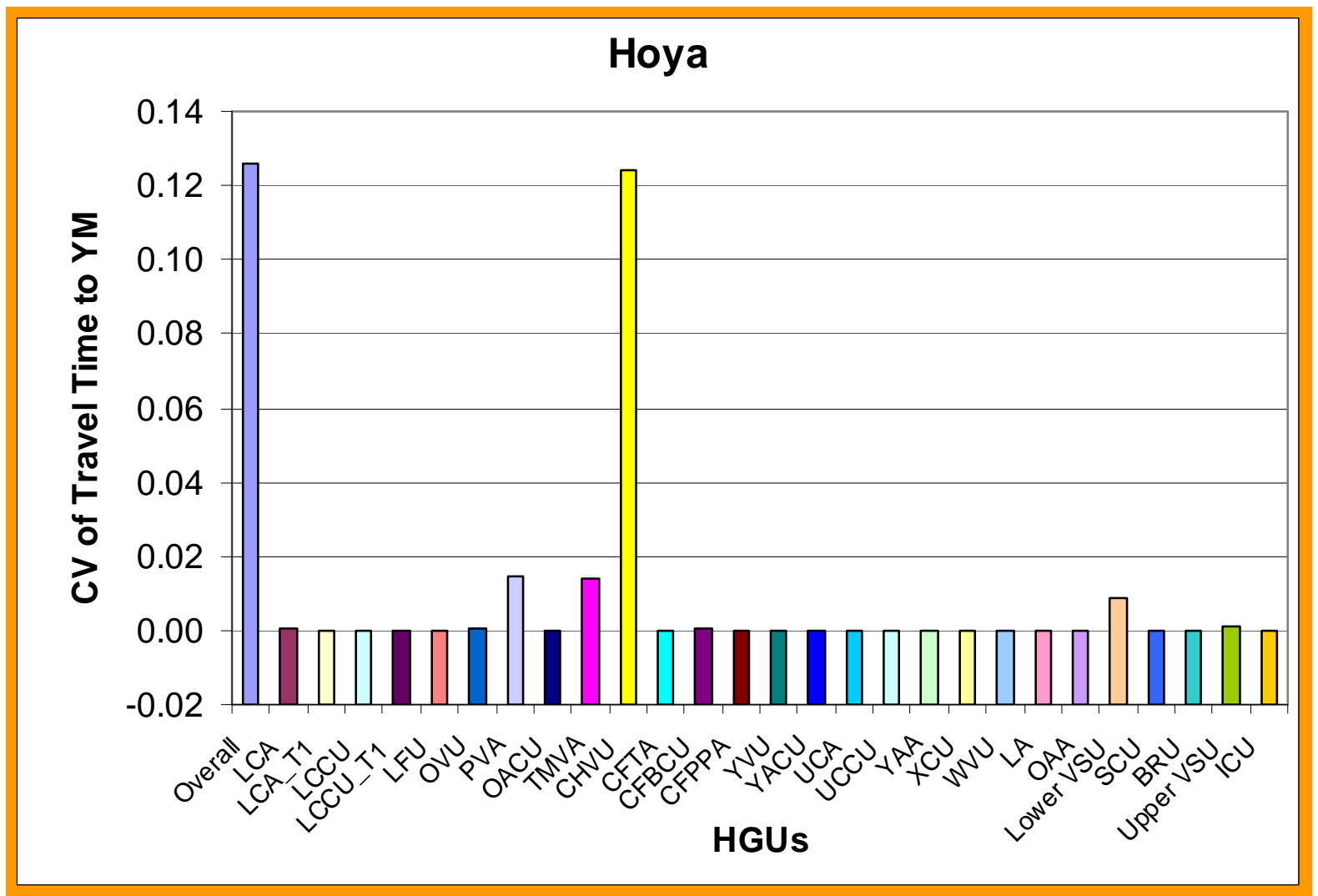

Figure B43. Coefficient of variation $(\mathrm{CV})$ of minimum travel time to the YM area from Hoya, in relation to the effective-porosity uncertainties of Hydrogeologic Units (HGUs) when only one HGU has randomly variable effective-porosity and the porosities for other HGUs are set to equal the mean values under 1998 pumping conditions. 


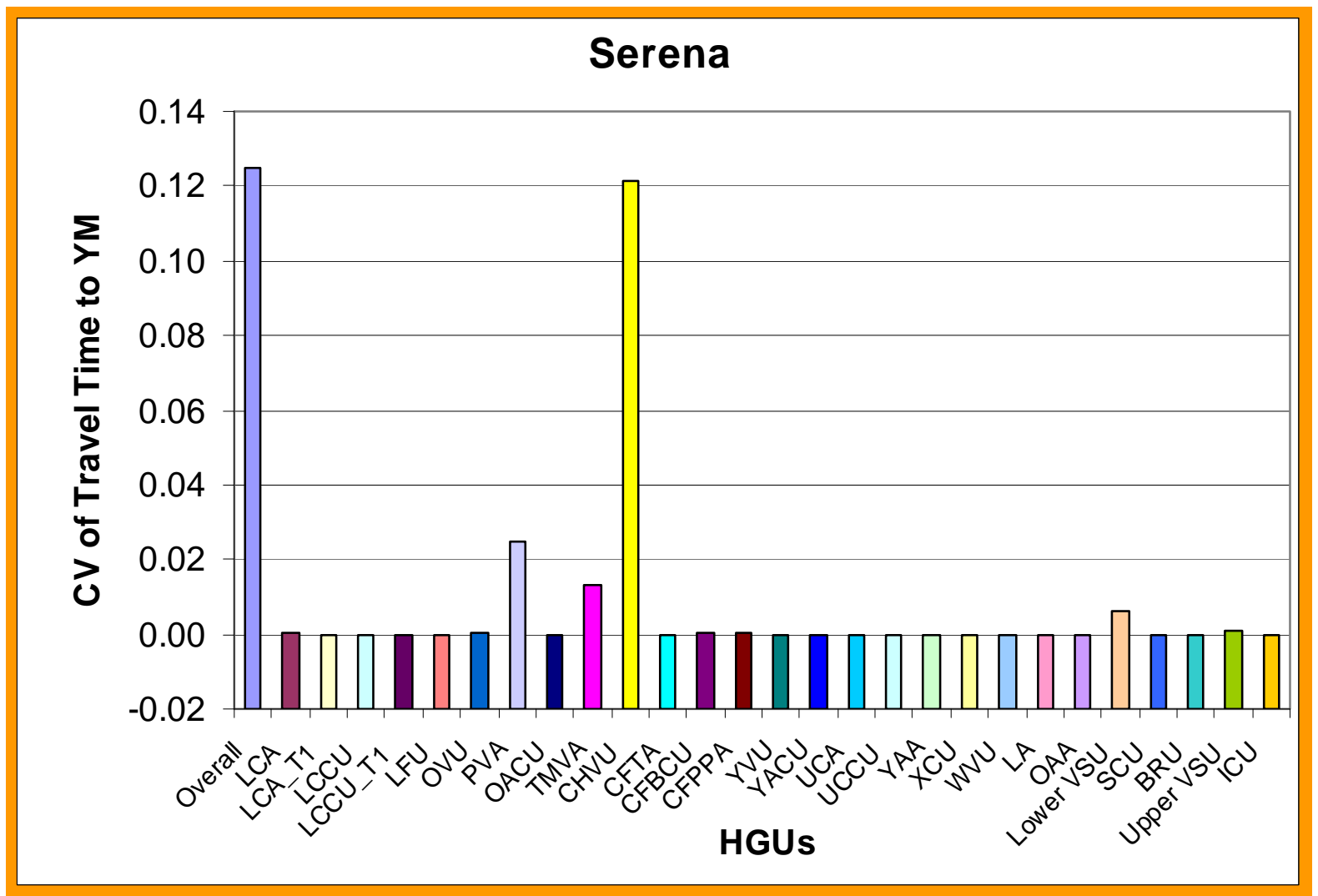

Figure B43. Coefficient of variation $(\mathrm{CV})$ of minimum travel time to the YM area from Serena, in relation to the effective-porosity uncertainties of Hydrogeologic Units (HGUs) when only one HGU has randomly variable effective-porosity and the porosities for other HGUs are set to equal the mean values under 1998 pumping conditions. 


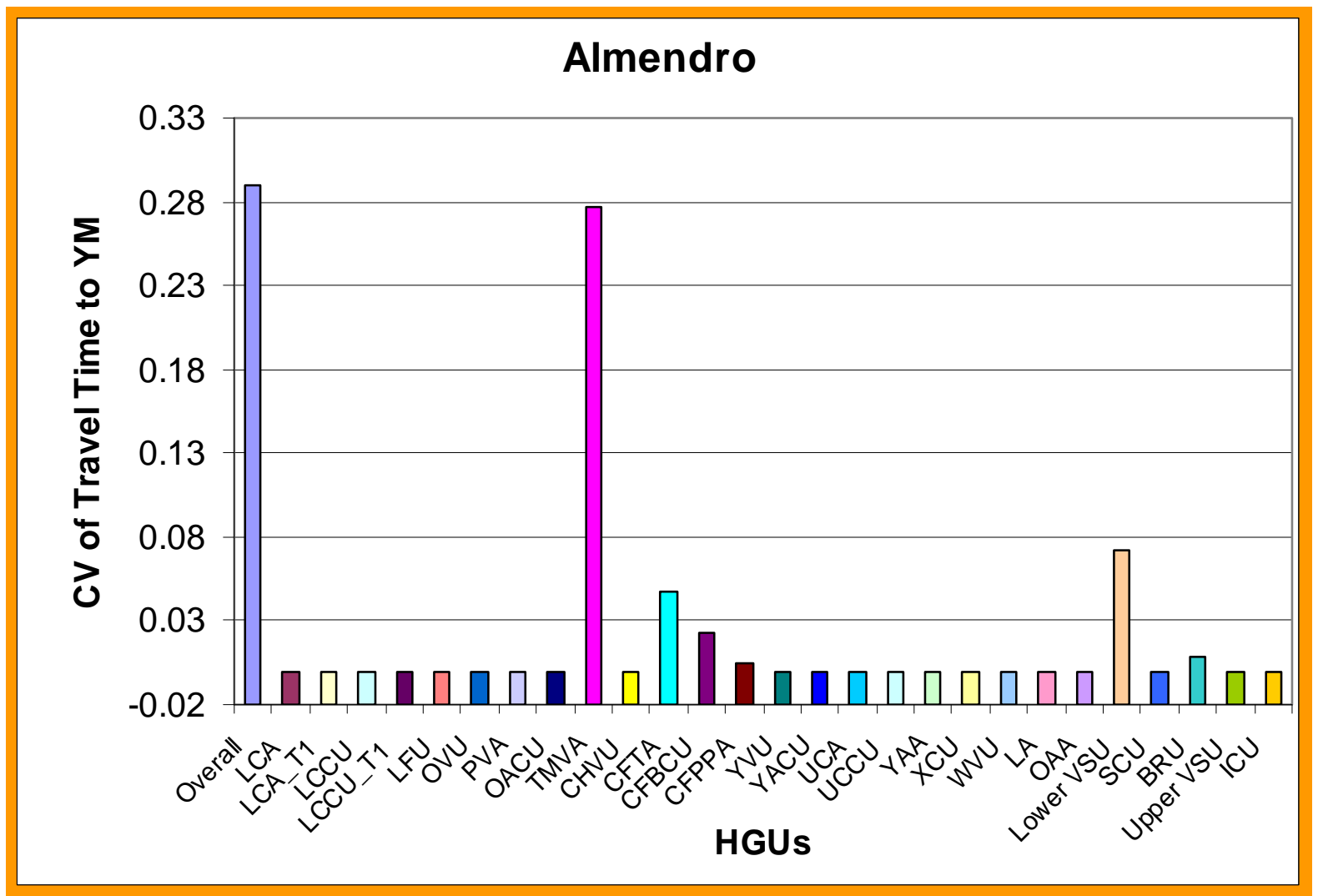

Figure B44. Coefficient of variation (CV) of minimum travel time to the YM area from Almendro, in relation to the effective-porosity uncertainties of Hydrogeologic Units (HGUs) when only one HGU has randomly variable effective-porosity and the porosities for other HGUs are set to equal the mean values under 1998 pumping conditions. 


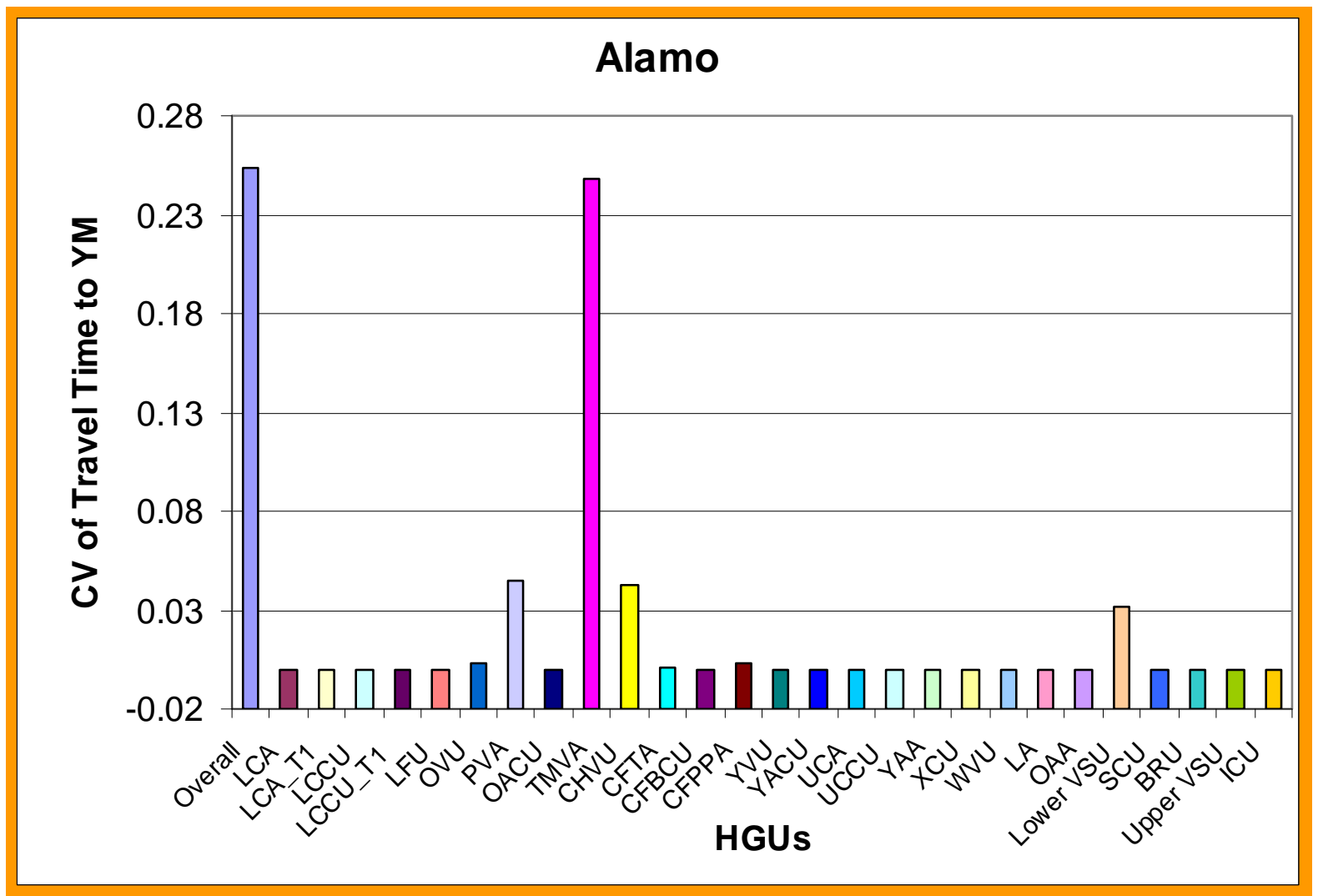

Figure B45. Coefficient of variation $(\mathrm{CV})$ of minimum travel time to the YM area from Alamo, in relation to the effective-porosity uncertainties of Hydrogeologic Units (HGUs) when only one HGU has randomly variable effective-porosity and the porosities for other HGUs are set to equal the mean values under 1998 pumping conditions. 


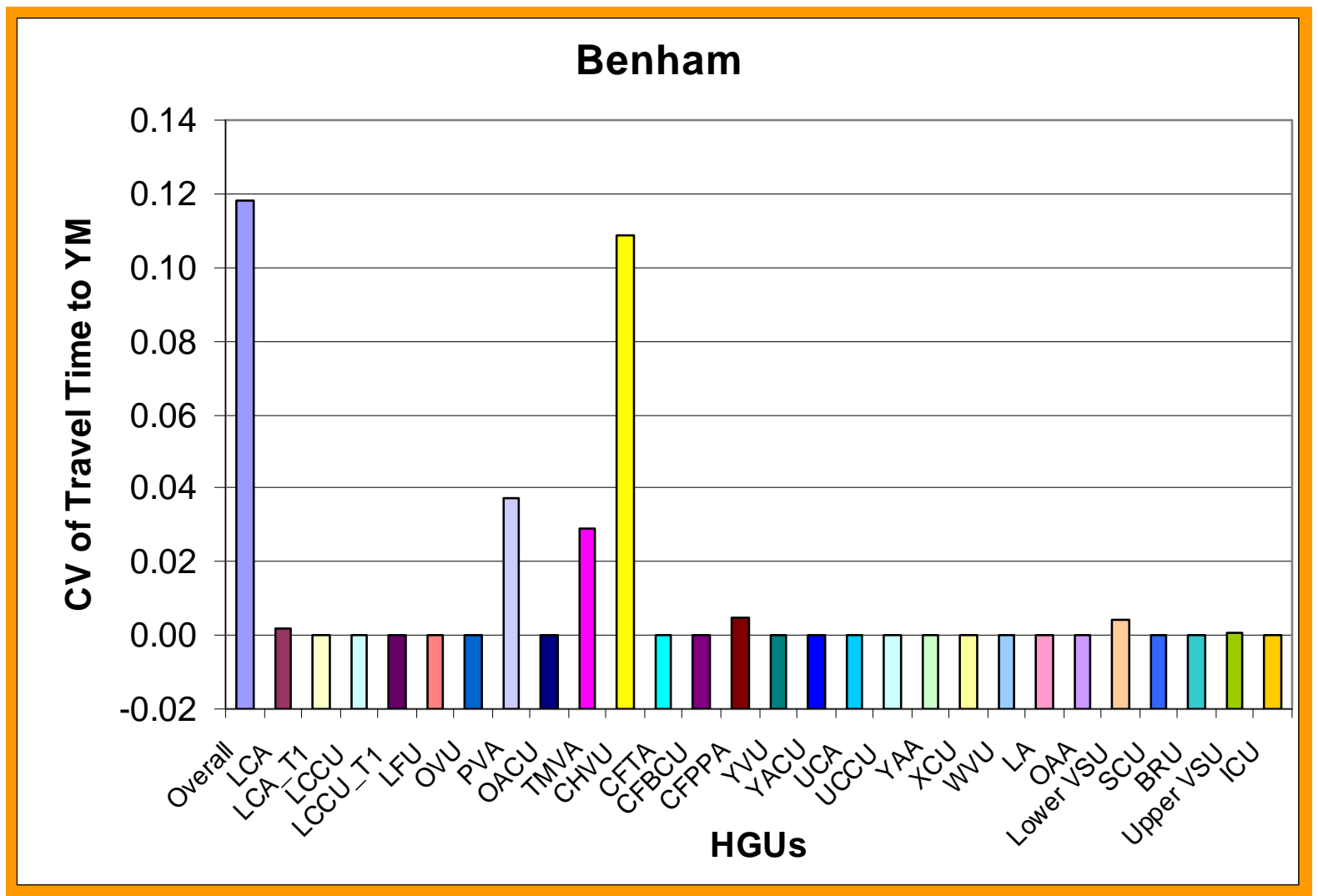

Figure B46. Coefficient of variation $(\mathrm{CV})$ of minimum travel time to the YM area from Benham, in relation to the effective-porosity uncertainties of Hydrogeologic Units (HGUs) when only one HGU has randomly variable effective-porosity and the porosities for other HGUs are set to equal the mean values under 1998 pumping conditions. 


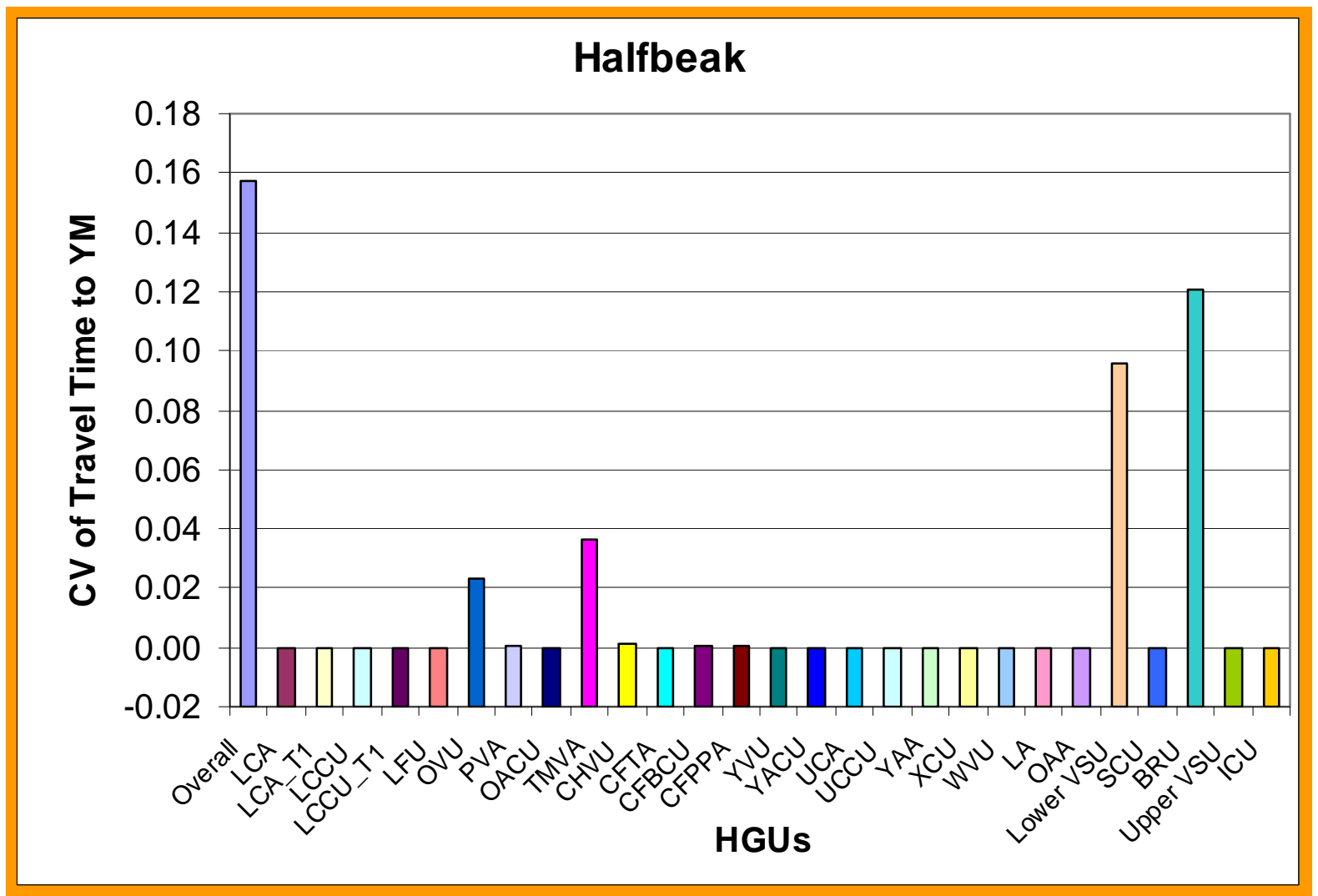

Figure B47. Coefficient of variation (CV) of minimum travel time to the YM area from Halfbeak, in relation to the effective-porosity uncertainties of Hydrogeologic Units (HGUs) when only one HGU has randomly variable effective-porosity and the porosities for other HGUs are set to equal the mean values under 1998 pumping conditions. 


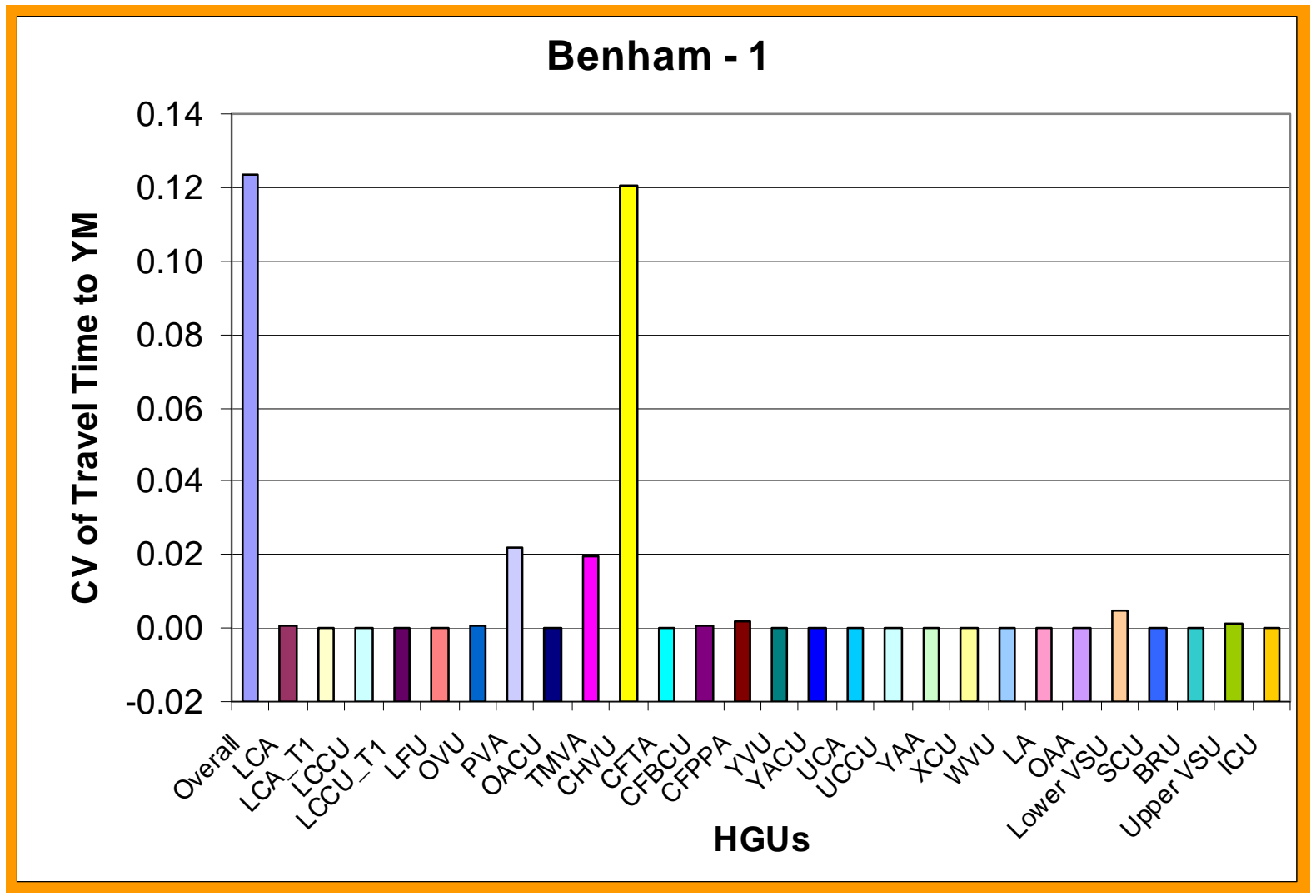

Figure B48. Coefficient of variation $(\mathrm{CV})$ of minimum travel time to the YM area from Benham - 1, in relation to the effective-porosity uncertainties of Hydrogeologic Units (HGUs) when only one HGU has randomly variable effective-porosity and the porosities for other HGUs are set to equal the mean values under 1998 pumping conditions. 


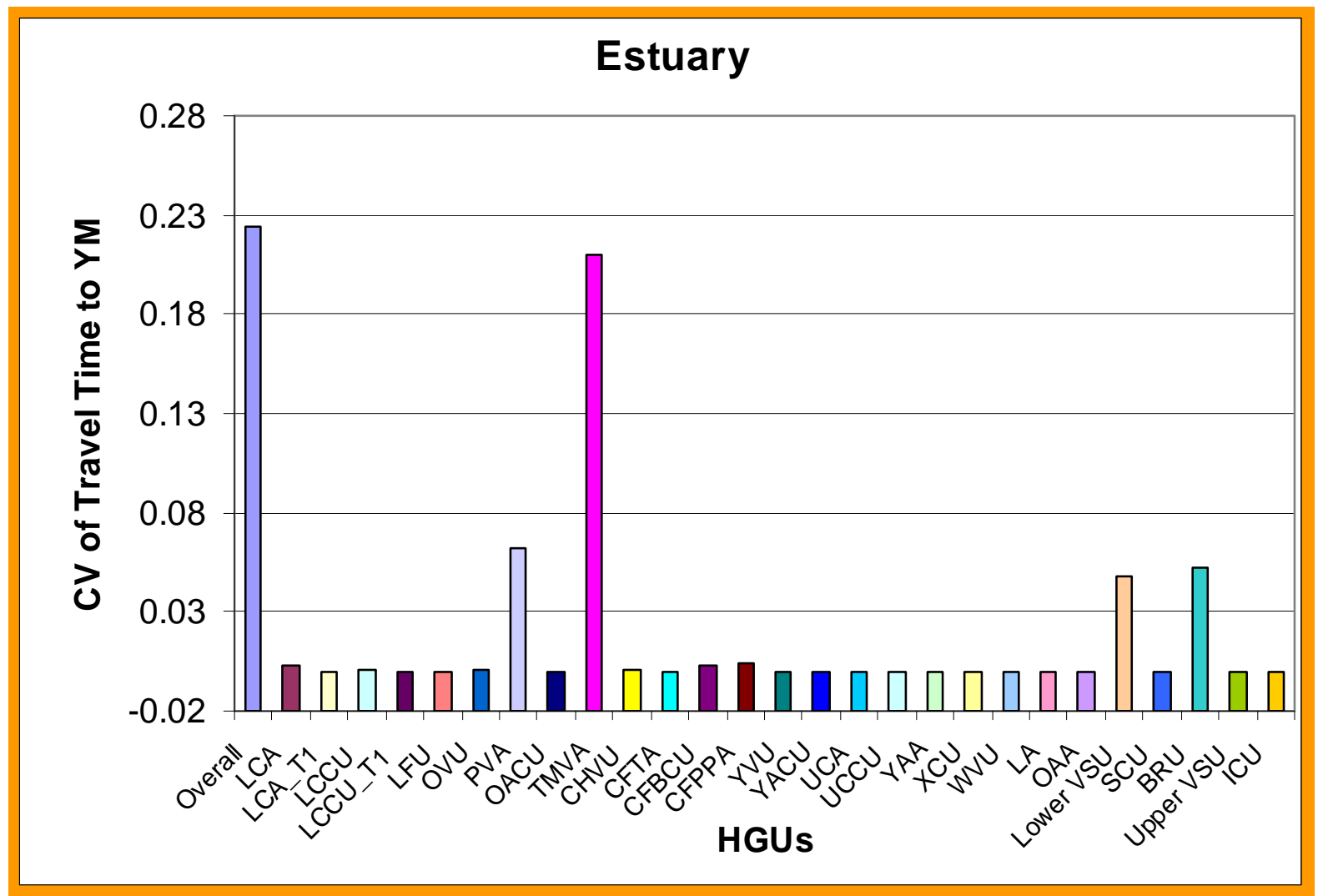

Figure B49. Coefficient of variation (CV) of minimum travel time to the YM area from Estuary, in relation to the effective-porosity uncertainties of Hydrogeologic Units (HGUs) when only one HGU has randomly variable effective-porosity and the porosities for other HGUs are set to equal the mean values under 1998 pumping conditions. 


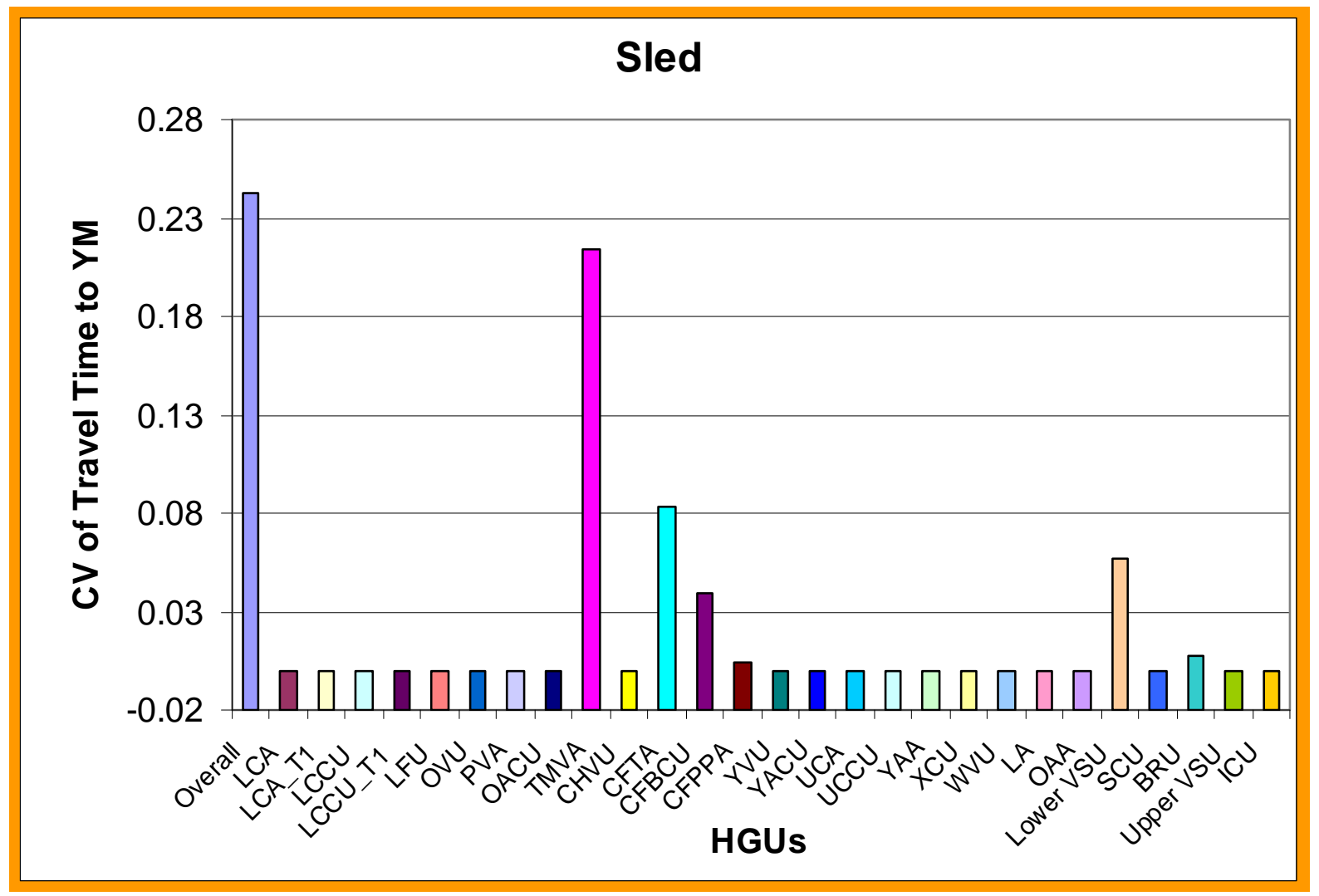

Figure B50. Coefficient of variation (CV) of minimum travel time to the YM area from Sled, in relation to the effective-porosity uncertainties of Hydrogeologic Units (HGUs) when only one HGU has randomly variable effective-porosity and the porosities for other HGUs are set to equal the mean values under 1998 pumping conditions. 


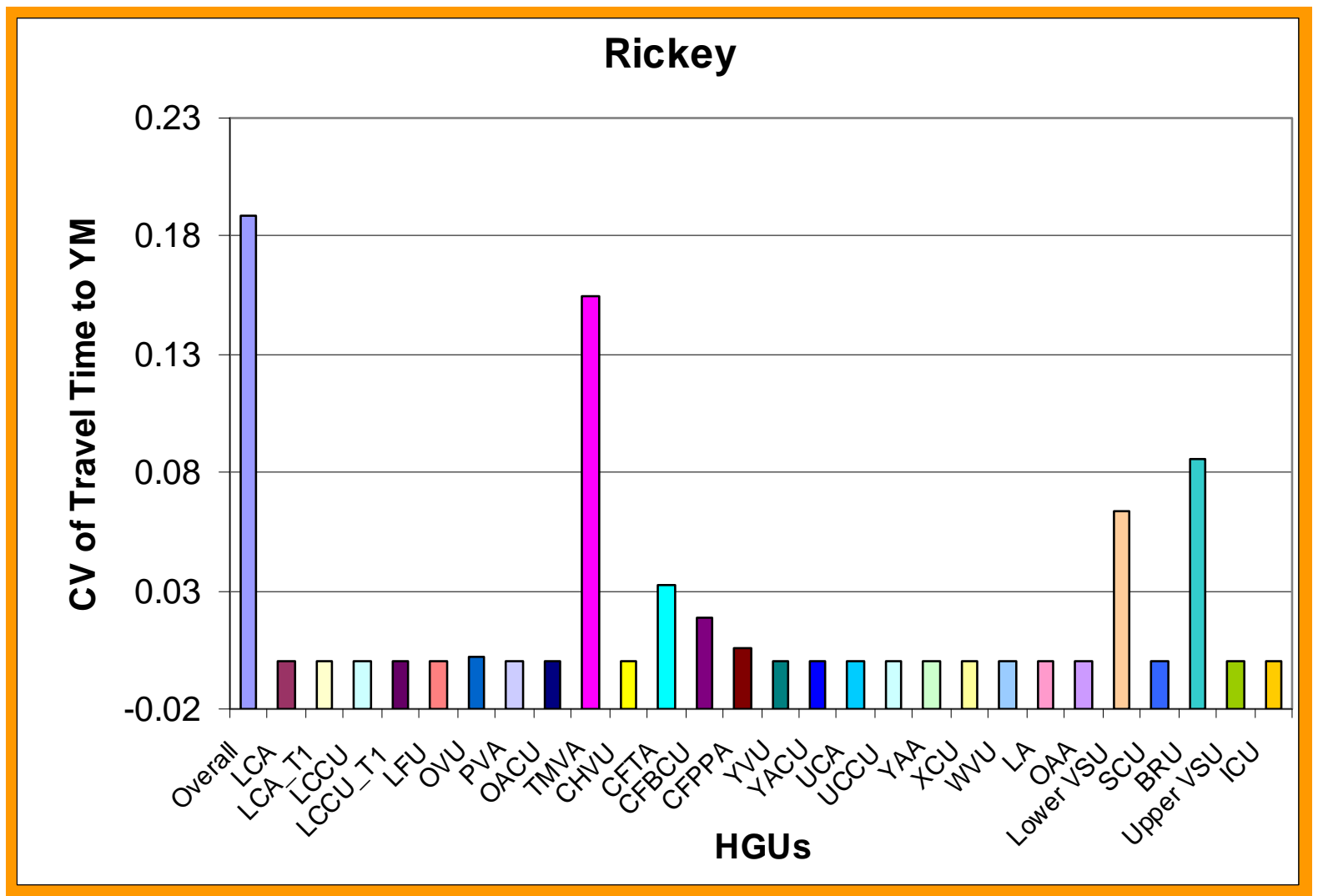

Figure B51. Coefficient of variation (CV) of minimum travel time to the YM area from Ricky, in relation to the effective-porosity uncertainties of Hydrogeologic Units (HGUs) when only one HGU has randomly variable effective-porosity and the porosities for other HGUs are set to equal the mean values under 1998 pumping conditions. 


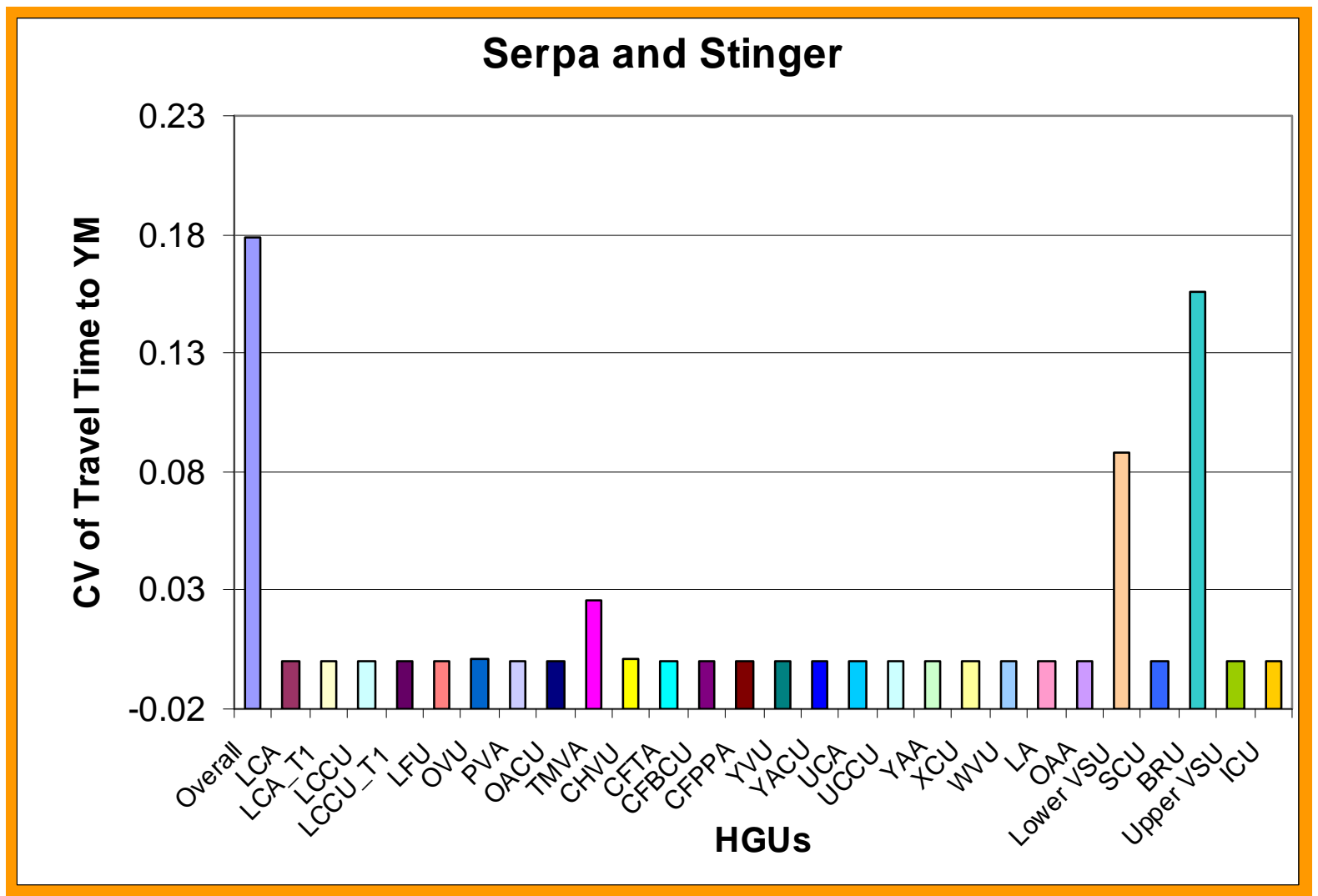

Figure B52. Coefficient of variation (CV) of minimum travel time to the YM area from Serpa and Stinger, in relation to the effective-porosity uncertainties of Hydrogeologic Units (HGUs) when only one HGU has randomly variable effective-porosity and the porosities for other HGUs are set to equal the mean values under 1998 pumping conditions. 


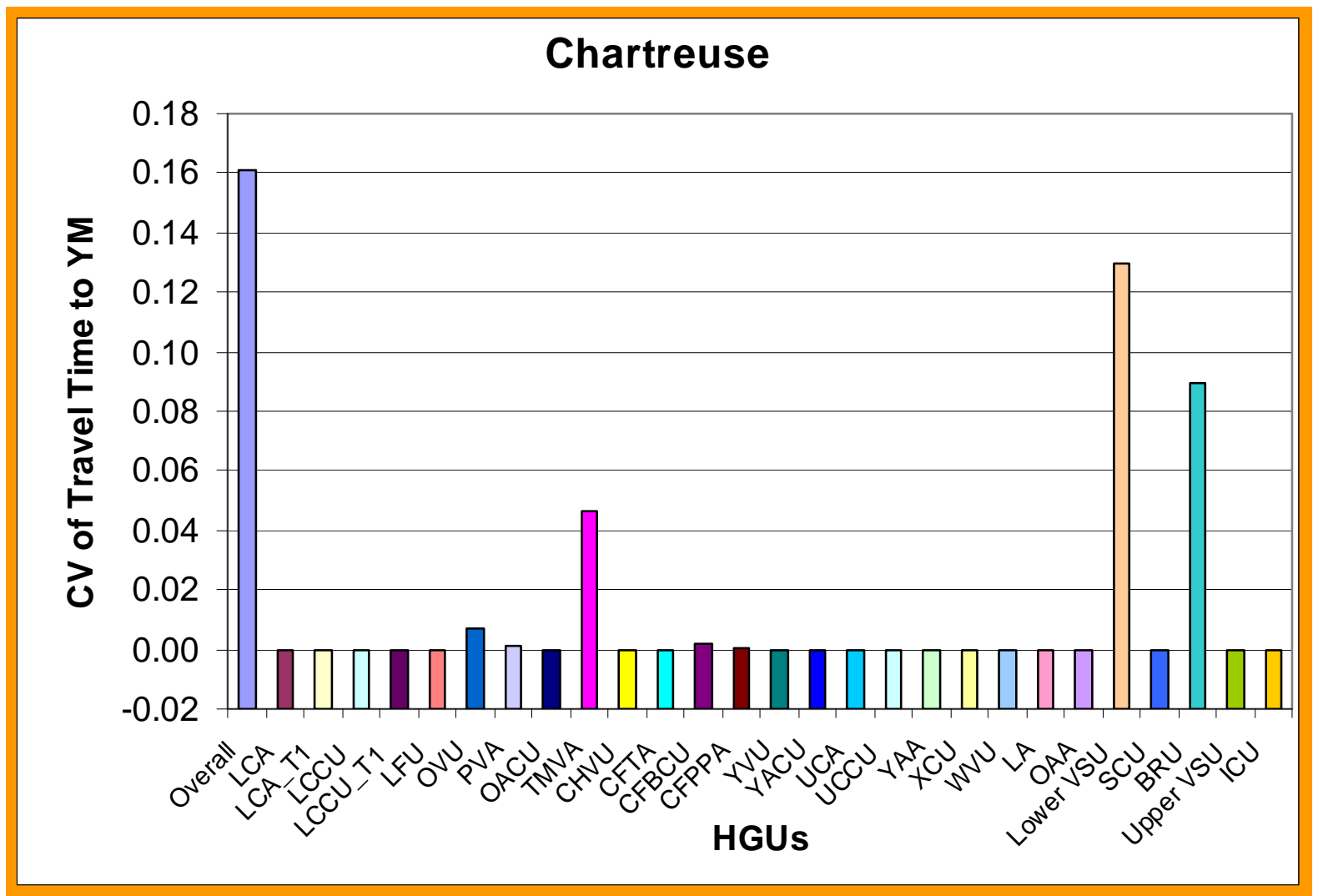

Figure B53. Coefficient of variation (CV) of minimum travel time to the YM area from Chartreuse, in relation to the effective-porosity uncertainties of Hydrogeologic Units (HGUs) when only one HGU has randomly variable effective-porosity and the porosities for other HGUs are set to equal the mean values under 1998 pumping conditions. 


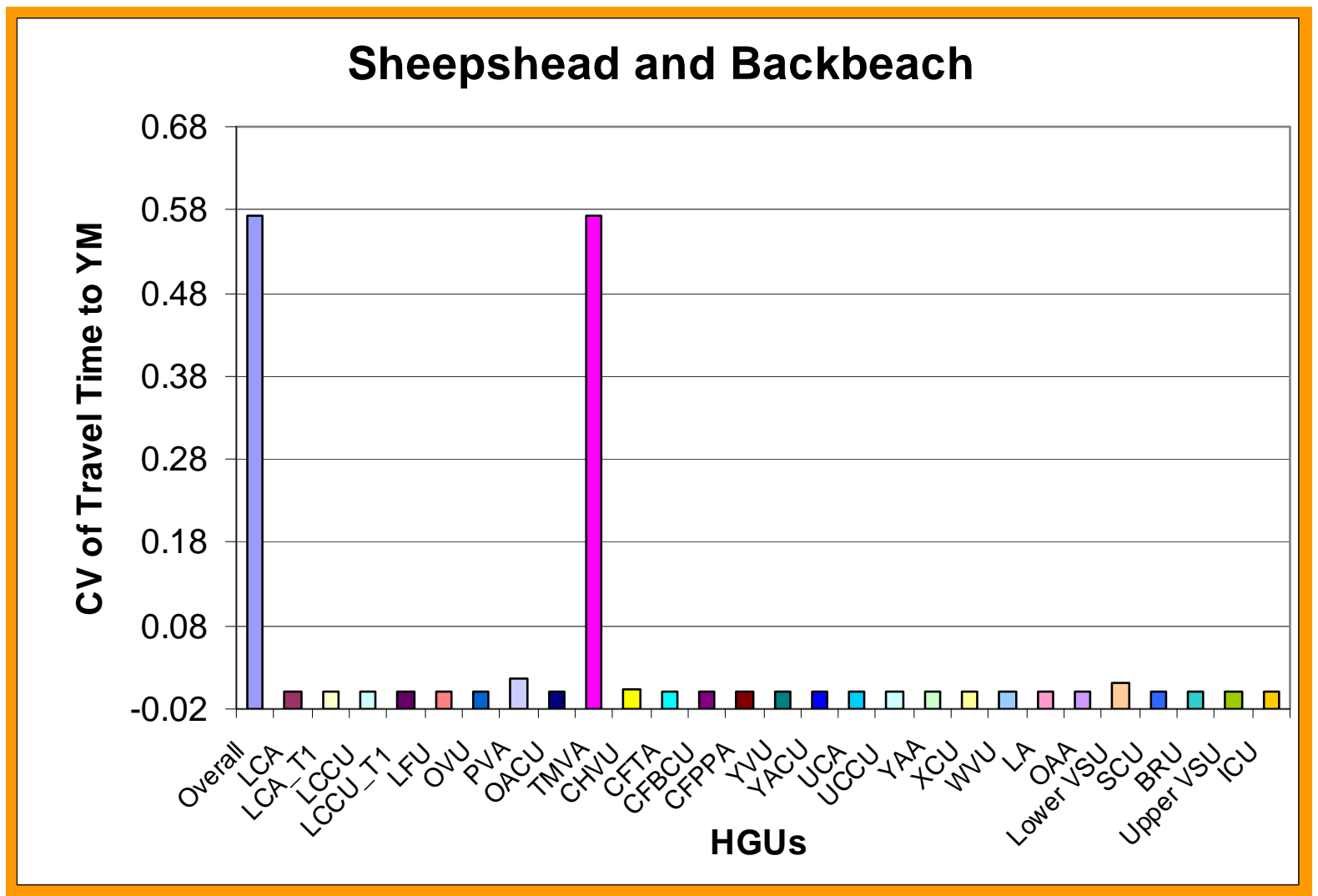

Figure B54. Coefficient of variation (CV) of minimum travel time to the YM area from Sheepshead and Backbeach, in relation to the effective-porosity uncertainties of Hydrogeologic Units (HGUs) when only one HGU has randomly variable effective-porosity and the porosities for other HGUs are set to equal the mean values under 1998 pumping conditions. 


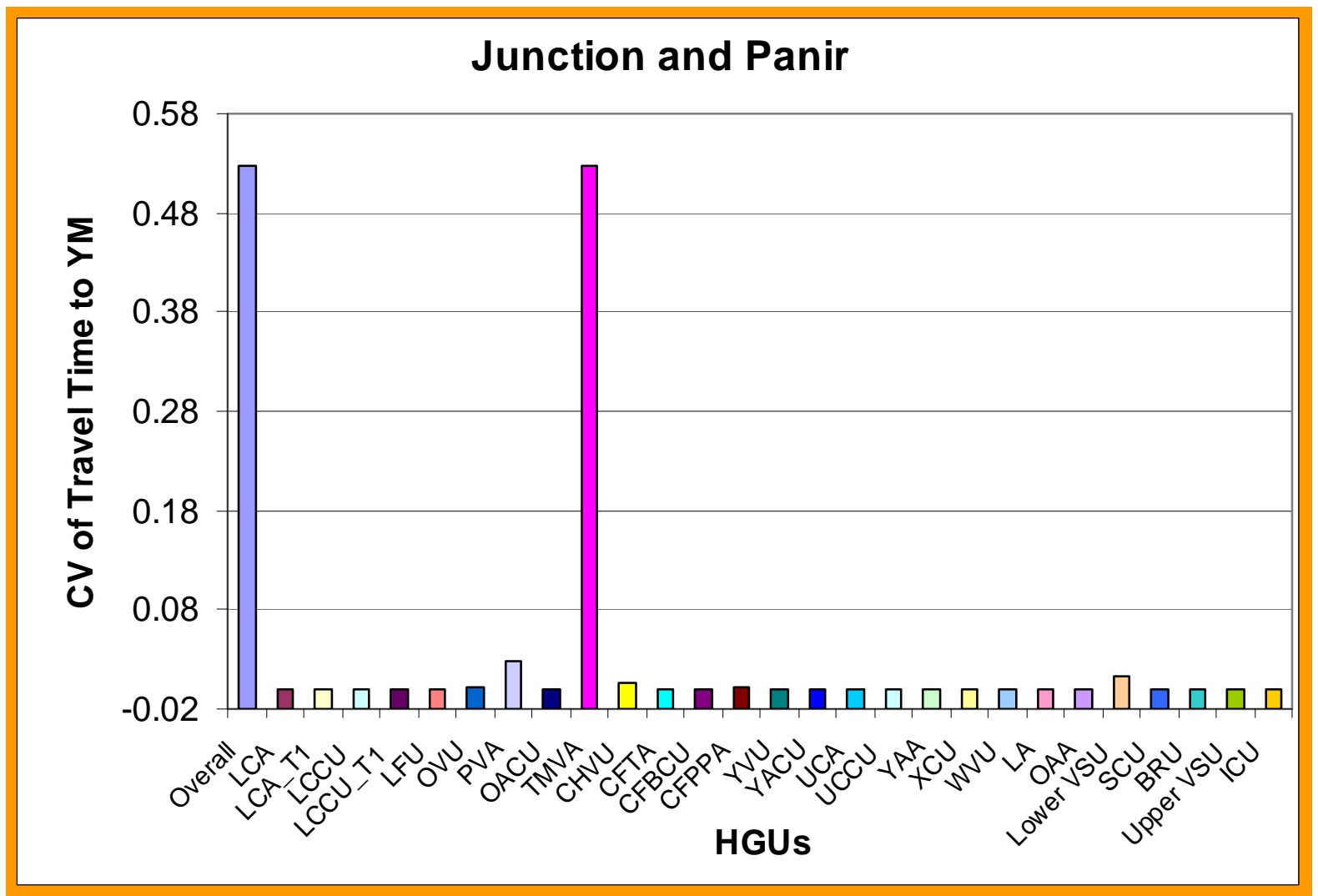

Figure B55. Coefficient of variation $(\mathrm{CV})$ of minimum travel time to the YM area from Junction and Panir, in relation to the effective-porosity uncertainties of Hydrogeologic Units (HGUs) when only one HGU has randomly variable effective-porosity and the porosities for other HGUs are set to equal the mean values under 1998 pumping conditions. 


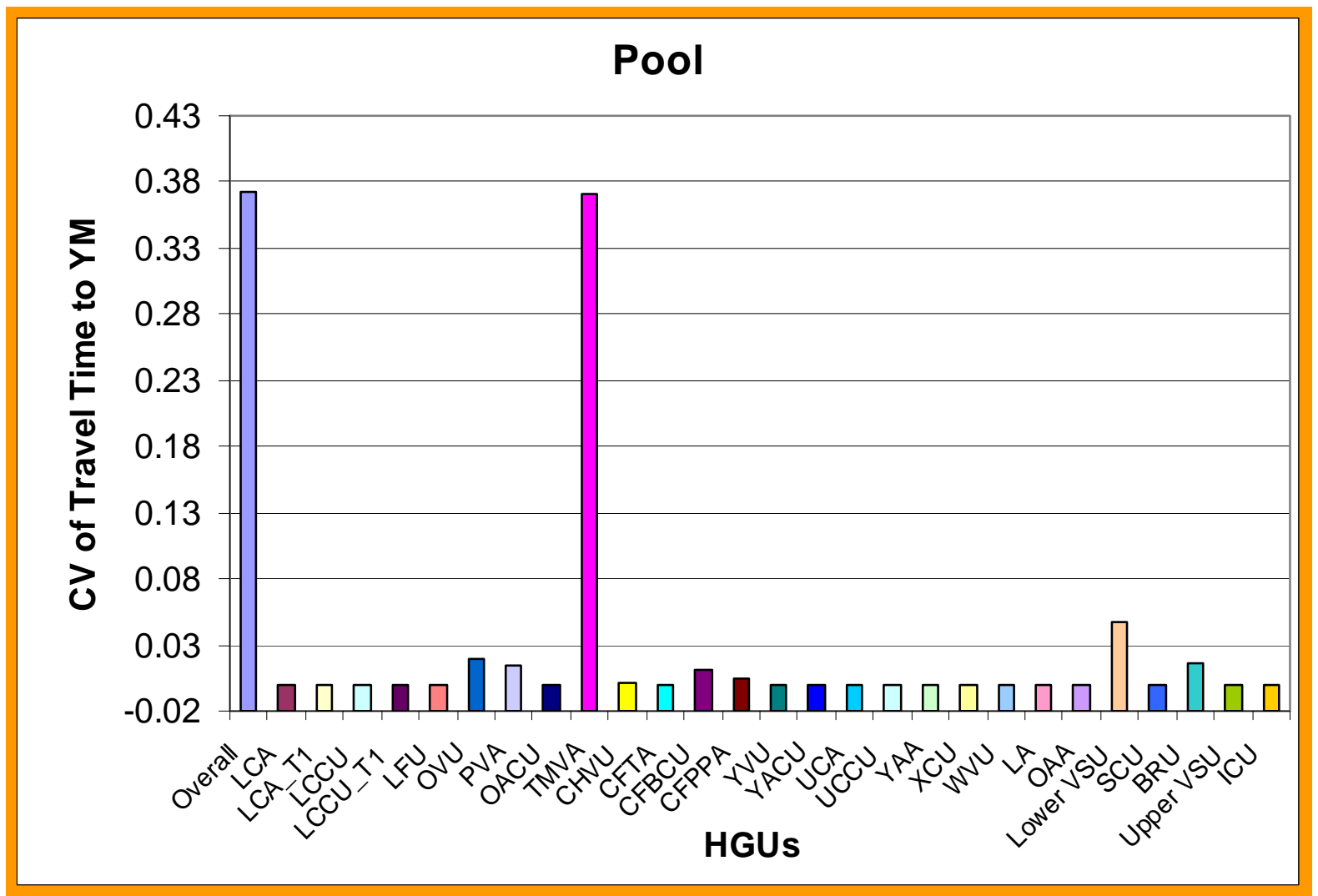

Figure B56. Coefficient of variation (CV) of minimum travel time to the YM area from Pool, in relation to the effective-porosity uncertainties of Hydrogeologic Units (HGUs) when only one HGU has randomly variable effective-porosity and the porosities for other HGUs are set to equal the mean values under 1998 pumping conditions. 


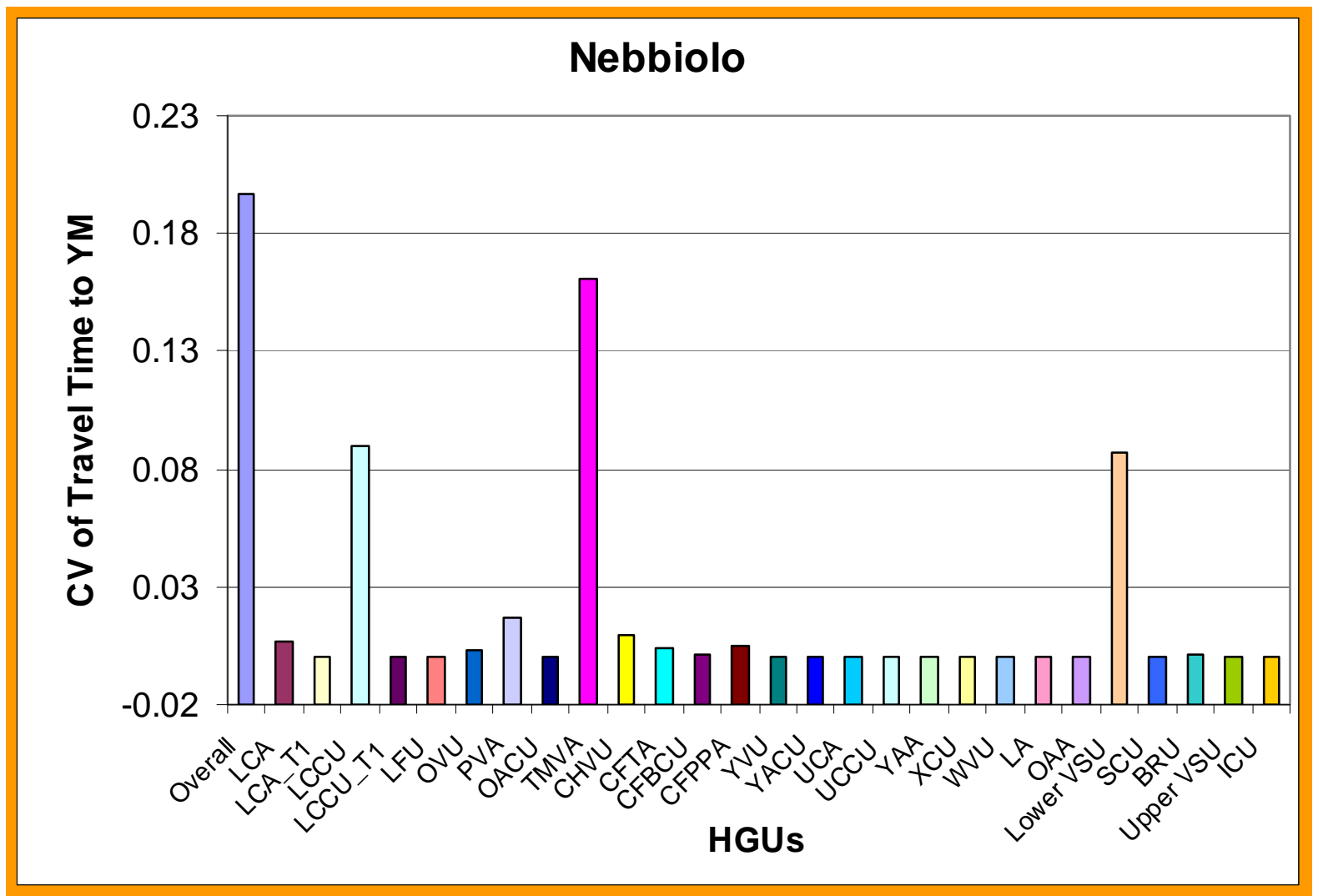

Figure B57. Coefficient of variation (CV) of minimum travel time to the YM area from Nebbiolo, in relation to the effective-porosity uncertainties of Hydrogeologic Units (HGUs) when only one HGU has randomly variable effective-porosity and the porosities for other HGUs are set to equal the mean values under 1998 pumping conditions. 


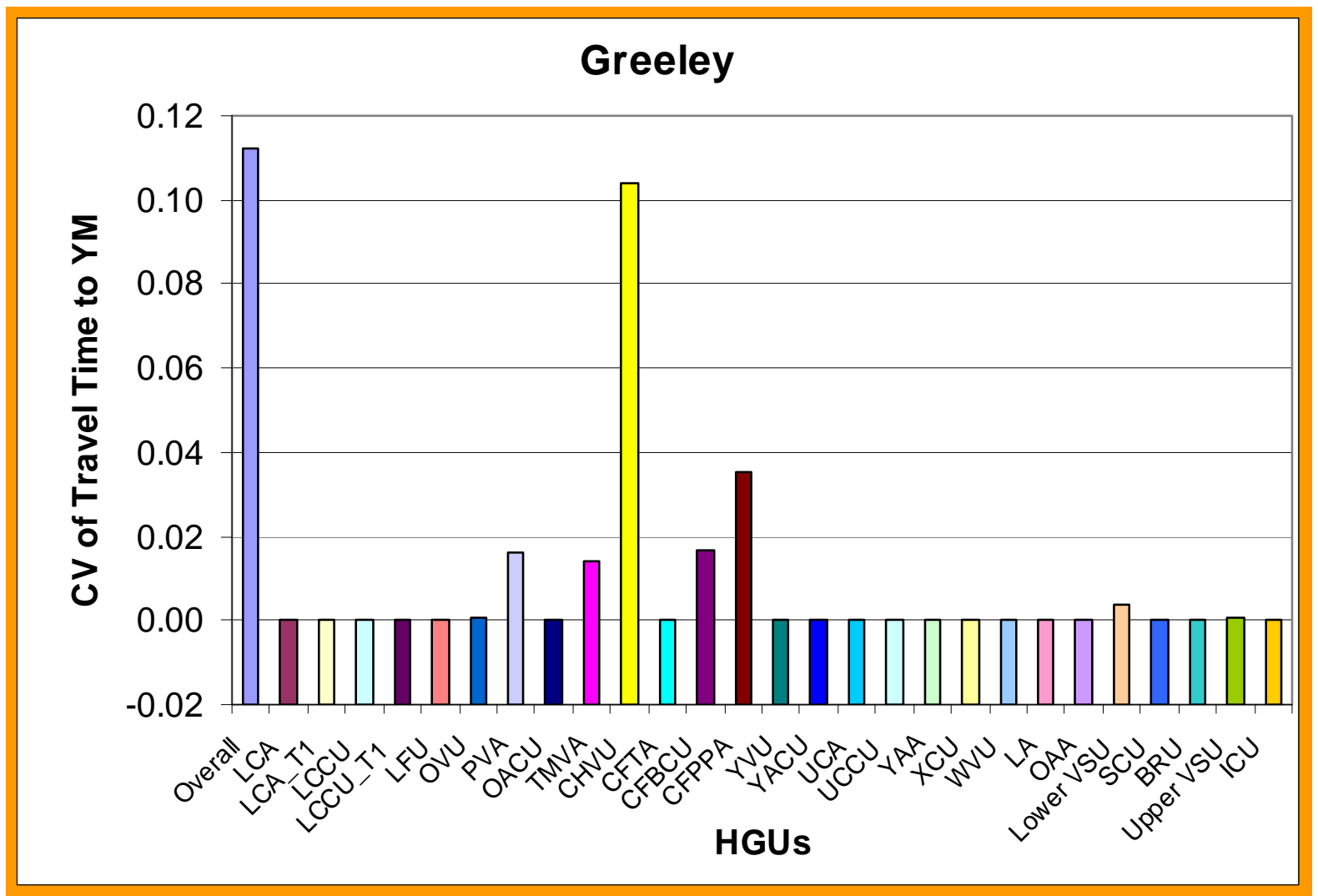

Figure B58. Coefficient of variation (CV) of minimum travel time to the YM area from Greeley, in relation to the effective-porosity uncertainties of Hydrogeologic Units (HGUs) when only one HGU has randomly variable effective-porosity and the porosities for other HGUs are set to equal the mean values under 1998 pumping conditions. 


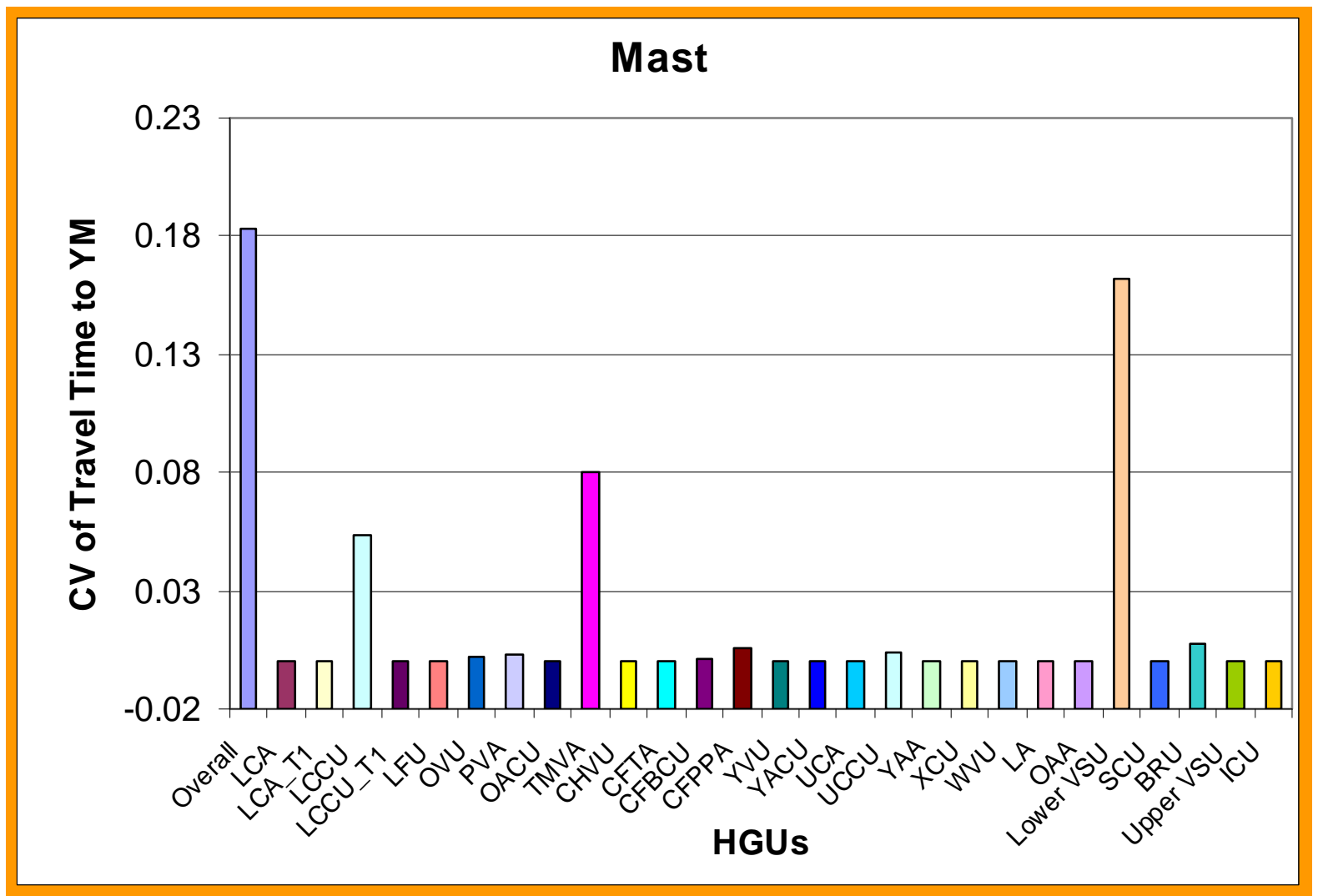

Figure B59. Coefficient of variation (CV) of minimum travel time to the YM area from Mast, in relation to the effective-porosity uncertainties of Hydrogeologic Units (HGUs) when only one HGU has randomly variable effective-porosity and the porosities for other HGUs are set to equal the mean values under 1998 pumping conditions. 


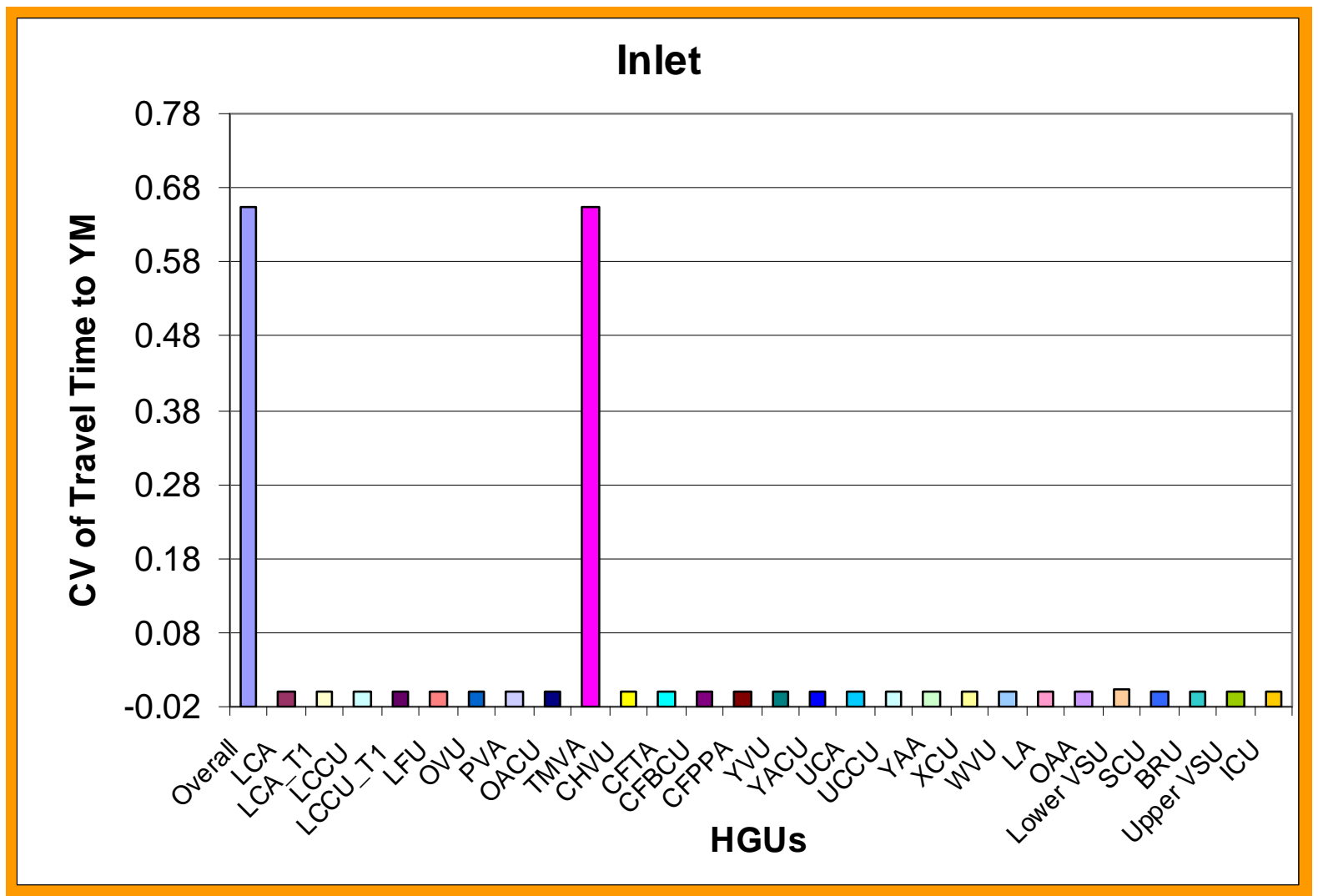

Figure B60. Coefficient of variation $(\mathrm{CV})$ of minimum travel time to the YM area from Inlet, in relation to the effective-porosity uncertainties of Hydrogeologic Units (HGUs) when only one HGU has randomly variable effective-porosity and the porosities for other HGUs are set to equal the mean values under 1998 pumping conditions. 


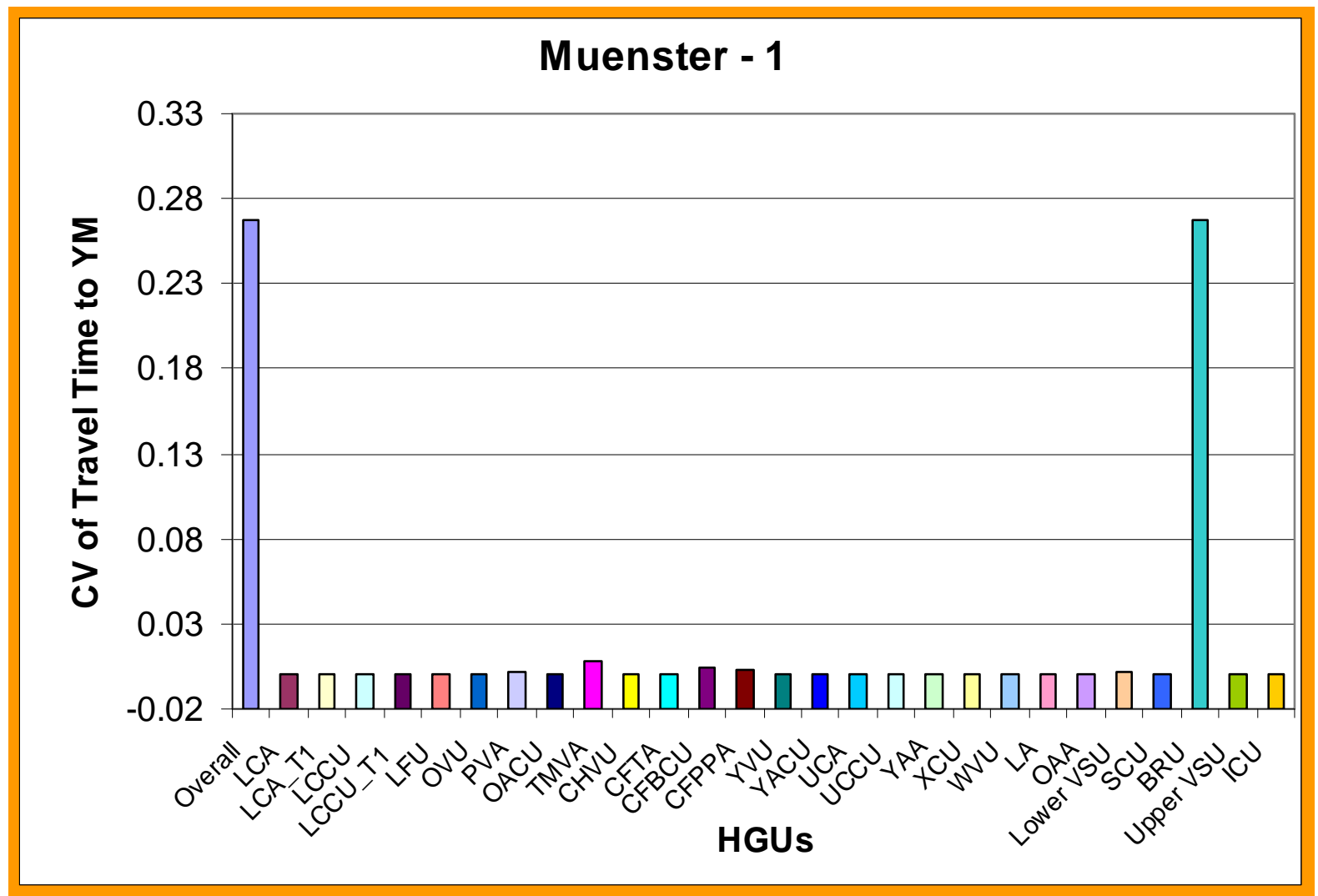

Figure B61. Coefficient of variation (CV) of minimum travel time to the YM area from Muenster - 1, in relation to the effective-porosity uncertainties of Hydrogeologic Units (HGUs) when only one HGU has randomly variable effective-porosity and the porosities for other HGUs are set to equal the mean values under 1998 pumping conditions. 


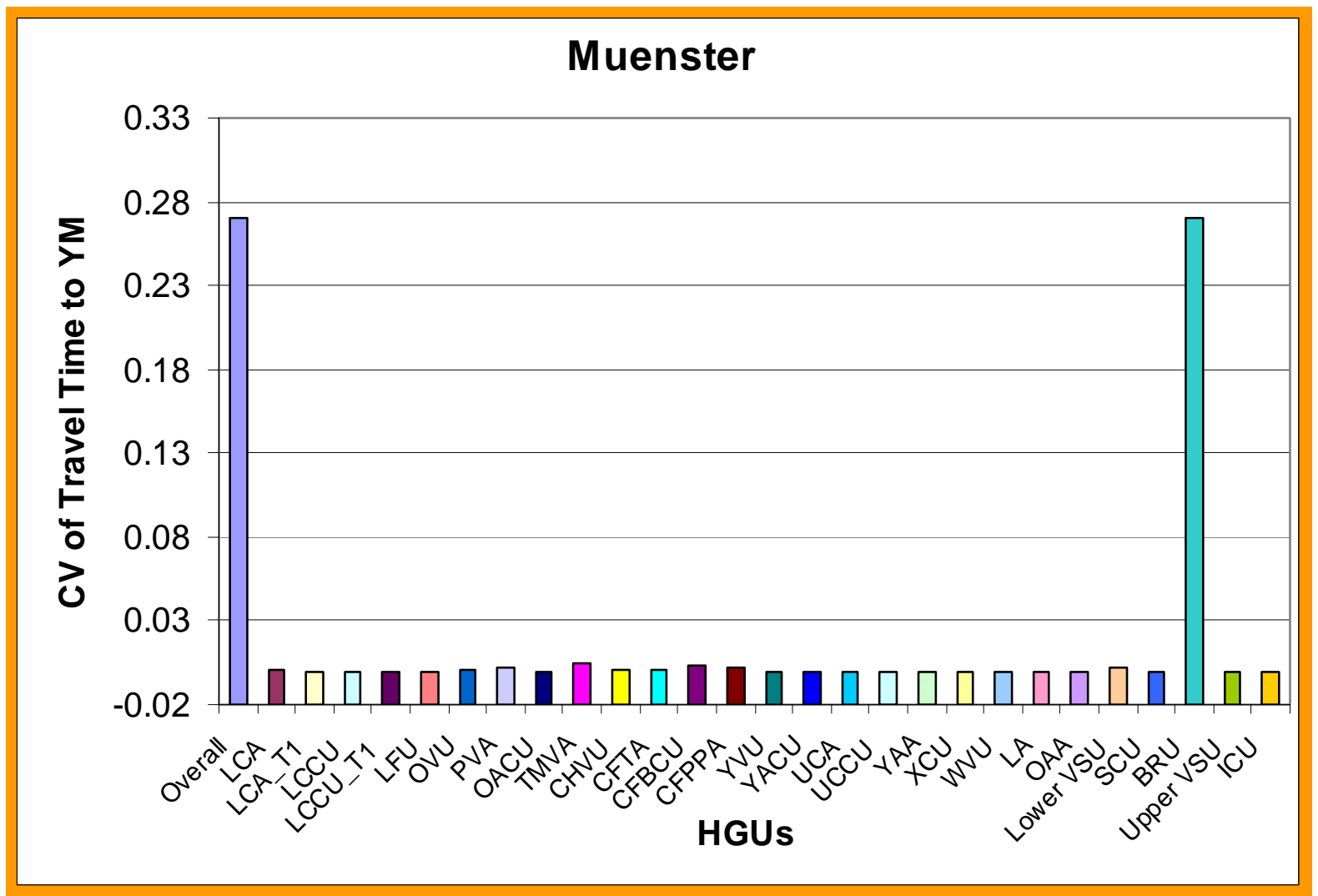

Figure B62. Coefficient of variation (CV) of minimum travel time to the YM area from Muenster, in relation to the effective-porosity uncertainties of Hydrogeologic Units (HGUs) when only one HGU has randomly variable effective-porosity and the porosities for other HGUs are set to equal the mean values under 1998 pumping conditions. 


\section{APPENDIX C:}

Distribution of the minimum travel time to YM area from all detonations under two pumping conditions and three effective-porosity sets

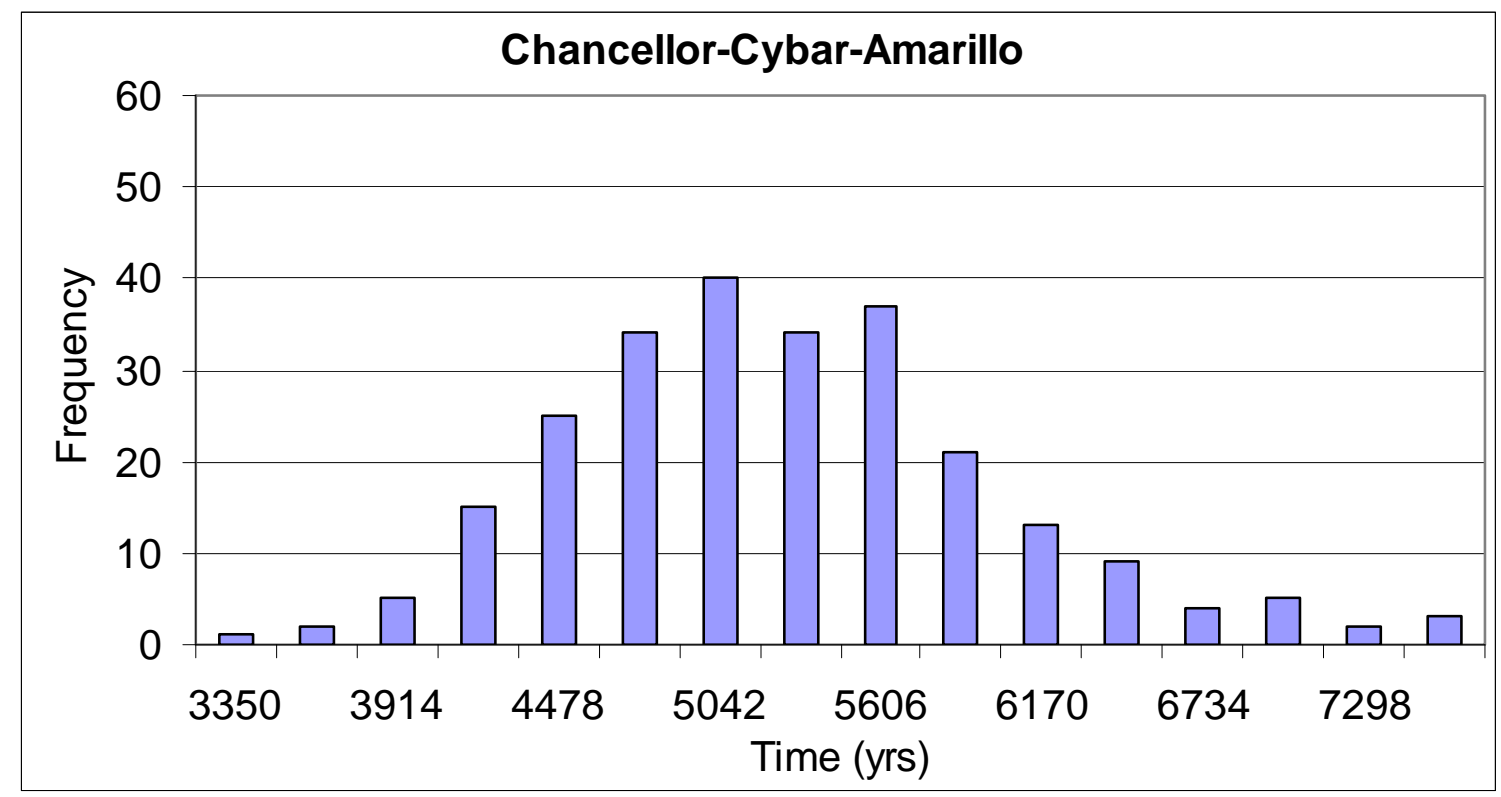

Figure $\mathrm{C} 1$. Distribution of minimum travel time from Chancellor-Cybar-Amarillo to YM boundaries based on effective-porosity Set 1 for pre-pumping scenario.

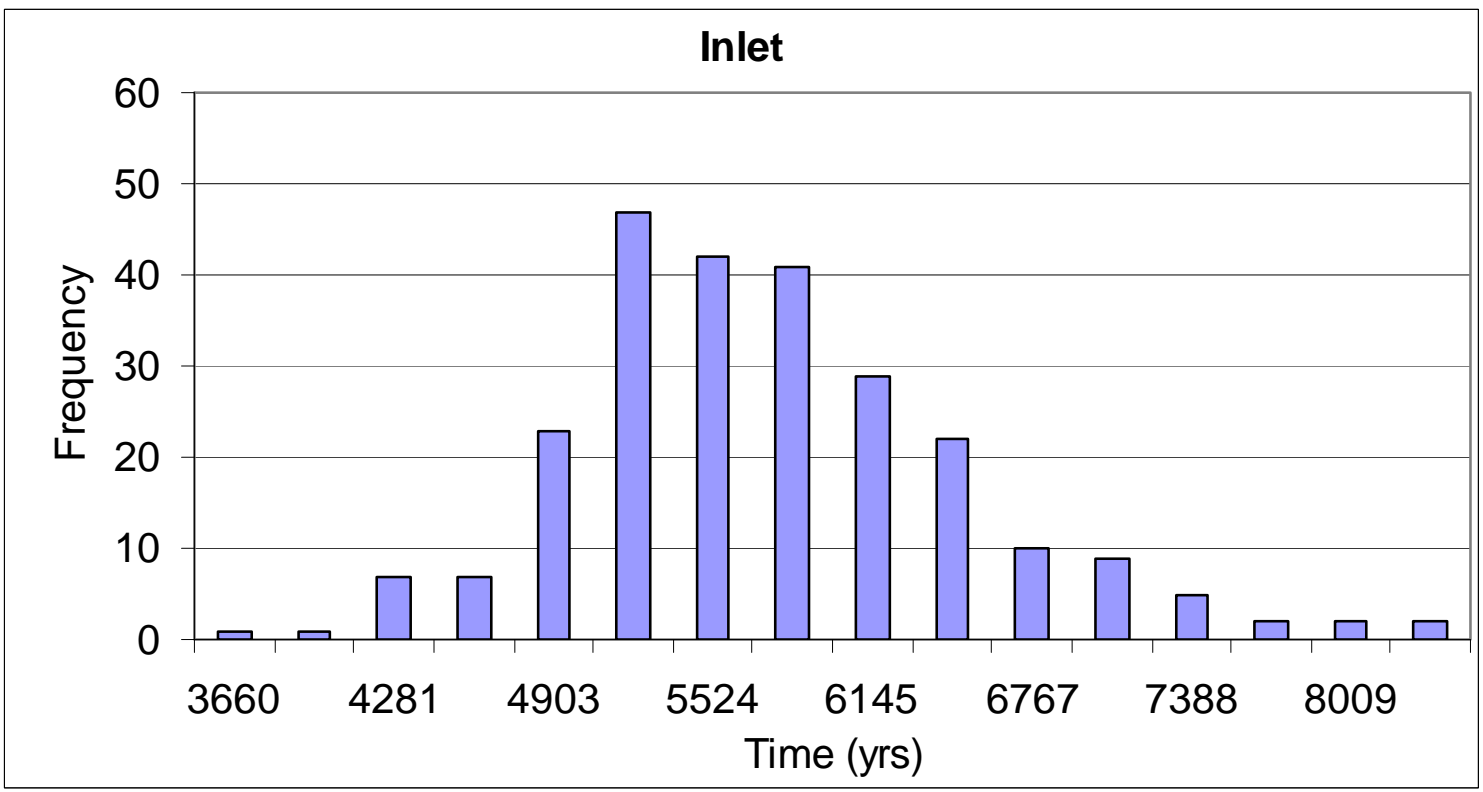

Figure C2. Distribution of minimum travel time from Inlet to YM boundaries based on effective-porosity Set 1 for pre-pumping scenario. 


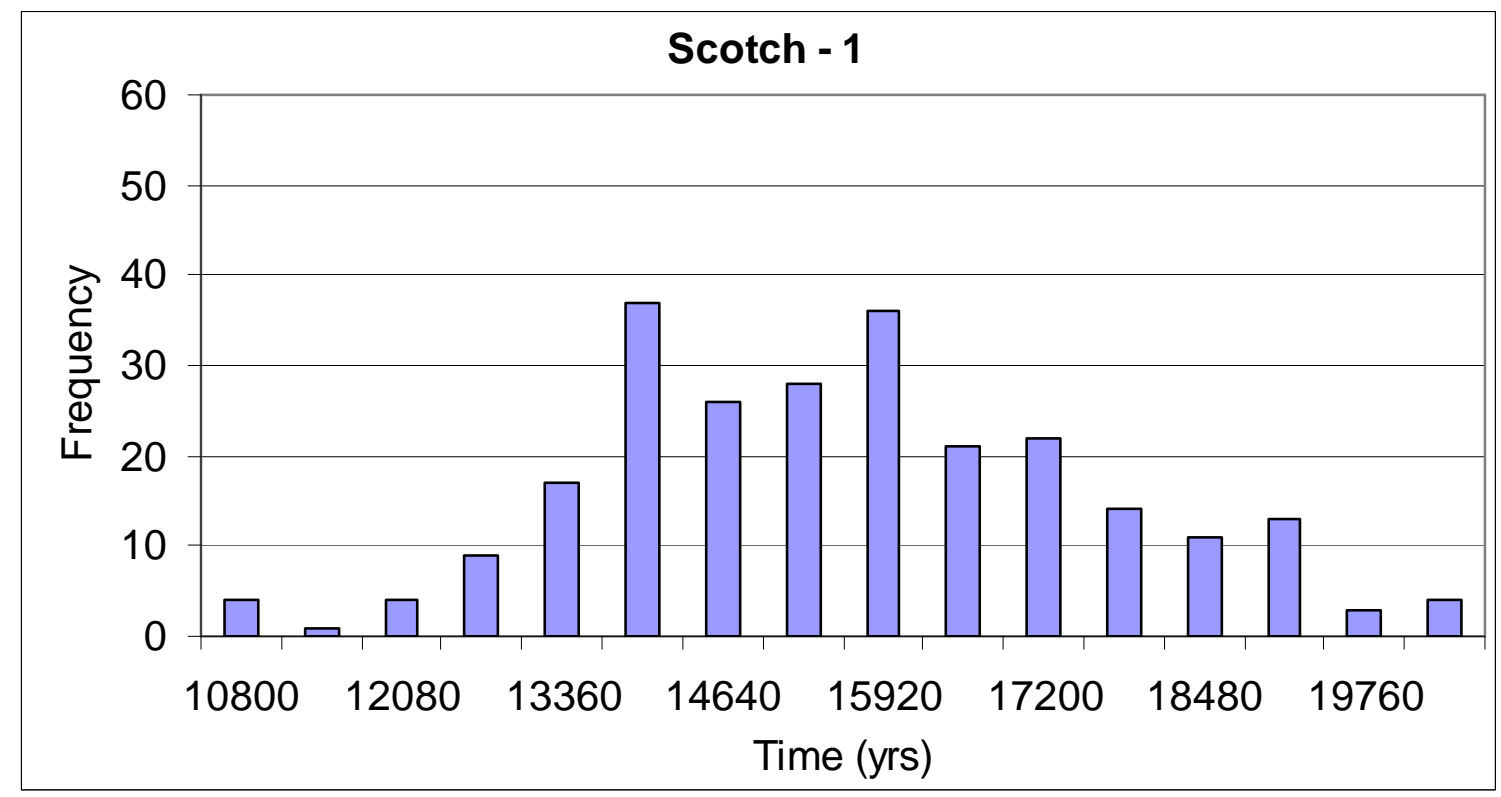

Figure C3. Distribution of minimum travel time from Scotch -1 to YM boundaries based on effective-porosity Set 1 for pre-pumping scenario.

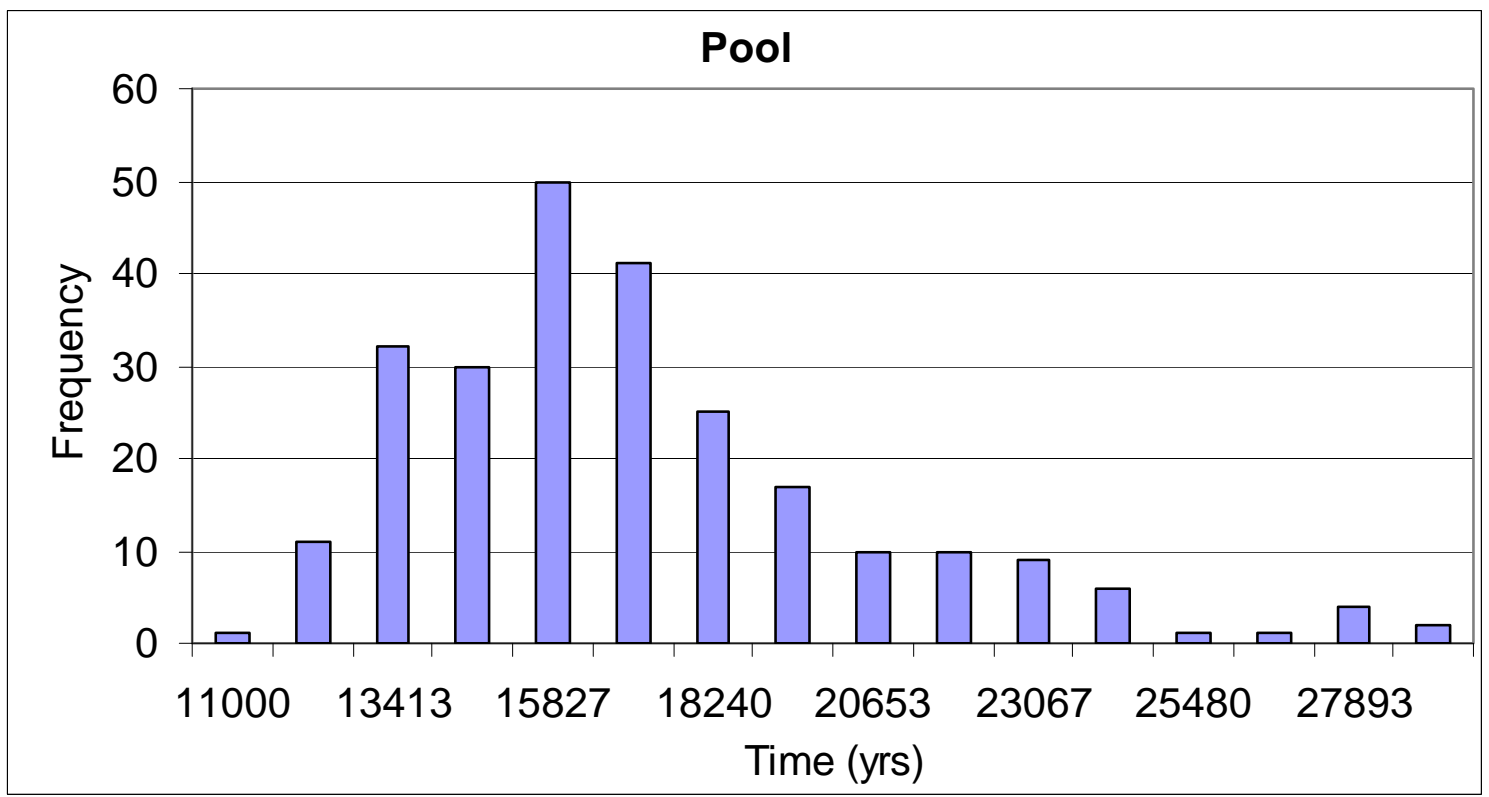

Figure C4. Distribution of minimum travel time from Pool to YM boundaries based on effective-porosity Set 1 for pre-pumping scenario. 


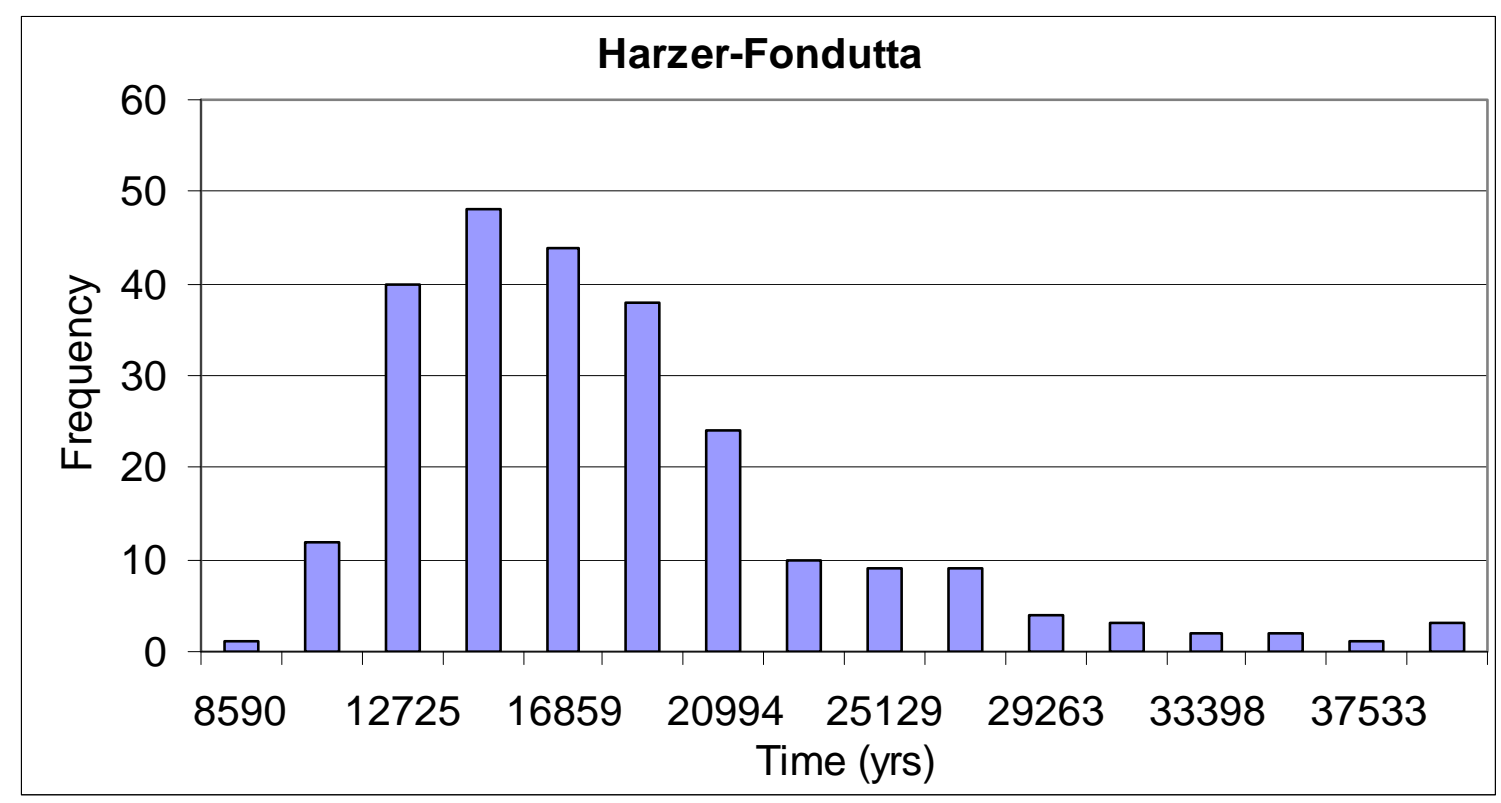

Figure C5. Distribution of minimum travel time from Harzer-Fondutta to YM boundaries based on effective-porosity Set 1 for pre-pumping scenario.

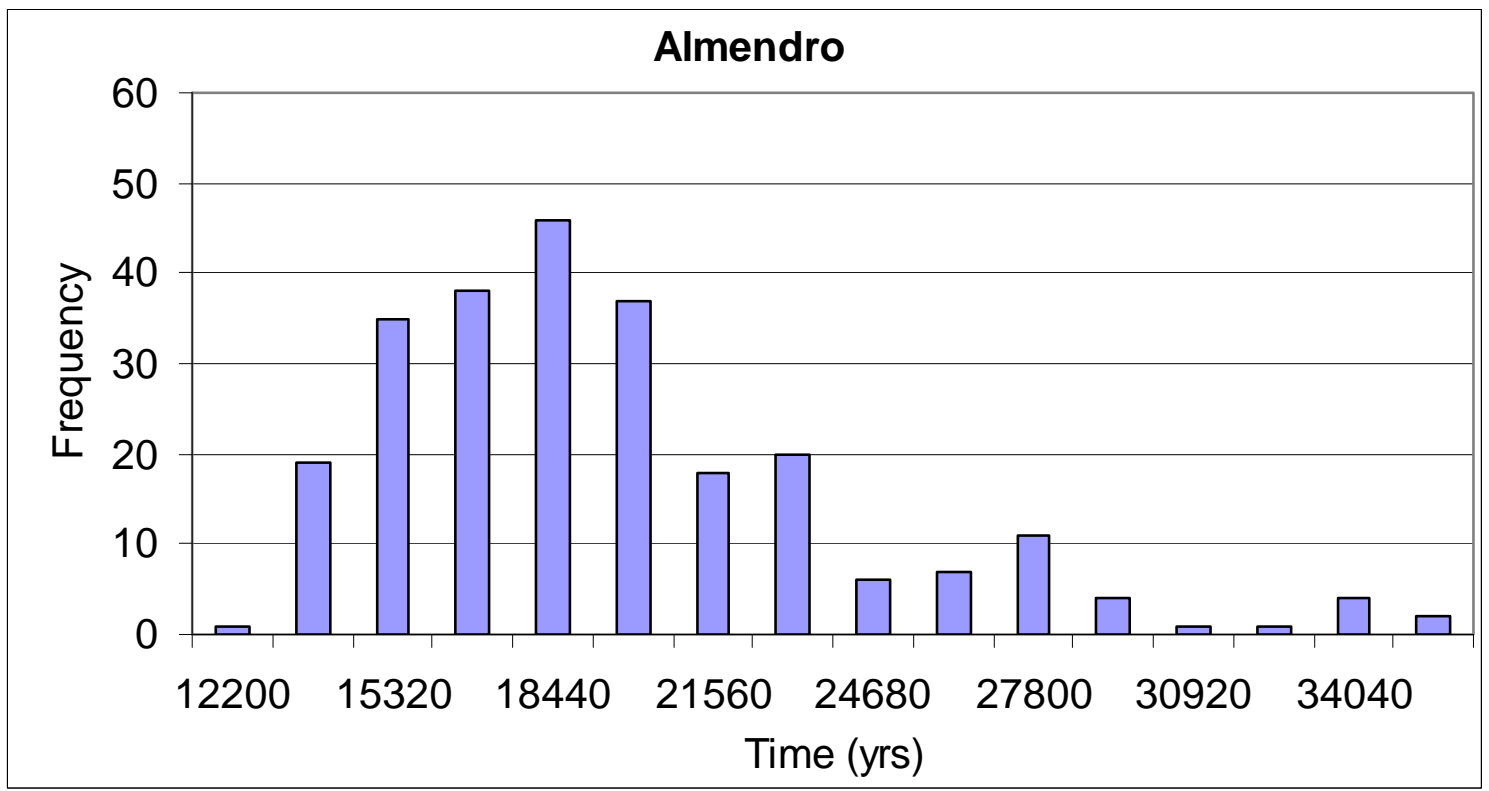

Figure C6. Distribution of minimum travel time from Almendro to YM boundaries based on effective-porosity Set 1 for pre-pumping scenario. 


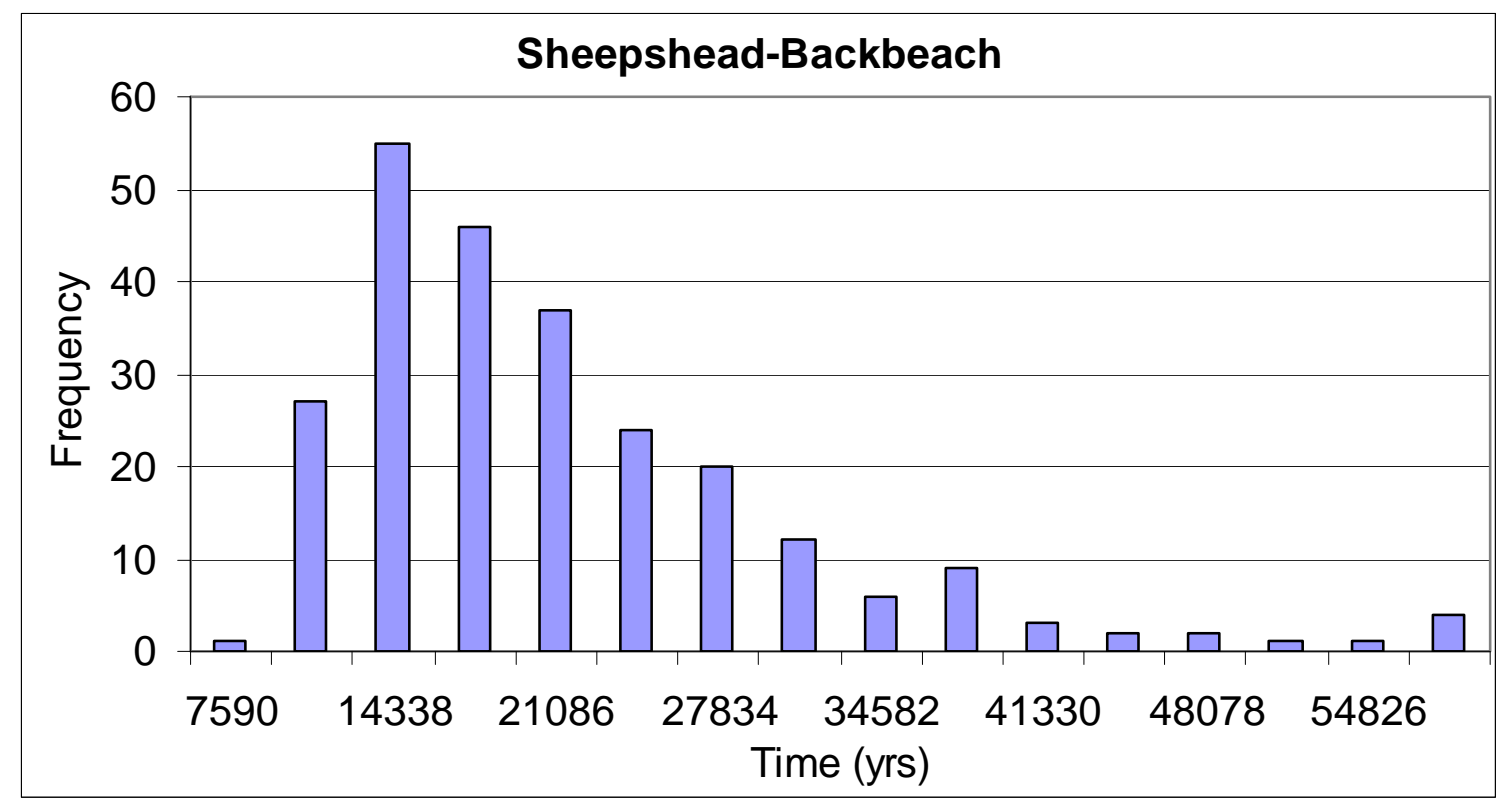

Figure C7. Distribution of minimum travel time from Sheepshead-Backbeach to YM boundaries based on effective-porosity Set 1 for pre-pumping scenario.

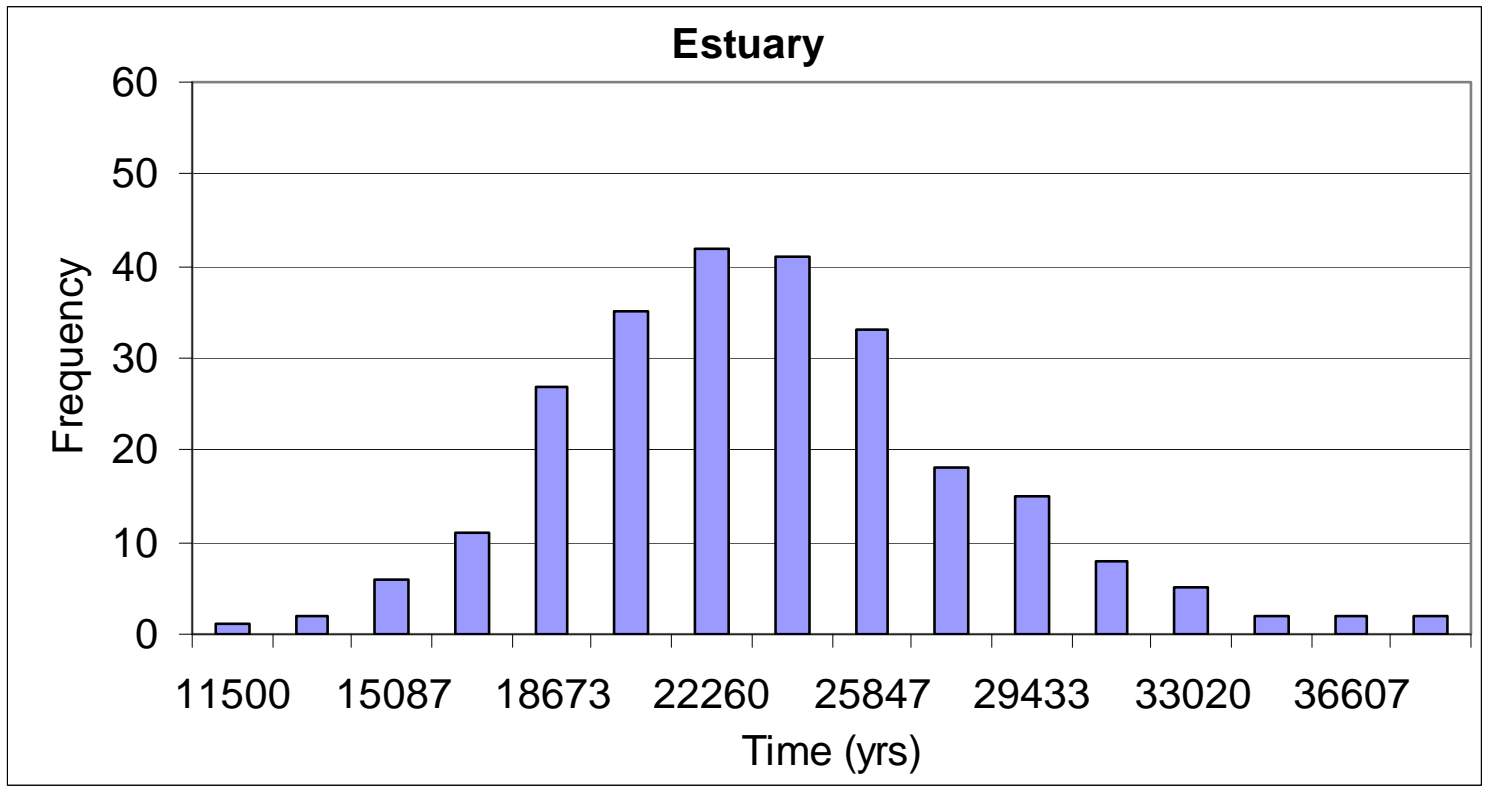

Figure C8. Distribution of minimum travel time from Estuary to YM boundaries based on effective-porosity Set 1 for pre-pumping scenario. 


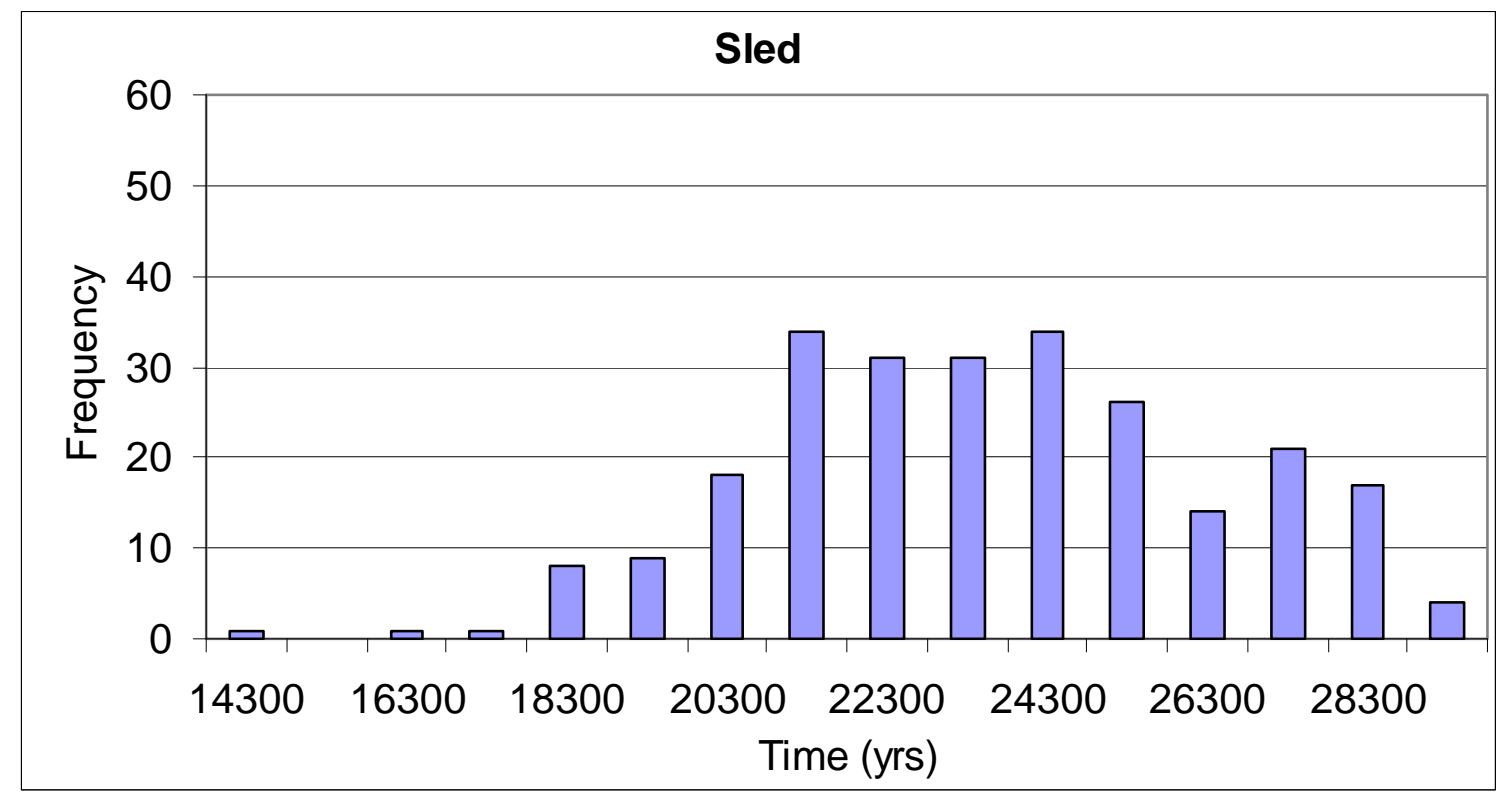

Figure C9. Distribution of minimum travel time from Sled to YM boundaries based on effective-porosity Set 1 for pre-pumping scenario.

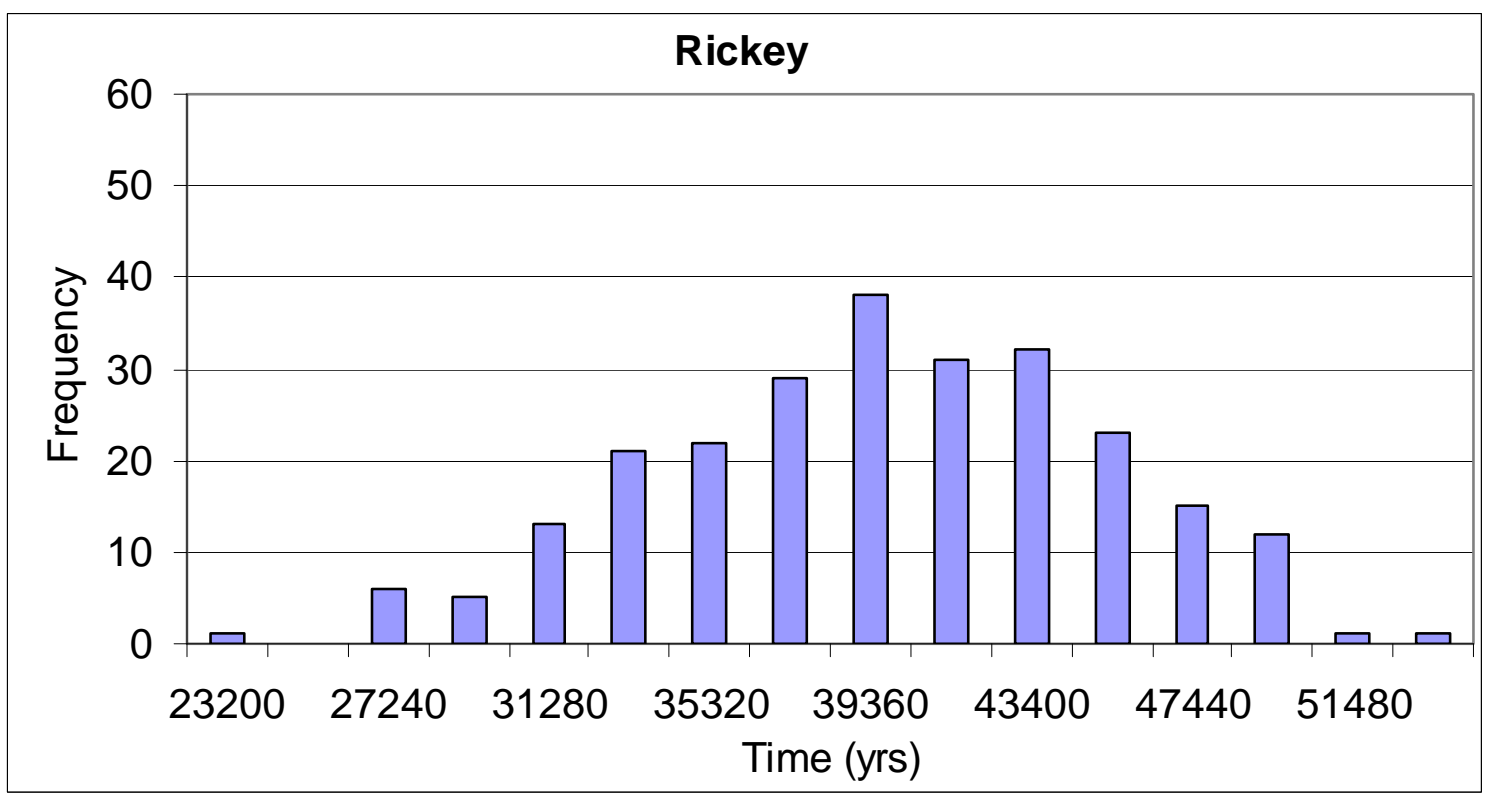

Figure C10. Distribution of minimum travel time from Ricky to YM boundaries based on effective-porosity Set 1 for pre-pumping scenario. 


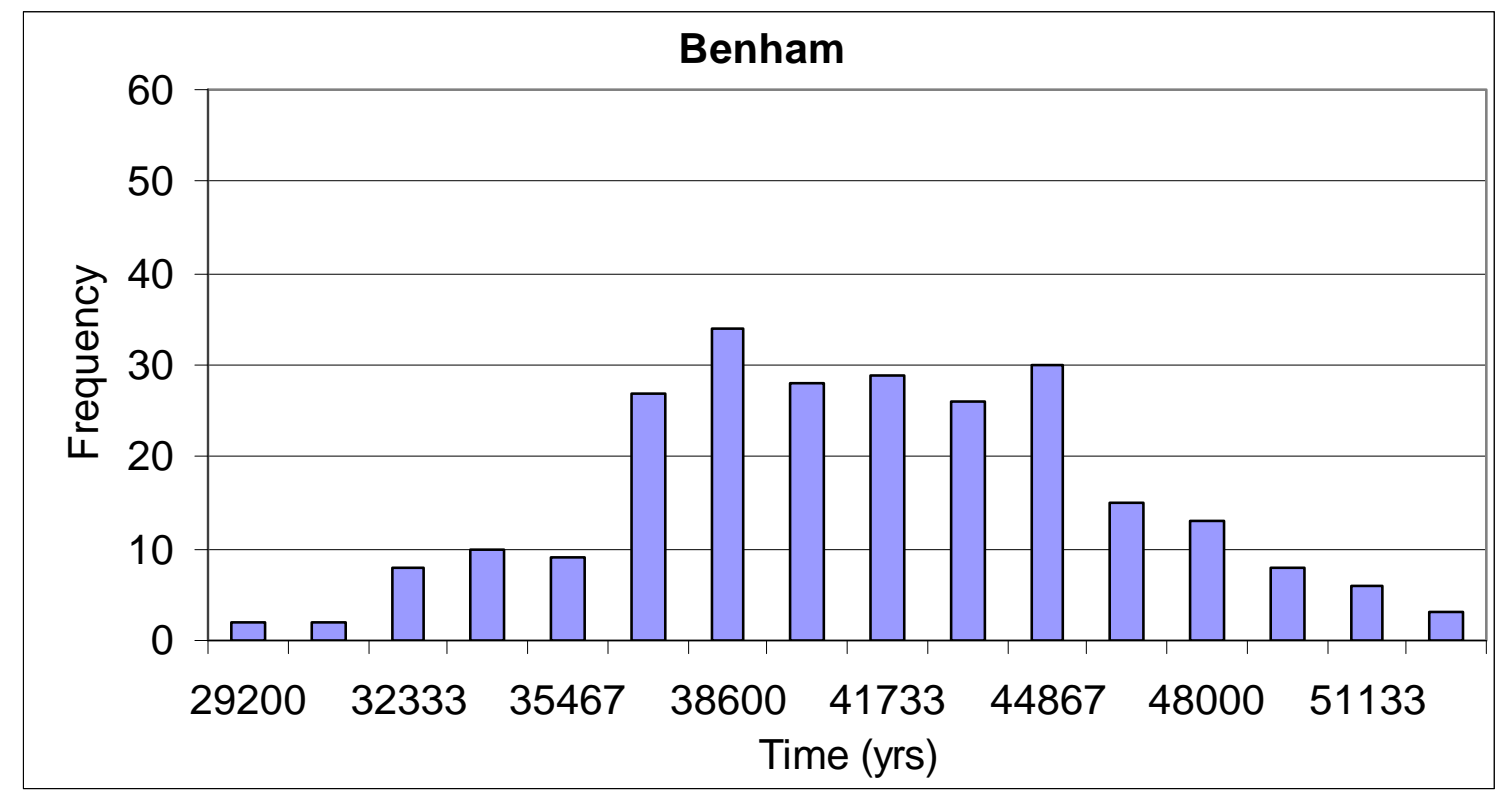

Figure C11. Distribution of minimum travel time from Benham to YM boundaries based on effective-porosity Set 1 for pre-pumping scenario.

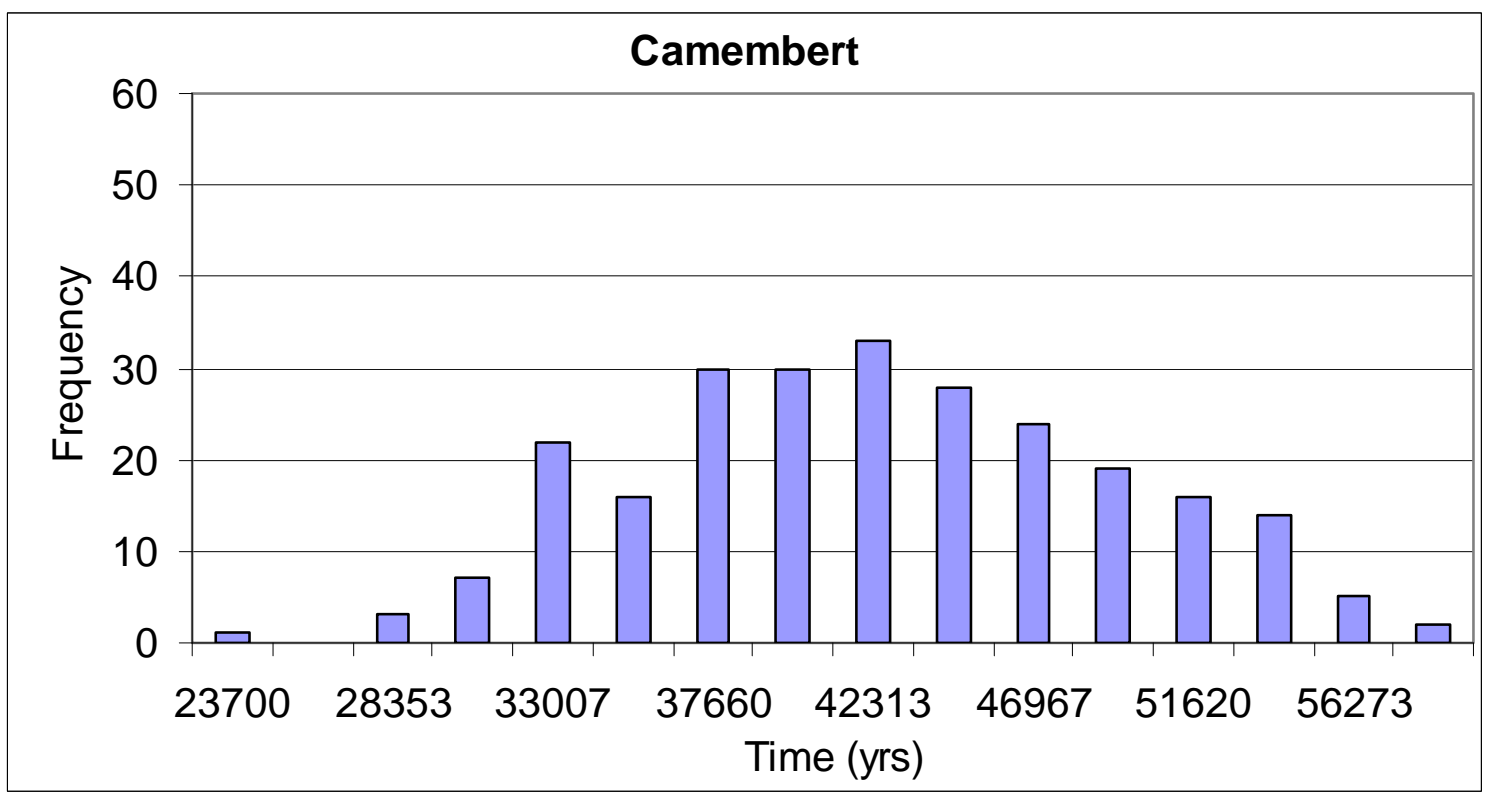

Figure C12. Distribution of minimum travel time from Camembert to YM boundaries based on effective-porosity Set 1 for pre-pumping scenario. 


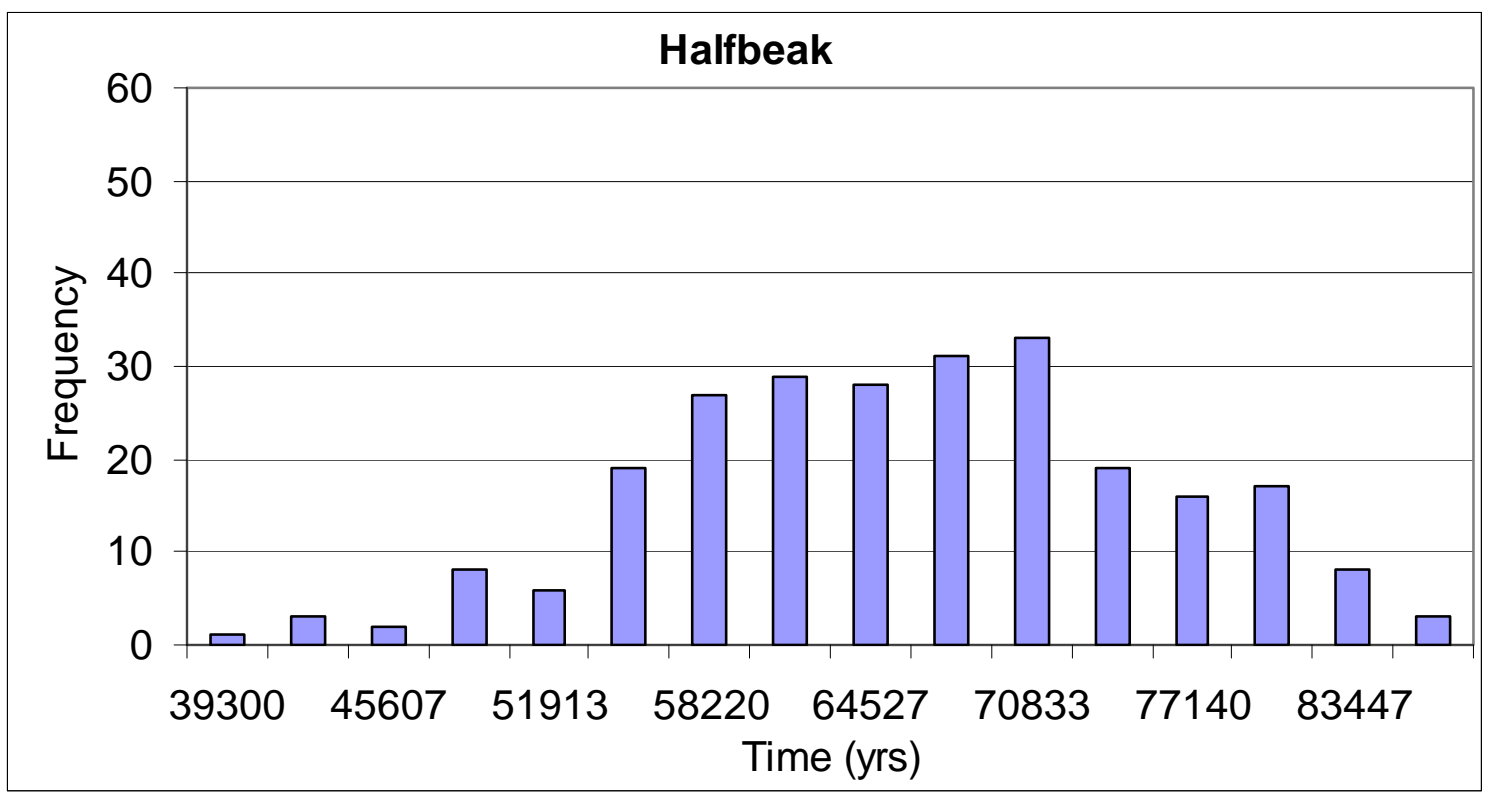

Figure C13. Distribution of minimum travel time from Halfbeak to YM boundaries based on effective-porosity Set 1 for pre-pumping scenario.

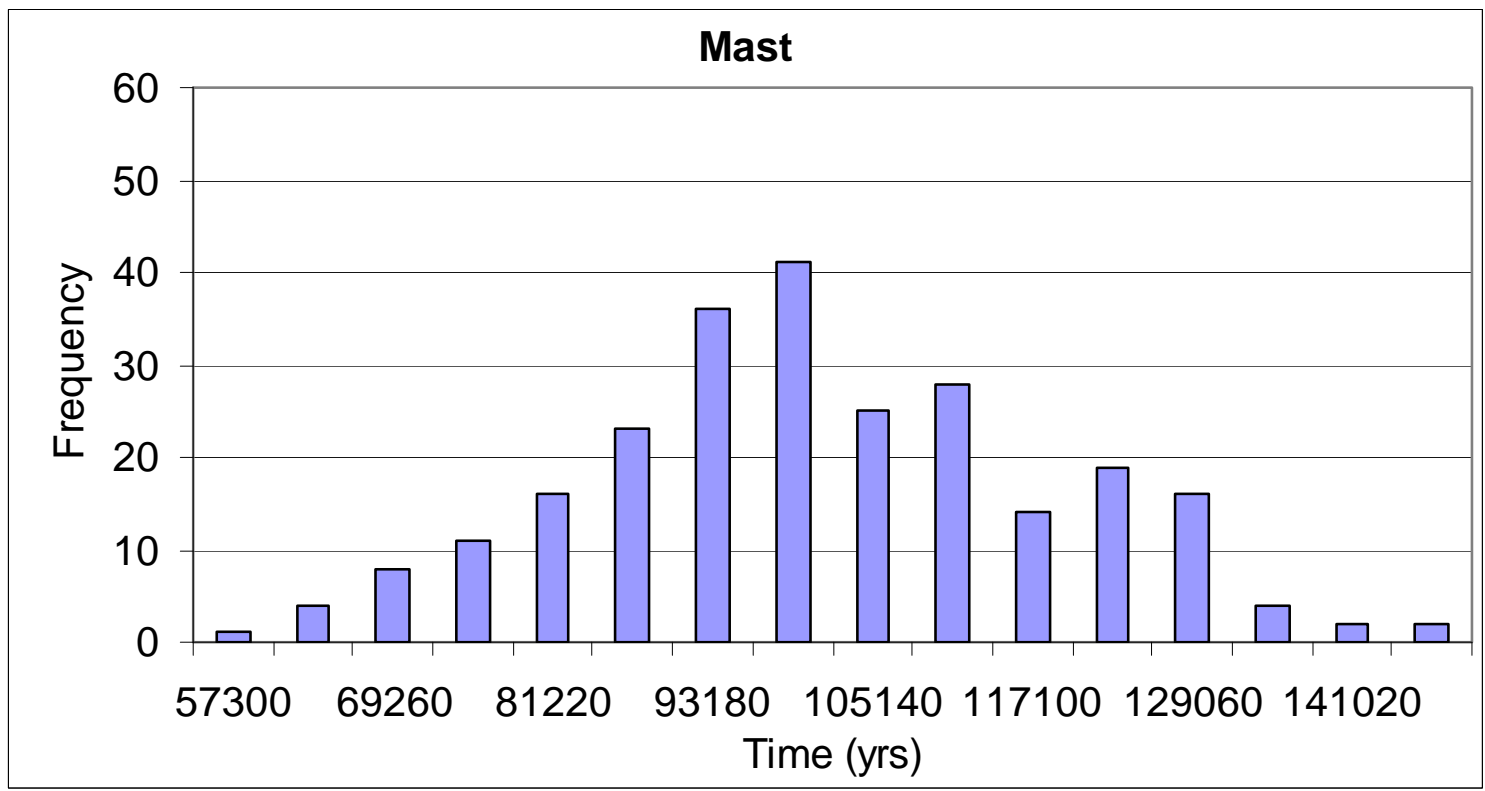

Figure C14. Distribution of minimum travel time from Mast to YM boundaries based on effective-porosity Set 1 for pre-pumping scenario. 


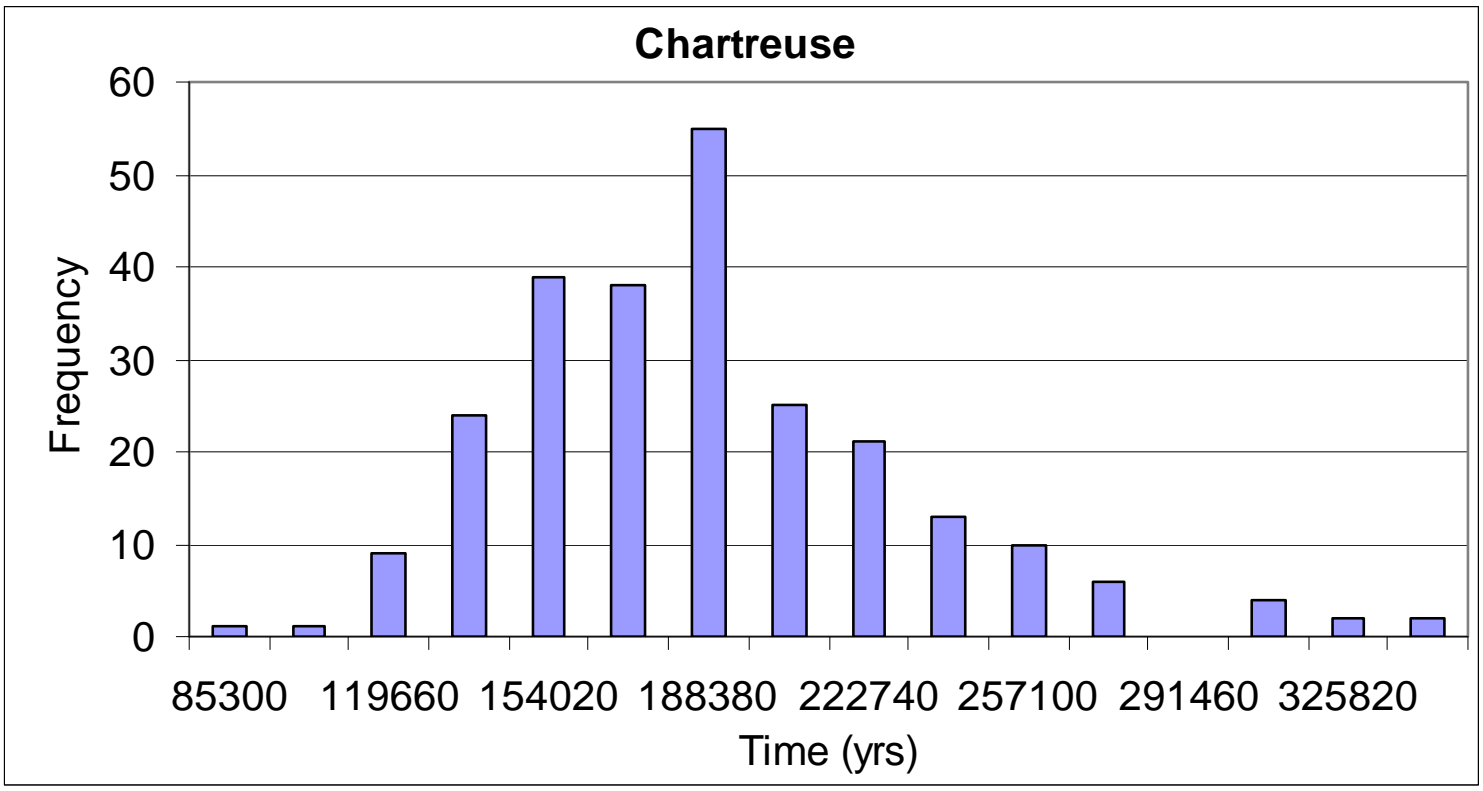

Figure C15. Distribution of minimum travel time from Chartreuse to YM boundaries based on effective-porosity Set 1 for pre-pumping scenario.

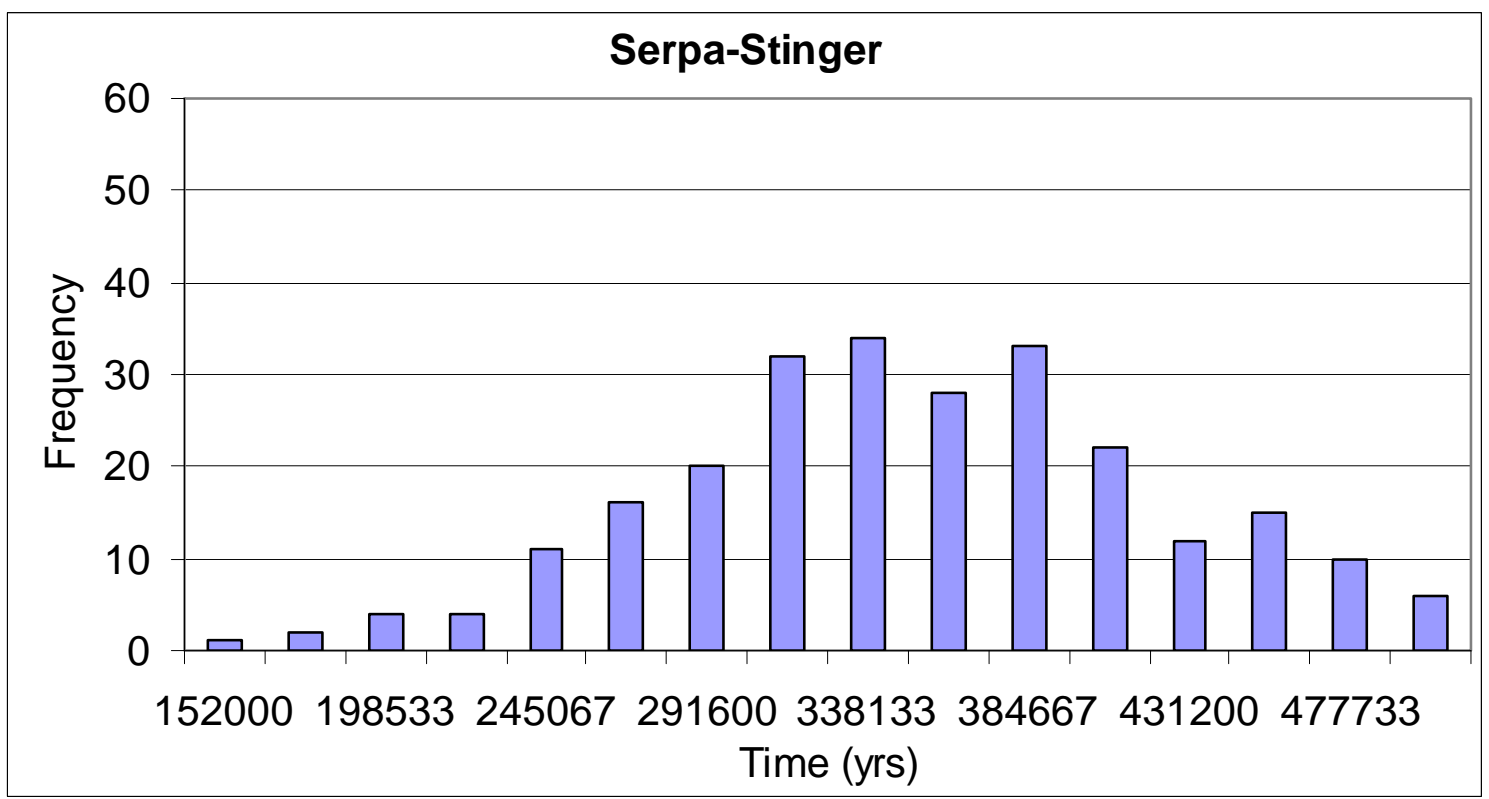

Figure C16. Distribution of minimum travel time from Serpa-Stinger to YM boundaries based on effective-porosity Set 1 for pre-pumping scenario. 


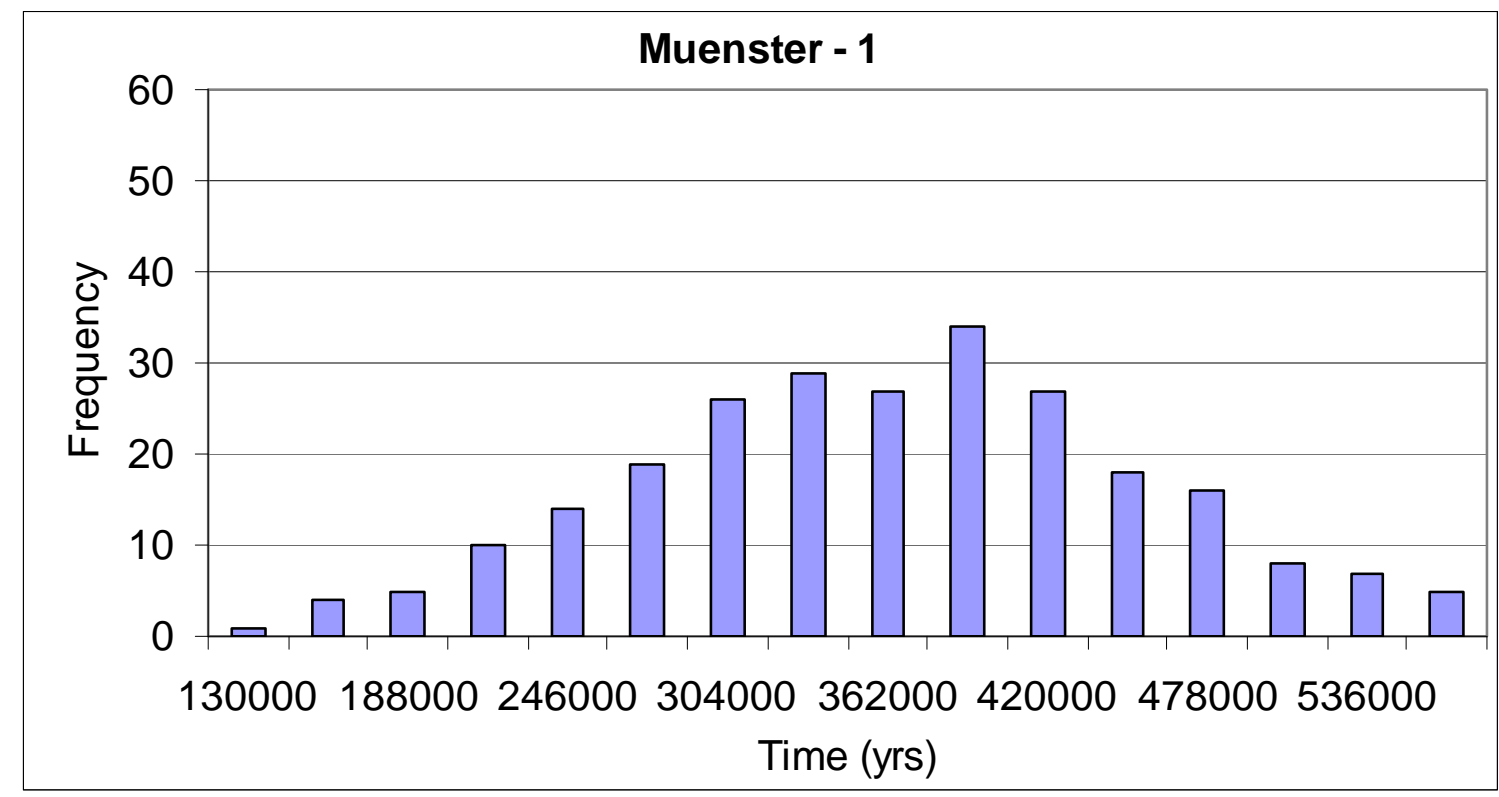

Figure C17. Distribution of minimum travel time from Muenster - 1 to YM boundaries based on effective-porosity Set 1 for pre-pumping scenario.

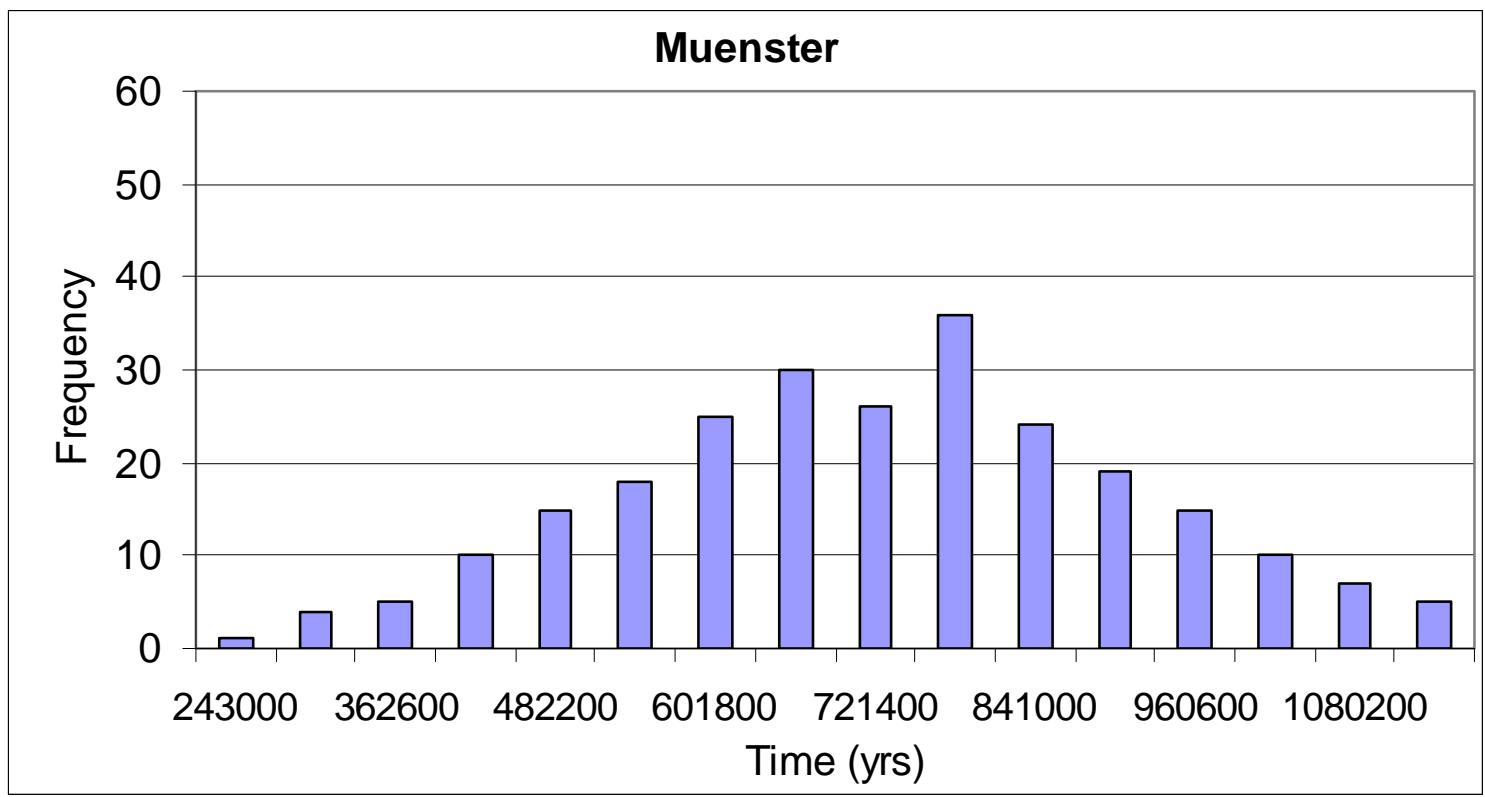

Figure C18. Distribution of minimum travel time from Muenster to YM boundaries based on effective-porosity Set 1 for pre-pumping scenario. 


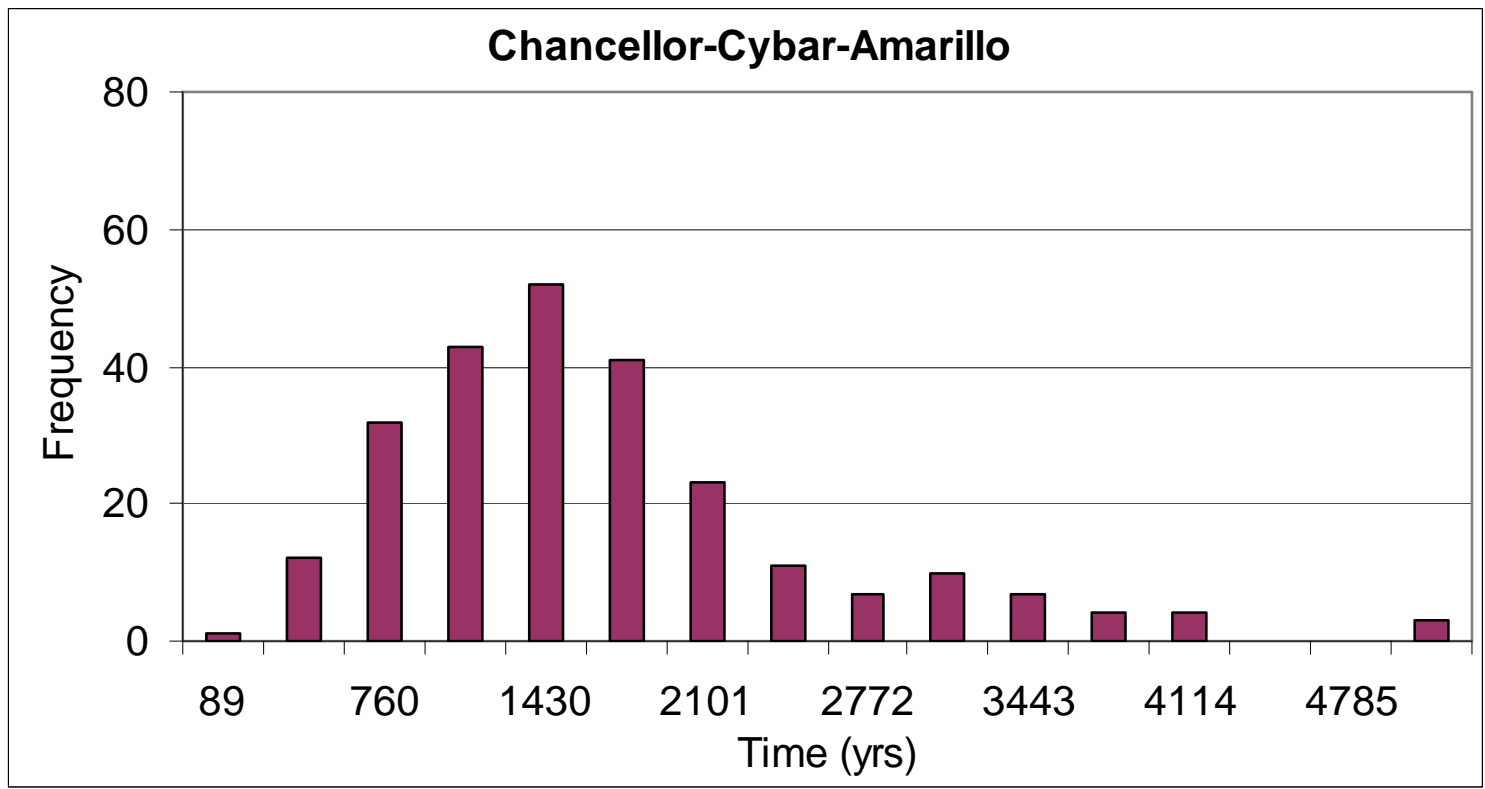

Figure C19. Distribution of minimum travel time from Chancellor-Cybar-Amarillo to YM boundaries based on effective-porosity Set 2 for pre-pumping scenario.

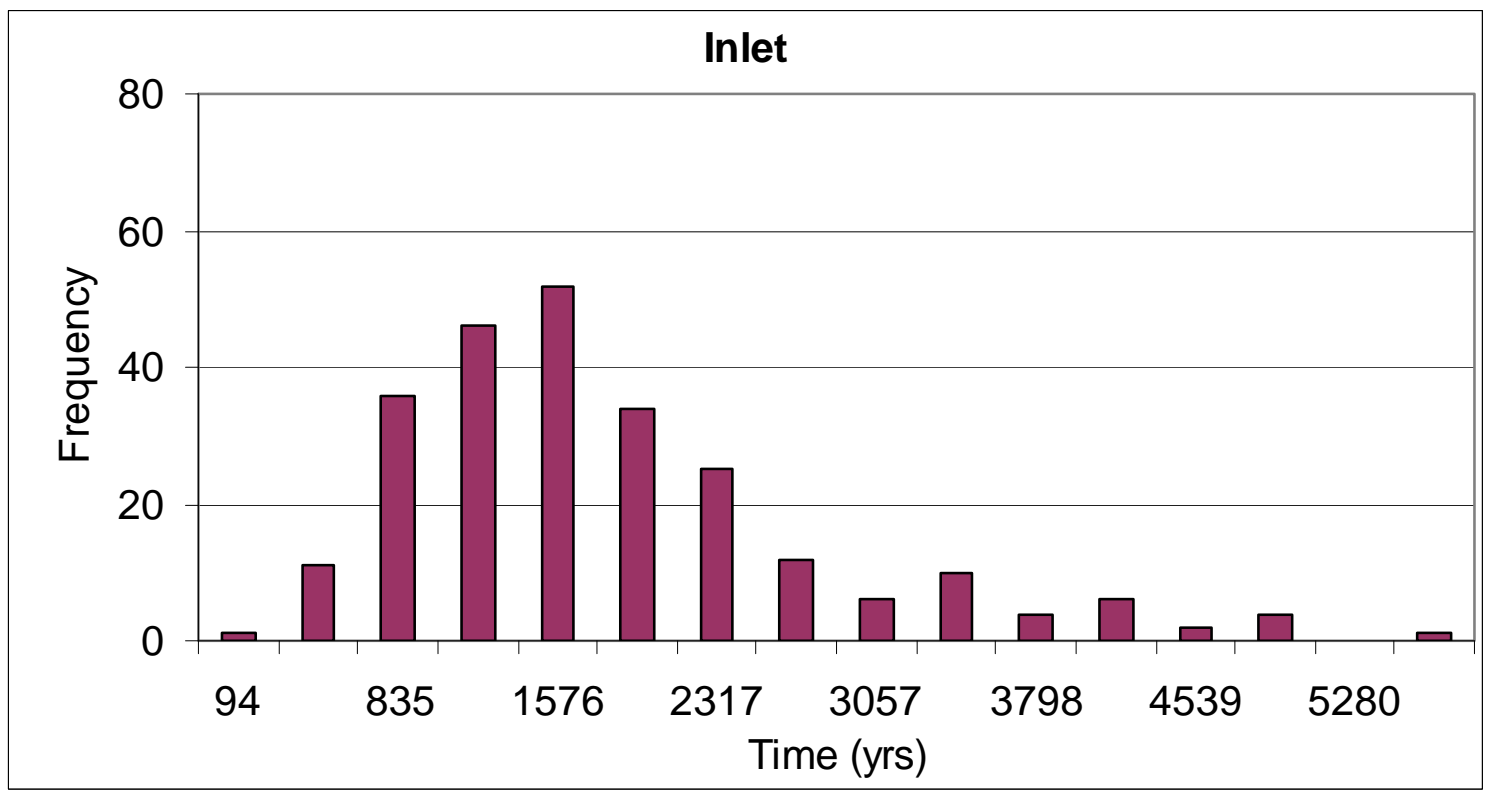

Figure C20. Distribution of minimum travel time from Inlet to YM boundaries based on effective-porosity Set 2 for pre-pumping scenario. 


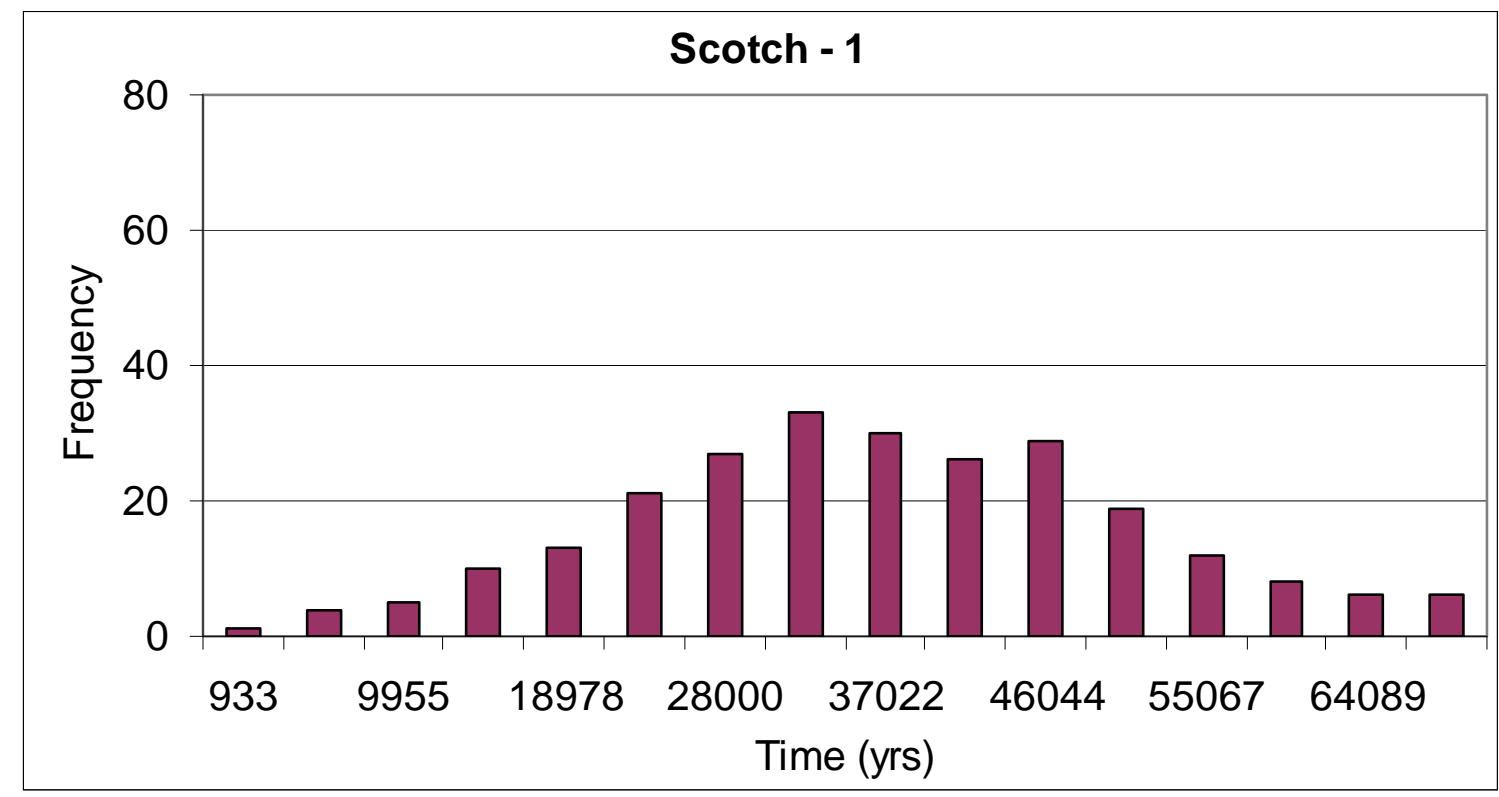

Figure C21. Distribution of minimum travel time from Scotch -1 to YM boundaries based on effective-porosity Set 2 for pre-pumping scenario.

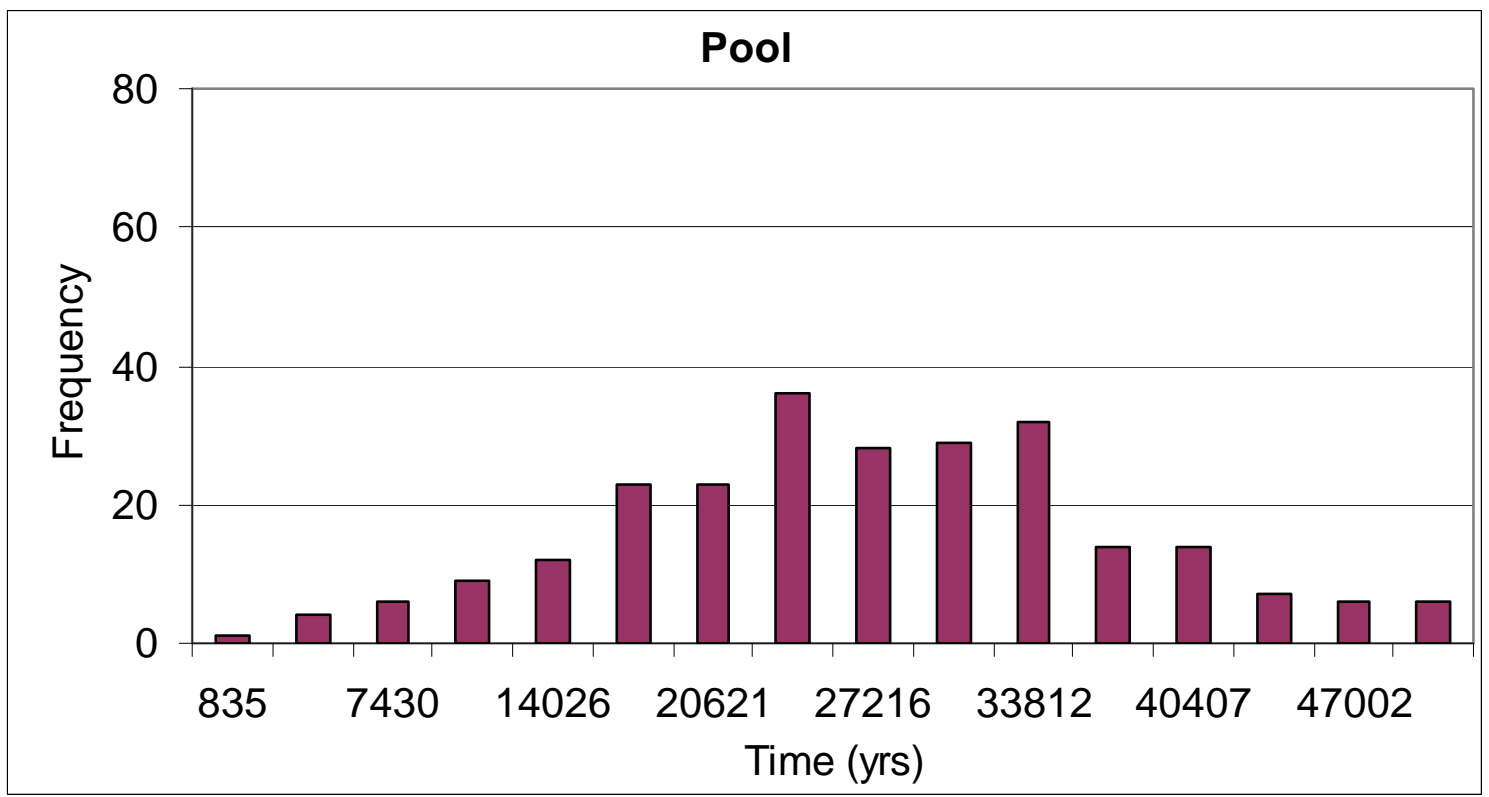

Figure C22. Distribution of minimum travel time from Pool to YM boundaries based on effective-porosity Set 2 for pre-pumping scenario. 


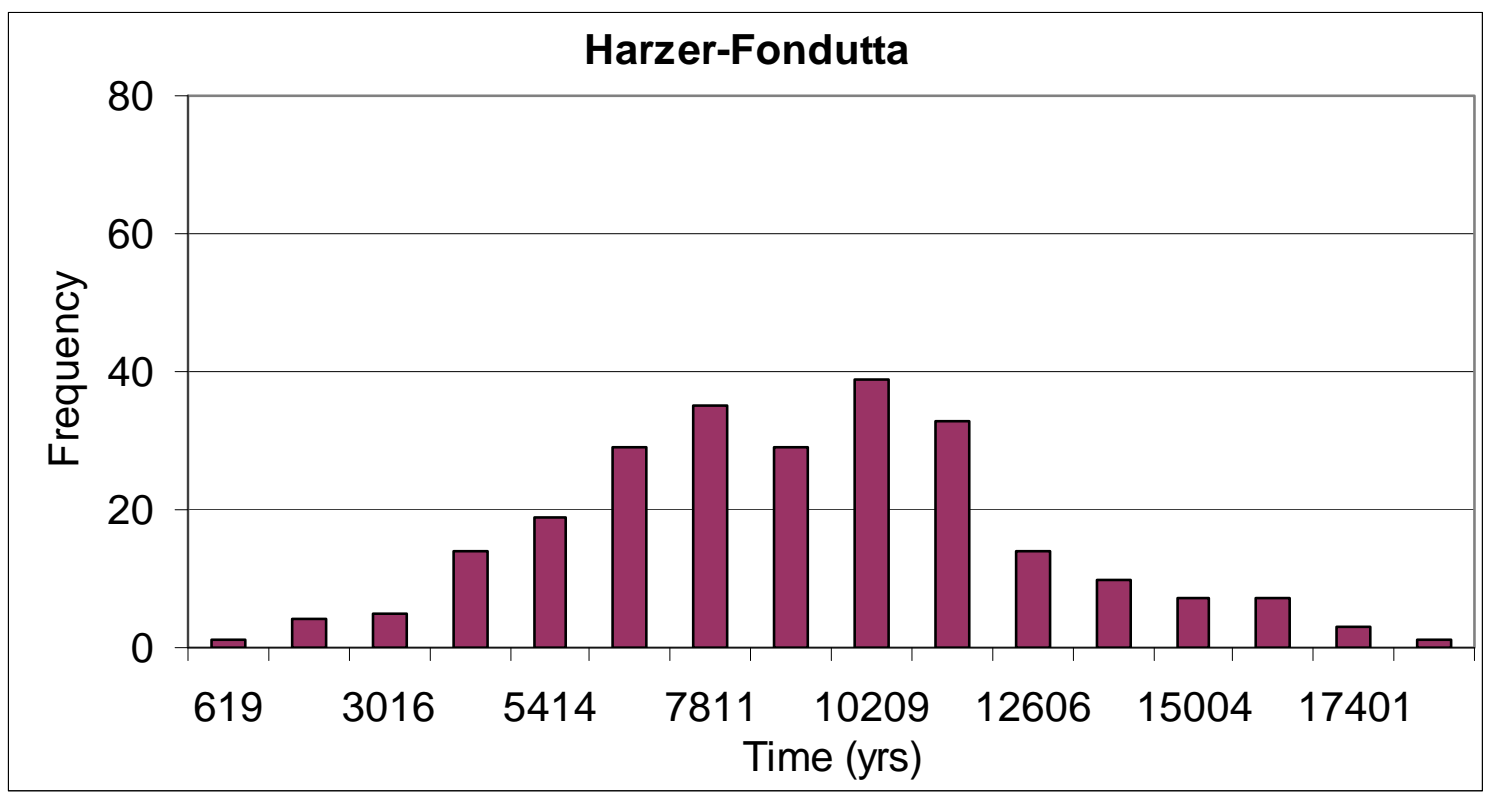

Figure C23. Distribution of minimum travel time from Harzer-Fondutta to YM boundaries based on effective-porosity Set 2 for pre-pumping scenario.

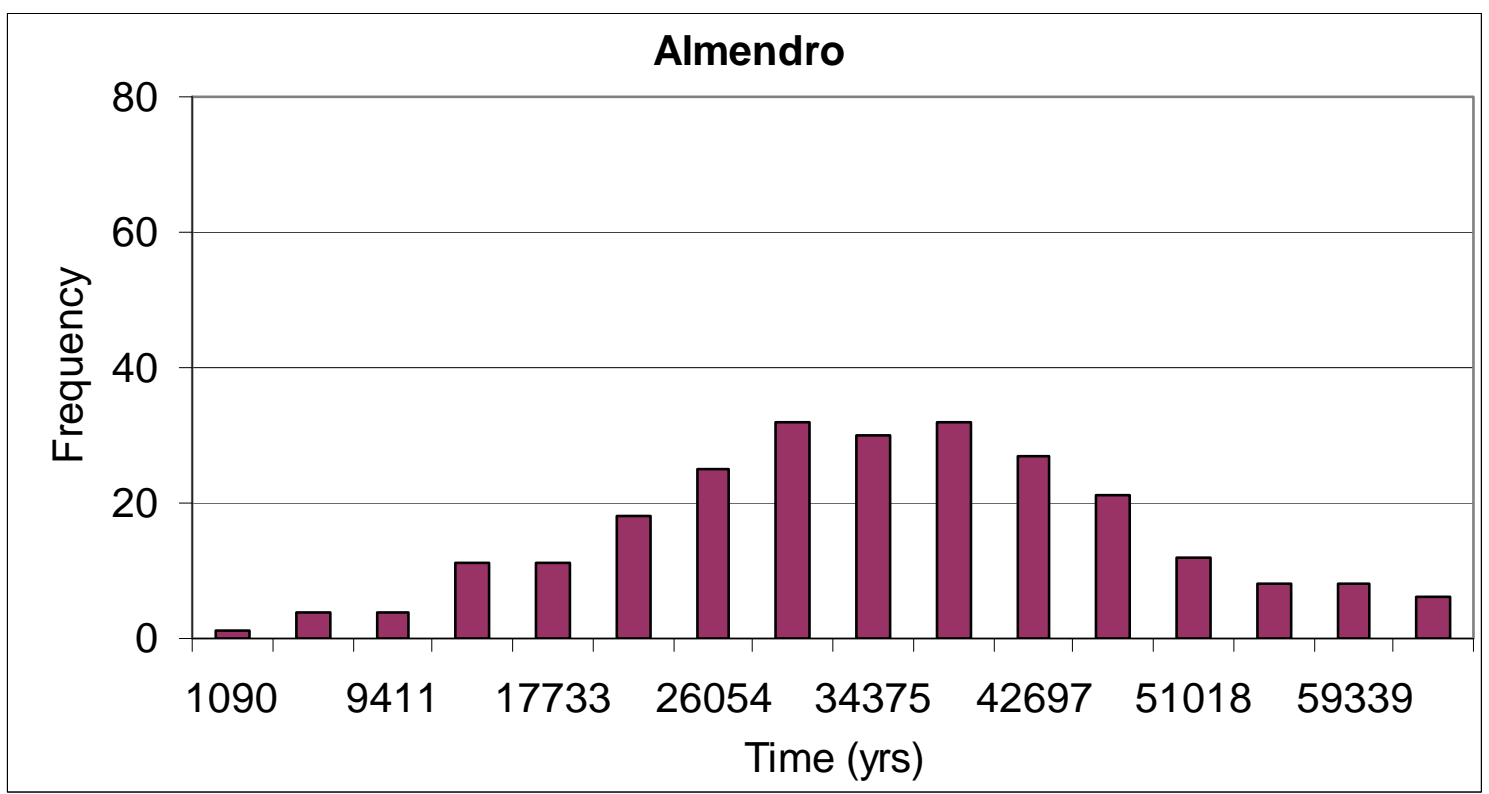

Figure C24. Distribution of minimum travel time from Almendro to YM boundaries based on effective-porosity Set 2 for pre-pumping scenario. 


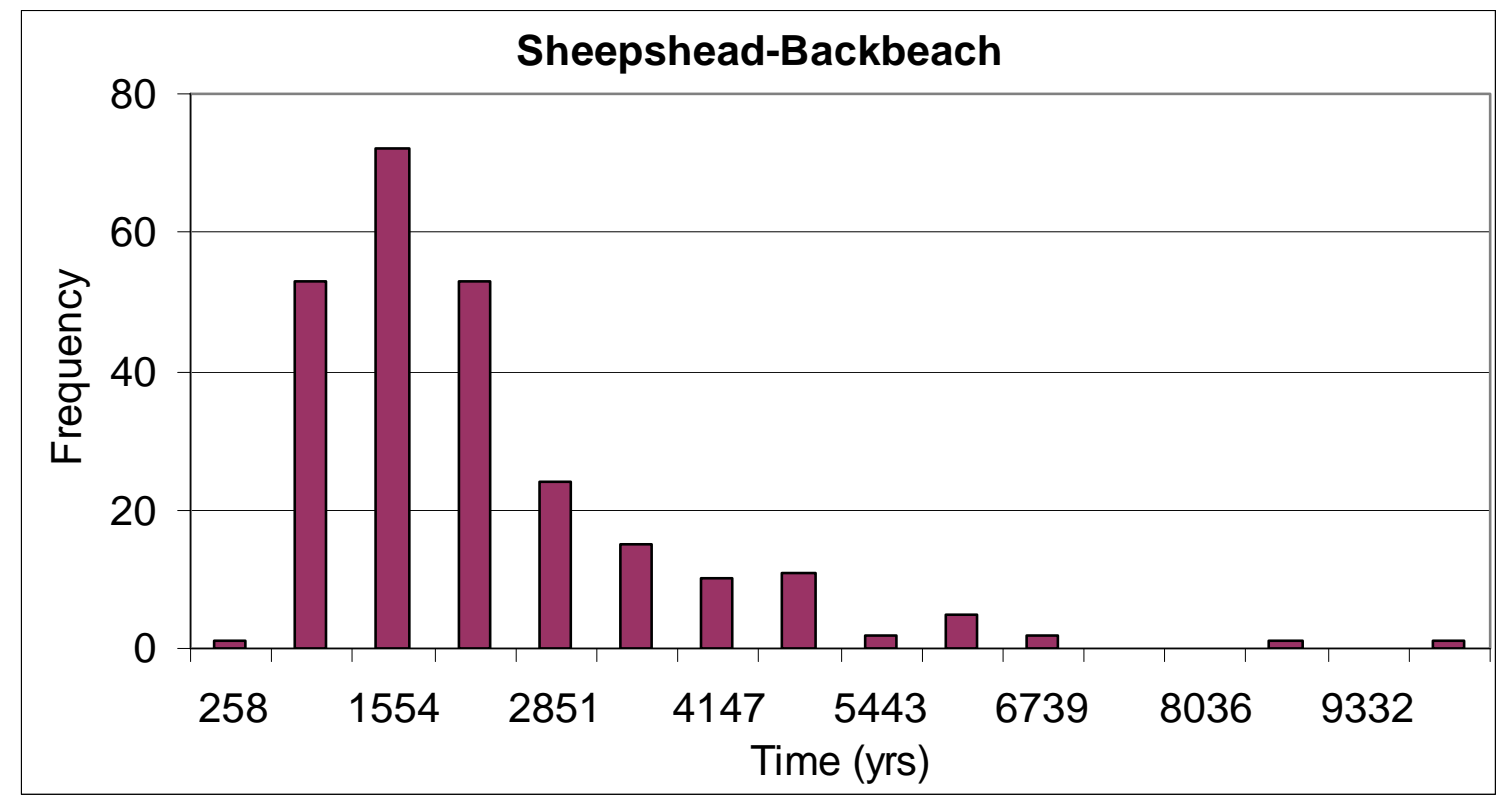

Figure C25. Distribution of minimum travel time from Sheepshead-Backbeach to YM boundaries based on effective-porosity Set 2 for pre-pumping scenario.

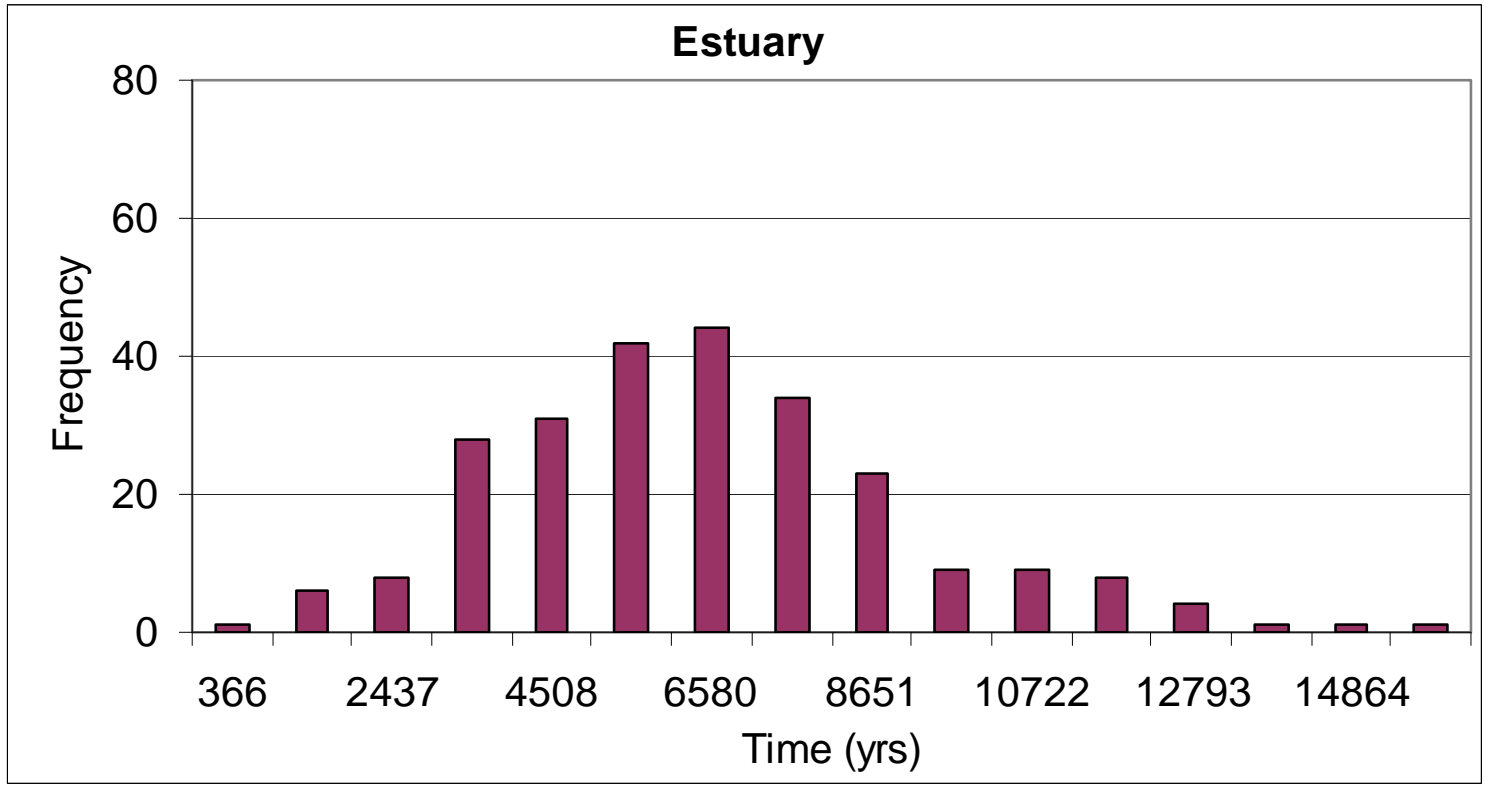

Figure C26. Distribution of minimum travel time from Estuary to YM boundaries based on effective-porosity Set 2 for pre-pumping scenario. 


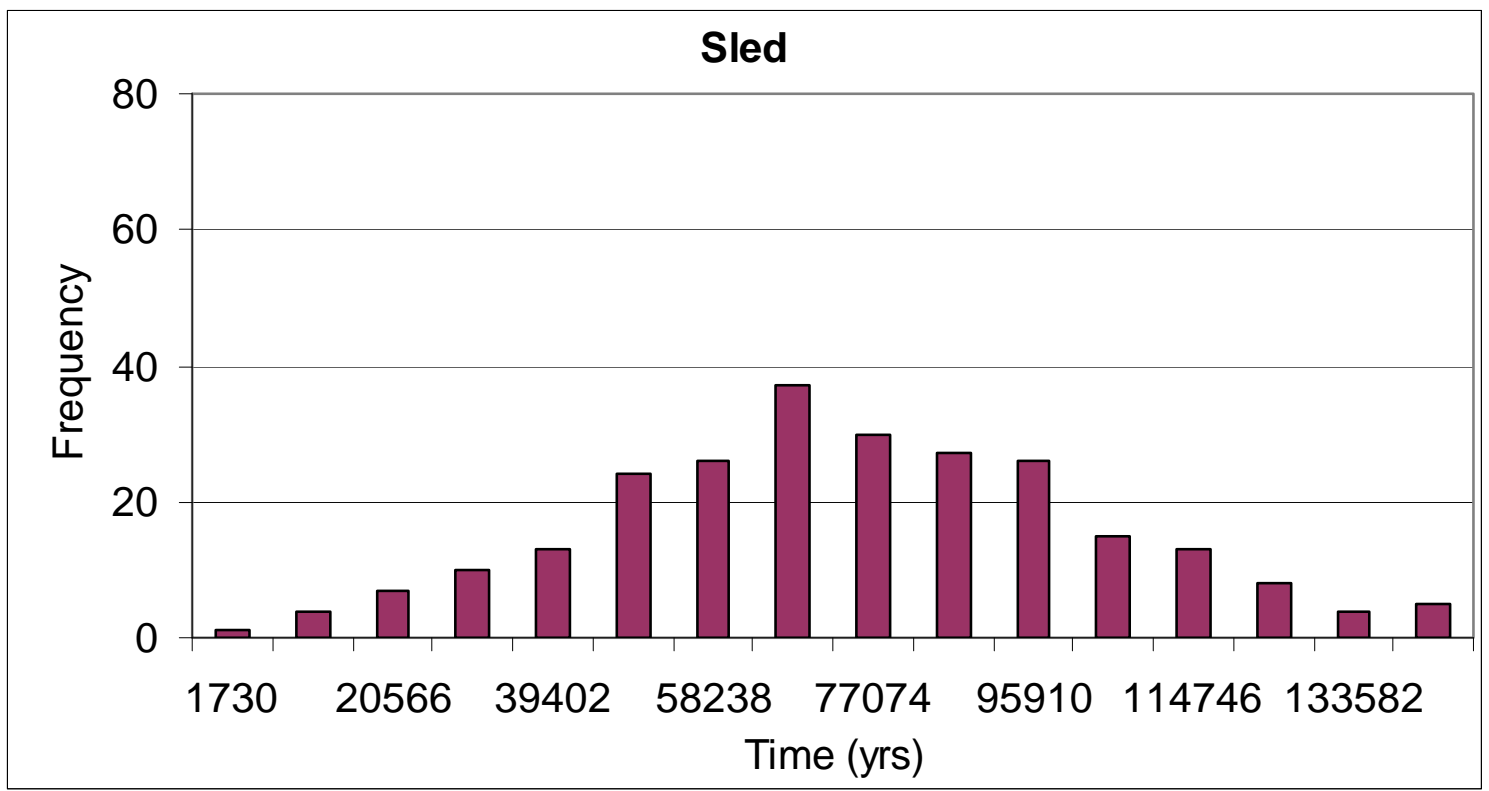

Figure C27. Distribution of minimum travel time from Sled to YM boundaries based on effective-porosity Set 2 for pre-pumping scenario.

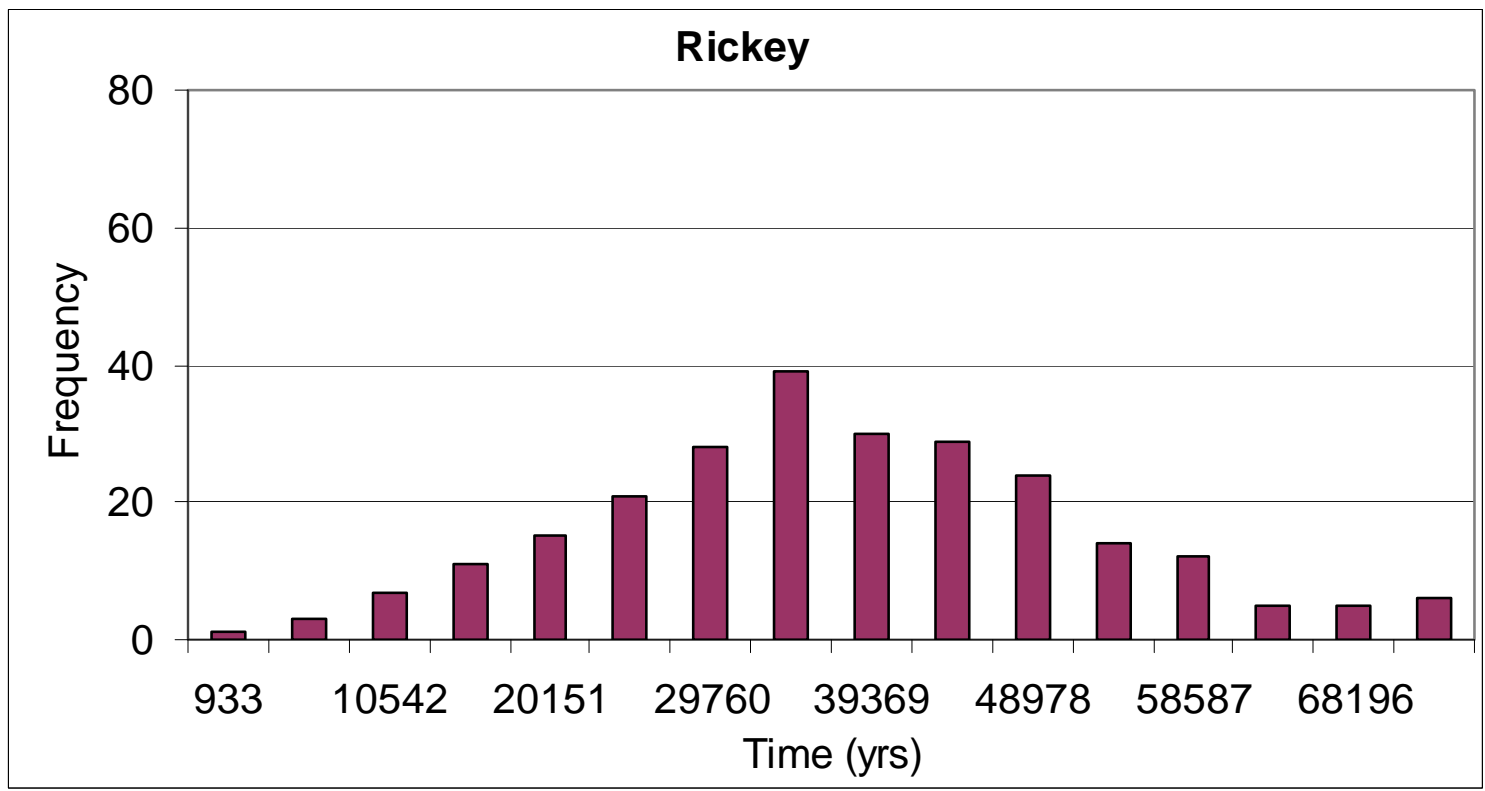

Figure C28. Distribution of minimum travel time from Ricky to YM boundaries based on effective-porosity Set 2 for pre-pumping scenario. 


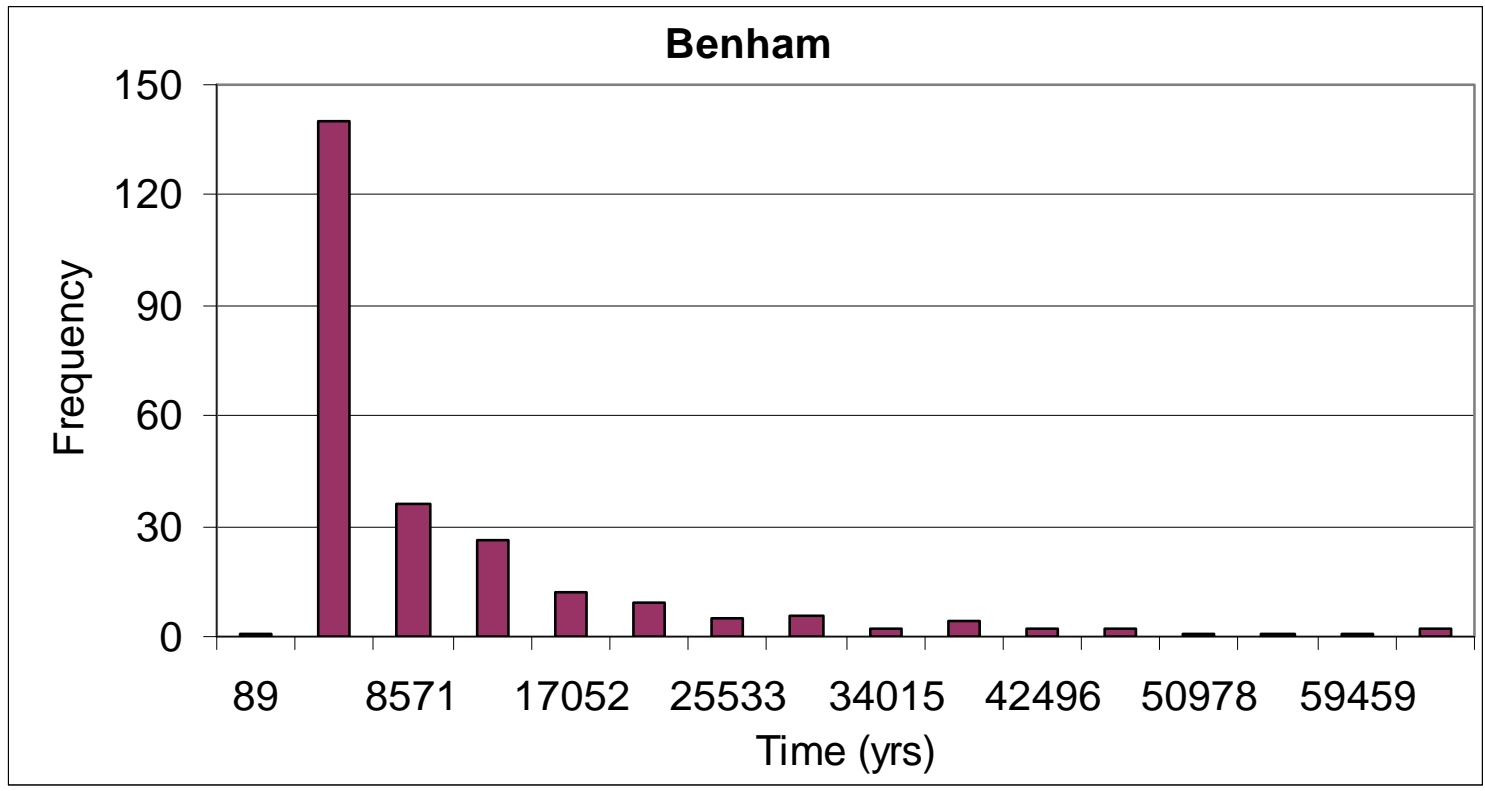

Figure C29. Distribution of minimum travel time from Benham to YM boundaries based on effective-porosity Set 2 for pre-pumping scenario.

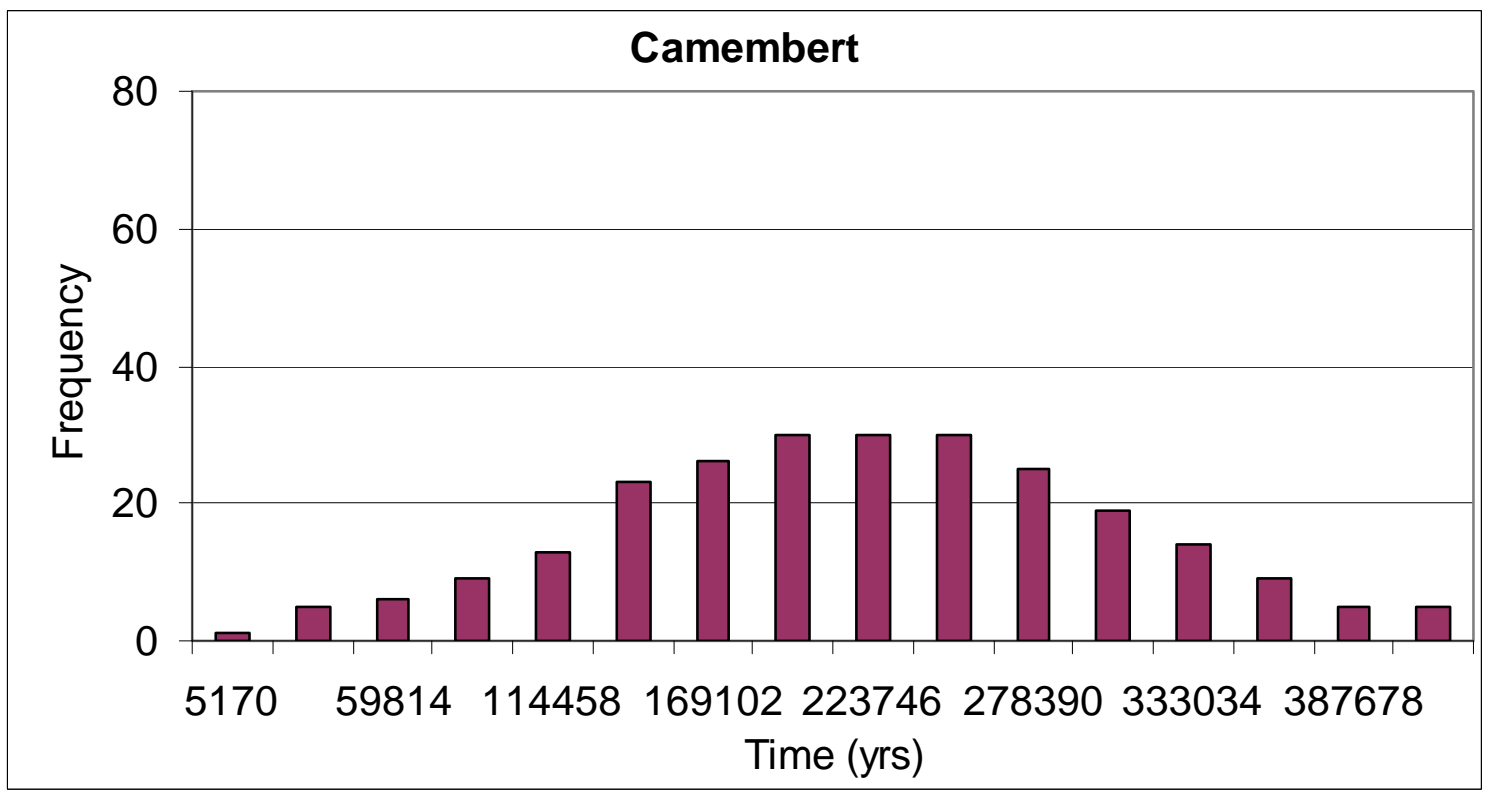

Figure C30. Distribution of minimum travel time from Camembert to YM boundaries based on effective-porosity Set 2 for pre-pumping scenario. 


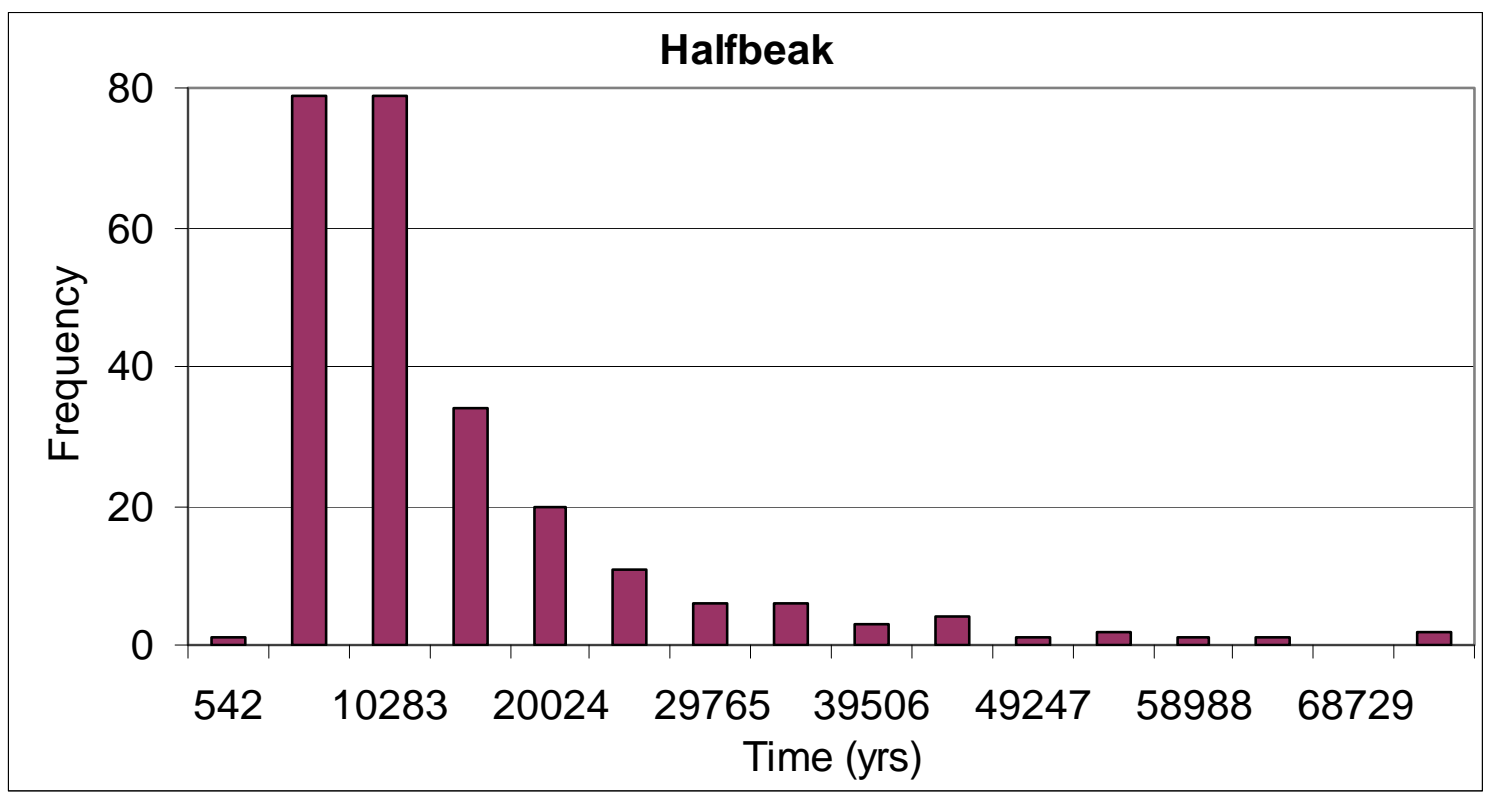

Figure C31. Distribution of minimum travel time from Halfbeak to YM boundaries based on effective-porosity Set 2 for pre-pumping scenario.

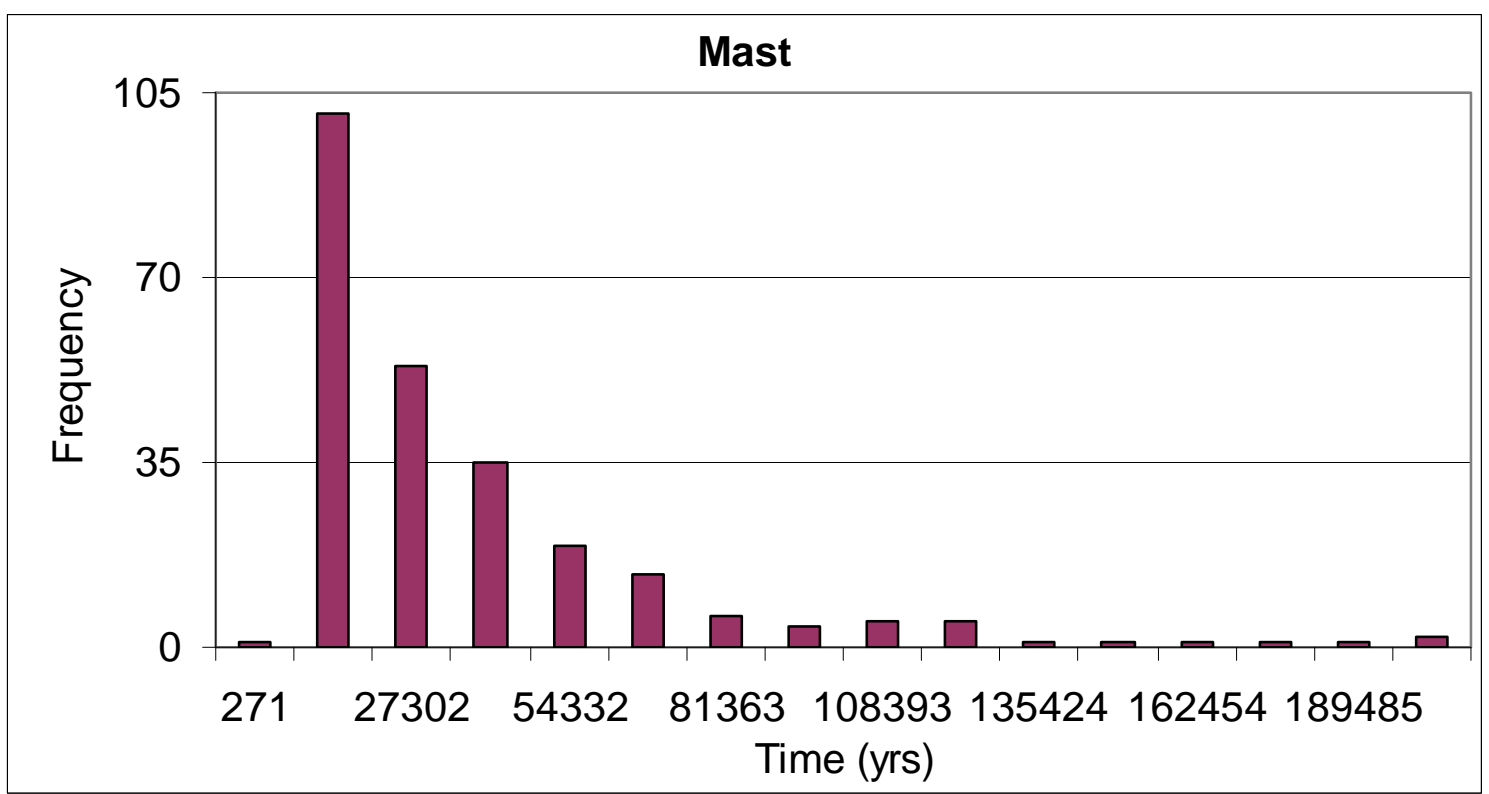

Figure C32. Distribution of minimum travel time from Mast to YM boundaries based on effective-porosity Set 2 for pre-pumping scenario. 


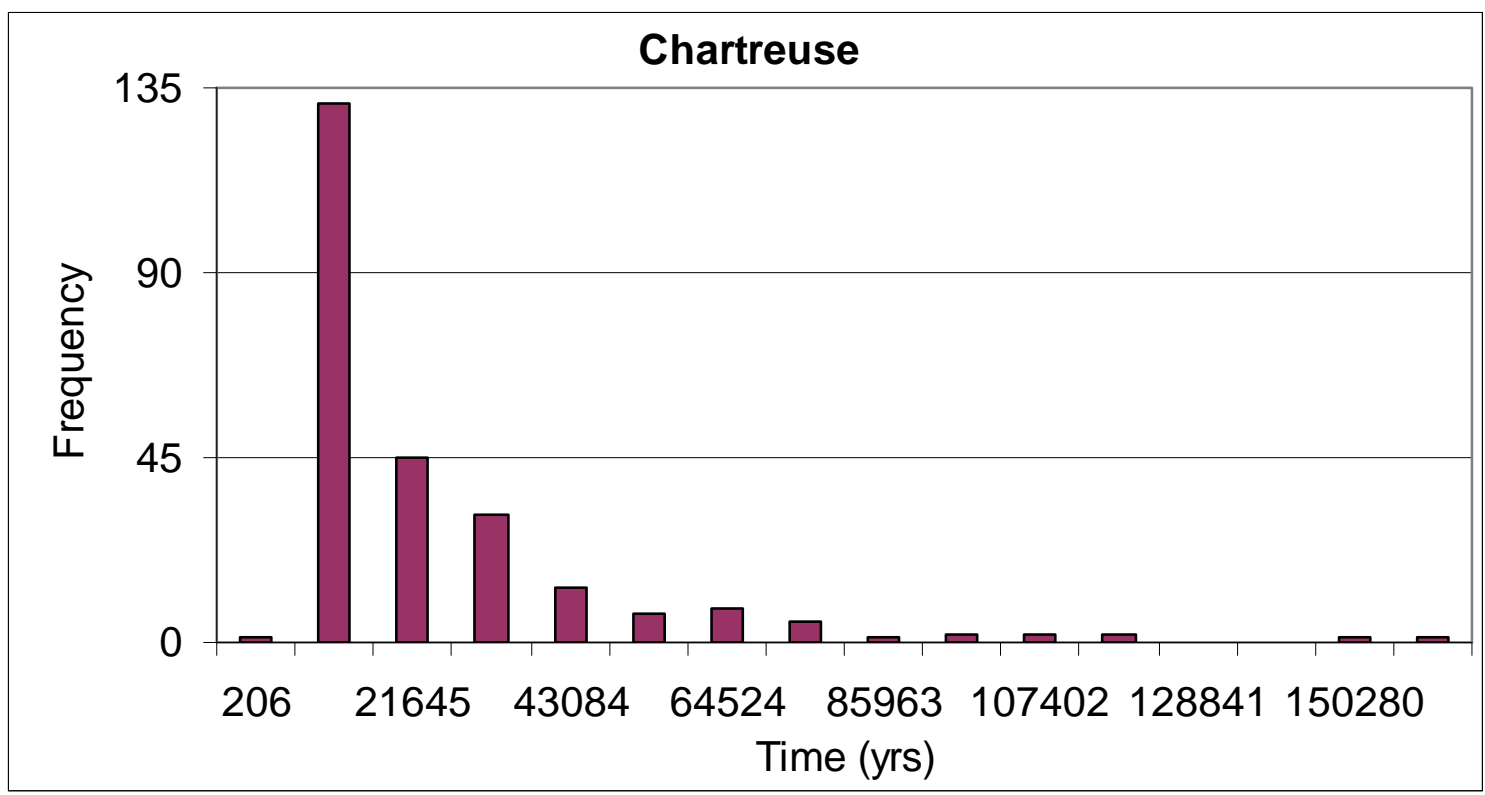

Figure C33. Distribution of minimum travel time from Chartreuse to YM boundaries based on effective-porosity Set 2 for pre-pumping scenario.

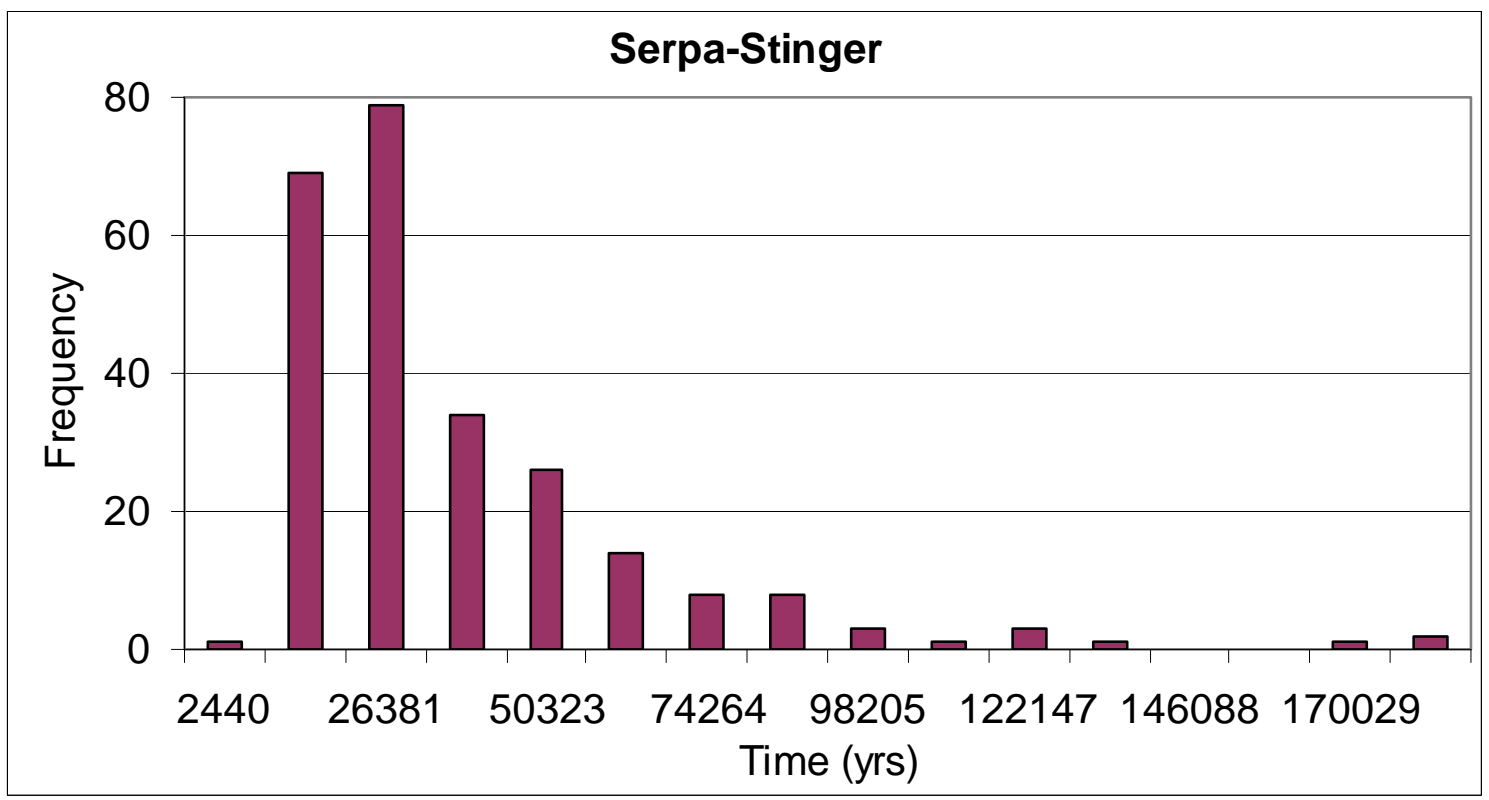

Figure C34. Distribution of minimum travel time from Serpa-Stinger to YM boundaries based on effective-porosity Set 2 for pre-pumping scenario. 


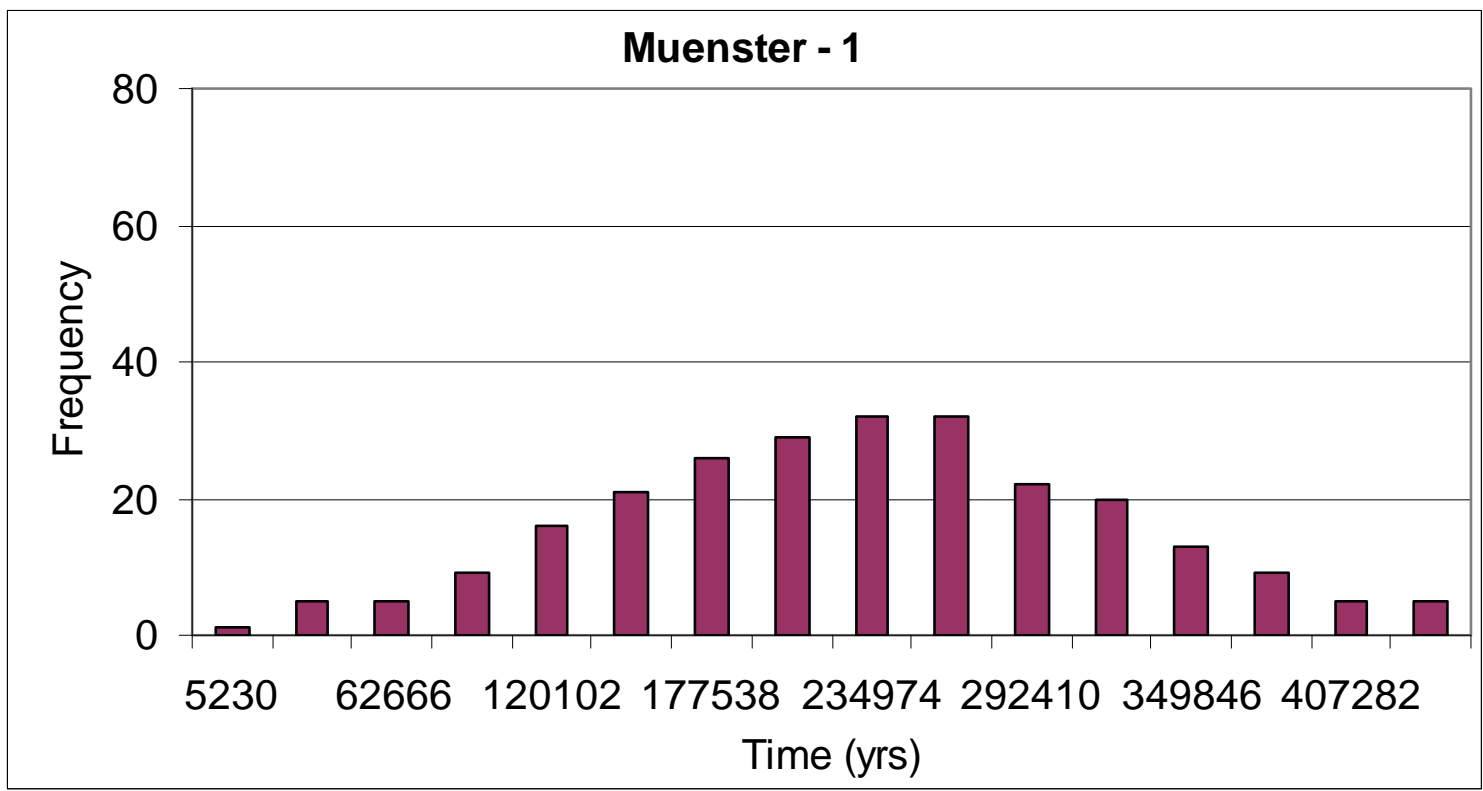

Figure C35. Distribution of minimum travel time from Muenster - 1 to YM boundaries based on effective-porosity Set 2 for pre-pumping scenario.

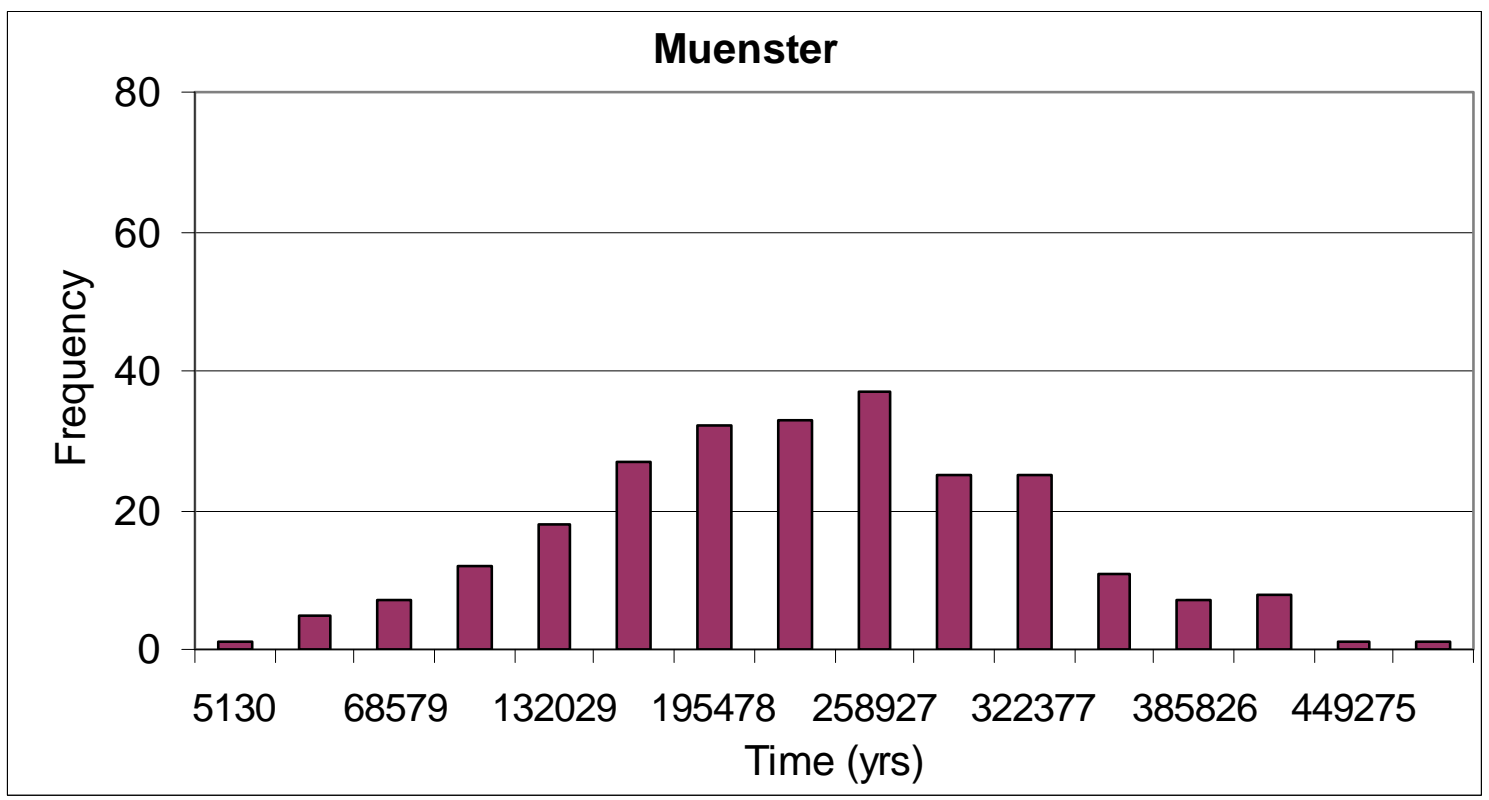

Figure C36. Distribution of minimum travel time from Muenster to YM boundaries based on effective-porosity Set 2 for pre-pumping scenario. 


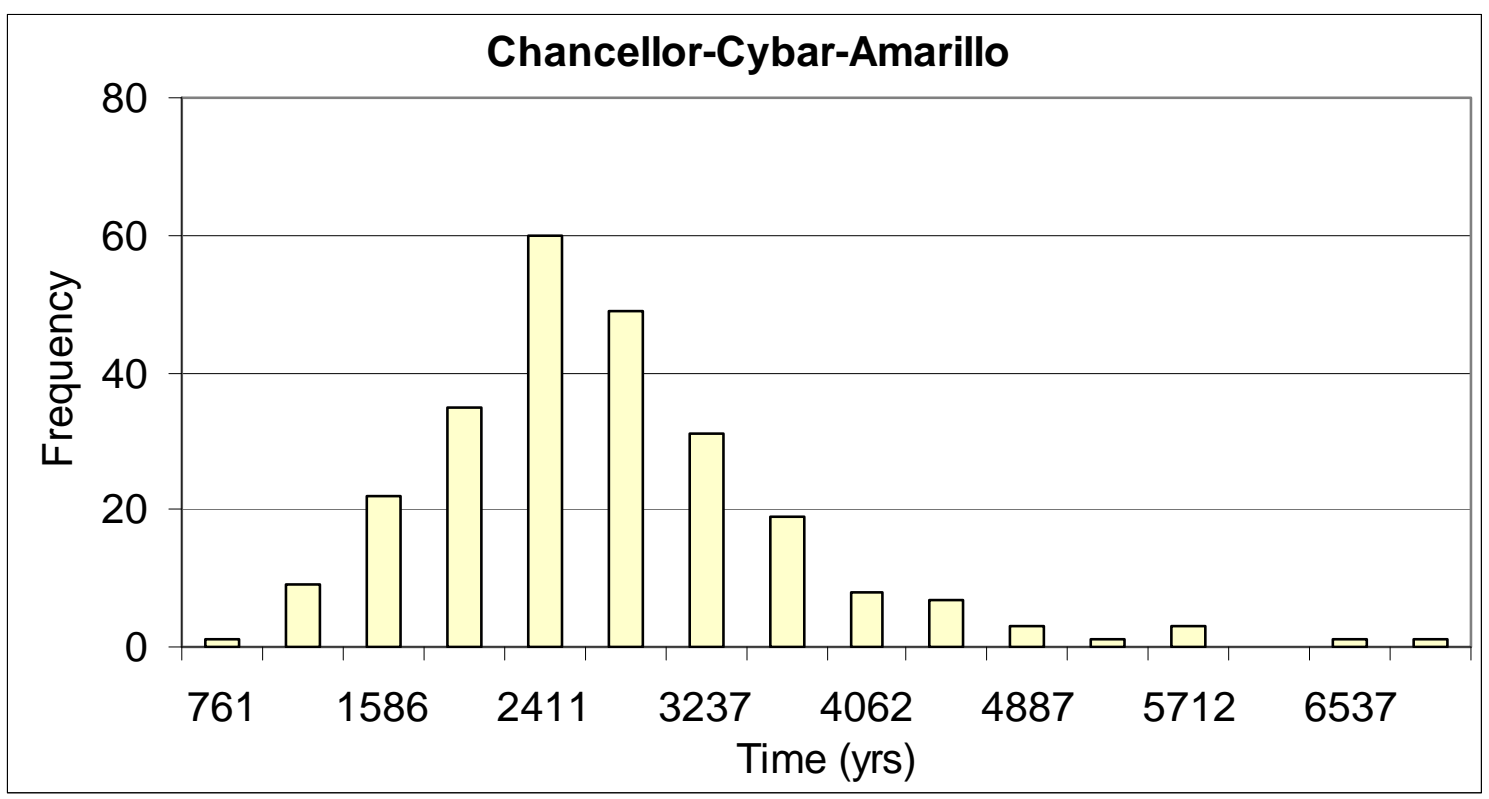

Figure C37. Distribution of minimum travel time from Chancellor-Cybar-Amarillo to YM boundaries based on effective-porosity Set 3 for pre-pumping scenario.

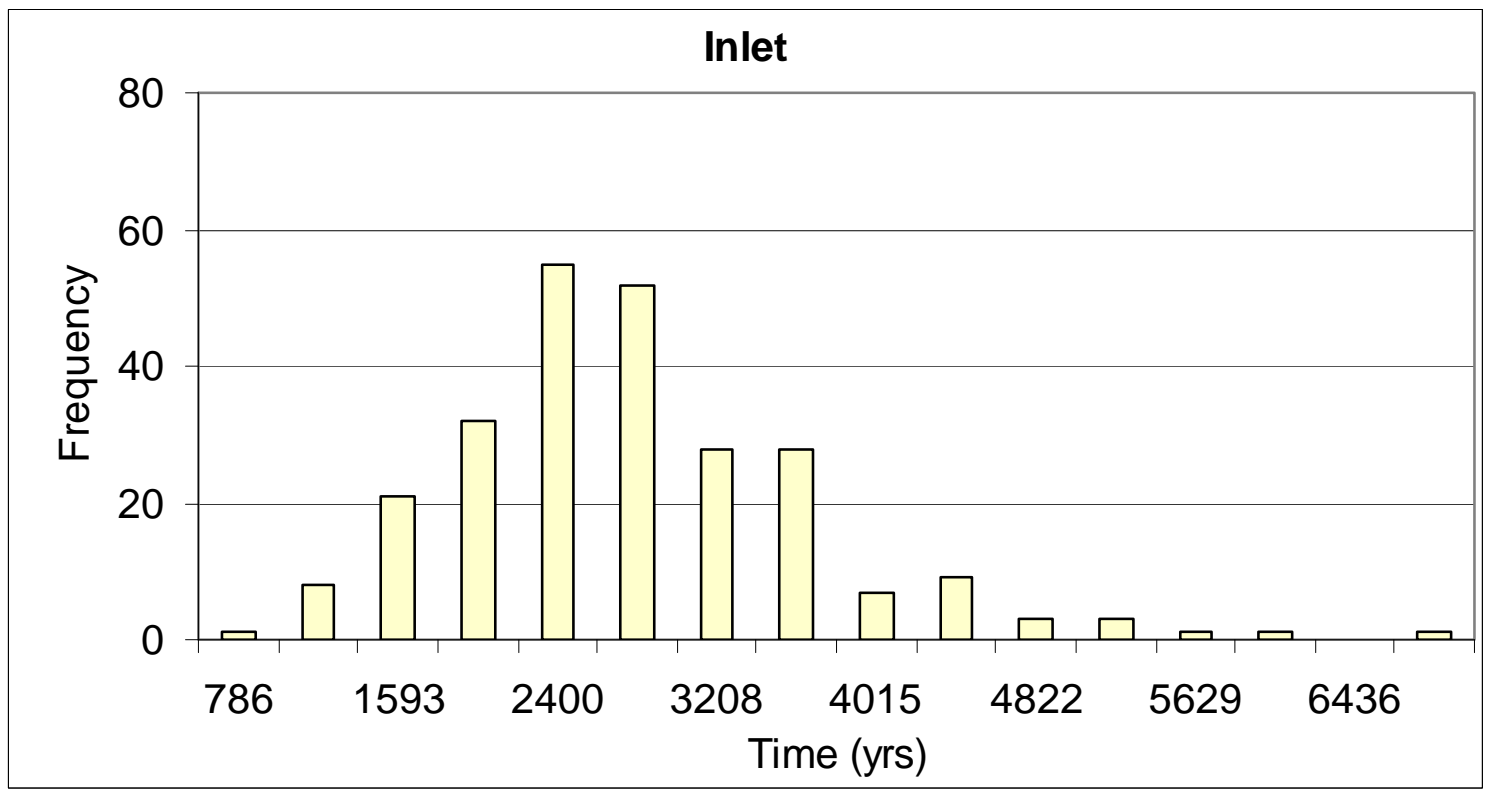

Figure C38. Distribution of minimum travel time from Inlet to YM boundaries based on effective-porosity Set 3 for pre-pumping scenario. 


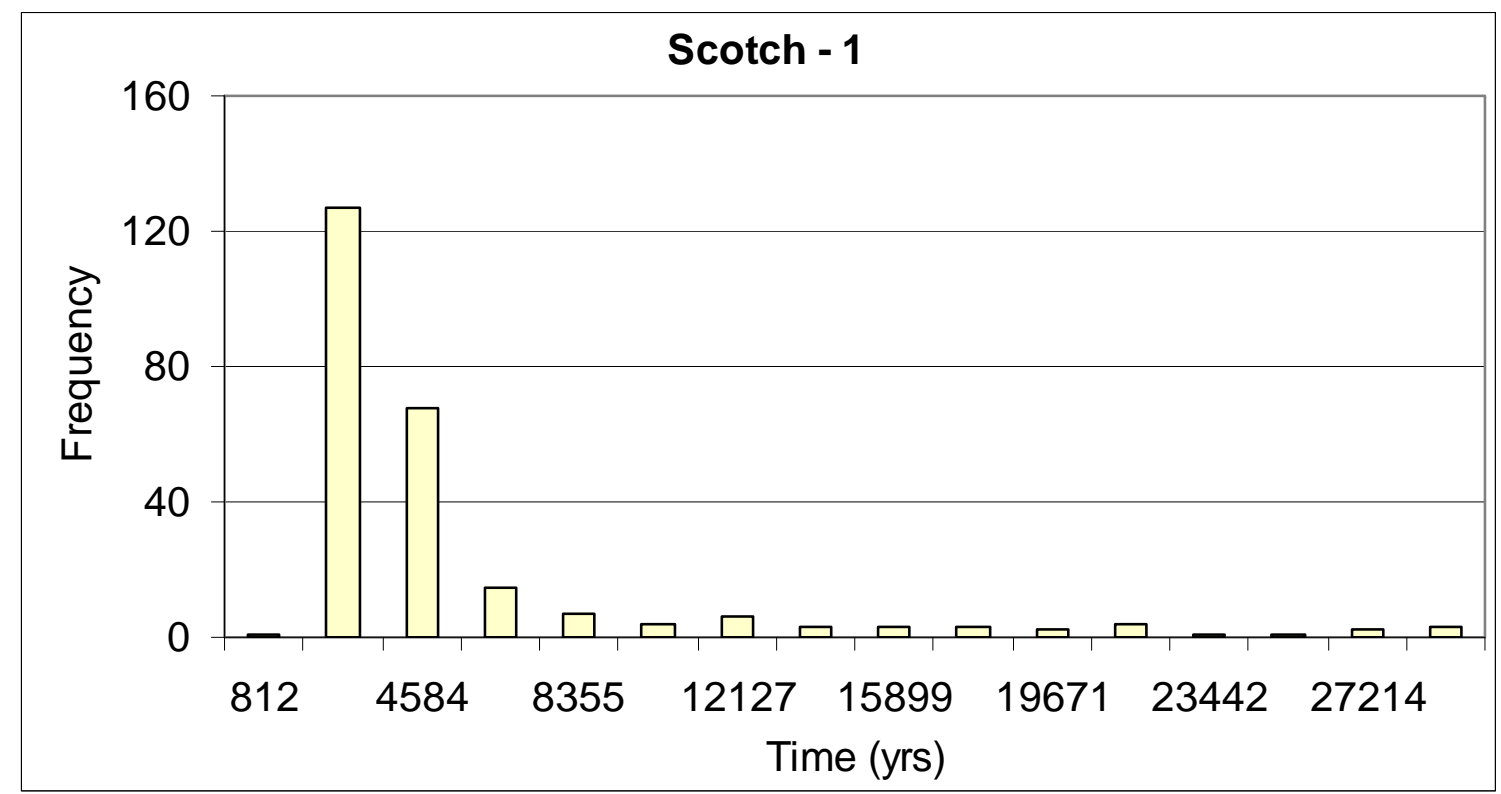

Figure C39. Distribution of minimum travel time from Scotch -1 to YM boundaries based on effective-porosity Set 3 for pre-pumping scenario.

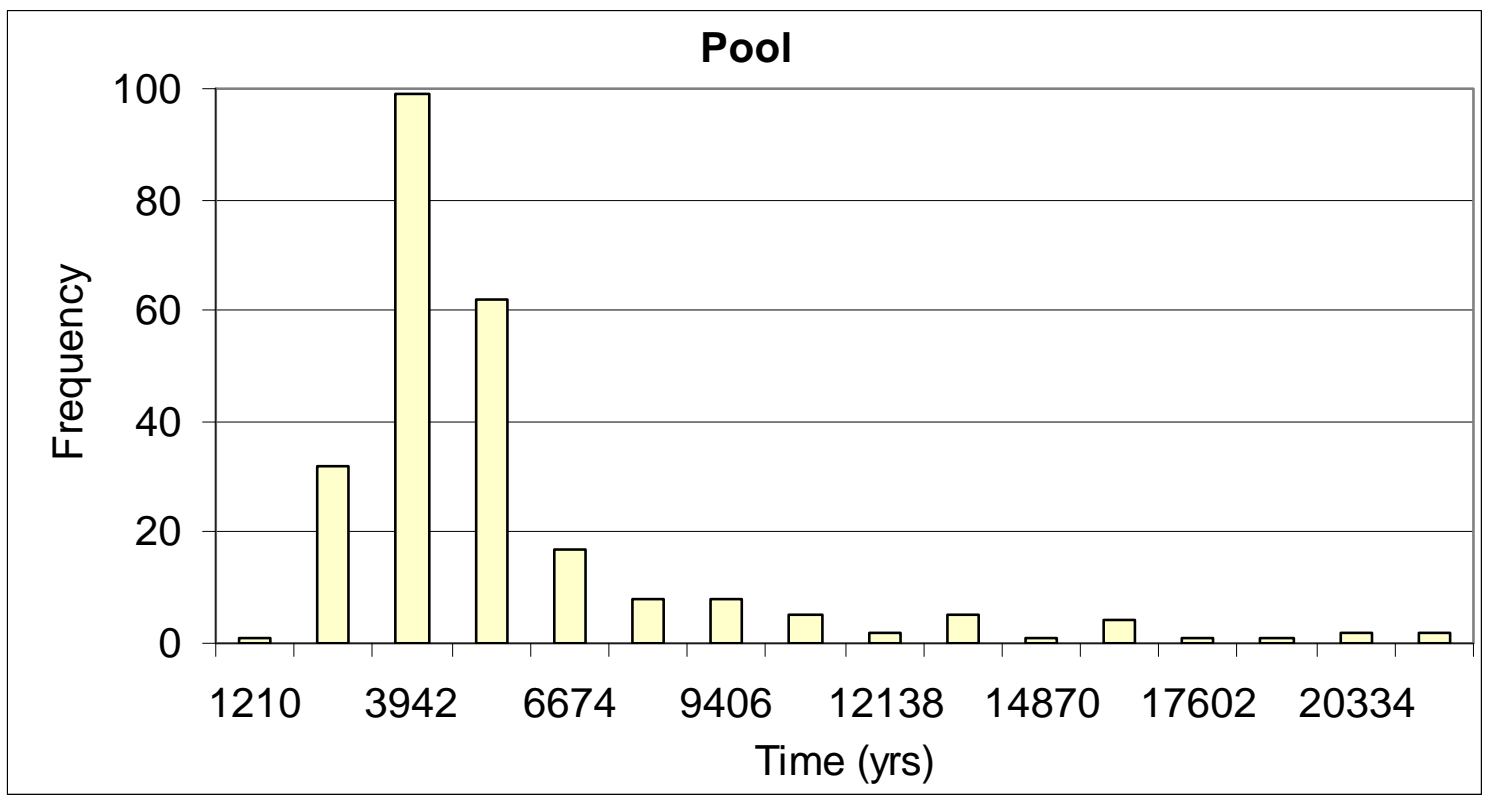

Figure C40. Distribution of minimum travel time from Pool to YM boundaries based on effective-porosity Set 3 for pre-pumping scenario. 


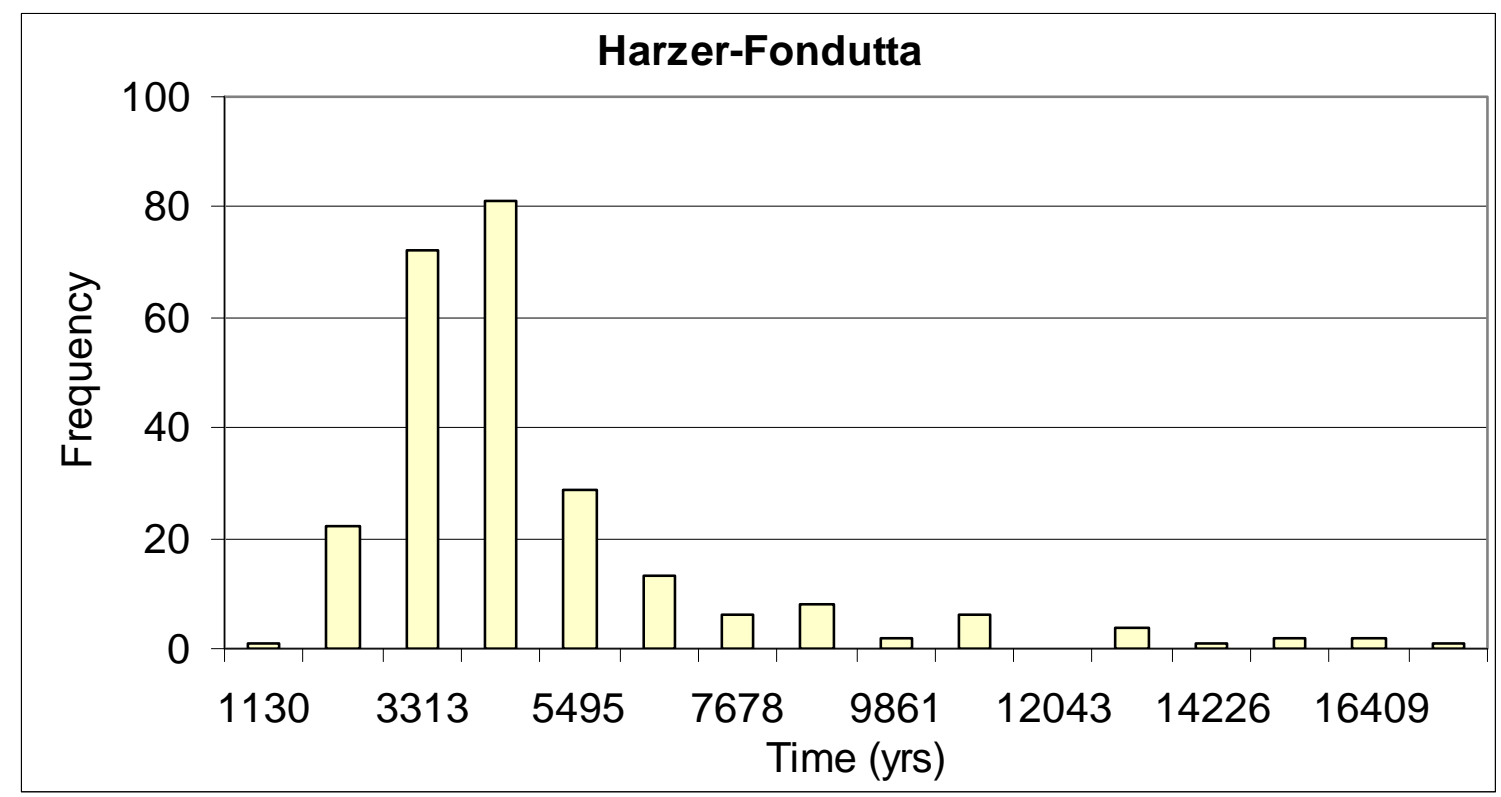

Figure C41. Distribution of minimum travel time from Harzer-Fondutta to YM boundaries based on effective-porosity Set 3 for pre-pumping scenario.

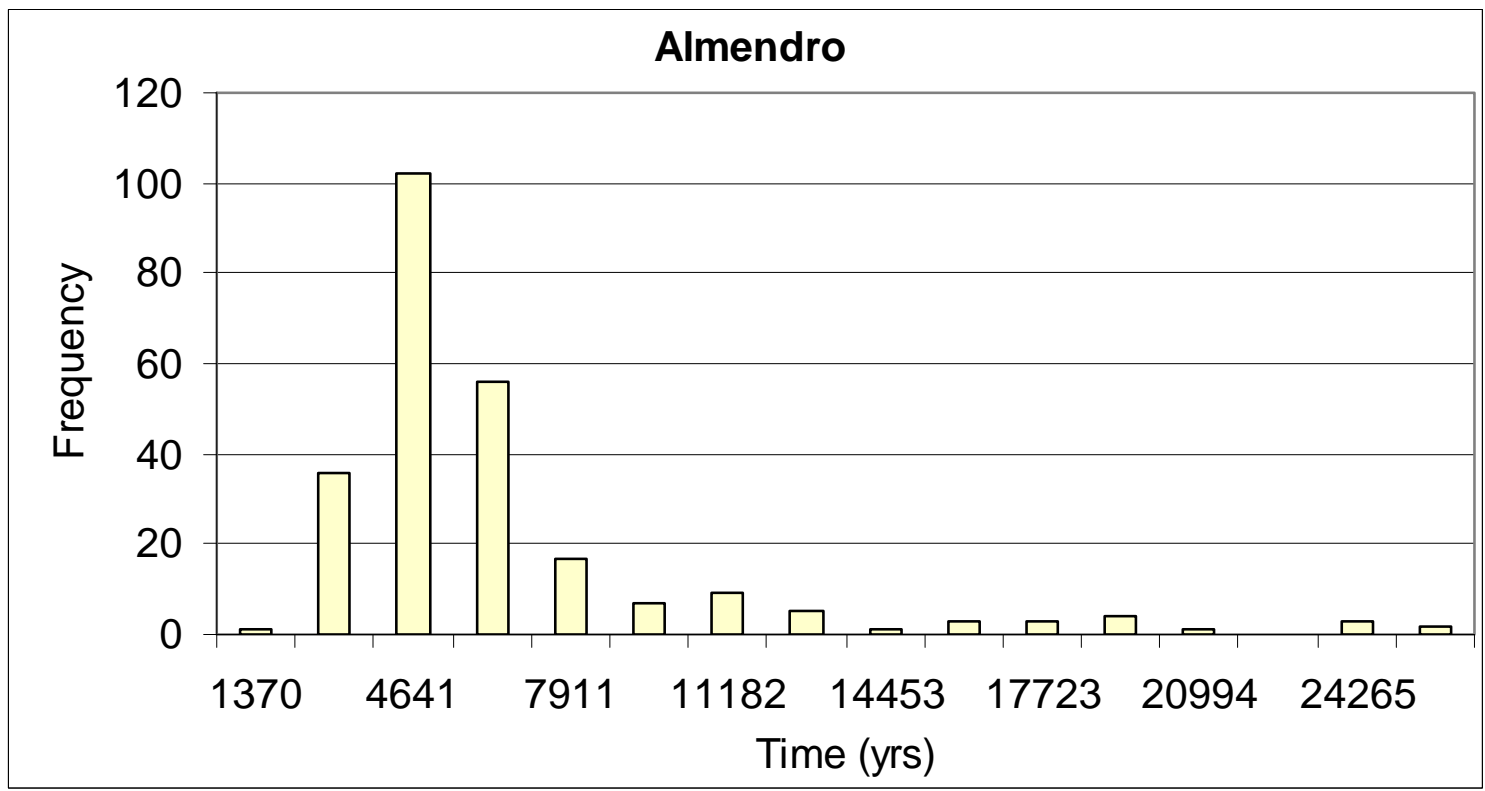

Figure C42. Distribution of minimum travel time from Almendro to YM boundaries based on effective-porosity Set 3 for pre-pumping scenario. 


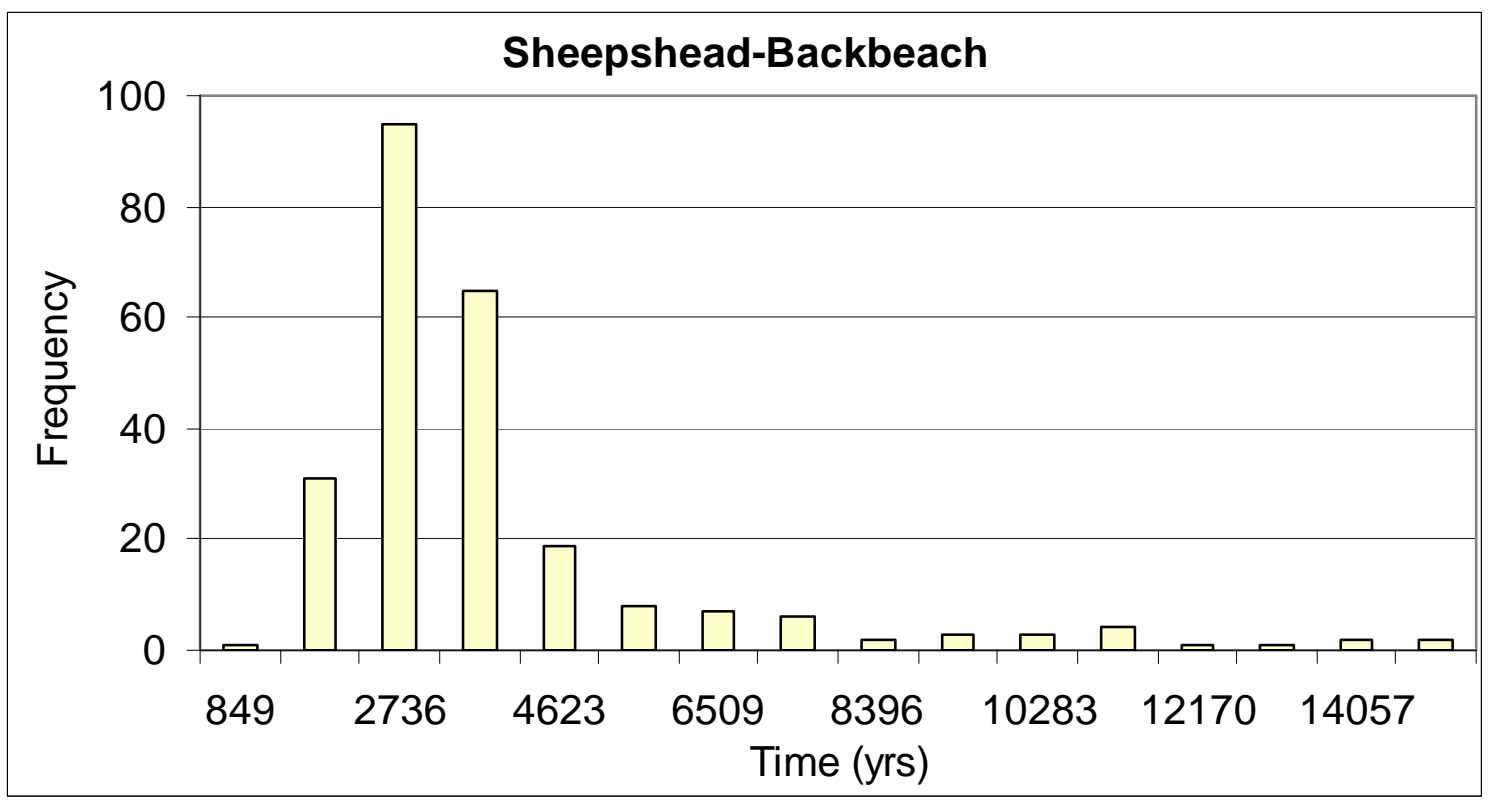

Figure C43. Distribution of minimum travel time from Sheepshead-Backbeach to YM boundaries based on effective-porosity Set 3 for pre-pumping scenario. 


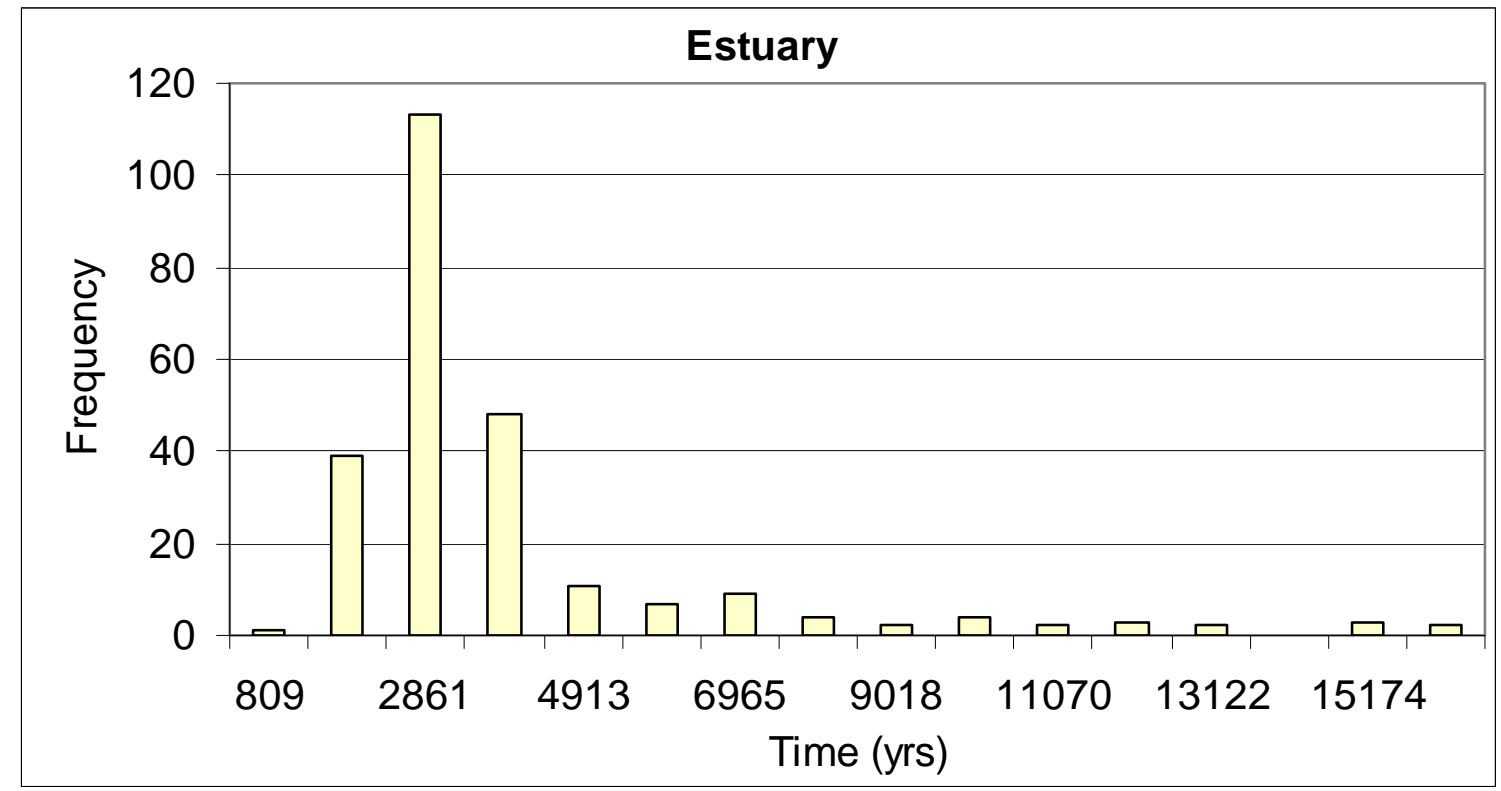

Figure C44. Distribution of minimum travel time from Estuary to YM boundaries based on effective-porosity Set 3 for pre-pumping scenario.

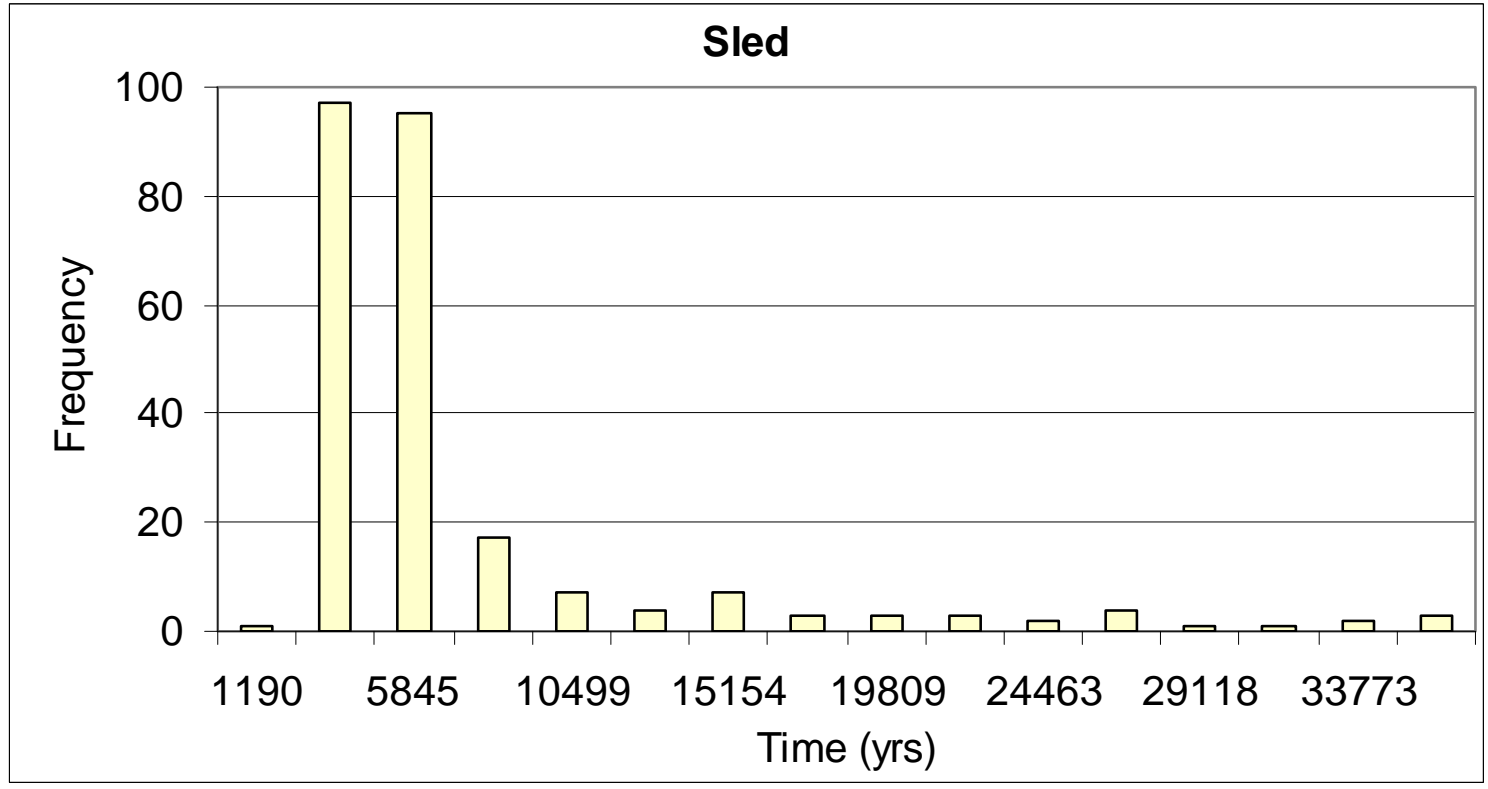

Figure C45. Distribution of minimum travel time from Sled to YM boundaries based on effective-porosity Set 3 for pre-pumping scenario. 


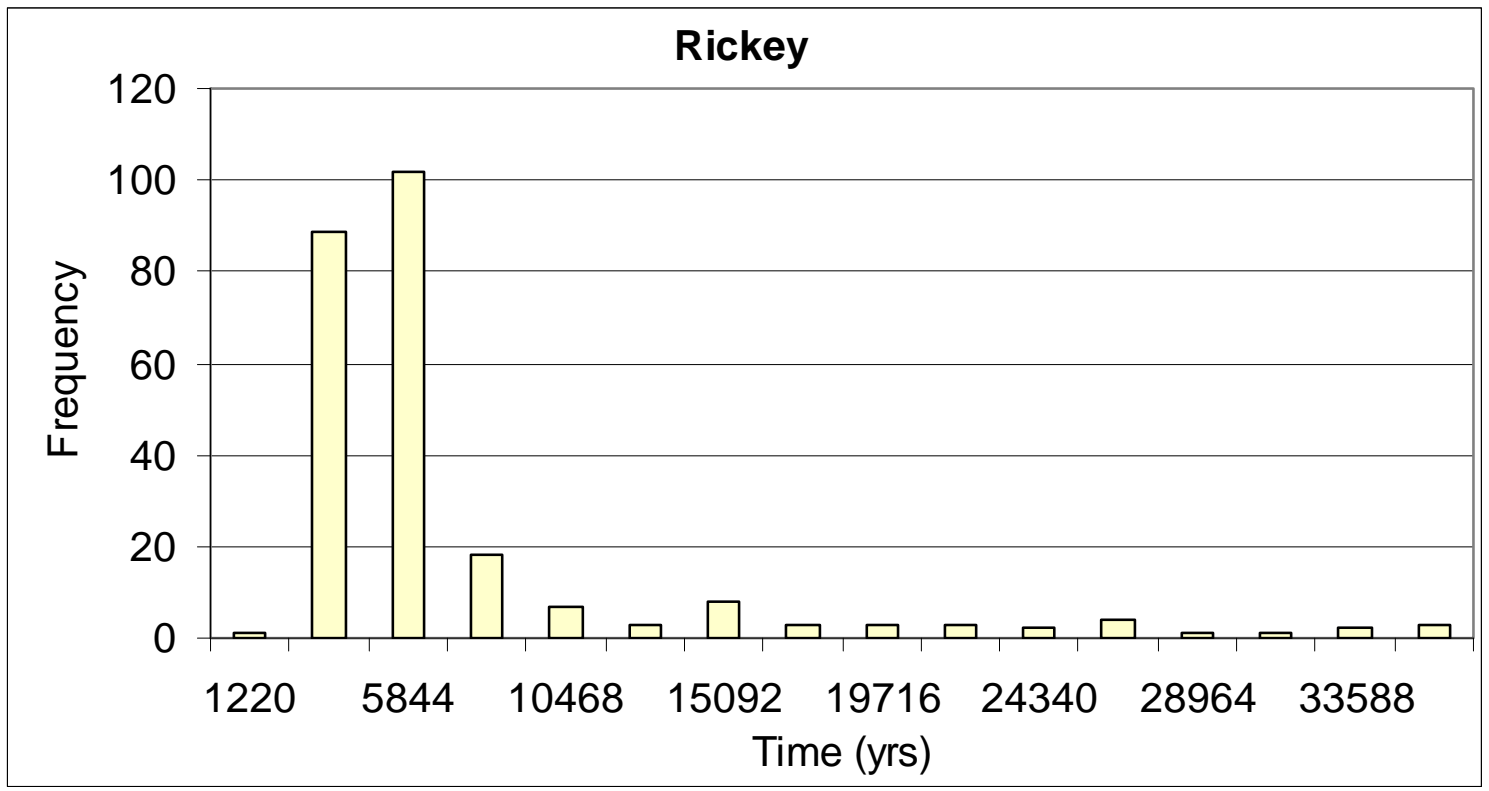

Figure C46. Distribution of minimum travel time from Ricky to YM boundaries based on effective-porosity Set 3 for pre-pumping scenario.

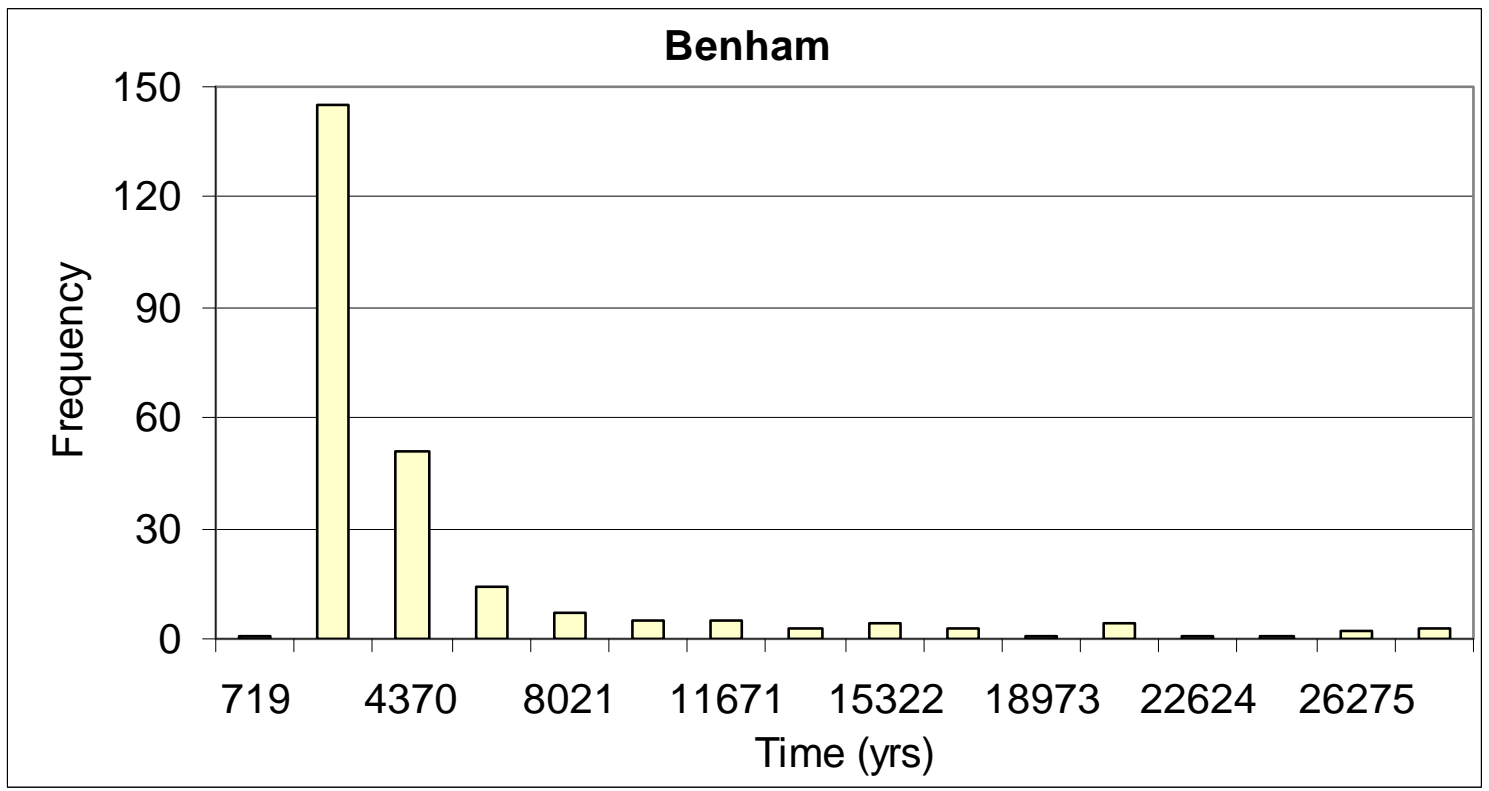

Figure C47. Distribution of minimum travel time from Benham to YM boundaries based on effective-porosity Set 3 for pre-pumping scenario. 


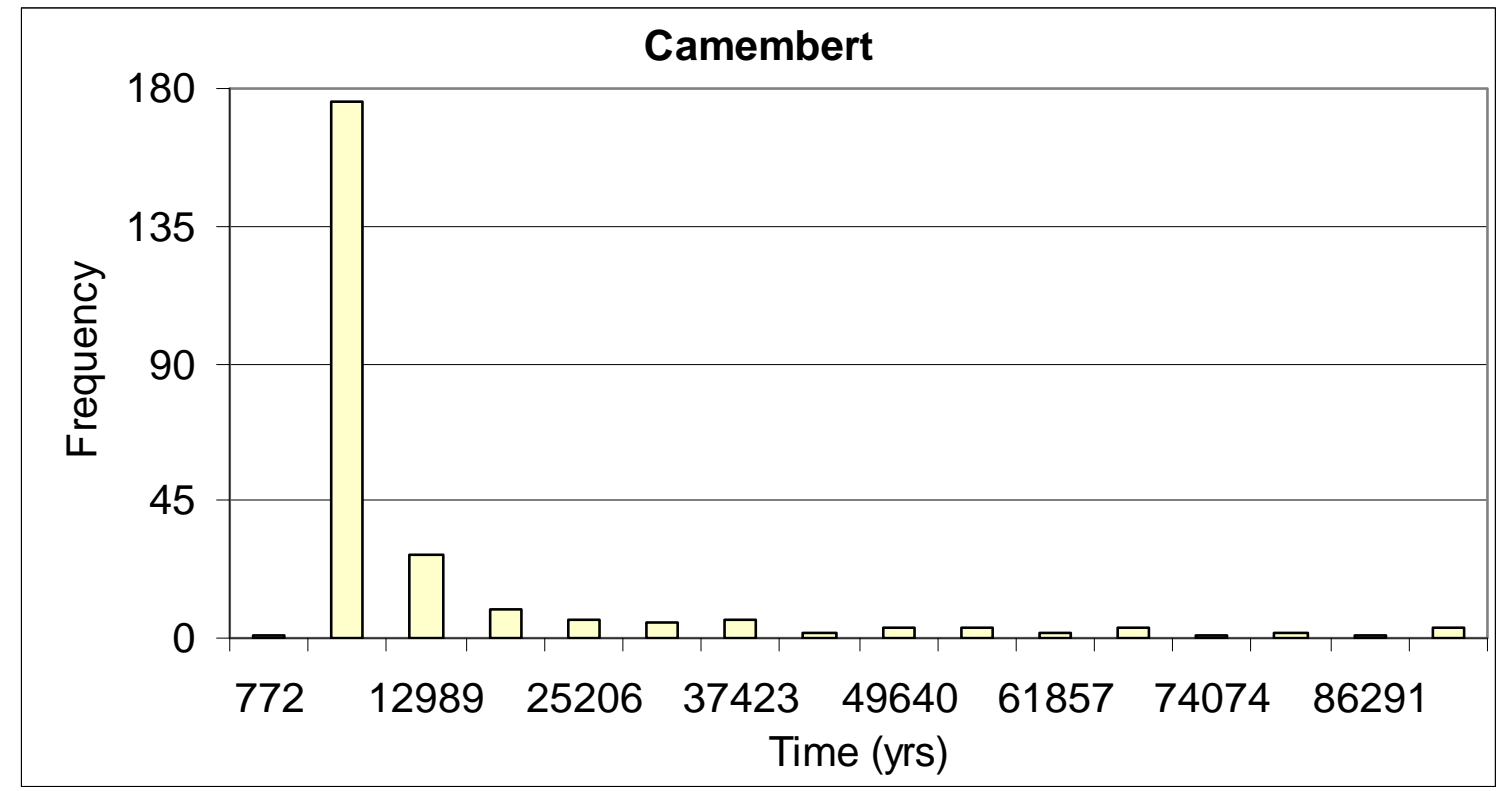

Figure C48. Distribution of minimum travel time from Camembert to YM boundaries based on effective-porosity Set 3 for pre-pumping scenario.

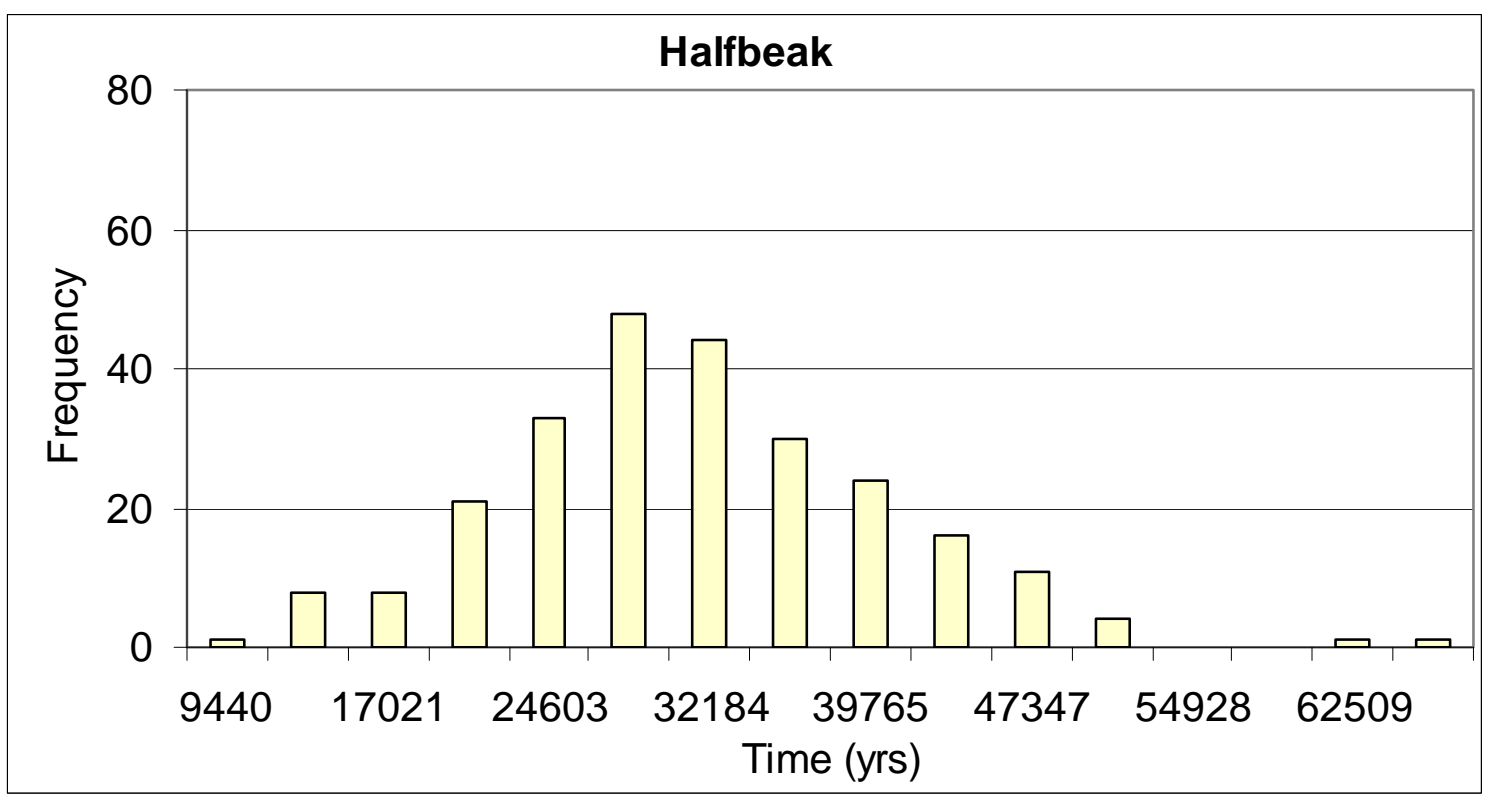

Figure C49. Distribution of minimum travel time from Halfbeak to YM boundaries based on effective-porosity Set 3 for pre-pumping scenario. 


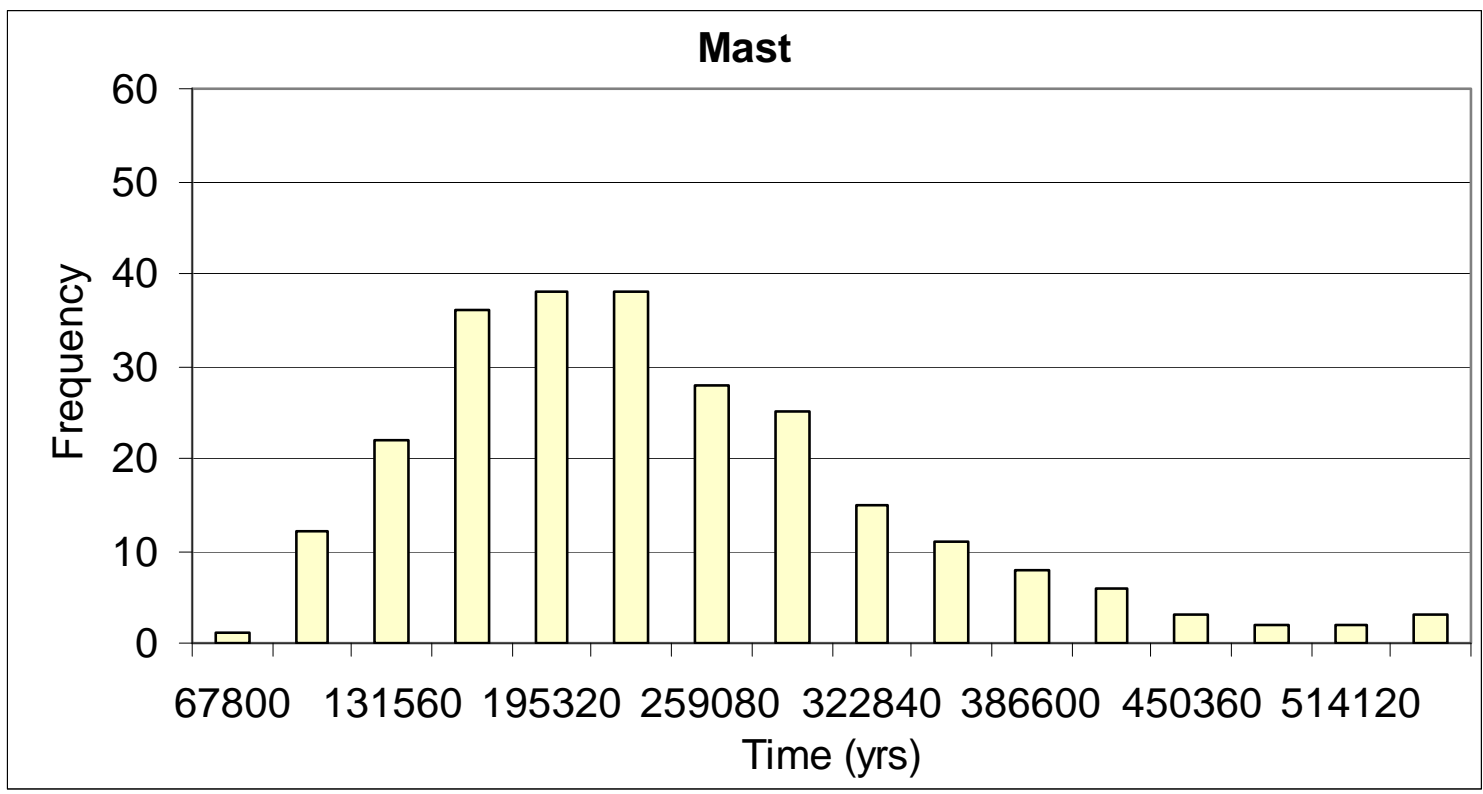

Figure C50. Distribution of minimum travel time from Mast to YM boundaries based on effective-porosity Set 3 for pre-pumping scenario.

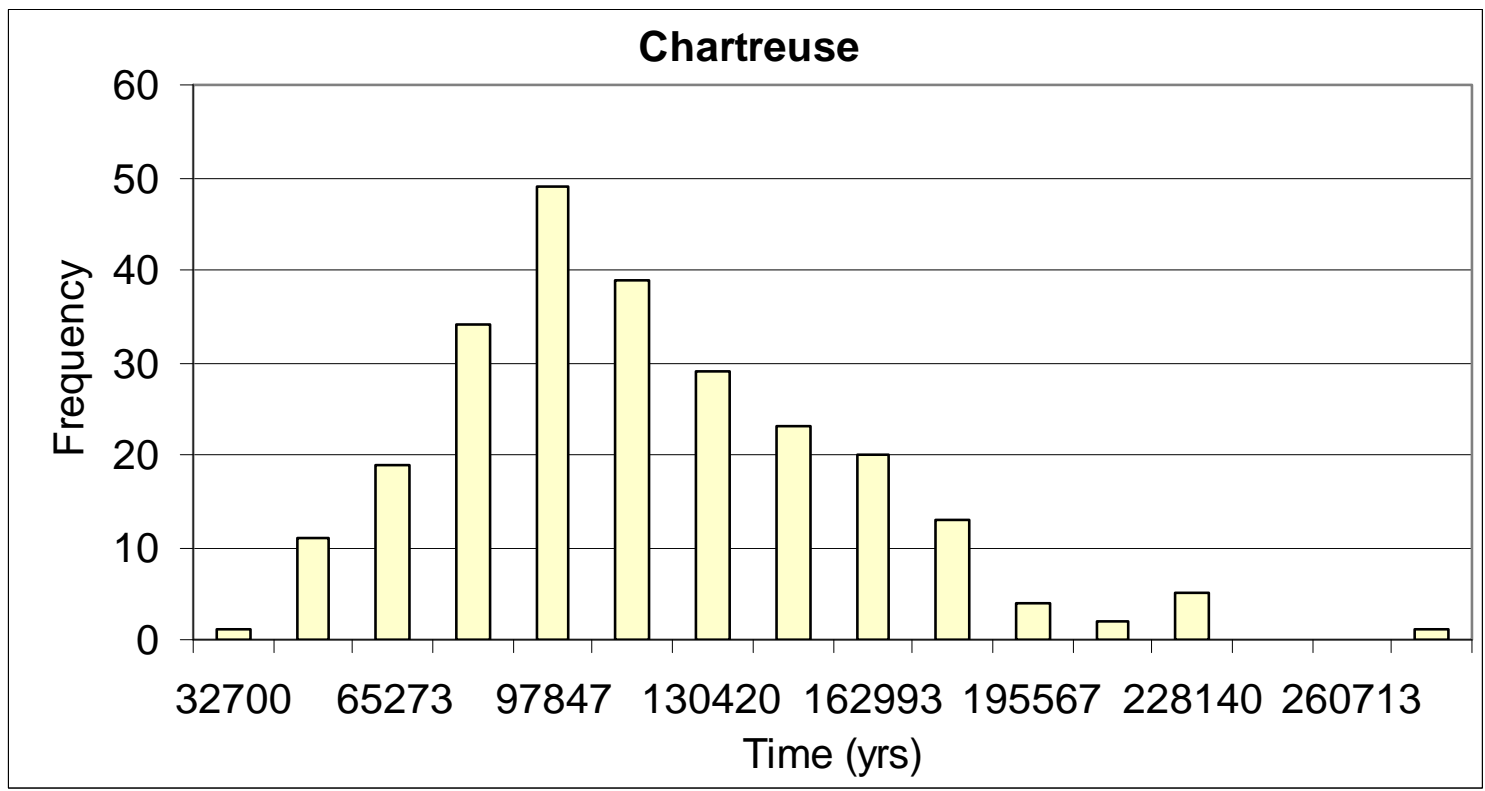

Figure C51. Distribution of minimum travel time from Chartreuse to YM boundaries based on effective-porosity Set 3 for pre-pumping scenario. 


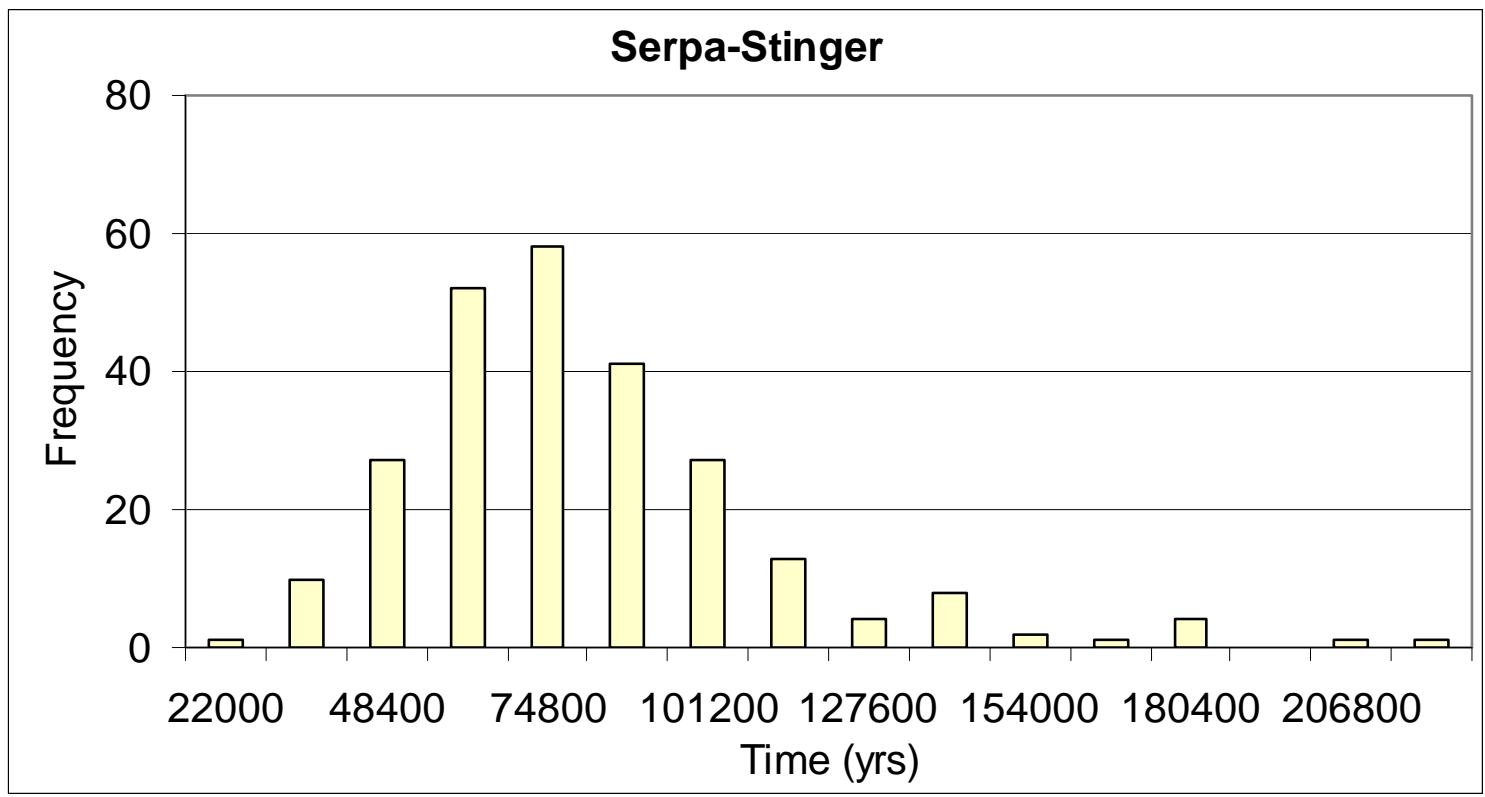

Figure C52. Distribution of minimum travel time from Serpa-Stinger to YM boundaries based on effective-porosity Set 3 for pre-pumping scenario.

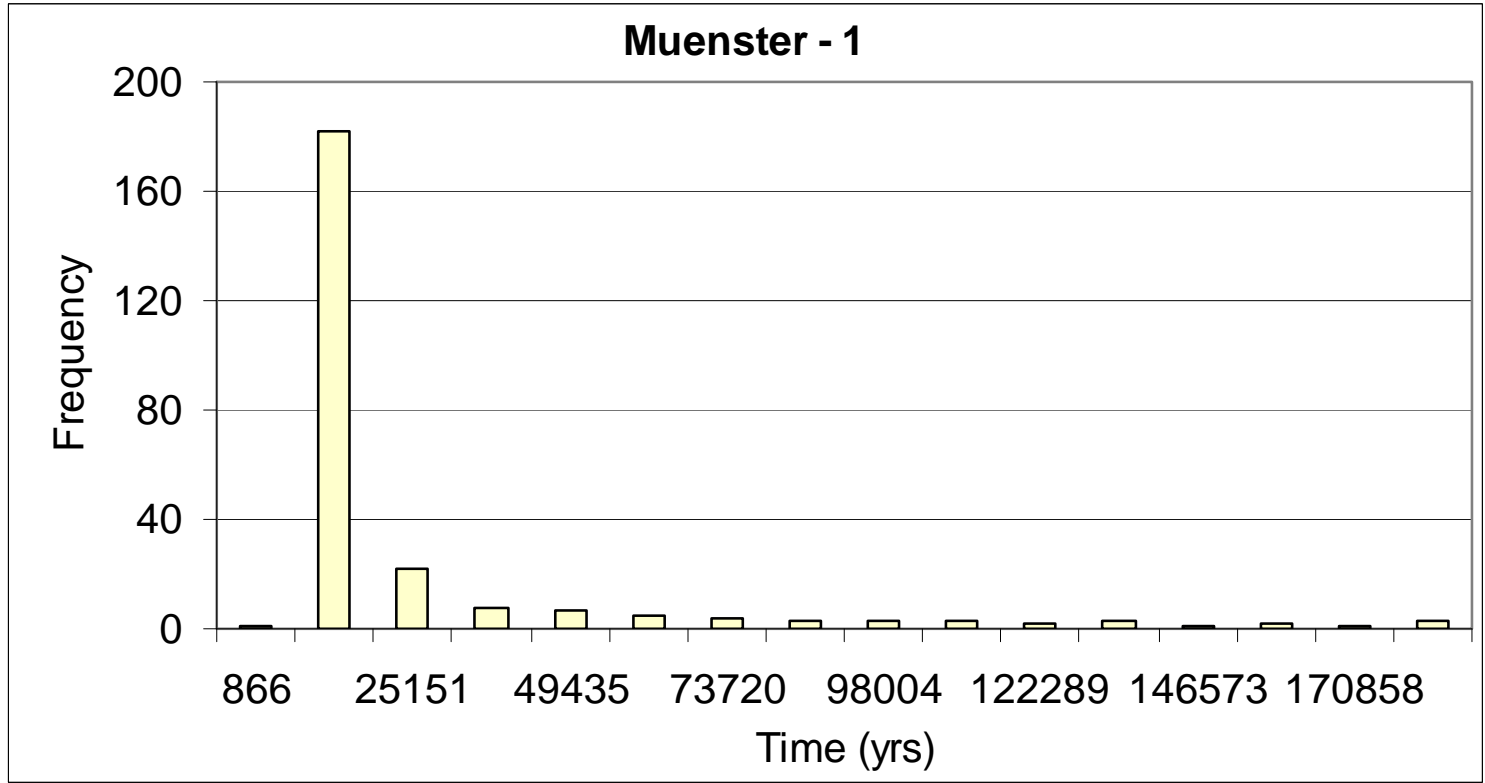

Figure C53. Distribution of minimum travel time from Muenster -1 to YM boundaries based on effective-porosity Set 3 for pre-pumping scenario. 


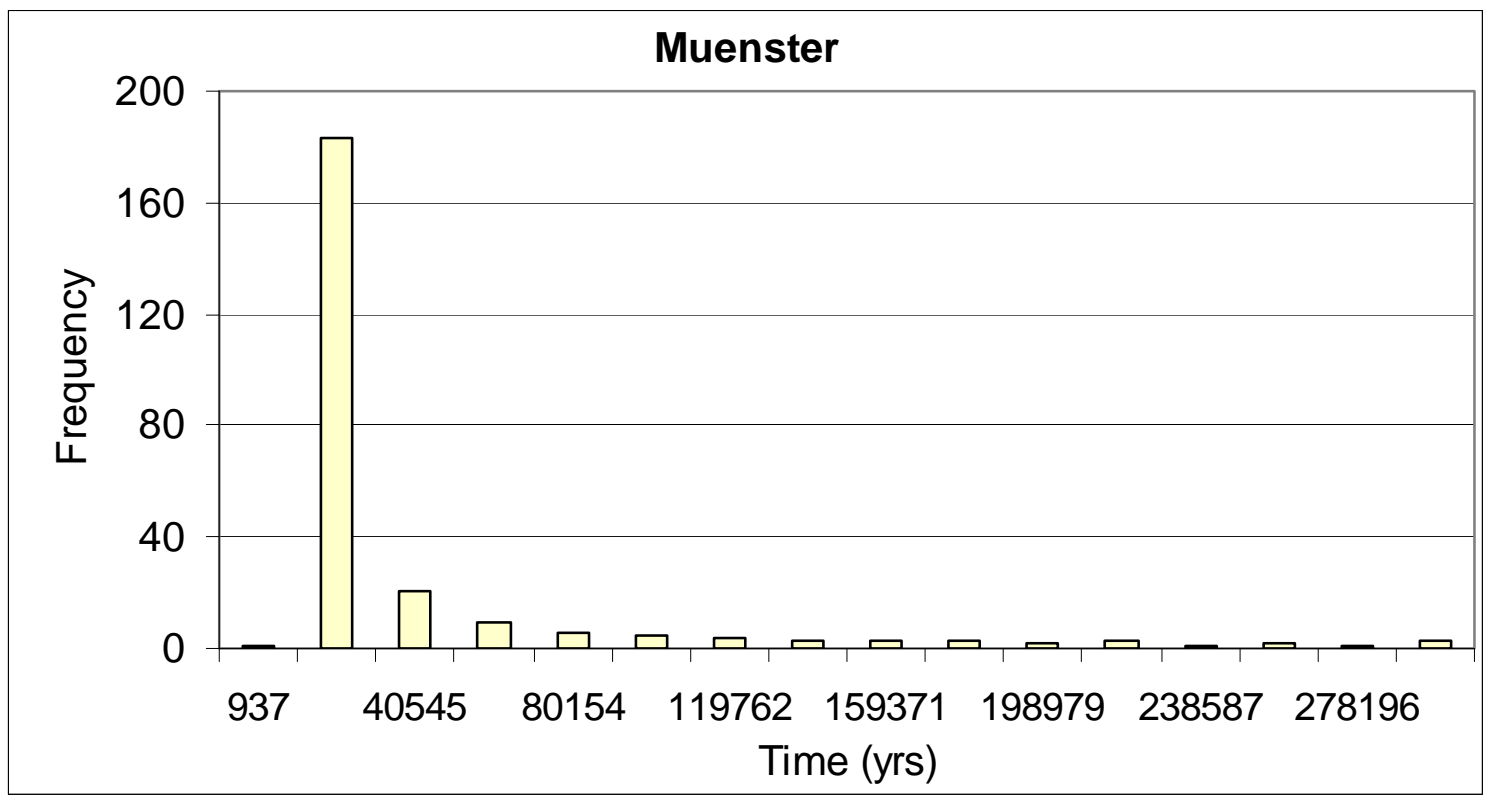

Figure C54. Distribution of minimum travel time from Muenster to YM boundaries based on effective-porosity Set 3 for pre-pumping scenario.

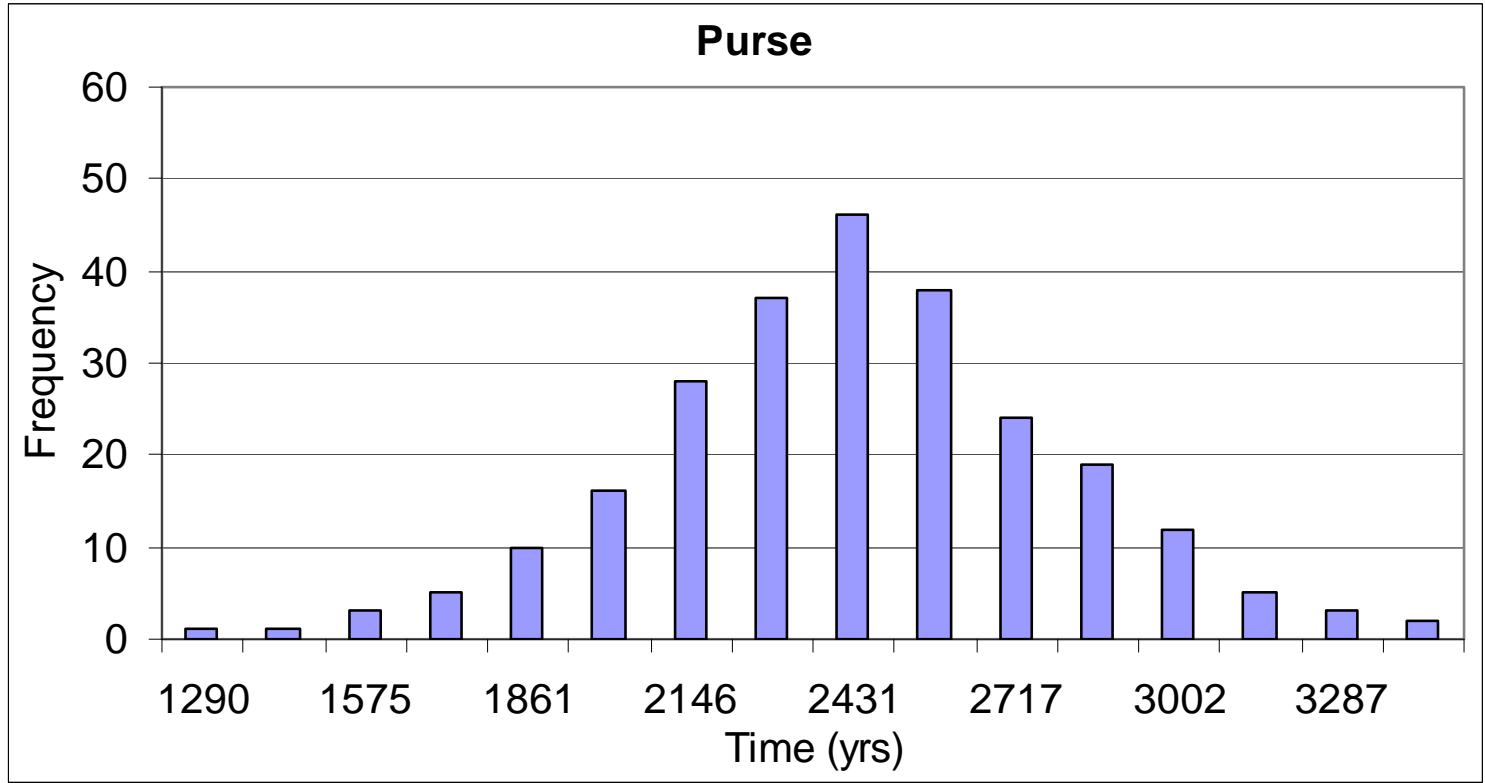

Figure C55. Distribution of minimum travel time from Purse to YM boundaries based on effective-porosity Set 1 for 1998 scenario. 


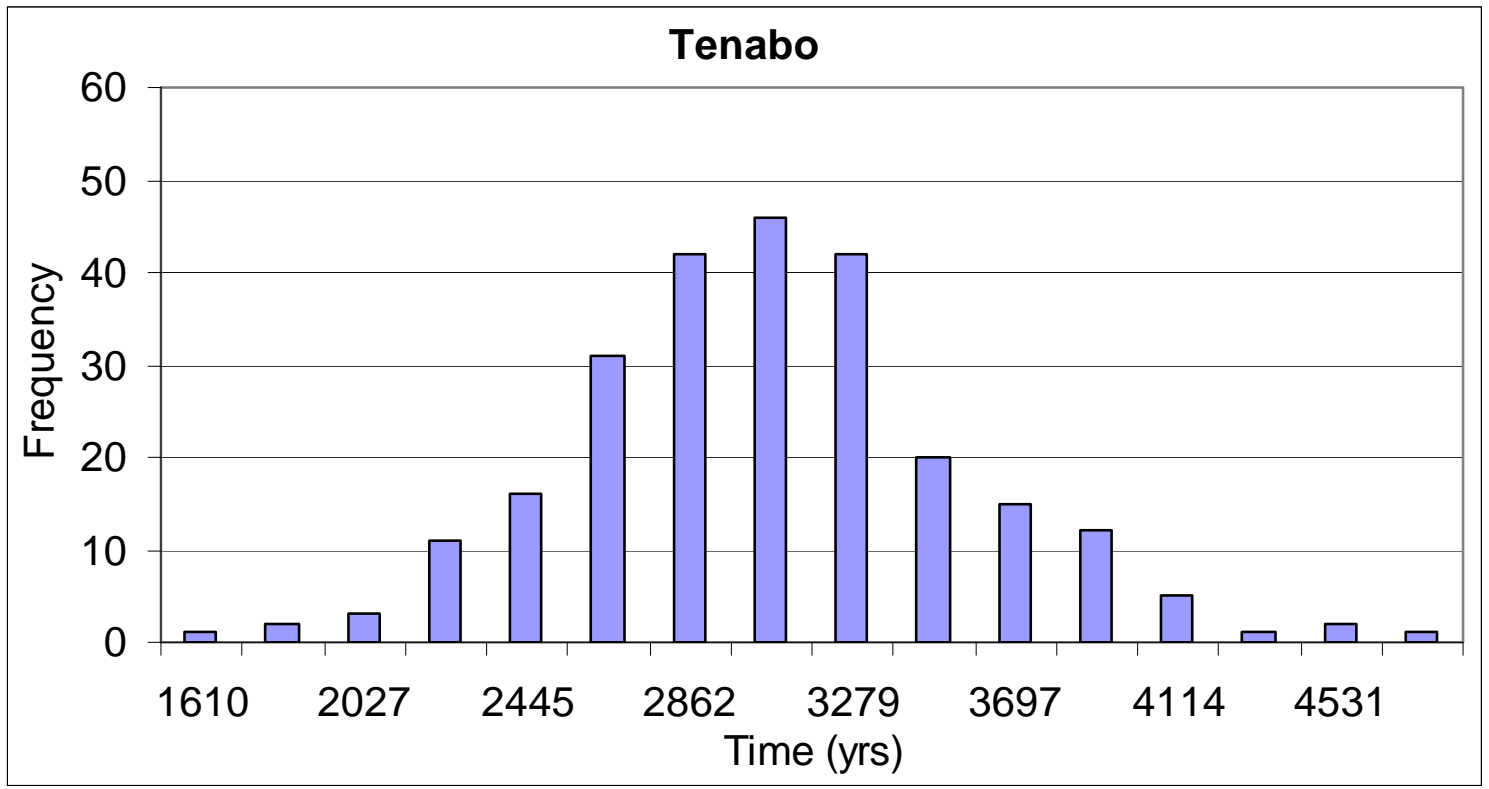

Figure C56. Distribution of minimum travel time from Tenabo to YM boundaries based on effective-porosity Set 1 for 1998 scenario.

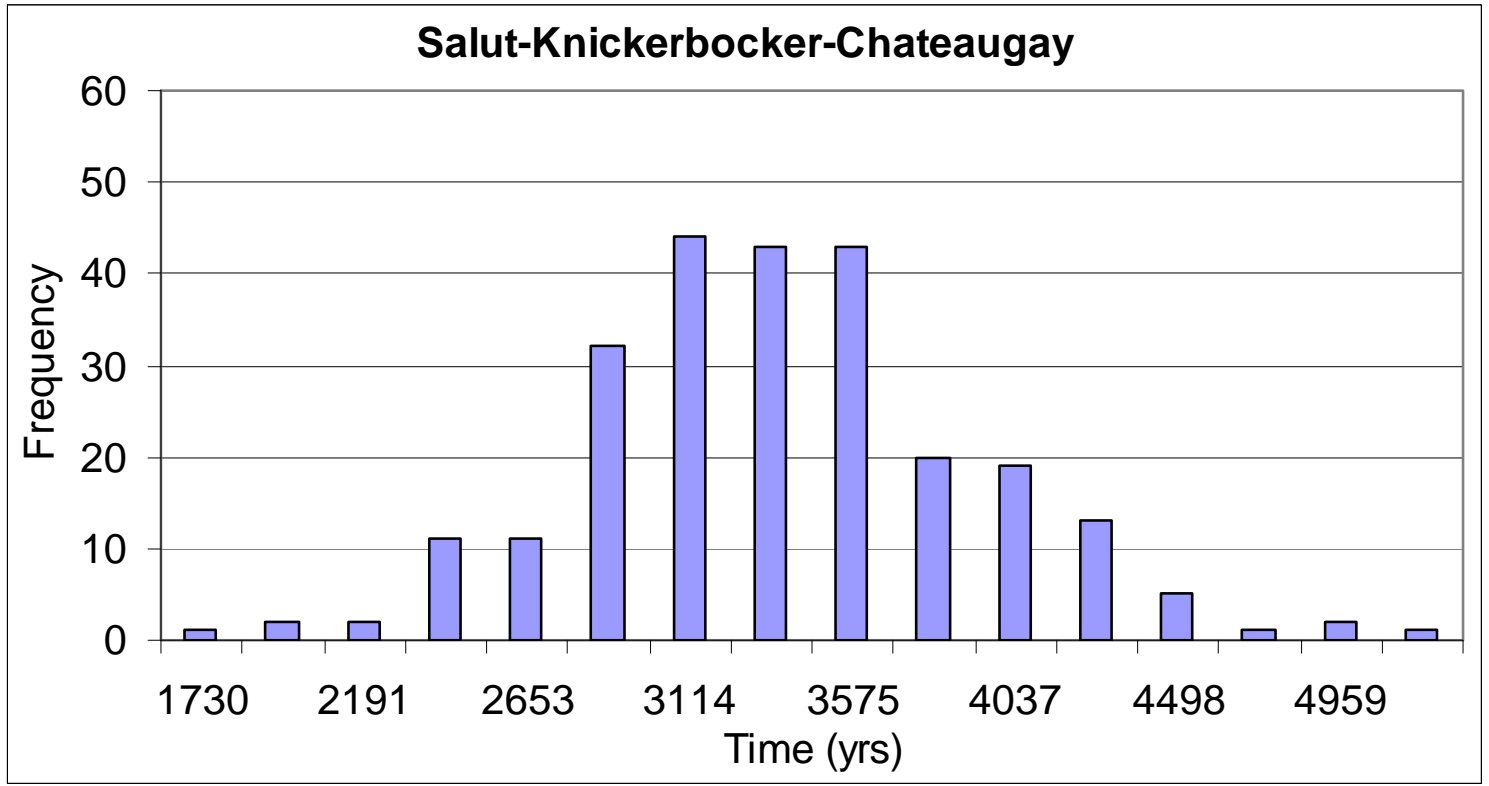

Figure C57. Distribution of minimum travel time from Salut-Knickerbocker-Chateaugay to YM boundaries based on effective-porosity Set 1 for 1998 scenario. 


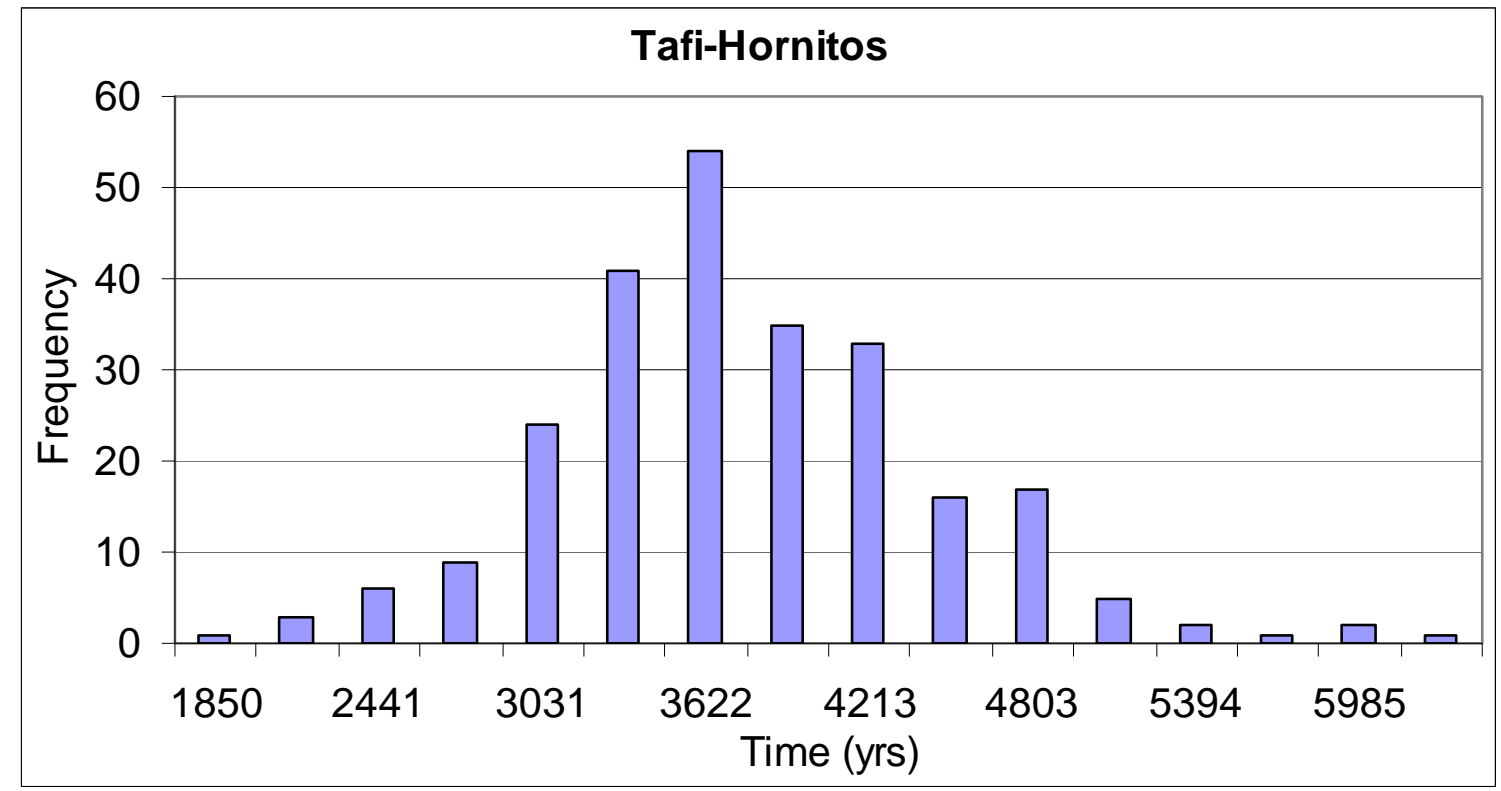

Figure C58. Distribution of minimum travel time from Tafi-Hornitos to YM boundaries based on effective-porosity Set 1 for 1998 scenario.

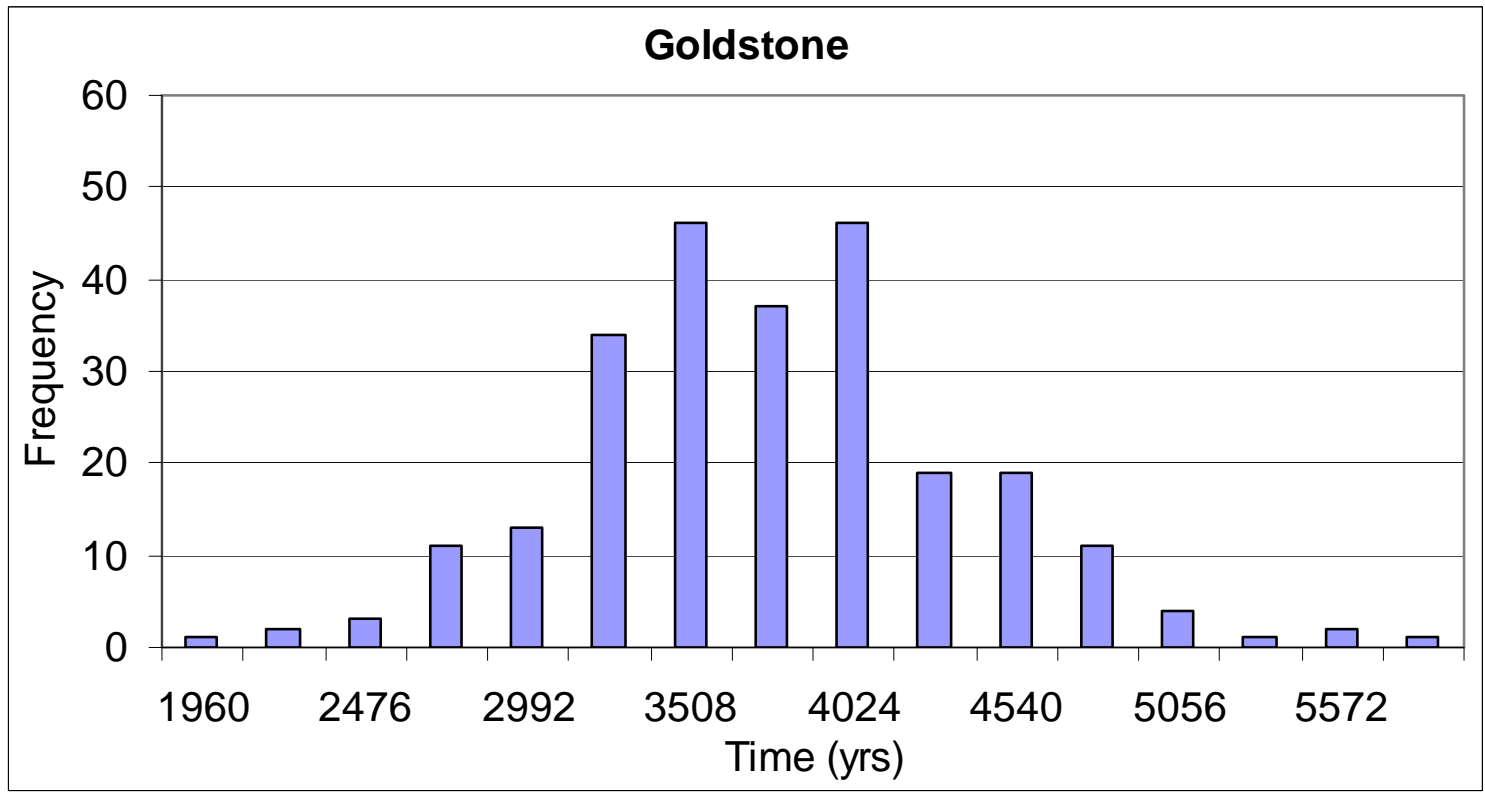

Figure C59. Distribution of minimum travel time from Goldstone to YM boundaries based on effective-porosity Set 1 for 1998 scenario. 


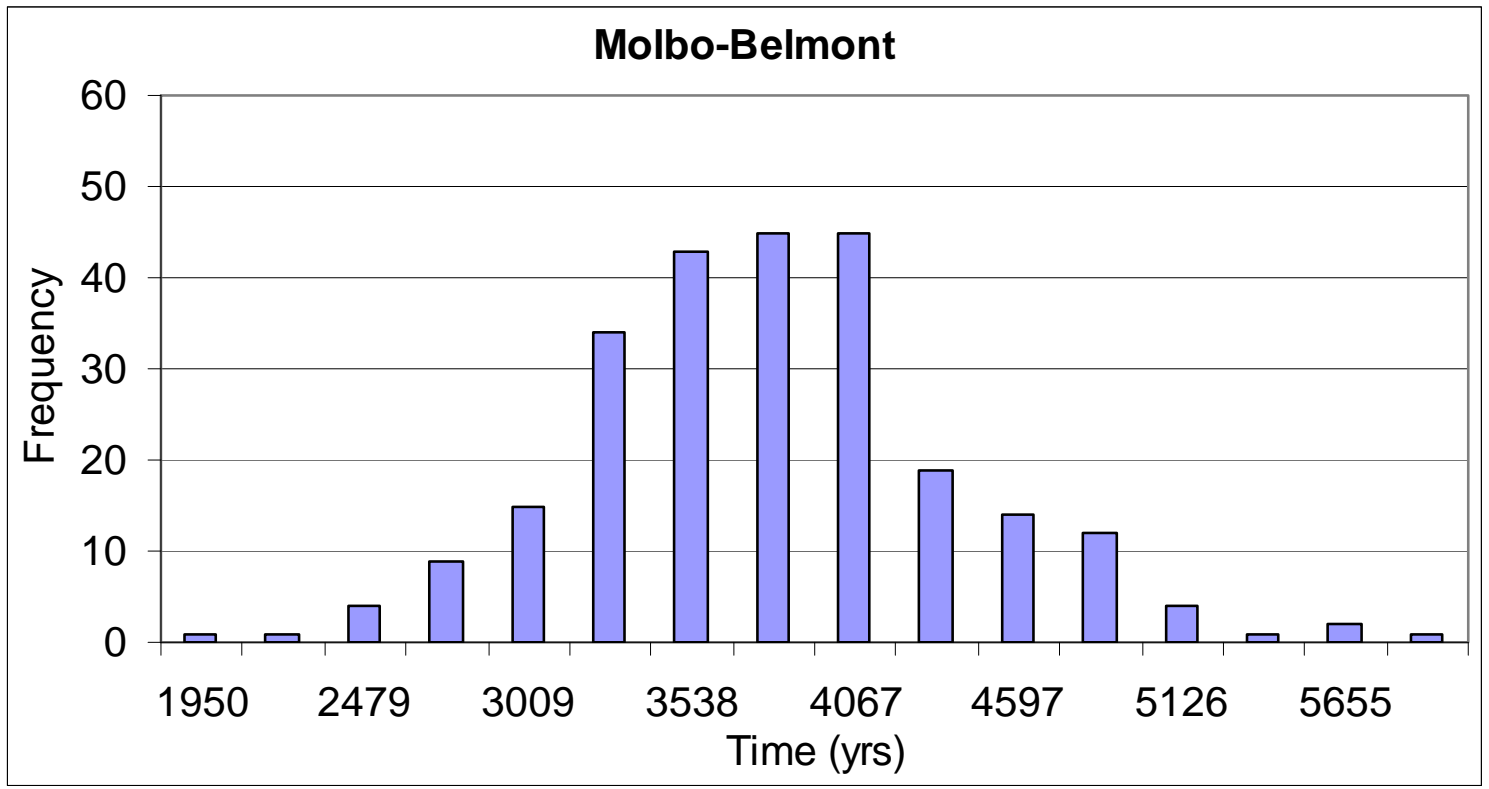

Figure C60. Distribution of minimum travel time from Molbo-Belmont to YM boundaries based on effective-porosity Set 1 for 1998 scenario.

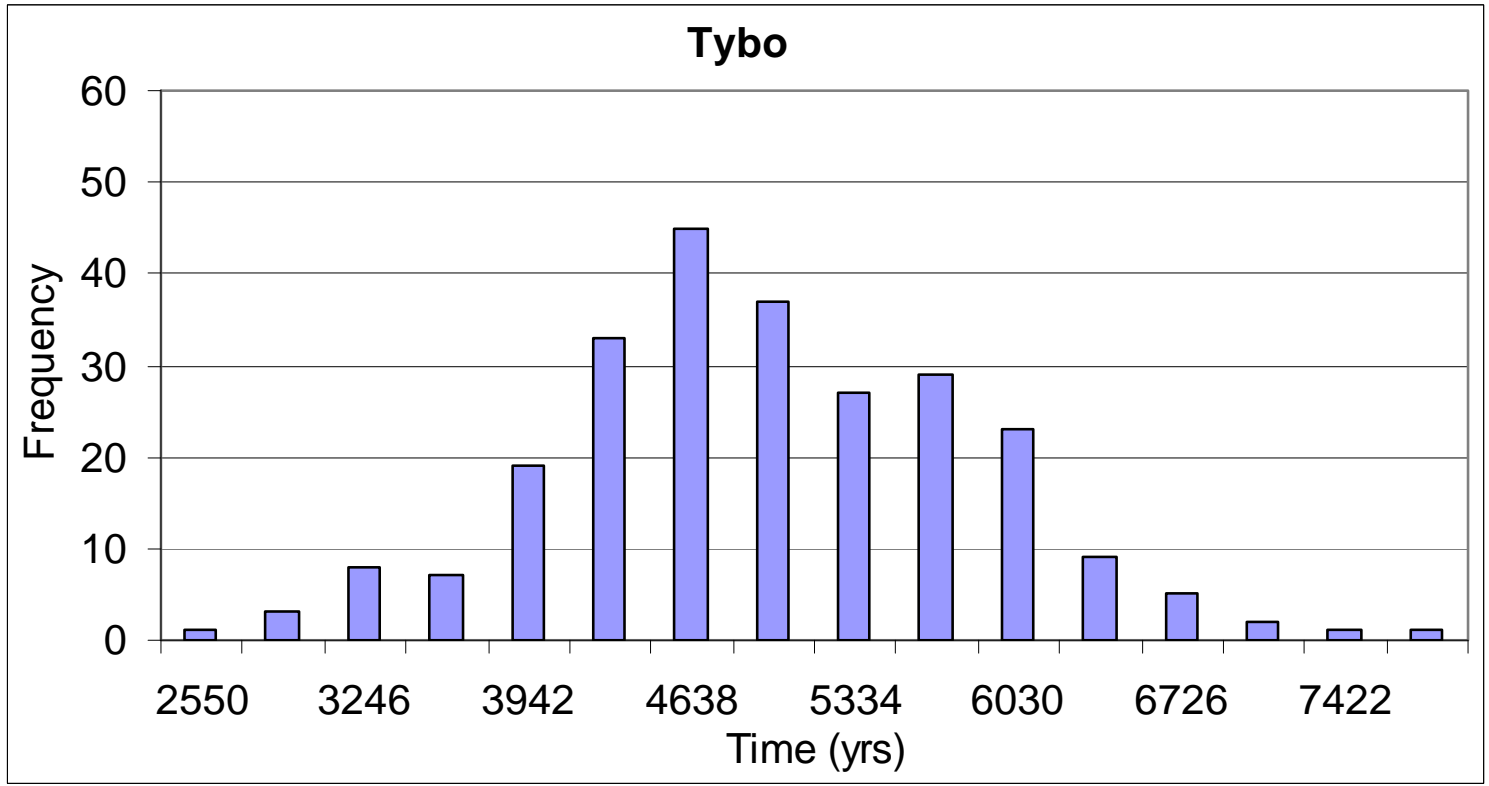

Figure C61. Distribution of minimum travel time from Tybo to YM boundaries based on effective-porosity Set 1 for 1998 scenario. 


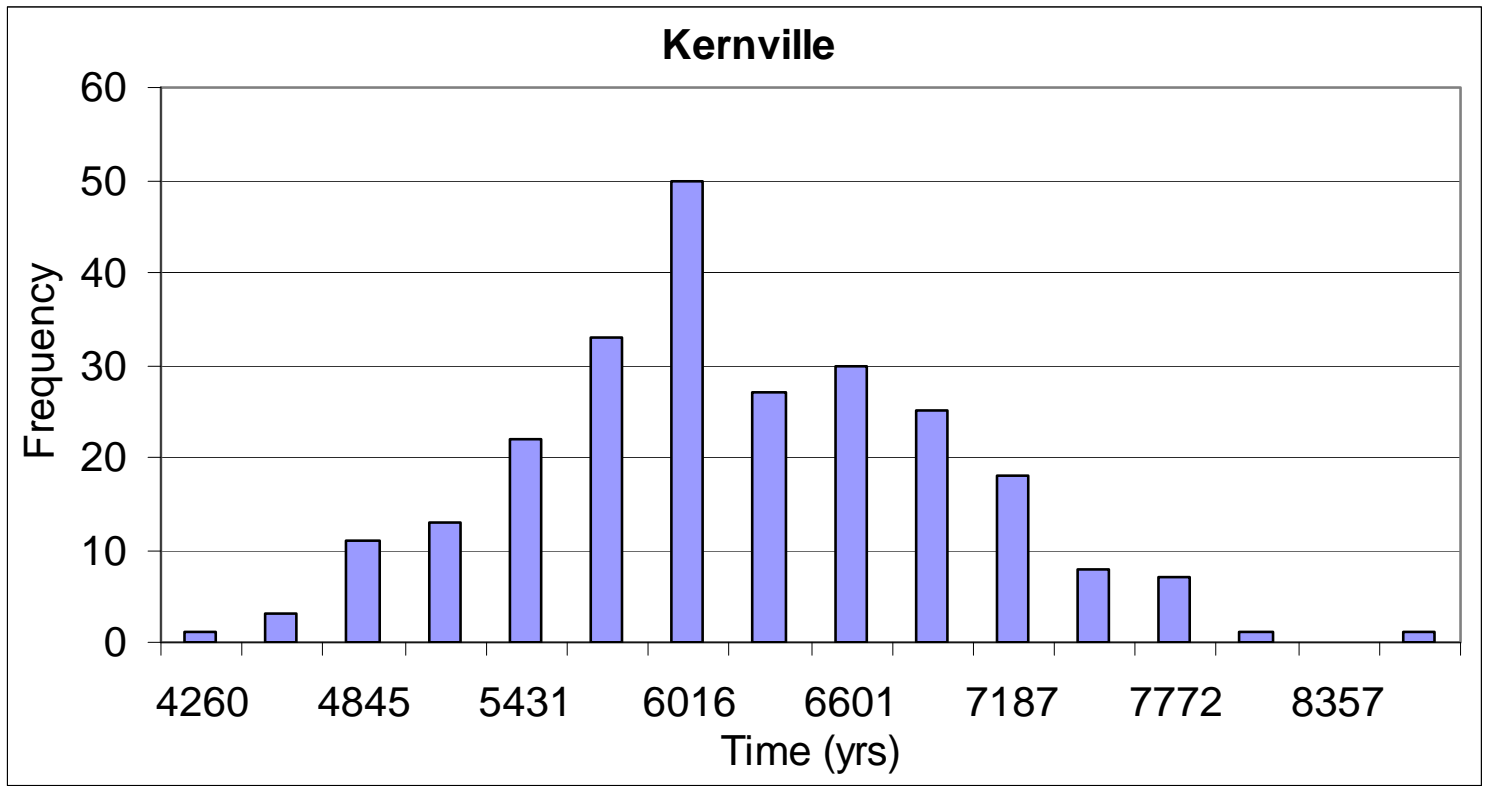

Figure C62. Distribution of minimum travel time from Kernville to YM boundaries based on effective-porosity Set 1 for 1998 scenario.

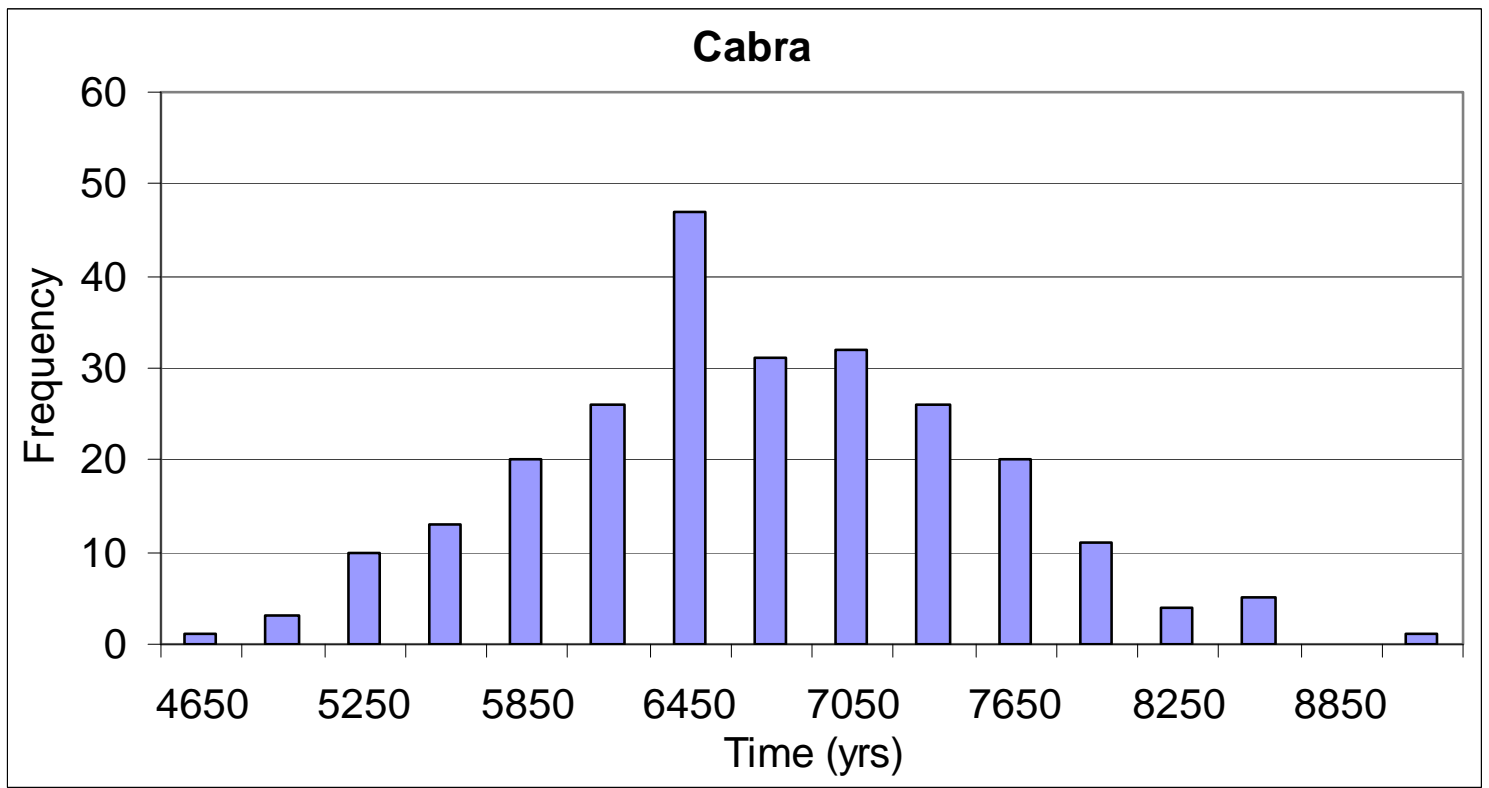

Figure C63. Distribution of minimum travel time from Cabra to YM boundaries based on effective-porosity Set 1 for 1998 scenario. 


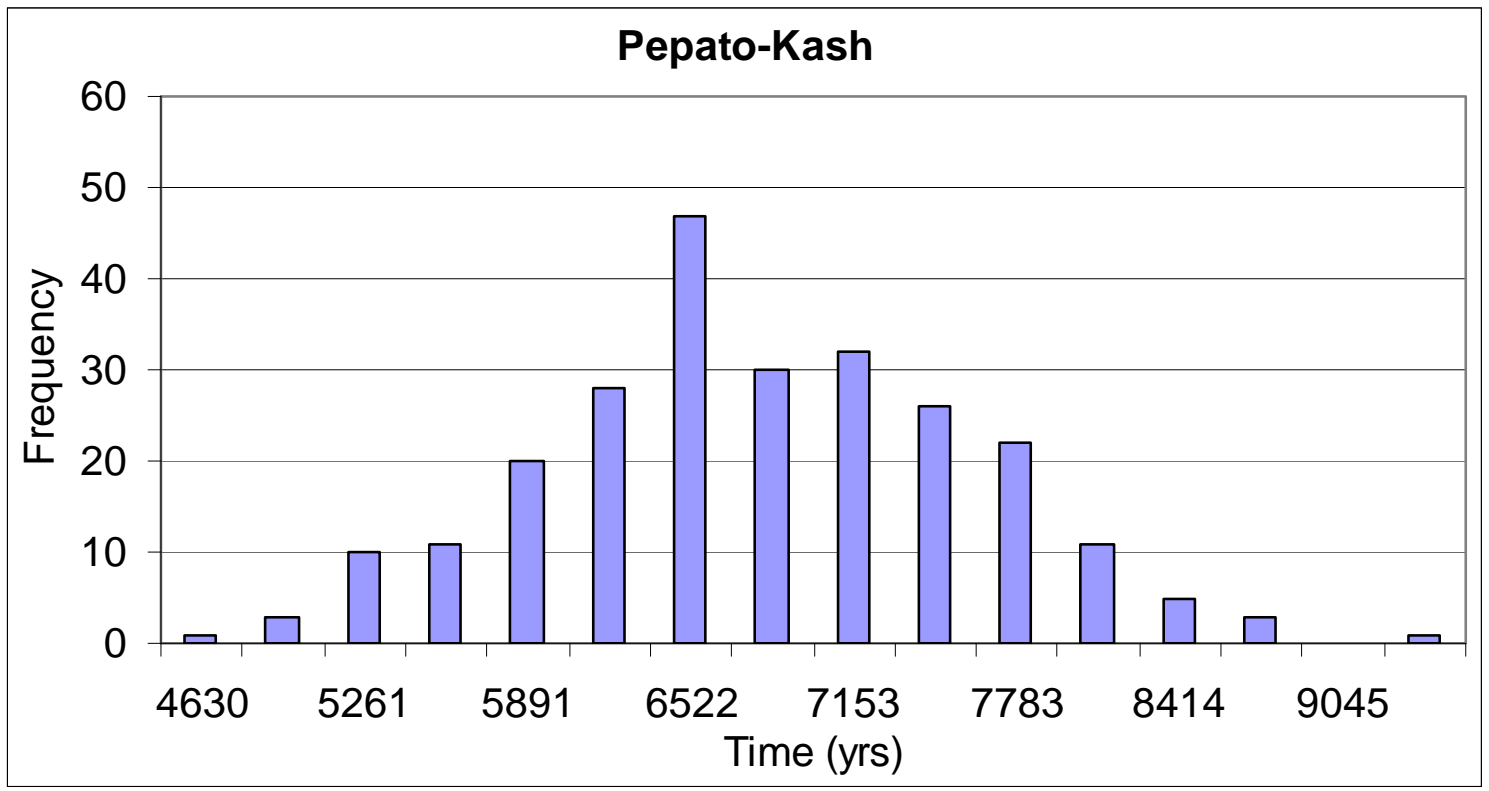

Figure C64. Distribution of minimum travel time from Pepato-Kash to YM boundaries based on effective-porosity Set 1 for 1998 scenario.

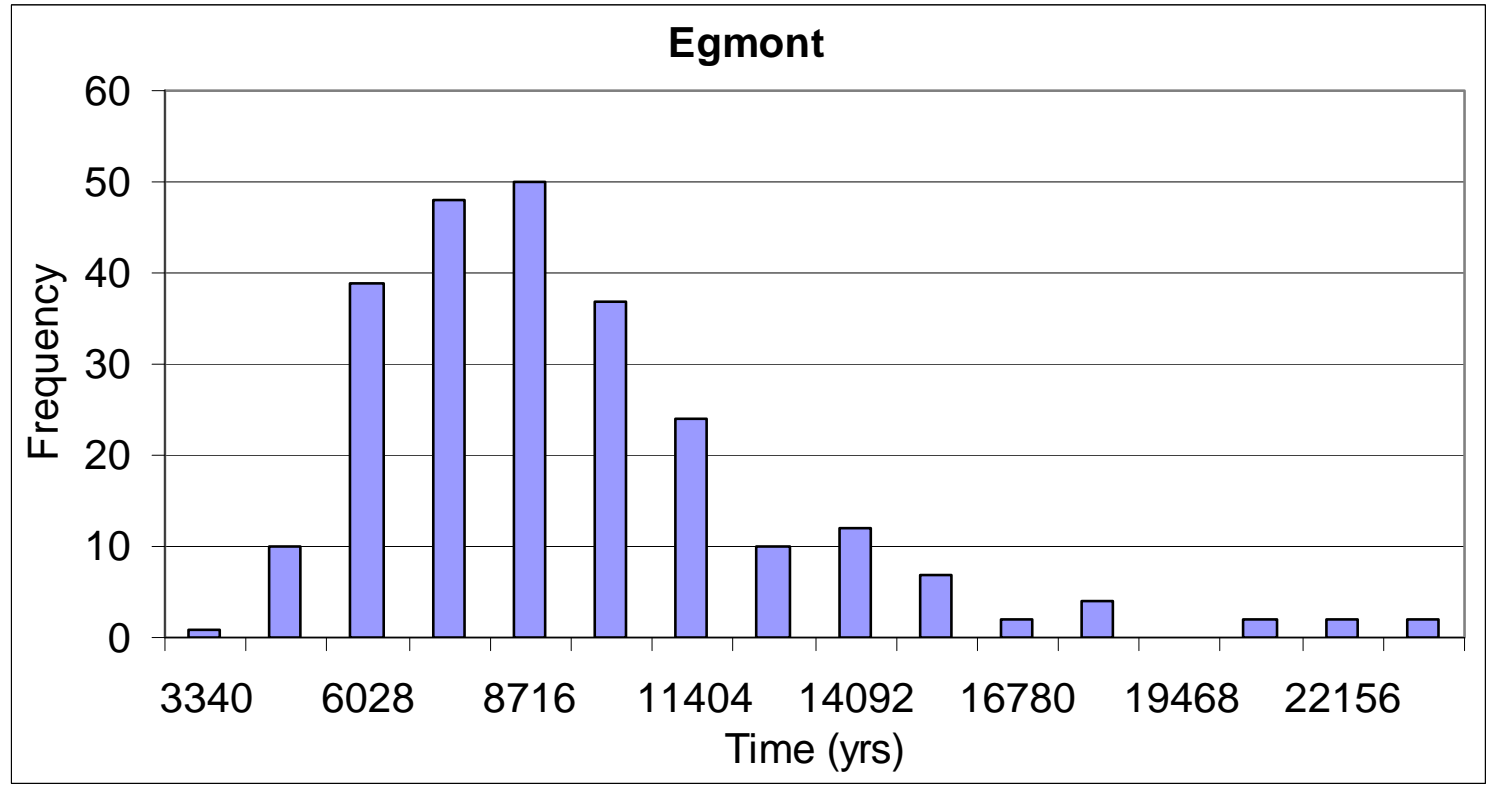

Figure C65. Distribution of minimum travel time from Egmont to YM boundaries based on effective-porosity Set 1 for 1998 scenario. 


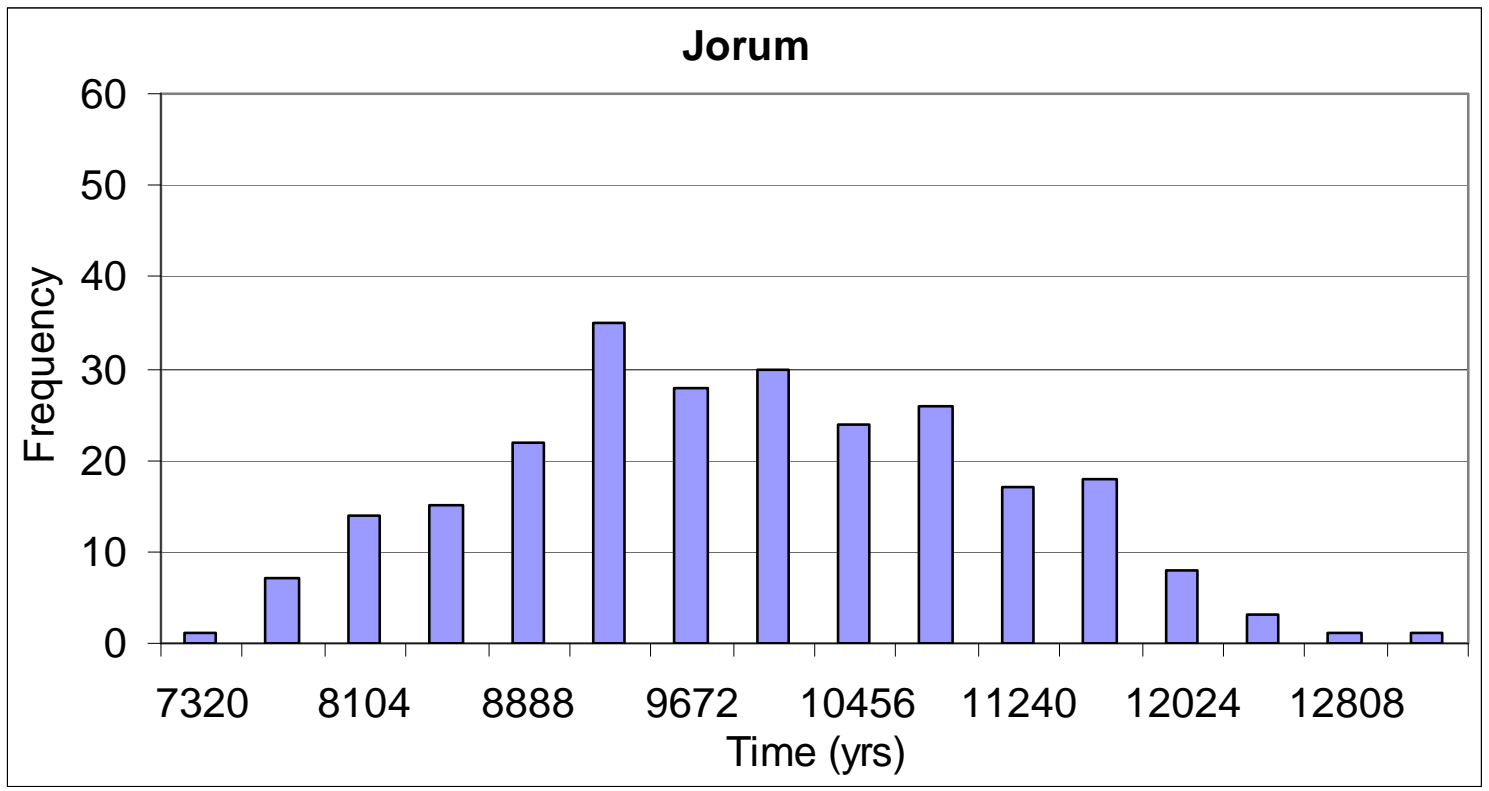

Figure C66. Distribution of minimum travel time from Jorum to YM boundaries based on effective-porosity Set 1 for 1998 scenario.

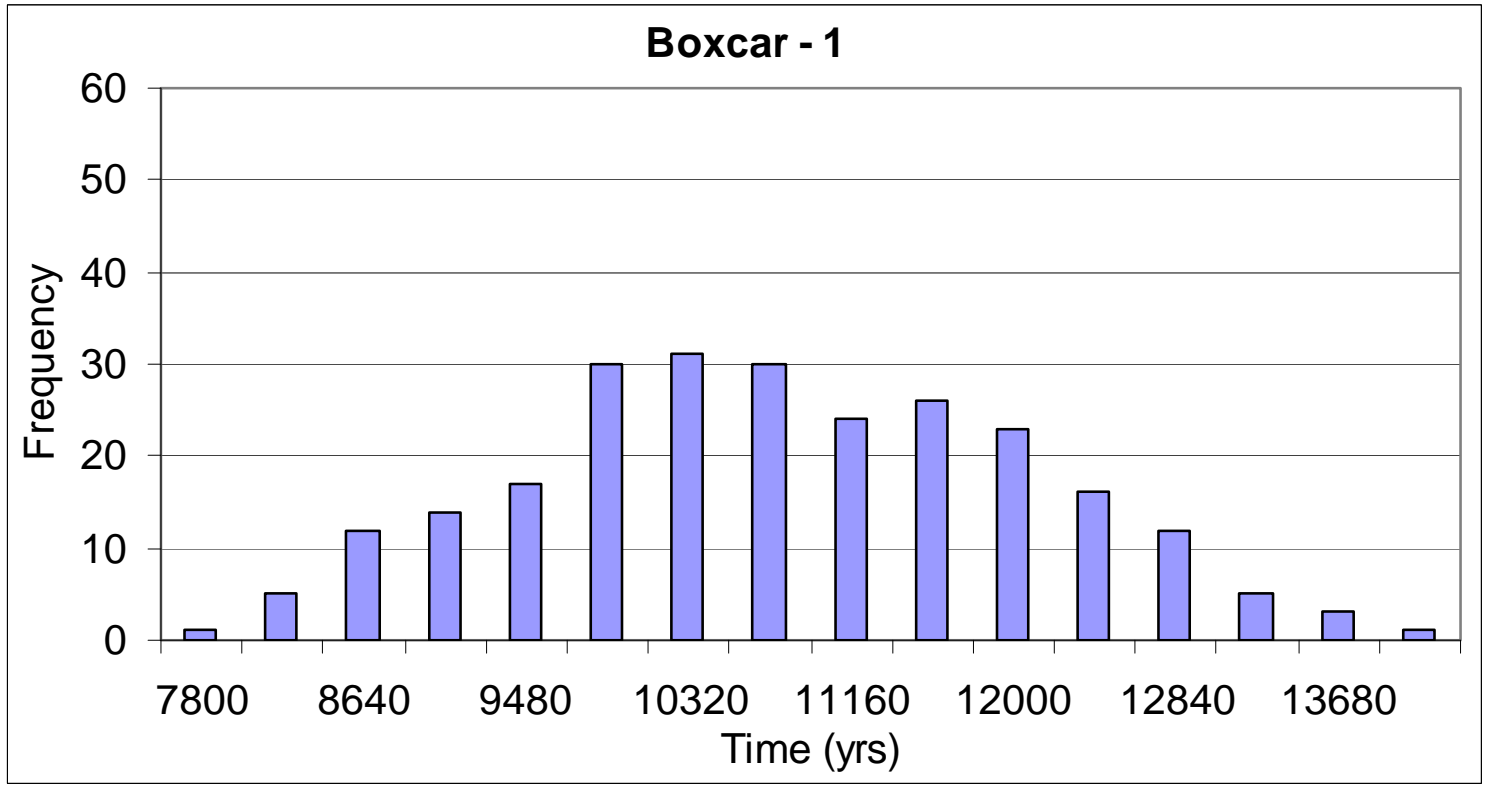

Figure C67. Distribution of minimum travel time from Boxcar -1 to YM boundaries based on effective-porosity Set 1 for 1998 scenario. 


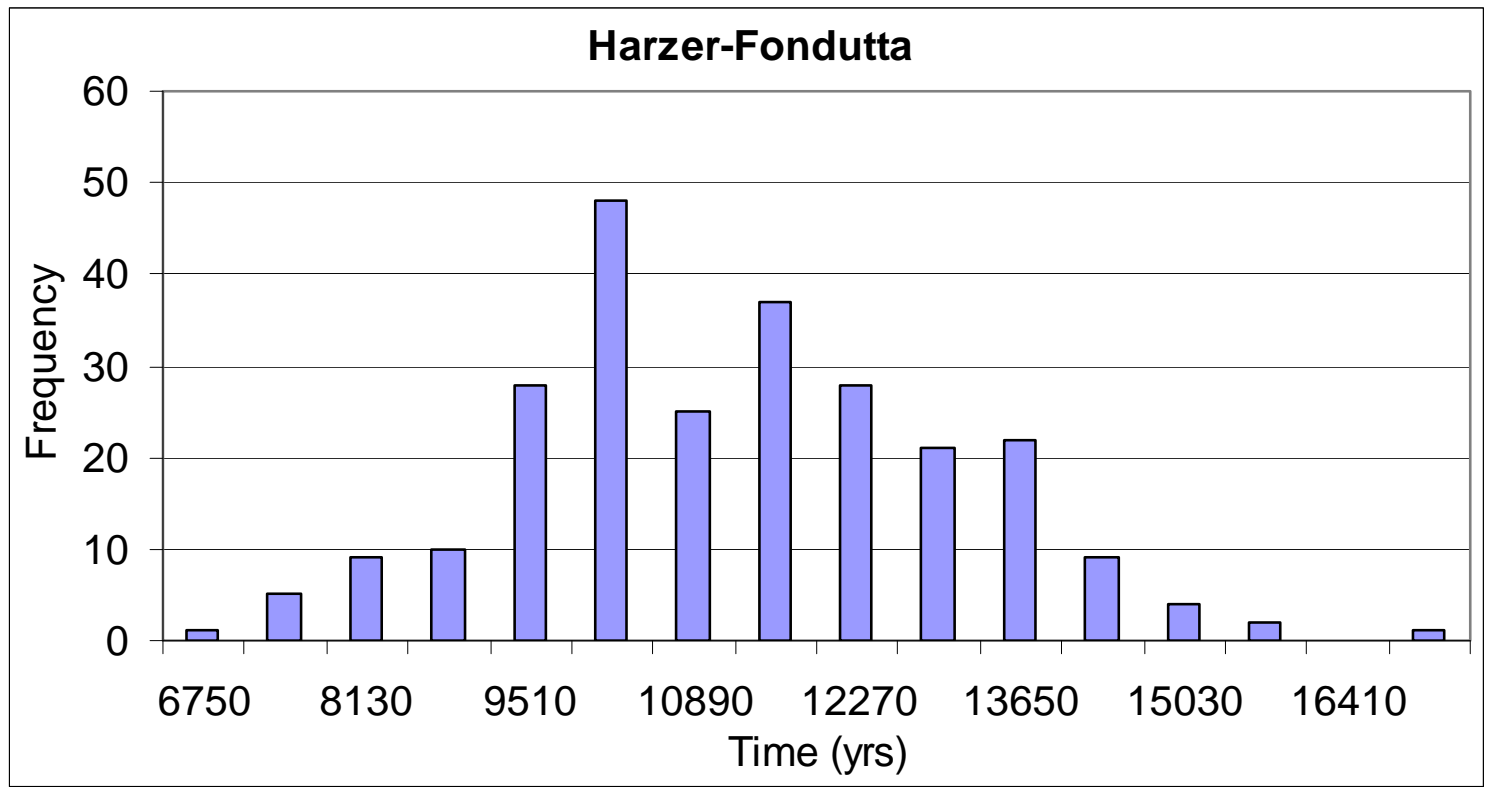

Figure C68. Distribution of minimum travel time from Harzer-Fondutta to YM boundaries based on effective-porosity Set 1 for 1998 scenario.

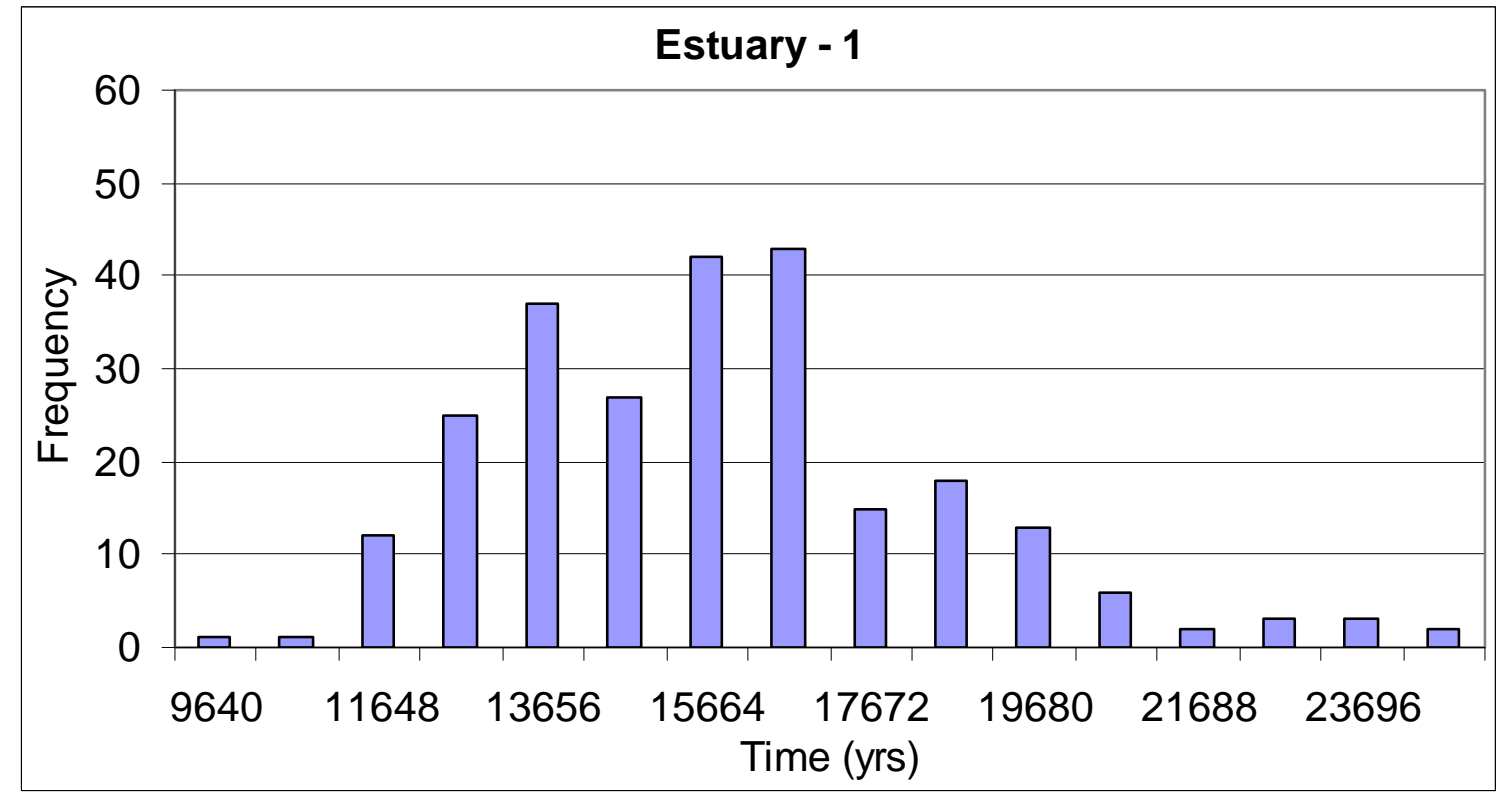

Figure C69. Distribution of minimum travel time from Estuary -1 to YM boundaries based on effective-porosity Set 1 for 1998 scenario. 


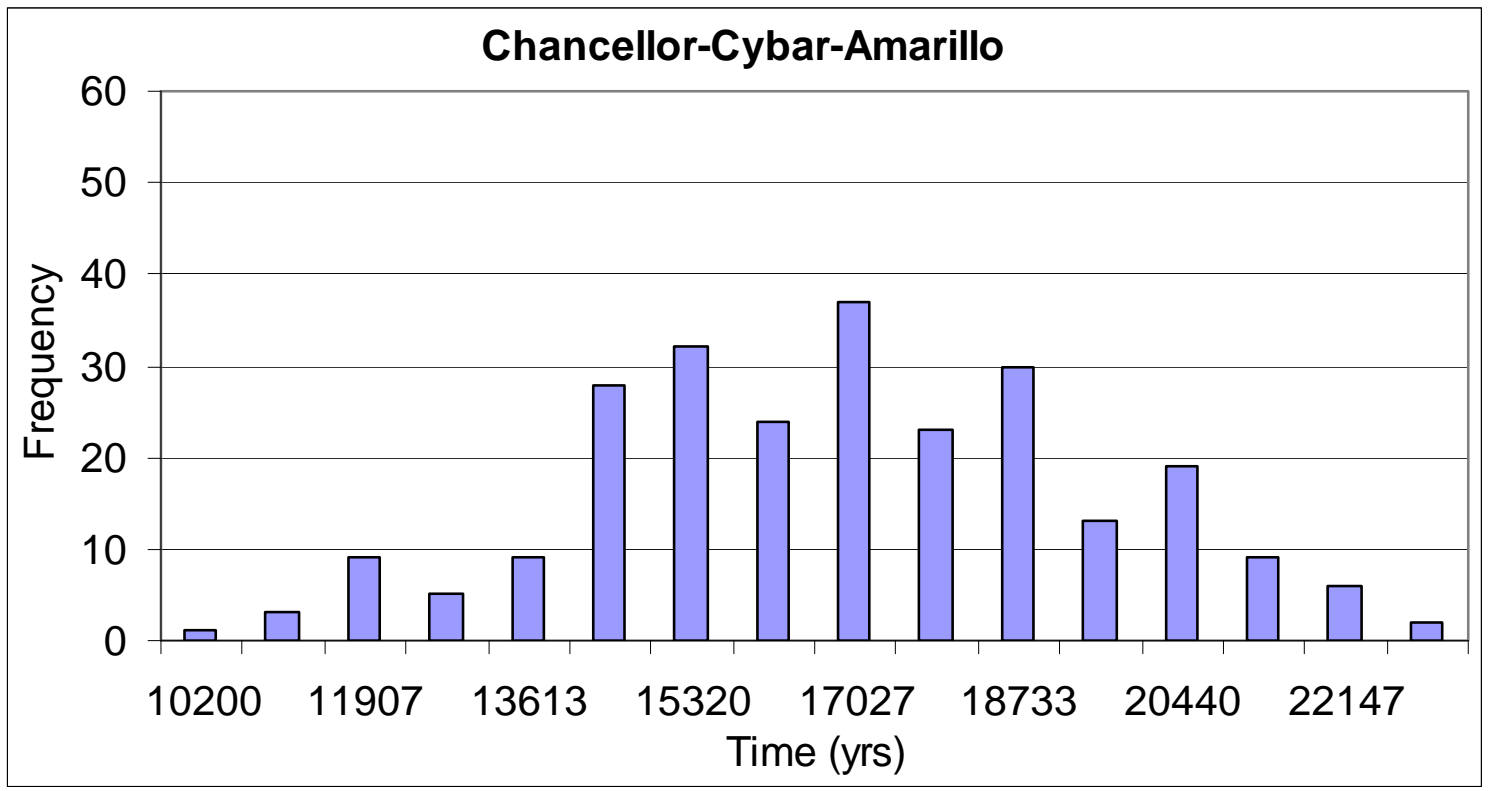

Figure C70. Distribution of minimum travel time from Chancellor-Cybar-Amarillo to YM boundaries based on effective-porosity Set 1 for 1998 scenario.

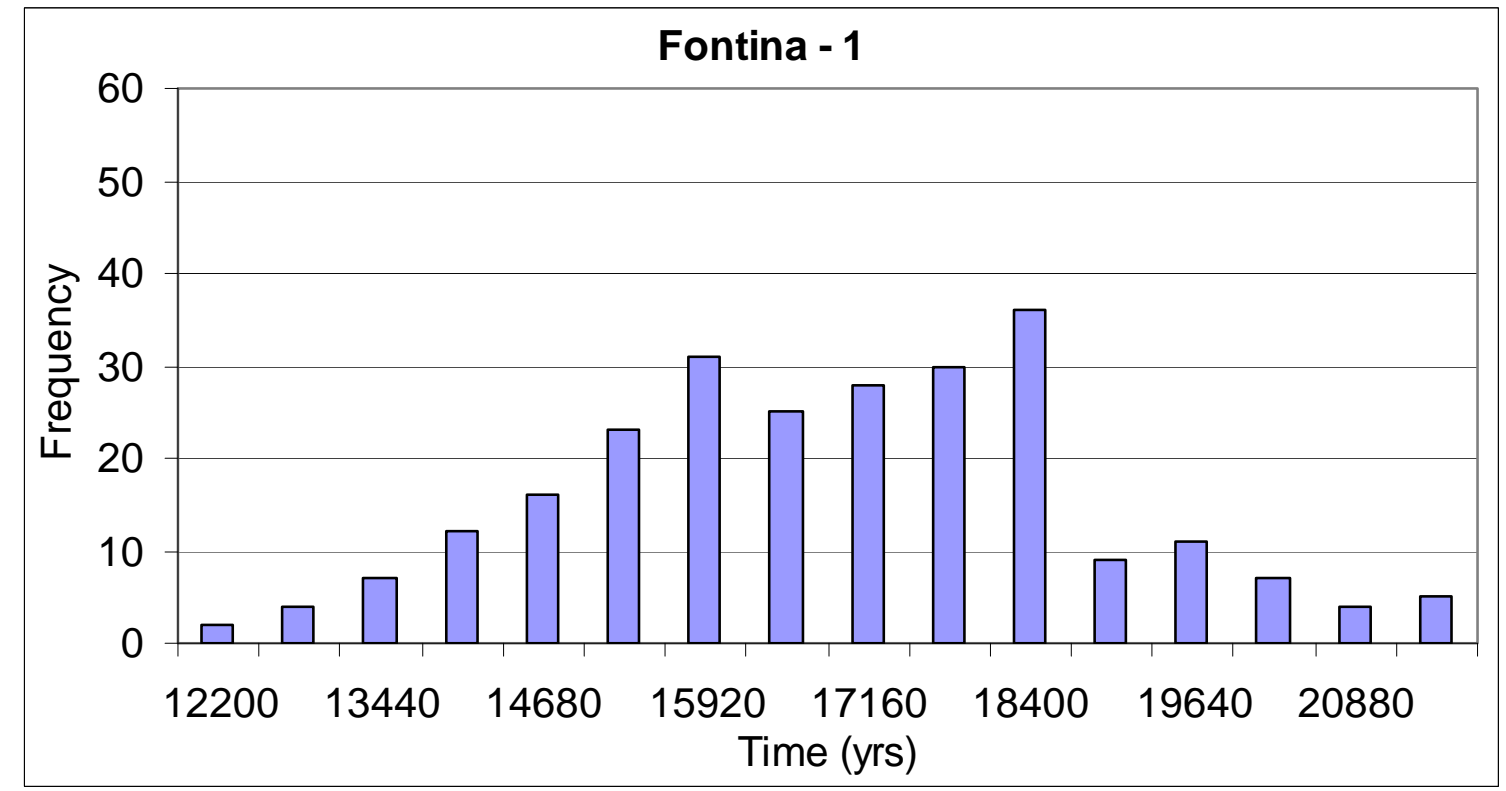

Figure C71. Distribution of minimum travel time from Fontina -1 to YM boundaries based on effective-porosity Set 1 for 1998 scenario. 


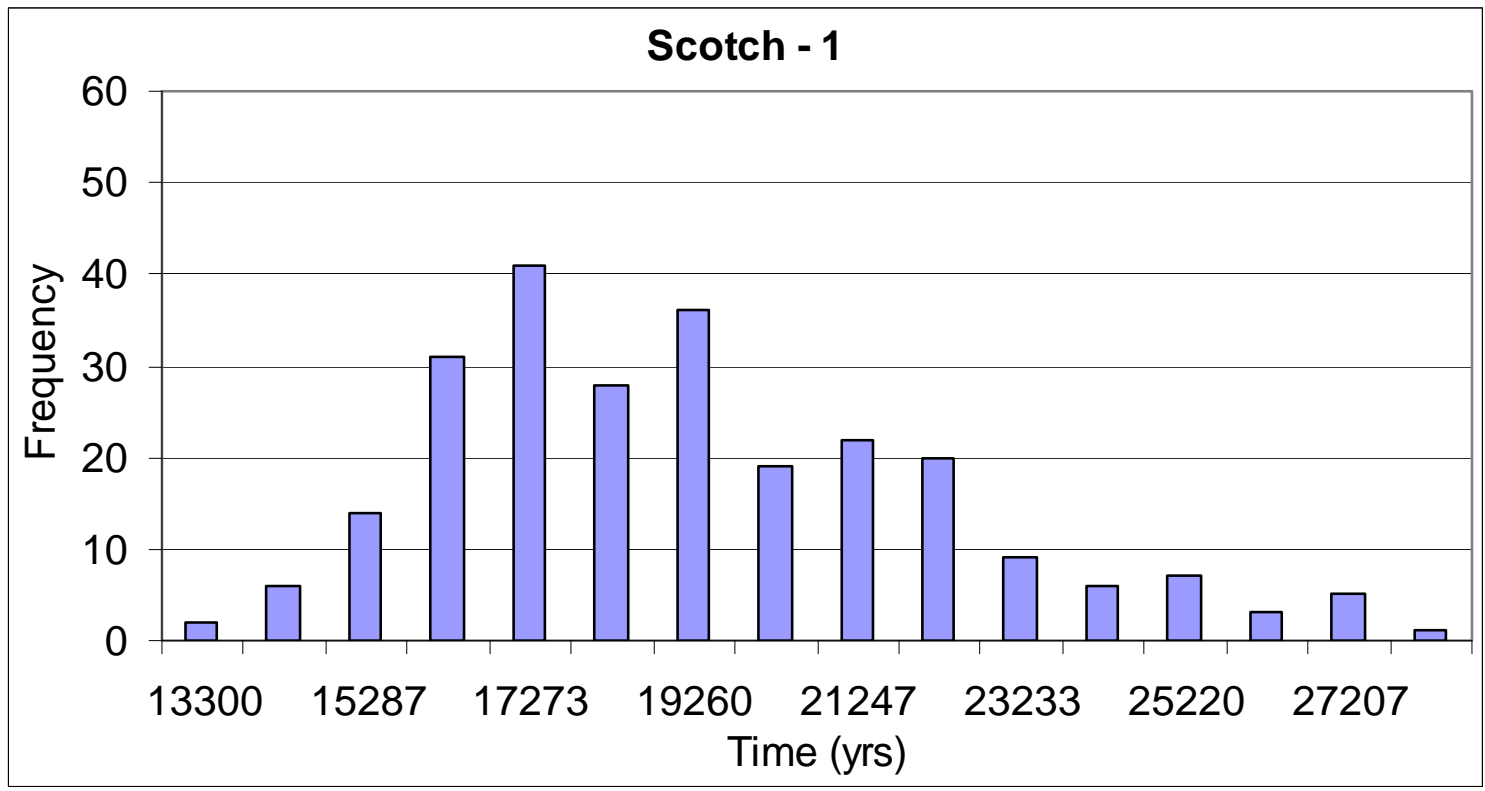

Figure C72. Distribution of minimum travel time from Scotch -1 to YM boundaries based on effective-porosity Set 1 for 1998 scenario.

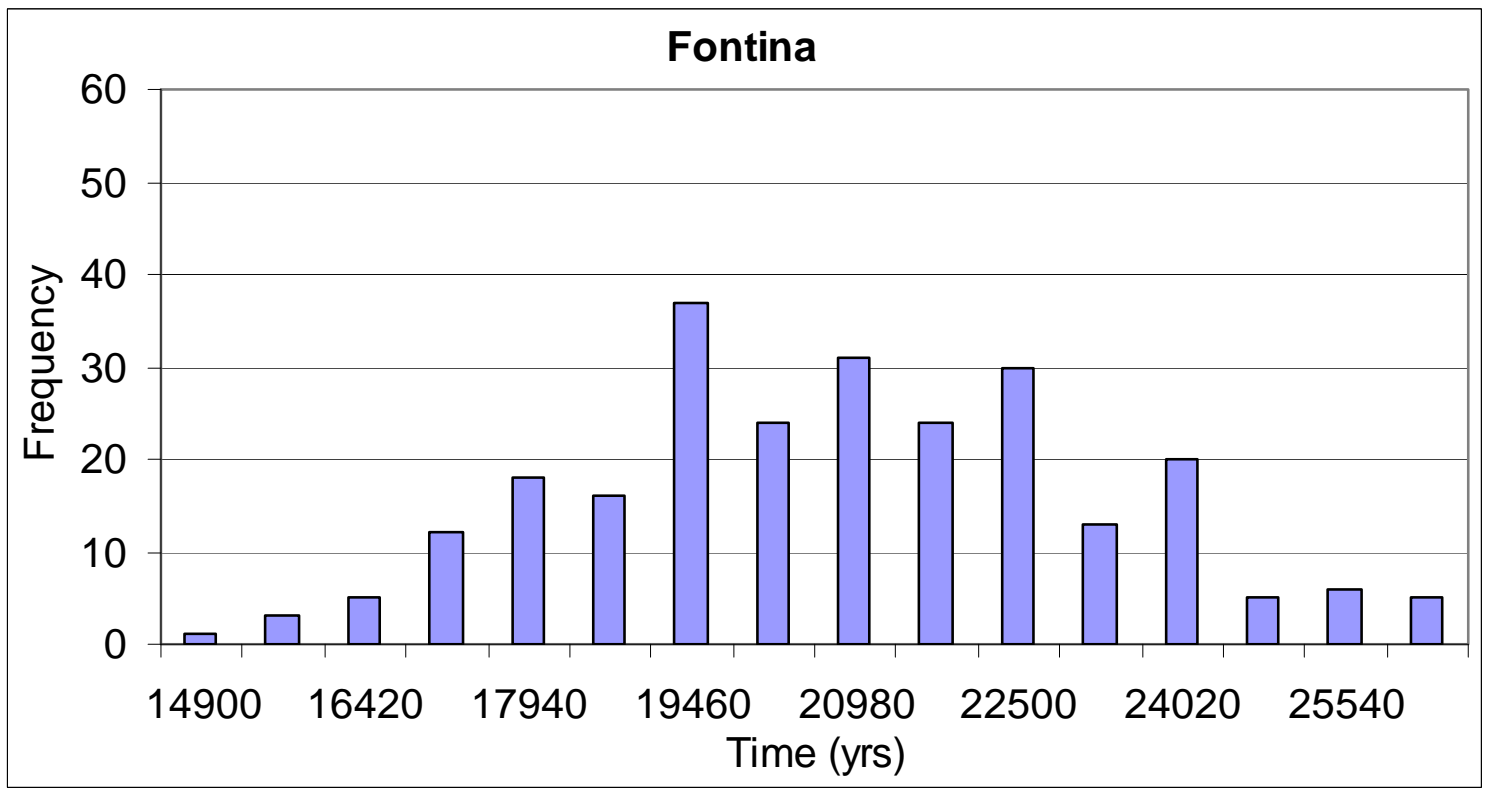

Figure C73. Distribution of minimum travel time from Fontina to YM boundaries based on effective-porosity Set 1 for 1998 scenario. 


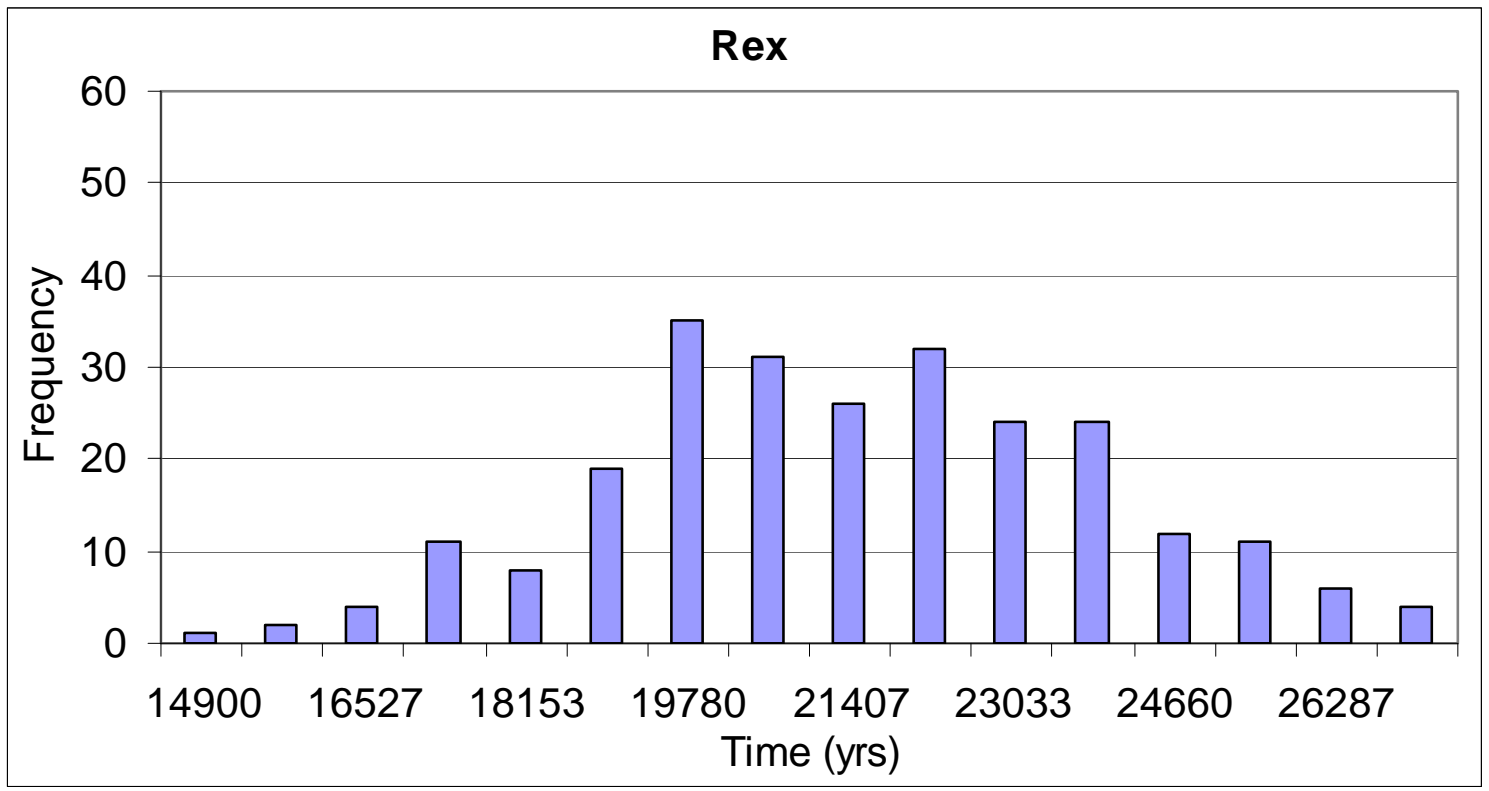

Figure C74. Distribution of minimum travel time from Rex to YM boundaries based on effective-porosity Set 1 for 1998 scenario.

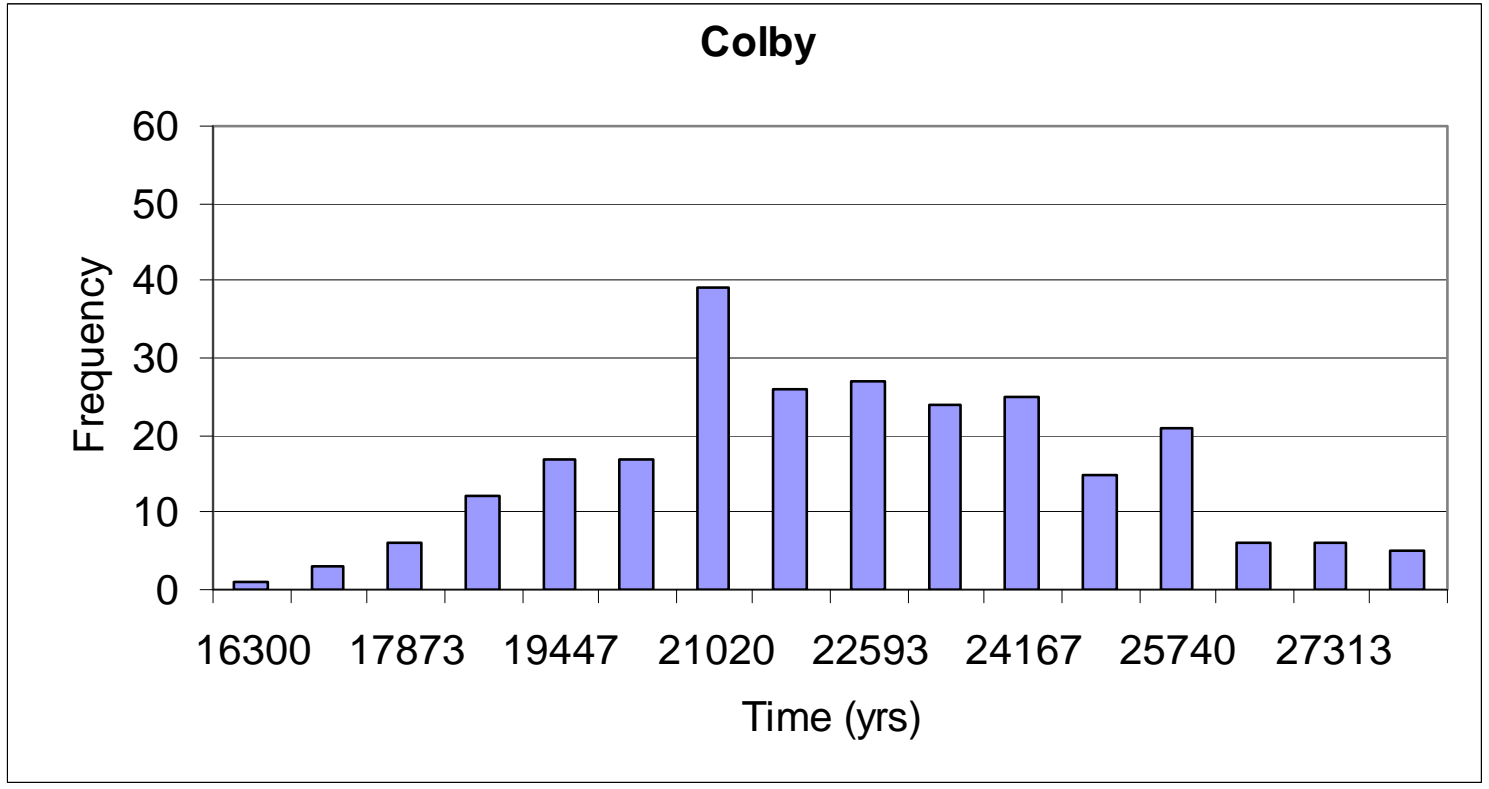

Figure C75. Distribution of minimum travel time from Colby to YM boundaries based on effective-porosity Set 1 for 1998 scenario. 


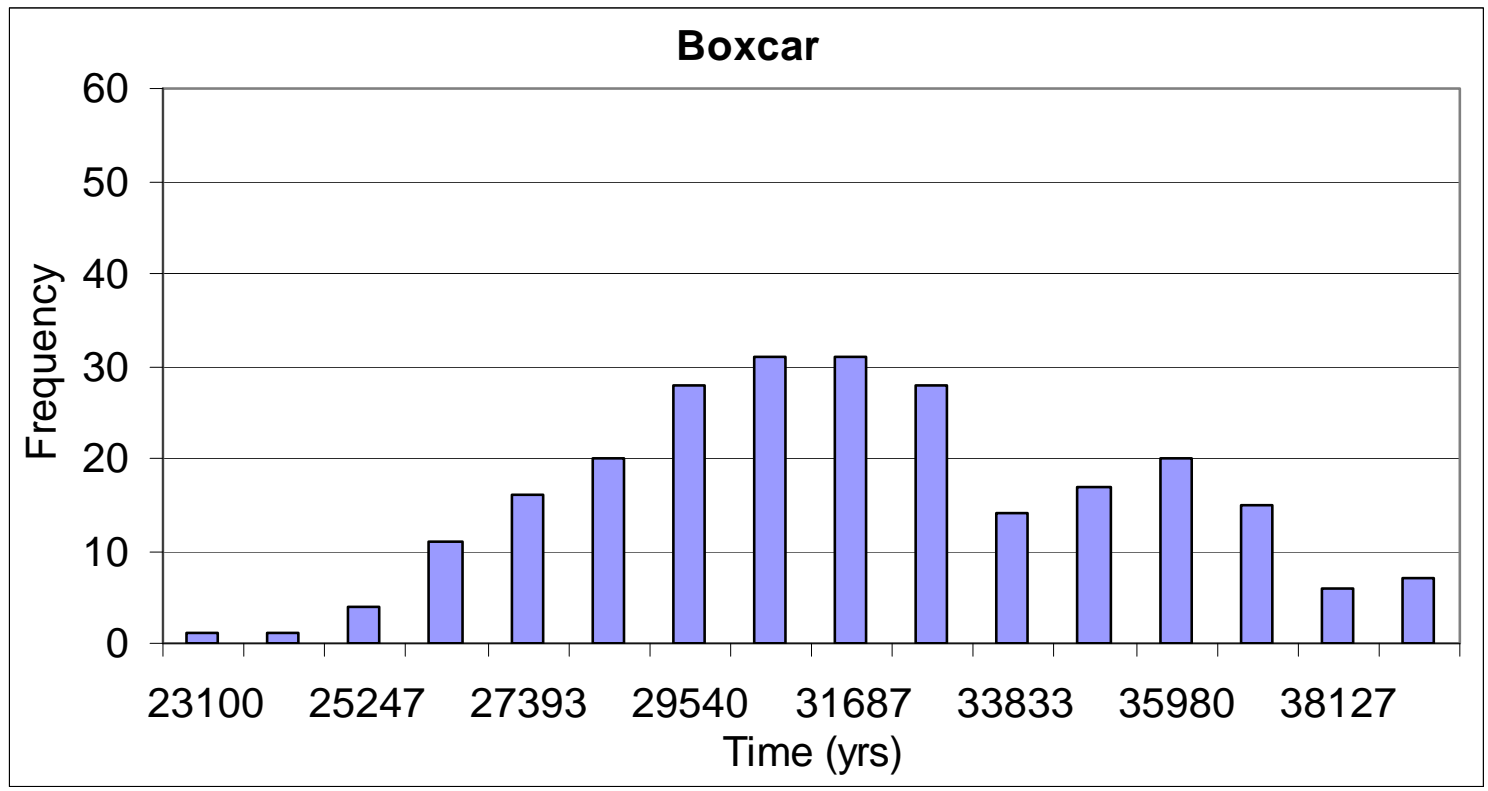

Figure C76. Distribution of minimum travel time from Boxcar to YM boundaries based on effective-porosity Set 1 for 1998 scenario.

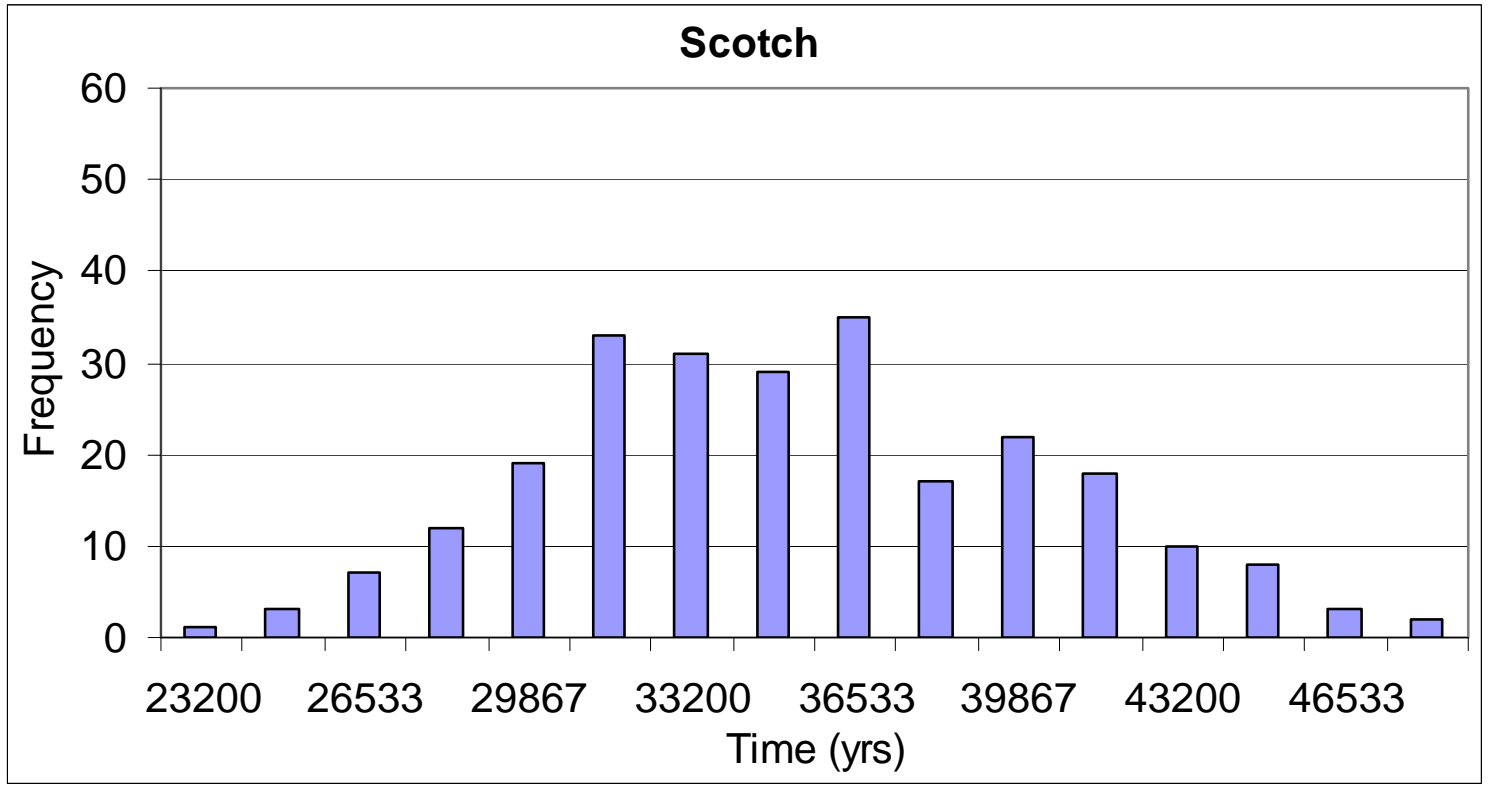

Figure C77. Distribution of minimum travel time from Scotch to YM boundaries based on effective-porosity Set 1 for 1998 scenario. 


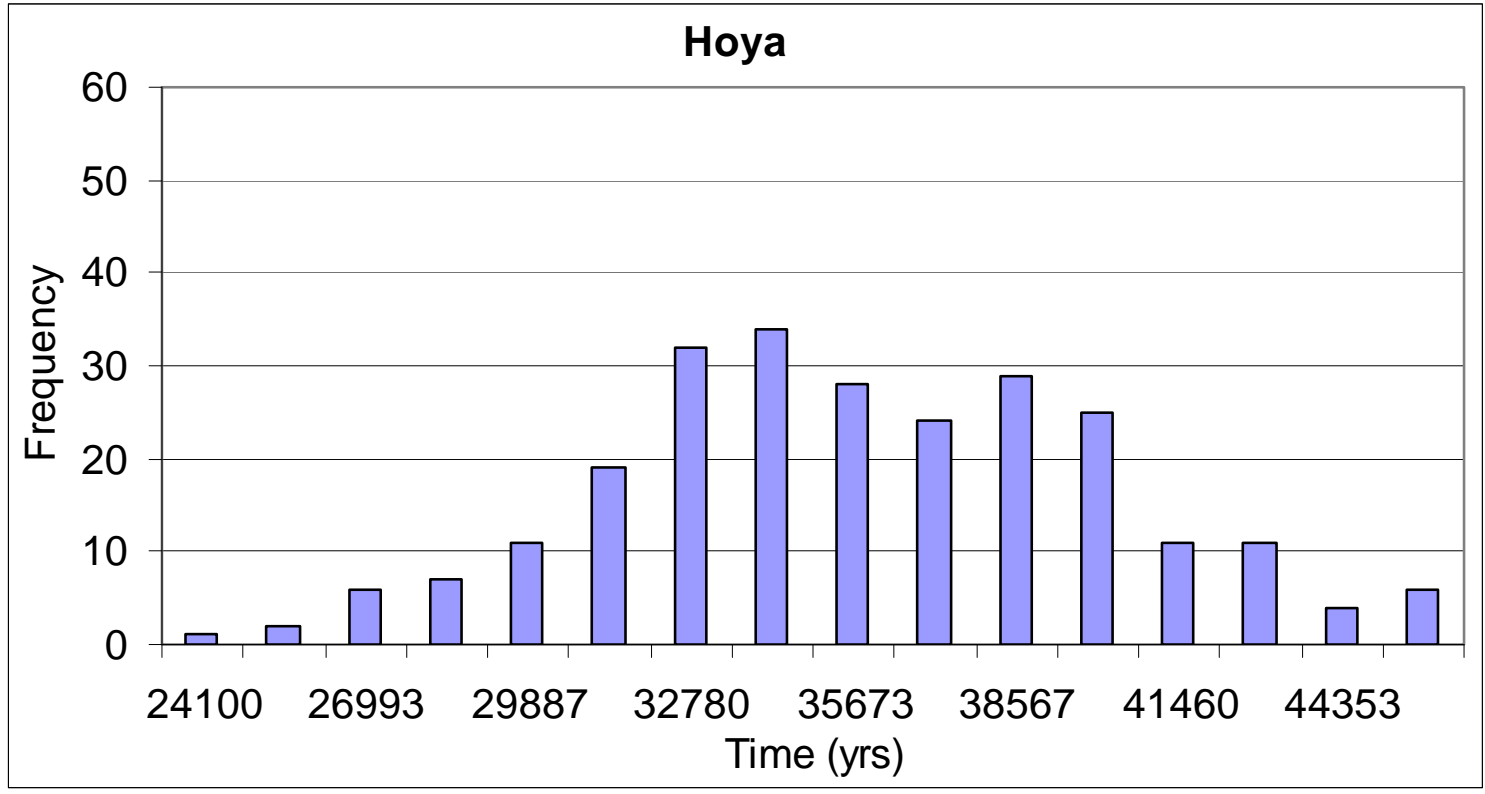

Figure C78. Distribution of minimum travel time from Hoya to YM boundaries based on effective-porosity Set 1 for 1998 scenario.

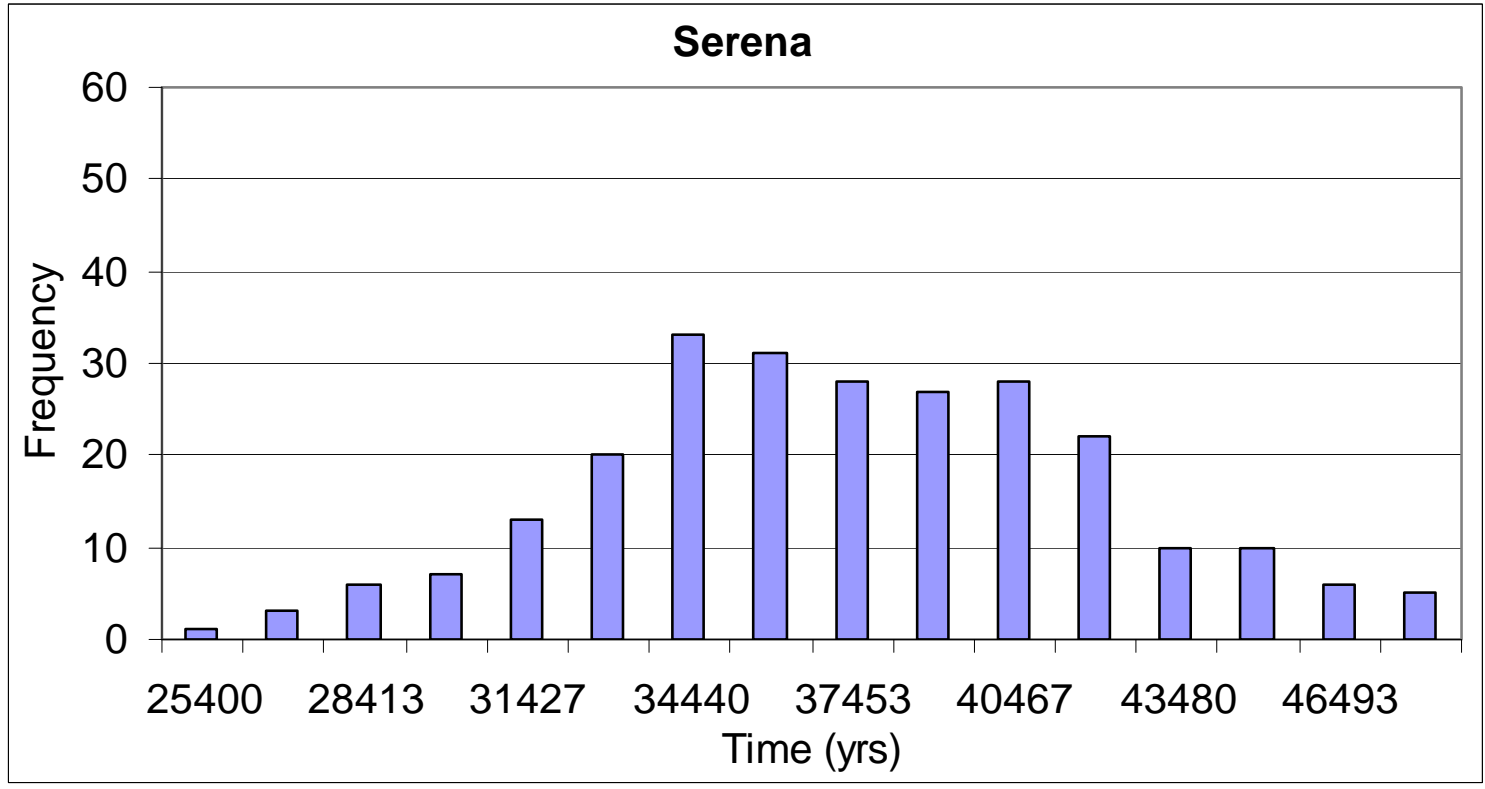

Figure C79. Distribution of minimum travel time from Serena to YM boundaries based on effective-porosity Set 1 for 1998 scenario. 


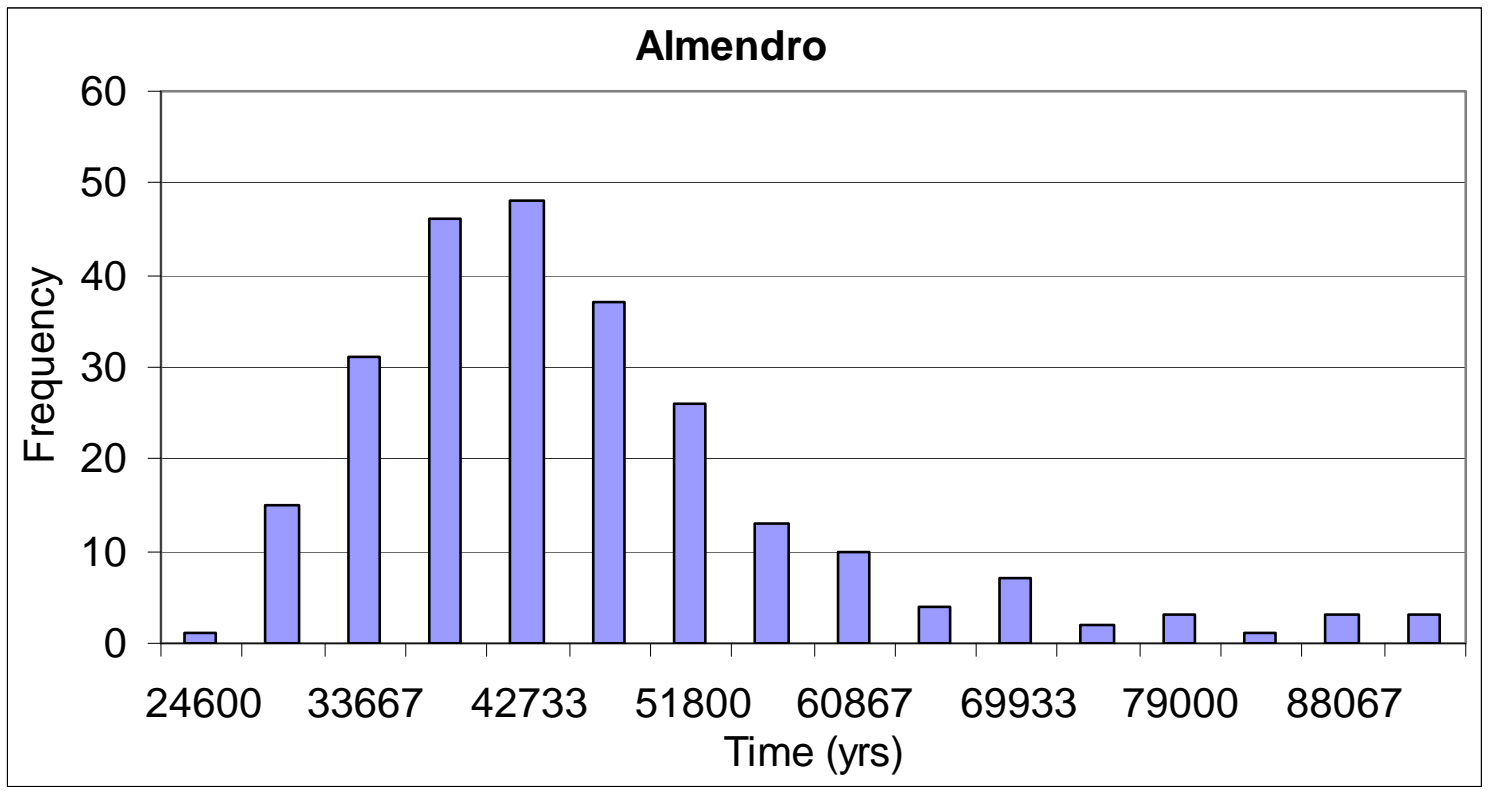

Figure C80. Distribution of minimum travel time from Almendro to YM boundaries based on effective-porosity Set 1 for 1998 scenario.

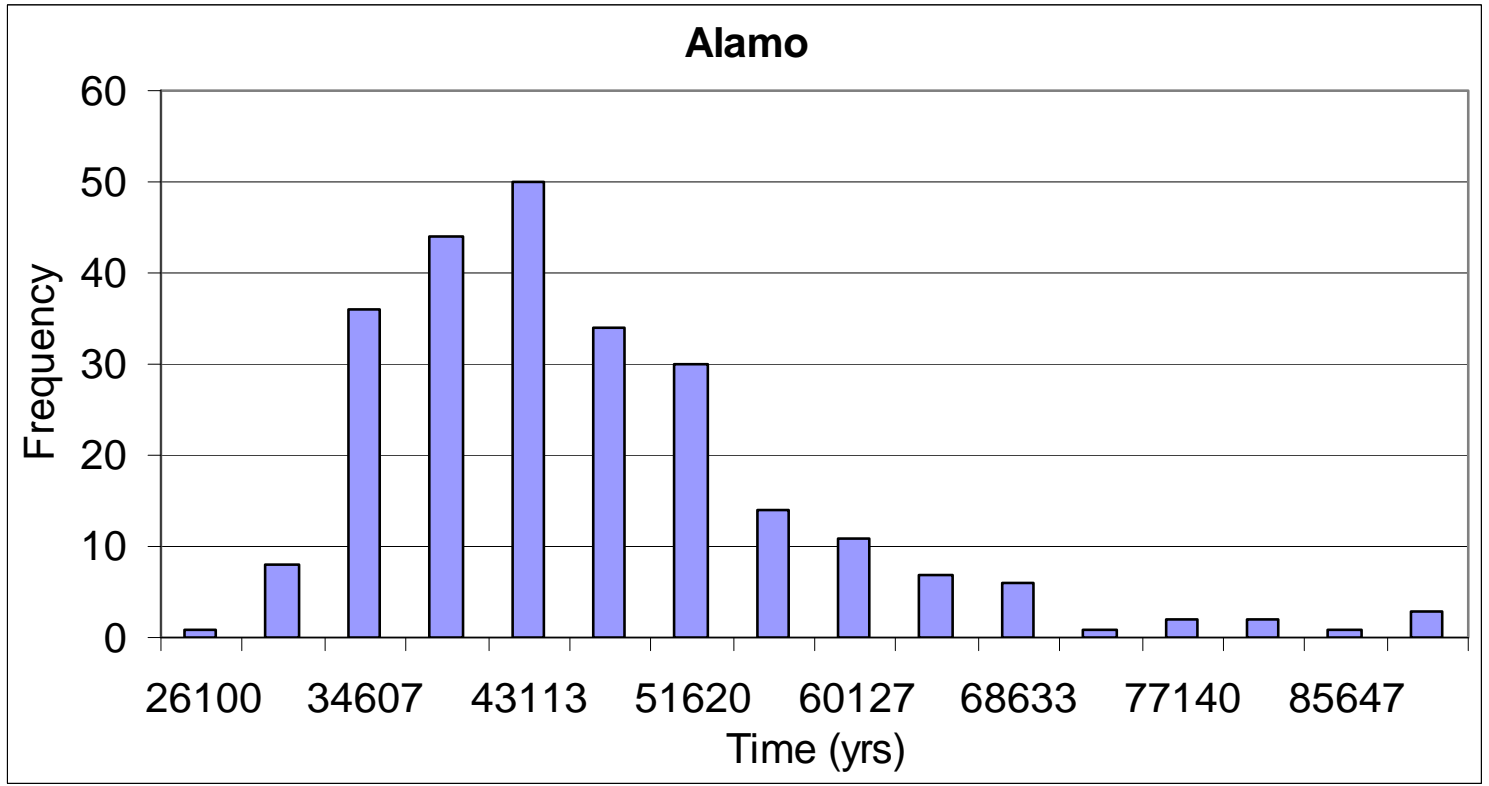

Figure C81. Distribution of minimum travel time from Alamo to YM boundaries based on effective-porosity Set 1 for 1998 scenario. 


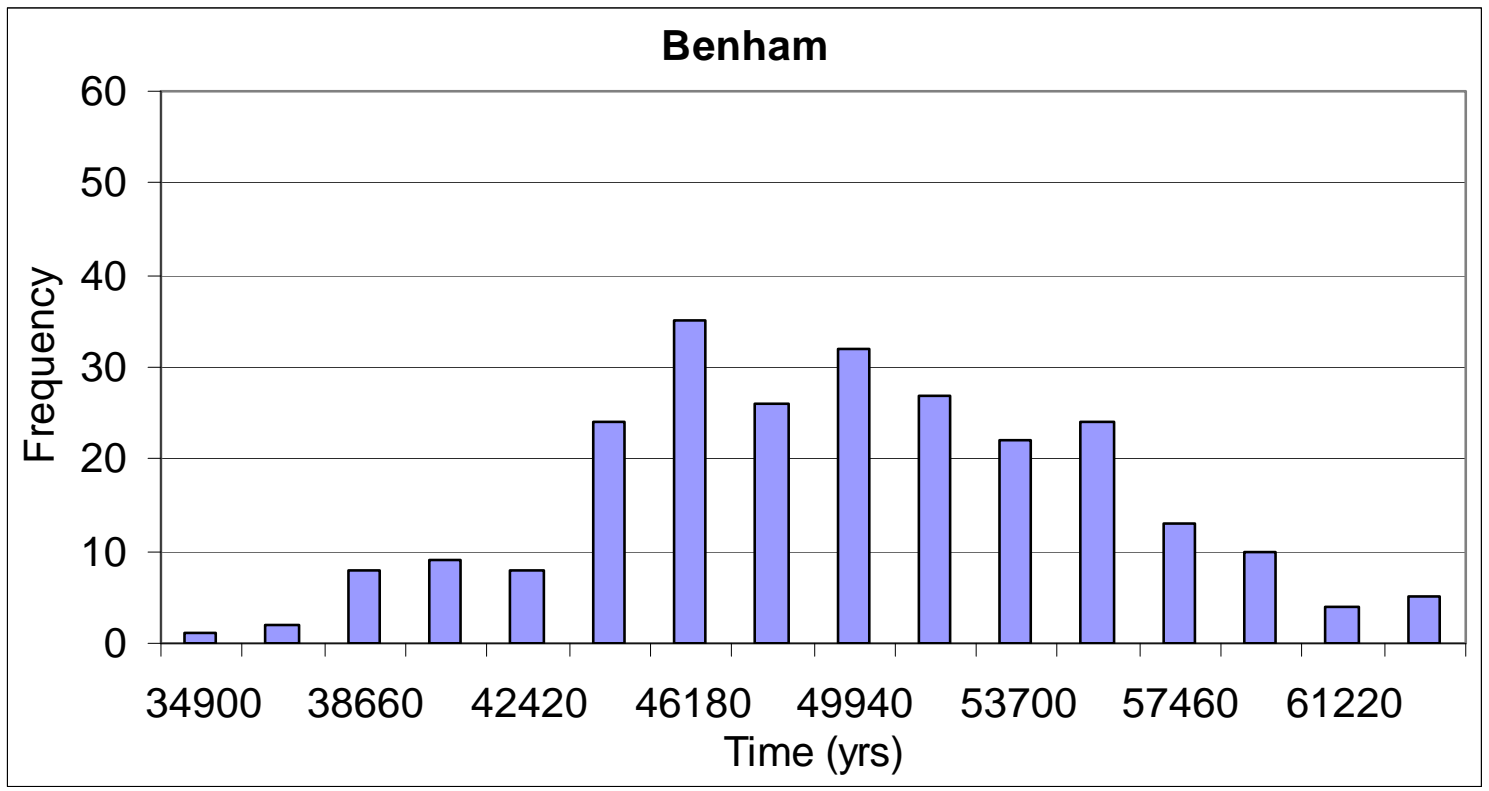

Figure C82. Distribution of minimum travel time from Benham to YM boundaries based on effective-porosity Set 1 for 1998 scenario.

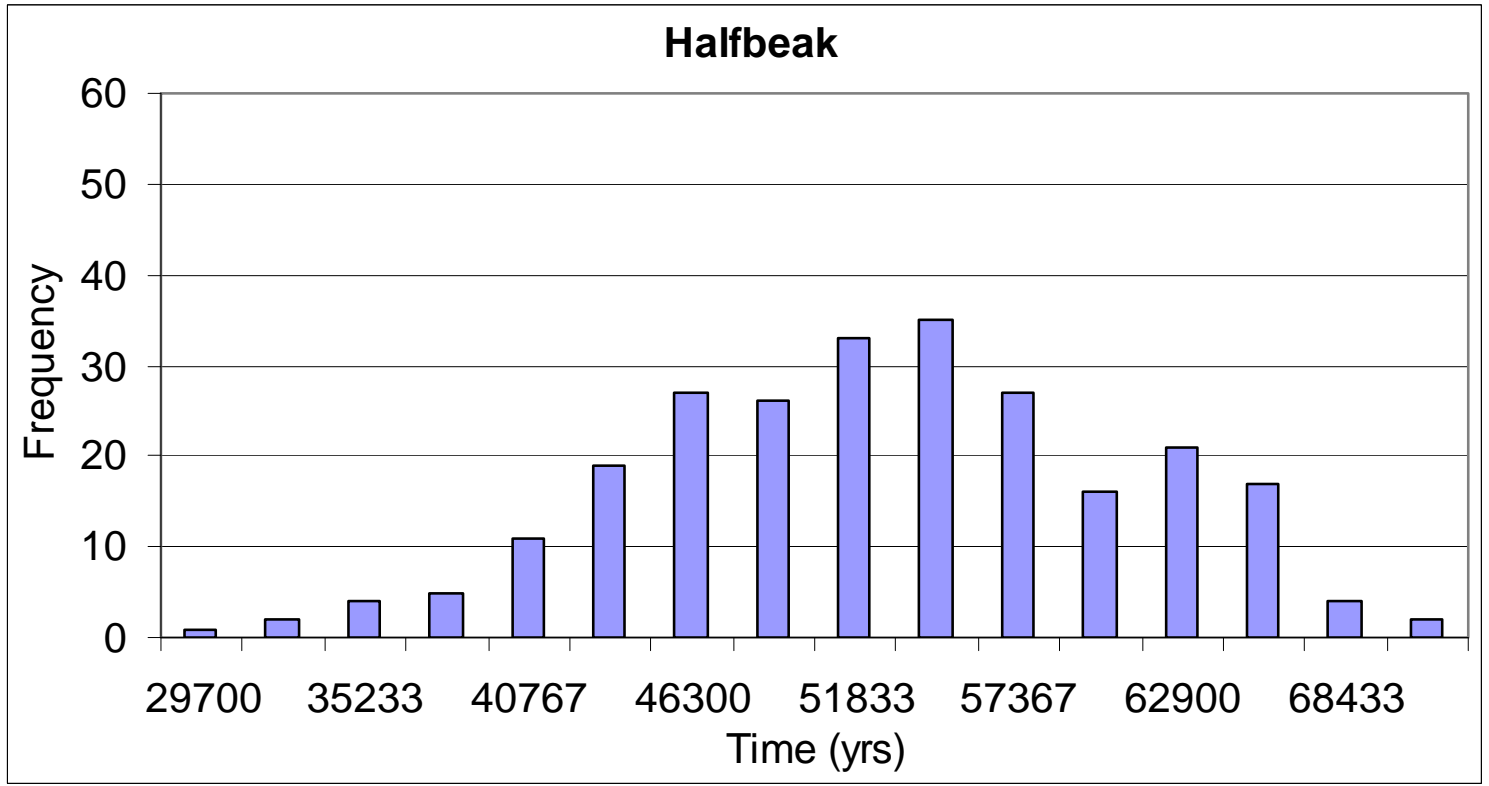

Figure C83. Distribution of minimum travel time from Halfbeak to YM boundaries based on effective-porosity Set 1 for 1998 scenario. 


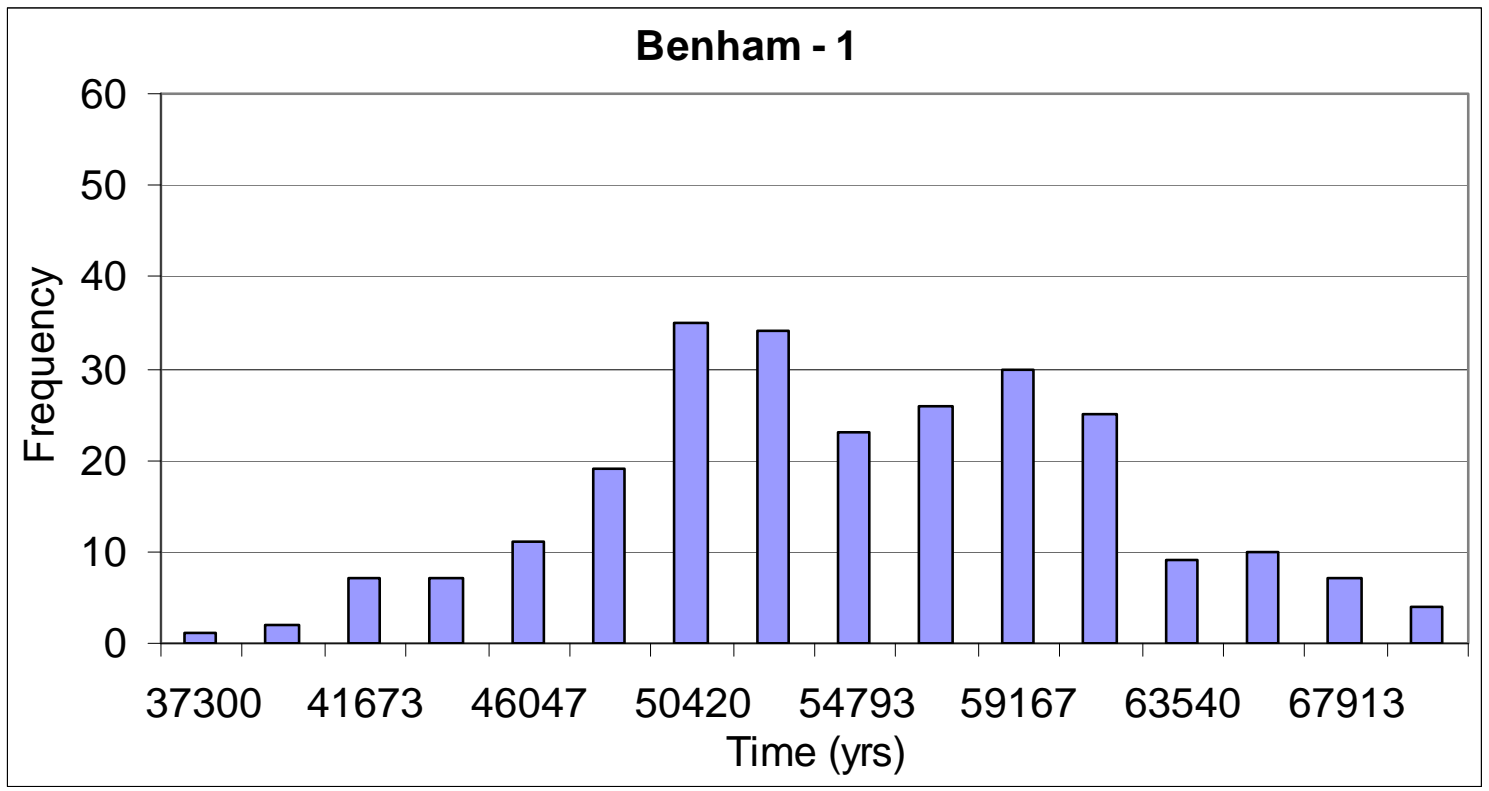

Figure C84. Distribution of minimum travel time from Benham -1 to YM boundaries based on effective-porosity Set 1 for 1998 scenario.

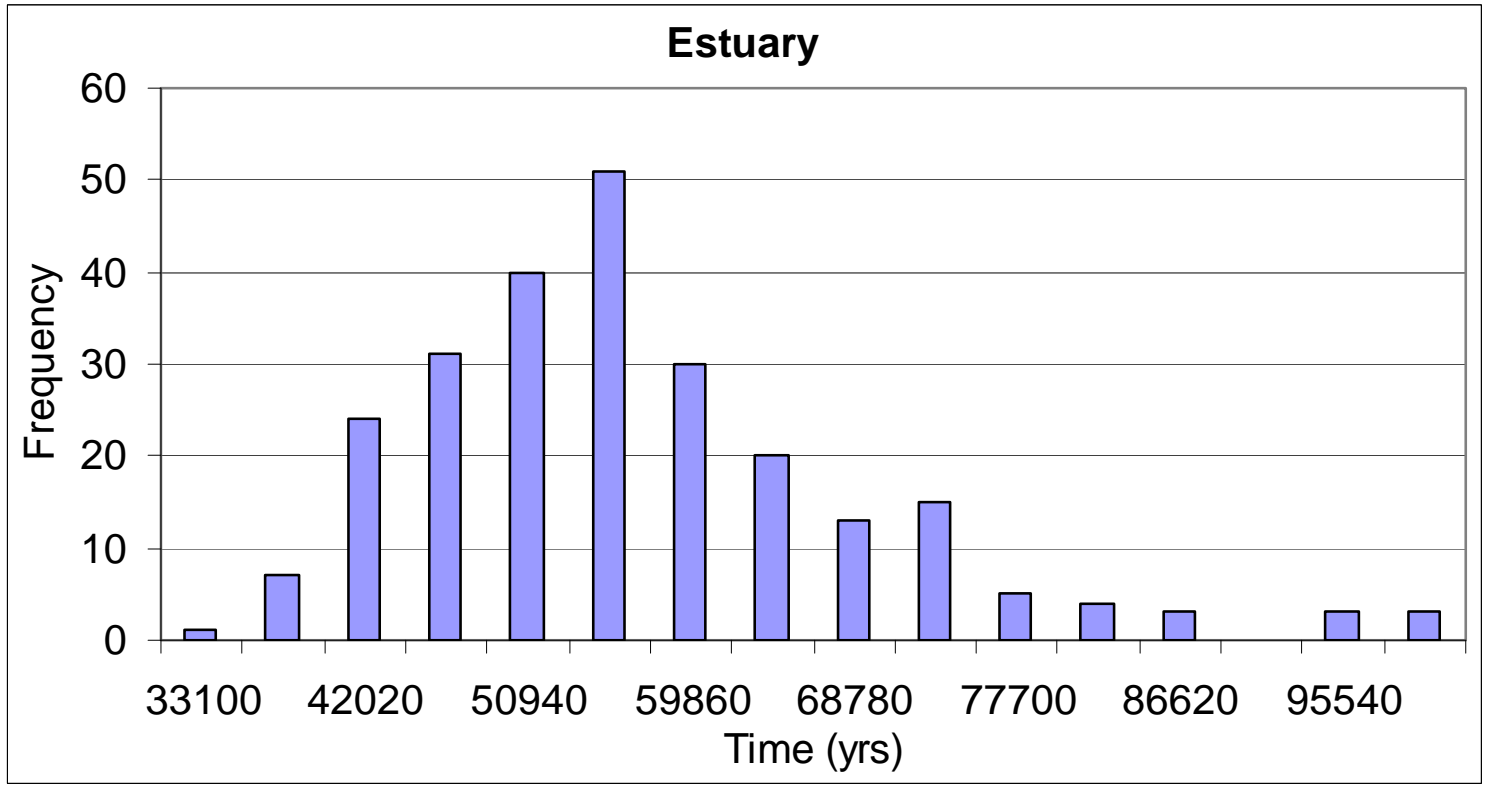

Figure C85. Distribution of minimum travel time from Estuary to YM boundaries based on effective-porosity Set 1 for 1998 scenario. 


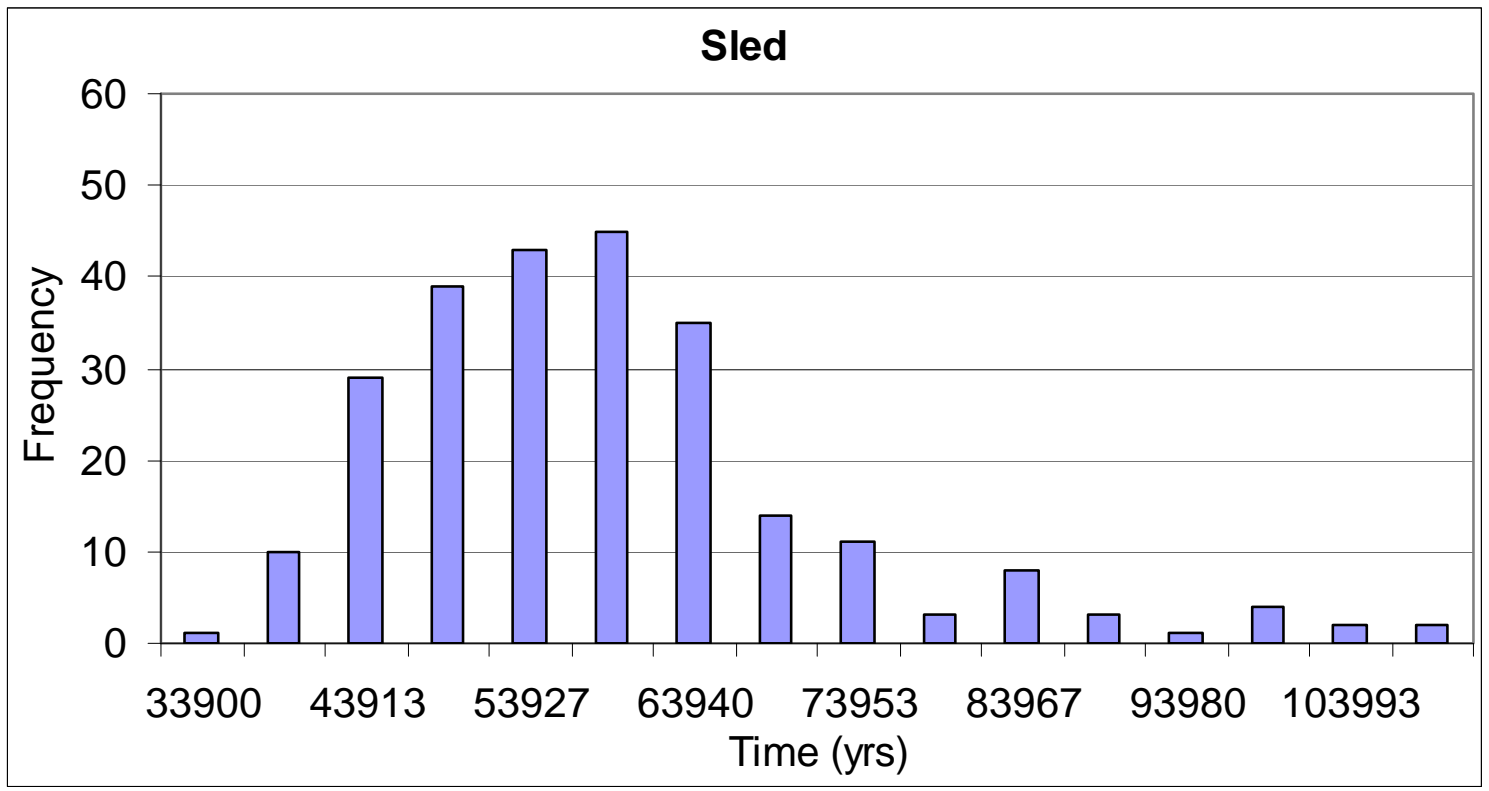

Figure C86. Distribution of minimum travel time from Sled to YM boundaries based on effective-porosity Set 1 for 1998 scenario.

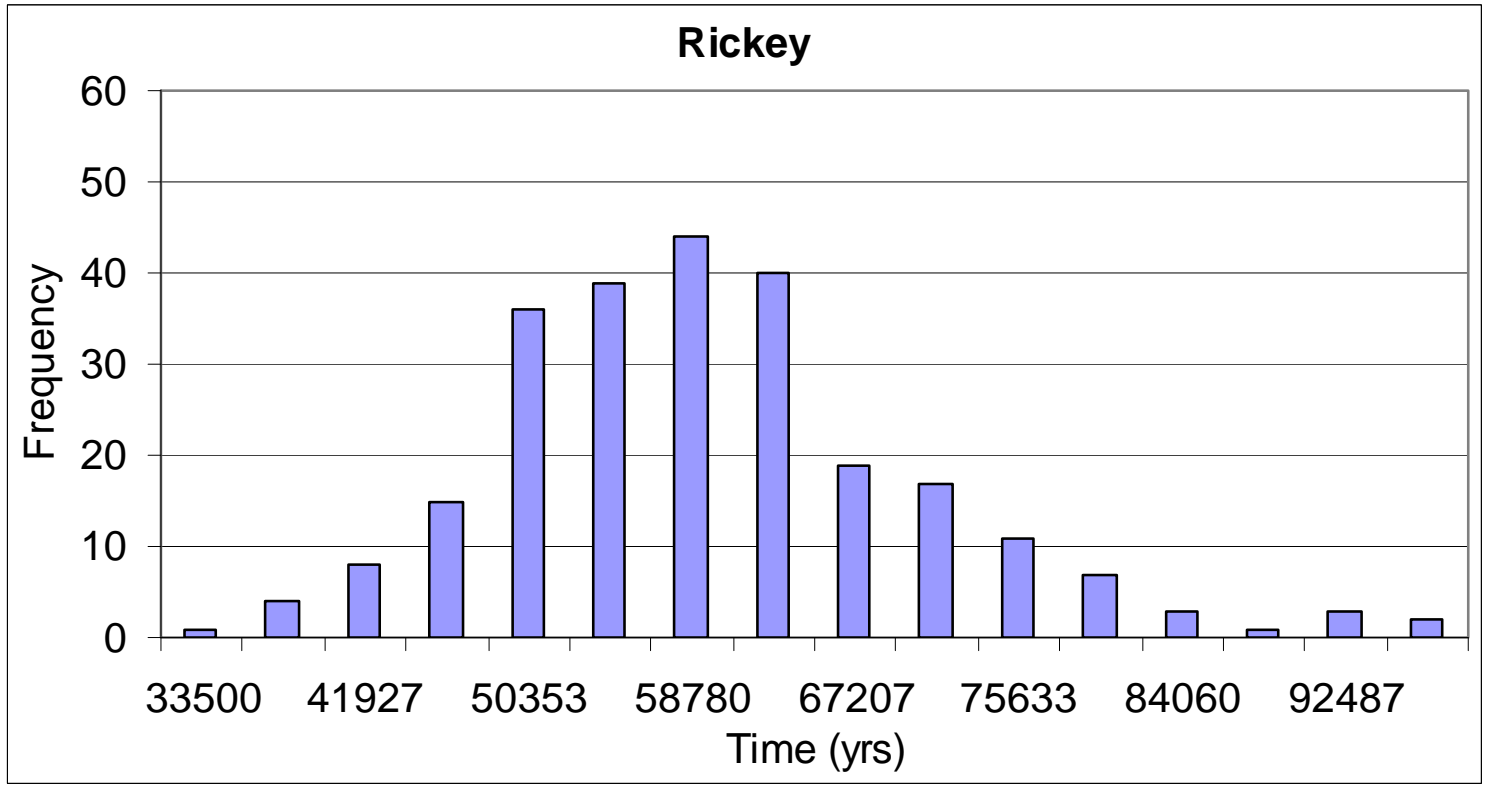

Figure C87. Distribution of minimum travel time from Rickey to YM boundaries based on effective-porosity Set 1 for 1998 scenario. 


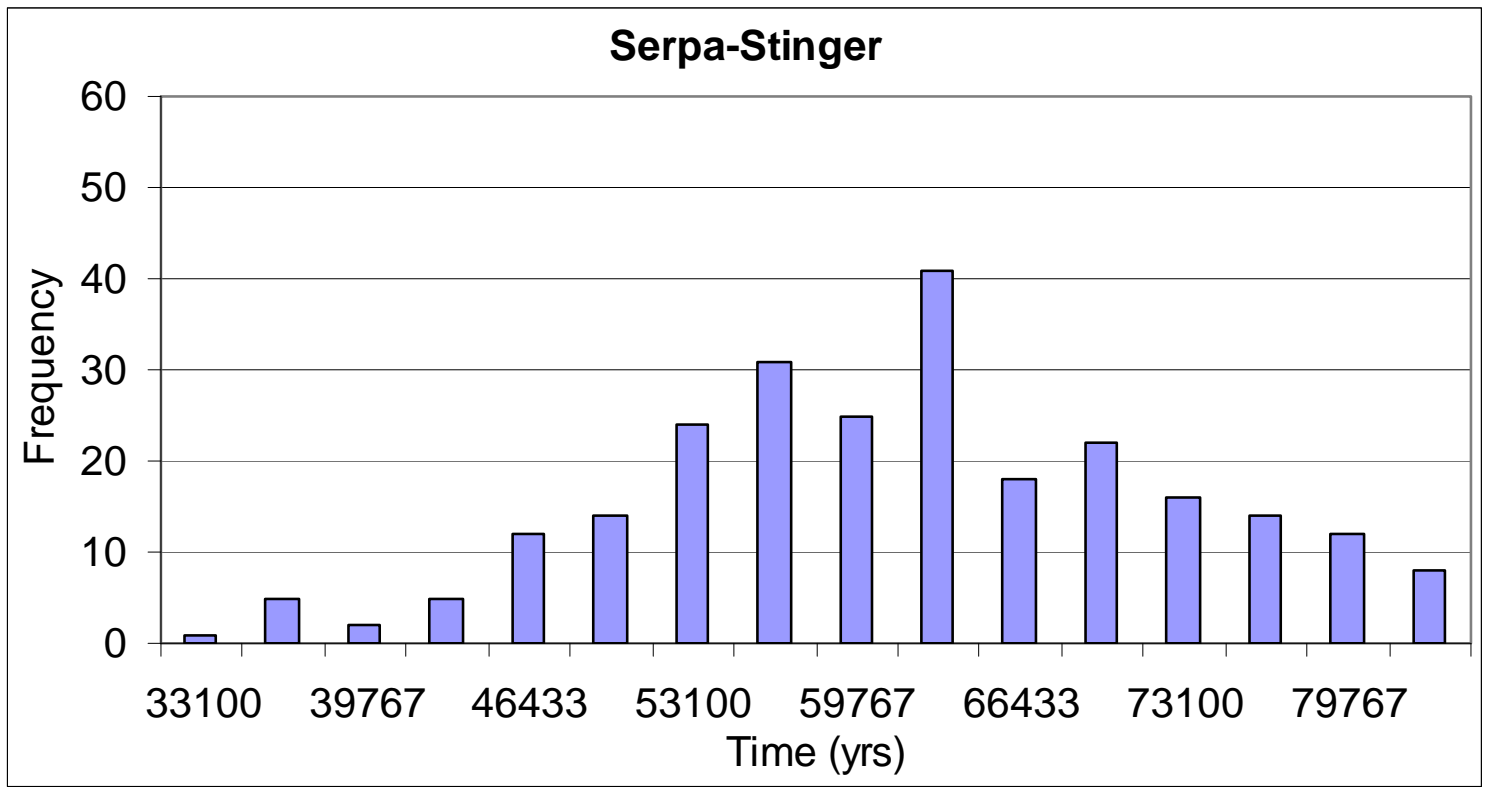

Figure C88. Distribution of minimum travel time from Serpa-Stinger to YM boundaries based on effective-porosity Set 1 for 1998 scenario.

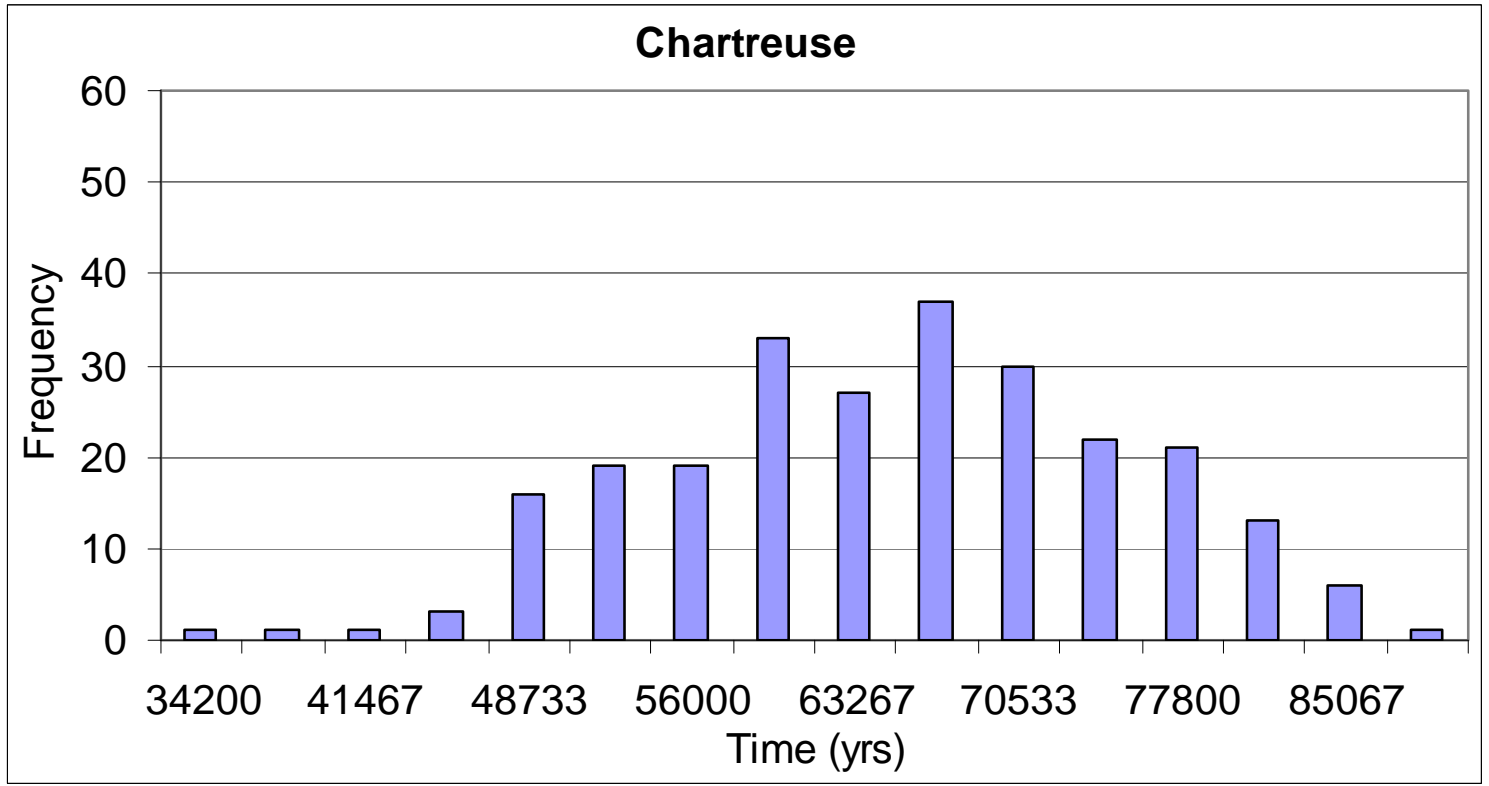

Figure C89. Distribution of minimum travel time from Chartreuse to YM boundaries based on effective-porosity Set 1 for 1998 scenario. 


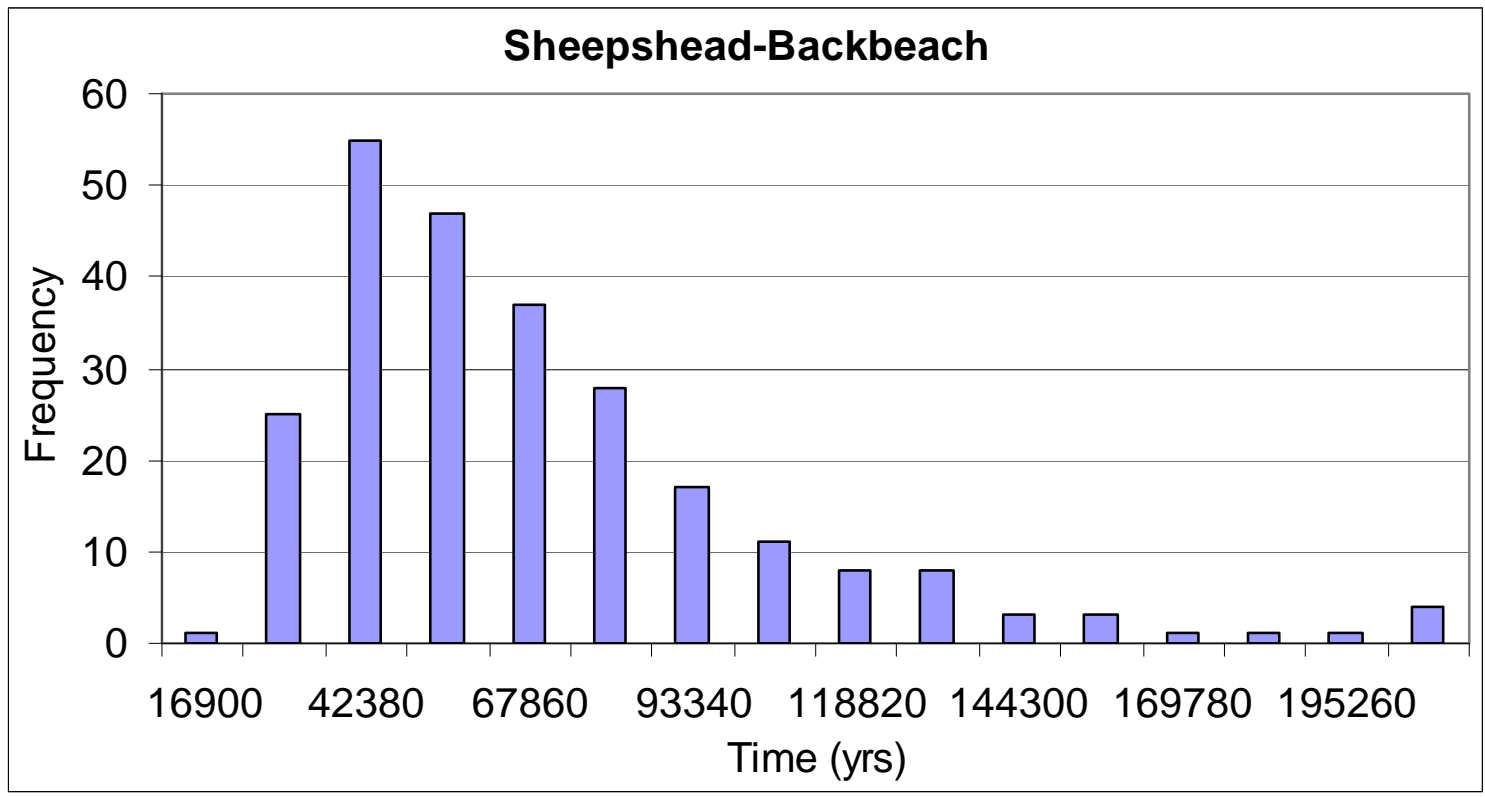

Figure C90. Distribution of minimum travel time from Sheepshead-Backbeach to YM boundaries based on effective-porosity Set 1 for 1998 scenario.

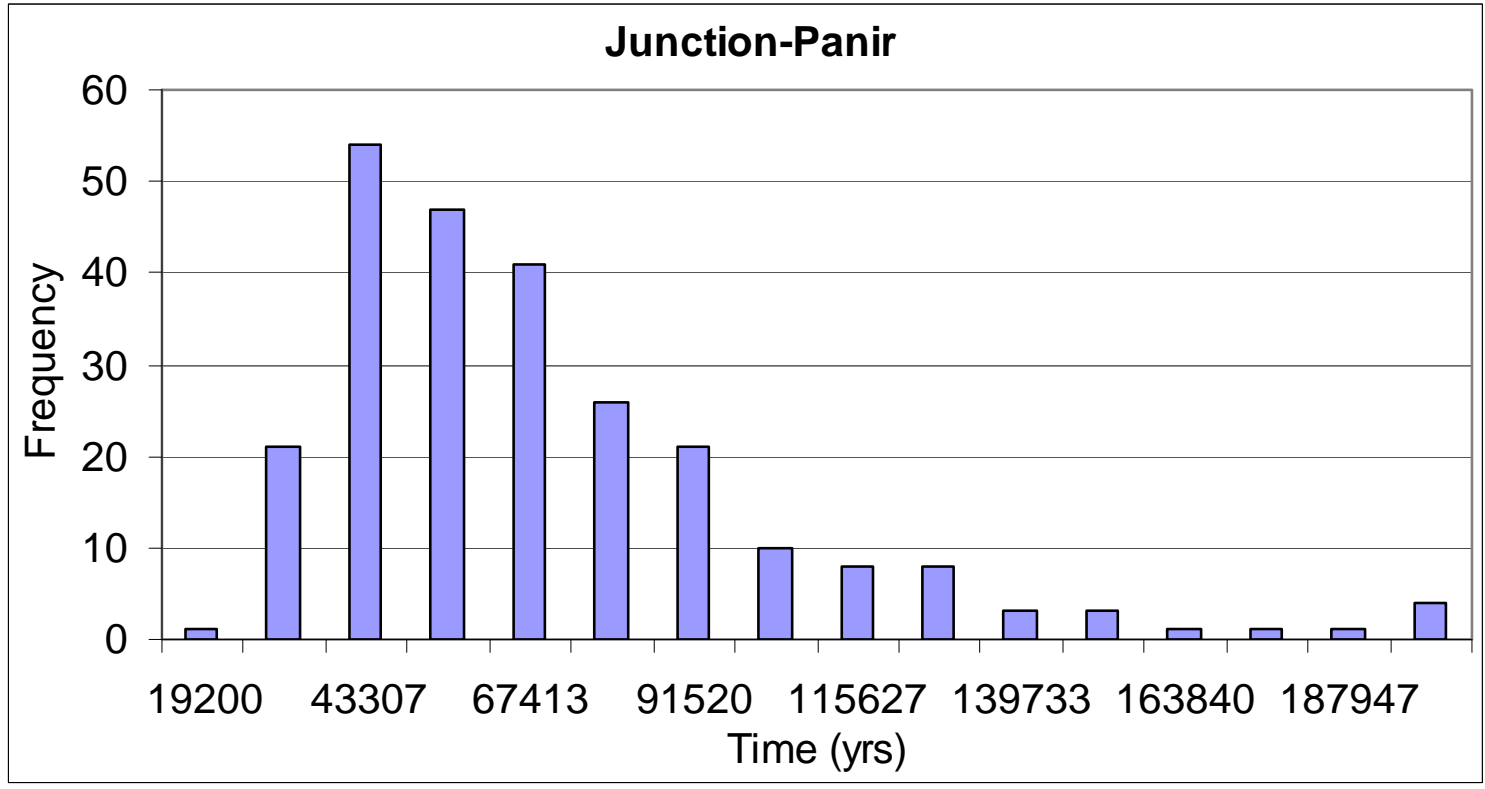

Figure C91. Distribution of minimum travel time from Junction-Panir to YM boundaries based on effective-porosity Set 1 for 1998 scenario. 


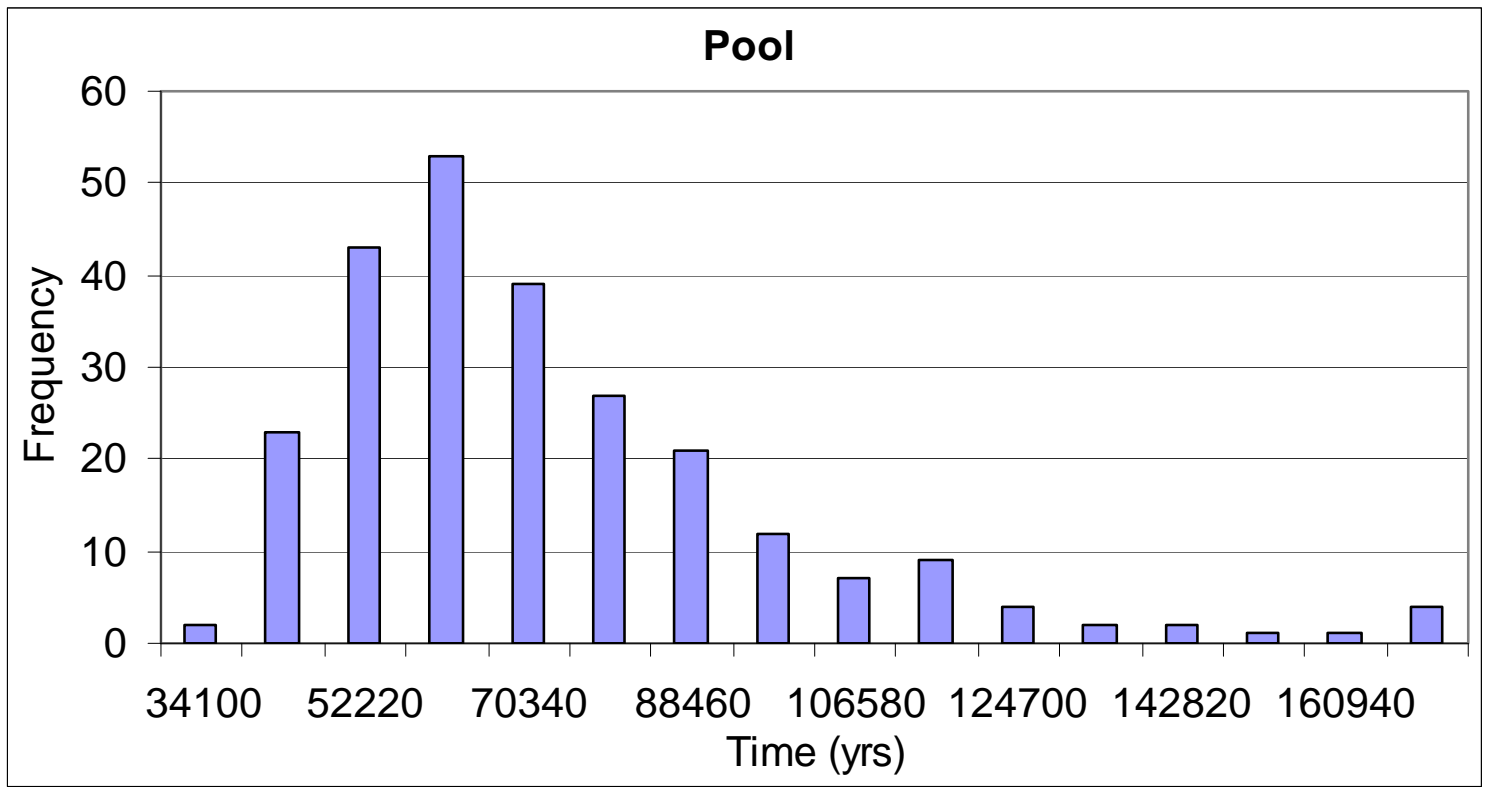

Figure C92. Distribution of minimum travel time from Pool to YM boundaries based on effective-porosity Set 1 for 1998 scenario.

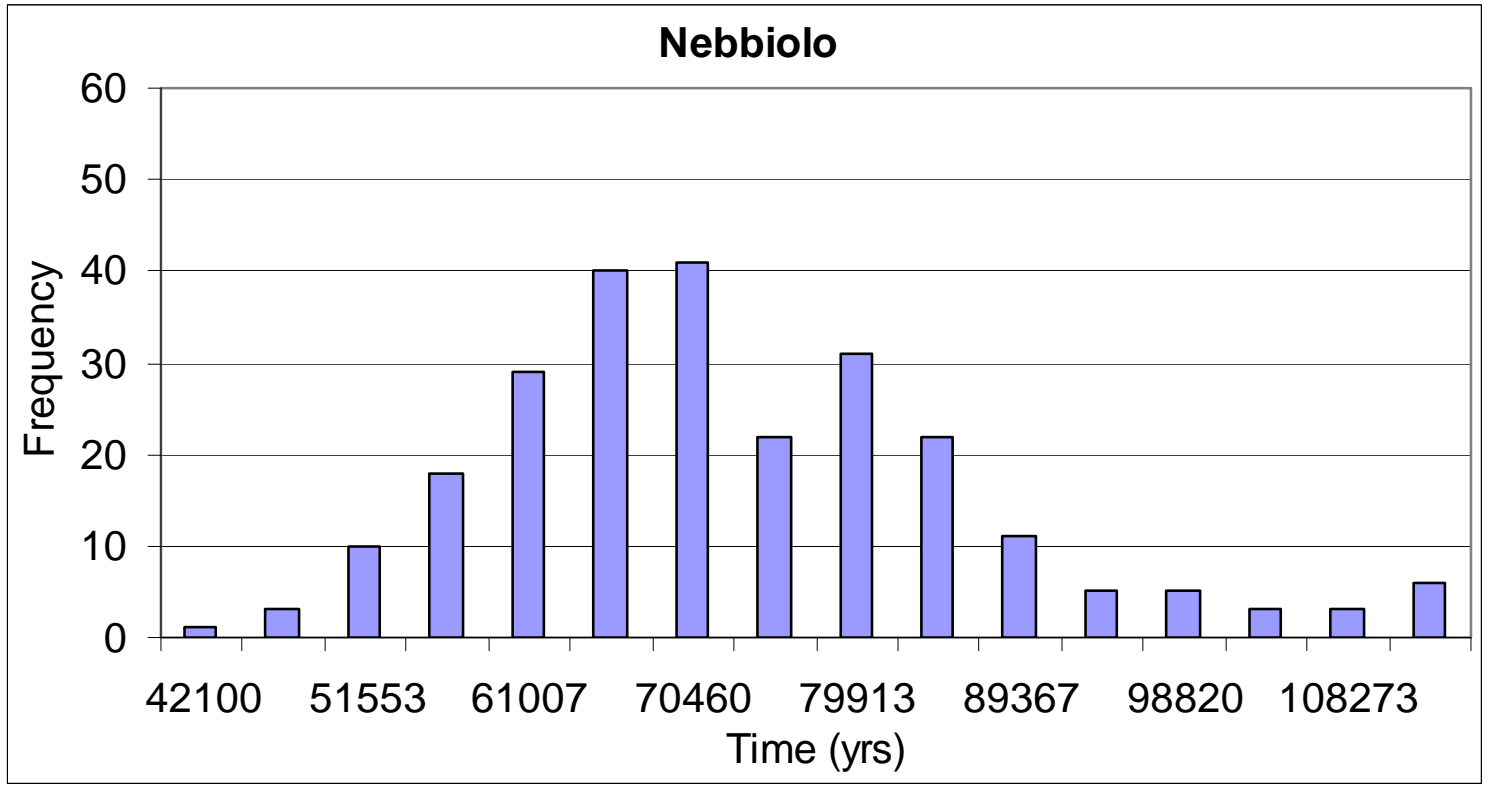

Figure C93. Distribution of minimum travel time from Nebbiolo to YM boundaries based on effective-porosity Set 1 for 1998 scenario. 


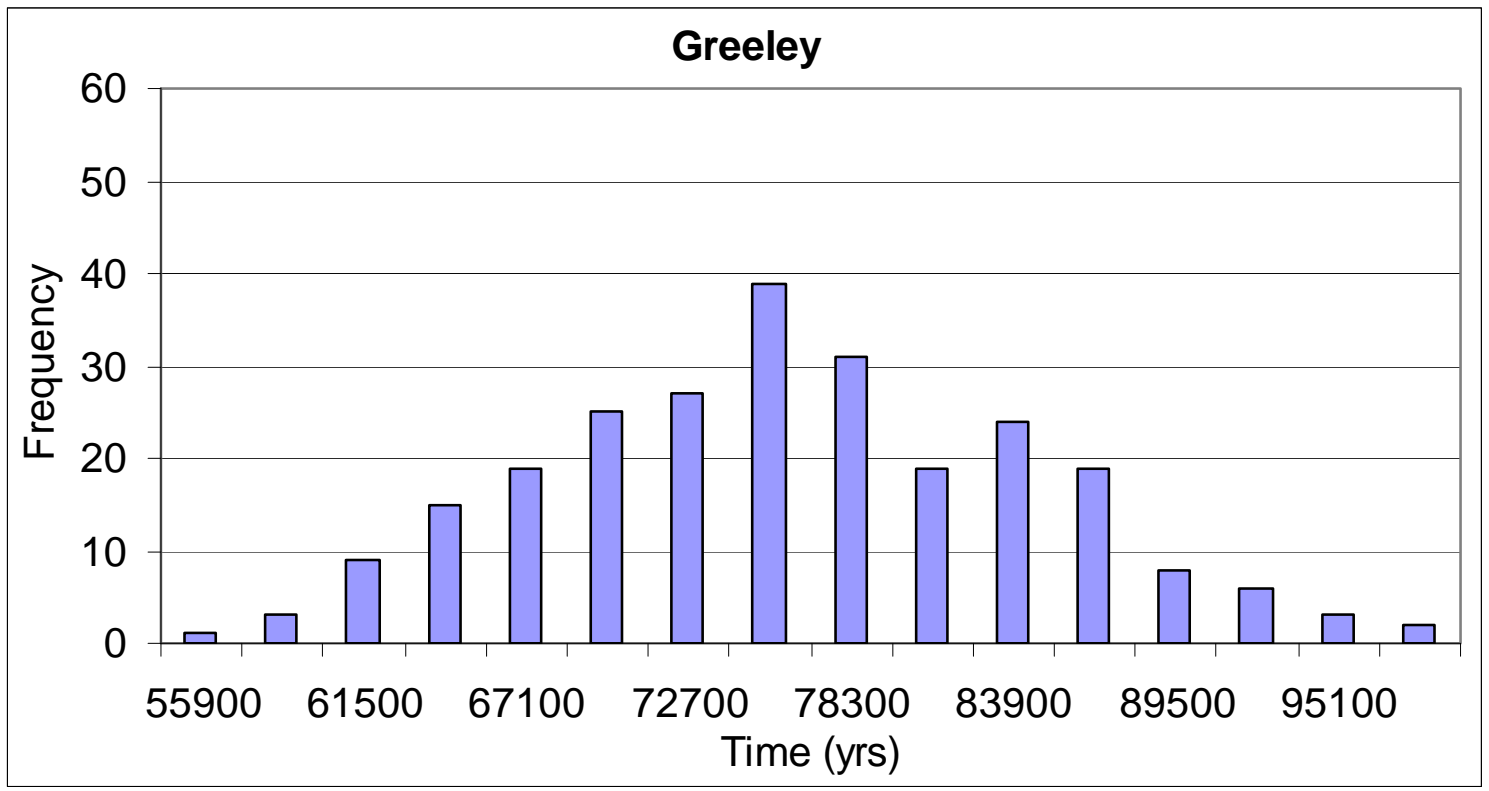

Figure C94. Distribution of minimum travel time from Greenley to YM boundaries based on effective-porosity Set 1 for 1998 scenario.

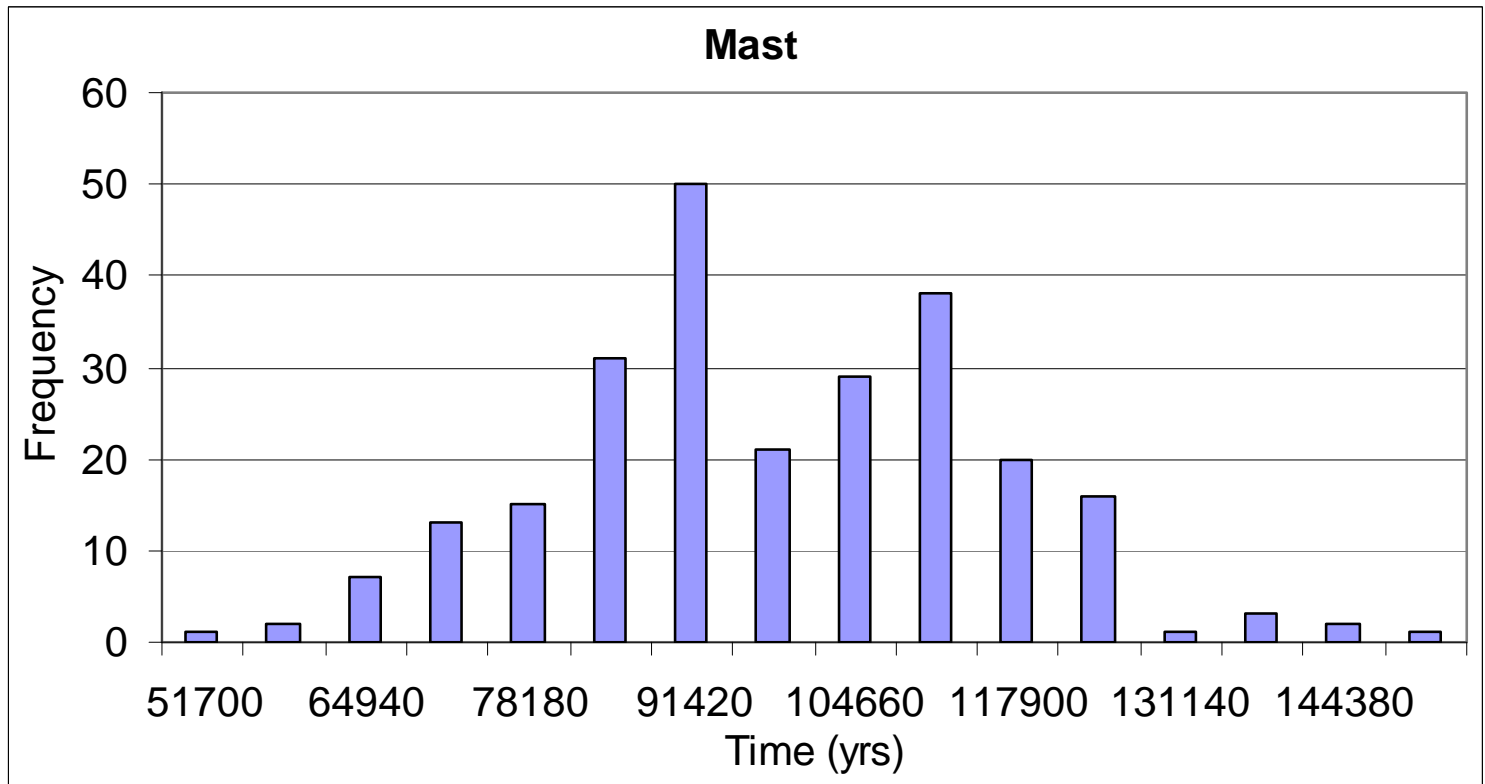

Figure C95. Distribution of minimum travel time from Mast to YM boundaries based on effective-porosity Set 1 for 1998 scenario. 


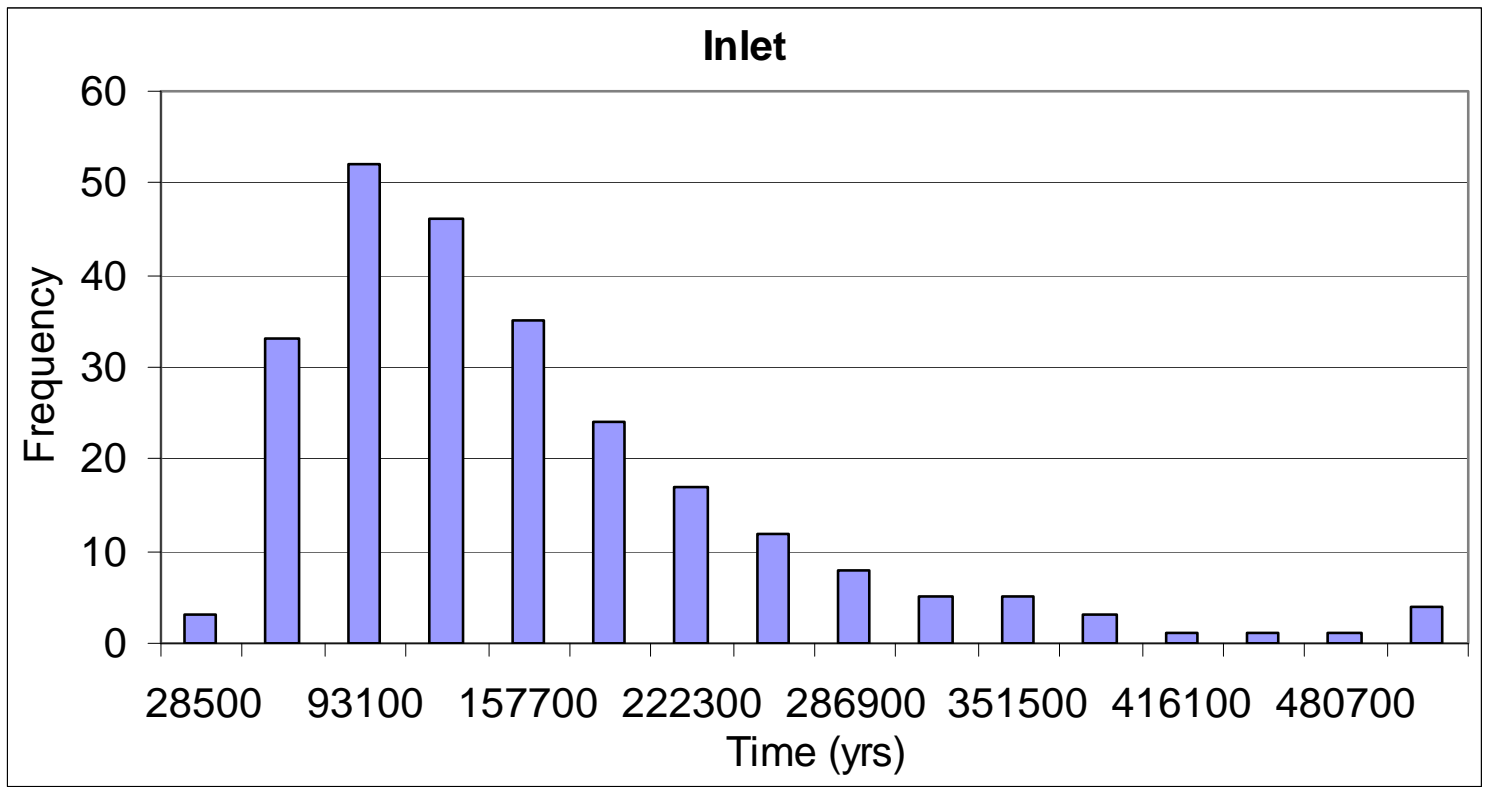

Figure C96. Distribution of minimum travel time from Inlet to YM boundaries based on effective-porosity Set 1 for 1998 scenario.

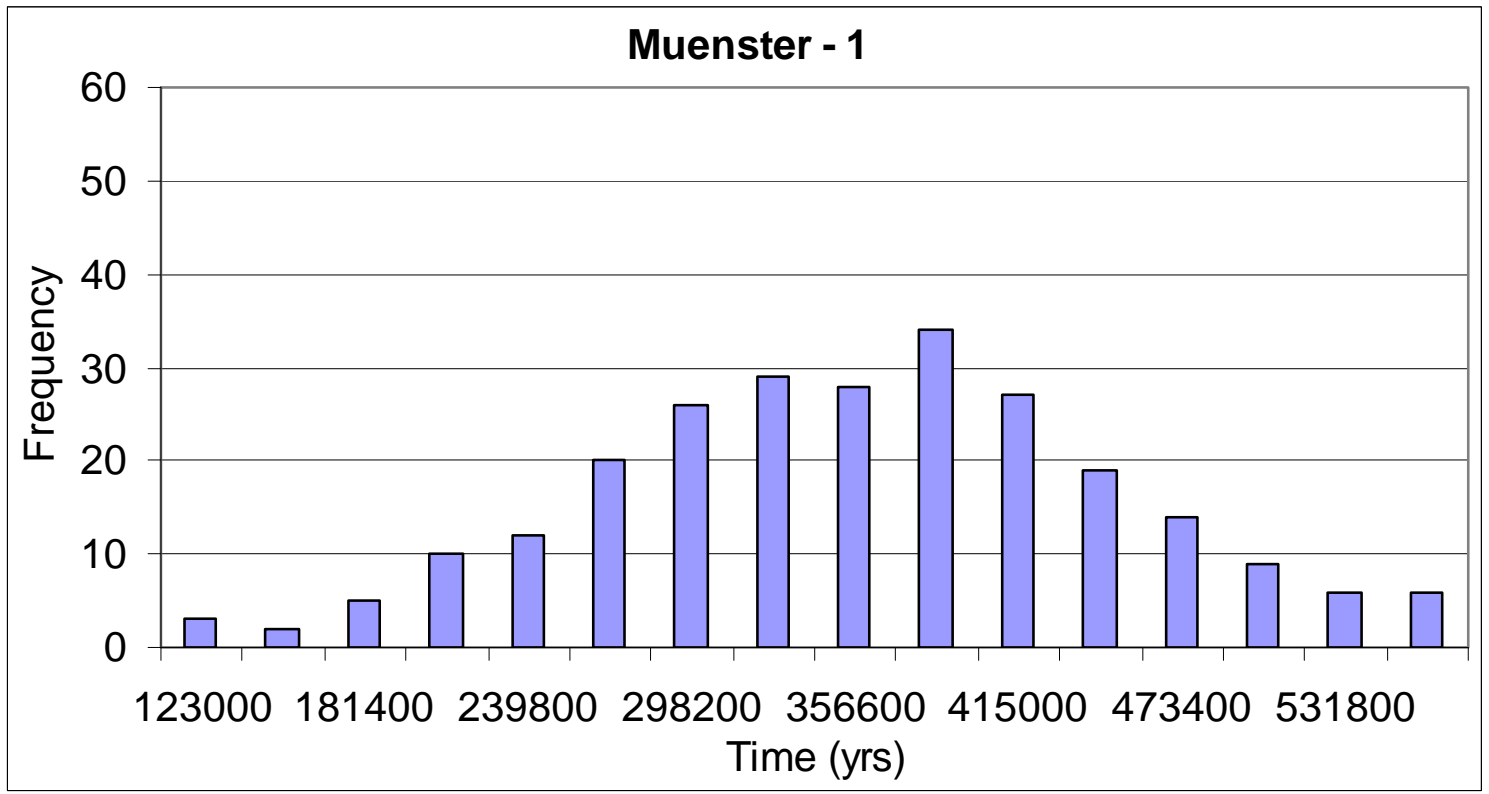

Figure C97. Distribution of minimum travel time from Muenster -1 to YM boundaries based on effective-porosity Set 1 for 1998 scenario. 


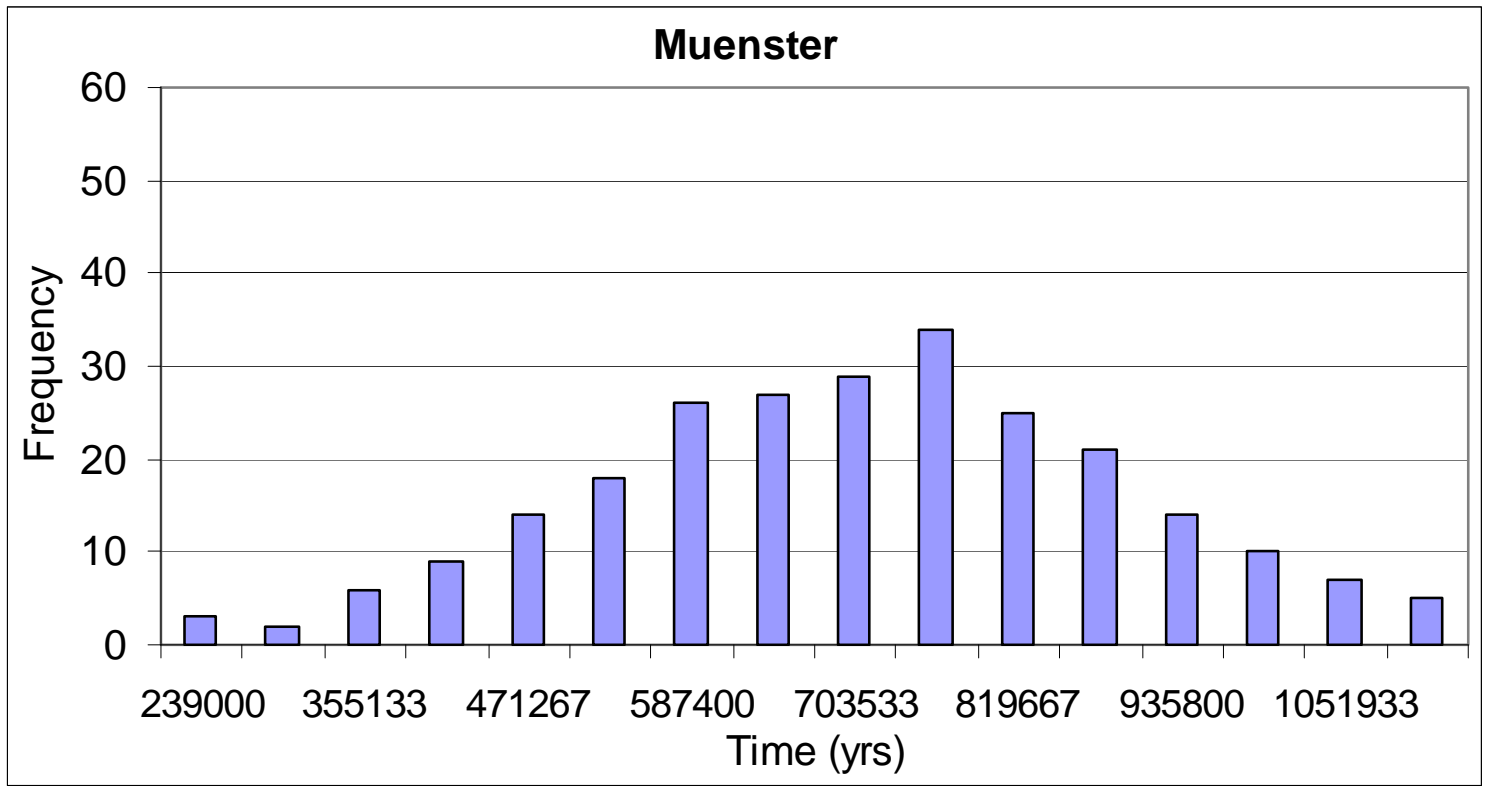

Figure C98. Distribution of minimum travel time from Muenster to YM boundaries based on effective-porosity Set 1 for 1998 scenario.

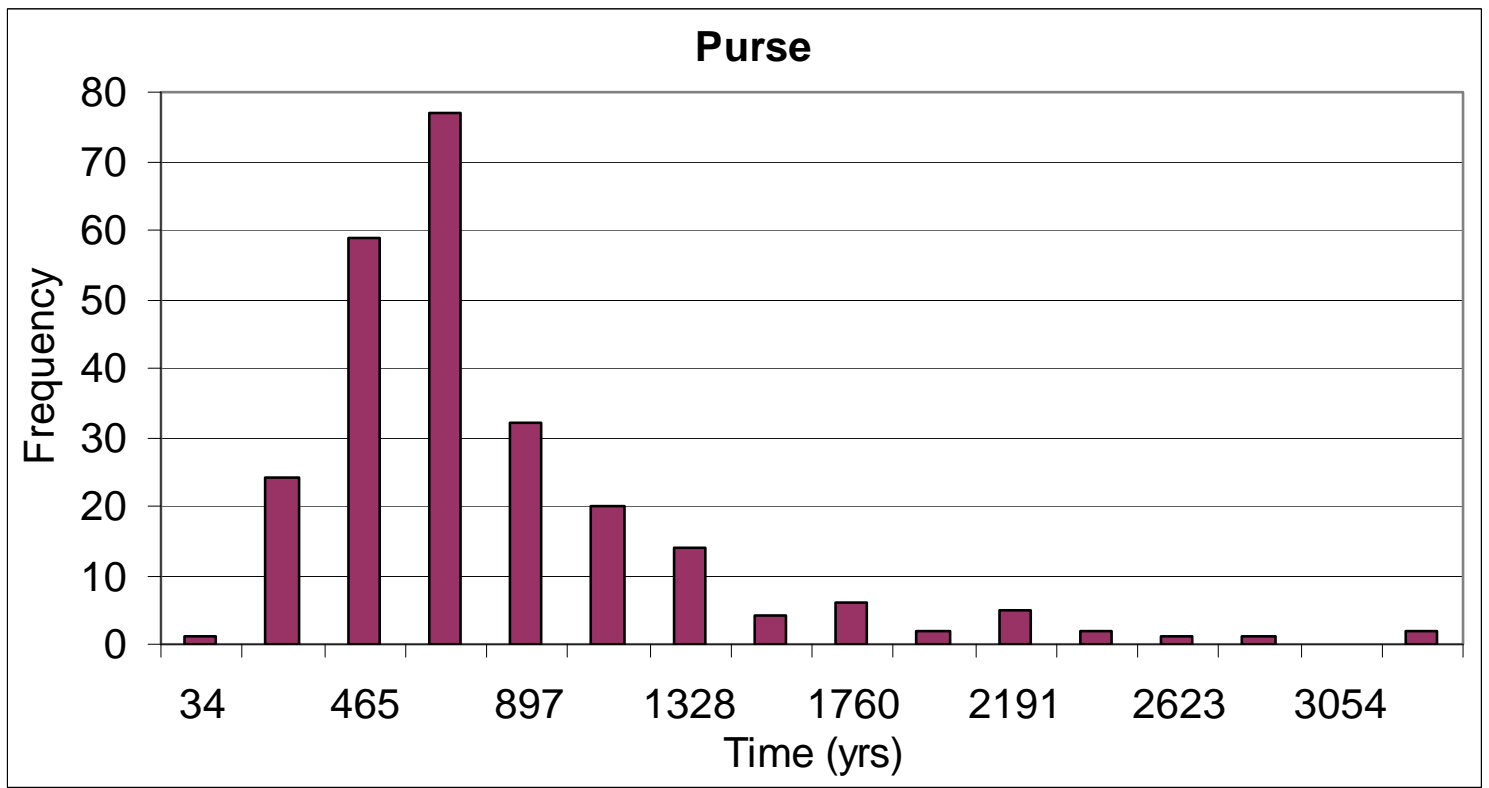

Figure C99. Distribution of minimum travel time from Purse to YM boundaries based on effective-porosity Set 2 for 1998 scenario. 


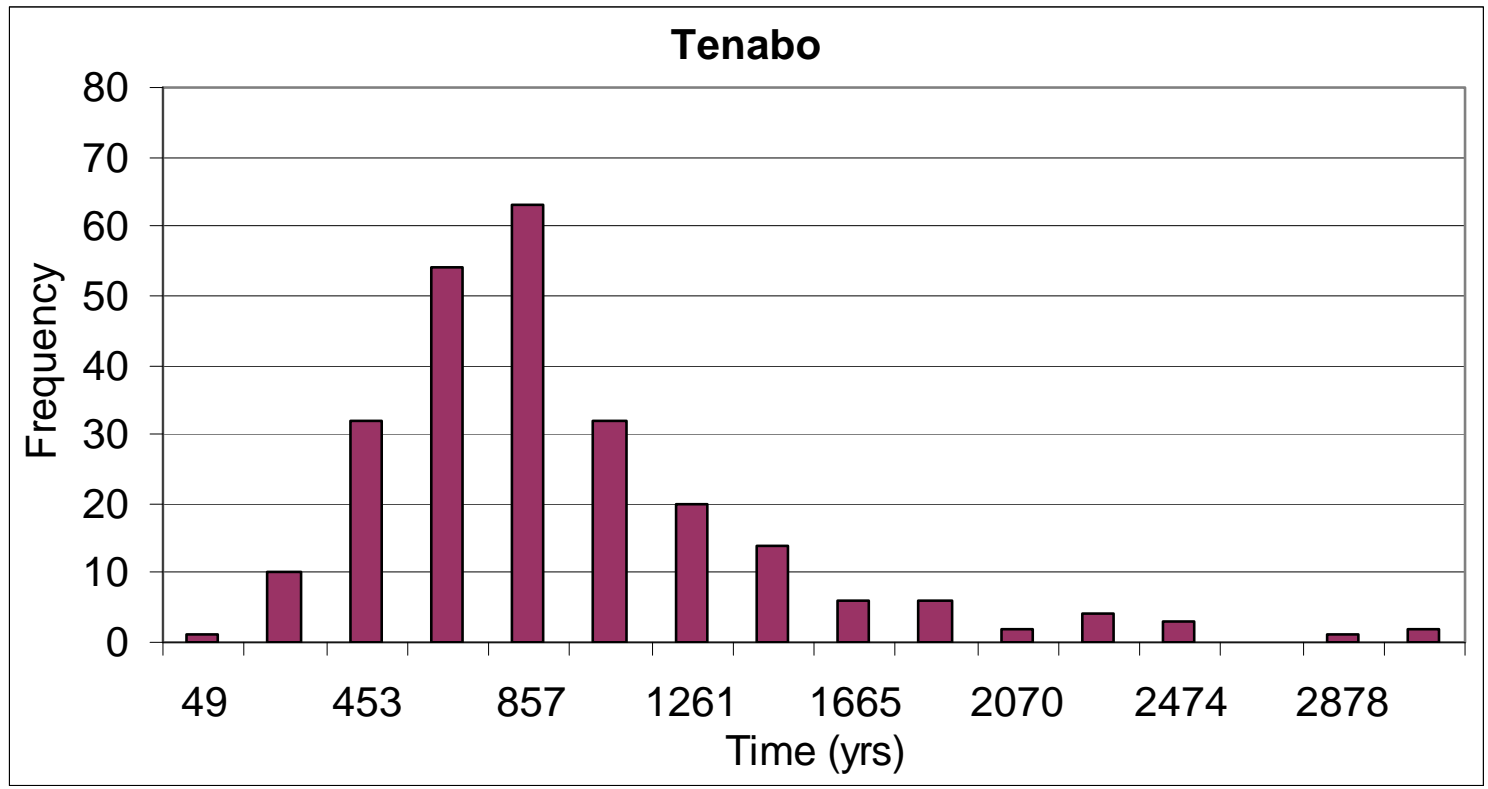

Figure C100. Distribution of minimum travel time from Tenabo to YM boundaries based on effective-porosity Set 2 for 1998 scenario.

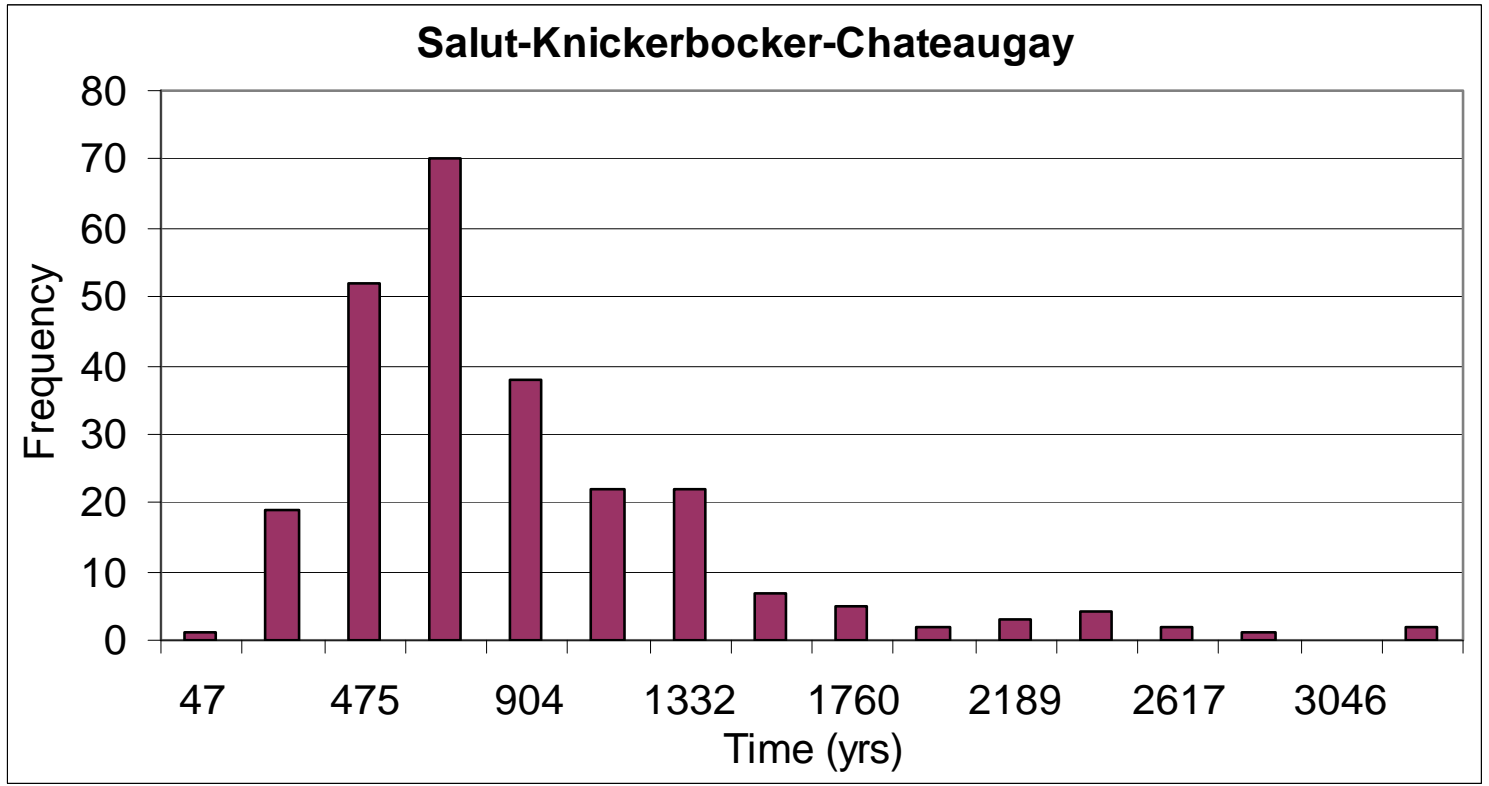

Figure C101. Distribution of minimum travel time from Salut-Knickerbocker-Chateaugay to YM boundaries based on effective-porosity Set 2 for 1998 scenario. 


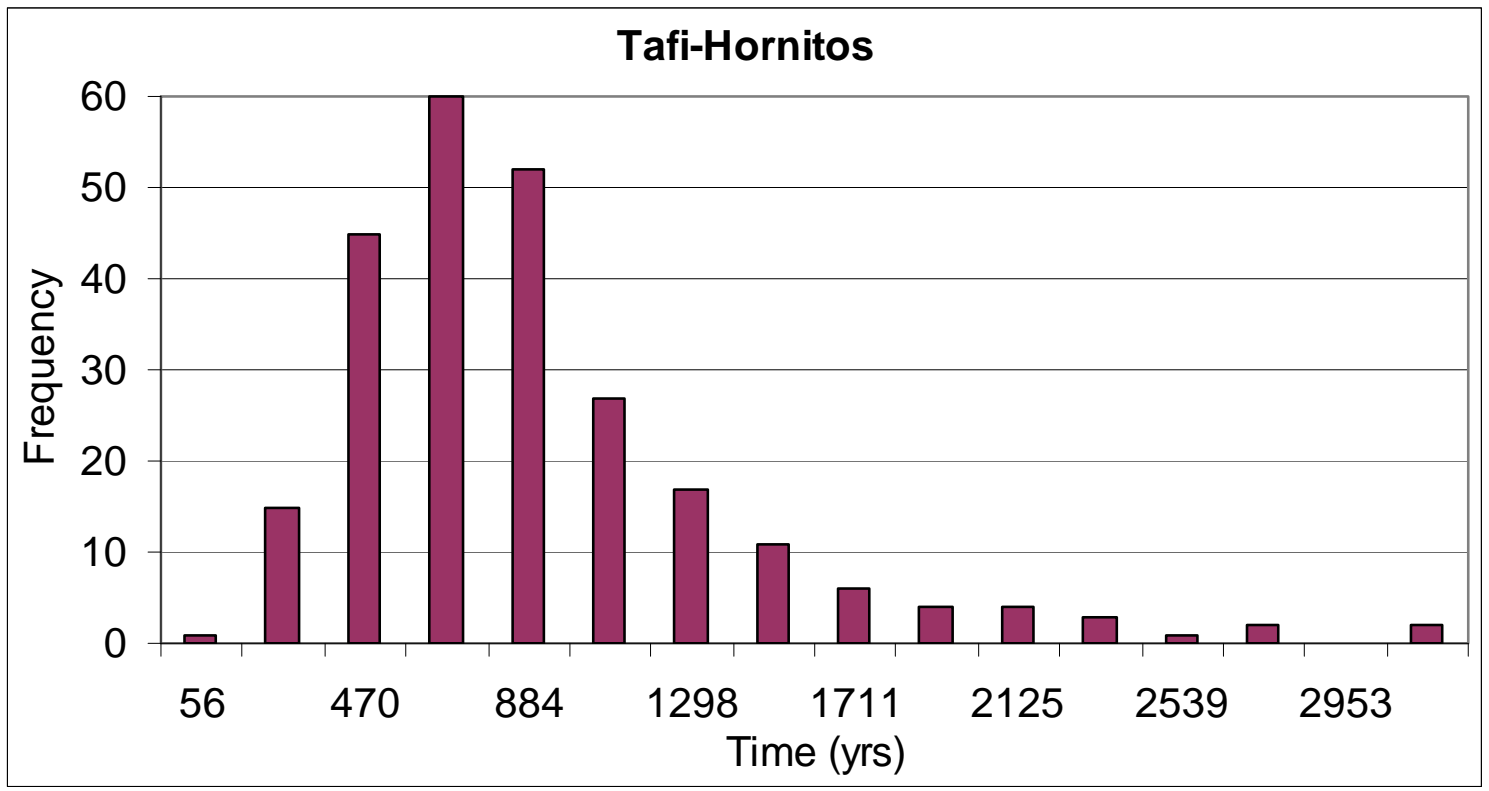

Figure C102. Distribution of minimum travel time from Tafi-Hornitos to YM boundaries based on effective-porosity Set 2 for 1998 scenario.

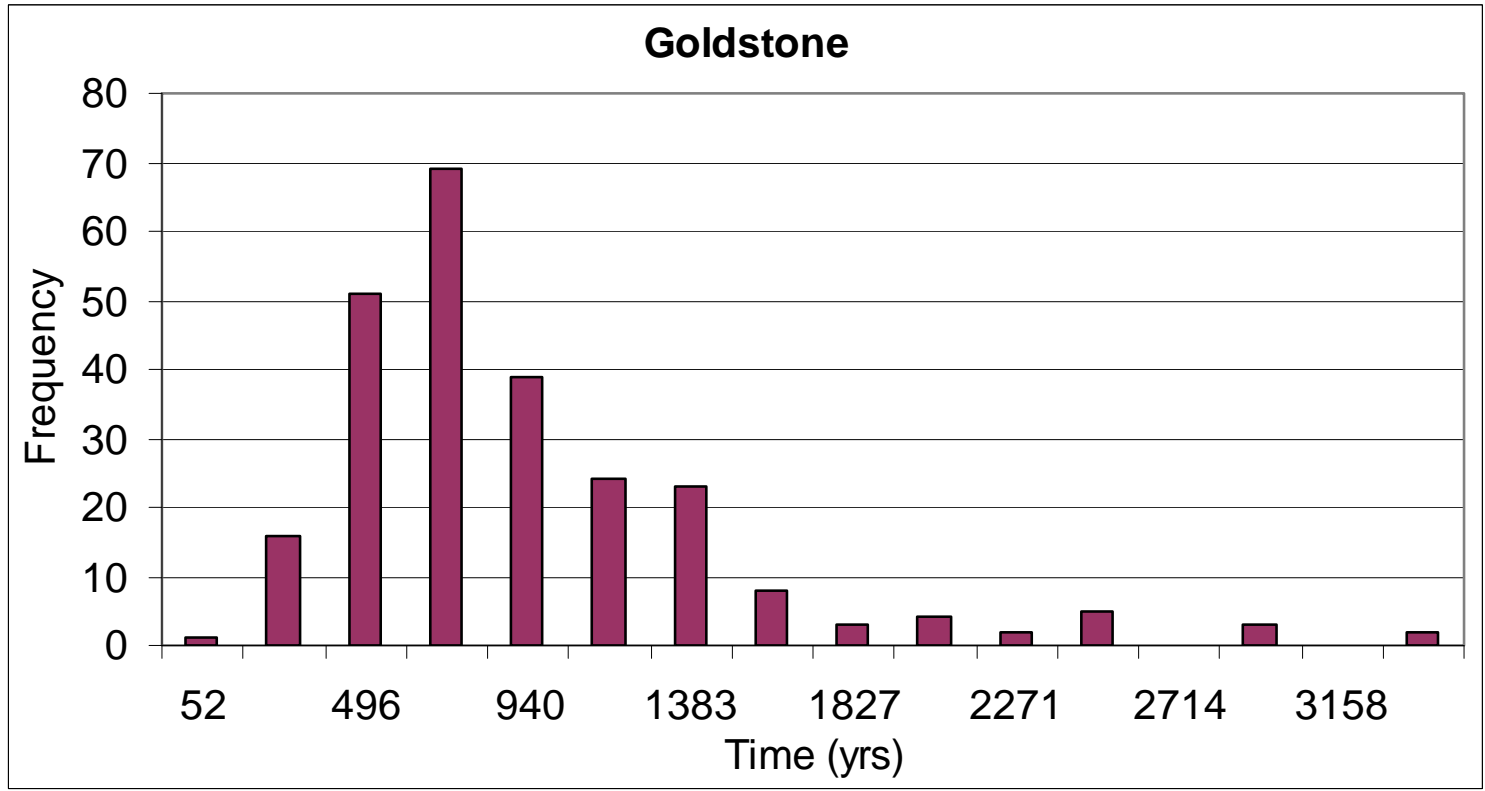

Figure C103. Distribution of minimum travel time from Goldstone to YM boundaries based on effective-porosity Set 2 for 1998 scenario. 


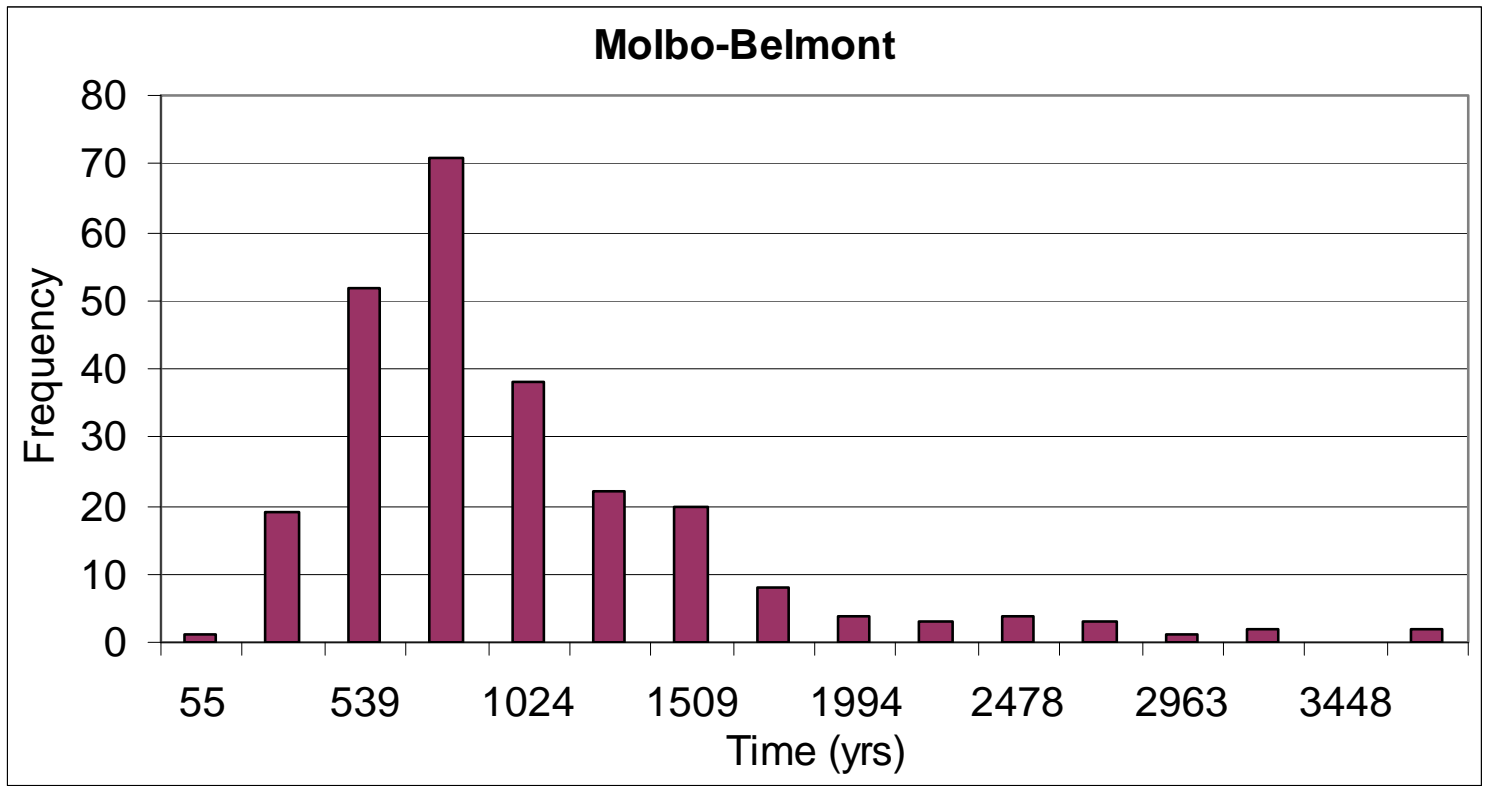

Figure C104. Distribution of minimum travel time from Molbo-Belmont to YM boundaries based on effective-porosity Set 2 for 1998 scenario.

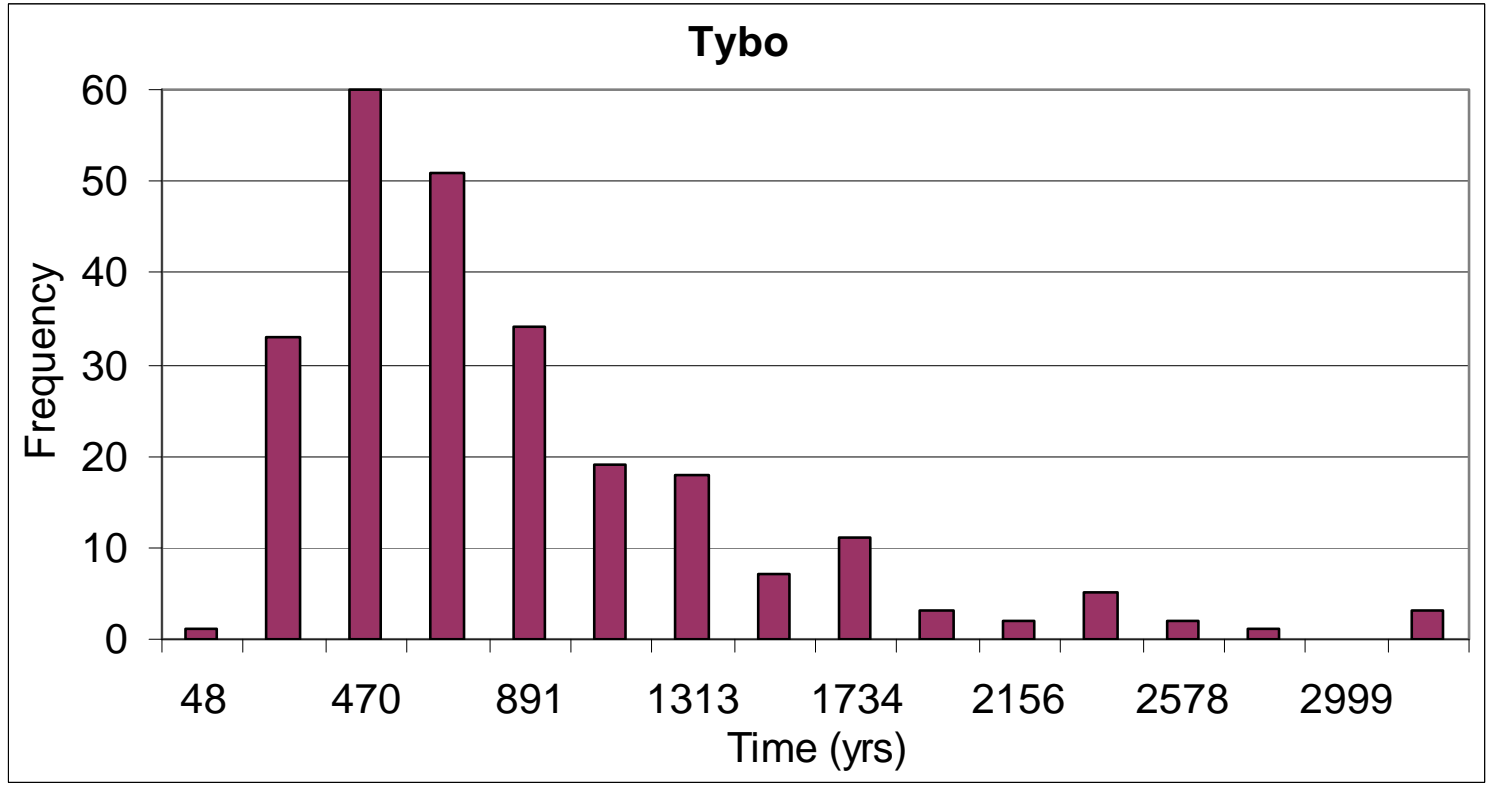

Figure C105. Distribution of minimum travel time from Tybo to YM boundaries based on effective-porosity Set 2 for 1998 scenario. 


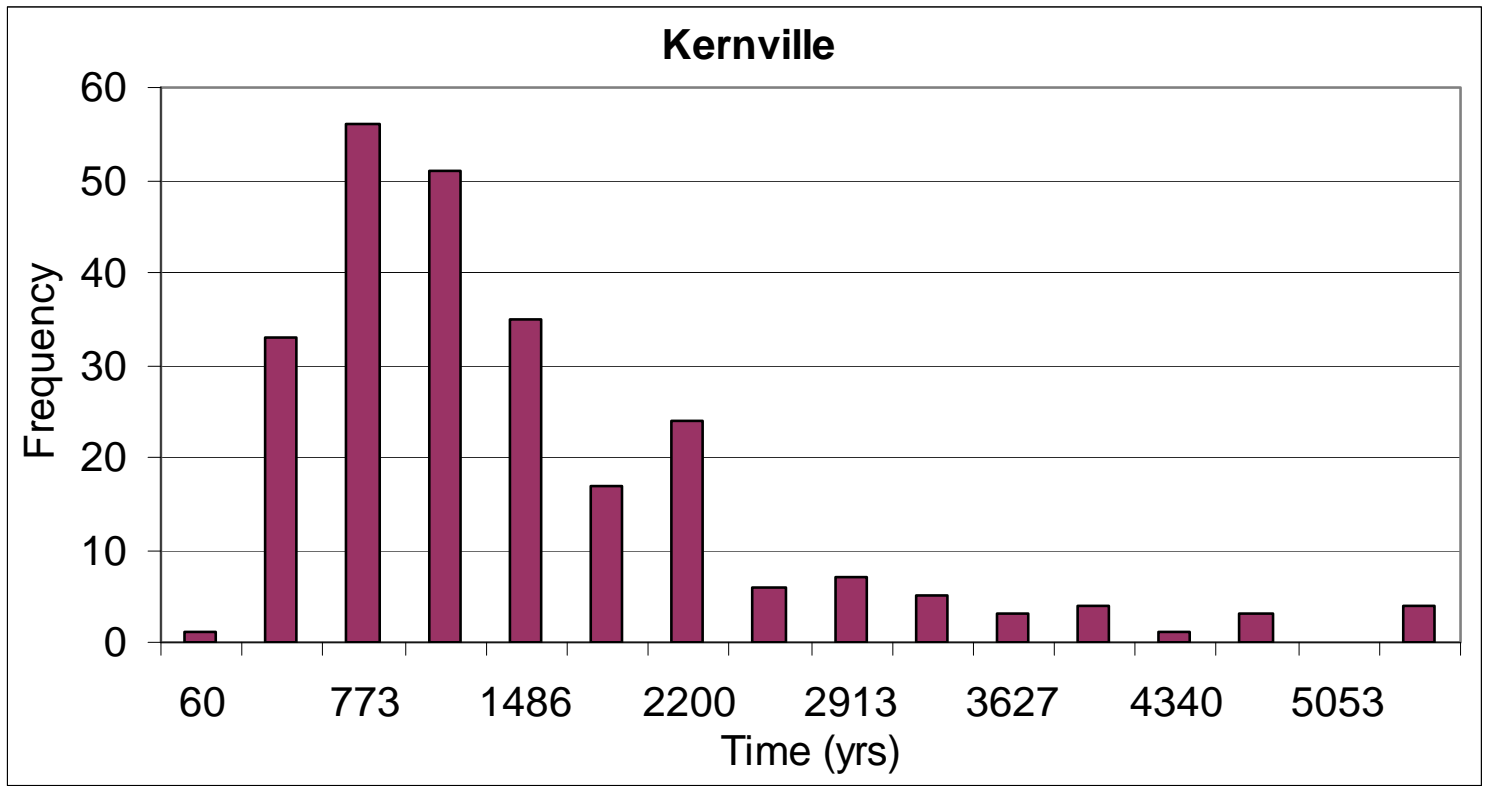

Figure C106. Distribution of minimum travel time from Kernville to YM boundaries based on effective-porosity Set 2 for 1998 scenario.

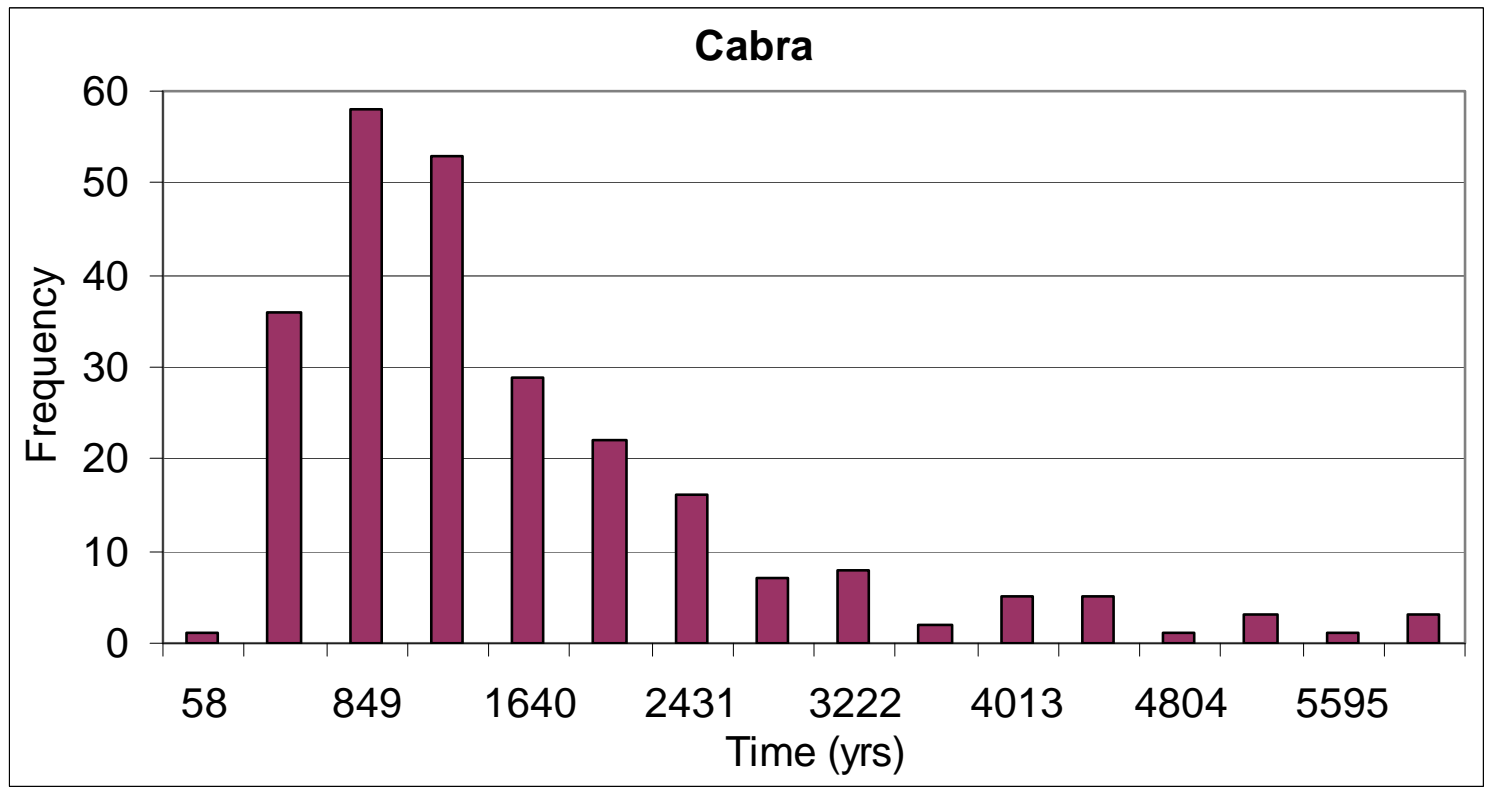

Figure C107. Distribution of minimum travel time from Cabra to YM boundaries based on effective-porosity Set 2 for 1998 scenario. 


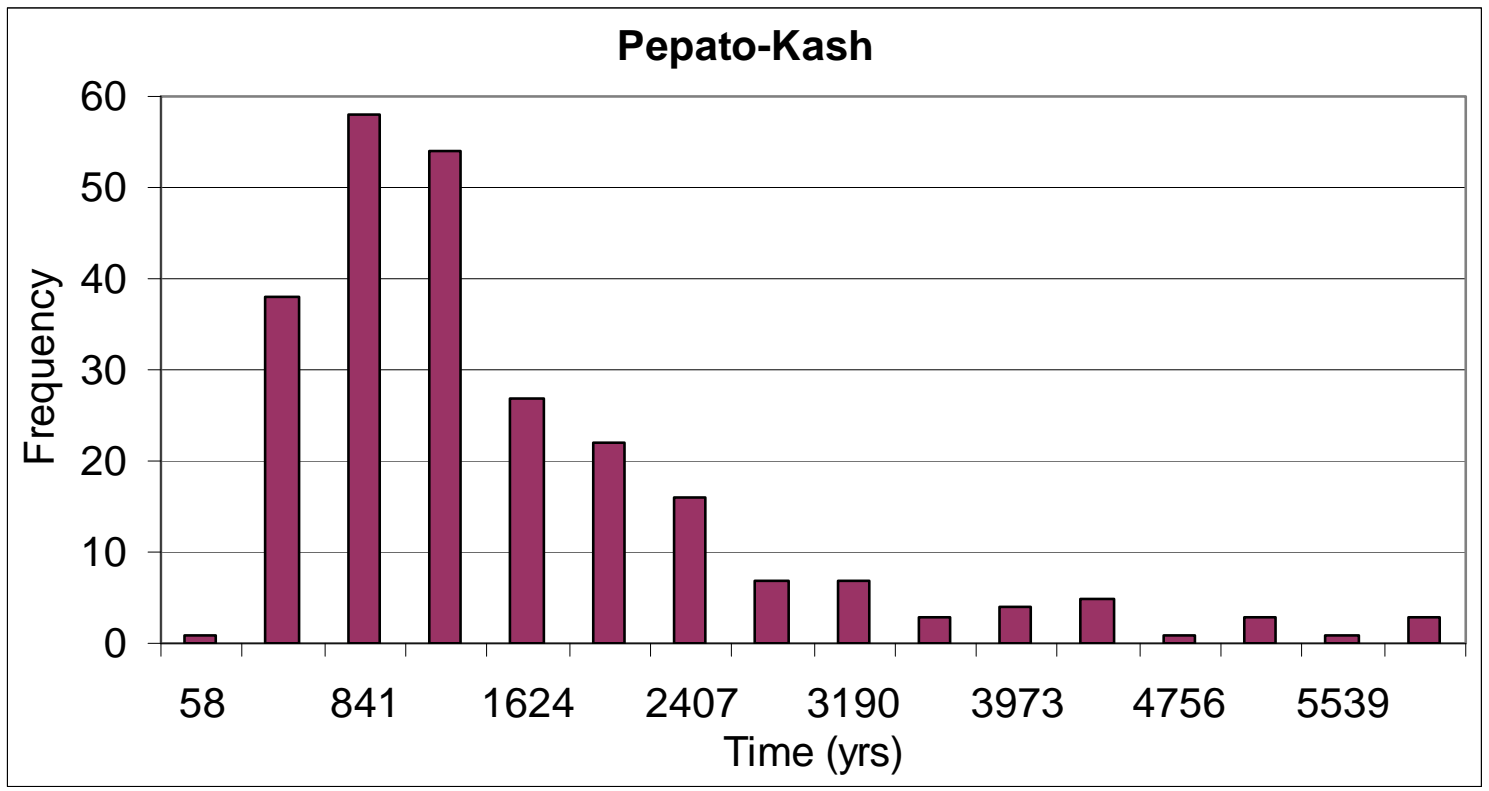

Figure C108. Distribution of minimum travel time from Pepato-Kash to YM boundaries based on effective-porosity Set 2 for 1998 scenario.

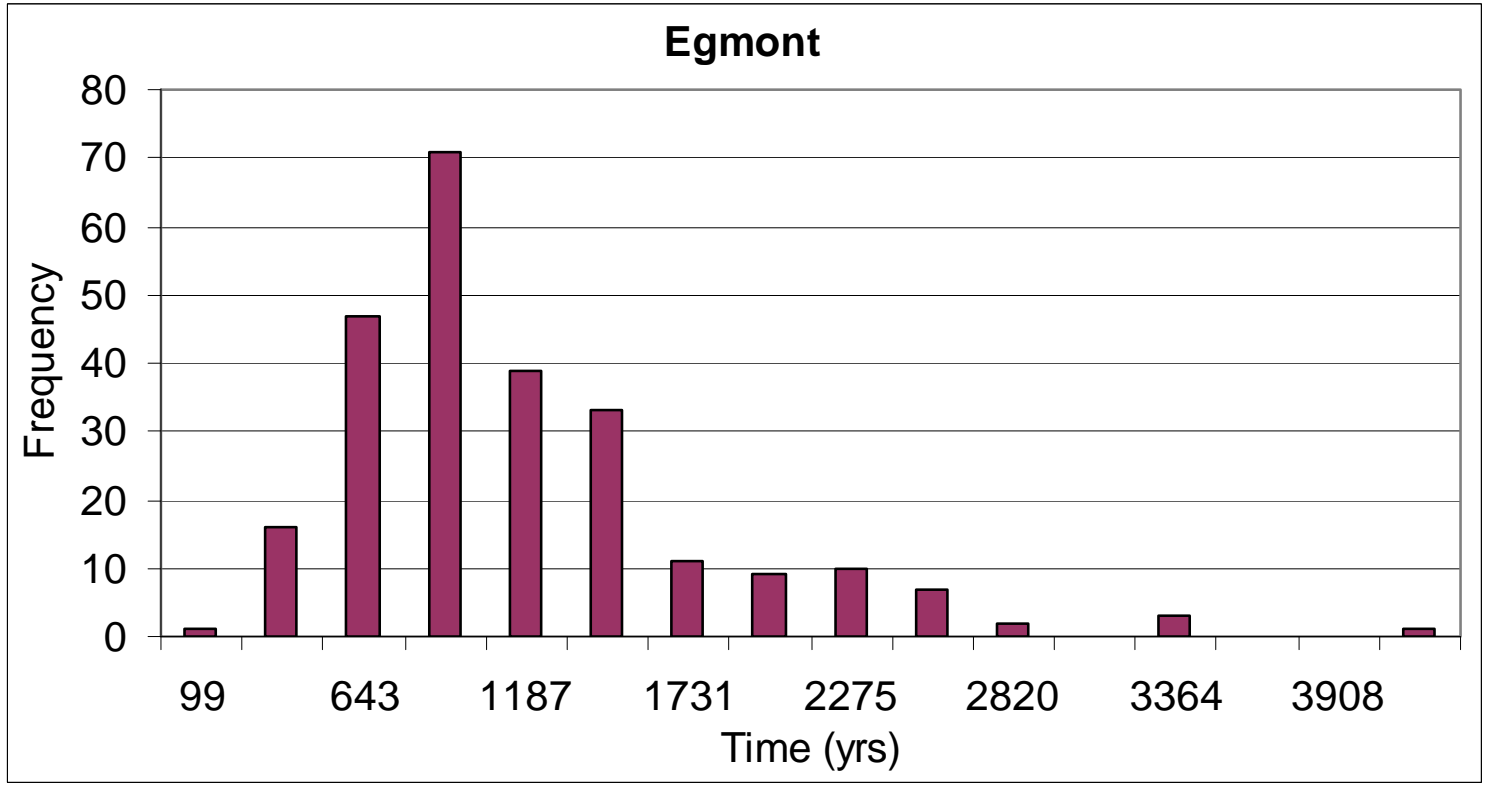

Figure C109. Distribution of minimum travel time from Egmont to YM boundaries based on effective-porosity Set 2 for 1998 scenario. 


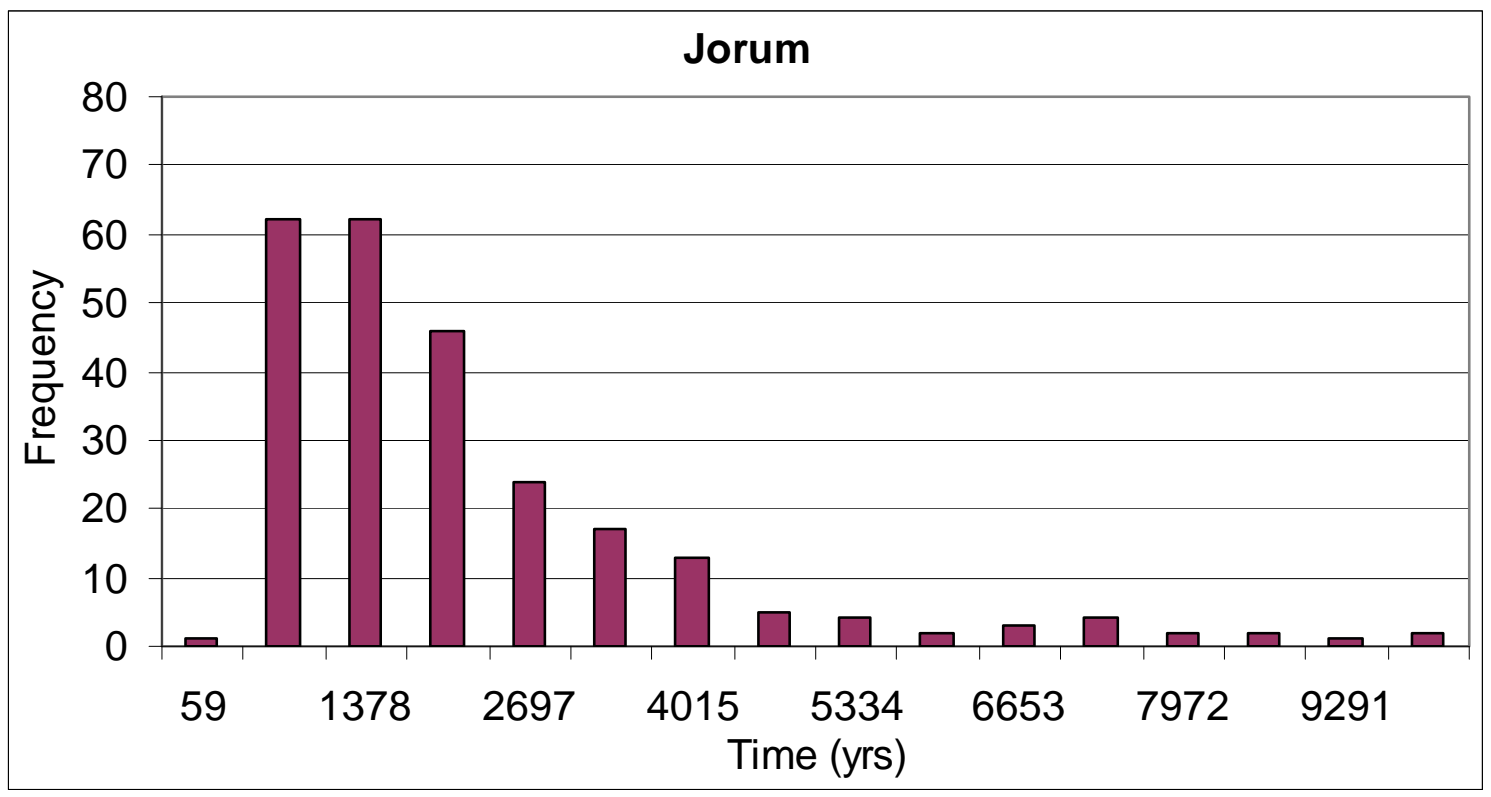

Figure C110. Distribution of minimum travel time from Jorum to YM boundaries based on effective-porosity Set 2 for 1998 scenario.

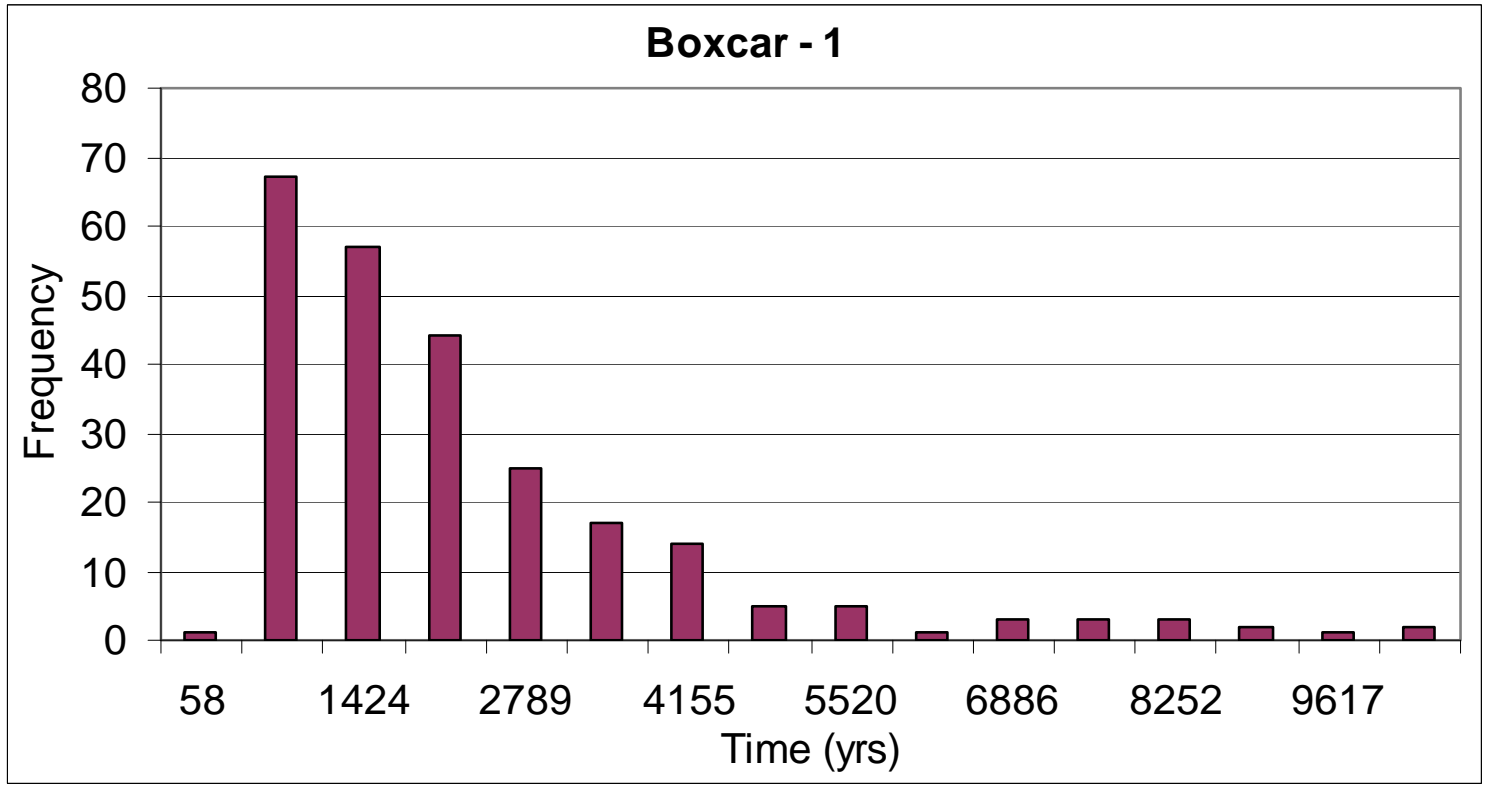

Figure C111. Distribution of minimum travel time from Boxcar -1 to YM boundaries based on effective-porosity Set 2 for 1998 scenario. 


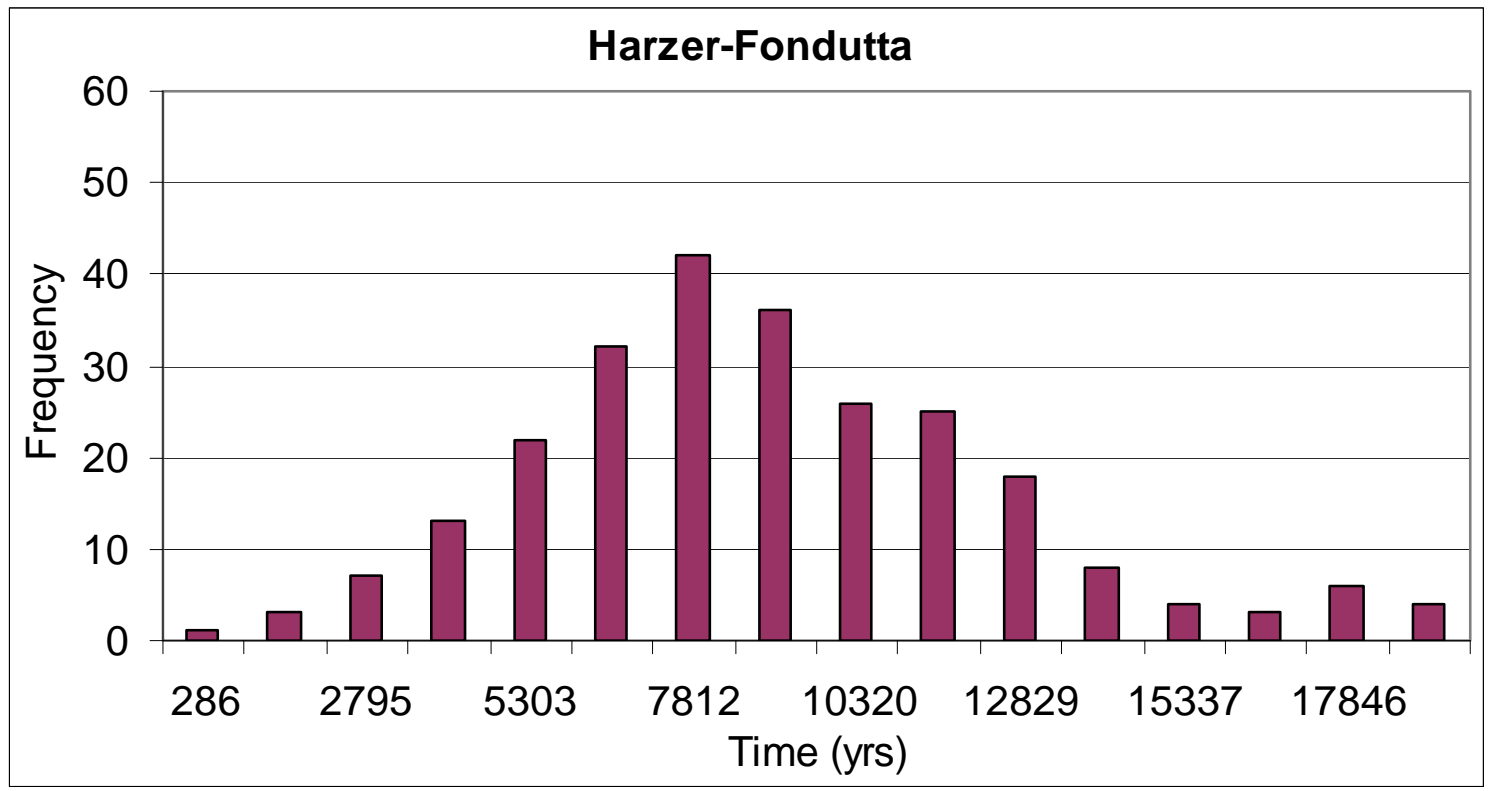

Figure C112. Distribution of minimum travel time from Harzer-Fondutta to YM boundaries based on effective-porosity Set 2 for 1998 scenario.

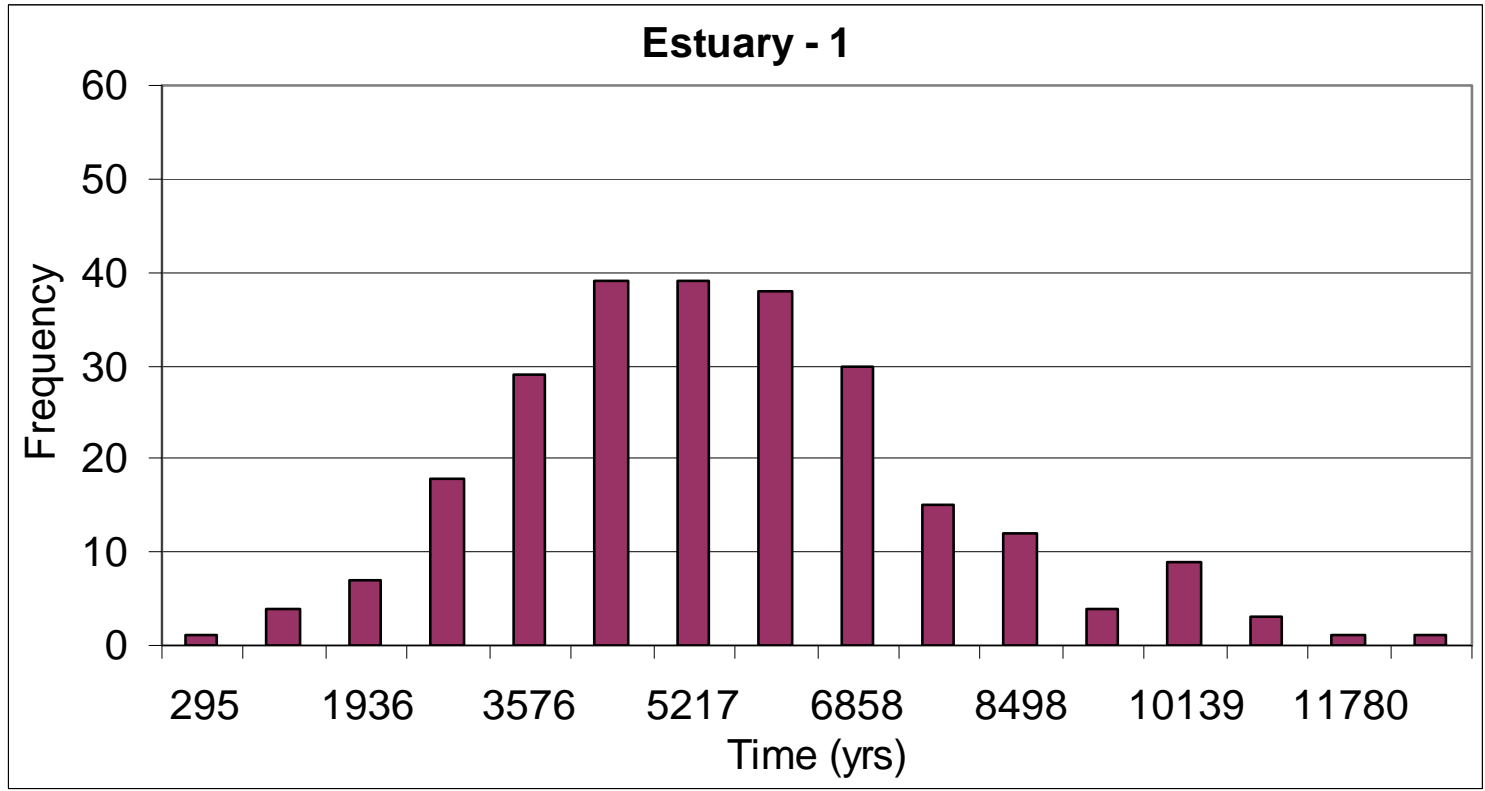

Figure C113. Distribution of minimum travel time from Estuary -1 to YM boundaries based on effective-porosity Set 2 for 1998 scenario. 


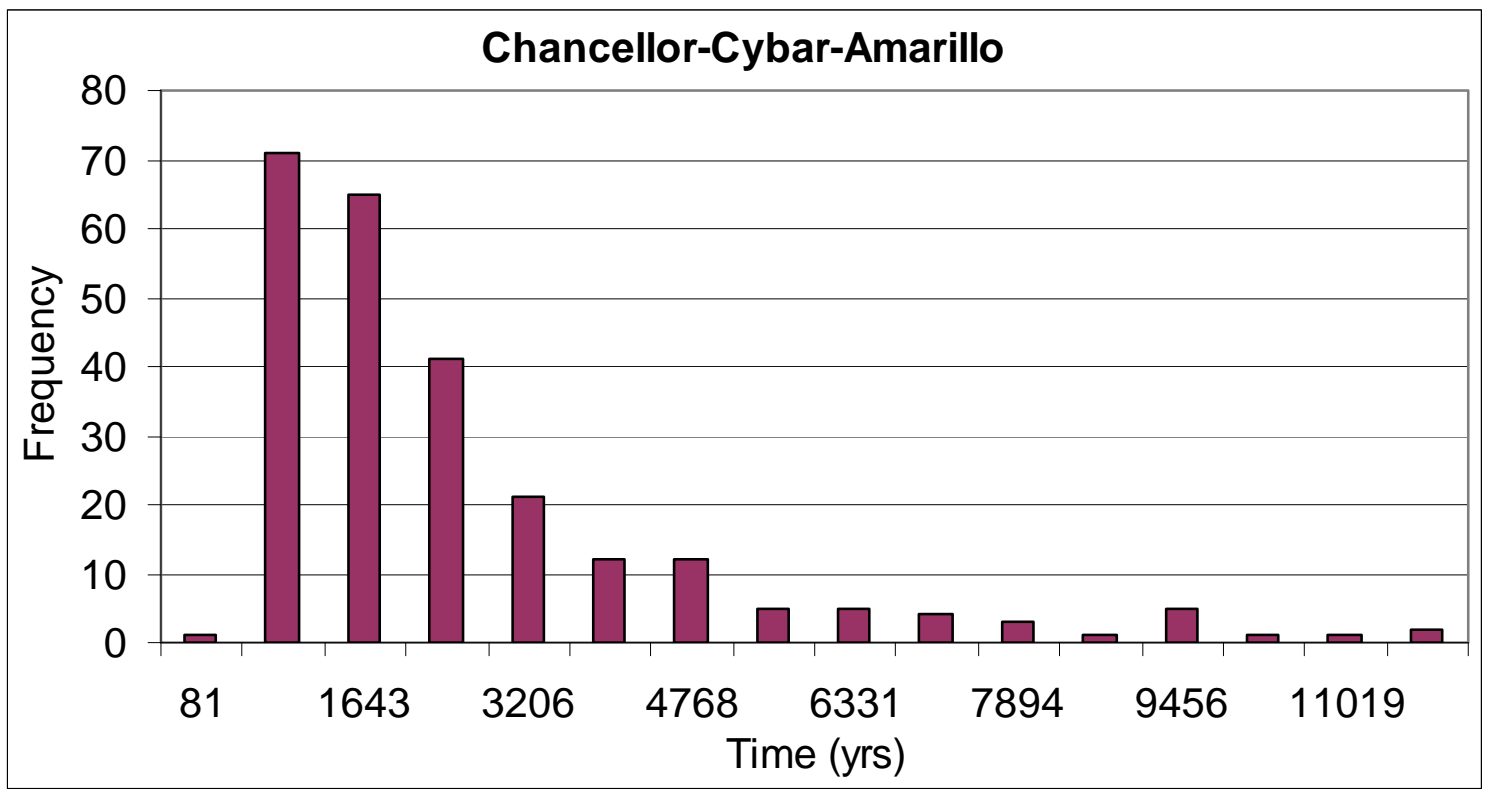

Figure C114. Distribution of minimum travel time from Chancellor-Cybar-Amarillo to YM boundaries based on effective-porosity Set 2 for 1998 scenario.

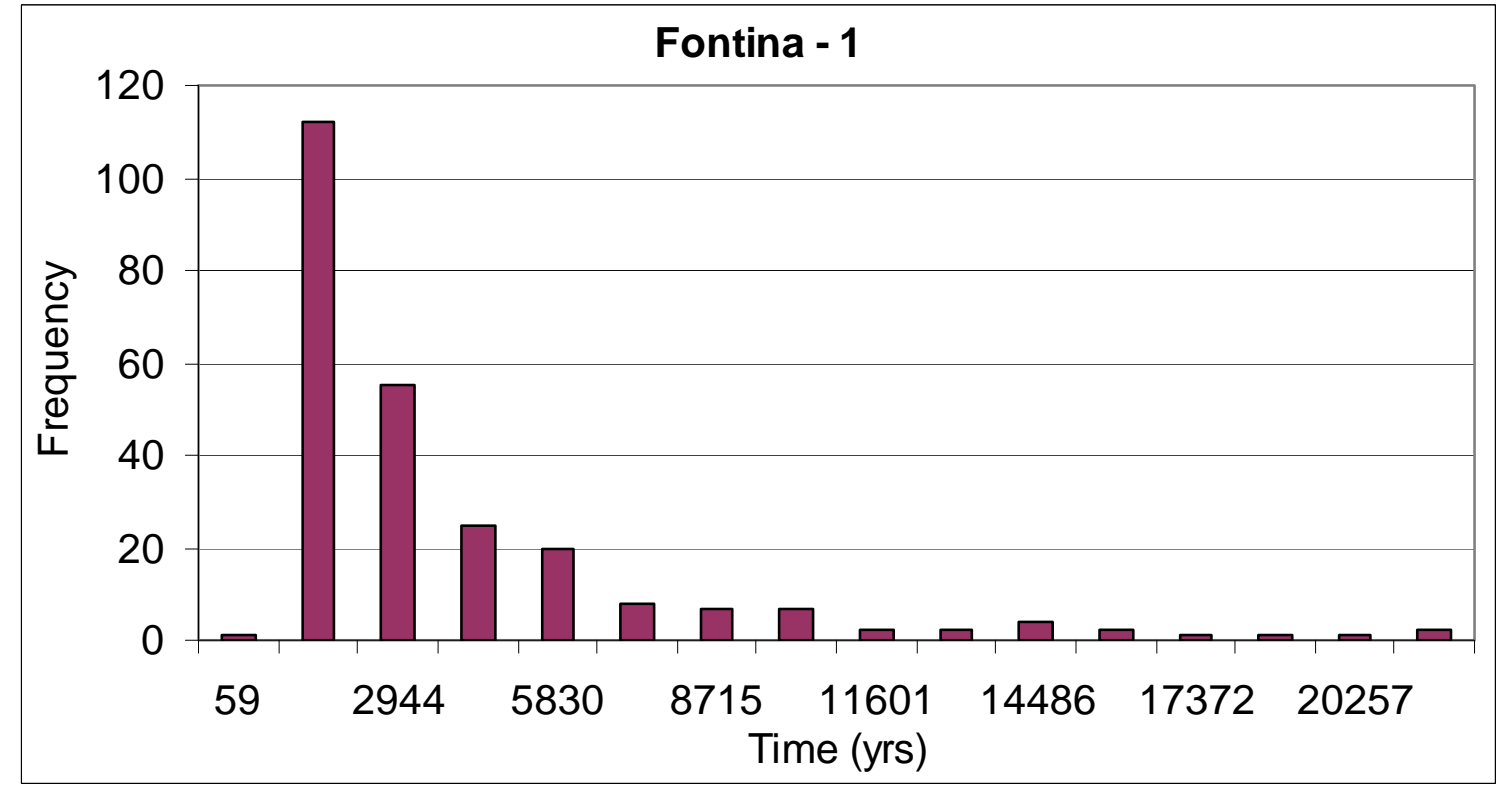

Figure C115. Distribution of minimum travel time from Fontina -1 to YM boundaries based on effective-porosity Set 2 for 1998 scenario. 


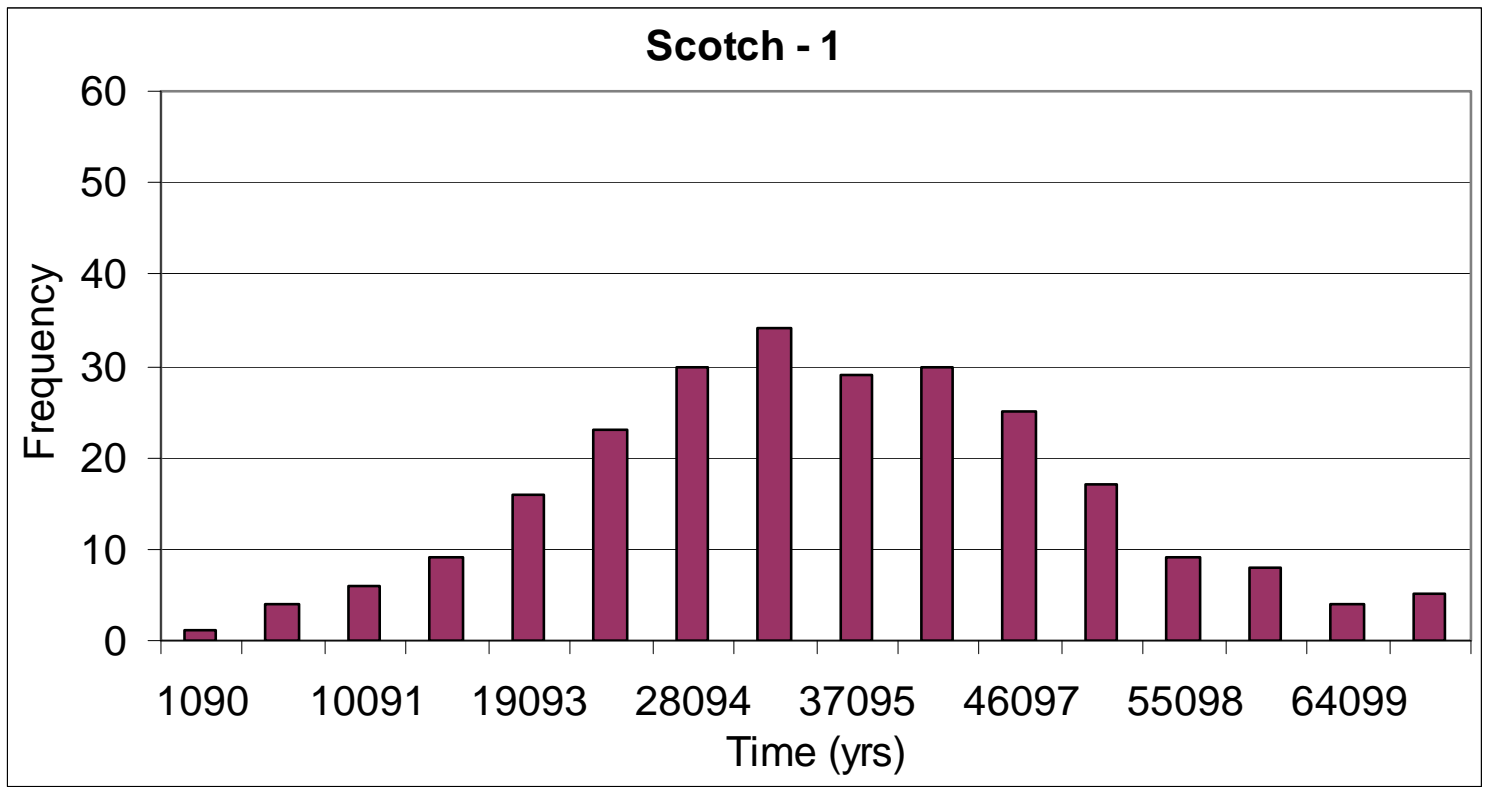

Figure C116. Distribution of minimum travel time from Scotch -1 to YM boundaries based on effective-porosity Set 2 for 1998 scenario.

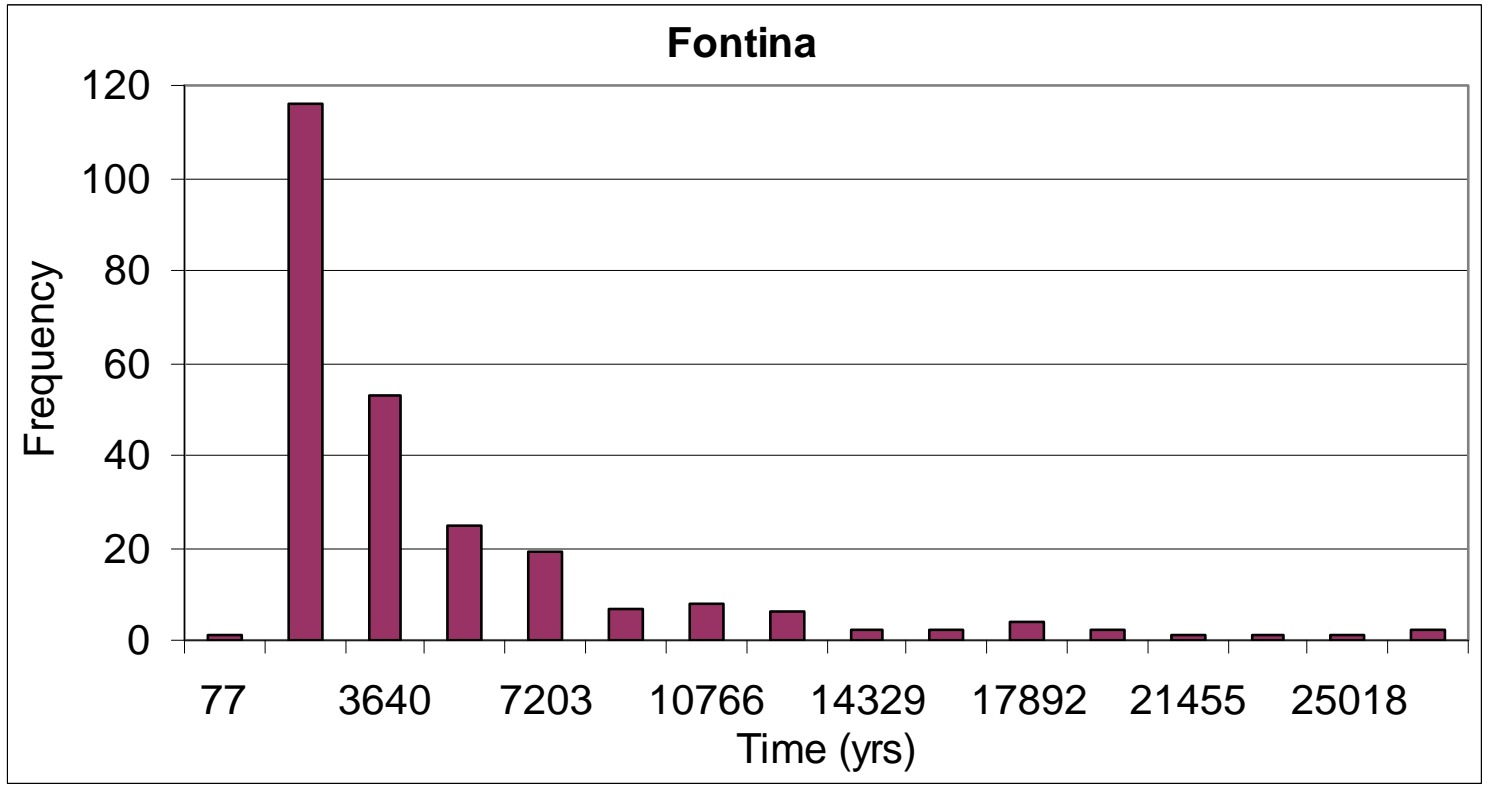

Figure C117. Distribution of minimum travel time from Fontina to YM boundaries based on effective-porosity Set 2 for 1998 scenario. 


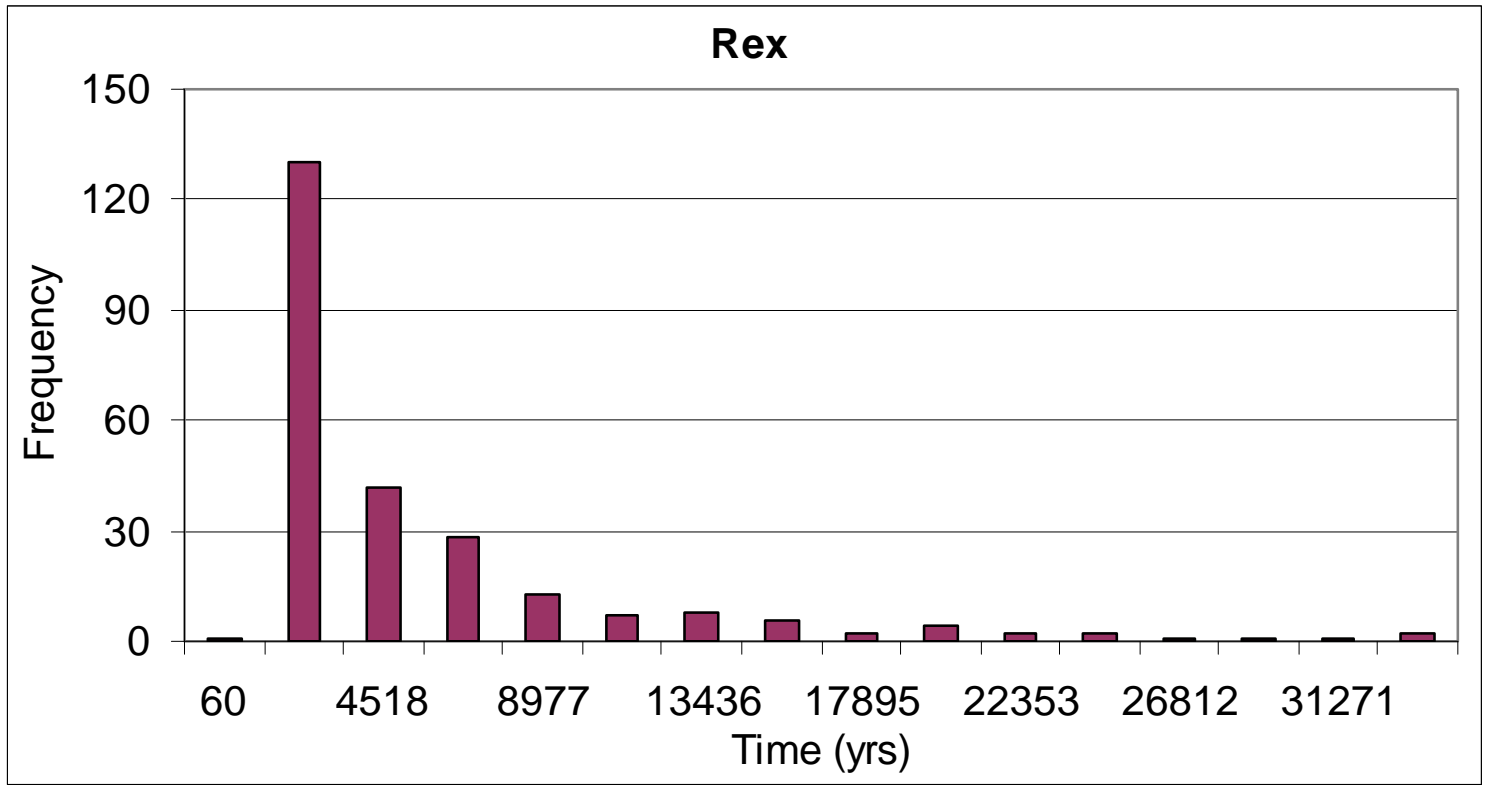

Figure C118. Distribution of minimum travel time from Rex to YM boundaries based on effective-porosity Set 2 for 1998 scenario.

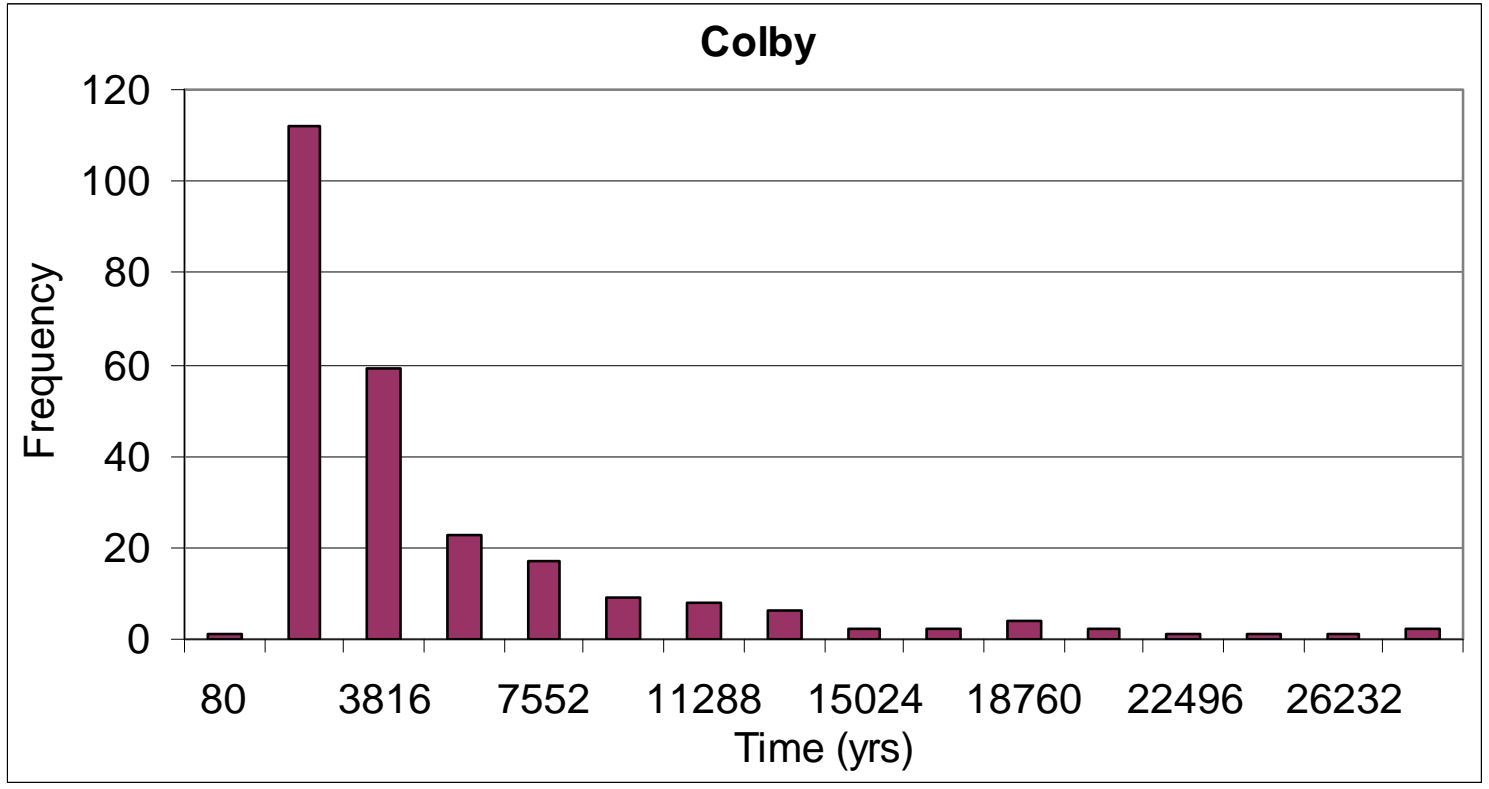

Figure C119. Distribution of minimum travel time from Colby to YM boundaries based on effective-porosity Set 2 for 1998 scenario. 


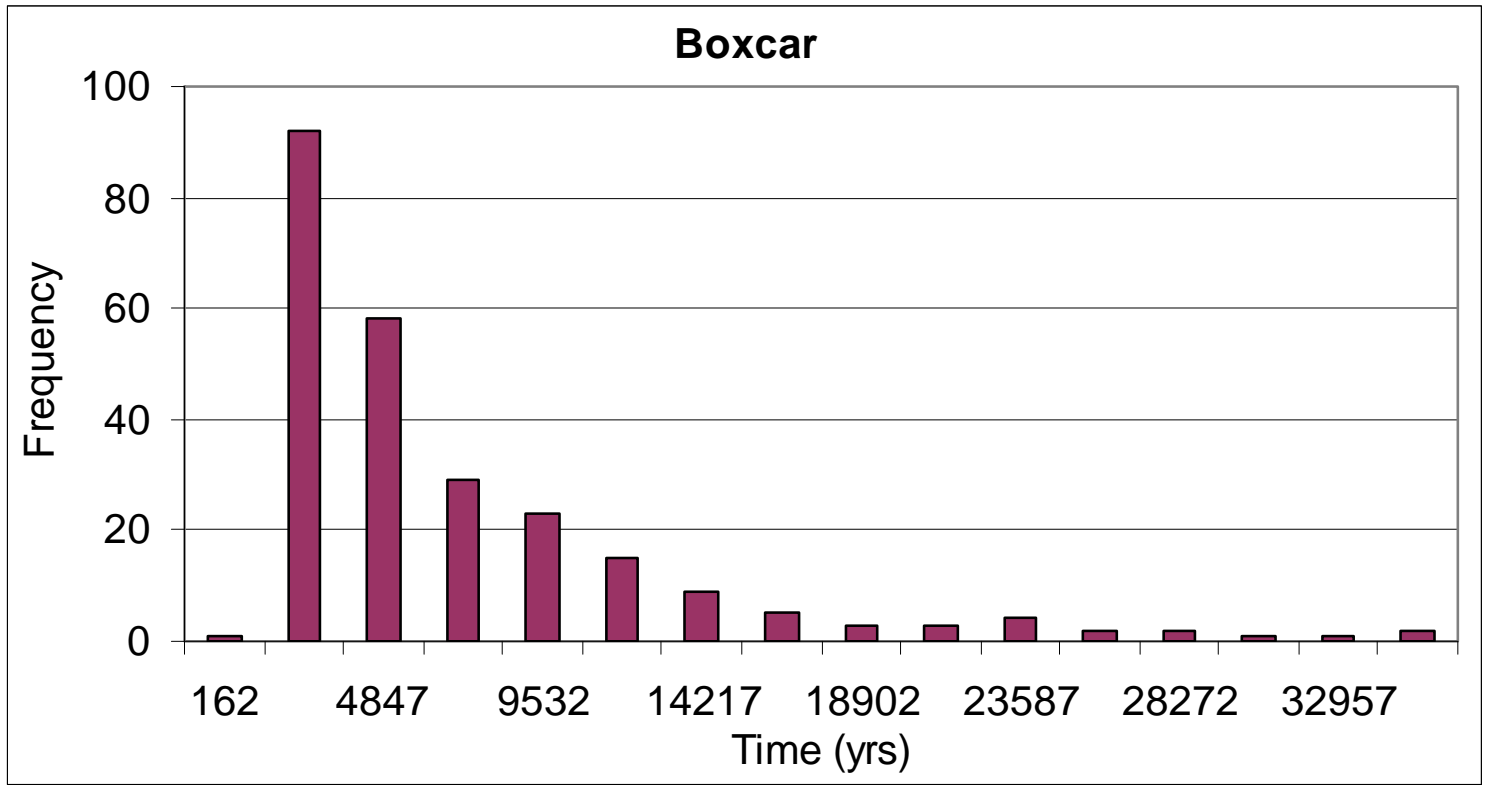

Figure C120. Distribution of minimum travel time from Boxcar to YM boundaries based on effective-porosity Set 2 for 1998 scenario.

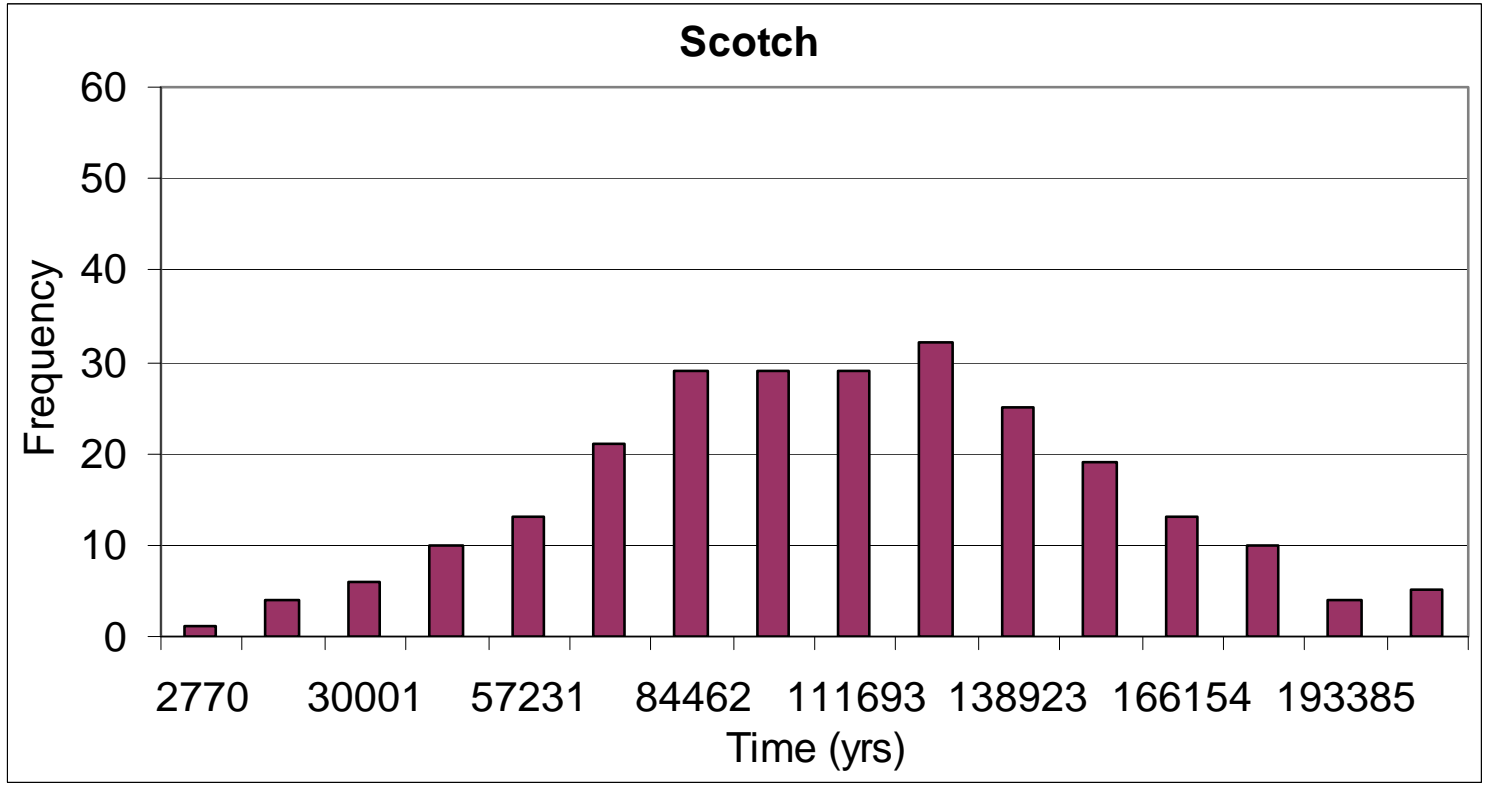

Figure C121. Distribution of minimum travel time from Scotch to YM boundaries based on effective-porosity Set 2 for 1998 scenario. 


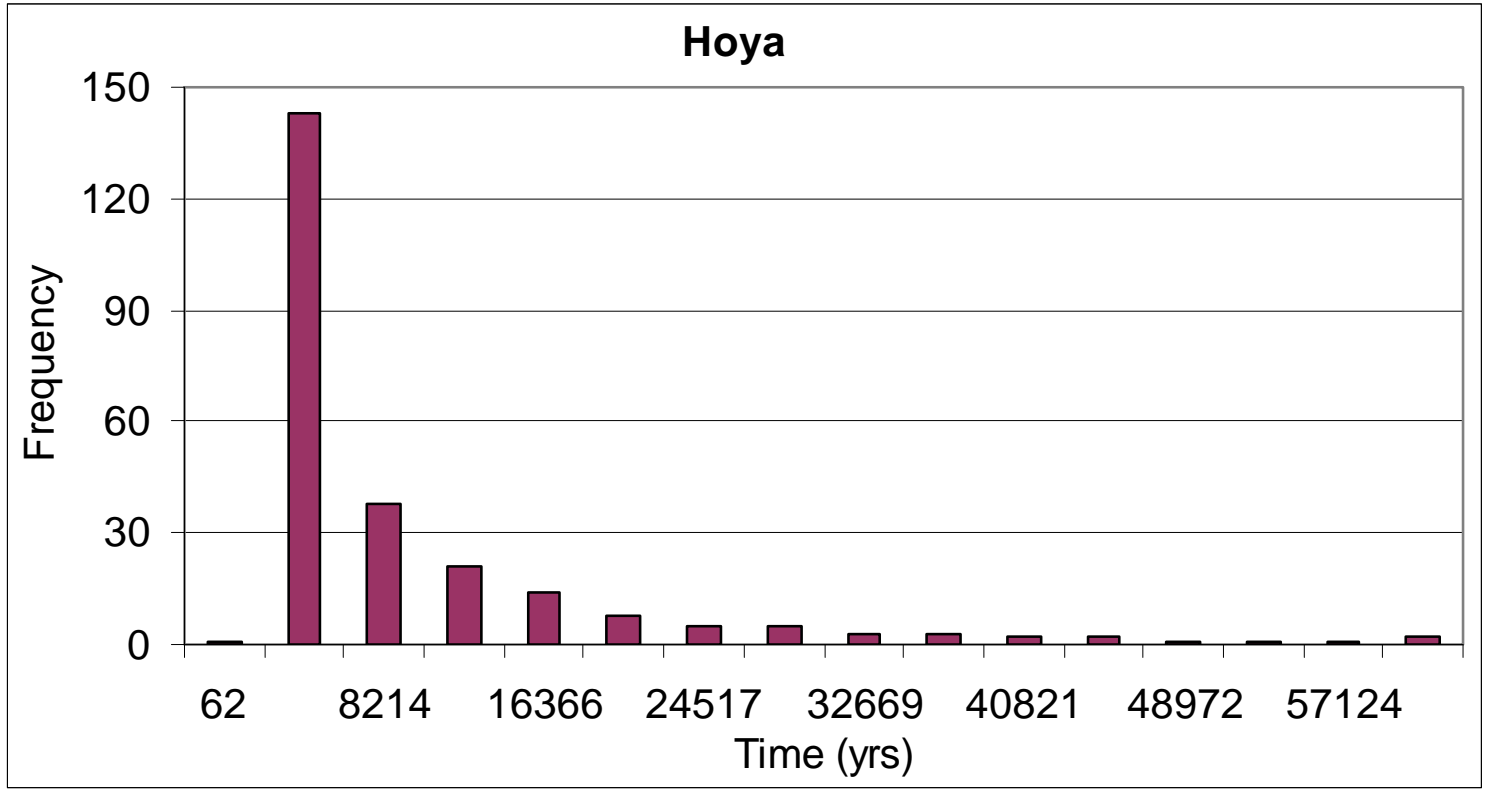

Figure C122. Distribution of minimum travel time from Hoya to YM boundaries based on effective-porosity Set 2 for 1998 scenario.

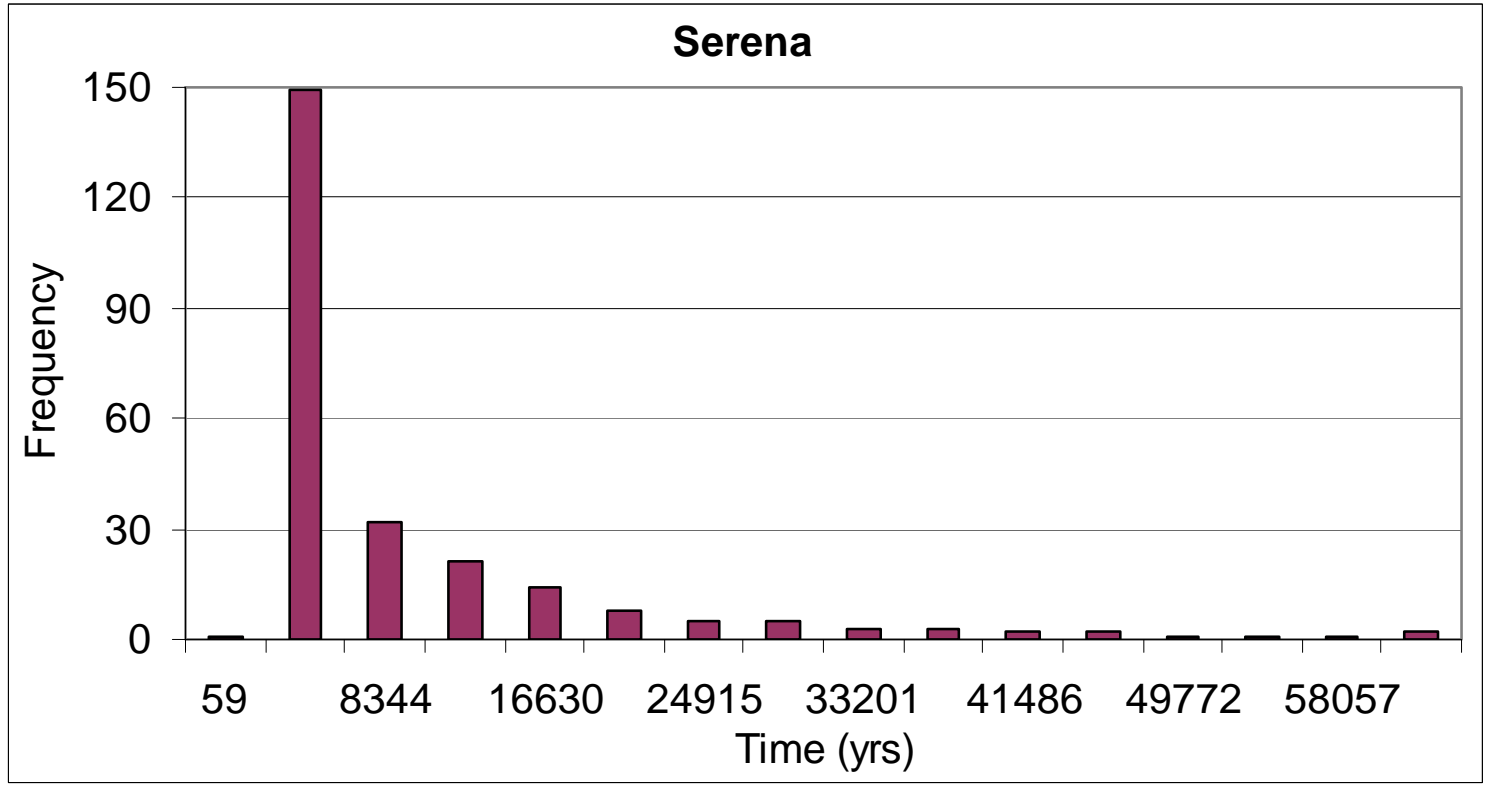

Figure C123. Distribution of minimum travel time from Serena to YM boundaries based on effective-porosity Set 2 for 1998 scenario. 


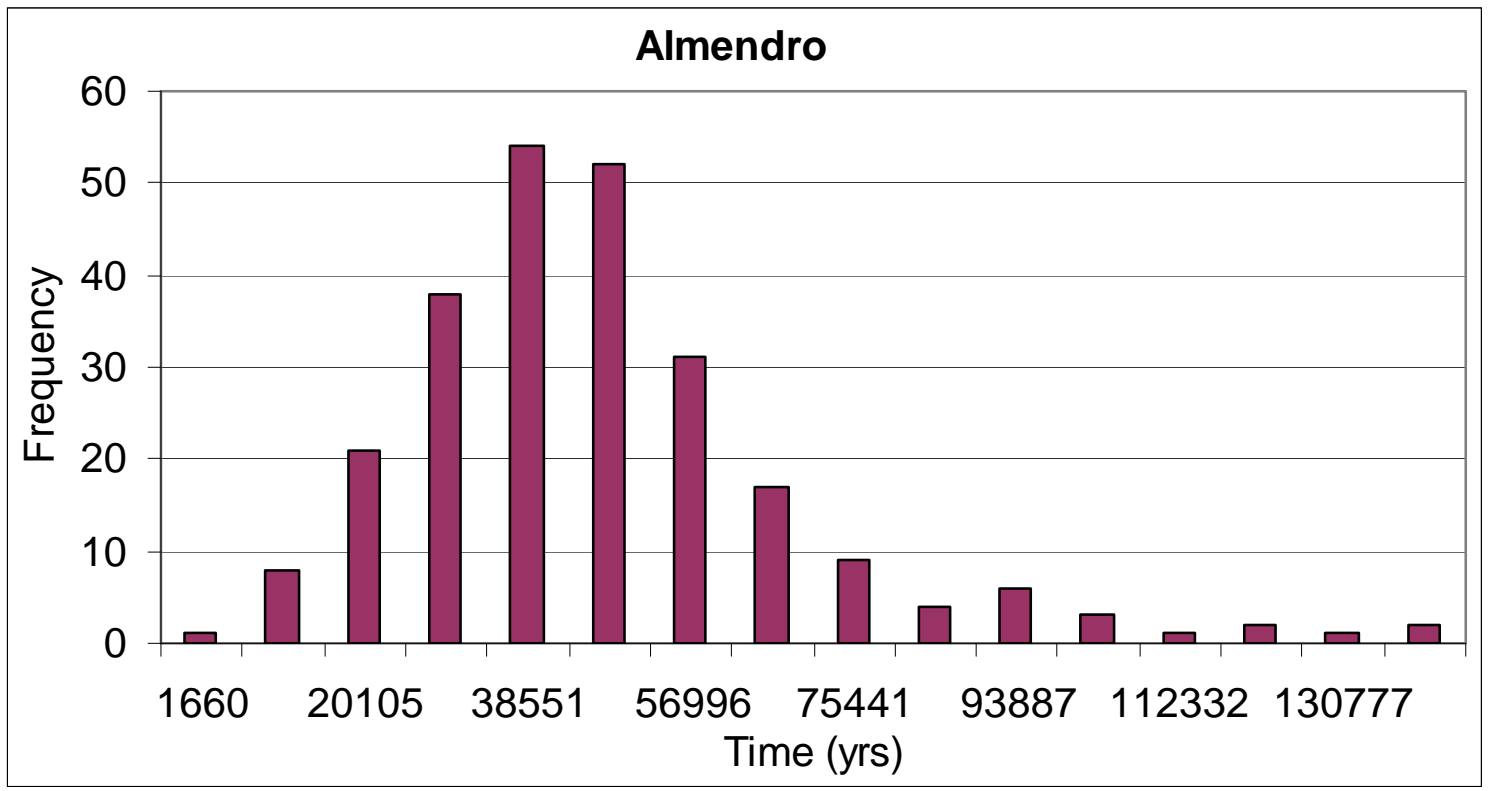

Figure C124. Distribution of minimum travel time from Almendro to YM boundaries based on effective-porosity Set 2 for 1998 scenario.

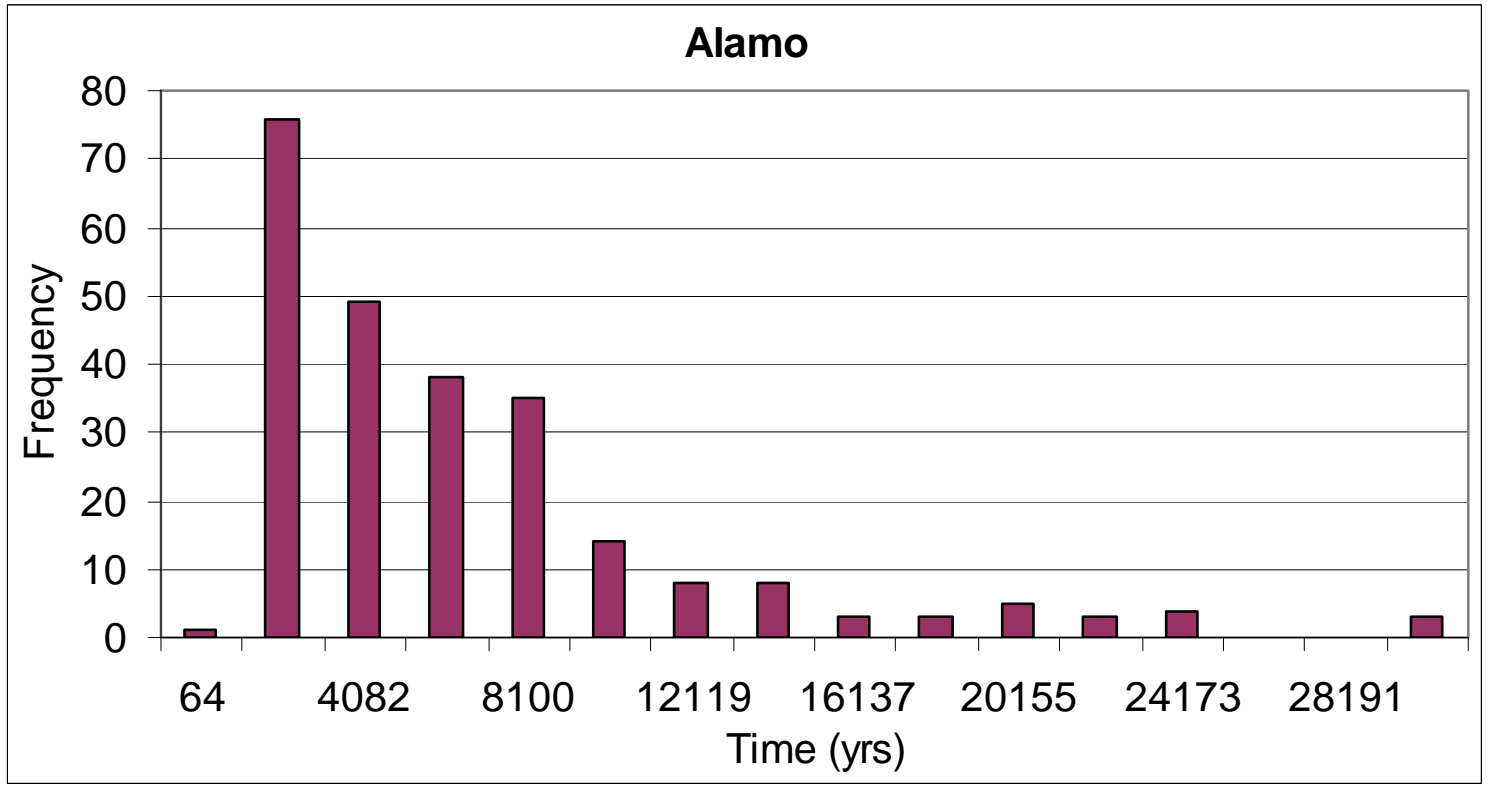

Figure C125. Distribution of minimum travel time from Alamo to YM boundaries based on effective-porosity Set 2 for 1998 scenario. 


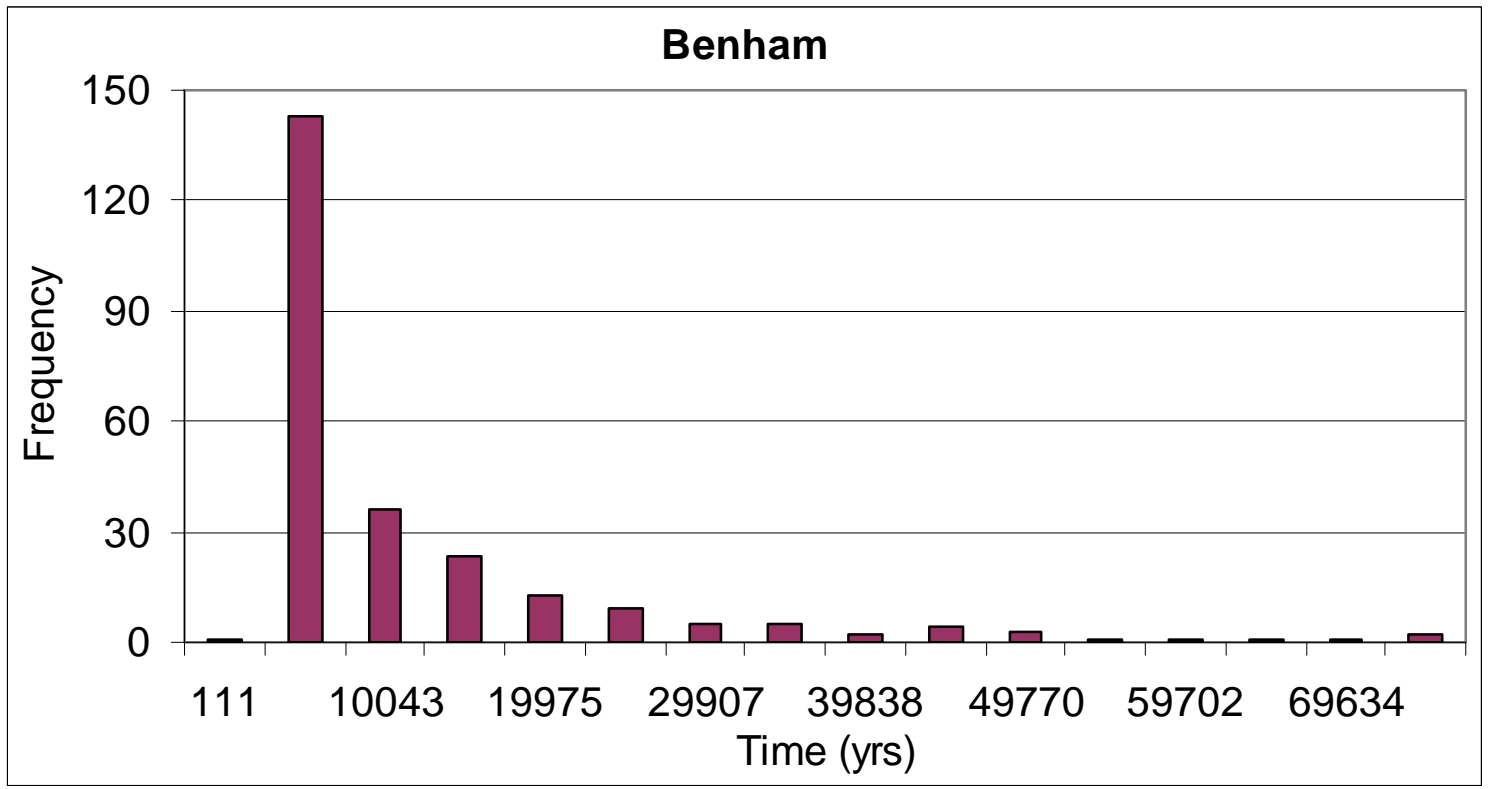

Figure C126. Distribution of minimum travel time from Benham to YM boundaries based on effective-porosity Set 2 for 1998 scenario.

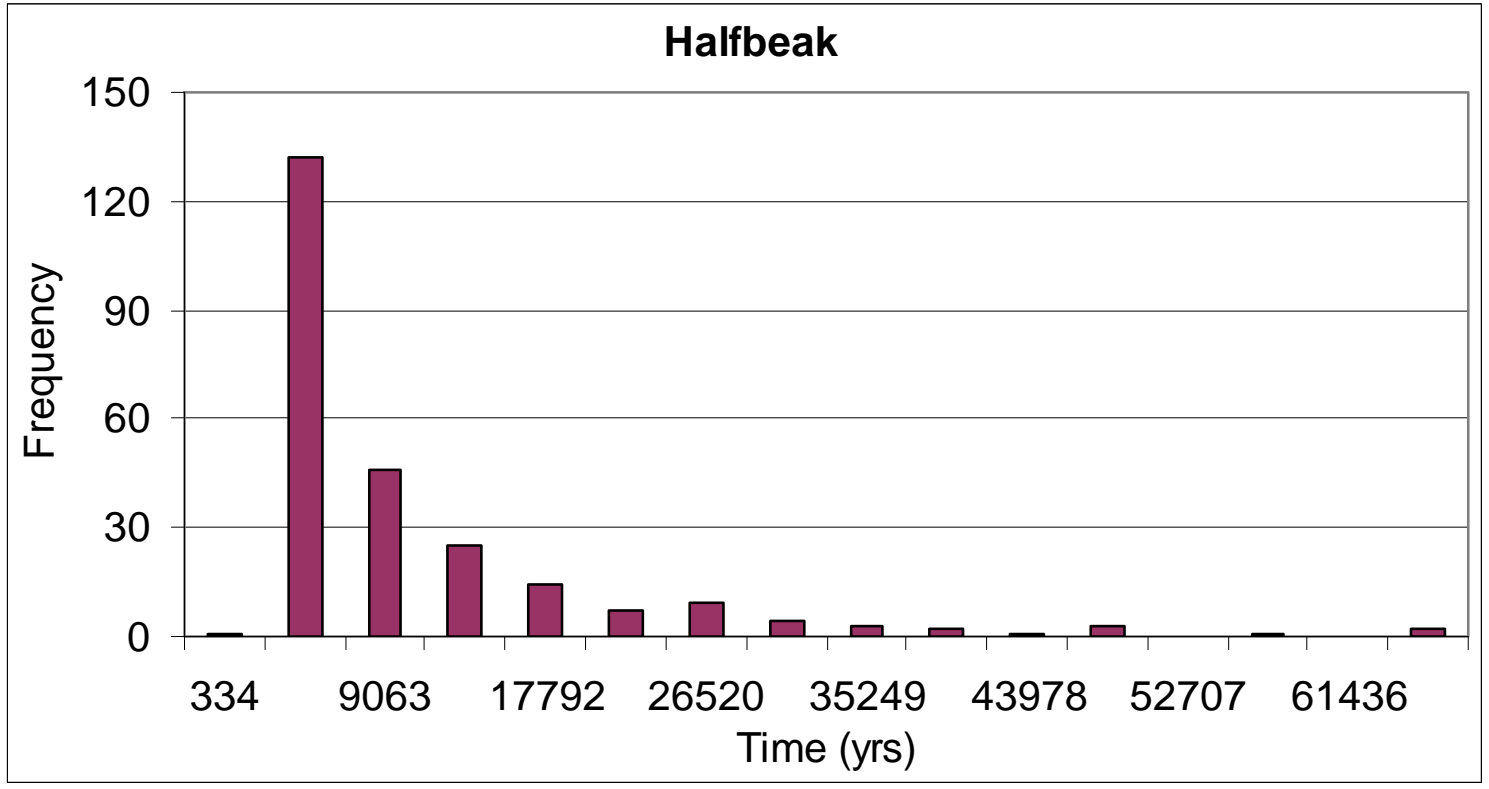

Figure C127. Distribution of minimum travel time from Halfbeak to YM boundaries based on effective-porosity Set 2 for 1998 scenario. 


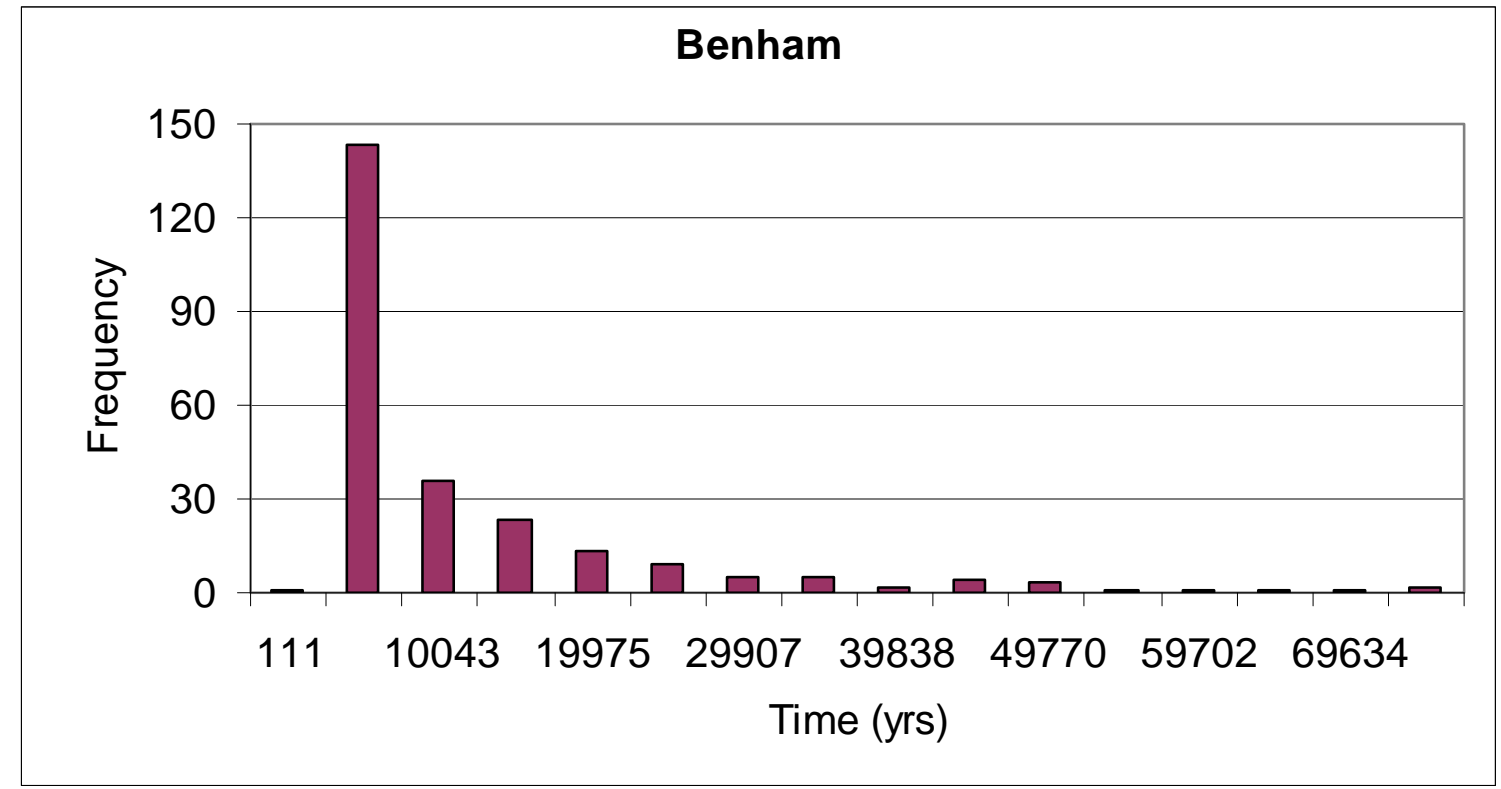

Figure C128. Distribution of minimum travel time from Benham -1 to YM boundaries based on effective-porosity Set 2 for 1998 scenario.

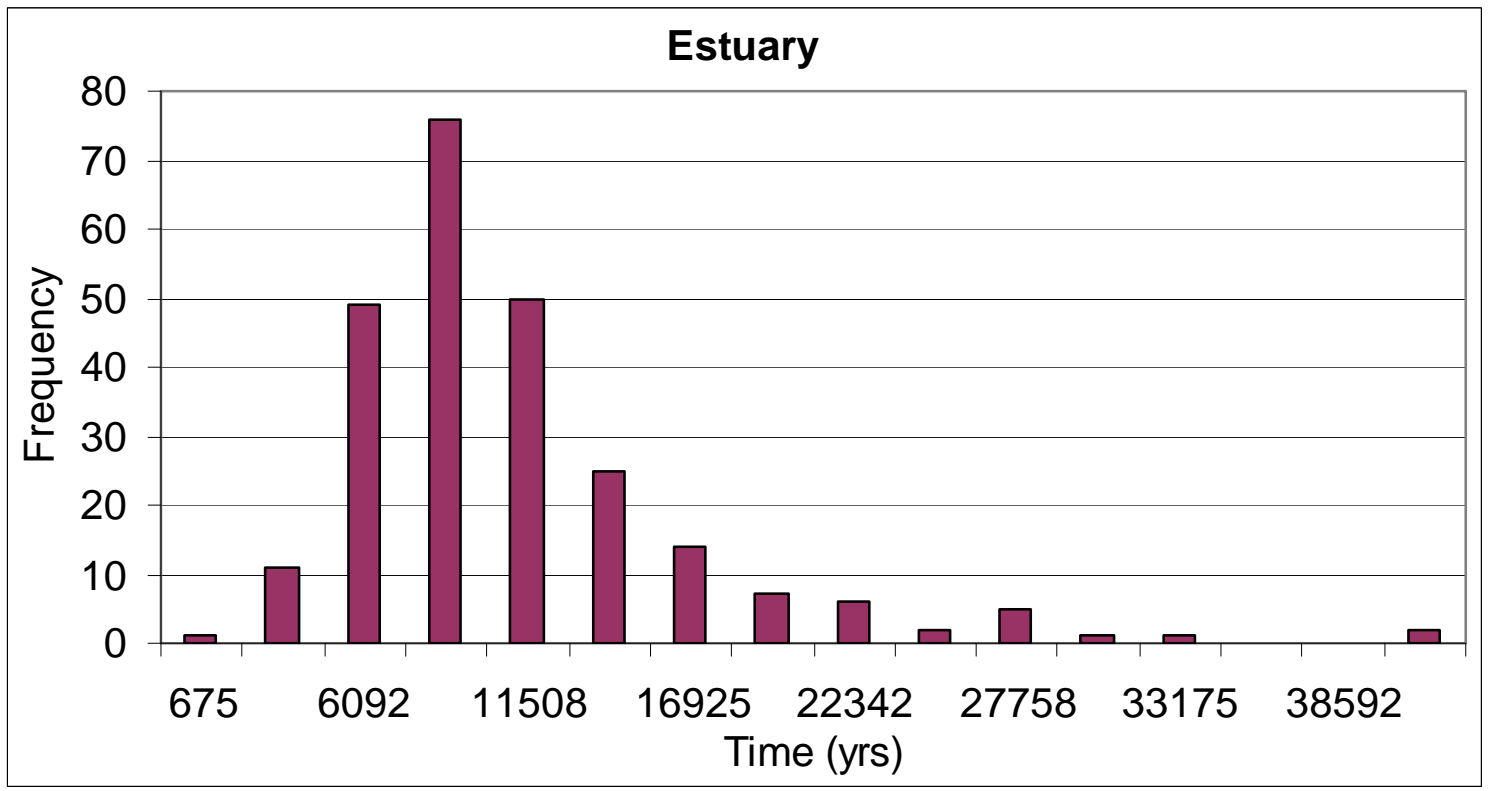

Figure C129. Distribution of minimum travel time from Estuary to YM boundaries based on effective-porosity Set 2 for 1998 scenario. 


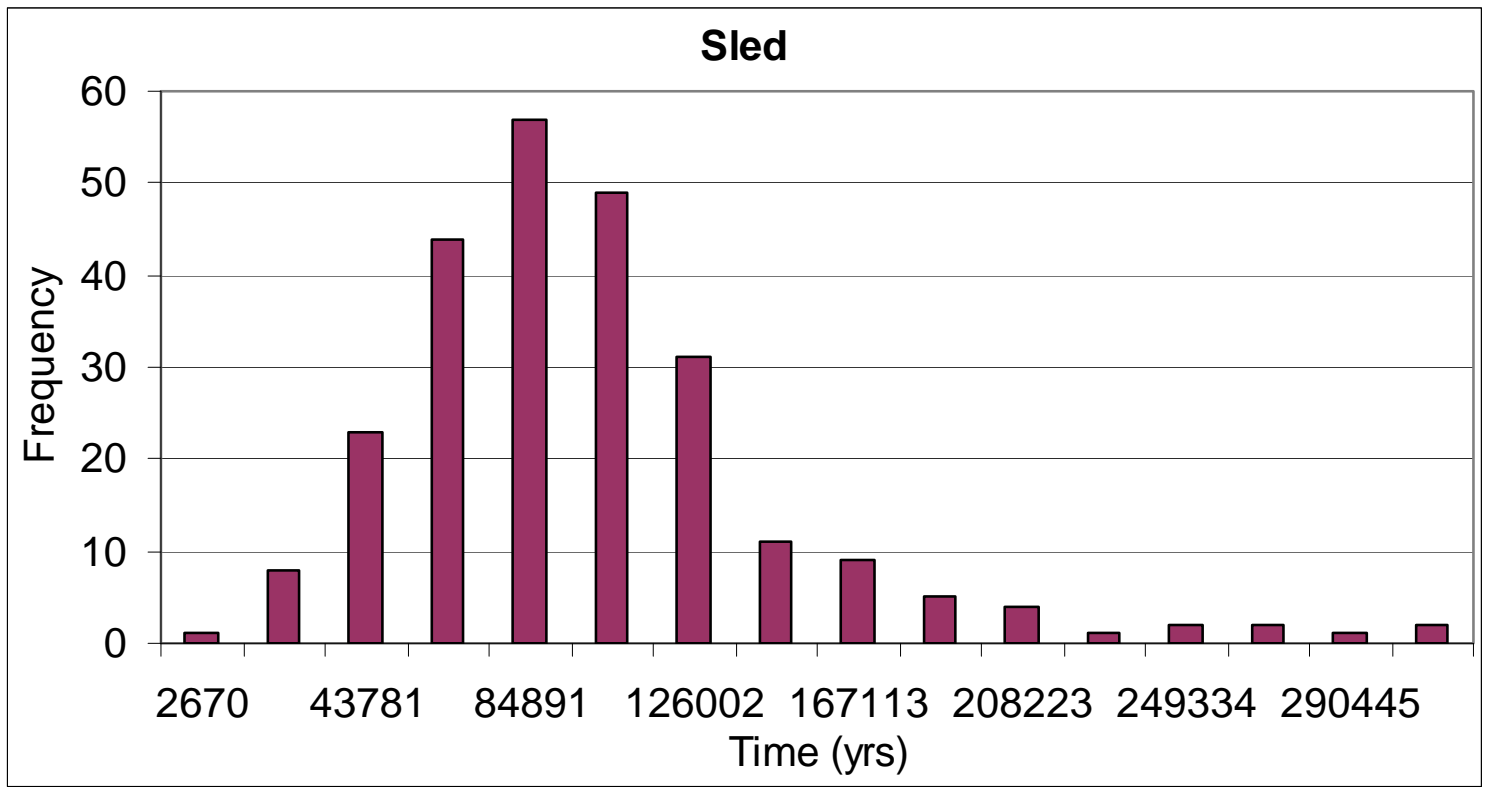

Figure C130. Distribution of minimum travel time from Sled to YM boundaries based on effective-porosity Set 2 for 1998 scenario.

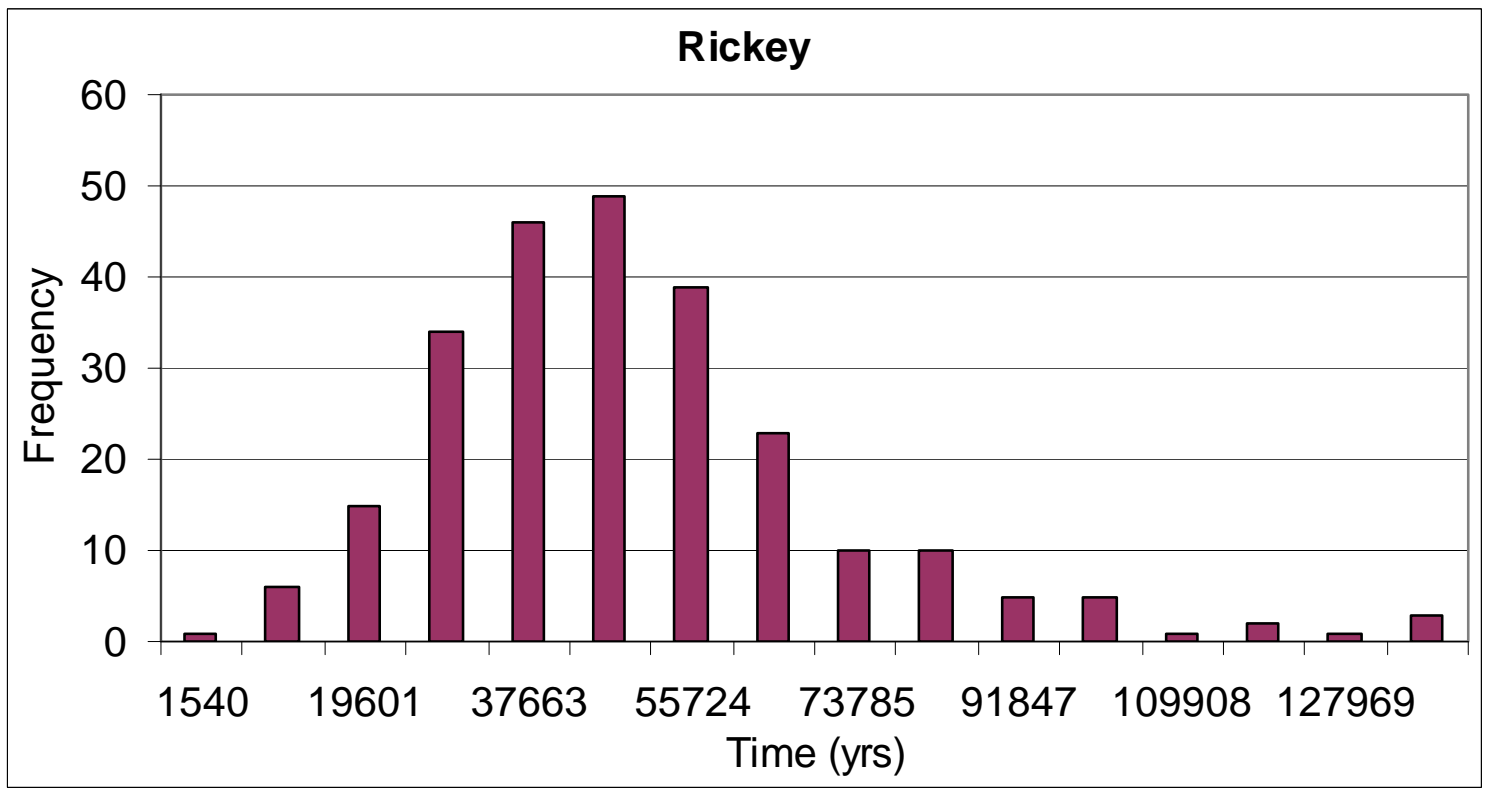

Figure C131. Distribution of minimum travel time from Rickey to YM boundaries based on effective-porosity Set 2 for 1998 scenario. 


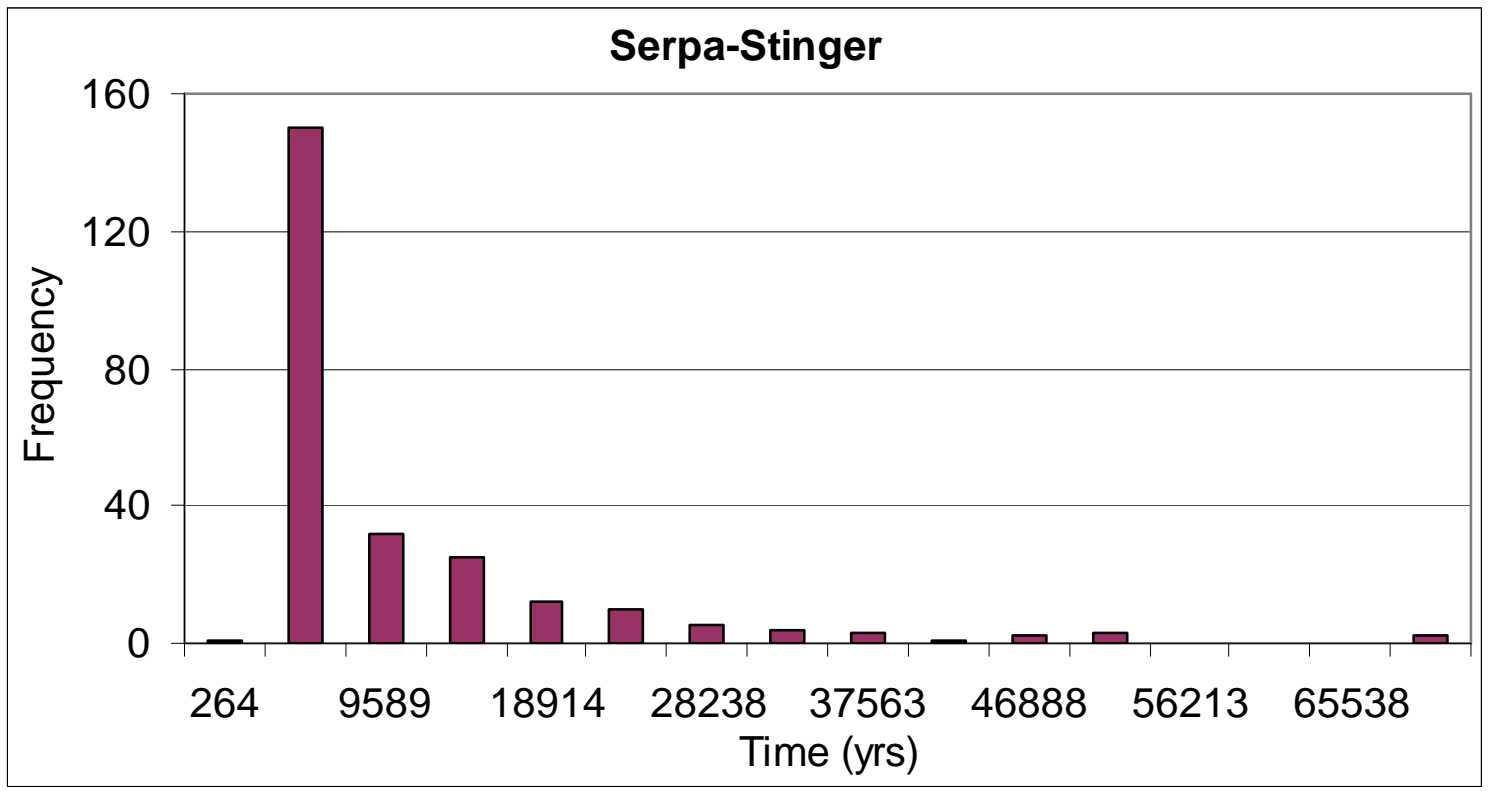

Figure C132. Distribution of minimum travel time from Serpa-Stinger to YM boundaries based on effective-porosity Set 2 for 1998 scenario.

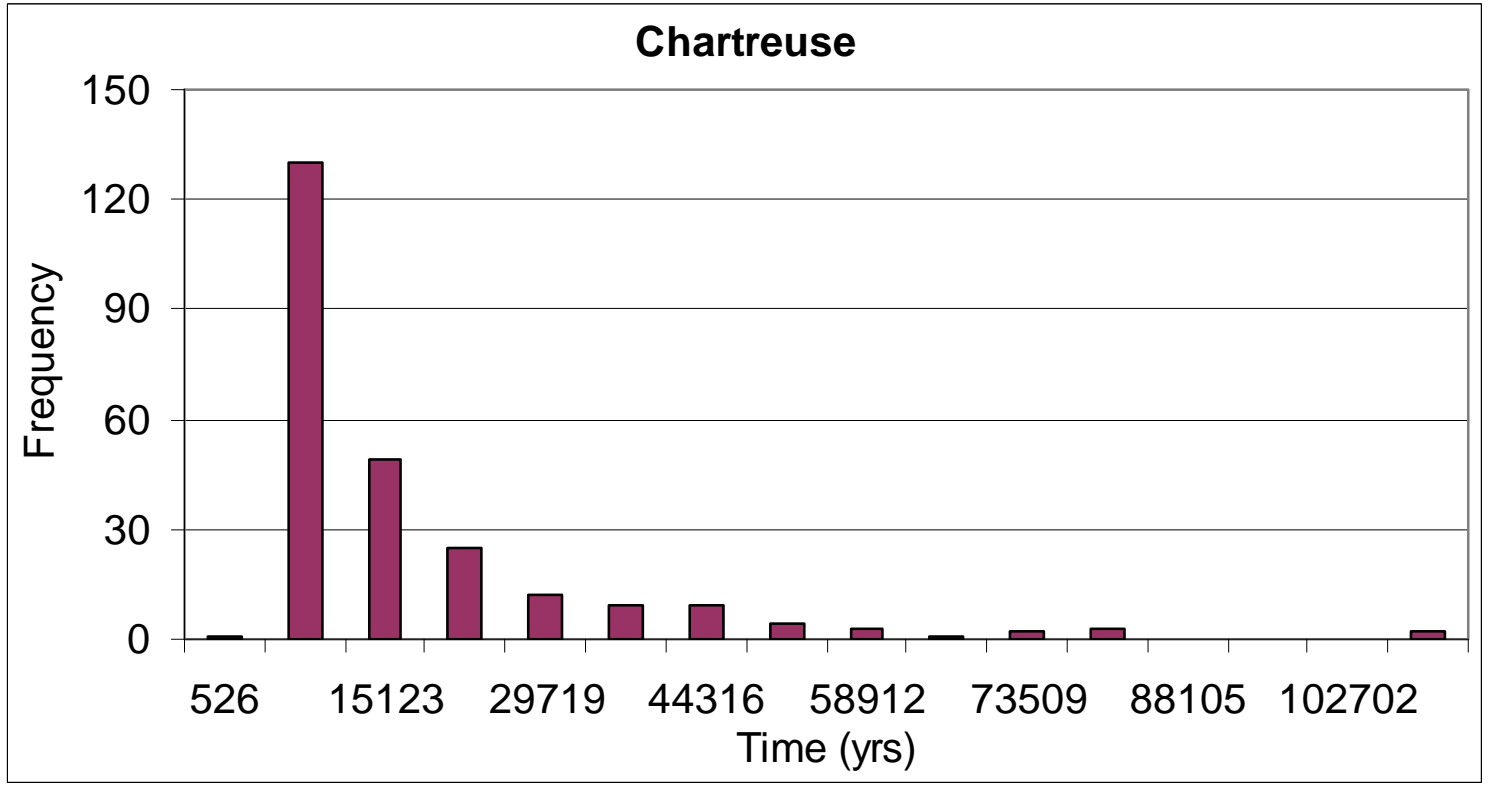

Figure C133. Distribution of minimum travel time from Chartreuse to YM boundaries based on effective-porosity Set 2 for 1998 scenario. 


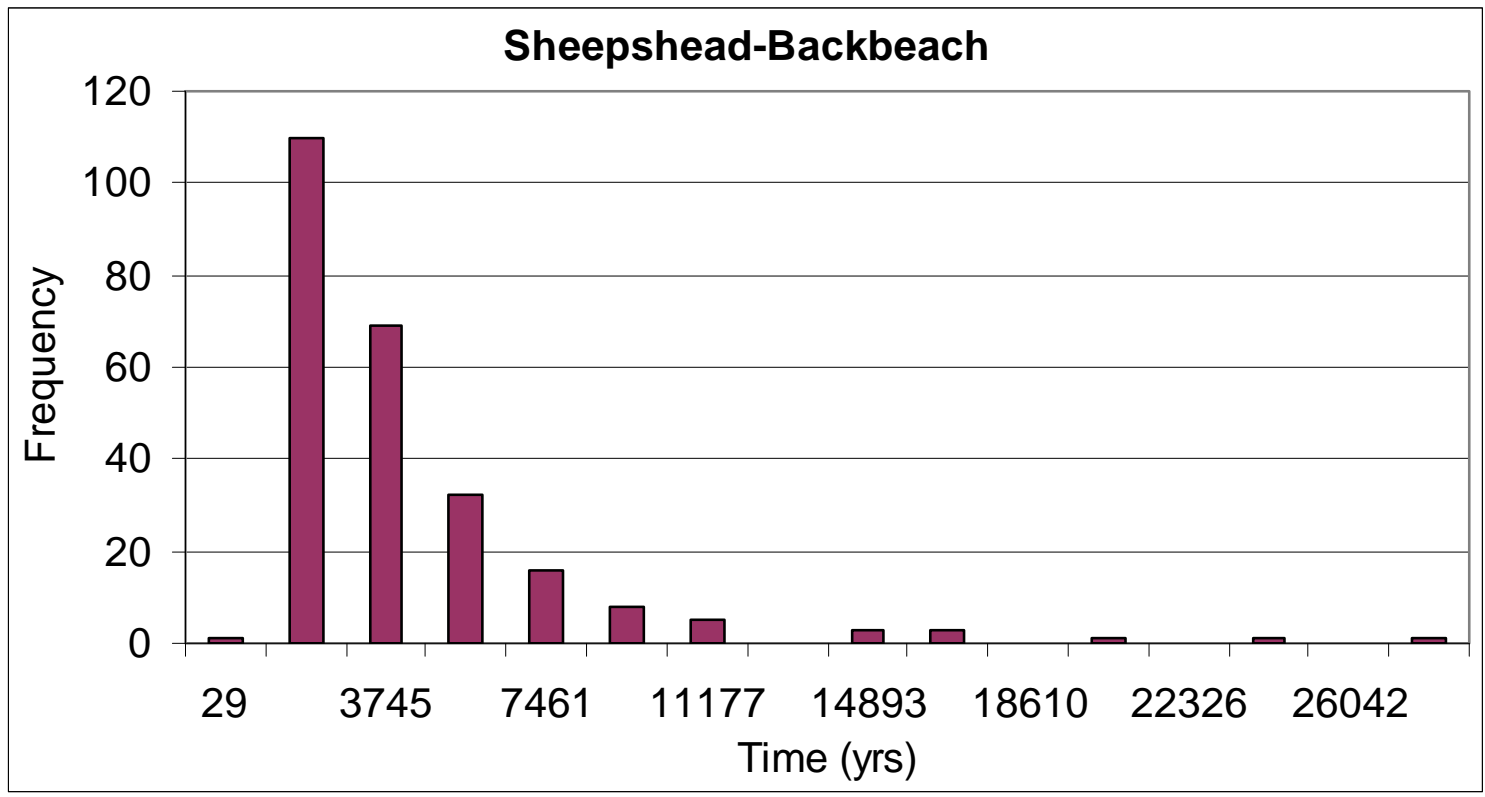

Figure C134: Distribution of minimum travel time from Sheepshead-Backbeach to YM boundaries based on effective-porosity Set 2 for 1998 scenario.

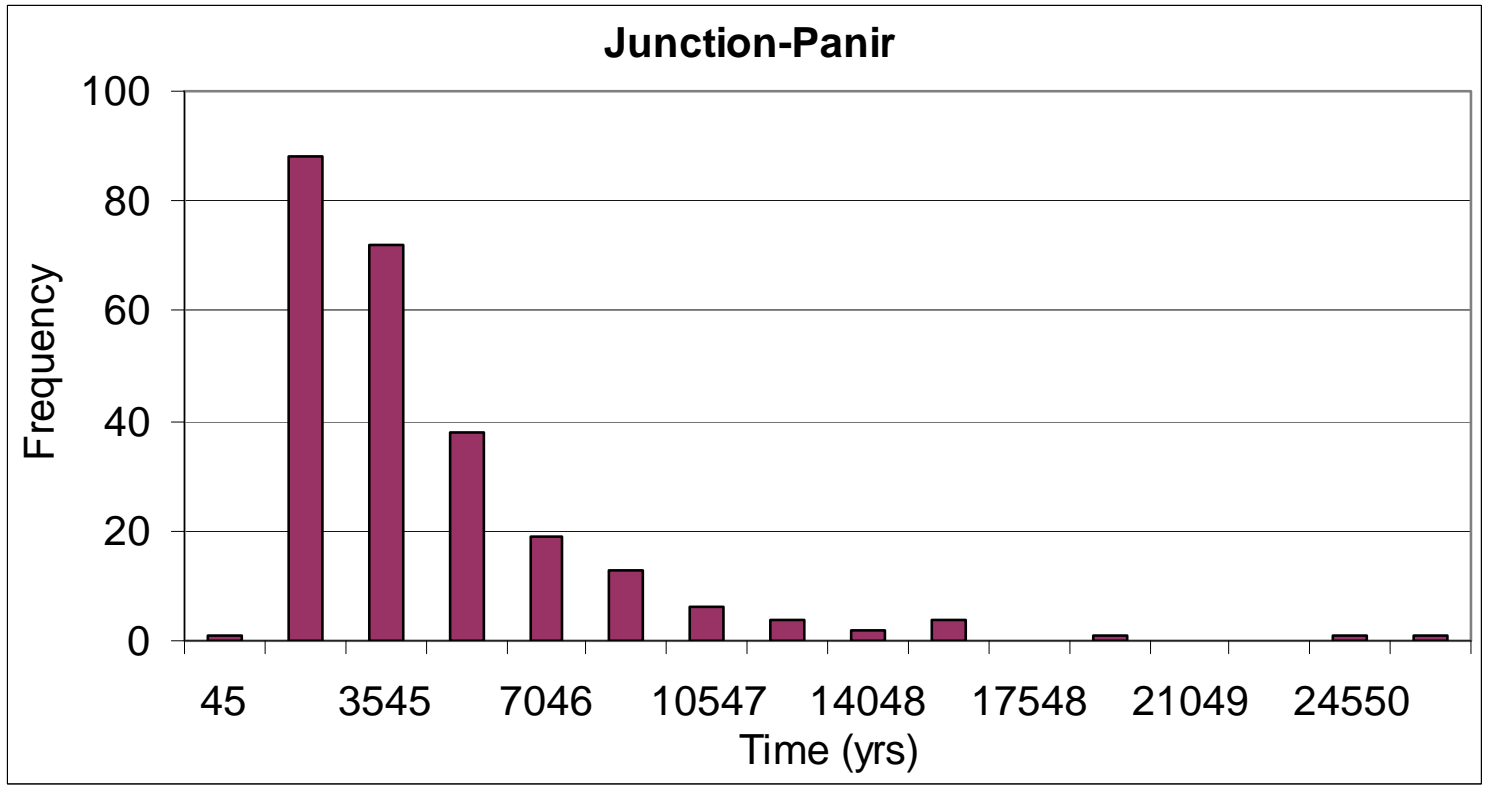

Figure C135: Distribution of minimum travel time from Junction-Panir to YM boundaries based on effective-porosity Set 2 for 1998 scenario. 


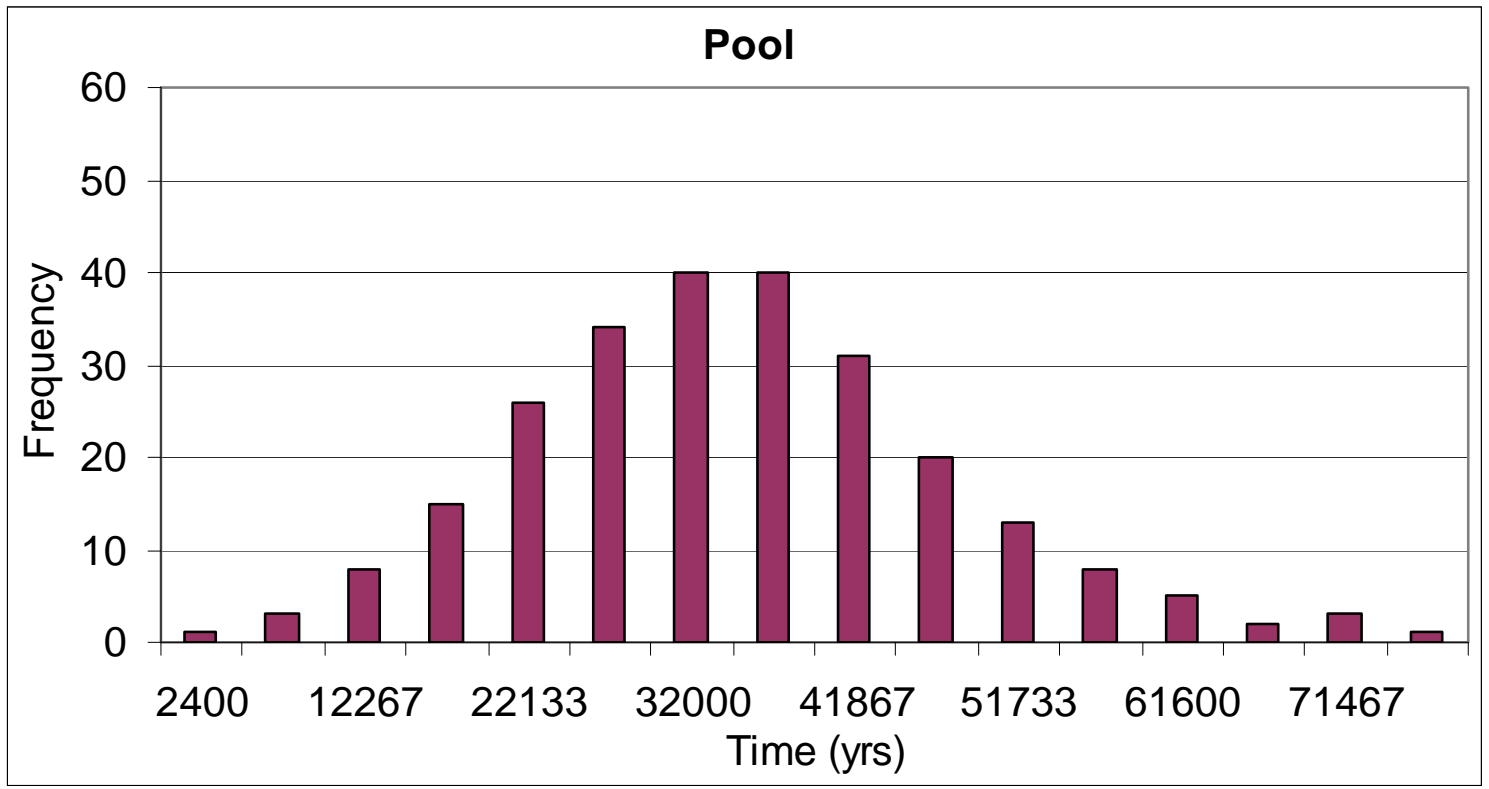

Figure C136: Distribution of minimum travel time from Pool to YM boundaries based on effective-porosity Set 2 for 1998 scenario.

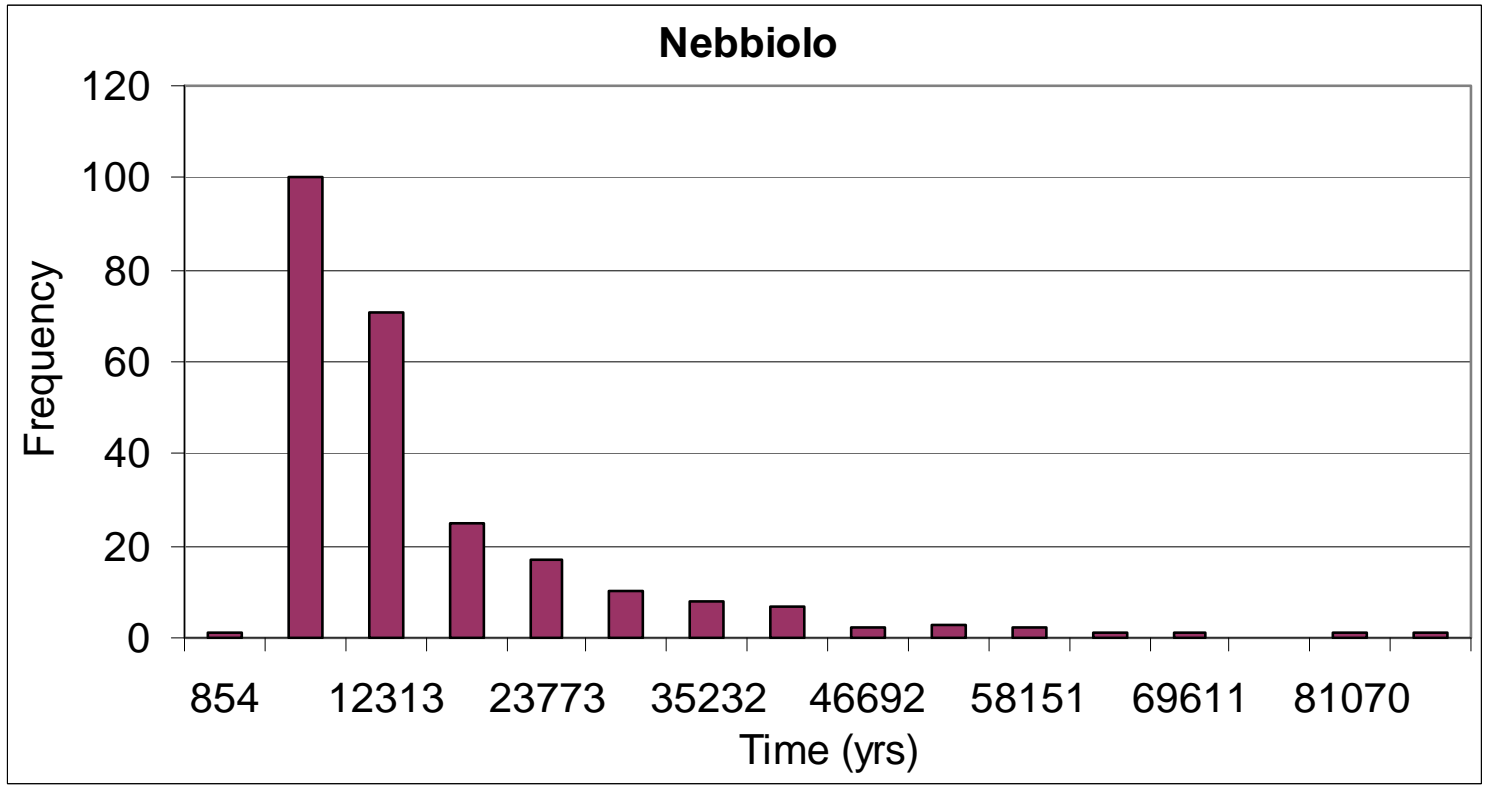

Figure C137: Distribution of minimum travel time from Nebbiolo to YM boundaries based on effective-porosity Set 2 for 1998 scenario. 


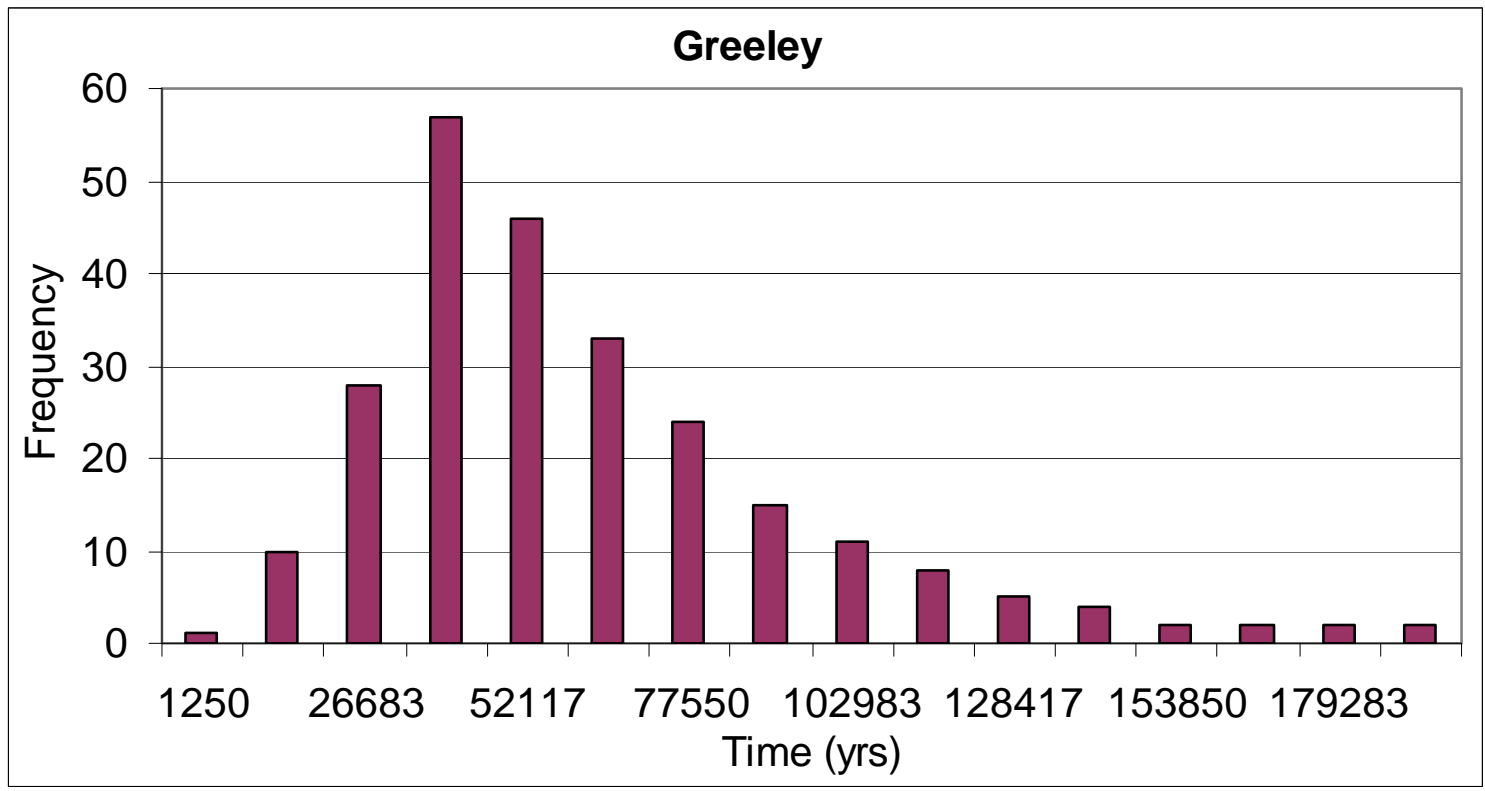

Figure C138: Distribution of minimum travel time from Greenley to YM boundaries based on effective-porosity Set 2 for 1998 scenario.

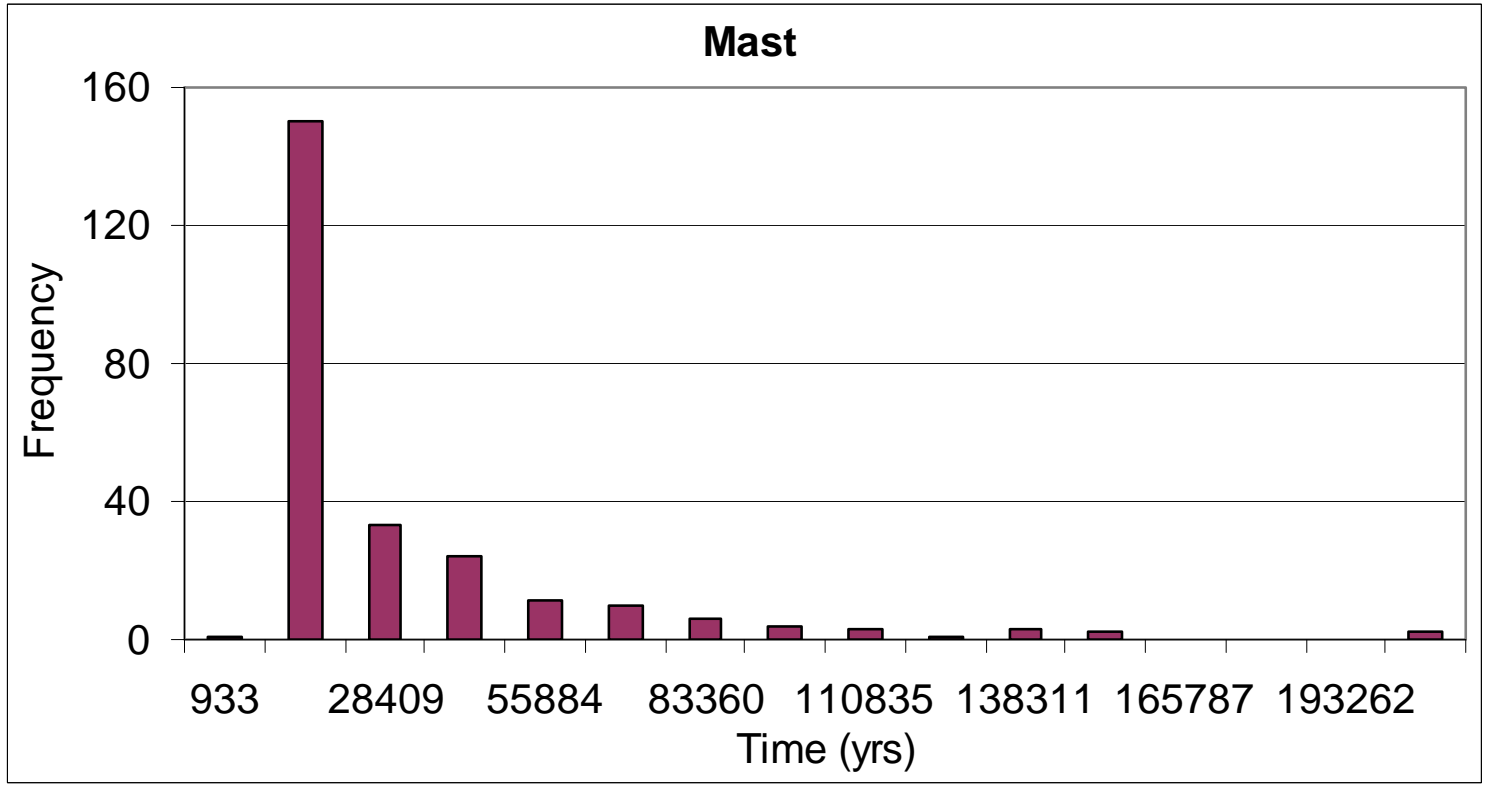

Figure C139: Distribution of minimum travel time from Mast to YM boundaries based on effective-porosity Set 2 for 1998 scenario. 


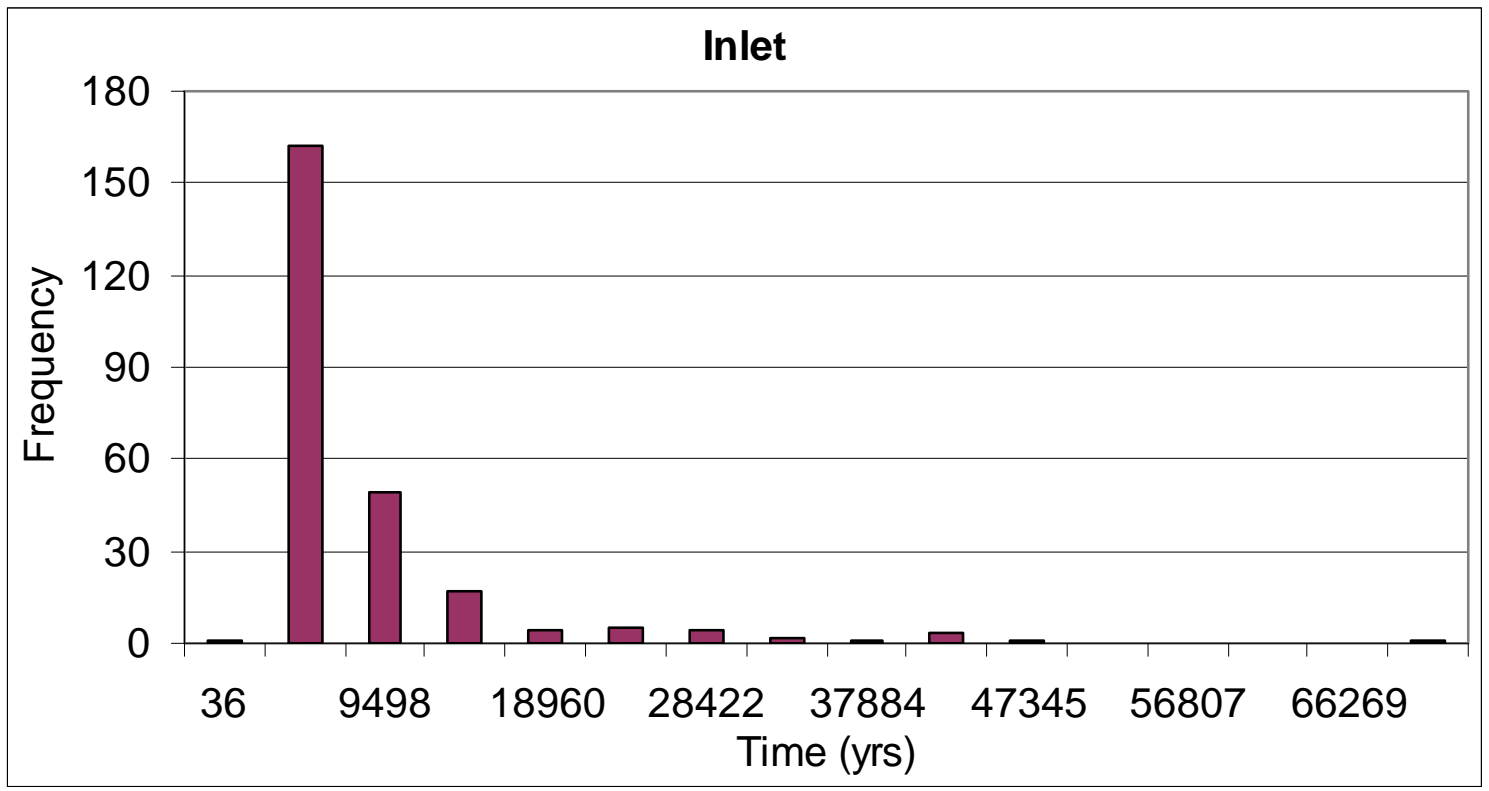

Figure C140: Distribution of minimum travel time from Inlet to YM boundaries based on effective-porosity Set 2 for 1998 scenario.

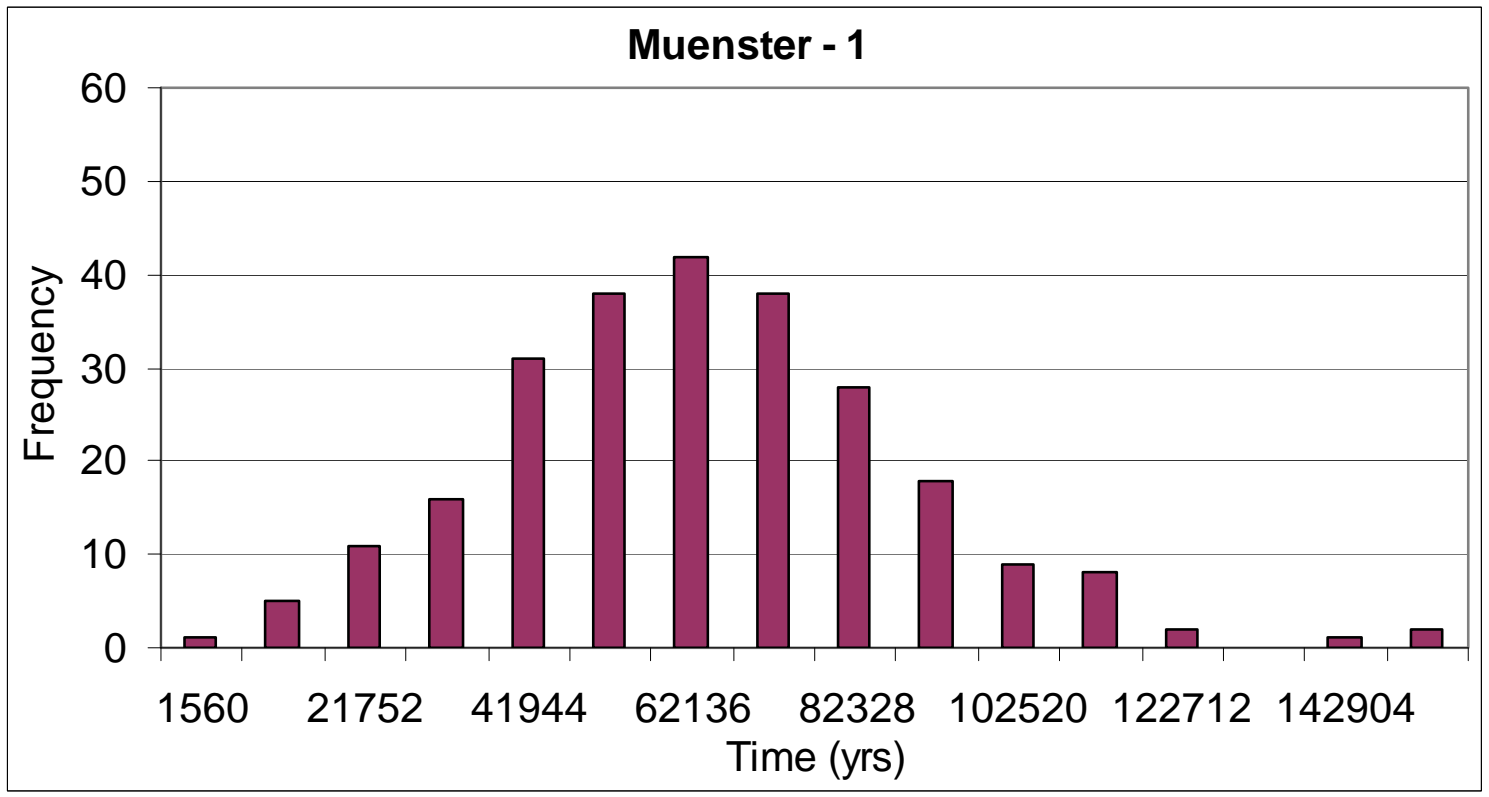

Figure C141: Distribution of minimum travel time from Muenster - 1 to YM boundaries based on effective-porosity Set 2 for 1998 scenario. 


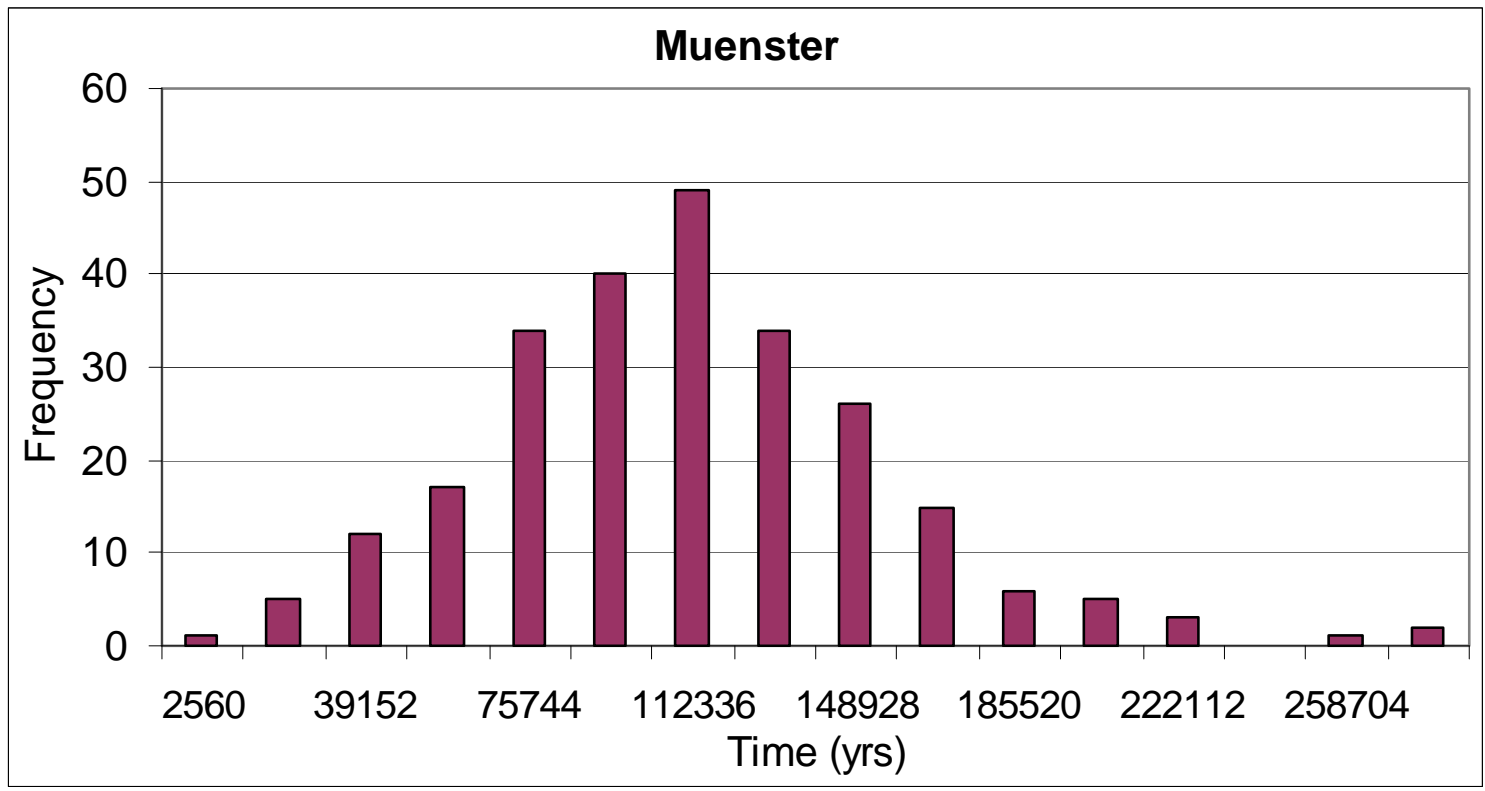

Figure C142: Distribution of minimum travel time from Muenster to YM boundaries based on effective-porosity Set 2 for 1998 scenario.

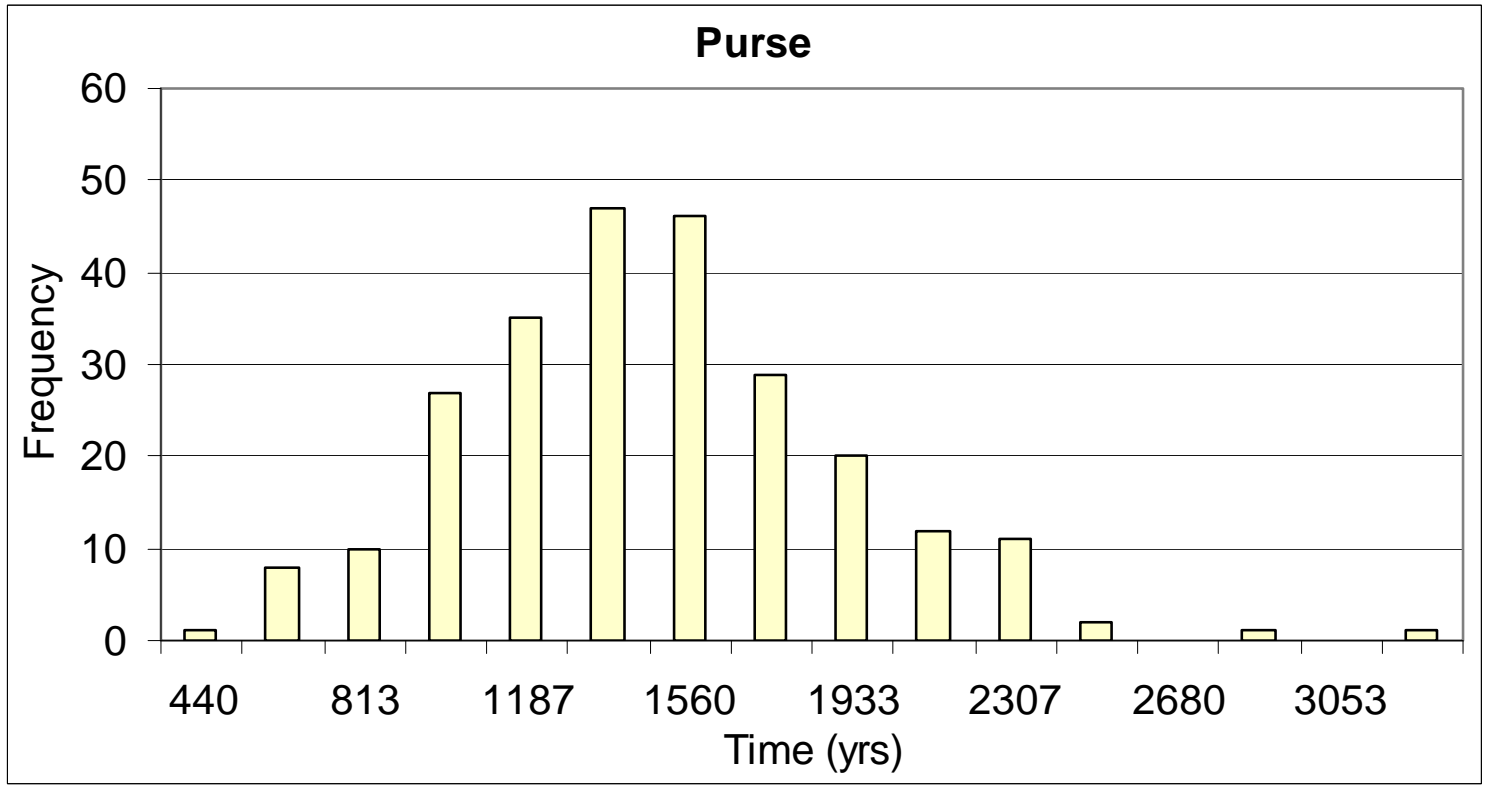

Figure C143: Distribution of minimum travel time from Purse to YM boundaries based on effective-porosity Set 3 for 1998 scenario. 


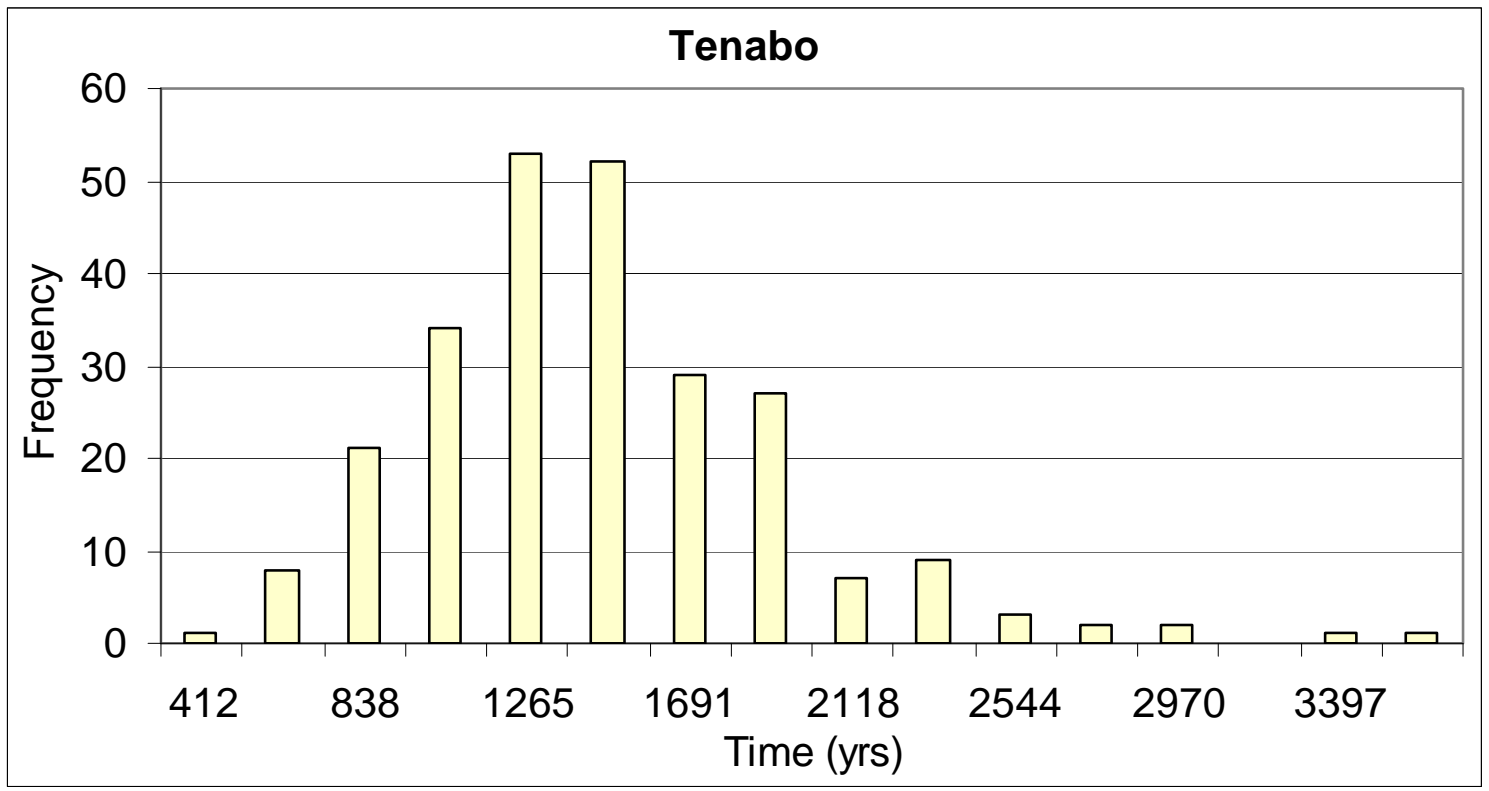

Figure C144: Distribution of minimum travel time from Tenabo to YM boundaries based on effective-porosity Set 3 for 1998 scenario.

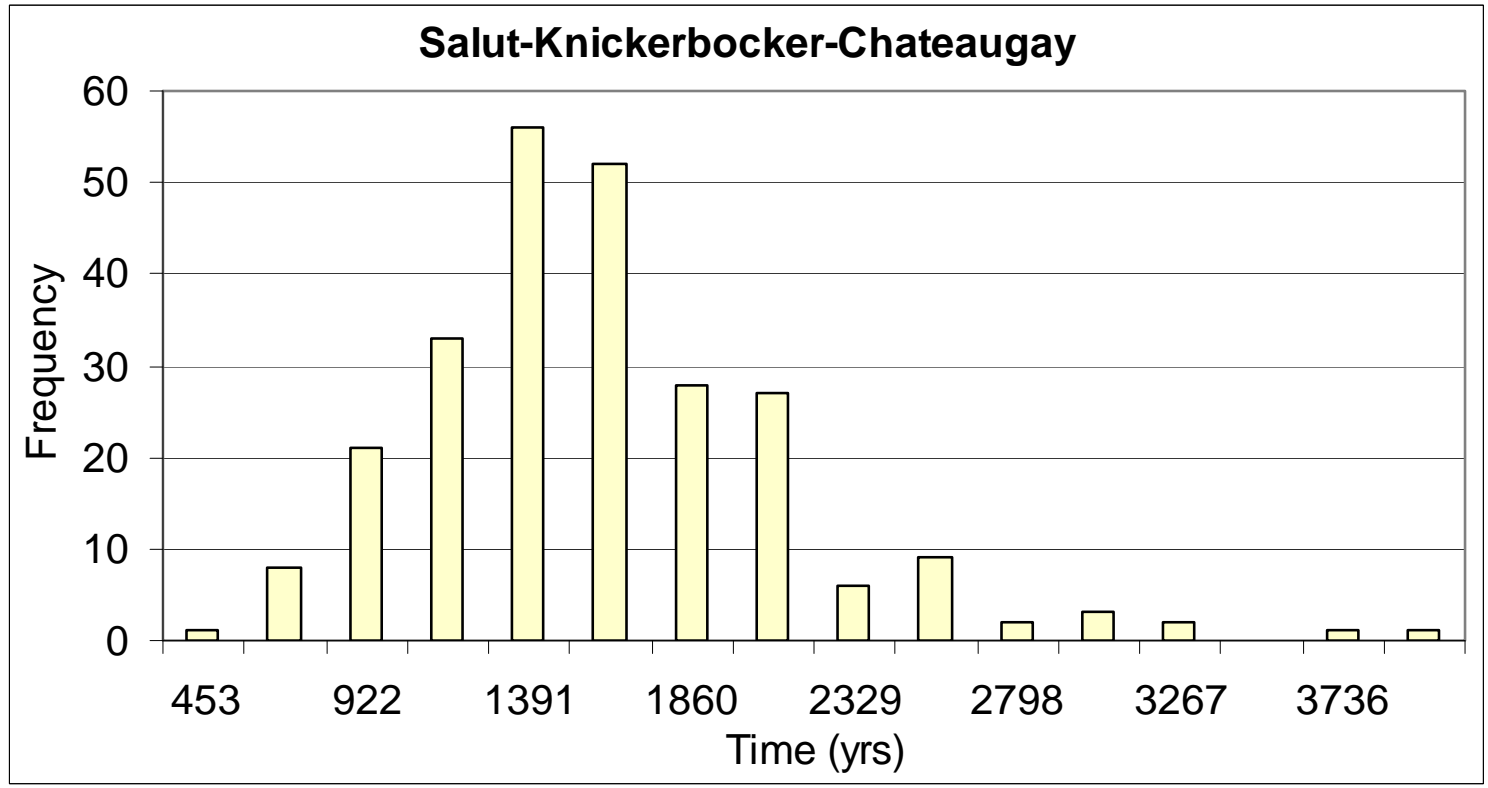

Figure C145: Distribution of minimum travel time from Salut-Knickerbocker-Chateaugay to YM boundaries based on effective-porosity Set 3 for 1998 scenario. 


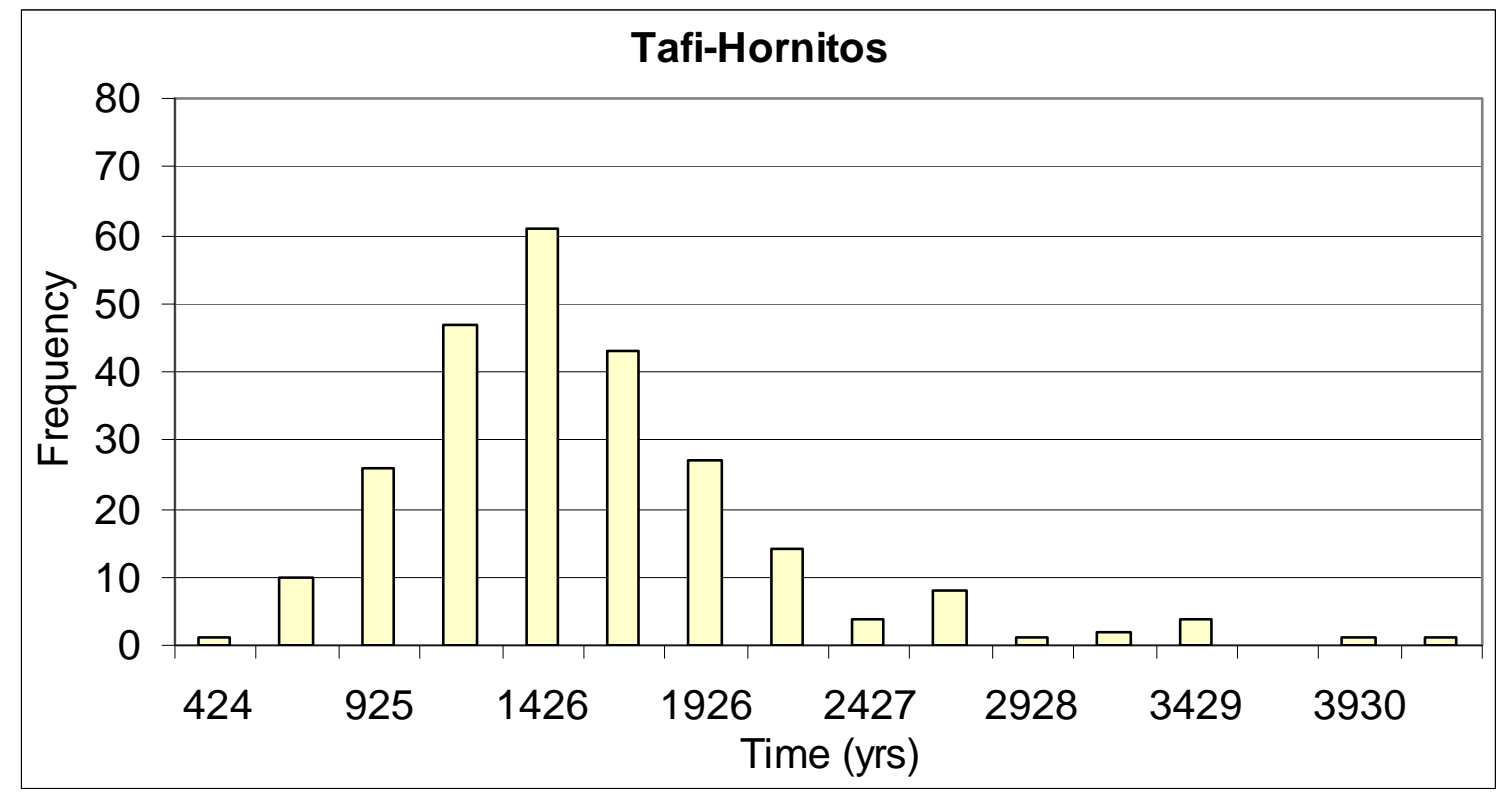

Figure C146: Distribution of minimum travel time from Tafi-Hornitos to YM boundaries based on effective-porosity Set 3 for 1998 scenario.

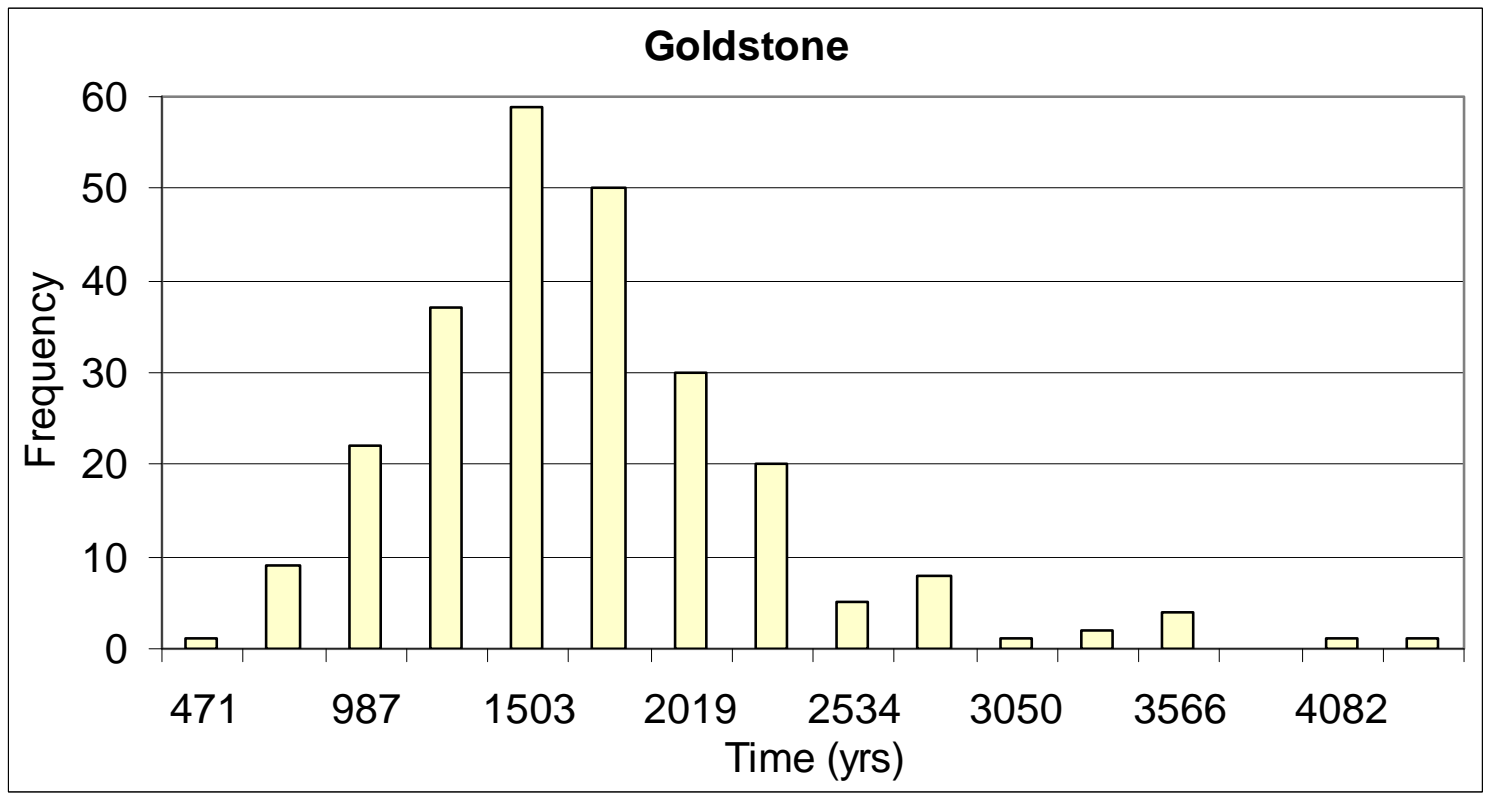

Figure C147: Distribution of minimum travel time from Goldstone to YM boundaries based on effective-porosity Set 3 for 1998 scenario. 


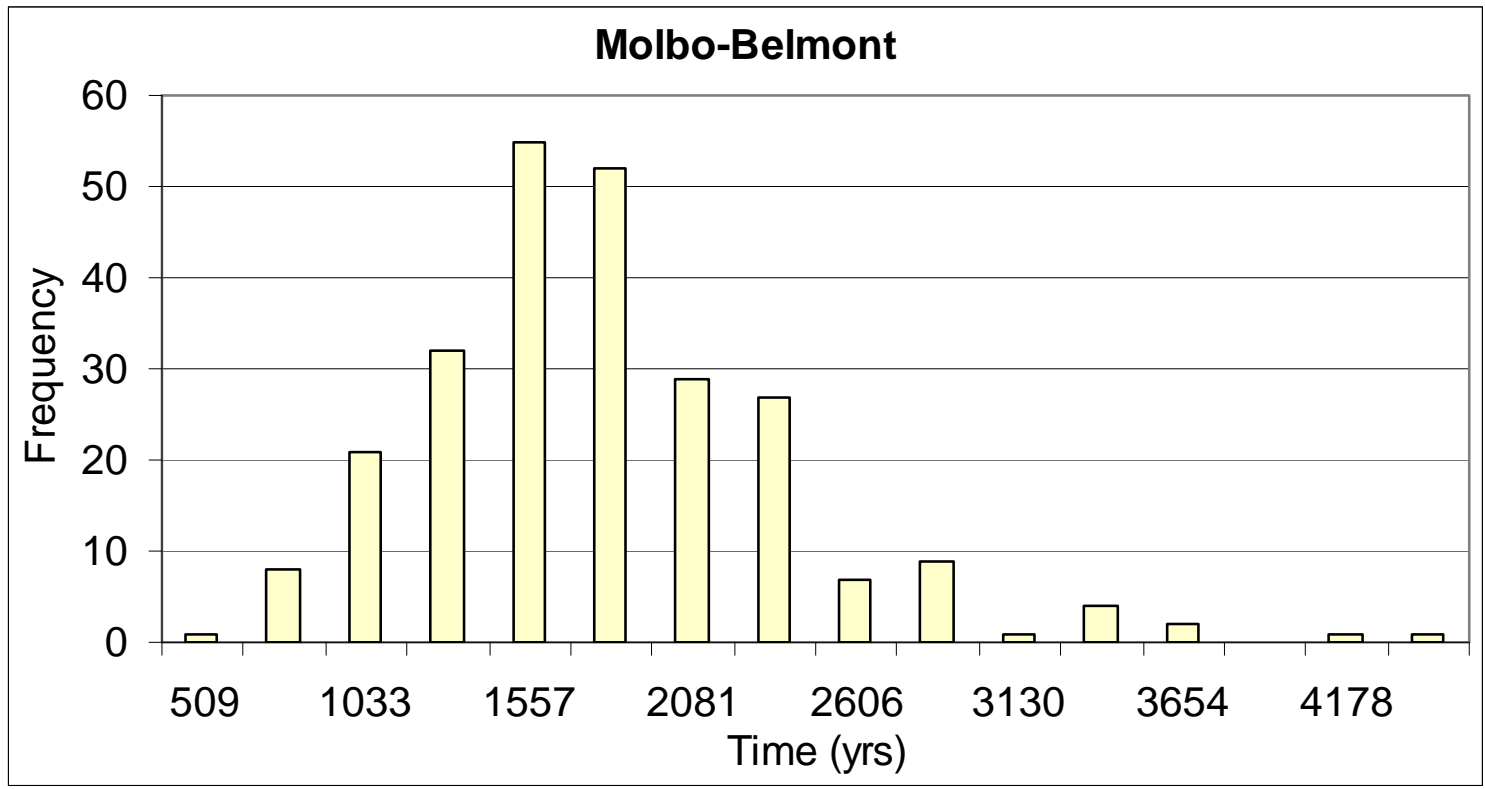

Figure C148: Distribution of minimum travel time from Molbo-Belmont to YM boundaries based on effective-porosity Set 3 for 1998 scenario.

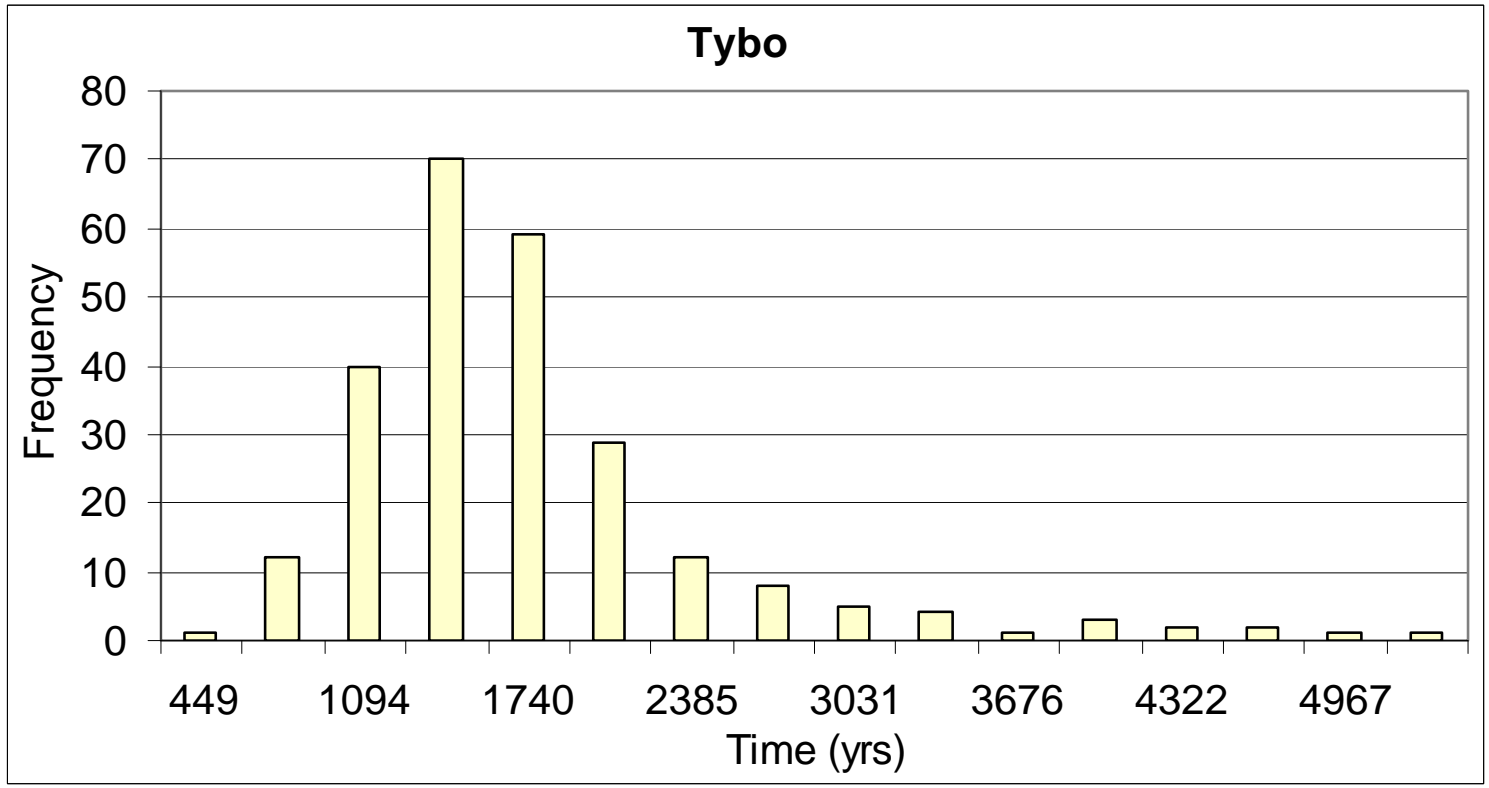

Figure C149: Distribution of minimum travel time from Tybo to YM boundaries based on effective-porosity Set 3 for 1998 scenario. 


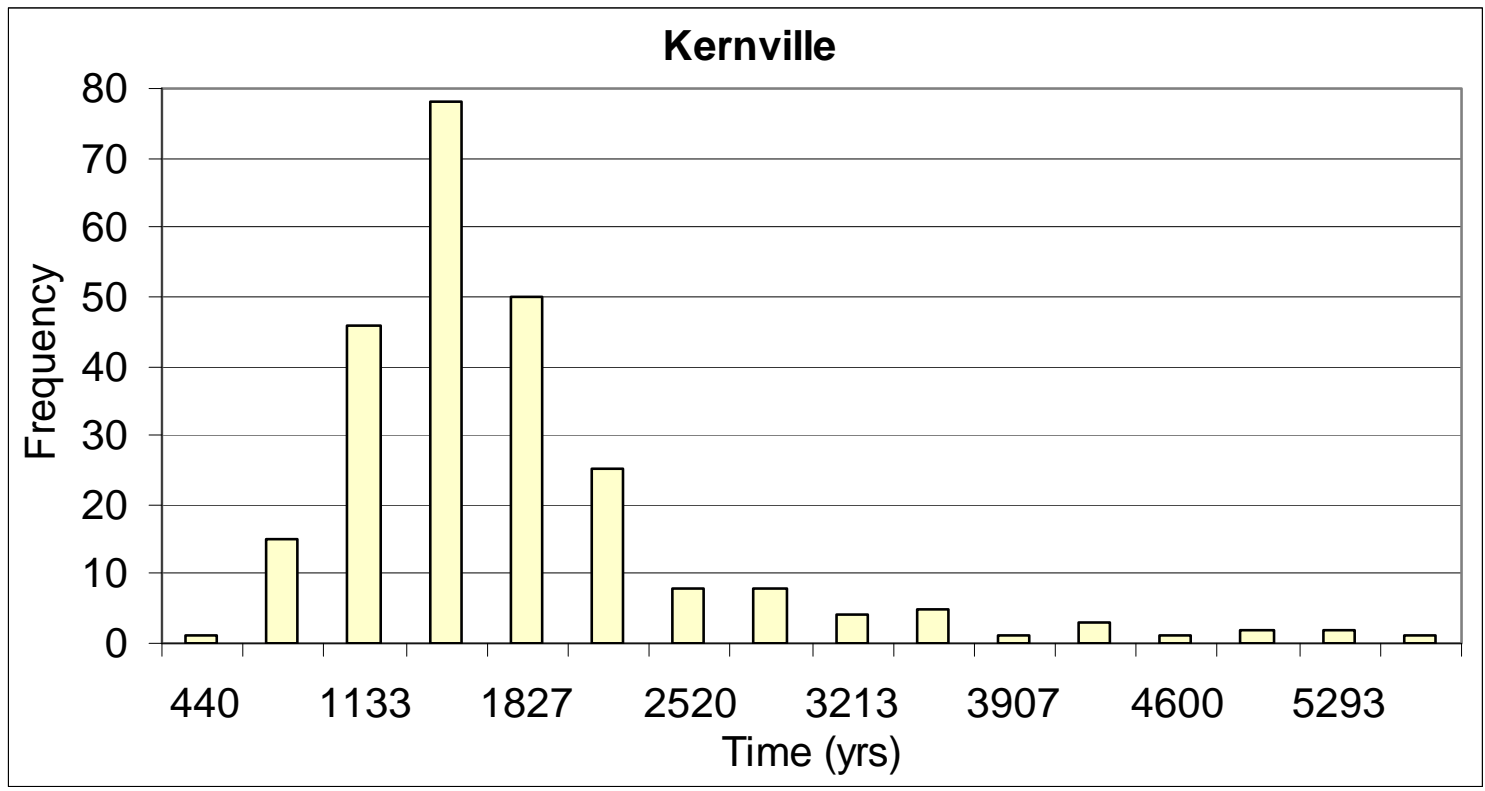

Figure C150: Distribution of minimum travel time from Kernville to YM boundaries based on effective-porosity Set 3 for 1998 scenario.

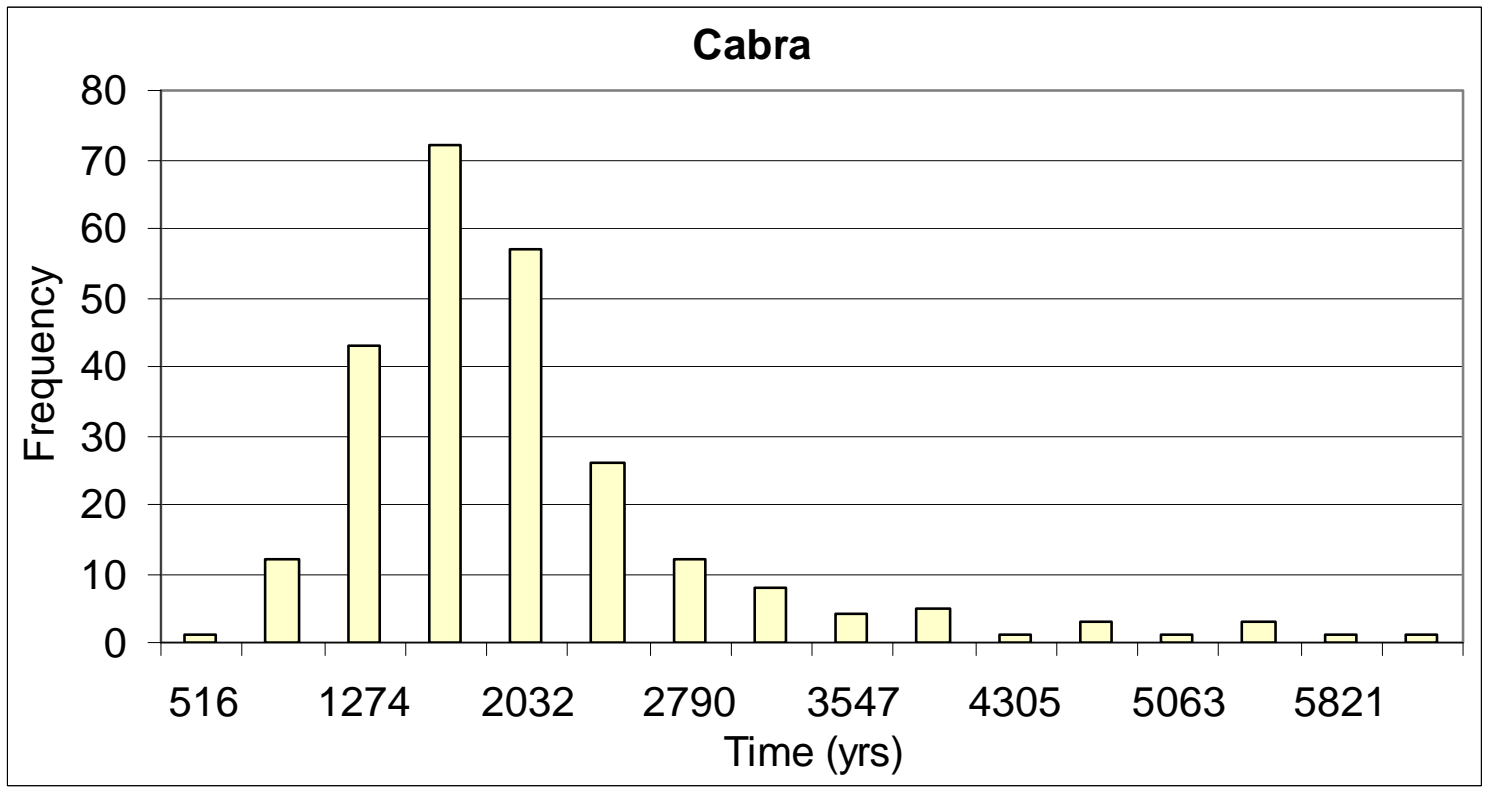

Figure C151: Distribution of minimum travel time from Cabra to YM boundaries based on effective-porosity Set 3 for 1998 scenario. 


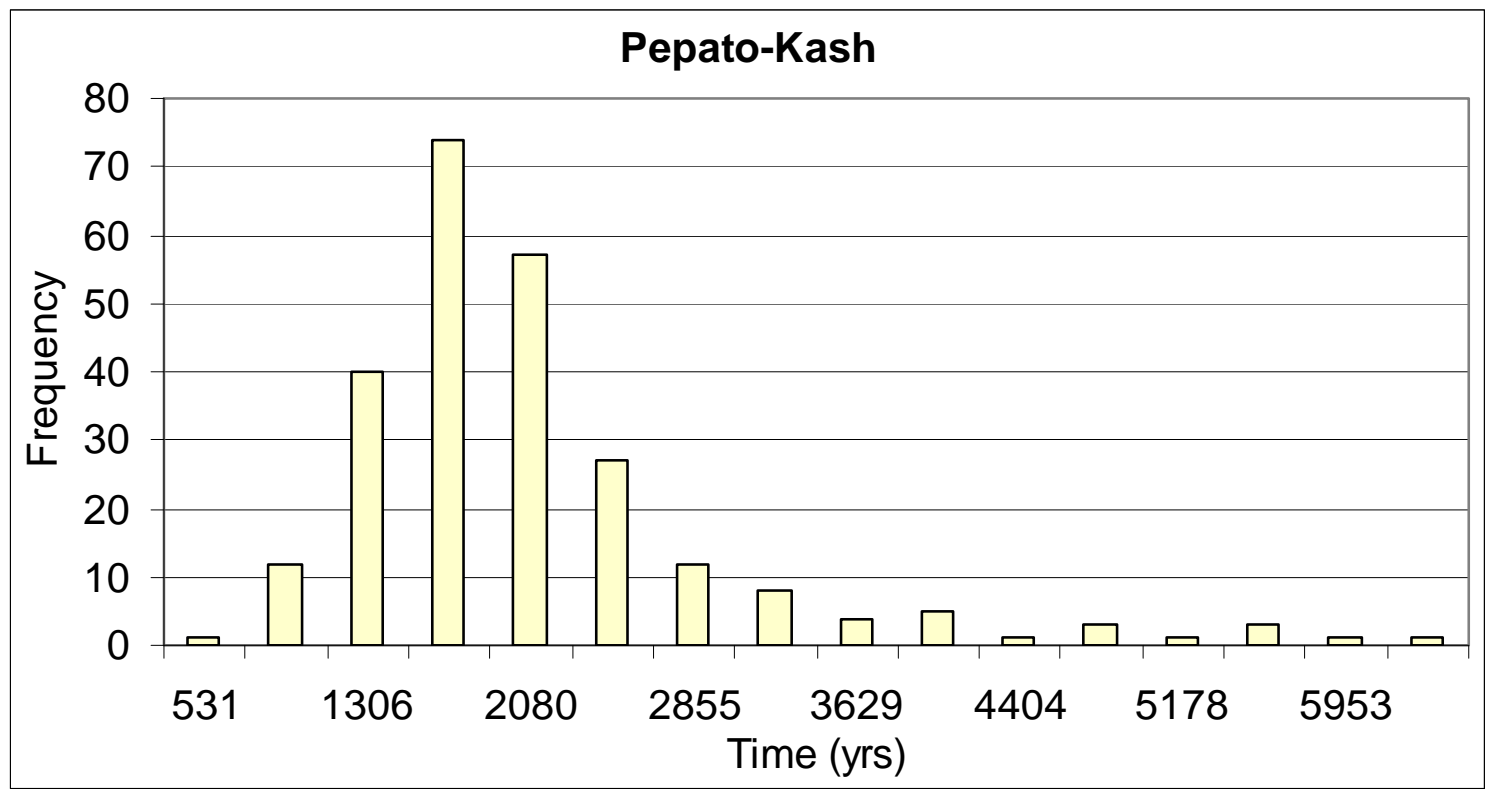

Figure C152: Distribution of minimum travel time from Pepato-Kash to YM boundaries based on effective-porosity Set 3 for 1998 scenario.

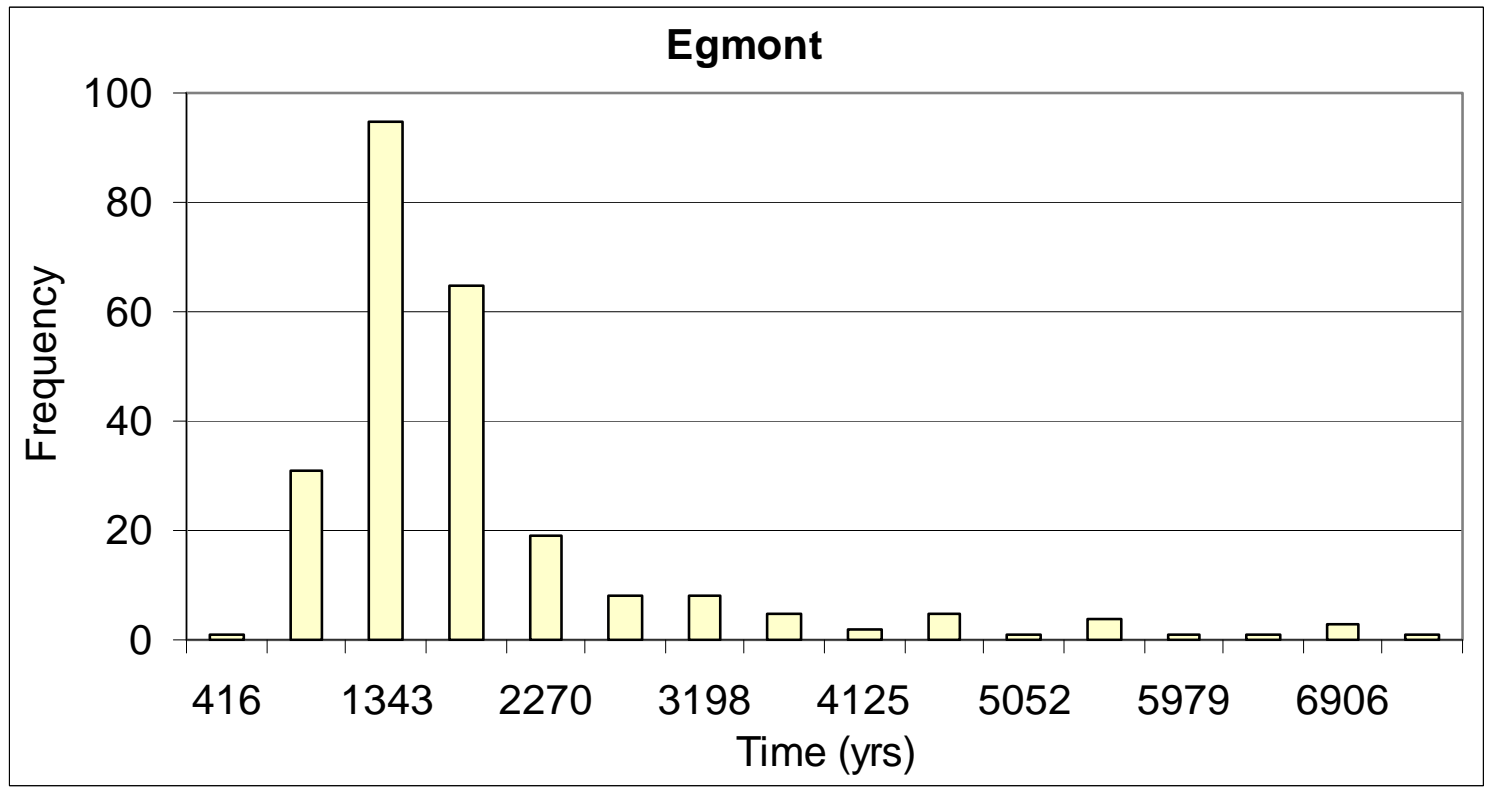

Figure C153: Distribution of minimum travel time from Egmont to YM boundaries based on effective-porosity Set 3 for 1998 scenario. 


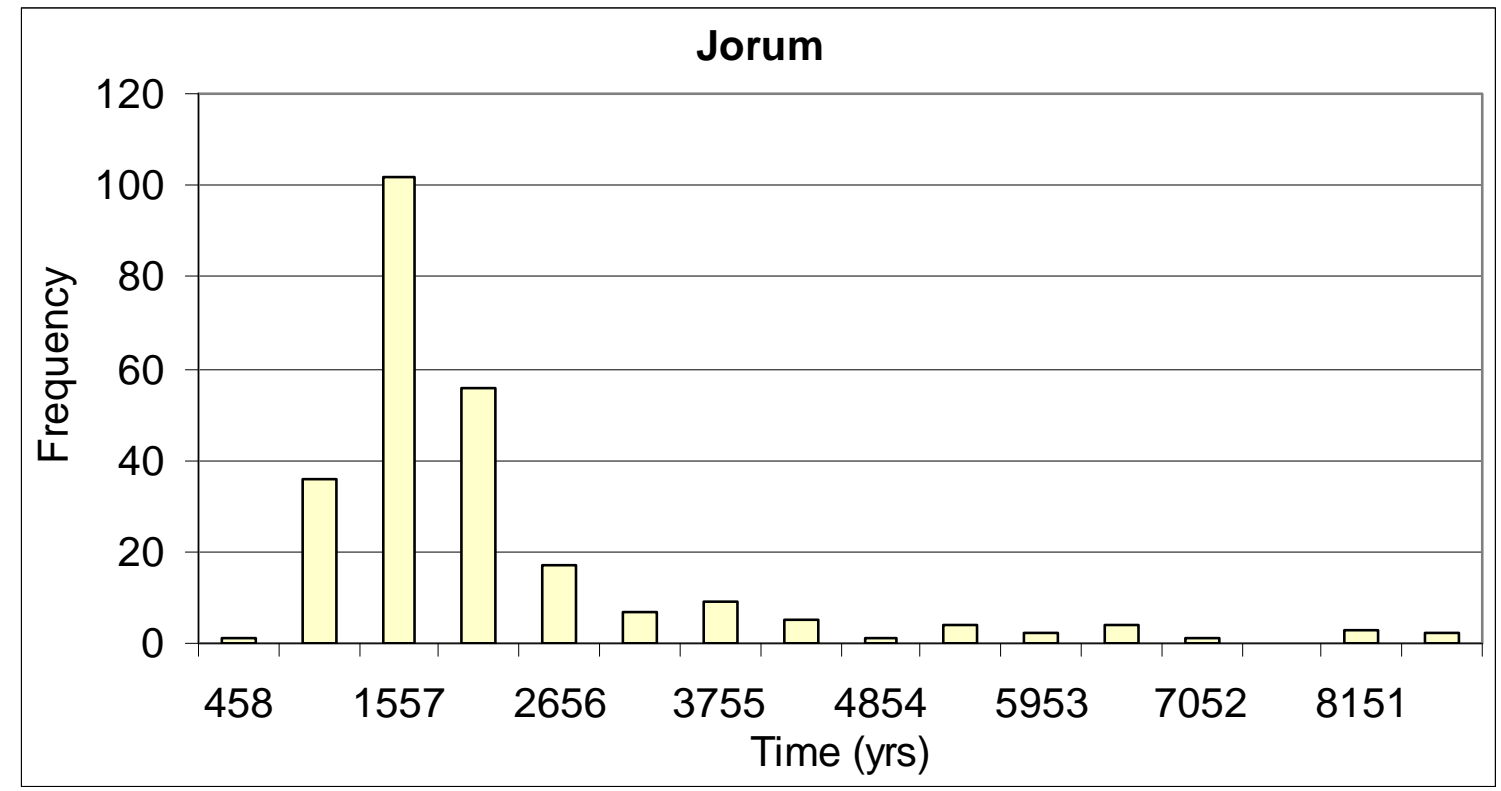

Figure C154: Distribution of minimum travel time from Jorum to YM boundaries based on effective-porosity Set 3 for 1998 scenario.

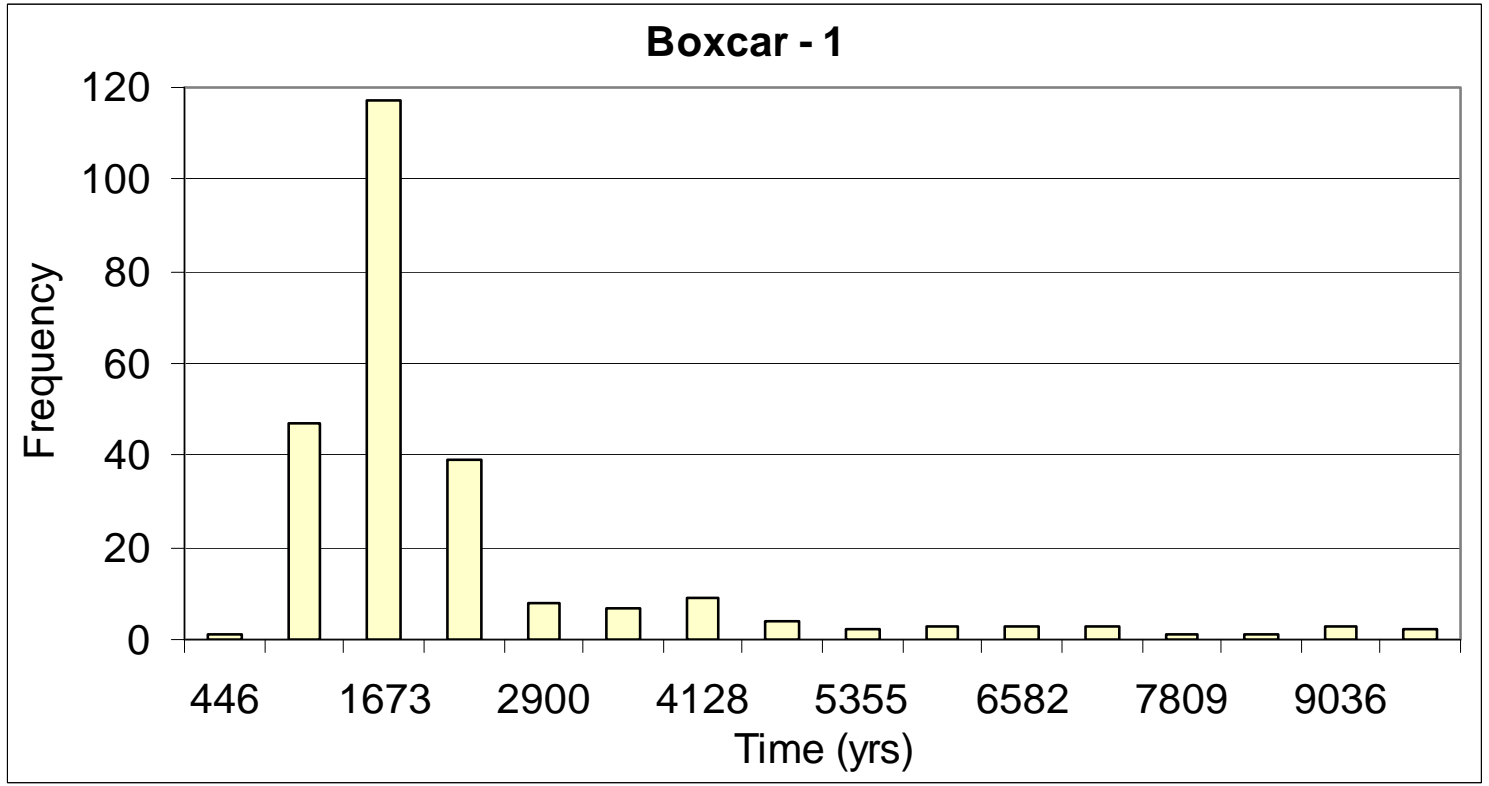

Figure C155: Distribution of minimum travel time from Boxcar -1 to YM boundaries based on effective-porosity Set 3 for 1998 scenario. 


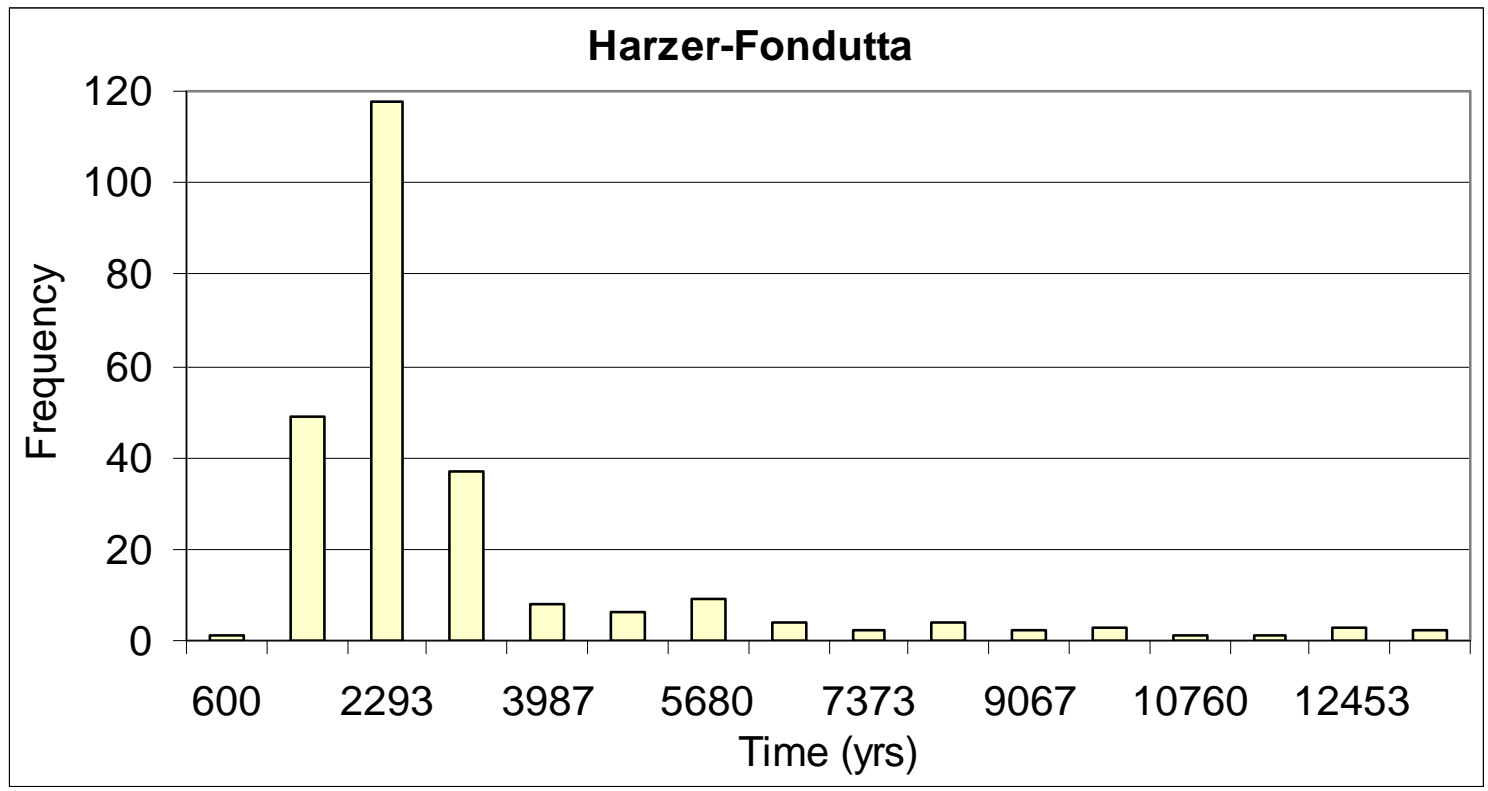

Figure C156: Distribution of minimum travel time from Harzer-Fondutta to YM boundaries based on effective-porosity Set 3 for 1998 scenario.

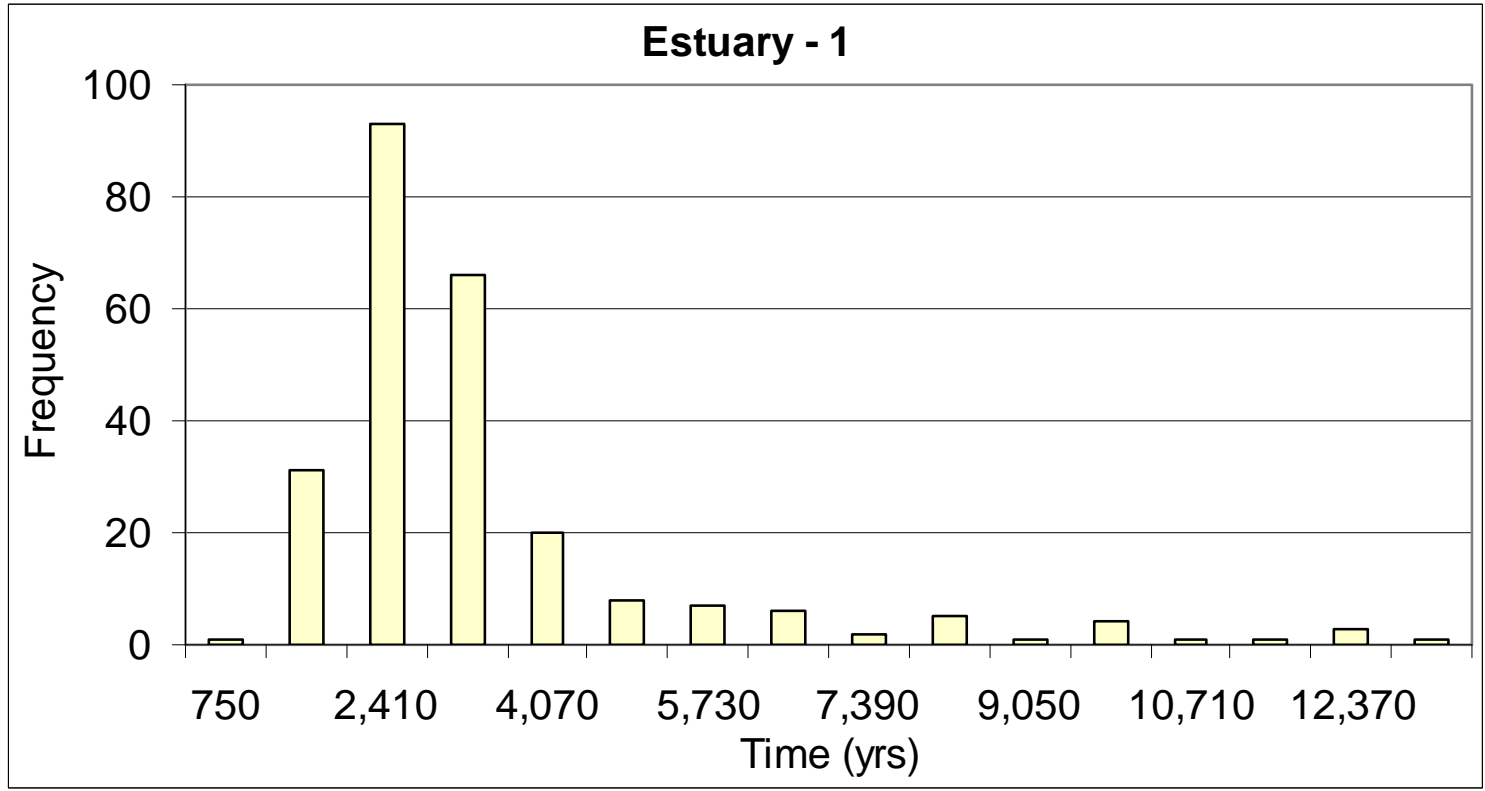

Figure C157: Distribution of minimum travel time from Estuary -1 to YM boundaries based on effective-porosity Set 3 for 1998 scenario. 


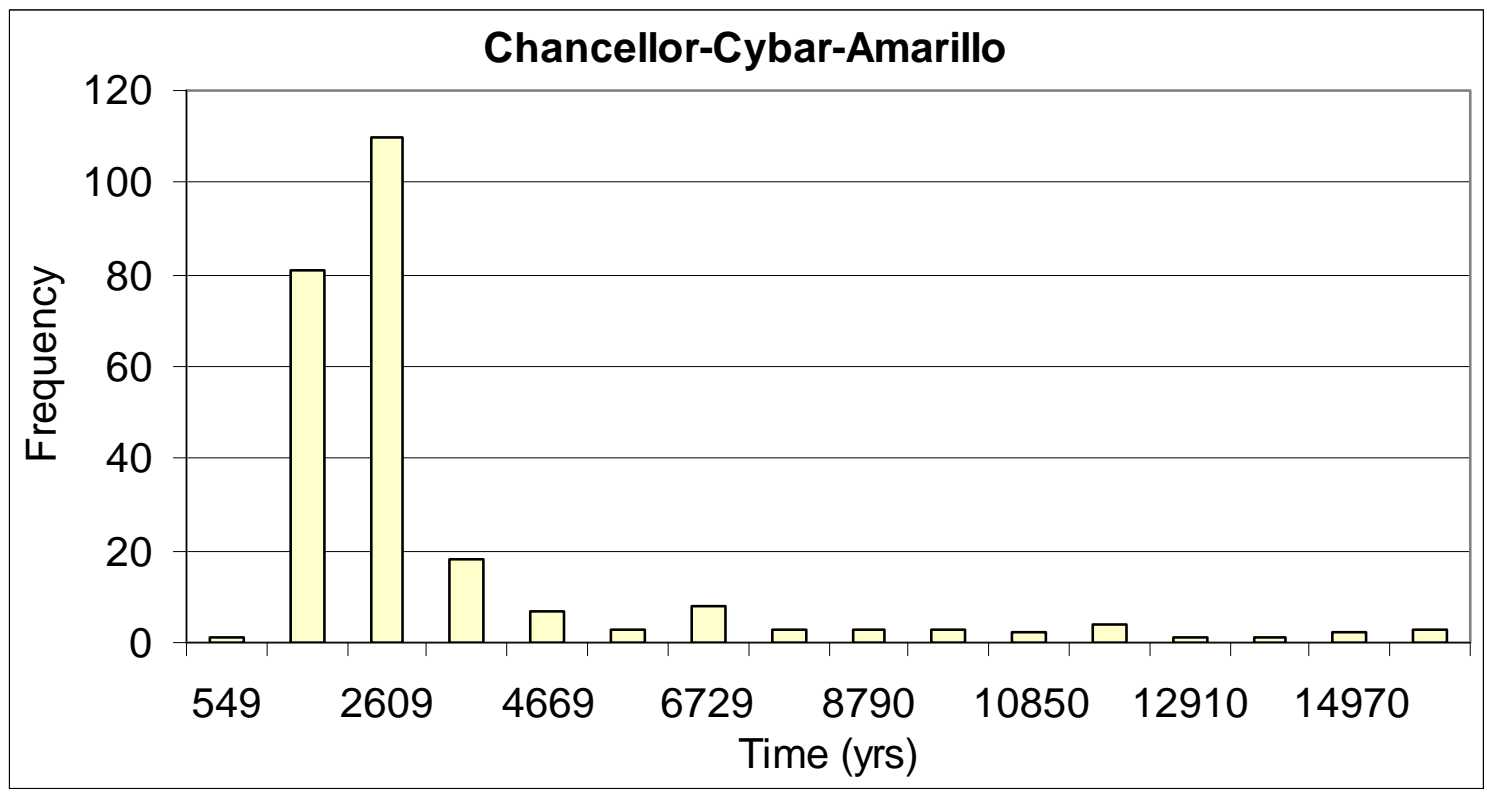

Figure C158: Distribution of minimum travel time from Chancellor-Cybar-Amarillo to YM boundaries based on effective-porosity Set 3 for 1998 scenario.

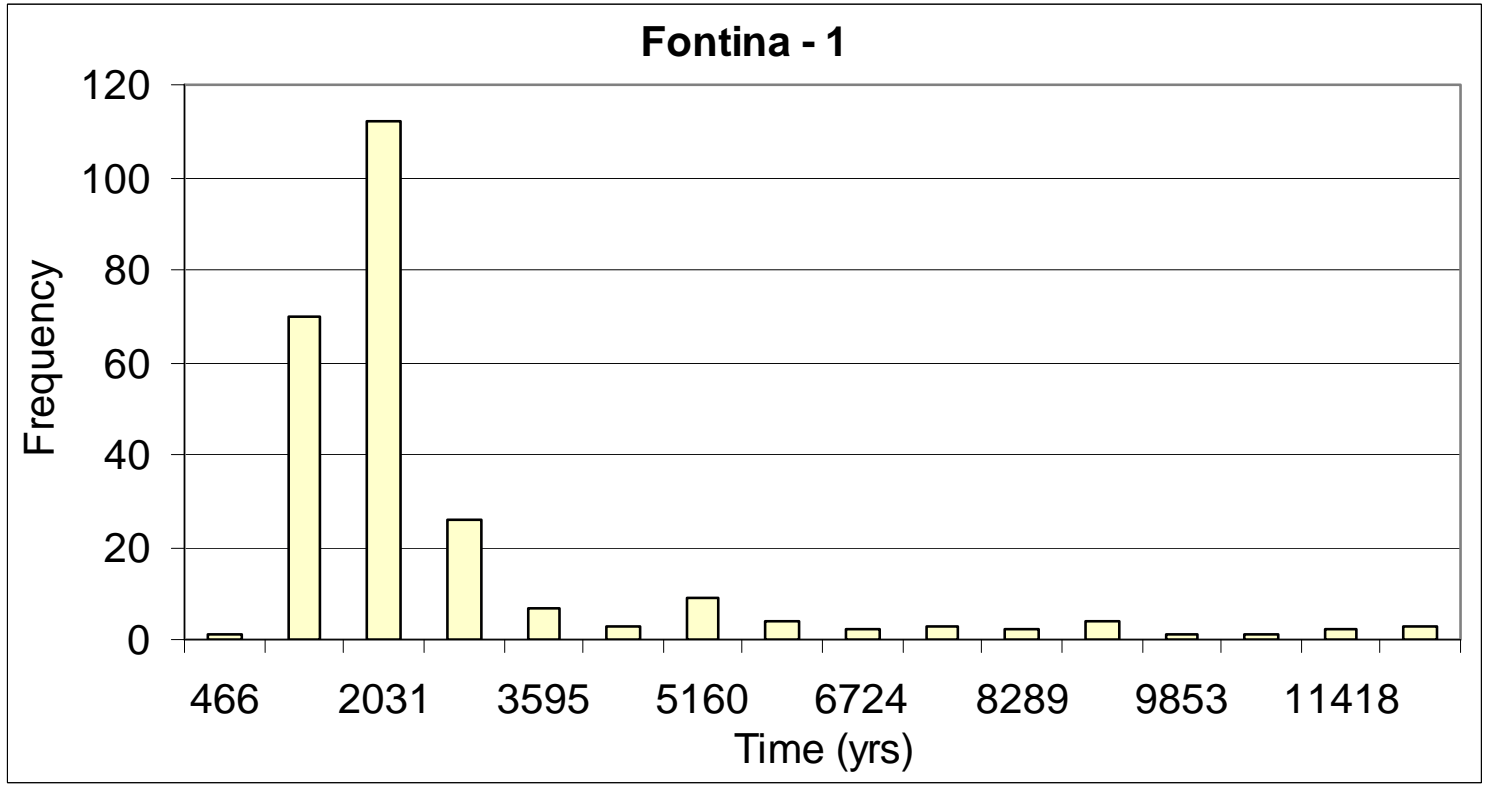

Figure C159: Distribution of minimum travel time from Fontina -1 to YM boundaries based on effective-porosity Set 3 for 1998 scenario. 


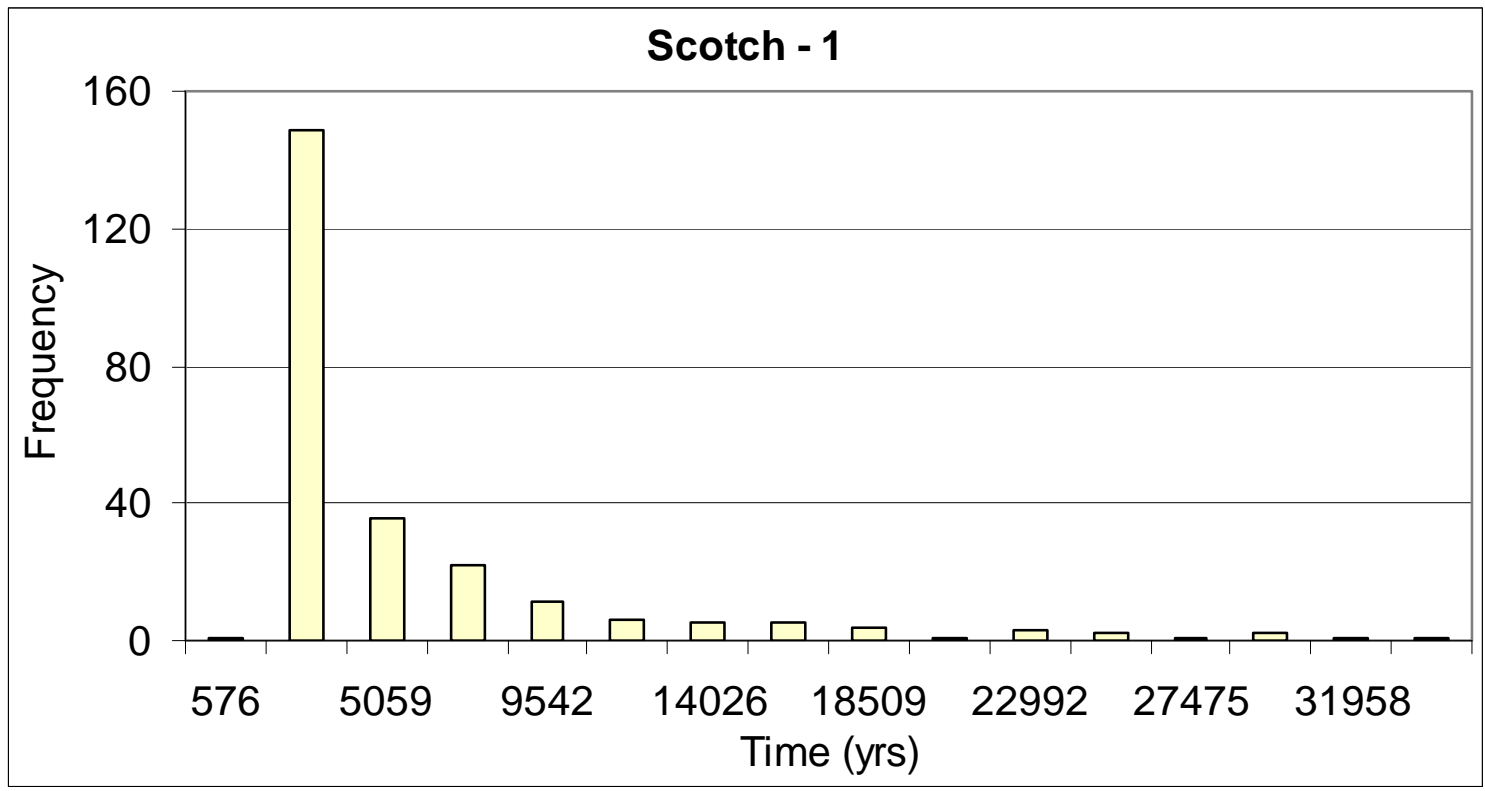

Figure C160: Distribution of minimum travel time from Scotch -1 to YM boundaries based on effective-porosity Set 3 for 1998 scenario.

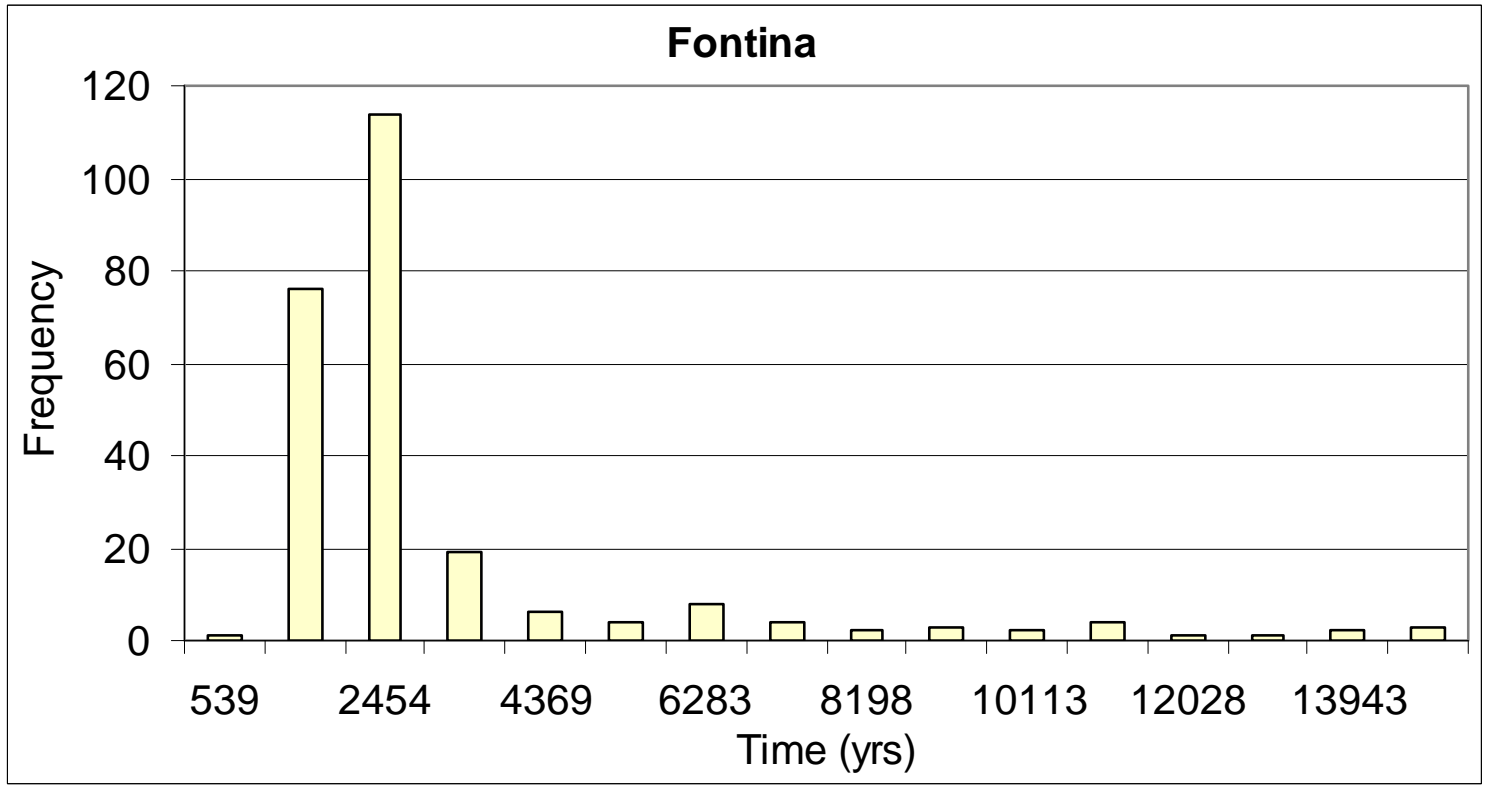

Figure C161: Distribution of minimum travel time from Fontina to YM boundaries based on effective-porosity Set 3 for 1998 scenario. 


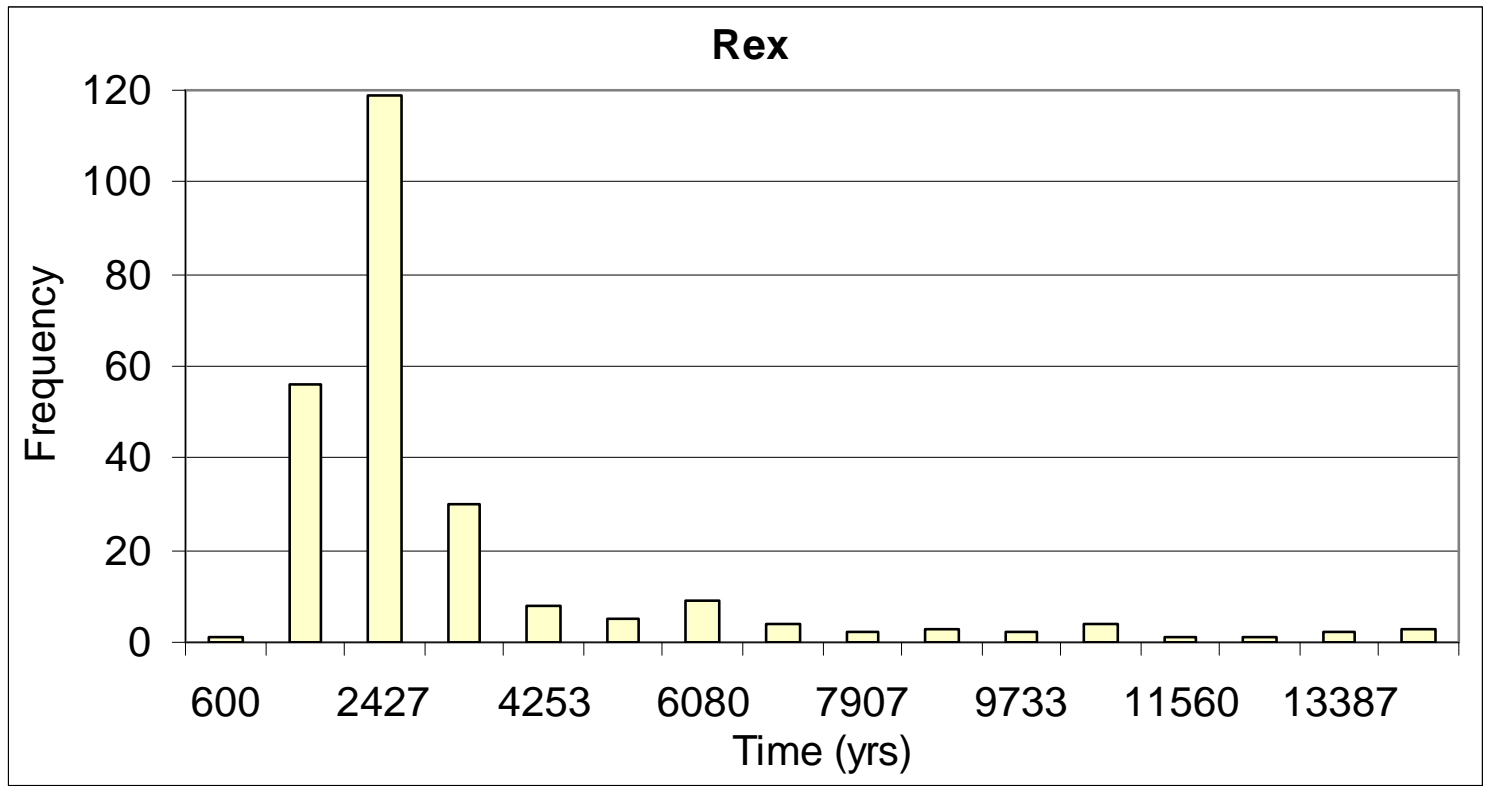

Figure C162: Distribution of minimum travel time from Rex to YM boundaries based on effective-porosity Set 3 for 1998 scenario.

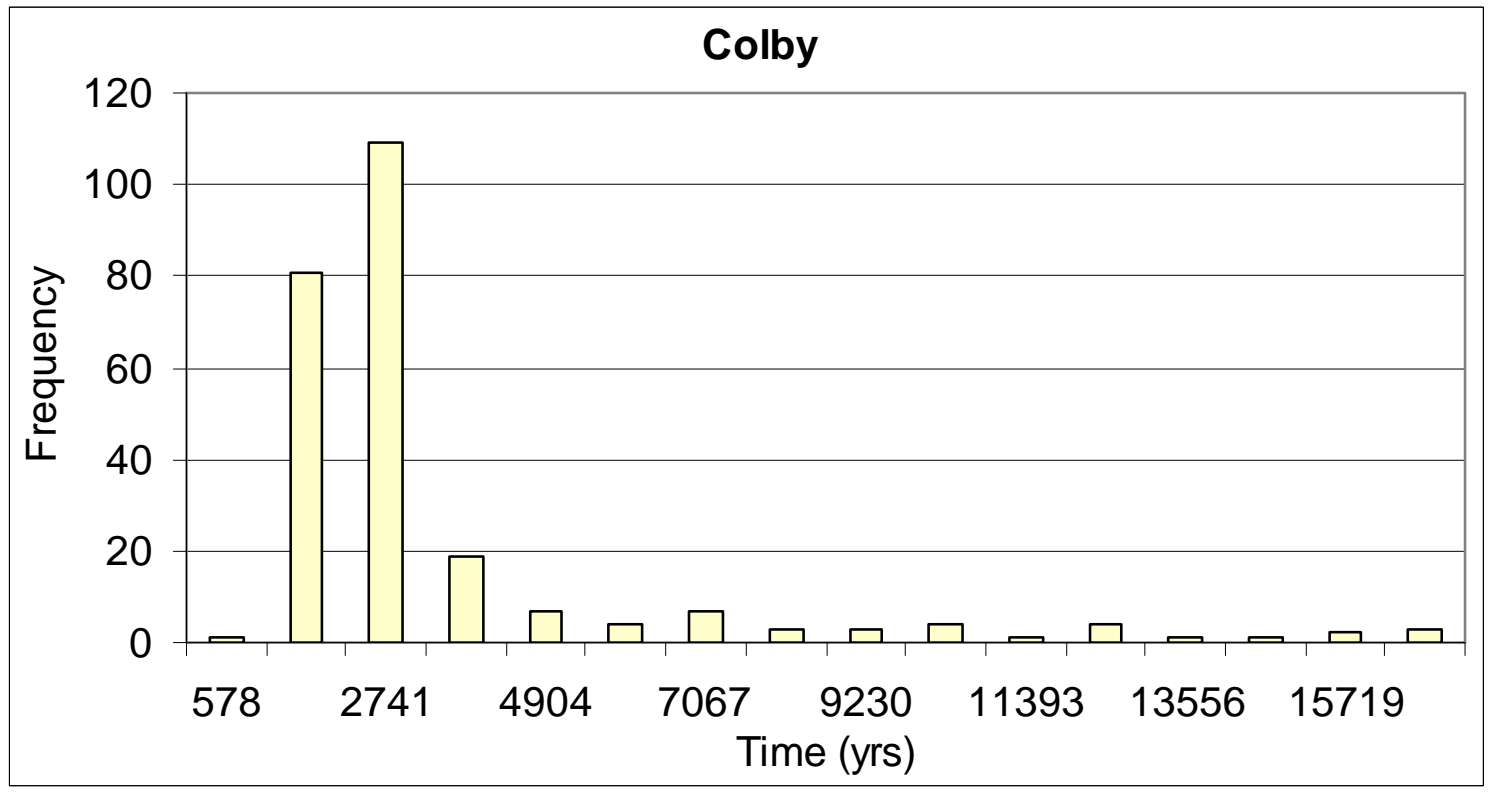

Figure C163: Distribution of minimum travel time from Colby to YM boundaries based on effective-porosity Set 3 for 1998 scenario. 


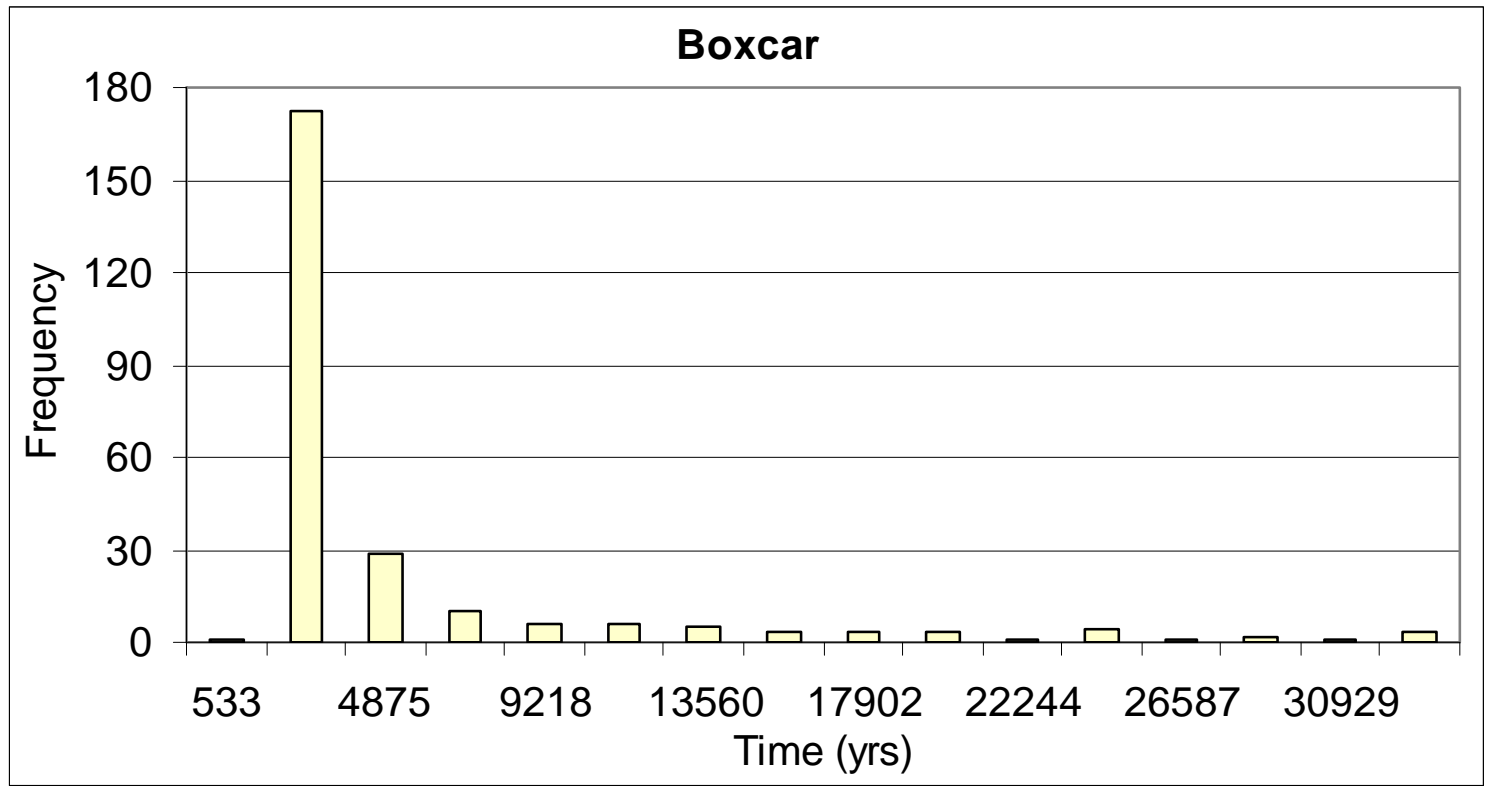

Figure C164: Distribution of minimum travel time from Boxcar to YM boundaries based on effective-porosity Set 3 for 1998 scenario.

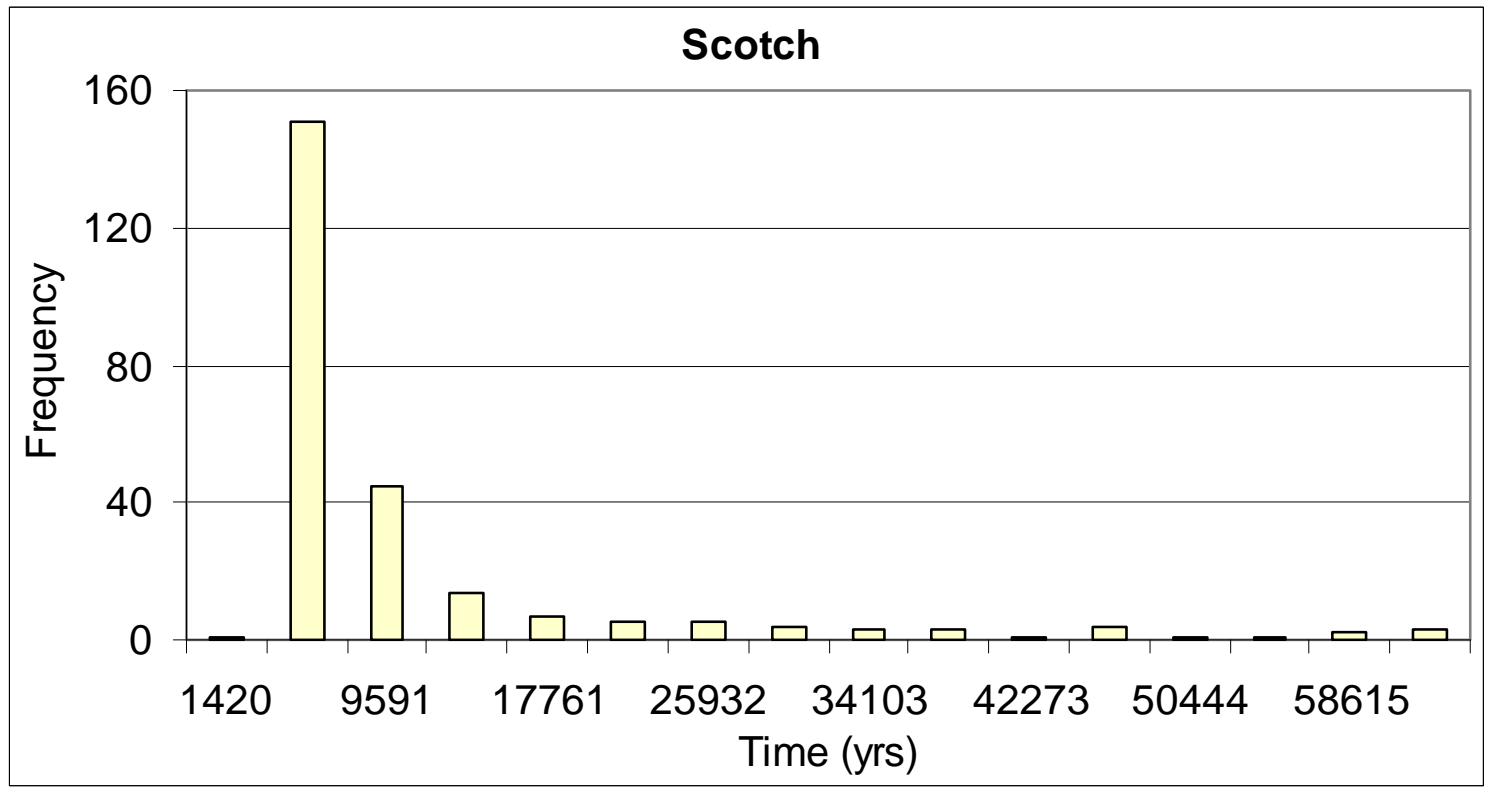

Figure C165: Distribution of minimum travel time from Scotch to YM boundaries based on effective-porosity Set 3 for 1998 scenario. 


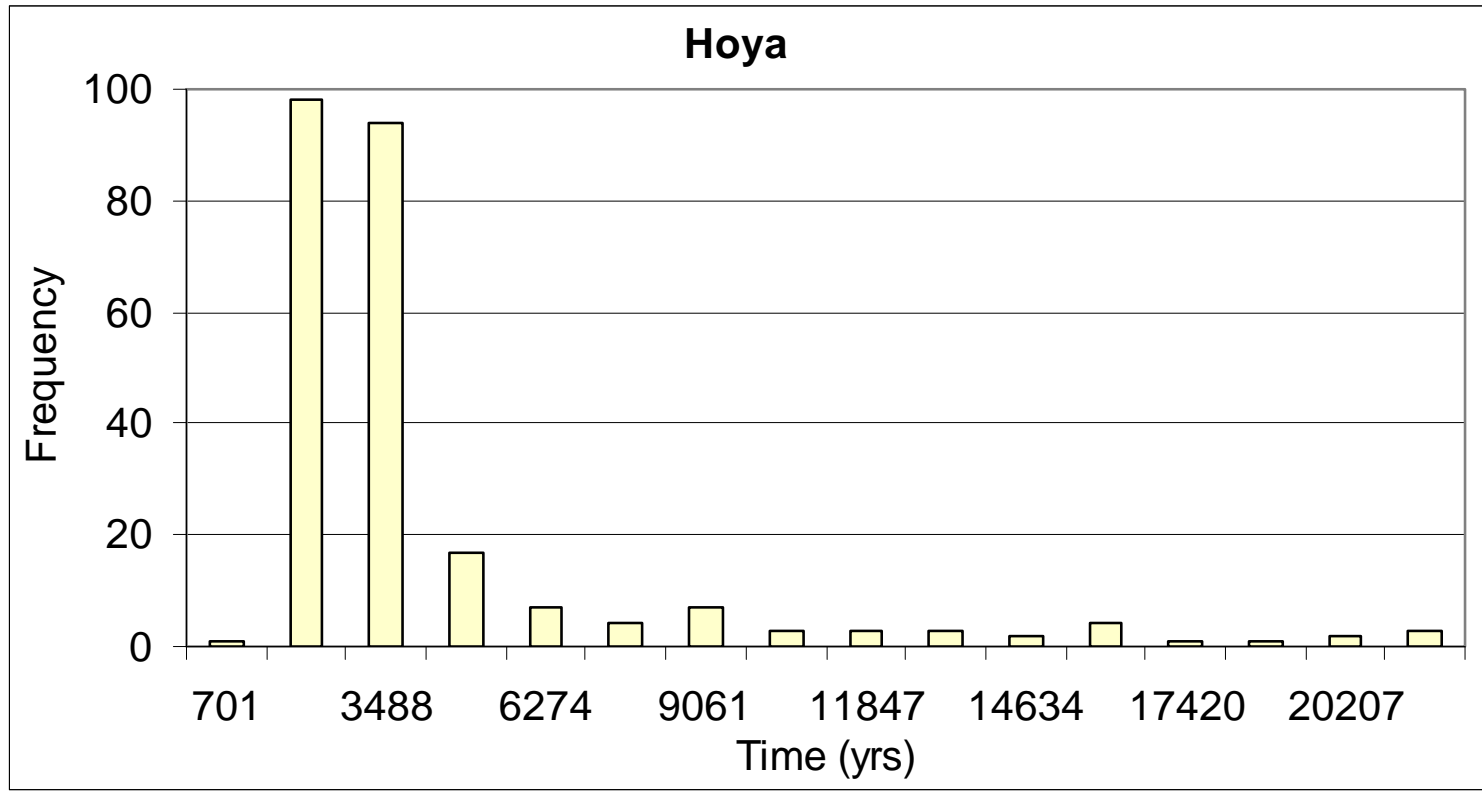

Figure C166: Distribution of minimum travel time from Hoya to YM boundaries based on effective-porosity Set 3 for 1998 scenario.

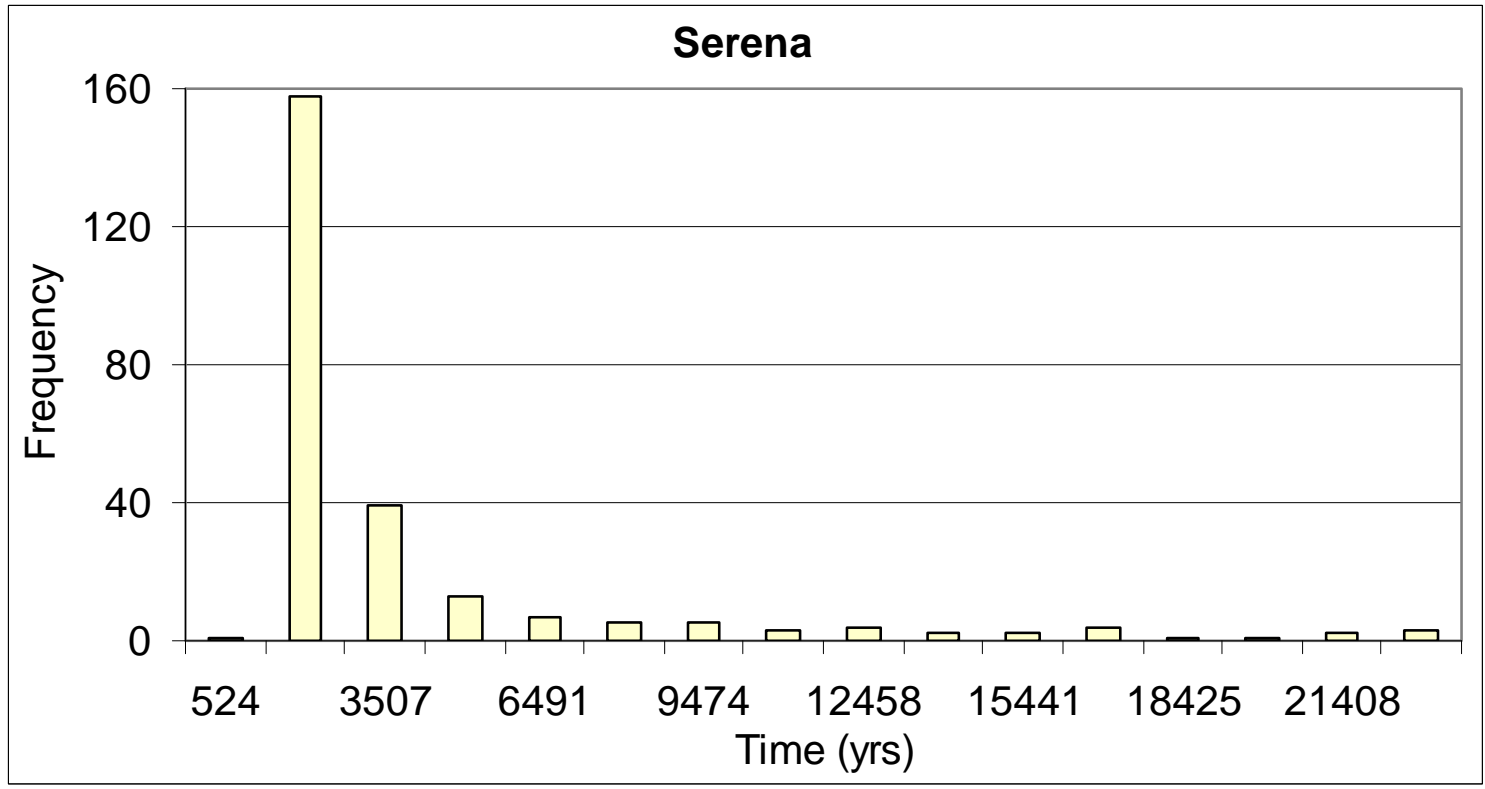

Figure C167: Distribution of minimum travel time from Serena to YM boundaries based on effective-porosity Set 3 for 1998 scenario. 


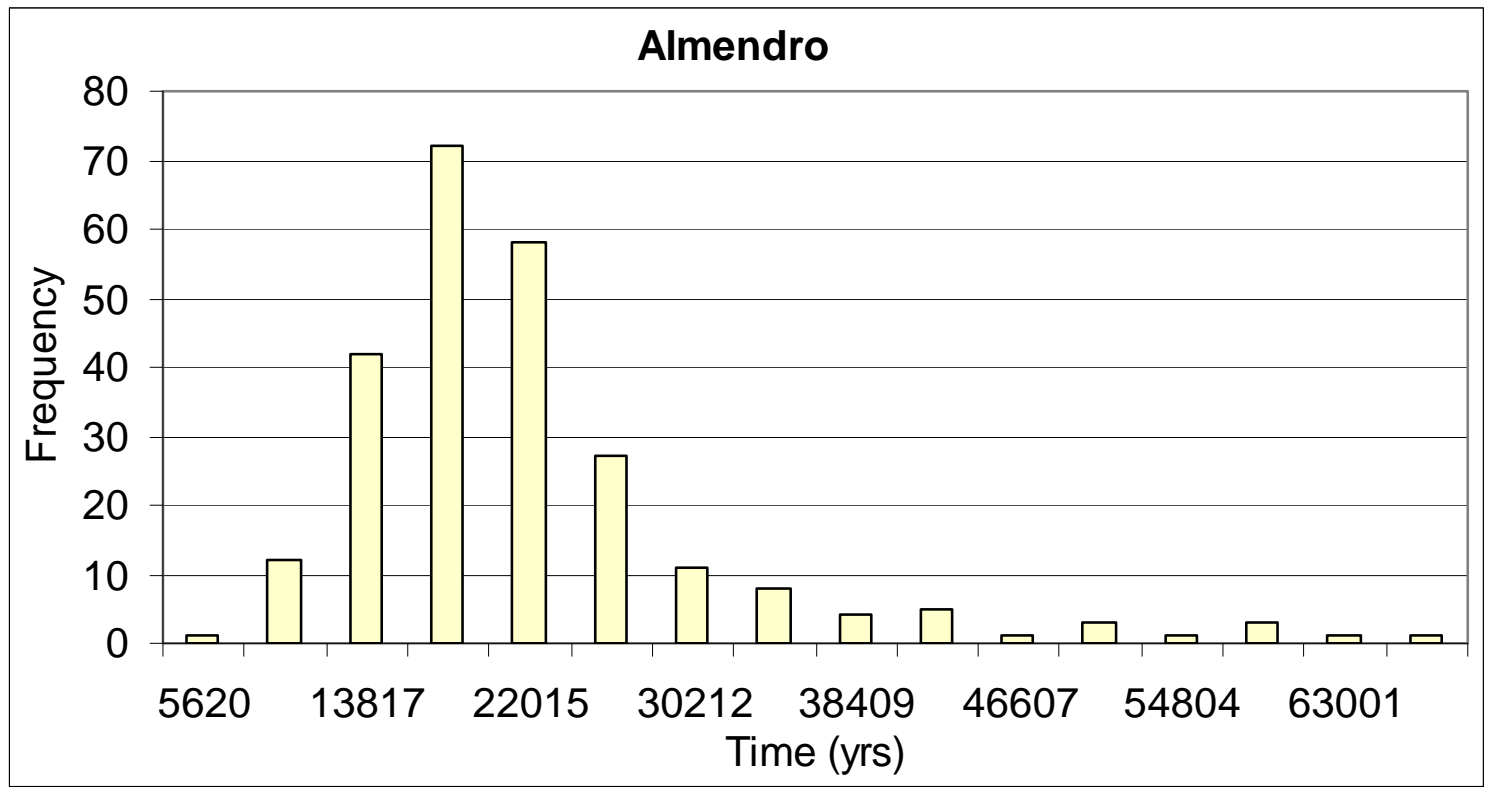

Figure C168: Distribution of minimum travel time from Almendro to YM boundaries based on effective-porosity Set 3 for 1998 scenario.

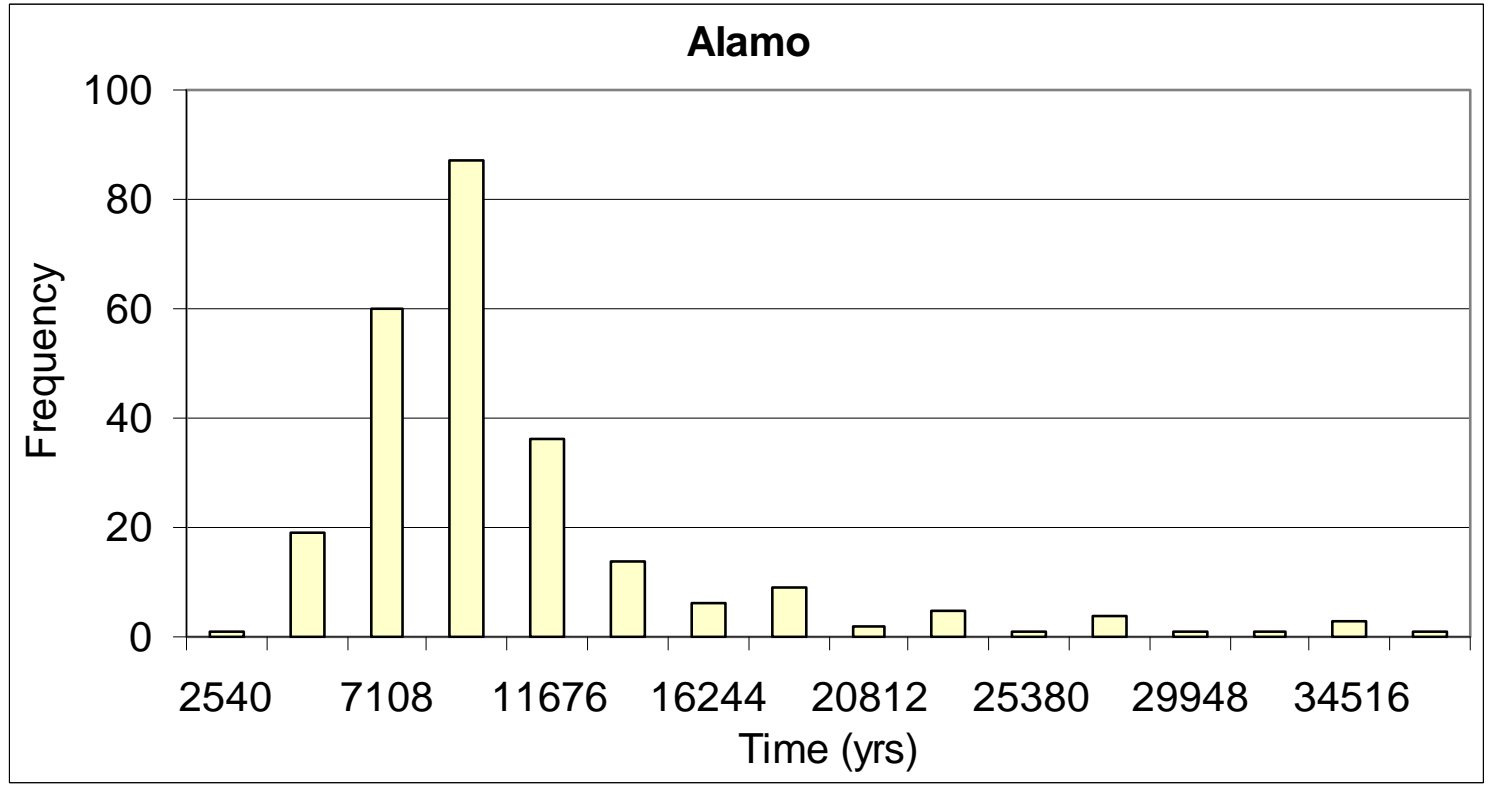

Figure C169: Distribution of minimum travel time from Alamo to YM boundaries based on effective-porosity Set 3 for 1998 scenario. 


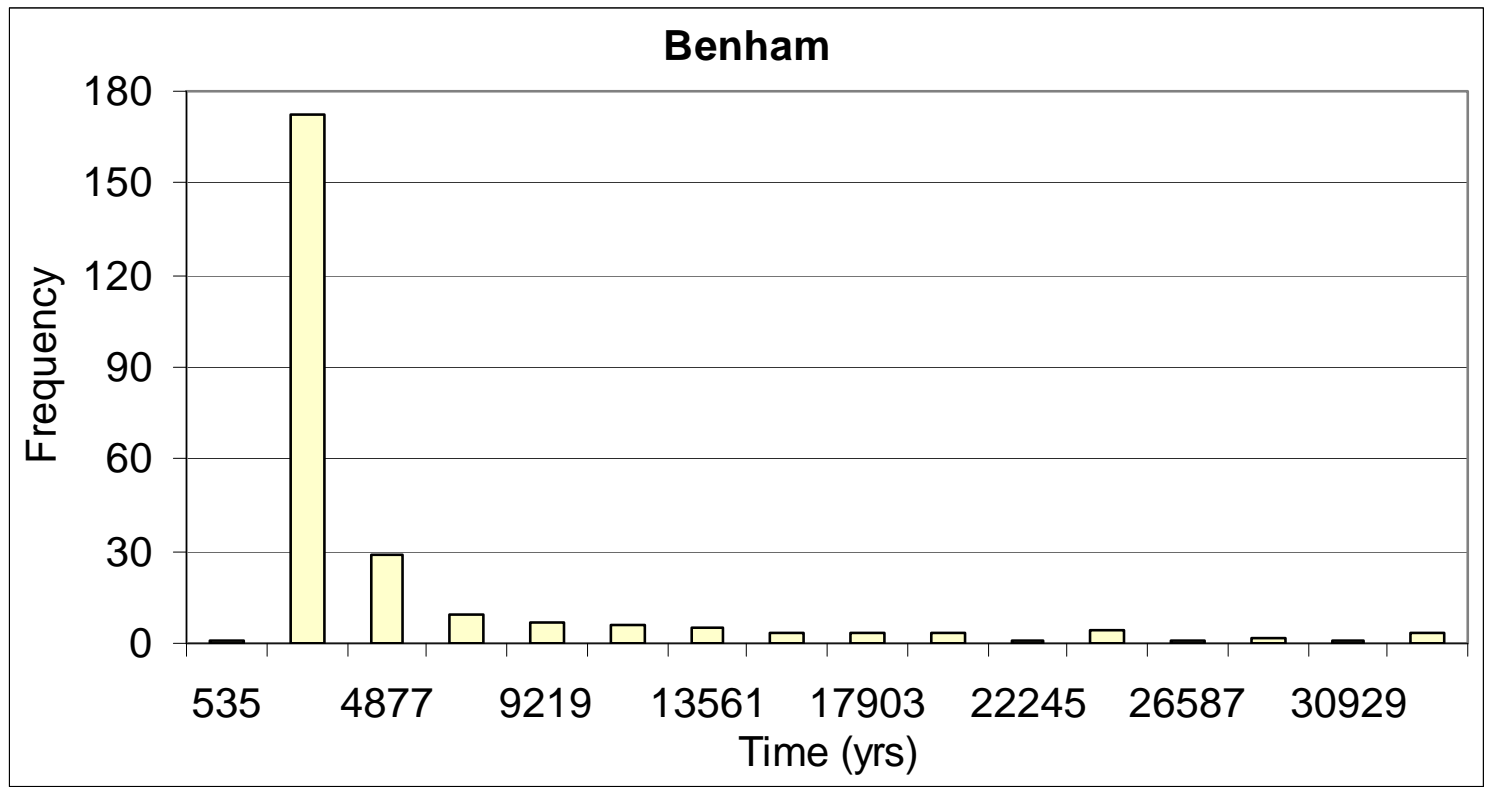

Figure C170: Distribution of minimum travel time from Benham to YM boundaries based on effective-porosity Set 3 for 1998 scenario.

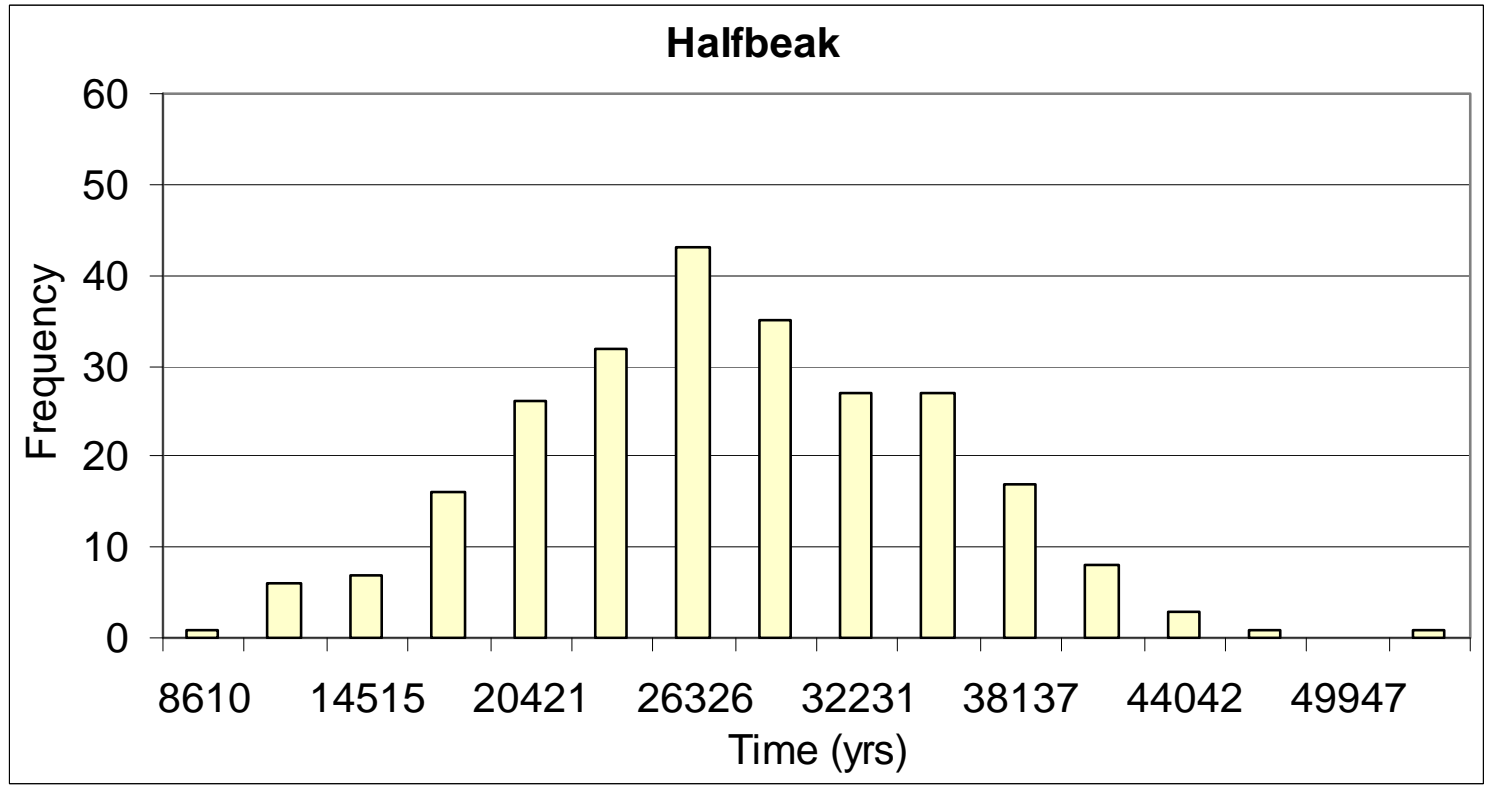

Figure C171: Distribution of minimum travel time from Halfbeak to YM boundaries based on effective-porosity Set 3 for 1998 scenario. 


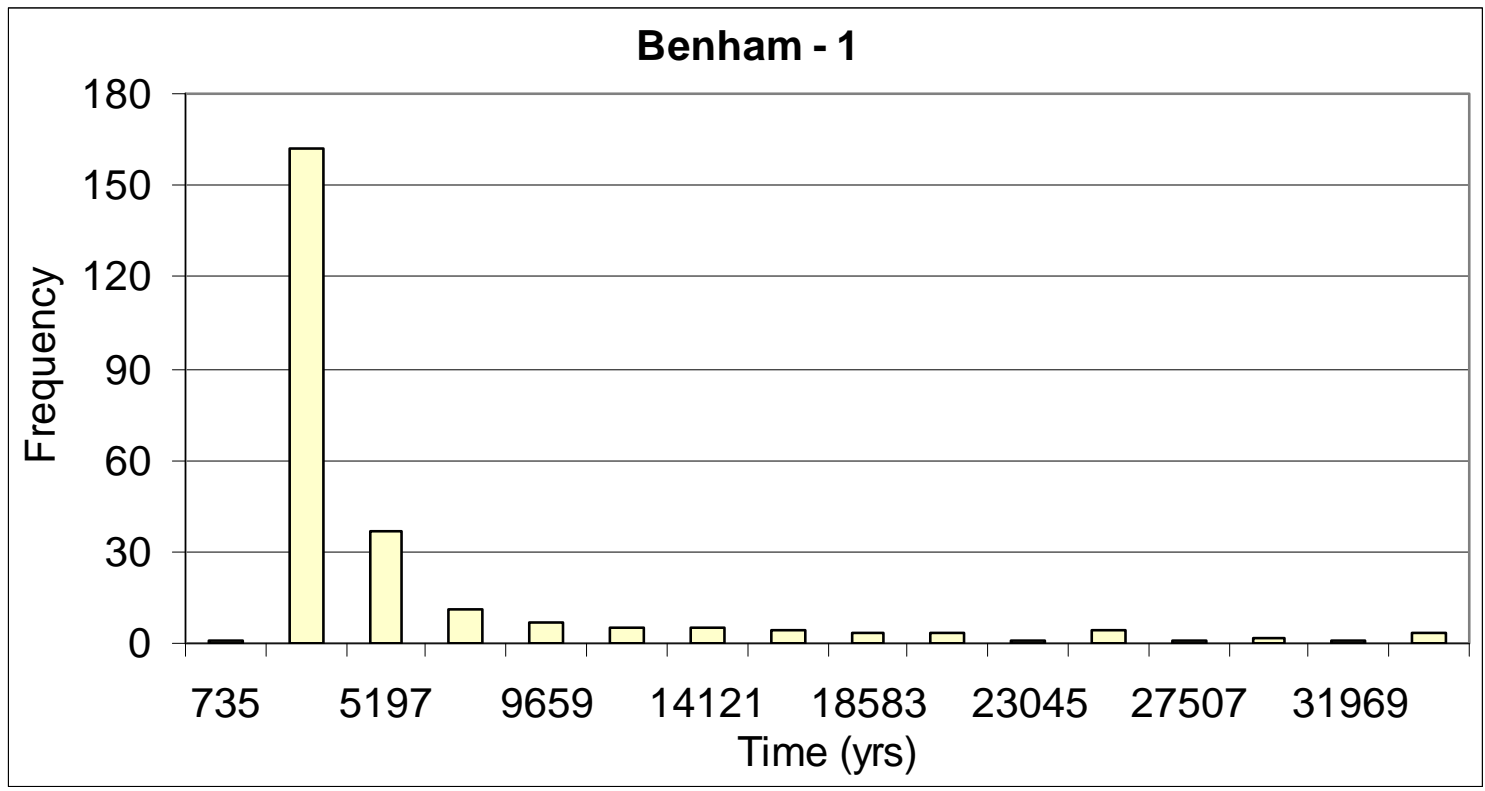

Figure C172: Distribution of minimum travel time from Benham -1 to YM boundaries based on effective-porosity Set 3 for 1998 scenario.

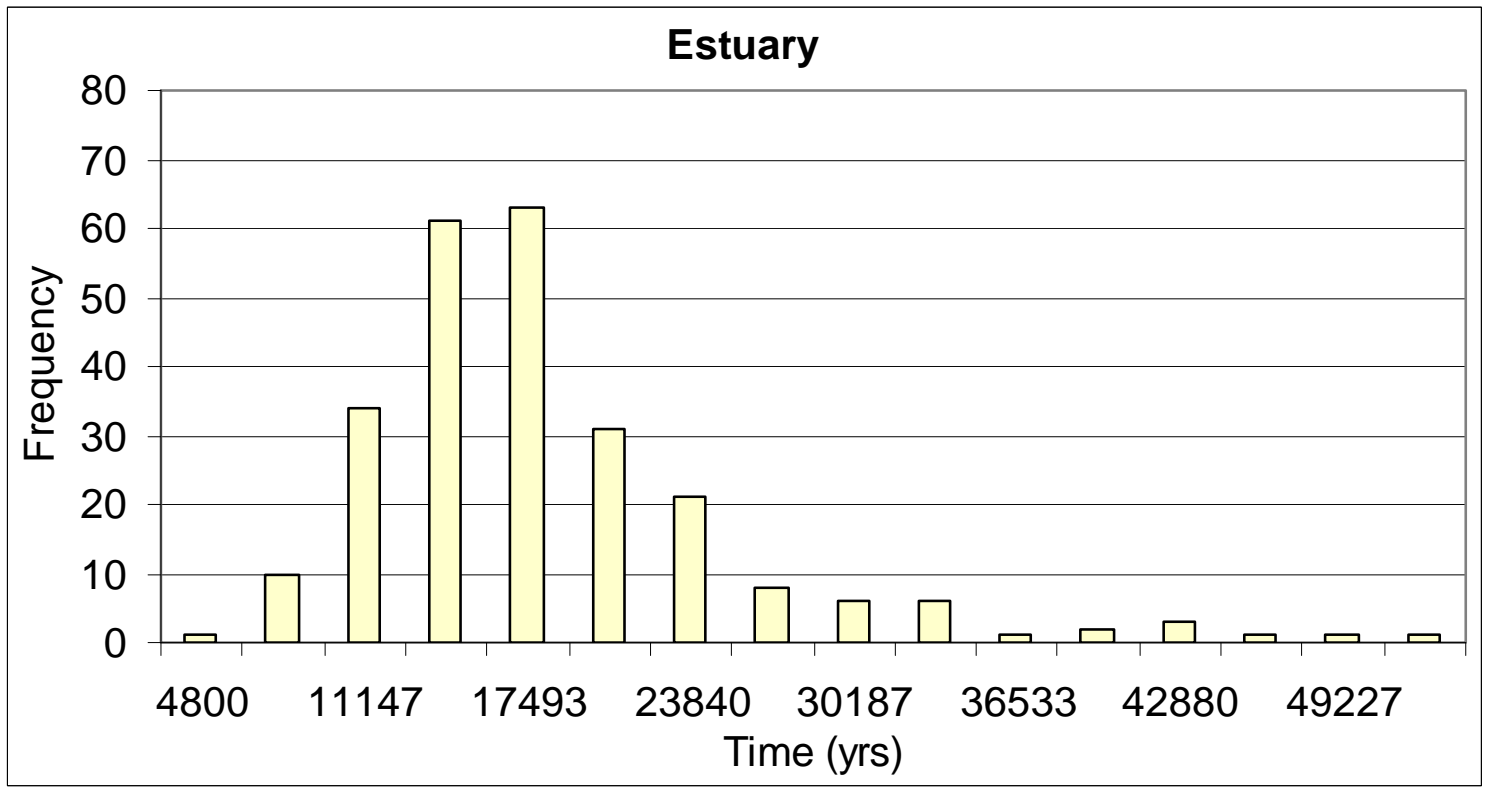

Figure C173: Distribution of minimum travel time from Estuary to YM boundaries based on effective-porosity Set 3 for 1998 scenario. 


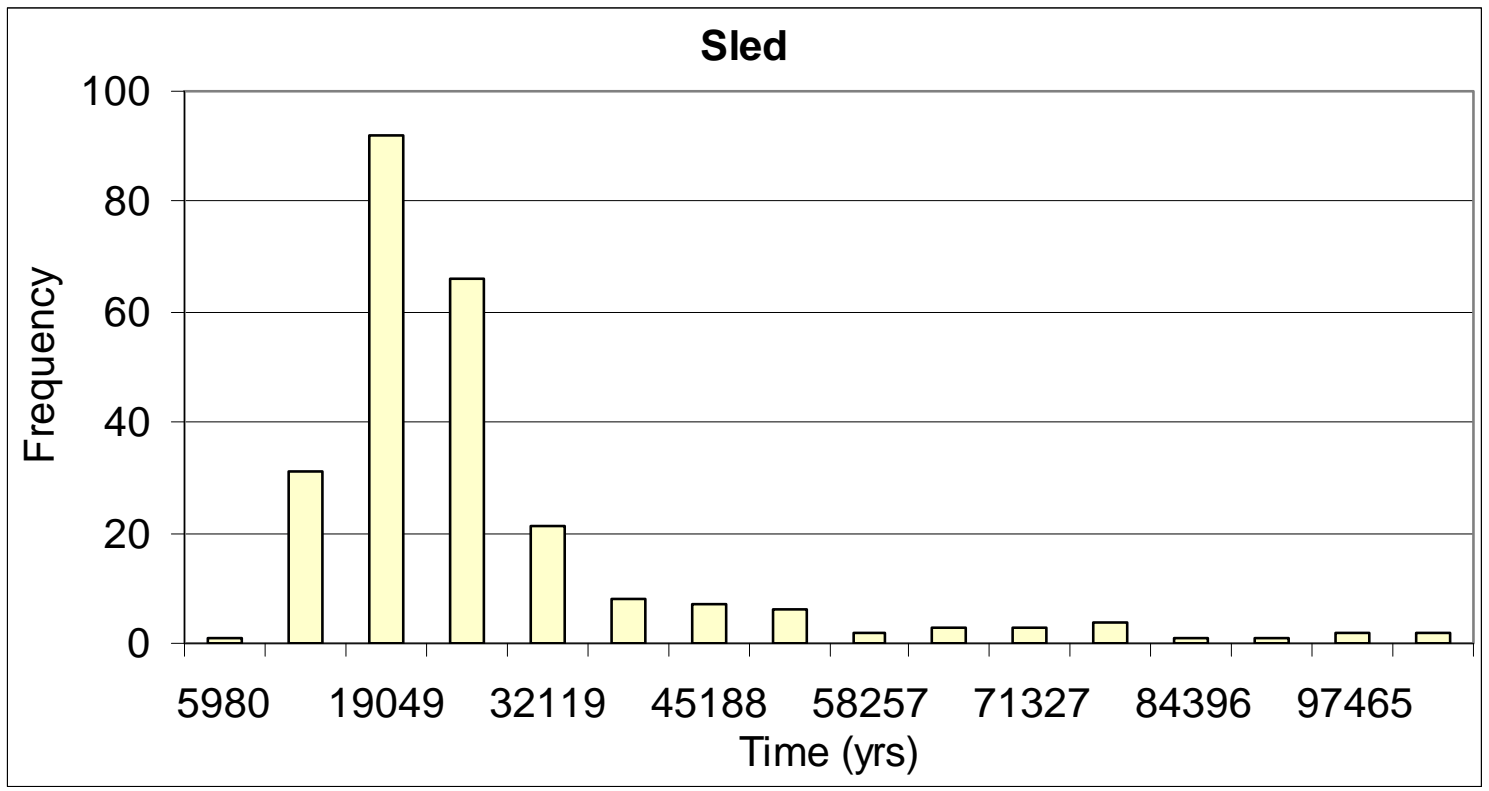

Figure C174: Distribution of minimum travel time from Sled to YM boundaries based on effective-porosity Set 3 for 1998 scenario.

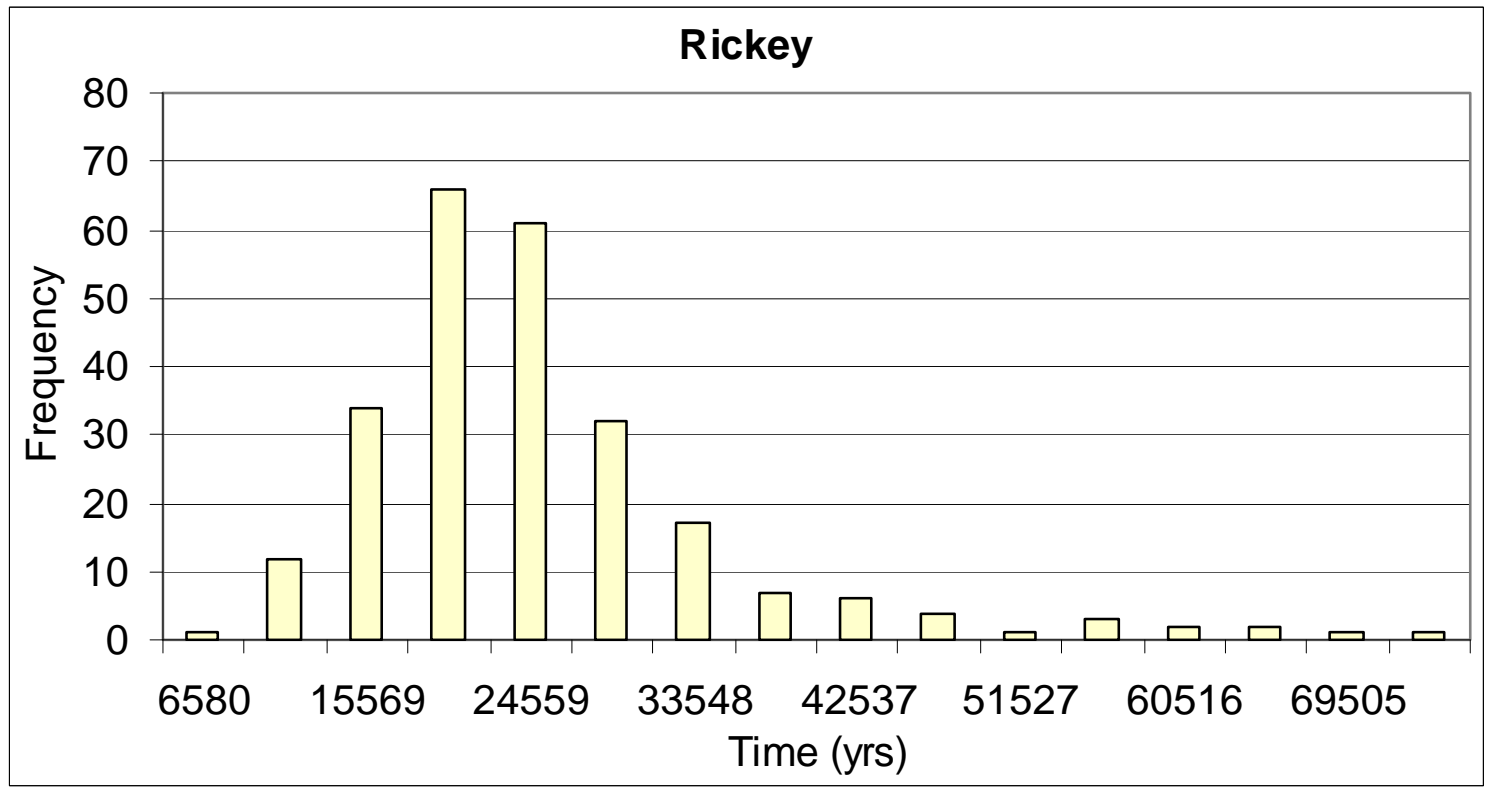

Figure C175: Distribution of minimum travel time from Rickey to YM boundaries based on effective-porosity Set 3 for 1998 scenario. 


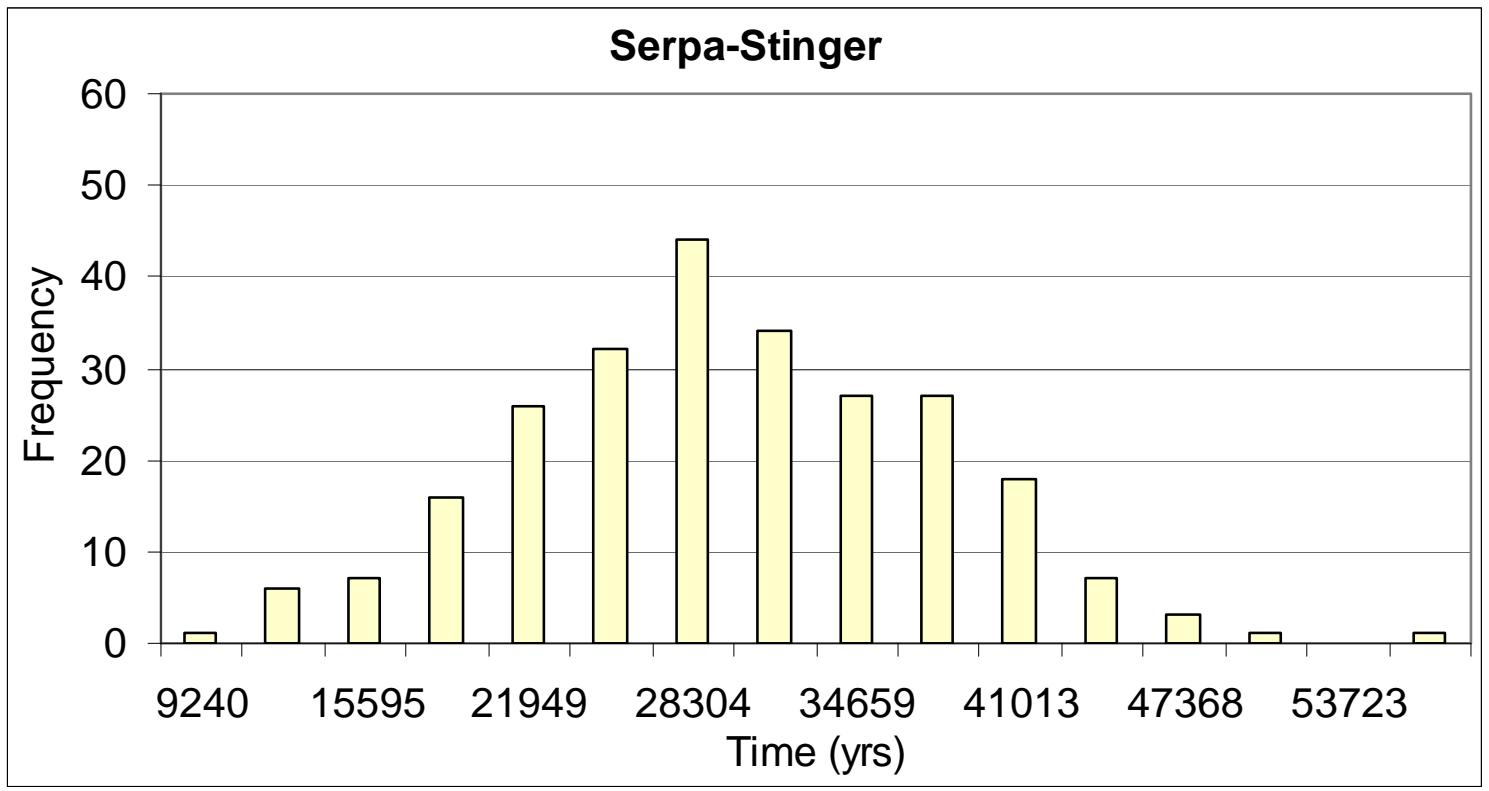

Figure C176: Distribution of minimum travel time from Serpa-Stinger to YM boundaries based on effective-porosity Set 3 for 1998 scenario.

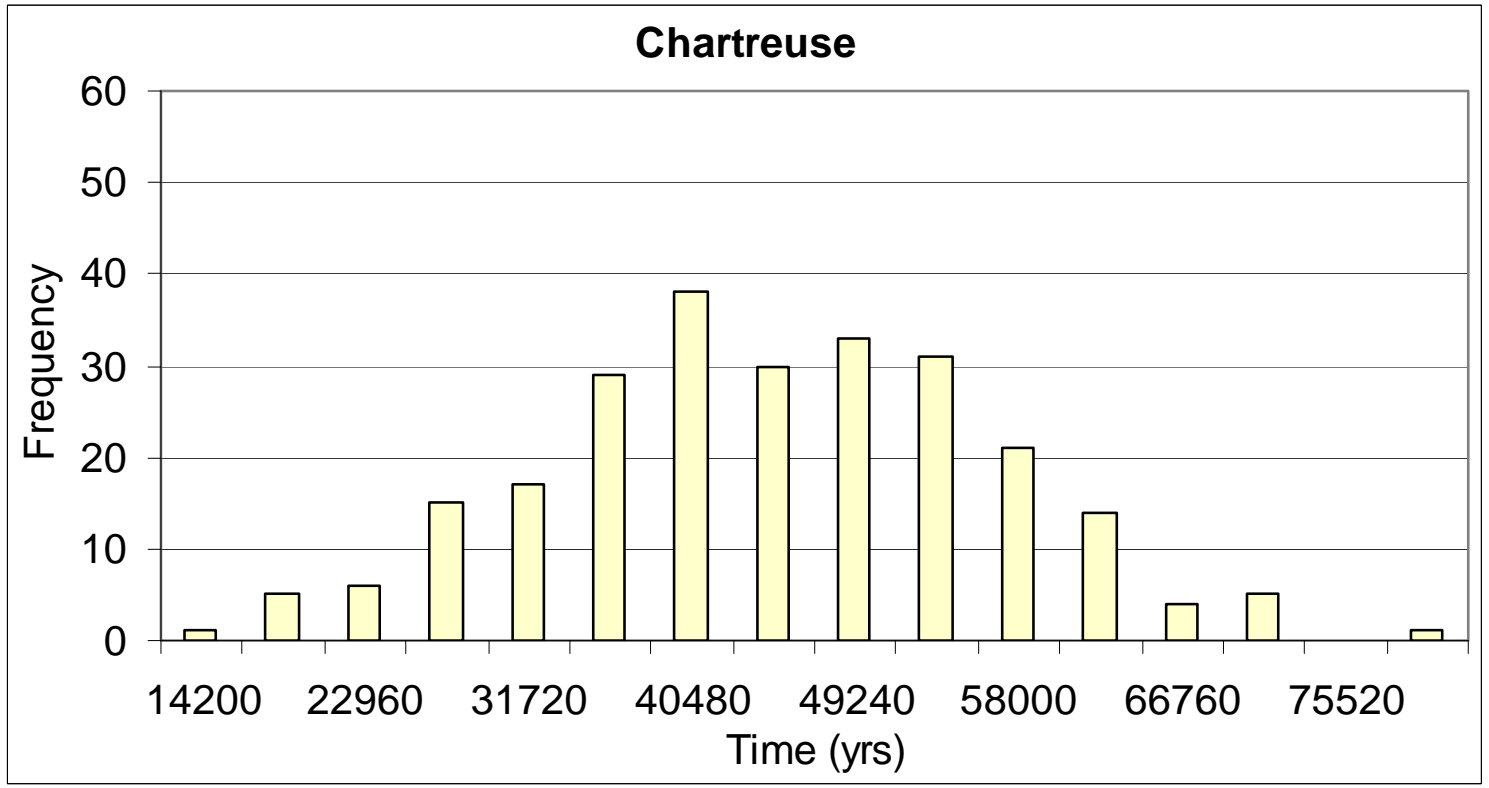

Figure C177: Distribution of minimum travel time from Chartreuse to YM boundaries based on effective-porosity Set 3 for 1998 scenario. 


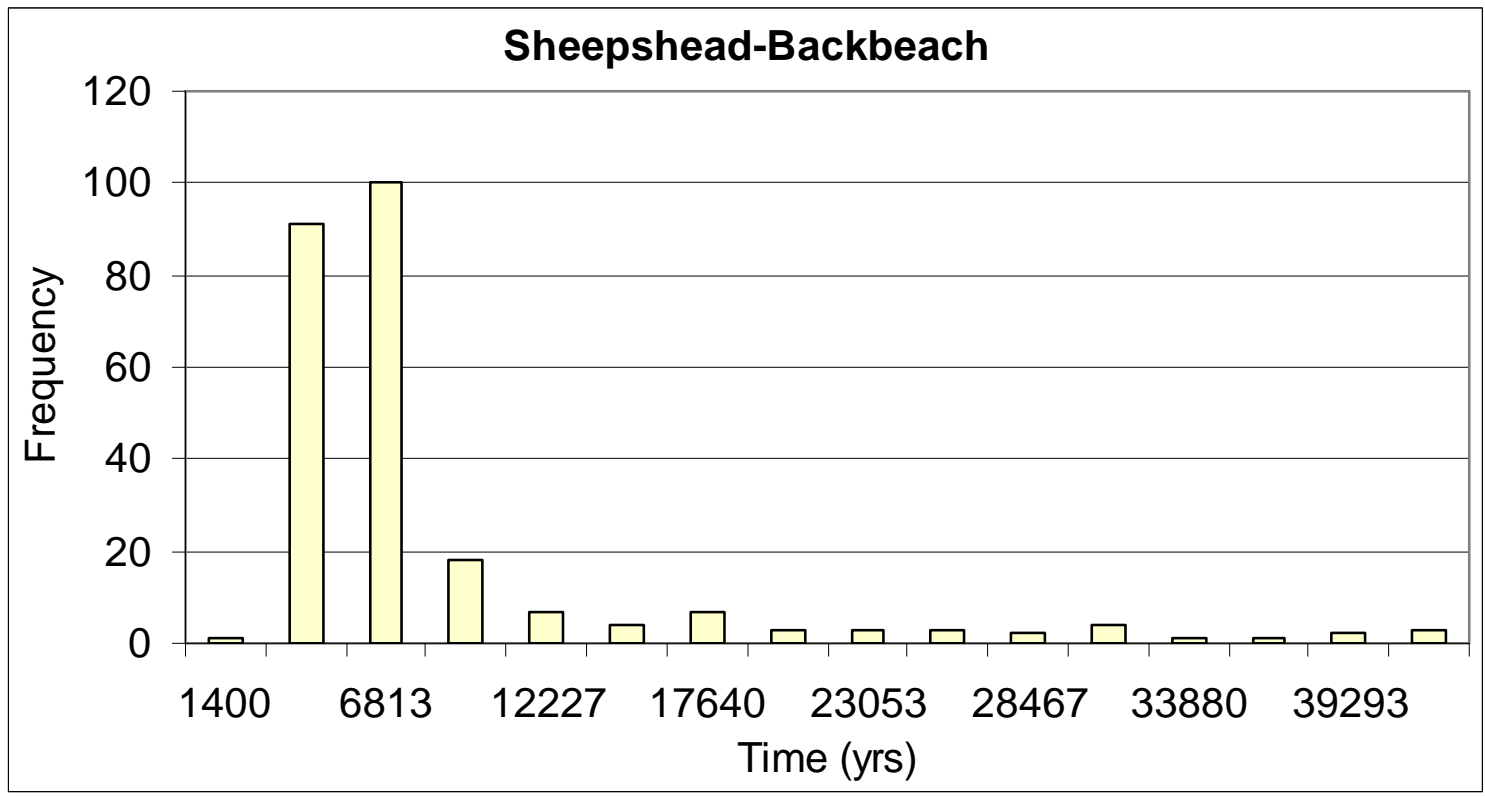

Figure C178: Distribution of minimum travel time from Sheepshead-Backbeach to YM boundaries based on effective-porosity Set 3 for 1998 scenario.

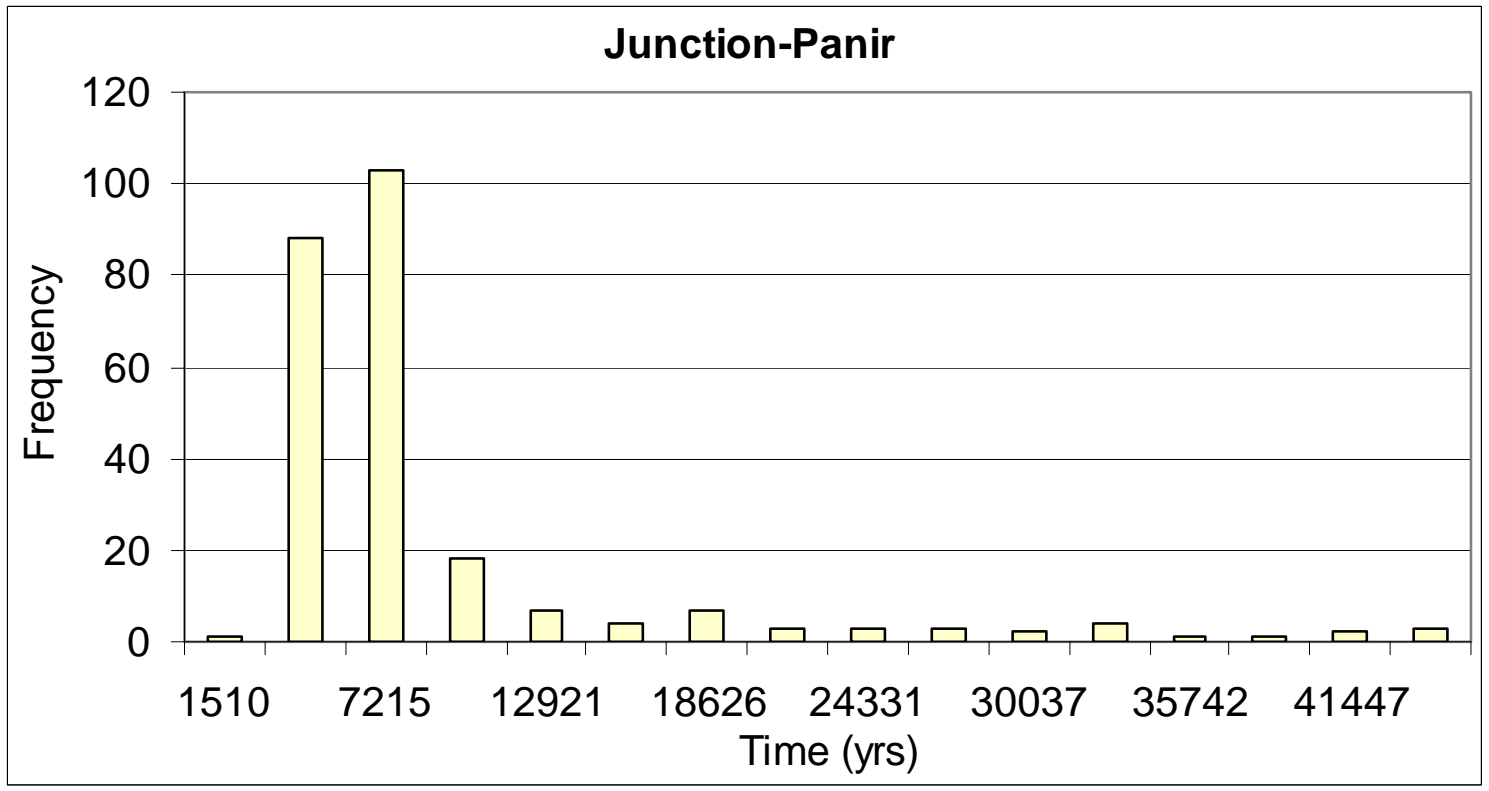

Figure C179: Distribution of minimum travel time from Junction-Panir to YM boundaries based on effective-porosity Set 3 for 1998 scenario. 


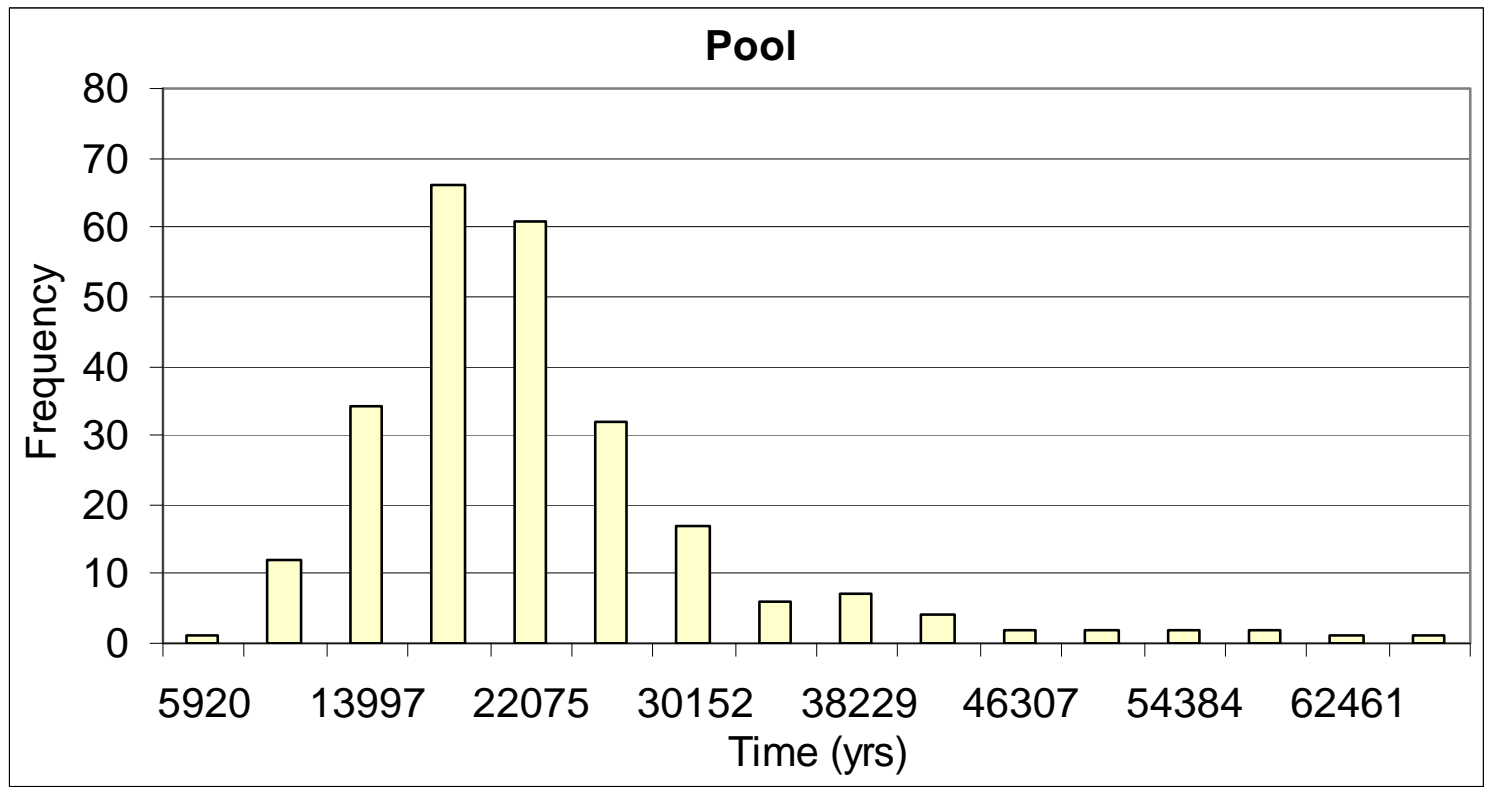

Figure C180: Distribution of minimum travel time from Pool to YM boundaries based on effective-porosity Set 3 for 1998 scenario.

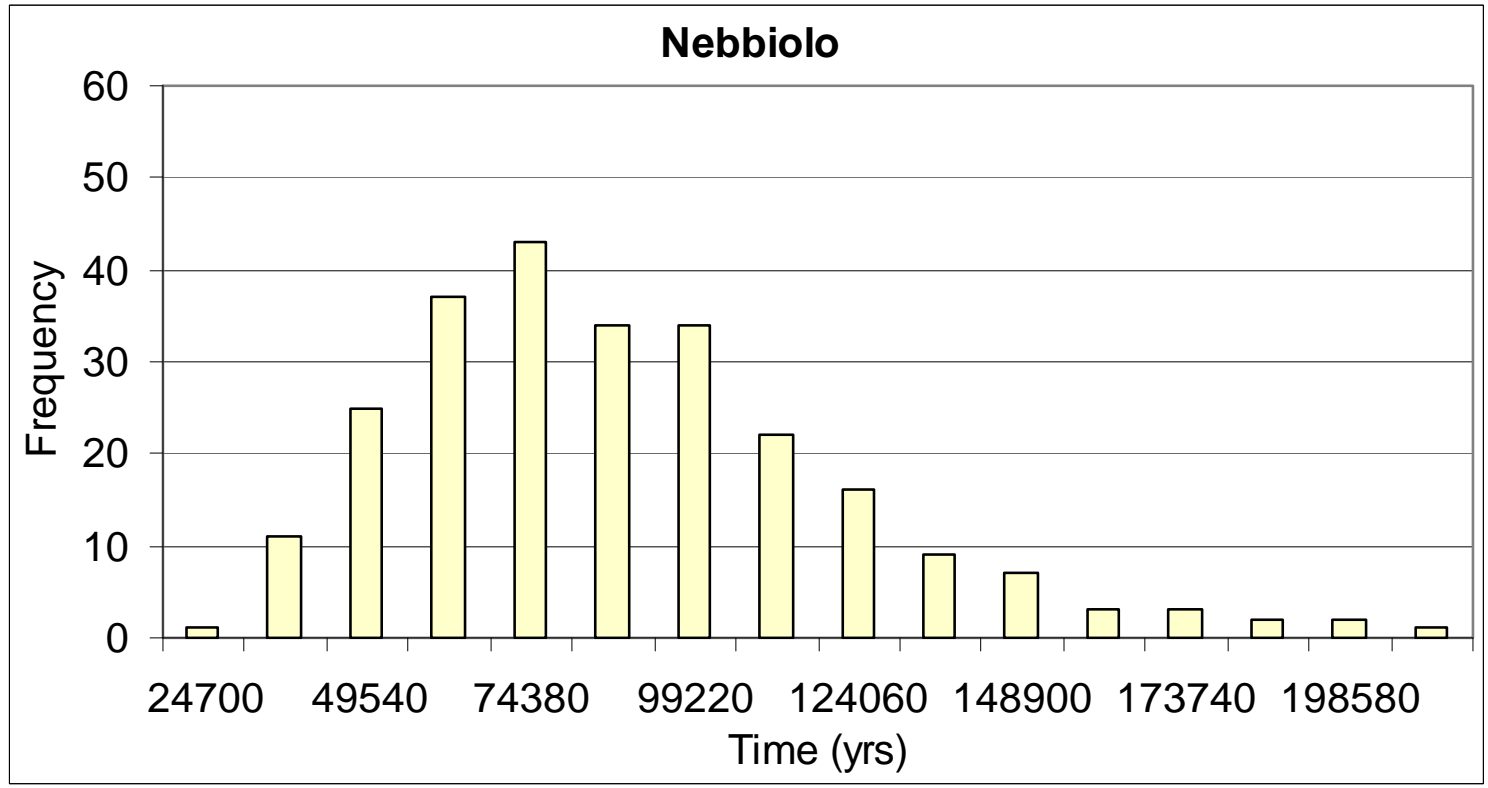

Figure C181: Distribution of minimum travel time from Nebbiolo to YM boundaries based on effective-porosity Set 3 for 1998 scenario. 


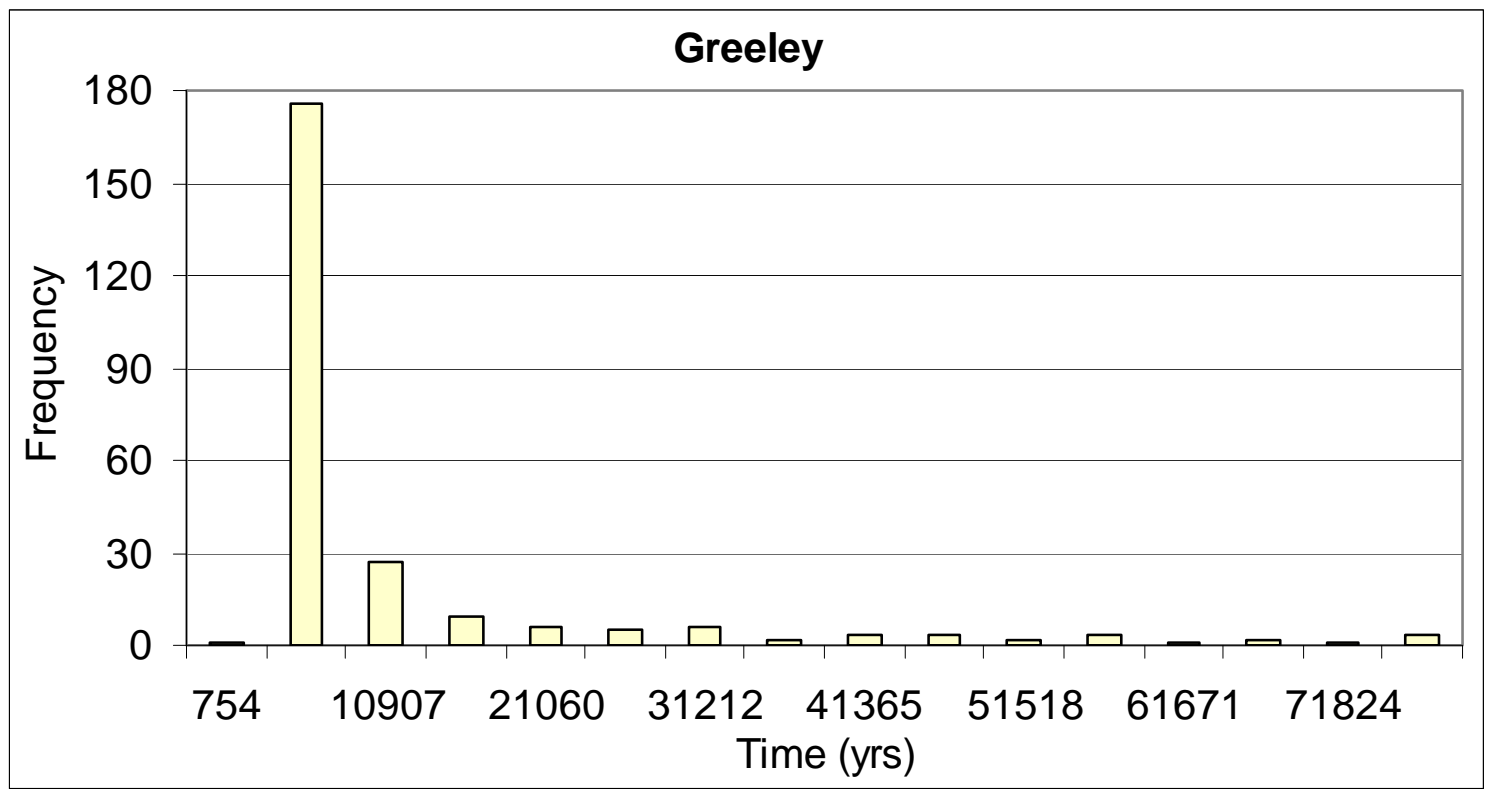

Figure C182: Distribution of minimum travel time from Greenley to YM boundaries based on effective-porosity Set 3 for 1998 scenario.

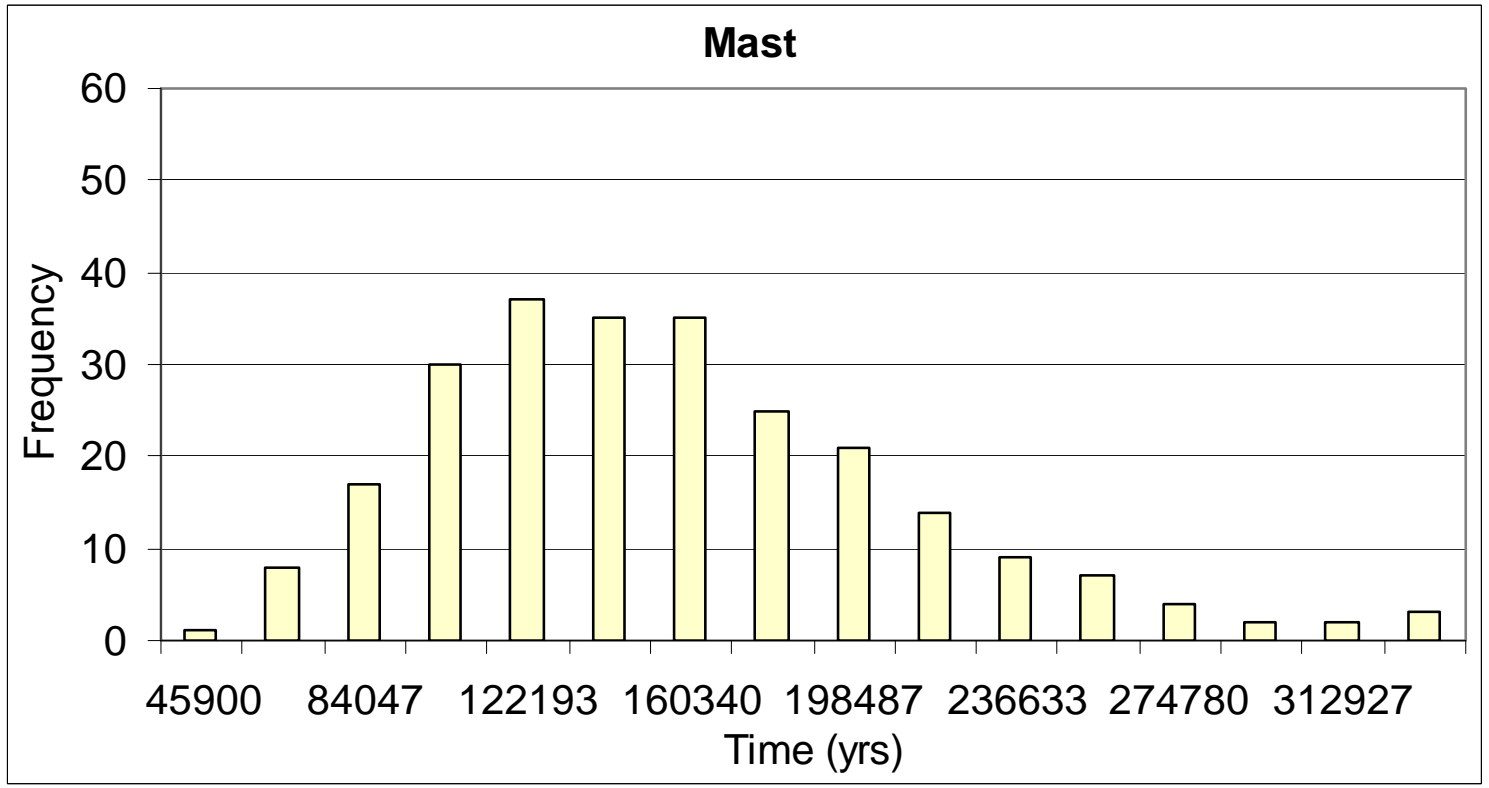

Figure C183: Distribution of minimum travel time from Mast to YM boundaries based on effective-porosity Set 3 for 1998 scenario. 


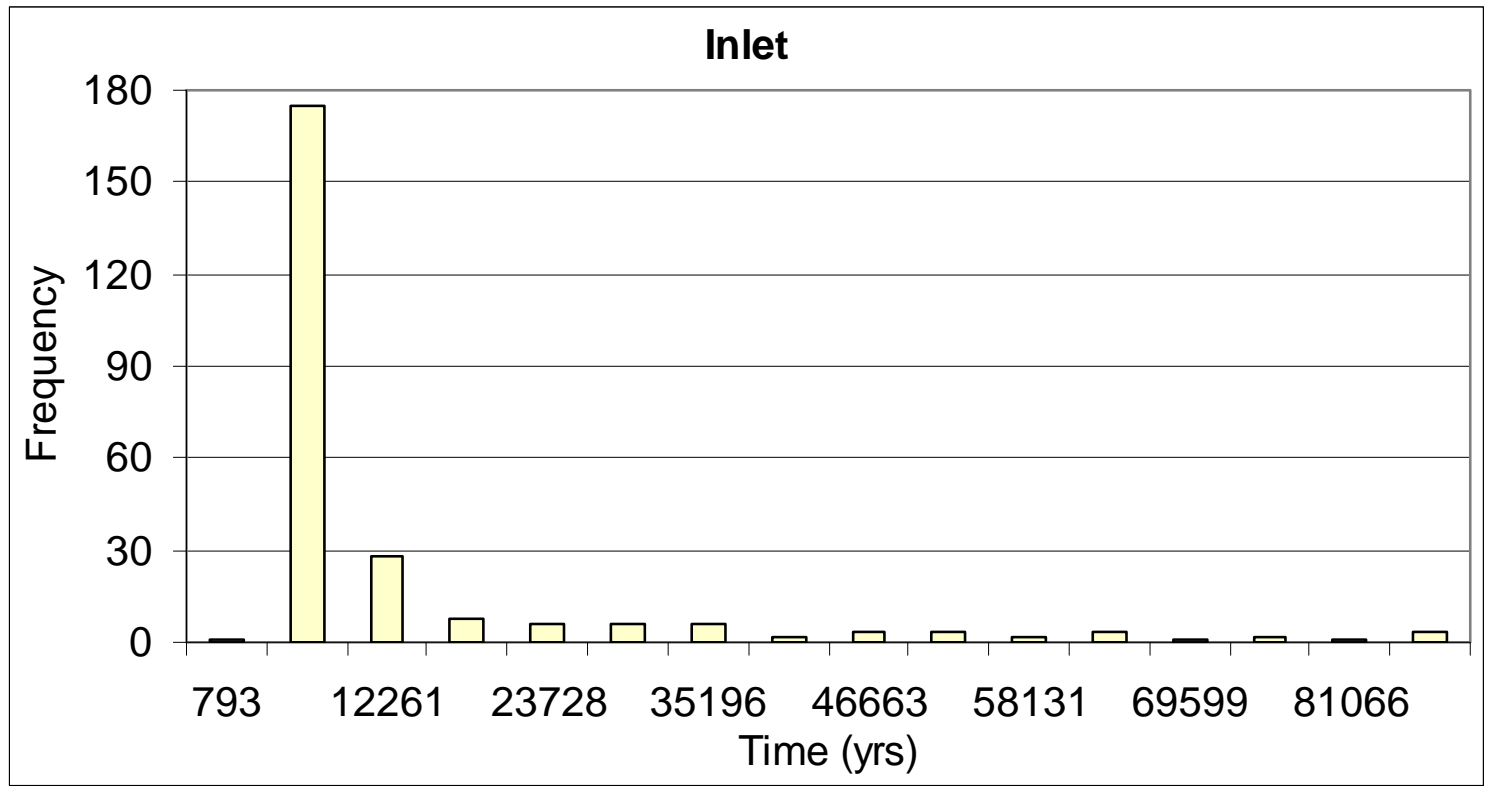

Figure C184: Distribution of minimum travel time from Inlet to YM boundaries based on effective-porosity Set 3 for 1998 scenario.

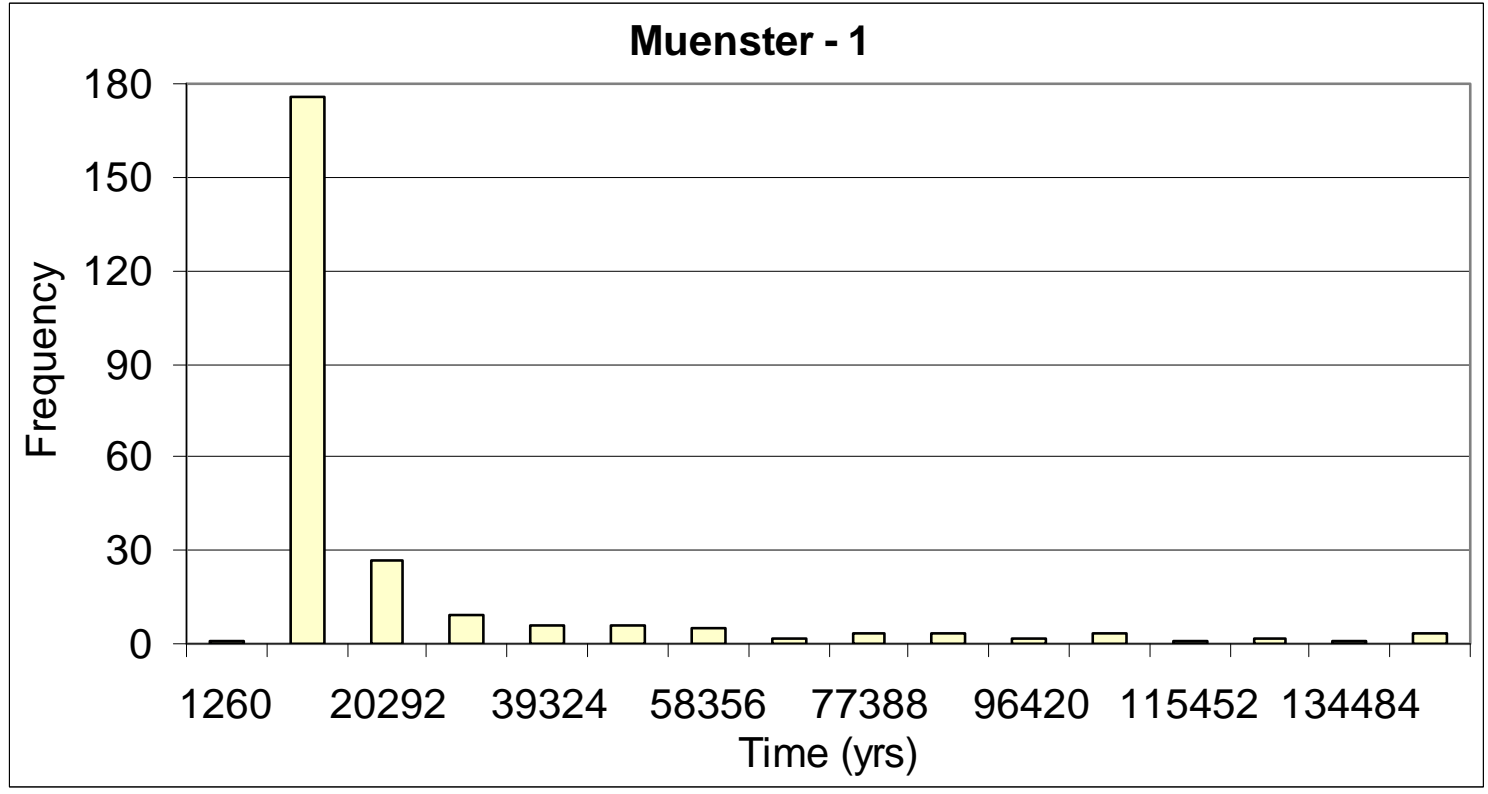

Figure C185: Distribution of minimum travel time from Muenster - 1 to YM boundaries based on effective-porosity Set 3 for 1998 scenario. 


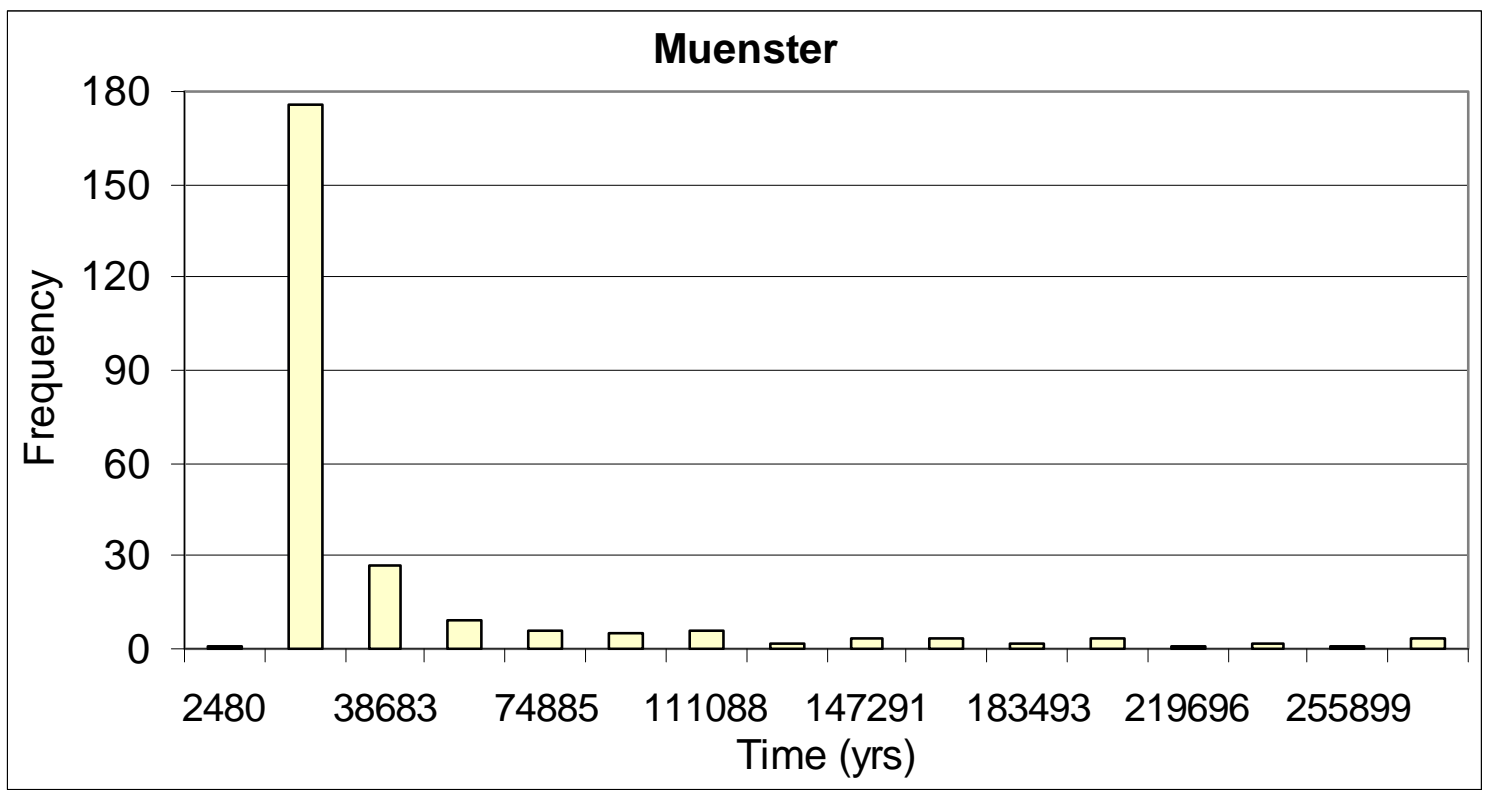

Figure C186: Distribution of minimum travel time from Muenster to YM boundaries based on effective-porosity Set 3 for 1998 scenario. 


\section{DISTRIBUTION}

Wayne R. Belcher

Yucca Mountain Project Office

Office of Civilian Radioactive Waste

Management

U. S. Department of Energy

1551 Hillshire Drive

Las Vegas, NV 89134

Jenny Chapman

Division of Hydrologic Sciences

Desert Research Institute

755 E. Flamingo Road

Las Vegas, NV 89119-7363

Drew Coleman

Yucca Mountain Project Office

Office of Civilian Radioactive Waste

Management

U. S. Department of Energy

1551 Hillshire Drive

Las Vegas, NV 89134

Russ Dyer

Yucca Mountain Project Office

Office of Civilian Radioactive Waste

Management

U. S. Department of Energy

1551 Hillshire Drive

Las Vegas, NV 89134

Bruce Hurley

Hydrology Program Manager

Environment, Safety \& Health Division

Nevada Site Office

National Nuclear Security Administration

U.S. Department of Energy

P.O. Box 98518

Las Vegas, NV 89193-8518

Marjory Jones

Division of Hydrologic Sciences

Desert Research Institute

2215 Raggio Parkway

Reno, NV 89512-1095
Levi Kryder

Geoscience Manager

Nye County Nuclear Waste Repository

Project Office

1210 E. Basin Rd., Ste 6

Pahrump, NV 89060

Peter Sanders

Environmental Restoration Division

Nevada Site Office

National Nuclear Security Administration

U.S. Department of Energy

P.O. Box 98518

Las Vegas, NV 89193-8518

Reina Serino, Contracting Specialist

Office of Business Services

NNSA Service Center

Pennsylvania and H Street, Bldg. 20388

P.O. Box 5400

Albuquerque, NM 87185-5400

Bonnie Thompson

Water Resources, Nevada District

U.S. Geological Survey

160 N. Stephanie Street

Henderson, NV 89074

Bill Wilborn

UGTA Federal Sub-Project Manager

Nevada Site Office

National Nuclear Security Administration

U.S. Department of Energy

P.O. Box 98518

Las Vegas, NV 89193-8518

Nevada State Library and Archives

State Publications

100 North Stewart Street

Carson City, NV 89701-4285

Archives

Getchell Library

University of Nevada, Reno

DeLaMare Library/262

University of Nevada, Reno 


\author{
Document Section, Library \\ University of Nevada, Las Vegas \\ 4505 Maryland Parkway \\ Las Vegas, NV 89154 \\ Library \\ Southern Nevada Science Center \\ Desert Research Institute \\ 755 E. Flaming Road \\ Las Vegas, NV 89119-7363 \\ Public Reading Facility \\ c/o Nuclear Testing Archive \\ Nevada Site Office \\ National Nuclear Security Administration \\ U.S. Department of Energy \\ P.O. Box 98521, M/S 400 \\ Las Vegas, NV 89193-8521 \\ (CD)
}

Technical Library

Nevada Site Office

National Nuclear Security Administration

U.S. Department of Energy

P.O. Box 98518

Las Vegas, NV 89193-8518

(CD)

Office of Scientific and Technical Information

U.S. Department of Energy

P.O. Box 62

Oak Ridge, TN 37831-9939

(electronic copy) 